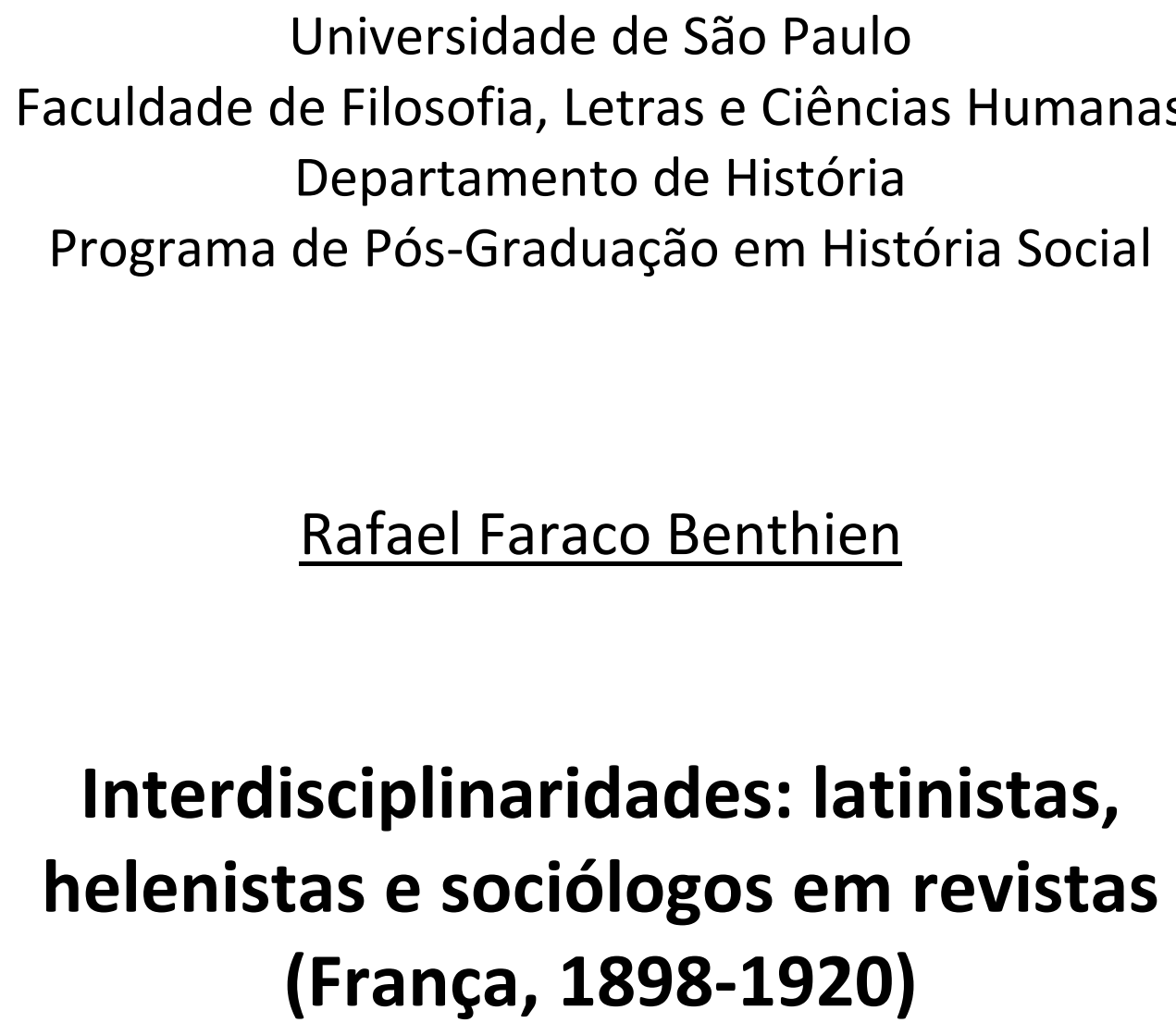

(VERSÃO CORRIGIDA)

São Paulo,

Março de 2011 


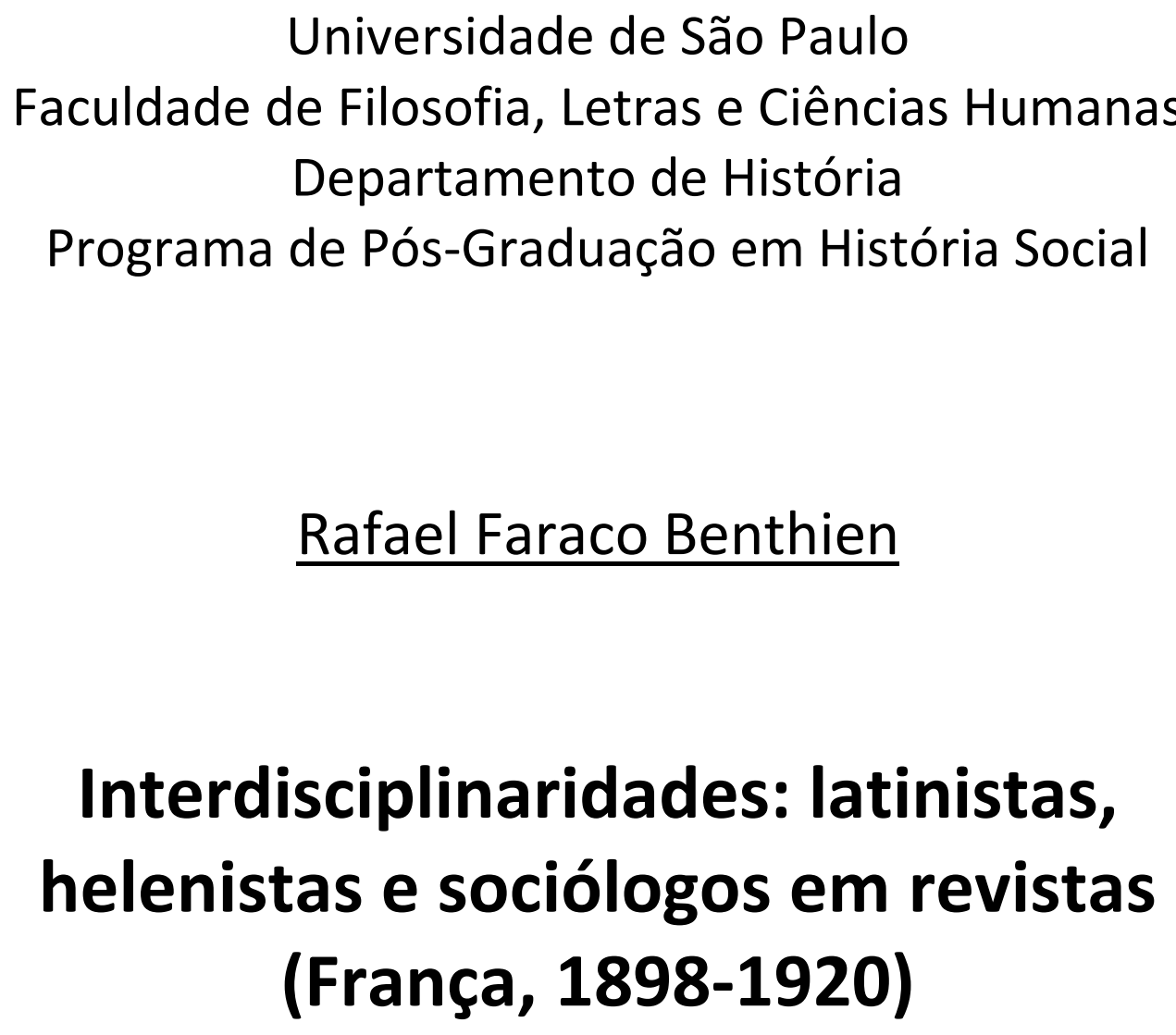

Tese apresentada ao Programa de PósGraduação em História Social como prérequisito para a obtenção do título de doutor.

Orientador: Prof. Dr. Francisco Murari Pires

(VERSÃO CORRIGIDA)

São Paulo,

Março de 2011 


\section{Para Waleska.}


O progresso do conhecimento, no caso da ciência social, supõe um progresso no conhecimento das condições de conhecimento.

Pierre Bourdieu 


\section{AgRADECIMENTOS}

A presente tese é uma autobiografia impessoal. Ela sinaliza para o esforço crítico de alguém que, desde cedo engajado nos estudos clássicos e nas ciências sociais, quis refletir sobre como esses saberes foram e são socialmente produzidos. Mas isso não é tudo. Aqui e ali, em suas linhas e entrelinhas, todos aqueles com quem tive a chance de compartilhar os últimos quatro anos e meio deixaram suas marcas. Se enumerar é esquecer, ainda assim eu não poderia deixar de mencionar aqui indivíduos e de instituições que, retrospectivamente, me parecem terem sido determinantes para o trabalho.

Inicio meus agradecimentos mencionando os apoios da FAPESP e, no contexto de uma bolsa sanduíche, da CAPES. Sem as excepcionais condições de trabalho oferecidas por tais agências de fomento nada do que se vê aqui teria sido possível. Ainda no plano institucional, expresso minha gratidão para com os funcionários da Universidade de São Paulo, em especial João Roberto Patrinhani da Pró-Reitoria de Pós-Graduação, bem como o trio sempre prestativo e amigo que encontrei na Secretaria da Pós-Graduação de História, Osvaldo Medeiros, Priscila de Carvalho e Luiz Filipe da Silva Correia.

Quando meu doutorado teve início, em agosto de 2006, eu estava em Curitiba lecionando como professor substituto no Departamento de História da Universidade Federal do Paraná. Agradeço aos colegas que me acolheram de braços abertos e me auxiliaram nesse que era apenas meu segundo semestre de experiência docente, bem como aos alunos de Teoria da História II e História Medieval II. Tenho aí uma dívida particular com Carlos Alberto Medeiros Lima e Helenice Rodrigues da Silva, amigos e interlocutores.

Durante todo o ano de 2008 e em duas ocasiões diferentes em 2010, pude desenvolver partes da pesquisa na França. Essa primeira vivência concreta da diferença linguística, comportamental e institucional não teria sido suportável sem as várias amizades que aí tiveram início. Dentre as pessoas queridas que conheci na Maison du Brésil, destaco os nomes de Valter Lúcio de Oliveira, Fábio Carvalho, Renata Picão, Grégory Ponthière, Angélica Müller, Cristiane Oliveira, Camila Jourdan e Kenneth Günther. Para além do ambiente da Cité Universitaire, em seminários, festas, cinemas, cafés e restaurantes, tive ainda a sorte de cruzar o caminho de Laura e Lucile Chartain, Jessica Ozan, Catarine de Melo Baldan, Cristian Escorza, Marco-Antonio Machado, Barbara Maraux, Felipe Brandi, Aurelie Therond, Yann Coron e Manon Bosc. Guénolé Labey-Guimard merece um agradecimento especial: além de sua vontade de construir pontes capazes de amenizar a barreira da alteridade, auxiliou o desenvolvimento da presente pesquisa hospedando-me generosamente em sua casa e na de seus familiares não parisienses. 
Na École des Hautes Études en Sciences Sociales, instituição que me acolheu em Paris, descobri mestres e amigos. Evoco, em primeiro lugar, o nome de Afrânio Raul Garcia Júnior, o qual tornou o estágio possível ao aceitar ser meu supervisor. Ele não poupou esforços para fazer o trabalho avançar, vibrando com minhas "descobertas" e encorajando-me em momentos-chave. Jean-Pierre Faguer, que conheci graças a Afrânio, foi certamente meu mais constante e fiel interlocutor. Indicando-me bibliografias, eventos e seminários, ou ainda acompanhando-me a arquivos e entrevistas, sua presença aqui é de tal ordem que não seria exagero dizer que sem ele não haveria tese alguma. Pude ainda, em diversas ocasiões, receber importantes conselhos e informações de Dominique Merllié, Marcello Carastro, Etienne Hubert, Pierre Judet de La Combe e Johan Heilbron. Destaco também o diálogo com pesquisadores não pertencentes a essa instituição, em particular Camille Tarot, Sarah Rey e Brigitte Le Roux. André Laks, que eu havia conhecido durante meu mestrado, recebeu-me em diversas ocasiões, tornando também possível meu acesso tanto à biblioteca da École Normale Supérieure quanto ao filólogo Jean Bollack. Bollack, aliás, não satisfeito em responder às questões ligadas a minha pesquisa, concedeu-me ainda a honra de entrevistá-lo. Não há como agradecê-lo por isso.

$\mathrm{O}$ contato com arquivos é um capítulo à parte na história da presente tese. No Collège de France, todo o trabalho foi singularmente facilitado pela equipe da biblioteca da instituição, Claire Guttinger em especial. Na Bibliothèque Méjanes, em Aix-en-Provence, fui recebido com o maior dos profissionalismos por Philippe Ferrand e Michelle Allard. O mesmo pode ser dito dos funcionários do Institut Mémoires de l'Édition Contemporaine, em Paris e em Caen. Por fim, abro um parêntese especial quanto ao Musée d'Archéologie Nationale et Domaine National de Saint-Germain-en-Laye. Quando fui visitá-lo a primeira vez, estava interessado apenas nos arquivos pessoais e profissionais de Henri Hubert ali depositados. Para minha sorte, porém, encontrei também bons amigos e interlocutores. Meu muito obrigado a Loïc Hamon, Claire Aumeunier, Paul Chillon, Guillaume Goujon e, em especial, às sucessoras de Hubert no departamento de Arqueologia Comparada, Christine Lorre e Anaïs Boucher.

Da França para a Inglaterra. Em um curto estágio de um mês, realizado já no final da pesquisa, pude conhecer sociólogos e antropólogos do outro lado do Canal da Mancha. O convite partiu de William Pickering, presidente e um dos fundadores do British Center for Durkheimian Studies. Sua gentileza, interesse, invejável vivacidade e faro detetivesco não serão esquecidos. Por intermédio de Bill, obtive acesso ao sistema de bibliotecas local, assim como travei contato com Nick Allen, cujo trabalho passei a conhecer e admirar. Além de presenciarem a apresentação de parte da pesquisa nos quadros de um evento do centro, ambos aceitaram conversar em particular comigo e deram importantes contribuições ao 
trabalho. At last, but not least, agradeço à família Gordon-Colebrooke - Sarah, Jeremy, Jack, Liv e Charlie -, a qual aceitou receber a mim e a Waleska como hóspedes. Sentimo-nos aí como em casa.

Entre uma e outra viagem, em São Paulo ou em Curitiba, pude contar com o apoio de familiares e de bons amigos, alguns mais novos, outros de longa data. Seu Luiz, Dona Mara e Paty estiveram sempre lá, com atenção e afeto infinitos. Agradeço também a Sônia e Rodrigo Laux, Irô Floriano (in memoriam), Raquel Weiss, Joana Clímaco, Rafaela Deiab, Luis Filipe Silvério Lima, Miguel Soares Palmeira, Rodrigo Turin, Eduardo Dimitrov, Luiz Lima Vailati, Pedro Ipiranga Júnior, Carlos Ogawa, Bruno Hübscher, Germaine Mandelsaft, Maikon Augusto Delgado (o Magoo), André Luiz Cavazzani, Ricardo Sabbag, Rogério Cunha e Leonardo Marques. Pedro, confiando a mim e a Waleska sua casa, deu-me oportunidade de redigir boa parte da tese no mais propício dos ambientes. Rodrigo, Eduardo, Miguel e Magoo constituíram, por seus esforços combinados ou isolados, uma espécie de atelier de final de tese. Os três primeiros, comentando um ou outro subcapítulo, permitiram-me corrigir, esclarecer e aperfeiçoar ideias e encaminhamentos de pesquisa. Magoo, por sua vez, encarregou-se da revisão final do texto.

Por terem me emprestado seus olhos e ouvidos, agradeço ainda aos helenistas, historiadores, antropólogos, sociólogos e estatísticos brasileiros: Marcelo Rede, Sergio Miceli, José Antônio Dabdab Trabulsi, Márcia Consolim, Lygia Sigaud (in memoriam), Paulo Bittencourt e Flávio de Oliveira. Destaco, entre eles, o nome de Sergio Miceli. Além de sua presença marcante no momento da qualificação, ele me permitiu entrar em contato com Afrânio, contribuindo assim decisivamente para o avanço do trabalho.

E o que dizer de Francisco Murari Pires? Dotado de uma formação interdisciplinar no mais amplo sentido do termo, assim como dono de uma obra com estilo próprio, forjada com toda a erudição que ele pôde acumular ao longo dos anos, mas também contra ela, Francisco é mais que um simples professor/pesquisador. Ele é, em verdade, um projeto de ciência e de universidade. Com ele, as palavras não são desperdiçadas e os silêncios falam. Com ele, os dogmatismos, os jogos de salão e os corporativismos da Academia são rebaixados graças a uma reflexão intelectual séria, livre e inventiva. Foi um grande privilégio tê-lo tido como orientador, algo só superado pela satisfação de tê-lo como amigo.

As últimas palavras dos agradecimentos vão a quem dedico a tese. Na por vezes dura e sempre sublime tarefa de amar, Waleska esteve presente em todos os dias. Obrigado por quase dez anos de história que me ajudaram a ser quem eu sou. Obrigado também por estar disposta a transformar o teu e o meu futuro em algo nosso. 


\title{
RESUMO
}

Durante as décadas de 1890 e 1910, a sociologia adquiriu direito de cidadania na universidade francesa, passando a compor, em uma posição institucionalmente frágil e marginal, o leque das disciplinas ofertadas nas Faculdades de Letras. A presente tese se propõe a investigar os diálogos que os portadores desse saber "novo" travaram então com helenistas e latinistas, os quais representavam, por seu turno, disciplinas tradicionais e ainda hegemônicas no sistema de ensino daquele país. Para tanto, são aqui privilegiados os circuitos de ideias e de pessoas entre cinco revistas especializadas de perfil universitário: o Année Sociologique, o Bulletin de Correspondance Hellénique, os Mélanges d'Archéologie et d'Histoire, a Revue des Études Grecques e a Revue des Études Anciennes. A partir do exame dos sentidos de tal fluxo, procurase esclarecer quais condições epistemológicas e sociais tornaram possível uma interdisciplinaridade historicamente dada, problematizando tanto seus limites práticos quanto seu peso na definição de cada um dos saberes nela implicados.

Palavras-chave: Sociólogos, Latinistas, Helenistas, Universidade francesa (1898-1920), Interdisciplinaridade.

\begin{abstract}
During the 1890s and 1910s, sociology acquired citizenship rights within the French University system, and became part of the spectrum of disciplines offered at the various faculties of Letters all over the country, even though it kept holding an institutionally weak position. The purpose of this thesis is to examine the dialogues during this early period between the holders of this "new" knowledge and Hellenistic and Latin scholars, who, in turn, represented traditional disciplines which still dominated the French educational system. To that end, we focus upon the circuits of ideas and people represented in five specialized academic journals, i.e: Année Sociologique, Bulletin de Correspondance Hellénique, Mélanges d'Archéologie et d'Histoire, Revue des Etudes Grecques, and Revue des Etudes Anciennes. By analyzing the meanings of such a flow, we attempt to elucidate the epistemological and social conditions that allowed a historically given interdisciplinarity, questioning both its practical limits and its influence on the definition of each knowledge area.
\end{abstract}

Keywords: Sociologists, Latinists, Hellenists, French university (1898-1920), interdisciplinarity.

Contato: rfbenthien@hotmail.com 


\section{SUMÁRIO}

LISTA DE ABREVIAÇõES/NOTA SOBRE AS CITAÇÕES Xii

LISTA DE QUADROS (TABELAS) Xiii

LISTA DE IMAGENS $\quad$ XV

$\begin{array}{ll}\text { INTRODUÇÃO } & 1\end{array}$

Prólogo: Platão e as Ciências Sociais $\quad \mathbf{2}$

Da hegemonia absoluta dos liceus à relativa autonomia universitária $\quad \mathbf{4}$

[Caixa de texto: Universidades e grandes écoles] 6

$\begin{array}{ll}\text { Modos de fazer } & 10\end{array}$

CAPÍTULO 1 - A REVISTA dOS SOCIÓlogos E OS ESTUdOS GRECO-latinOS 13

1.1 - O ANNÉE SOCIOLOGIQUe E OS CLÁSSICOS GRECO-LATINOS

Uma revista atípica $\quad 15$

$\begin{array}{ll}\text { Por um comparatismo radical } & 18\end{array}$

De algumas formas sociológicas de classificação 20

Onde colocar Pausânias?

1.2 - OS COLABORADORES ANTIQUISANTS DE L'ANNÉE SOCIOLOGIQUE

Entre amizades e comparatismos $\quad \mathbf{4 4}$

A adesão de jovens especialistas $\quad \mathbf{5 2}$

$\begin{array}{ll}\text { CAPÍtUlo 2 - As REVISTAS dos ANTIQUISANTS E A SOCIOLOGIA } & 60\end{array}$

2.1-O BULletin de CoRrespondance Hellenique

A École Française d'Athènes $\quad 65$

[Caixa de texto: "Ateniense"] $\quad 68$

Criação e estrutura do $\mathrm{BCH}$

[Caixa de texto: "Os diretores da EFA"]

Padrões de recrutamento $\quad \mathbf{7 4}$

A recepção da sociologia no Bulletin de Correspondance Hellénique $\quad \mathbf{8 0}$

Os sociólogos no Bulletin de Correspondance Hellénique 82

2.2-OS MÉLANGES D'ARCHÉOLOGIE ET D'HISTOIRE

A École Française de Rome $\quad 87$

A estrutura dos MAH $\quad 90$

Edmond Le Blant e Louis Duchesne $\quad 91$

$\begin{array}{ll}\text { Padrões de recrutamento } & 95\end{array}$

A recepção da sociologia nos Mélanges d'Archéologie et d'Histoire $\quad 102$ 
Uma instituição de elite

[Caixa de texto: A AEEG e o sistema de ensino francês]

Do anuário à revista

Dois diretores

[Caixa de texto: A Villa Kérylos]

O helenismo é um humanismo

Padrões de recrutamento

A recepção da sociologia na Revue des Études Grecques

Os sociólogos na Revue des Études Grecques

[Caixa de texto: Uma forma antiga de contrato entre os trácios]

Antecedentes institucionais e a caracterização de uma equipe

[Caixa de texto: Novas posições se consolidam]

O grupo antes do grupo (I): uma formação de elite

[Caixa de texto: Três retratos de normalianos por Salomon Reinach]

O grupo antes do grupo (II): reorientação e convergência

[Caixa de texto: Henri de la Ville de Mirmont (1858-1923)]

O todo e as partes

[Caixa de texto: A Dama de Elche]

Camille Jullian, patrono e patrão

[Caixa de texto: Do patriotismo gaulês]

O "incidente" Stapfer

Padrões de recrutamento

[Caixa de texto: Joseph Déchelette (1862-1914)]

A recepção da sociologia na Revue des Études Anciennes

Os sociólogos na Revue des Études Anciennes

Paris $\mathrm{x}$ província 
3.1 - OS DURKHEIMIANOS NO COLLÈGE DE FRANCE (1897-1918)

O Collège de France (I): disposições heréticas

O Collège de France (II): um sistema de recrutamento particular

O Collège de France (III): linhas de força

Durkheim: os primeiros e paradigmáticos fracassos

[Caixa de texto: Monsieur Schmidt]

Meillet: a tranqüila eleição de uma unanimidade

Fossey: um sucesso "ilegítimo"

Mauss e seu duplo fracasso

[Caixa de texto: O testemunho de van Gennep]

Simiand: não à sociologia, não ao socialismo

Considerações finais

3.2 - OS DURKHeimianos, SALOMON ReINACH E o MusÉE des ANTIQUITÉS NATIONALES

Alexandre Bertrand e os primórdios do Museu de Saint-Germain

Salomon Reinach, prodígio e polígrafo

Entre tensões e afinidades eletivas

Um museu aberto à sociologia

[Caixa de texto: O Deus com o Martelo]

Considerações finais

3.3 - AS CONTRIBUIÇÕES DOS DURKHEIMIANOS AO DICTIONNAIRE DES ANTIQUITÉS

GRECQUES ET ROMAINES

O Dictionnaire des Antiquités Grecques et Romaines

Henri Hubert, uma jovem promessa entre os antiquisants

Paul Huvelin, o especialista consagrado

Notas sobre o lugar da sociologia no DAGR e o do DAGR na sociologia

CONCLUSÃo

Interdisciplinaridades (I): observações sobre a teoria do campo

AneXo 


\section{LISTA DE ABREVIAÇÕES/NOTA SOBRE AS CITAÇÕES}

Em função das alusões recorrentes a um conjunto relativamente pequeno de periódicos acadêmicos e instituições, optou-se aqui por adotar as abreviações que seguem listadas abaixo. No caso das revistas, essas siglas serão também utilizadas para fins de citação seguindo o seguinte padrão: SIGLA, ANO: PÁGINA (ex: BCH, 1909: 105-109). A única exceção se aplica à Revue Archéologique (RA), que publicava a cada ano dois volumes com paginações independentes. Nesse caso, indica-se o semestre após o ano (ex: RA, 1899/2: 145-167).

\section{Abreviações de Periódicos e Dicionários}

Année Sociologique (AS)

Bulletin de Correspondance Hellenique (BCH)

Dictionnaire des Antiquités Grecques et Romaines (DAGR)

Mélanges d'Archéologie et Histoire (MAH)

Revue Archéolofique (RA)

Revue Celtique (RC)

Revue des Études Anciennes (REA)

Revue des Études Grecques (REG)

Revue de l'Histoire des Religions (RHR)

Revue de Métaphysique et de Morale (RMM)

Revue des Universités du Midi (RUM)

\section{INSTITUIÇÕES}

Académie des Beaux-Arts (ABA)

Académie Française (AF)

Académie des Inscriptions et Belles-Lettres (AIBL)

Académie des Sciences (AdS)

Académie des Sciences Morales et Politiques (ASMP)

Association pour l'Encouragement des Études Grecques en France (AAEG)

Bibliothèque Nationale de France (BNF)

Collège de France (CF).

École Française d'Athènes (EFA)

École Française de Rome (EFR)

École Normale Supérieure (ENS)

École Pratique des Hautes Études (EPHE)

Institut Mémoires de l'Édition Contemporaine (IMEC)

Musée des Antiquités Nationales (MAN) 


\section{LISTA DE QUADROS (TABELAS)}

Quadro 1.1.1 - A presença da antiguidade greco-latina em L'Année Sociologique (1898).

Quadro 1.1.2 - A presença da antiguidade greco-latina em L'Année Sociologique (1899).

Quadro 1.1.3 - A presença da antiguidade greco-latina em L'Année Sociologique (1900).

Quadro 1.1.4 - A presença da antiguidade greco-latina em L'Année Sociologique (1901).

Quadro 1.1.5 - A presença da antiguidade greco-latina em L'Année Sociologique (1902).

Quadro 1.1.6 - A presença da antiguidade greco-latina em L'Année Sociologique (1903).

Quadro 1.1.7 - A presença da antiguidade greco-latina em L'Année Sociologique (1904).

Quadro 1.1.8 - A presença da antiguidade greco-latina em L'Année Sociologique (1905).

Quadro 1.1.9 - A presença da antiguidade greco-latina em L'Année Sociologique (1906).

Quadro 1.1.10 - A presença da antiguidade greco-latina em L'Année Sociologique (1907). 36

Quadro 1.1.11 - A presença da antiguidade greco-latina em L'Année Sociologique (1910). 38

Quadro 1.1.12 - A presença da antiguidade greco-latina em L'Année Sociologique (1913). 40

Quadro 2.1.1 - Padrões de recrutamento - autores de artigos (BCH, 1877-1887). 75

Quadro 2.1.2 - Padrões de recrutamento - autores de artigos (BCH, 1888-1898). 76

Quadro 2.1.3 - Padrões de recrutamento - autores de artigos (BCH, 1899-1909). 77

Quadro 2.1.4 - Padrões de recrutamento - autores de artigos (BCH, 1910-1920). 78

Quadro 2.2.1 - Padrões de recrutamento - autores de artigos (MAH, 1881-1887). 96

Quadro 2.2.2 - Padrões de recrutamento - autores de artigos (MAH, 1888-1898). $\quad 97$

Quadro 2.2.3 - Padrões de recrutamento - autores de artigos (MAH, 1899-1909). 98

Quadro 2.2.4 - Padrões de recrutamento - autores de artigos (MAH, 1910-1920). 99

Quadro 2.3.1 - Padrões de recrutamento - autores de artigos (REG, 1888-1898). 128

Quadro 2.3.2 - Padrões de recrutamento - autores de artigos (REG, 1899-1809). 129

Quadro 2.3.3 - Padrões de recrutamento - autores de artigos (REG, 1910-1920). 130

Quadro 2.3.4-REG - 1899-1906. Frequência de publicação, trajetória pessoal e 133 institucional.

Quadro 2.3.5 - REG - 1907-1913. Frequência de publicação, trajetória pessoal e institucional.

Quadro 2.3.6-REG - 1914-1920. Frequência de publicação, trajetória pessoal e institucional.

Quadro 2.4.1 - Trajetória escolar e background familiar dos fundadores da REA.

Quadro 2.4.2 - Número absoluto e relativo de cadeiras associadas aos estudos grecolatinos nas Faculdades de Letras francesas (1865-1928).

Quadro 2.4.3 - Números absoluto e relativo de artigos (articles de fond) por área 
temática da REA.

Quadro 2.4.4 - Padrões de recrutamento - autores de artigos (REA, 1899-1909).

Quadro 2.4.5 - Padrões de recrutamento - autores de artigos (REA, 1910-1920).

Quadro 2.4.6-REA - 1899-1906. Frequência de publicação, trajetória pessoal e institucional.

Quadro 2.4.7 - REA - 1907-1913. Frequência de publicação, trajetória pessoal e institucional.

Quadro 2.4.8 - REA - 1914-1920. Frequência de publicação, trajetória pessoal e institucional.

Quadro 2.5.1. - Instituições dedicadas aos estudos greco-latinos (1846-1923)

Quadro 2.5.2 - Revistas dedicadas aos estudos greco-latinos (1877-1923)

Quadro 2.5.3 - O espaço das revistas dos helenistas, dos latinistas e dos sociólogos

Quadro 3.1.1 - Cadeiras nominalmente relacionadas ás ciências sociais criadas no

Collège de France (1897-1918).

Quadro 3.1.2 - Candidaturas de sociólogos durkheimianos ao Collège de France 1918.

Quadro 3.1.3 - Composição do CF (1897-1918): "cientistas" e "literários" (em números absolutos e relativos).

Quadro 3.1.4 - A composição do CF (1897-1918): o quinhão das Academias (em números absolutos e relativos).

Quadro 3.2.1 - Apreciações críticas dos trabalhos de Salomon Reinach em L'Année Sociologique (1898-1905).

Quadro 3.2.2 - Apreciações críticas dos trabalhos de Salomon Reinach em L'Année Sociologique (1906-1913).

Quadro 3.3.1 - DAGR: periodicidade e conteúdo.

Quadro 3.3.2 - Henri Hubert e o DAGR.

Quadro 3.3.3 - Paul Huvelin e o DAGR. 


\section{LISTA DE IMAGENS}

Encontram-se listadas abaixo as imagens (fotografias) citadas ao longo da tese.

Figura 2.3.1 - A baía de Beaulieu-sur-Mèr em julho de 2008.

Figura 2.3.2 - O átrio central da Villa Kérylos.

Figura 2.3.3 - A disputa da lira entre Hermes e Apolo.

Figura 2.3.4 - A sala de refeições (triklinos) da Villa Kérylos.

Figura 2.3.5 - Detalhe do quarto de Théodore Reinach, no segundo andar da Villa

Kérylos.

Figura 2.4.1 - O Busto antigo intitulado "A Dama de Elche".

Figura 2.4.2 - A Dama de Elche na folha de rosto da REA.

Figura 3.2.1 - A Sala de Marte ou Sala de Arqueologia Comparada no início do século XX.

Figura 3.2.2 - A Sala de Marte ou Sala de Arqueologia Comparada no início do século

XXI.

Figura 3.2.3 - Exemplo atual de vitrine da Sala de Arqueologia Comparada. 
INTRODUÇÃO 
presente tese estuda, na perspectiva de uma história social das ciências sociais, os diálogos entre latinistas, helenistas e sociólogos durkheimianos na França da Terceira República, dando ênfase ao período que se estende de 1898 (ano de lançamento de l'Année Sociologique) a 1920 (imediato pós-guerra). Tendo como principal suporte documental os periódicos científicos dedicados à sociologia e aos estudos greco-latinos, ela intenta explicar eventuais tensões e afinidades eletivas que marcaram nesses espaços a circulação de idéias e de indivíduos. Mas não se quer aqui apenas analisar uma interdisciplinaridade episódica. Trata-se também de restituir a importância de tais diálogos para a constituição de cada uma das disciplinas em questão.

\section{Prólogo: Platão e as CIÊnCIAS Socials}

Na Paris de 1913, um artigo publicado na influente Revue de Métaphysique et de Morale teve seu papel no esforço que então se fazia para rediscutir o lugar dos clássicos grecolatinos no sistema educacional francês (RMM, 1913: 221-255). O título provocativo, Platon et La Science Sociale, sinalizava que nem mesmo o antigo filósofo escapara à tormenta. León Robin, recém-doutor e postulante a um assento permanente na Sorbonne, defendia ali que Platão, além de refletir cientificamente acerca da sociedade, antecipou algo do método e das conclusões de ninguém menos que Émile Durkheim. Com efeito, dizia Robin, o filósofo reservara em sua República "lugar importante aos fatos econômicos na explicação dos fatos sociais". Além do mais, concebera "a grande lei da divisão do trabalho social". E como se tudo isso já não bastasse, suas teses sobre o lugar da política na "educação científica hierarquizada" estariam em consonância com formulações recentes de Comte ${ }^{1}$.

Que Platão não fosse um pensador abstrato, apesar de nova, era uma ideia aceitável. O curioso aqui é a radicalização de uma leitura absolutamente oposta à idealista, que, vinte anos antes, dominava a questão. Com efeito, nos idos de 1890, Bergson ensinava no Liceu Henri IV o caráter arquetípico das ideias platônicas (BERGSON, 2005: 105-117). No mesmo período, um celebrado tratado histórico sobre o regime de terras na Grécia Antiga afirmava que a opinião do ateniense sobre questões sociais tinha "valor medíocre" (GUIRAUD, 1893:

\footnotetext{
${ }^{1}$ Os exemplos foram retirados respectivamente de RMM, 1913: 228, 238 e 254-5.
} 
587). E mesmo Durkheim em De la Division du Travail Social, embora tenha citado Aristóteles, ignorava solenemente o mestre do estagirita.

Mas o que ocorreu entre 1890 e 1910 para provocar tal reviravolta na fortuna crítica de Platão? A resposta é inequívoca: a sociologia aconteceu. Não se tratou, porém, de um processo simples. À medida que abria espaço nas instituições de ensino, negociando com elas rearranjos, a nova disciplina suscitava reações de simpatia ou de hostilidade por parte dos portadores dos saberes já consolidados. Para ter sucesso, ela tinha de sensibilizar ao menos alguns de seus colegas universitários quanto à importância das questões ditas sociológicas, incentivando a aplicação destas aos objetos daqueles.

Assim, Durkheim não agiu sozinho quando afirmou em Les Formes Élémentaires de La Vie Religieuse, de 1912, o lugar crucial de Platão no desenvolvimento das ciências positivas da sociedade (DURKHEIM, 1912: 623). Ele dialogava, em verdade, com especialistas na filosofia antiga simpáticos às ciências sociais. Dentre eles, Octave Hamelin, professor da Sorbonne e amigo próximo de Durkheim, já havia afirmado em 1904 o quanto a sociologia auxiliava o estudo da filosofia antiga (HAMELIN, 1931: 1-22). No ano seguinte, Victor Brochard, também professor da Sorbonne e um dos principais responsáveis pela ida de Durkheim a essa instituição, notou o quanto até mesmo as ideias "abstratas" de um Platão tinham raízes sociais e refletiam dilemas reais da vida em sociedade (BROCHARD, 1905).

Por certo, a polêmica acerca de um Platão "idealista" ou "positivista" é muito mais complexa do que essa curta série de citações deixa entrever. Também não coube a Robin encerrar a discussão, como sentenciou a única acolhida, bastante positiva, de seu artigo nas revistas especializadas nos estudos greco-latinos ${ }^{2}$. Em todo caso, tal episódio envolvendo Platão importa aqui mais por sensibilizar o analista moderno quanto ao lugar de destaque dos autores clássicos no universo em que a sociologia durkheimiana veio a se institucionalizar. De fato, não havia nada mais tradicional em todo o sistema educacional francês: do início do século XIX até meados do século XX, as línguas e as obras literárias greco-latinas ocuparam um espaço central nos currículos do ensino médio, o que as tornava indispensáveis aos mais prestigiados concursos e certificados de estudo. No ensino superior, até mesmo em decorrência das demandas de professores de liceus, helenistas e latinistas constituíam boa parte dos quadros das Faculdades de Letras, bem como de instituições como a École Pratique des Hautes Études e o Collège de France. Em outras palavras, o contato com esses antiquisants era inevitável para quem quisesse seguir uma carreira universitária na França.

\footnotetext{
${ }^{2}$ Em uma resenha publicada na Revue des Études Grecques, Émile Bréhier, embora não faça quaisquer referências a Durkheim, elogia as teses de Robin, as quais "parecerão convincentes a muitos". O próprio autor, no entanto, se isenta de tomar partido. Cf. REG, 1914: 359-360.
} 
Diante desse quadro, antes mesmo de apresentar em detalhes o material a ser aqui analisado ou discutir os encaminhamentos metodológicos da análise, cumpre compreender as linhas gerais do processo de construção do sistema de ensino francês.

\section{DA HEGEMONIA ABSOLUTA DOS LICEUS À RELATIVA AUTONOMIA UNIVERSITÁRIA}

O universitário brasileiro, diante da história recente e das particularidades do sistema de ensino no qual ele próprio está inserido, tem dificuldades para refletir acerca do caso francês. Na França, afinal, as universidades são, ao menos nominalmente, muito mais antigas. Além disso, lá tudo converge para Paris, enquanto aqui há um regionalismo mais pronunciado, visível nos descompassos que aproximam e separam as diferentes unidades de ensino federais, estaduais e privadas. E o que dizer dos estatutos que distinguem as grandes instituições francesas: as universidades, as Grandes Écoles, o Collège de France e aquelas voltadas apenas à pesquisa, tais como a École Pratique des Hautes Études e a École des Hautes Études en Sciences Sociales? Não há nada análogo a essa divisão do trabalho intelectual nos trópicos. Por fim, considere-se ainda os vínculos entre o ensino secundário e superior nos dois países. No Brasil, cada um desses domínios constitui um mercado à parte, com padrões de recrutamento e planos de carreira relativamente autônomos um frente ao outro. Na França, ao contrário, a passagem como docente pelo secundário era, ao menos até as décadas de 1960 e 1970, uma etapa quase obrigatória para ingressar, anos mais tarde, no ensino superior.

Importa ressaltar aqui, porém, que o sistema de ensino francês é, sob muitos aspectos, muito mais recente do que se possa imaginar ${ }^{3}$. Se seus alicerces foram montados já no final do processo revolucionário, ele só atingiu uma complexidade similar à atual nas últimas décadas do século XIX, quando se constituíu aí de fato um nicho estável e relativamente autônomo voltado à pesquisa científica original. Pode-se, de modo esquemático, dividir a história desse sistema em duas partes, uma que vai do final das experiências pedagógicas revolucionárias até a década de 1870, caracterizada por uma hegemonia absoluta do ensino secundário, e outra marcada pela ascensão da universidade, no sentido moderno do termo, como instituição que se ocupa tanto do ensino como da pesquisa.

Durante a Revolução Francesa, com pouquíssimas exceções, tudo o que existia em termos de educação foi colocado em questão ${ }^{4}$. Até esse momento, eram as congregações

\footnotetext{
${ }^{3}$ Ele é muito mais recente, por exemplo, se comparado ao caso dos principados alemães desde o final do século XVIII, os quais já eram dotados de um sistema minimamente estruturado de educação universitária voltada à pesquisa. Veja-se, a esse respeito, RINGER, 2000: 29-128.

${ }^{4} \mathrm{O}$ Collège de France é um exemplo de instituição que não foi fechada ou profundamente modificada nesses anos. Ainda assim, como se verá mais adiante na presente tese (subcapítulo 3.1), ele passou então a ocupar no conjunto do sistema um novo papel.
} 
religiosas que coordenavam os colégios, os únicos aptos a fornecer uma base educacional, sendo esta dominada pelo ensino do latim e, em menor grau, do grego ${ }^{5}$. As universidades, por seu turno, eram divididas de acordo com os preceitos herdados do fim do medievo. Em primeiro lugar, como uma espécie de antessala, vinham as Faculdades de Artes. Cabia a elas preparar os alunos para a eventualidade de cursar as outras três faculdades existentes: Teologia, Direito e Medicina. Enquanto os professores dessas instituições provinham das corporações profissionais que as regiam, os colégios e as Faculdades de Artes eram dominados por quadros letrados pertencentes à Igreja Católica (DURKHEIM, 1999: 90-201).

As modificações revolucionárias afetaram sobretudo o que hoje se chamaria de ensino fundamental e médio. Com a ruptura com a Igreja em 1792, os colégios foram fechados, dando espaço para o aparecimento, alguns anos depois, das Écoles Centrales, nas quais o latim teve seu espaço drasticamente reduzido em detrimento das ciências naturais, da história, da matemática e da filosofia (MAYEUR, 2004: 56-70). Em paralelo a isso, os revolucionários criaram a primeira École Normale, a qual visava capacitar professores para atuar nas Écoles Centrales, dotando-os de um saber enciclopédico (HÜLTENSCHMIDT, 1990). Quanto ao ensino das Faculdades, ele foi vigiado ou suprimido em decorrência das posições políticas dos professores, sem que, de imediato, nada tenha sido feito para transformar a estrutura.

A ascensão de Napoleão Bonaparte nos anos que se seguiram veio acompanhada do arrefecimento dos ímpetos reformistas e do retorno do clero ao sistema educativo. As Écoles Centrales e a École Normale foram aos poucos substituídas por uma solução de compromisso, o Liceu. Embora controlado pelo estado, essa instituição criada em 1802 reintroduziu o ensino dos clássicos greco-latinos às salas de aulas, fazendo-os conviver apenas com a matemática ${ }^{6}$. Balzac, em um romance publicado em 1835, mas ambientado na transição do Primeiro Império à Restauração, O Lírio do Vale (Le Lys dans la Vallée), apresenta o seguinte retrato do sistema de ensino pela boca de seu protagonista: "As dores que eu havia sentido em família, na escola, no colégio, reencontrei-as em nova forma durante minha permanência no internato Lepître (...). Quando meus pais souberam que eu podia ser alimentado, vestido, empanturrado de latim e entupido de grego, ficou tudo resolvido" (BALZAC, 2006: 25). No mesmo romance, o conde de Mortsauf, profundamente oprimido pelo regime napoleônico, condenou com veemência as poucas inovações que subsistiram: "a educação moderna é fatal para as crianças. Nós as enchemos de matemática, nós as matamos a golpes de ciência e as gastamos antes do tempo. (...) Que século nos prepara esse ensino posto ao alcance de todos, senão prevenirmos o mal confiando a instrução pública às corporações religiosas!” (BALZAC, 2006: 58).

\footnotetext{
${ }^{5}$ Cf., a esse respeito, GRELL, 1992 (capítulo 1) e WAQUET, 1998: 17-23.

${ }^{6}$ Sobre a criação dos liceus, veja-se PROST, 2007: 105-109.
} 
Foi também obra do império napoleônico a primeira reestruturação do ensino superior. Em 1806 foi instituída a Universidade Imperial, composta de seis diferentes faculdades. Além da tríade tradicional já existente antes - Teologia, Direito e Medicina -, foram criadas outras três a partir da subdivisão das antigas Faculdades de Artes. Surgiram assim as Faculdades de Letras, de Ciências e de Artes. Suas principais atribuições consistiam em preparar seus alunos para os exames nacionais, a licence e a agrégation, cujos certificados davam a seu possuidor o direito de ingressar como professor no ensino primário e no secundário. Ou seja, em resumo, a vida universitária se reduzia, no início do século XIX, às demandas das profissões tradicionais e dos liceus. Como assinala Jean Bollack no anexo da presente tese, essa tendência foi hegemônica até fins da década de 1880, quando finalmente movimentos reformistas começaram a se fazer sentir.

\section{UNIVERSIDADES E GRANDES ÉCOLES}

O edifício da Universidade Imperial comportava, além das universidades, instituições que passaram a ser conhecidas como grandes écoles (a École Polytechnique, a École Normale Supérieure, a École des Chartes, entre outras). Seus currículos se sobrepunham em grande medida àquele ministrado nas Faculdades de Letras e de Ciência. Daí a pergunta: assim sendo, o que justificava a existência de ambas?

Havia aí, em primeiro lugar, uma diferença estatutária. As grandes écoles, ao contrário das universidades, garantiam a seus alunos acesso direto ao aparato do estado. Eles passavam a ser considerados, a partir do ingresso na instituição, funcionários públicos, o que lhes dava o direito de receber rendimentos.

Tal particularidade vinha atrelada a um rigoroso processo seletivo. Enquanto a democratização do ensino superior francês foi sendo feita com a ampliação das universidades, as grandes écoles se mantiveram em número reduzido, oferecendo poucas vagas. A exigência era tal que os liceus passaram, com o tempo, a fornecer cursos preparatórios para os concursos.
Por fim, os integrantes das grandes écoles se diferenciavam dos demais por viver em regime de internato (com moradia fornecida pelo estado) e por ter acesso a excepcionais condições de trabalho (bibliotecas e laboratórios equipados, professores entre os mais renomados em suas respectivas áreas, bem como reservas de postos e de bolsas de estudo para ex-alunos).

As forças políticas que sustentavam o Primeiro Império queriam com tal medida criar uma casta de funcionários fiéis e altamente capacitados. Os regimes políticos que $\mathrm{o}$ sucederam, da Restauração à Terceira República, não ousaram colocar em questão tal estrutura. Todos acabaram por se valer dela para seus próprios interesses.

Tanto no terreno dos estudos grecolatinos como no da sociologia, a grande école mais importante foi a École Normale Supérieure (ENS), refundada após as primeiras experiências revolucionárias em 1808. De tal instituição saíram não só políticos e escritores, mas também grande parte dos mais importantes pesquisadores nesses domínios específicos do saber. 
As reformas centralizadoras e o retorno do clero às atividades docentes deram o tom dos conflitos que marcaram a história posterior do sistema de ensino francês. Destaca-se aqui a tensão entre religião e laicidade. Ao menos até a década de 1870 , a despeito de algumas oscilações, o poder das congregações religosas se tornou cada vez maior na França. Em um primeiro momento, nas décadas de 1830 e 1840, o ensino da fé nas escolas e a autonomia dos quadros da Igreja Católica para compor suas próprias instituições ou atuar nos liceus do estado chegaram a ser limitados. Ainda assim, o quadro se inverteu com os desdobramentos da Revolução de 1848, em particular após as reações "termidorianas" que marcaram os primórdios o Segundo Império ${ }^{7}$. Nesse ínterim, o latim, a língua da Igreja, mas também a língua consagrada nas faculdades tradicionais (teologia, direito e medicina), manteve-se "rei", seguido pelo grego, pelo francês e, mais ao longe, por rudimentos de filosofia (apenas nas classes superioras dos liceus) e de matemática (WAQUET, 1997: 23-31).

Isso não significa, bem entendido, ausência de vida intelectual e científica na França. Ocorre apenas que, ao longo de boa parte do século XIX, esta passou ao largo ou às margens do sistema de ensino por intermédio de academias locais ou nacionais e de salões privados. Tal sistema perpetuava o mesmo padrão de sociabilidade dominante durante o Antigo Regime e teve um papel nada negligenciável tanto na gestação de certas tradições intelectuais nacionais (o positivismo comtista, por exemplo) como no desenvolvimento e na importação de novos autores e idéias $^{8}$. Os partidários de uma escola e de uma universidade laicas encontraram nesses espaços santuários e trincheiras, a partir dos quais eles puderam se aventurar, quando a oportunidade lhes foi apresentada, no aparato estatal e na universidade.

As primeiras modernizações importantes no seio do sistema de ensino francês surgiram ainda durante o Segundo Império. Em parte atendendo a demandas internas, em parte reagindo à ascensão internacional da Prússia, onde existia de fato uma universidade voltada à produção de conhecimento original, o estado francês apoiou a criação do ensino secundário profissionalizante (1863) e do primeiro centro voltado exclusivamente à formação de pesquisadores nas áreas de línguas, epigrafia, história e estudos religiosos, a École Pratique des Hautes Études $(1868)^{9}$. Tais iniciativas foram concebidas, porém, como apêndices do sistema, uma vez que não se tinha então condições de colocar em questão nem a centralidade do ensino clássico nem o tratamento retórico e literário dispensado ao estudo da letras e da história.

\footnotetext{
${ }^{7}$ Veja-se, em especial, as implicações da Loi Falloux (PROST, 2007: 213-216).

${ }^{8}$ Sobre a dinâmica desse modelo de sociabilidade, cf. DARNTON, 1989: 13-49 e HEILBRON, 2006: 31149.

${ }^{9}$ A seção relativa às ciências religiosas só foi criada, contudo, em 1886.
} 
Transformações efetivas só vieram a ocorrer na sequência, após a proclamação da Terceira República (1870). A derrota na Guerra Franco-Prussiana, marcada pela percepção da superioridade da rival também em termos científicos, atuou como um dos catalizadores de todo o processo. O outro incentivo, uma reviravolta na política nacional, veio da consolidação paulatina da nova república, a qual esteve em condições de assumir abertamente, já no final da década de 1870, bandeiras pró-ciência e anticlericais. No ensino médio, o latim, o grego e o francês passaram a dividir cada vez mais espaço com as línguas modernas e as ciências, ao ponto de, em 1902, tornar-se possível ingressar no ensino superior sem saber nenhuma língua antiga. Criou-se também um sistema minimamente voltado à pesquisa: o doutorado passou a ser valorizado como instrumento importante para a carreira docente. Além disso, o estado francês passou a financiar o envio de bolsistas para missões e estágios científicos no exterior (seja em instituições francesas, seja em universidades estrangeiras, sobretudo alemães). Por fim, houve uma desvalorização gradual, especialmente na área de letras, das abordagens puramente retóricas e estilísticas até então em voga ${ }^{10}$.

As instituições mais profundamente afetadas foram aquelas que antes se ocupavam quase que exclusivamente da produção de professores para o ensino secundário. As Faculdades de Ciências, de Letras e as instituições análogas entre as grandes écoles passaram então a incorporar novas disciplinas e a modernizar suas antigas atividades. Foi instituído, em suma, um polo de saberes "puros", ao lado do qual figuravam outros, mais "mundanos" e/ou ligados ao clero.

Tal processo foi muito mais complexo do que as páginas anteriores permitem entrever. Ainda assim, é importante reter suas linhas mais gerais a fim de compreender os diferentes caminhos que levaram latinistas, helenistas e sociólogos durkheimianos a se encontrarem, na última década do século XIX, nas instituições de ensino superior francesas.

O projeto de uma ciência positiva do mundo moral ou social chegou às universidades vindo de seu exterior. À exceção do breve período em que os "ideólogos" conseguiram impor algumas de suas bandeiras durante os primeiros anos da Revolução Francesa, as ciências sociais foram gestadas, como sugere Johan Heilbron, em academias ou salões políticocientíficos quase clandestinos (HEILBRON, 2006: 153-266). Reclamando a herança do comtismo e dialogando abertamente com os neokantianos franceses e alemães, Durkheim debutou no ensino superior na Bordeaux de 1887. Tratava-se, segundo Fournier, de uma

\footnotetext{
${ }^{10}$ Para mais detalhes sobre essas reformas, ocorridas sobretudo durante as décadas de 1880, $1890 \mathrm{e}$ 1900, cf. DURKHEIM, 1999: 351-366, MAYEUR, 2004: 581-635 e RINGER, 1992: $94-247$ (em uma instigante perspectiva comparando França e Alemanha).
} 
nomeação pensada a partir de cima, visando estimular a produção de conhecimento científico no campo das ciências sociais em território nacional, fazendo assim frente ao que então ocorria na universidade alemã ${ }^{11}$. Não por acaso, esta foi a primeira cadeira de ciências sociais jamais criada na universidade francesa. A organização de uma revista especializada e o desejo de construir um mínimo de consenso disciplinar virão na sequência.

Os helenistas e os latinistas, por sua vez, passaram a ter uma posição na moderna universidade francesa a partir de seu interior, como representantes de saberes tradicionais. De certo modo, esses profissionais existiram "desde sempre", uma vez que os liceus necessitavam continuamente de professores de grego e de latim. Isso não implicou, contudo, um imobilismo dos saberes que eles representavam. Em verdade, as reformas sucessivas do sistema de ensino os transformaram em verdadeiros campos de batalha. As línguas clássicas foram por vezes consideradas representantes dos interesses da Igreja, mas também utilizadas para atacar os dogmas religiosos, sobretudo via uma leitura "científica" dos textos sagrados. Elas foram também consideradas inúteis, pouco adaptadas a uma época em rápida transformação, e, ainda assim, defendidas como emblemas da razão e da beleza ${ }^{12}$. Em todo caso, os especialistas em Grécia e Roma antigas incorporaram, na segunda medade do século XIX, importantes e constantes inovações científicas. O desenvolvimento da arqueologia e da epigrafia os afetou imediatamente, assim como as novidades provenientes da Alemanha e da Inglaterra no campo da história e da filologia ${ }^{13}$. Muitos deles, críticos ao passado "literário" de suas disciplinas e dispostos a acompanhar e a fazer frente à erudição das demais potências européias, assumiram uma posição abertamente reformista.

O que se verá ao longo da presente tese é a descrição e a análise dos diálogos que marcaram esse primeiro encontro entre latinistas, helenistas e sociólogos durkheimianos na universidade francesa. Teriam estes, familiarizados com os autores e línguas clássicas desde os tempos do liceu, dialogado com os antiquisants de modo a fortalecer intelectual e institucionalmente suas posições? E quanto àqueles, acaso também procuraram os sociólogos com o mesmo interesse? Se sim, nos dois casos, com que intensidade e segundo que padrões

\footnotetext{
11 Veja-se FOURNIER, 2007: 105-106. Isso não significa, contudo, a ausência de outras escolas sociológicas atuando na França. Ocorre apenas que as demais tendências ou se mantiveram afastadas da universidade (em repartições públicas ou em associações privadas) ou, quando aí estiveram, não chegaram a constituir escola. Há uma extensa literatura sobre a questão. Cito CLARK, 1973, MUCHIELLI, 1998 e 2001, e CONSOLIM, 2008. O próprio Fournier (2007) trata com algum detalhe de nomes como Worms, Le Play, Espinas e Tarde em sua biografia de Durkheim.

12 Para mais detalhes sobre os dilemas e conflitos envolvendo o ensino dos clássicos, veja-se TRABULSI, 2008 e 1998.

${ }^{13} \mathrm{O}$ que não significa a inexistência de filtros ou tensões nessas importações. Sobre o caso da filologia alemã, por exemplo, veja-se BOLLACK, 1998a: 60-92 e WERNER, 1990: 11-21.
} 
isso se deu? Ora, a maneira mais eficaz de promover o avanço nos debates, com e contra as idéias preconcebidas acerca das historias disciplinares, passa necessariamente pela recuperação do maior número possível nexos que ligavam os portadores desses saberes entre si. Afinal, nenhuma disciplina se desenvolveu sem diálogos "para fora". Esta tese almeja assim contribuir com a história dos estudos clássicos e das ciências sociais ao recuperar nomes e circuitos talvez hoje pouco conhecidos, mas outrora familiares aos sociólogos e antiquisants da virada dos séculos XIX e XX.

\section{MODOS DE FAZER}

Existem inúmeras aproximações possíveis frente a diálogos entre portadores de saberes disciplinares diferentes. Pode-se, por exemplo, analisar seus livros publicados, checando se existem ou não neles referências cruzadas. Outro caminho possível é tomar como ponto de partida o arquivo pessoal de um autor, vendo em que medida ele revela, a partir de cartas, manuscritos ou agendas, vestígios que interessem à pesquisa. No presente caso, porém, optou-se por privilegar as revistas científicas de época. Ainda que comporte certa dose de arbitrariedade, tal escolha surge aqui como duplamente estratégica. Por um lado, as publicações acadêmicas servem como bom termômetro do processo de autonomização e de especialização disciplinar; de outro, tendo em vista o número ainda reduzido de revistas franceses no período e a importância do trânsito por esses espaços para a viabilização de uma carreira, trata-se de um recorte que a priori comporta uma quantidade relativamente pequena de pontos cegos.

Ainda assim, não foi considerada aqui a totalidade dos periódicos identificados seja com os estudos greco-latinos, seja com as ciências sociais francesas. No terreno dos clássicos, foram analisadas somente as publicações que se declaravam especializadas em Grécia e/ou em Roma antigas. Ficaram assim descartadas, entre outras, a Revue Archéologique, a Revue Épigraphique, a Revue Philologique, a Revue Celtique, a Revue des Études Juives e a Revue Historique, todas muito frequentadas por latinistas e por helenistas. Já quanto aos sociólogos, manteve-se a análise restrita apenas ao Année Sociologique, a primeira e única revista com um perfil propriamente universitário, ou seja, feita exclusivamente por professores instalados nas ou próximos às Faculdades de Letras e por seus alunos ${ }^{14}$.

Tendo em vista tal recorte, a entrada da presente pesquisa na Universidade francesa se deu a partir dos seguintes periódicos:

\footnotetext{
${ }^{14}$ Cf., em especial, KARADY, 1976 e CLARK, 1973.
} 
- L'Année Sociologique (AS), em 13 volumes, publicado, via editora Félix Alcan, por universitários franceses entre 1898 e 1913 (primeira série).

- Bulletin de Correspondance Hellénique (BCH), publicado pela École Française d'Athènes a partir de 1877.

- Mélanges d'Archéologie et Histoire (MAH), publicados pela École Française de Rome a partir de 1881.

- Revue des Études Grecques (REG), publicada pela Association pour l'Encouragement des Études grecques en France a partir de 1888.

- Revue des Études Anciennes (REA), publicada, via editora Feret \& Fils, por universitários franceses a partir de 1899.

O corpus documental assim delimitado explica, a reboque, o recorte temporal da tese. Como, em decorrência da eclosão da Primeira Guerra Mundial, a revista dos durkheimianos esteve ativa apenas durante o intervalo situado entre 1898 e 1913, a análise de seus diálogos com os antiquisants se viu reduzida a ele. Não obstante, tendo em vista que a equipe inicial de L'Année Sociologique (AS) continuou relativamente coesa e que alguns de seus membros seguiram publicando artigos e resenhas científicas durante o conflito, optou-se por estender a análise das revistas dos antiquisants até o período imediatamente posterior à desmobilização geral, ocorrida em 1919.

Para cada uma das revistas que compõe essa série documental principal o procedimento analítico foi o mesmo. Fez-se, em primeiro lugar, o levantamento dos artigos e das resenhas aí publicados, buscando igualmente compreender a história, os vínculos institucionais e a morfologia de cada periódico. Tal processo incluiu, à medida que a pesquisa avançou, investigações sobre a trajetória dos colaboradores das revistas (via necrológios, memórias e biografias), bem como a leitura de editoriais e de outros textos programáticos. Todos as informações coligidas foram então armazenadas em dois dispositivos: 1) arquivos relativos a cada periódico (os quais continham dados sobre editores, divisões administrativas e científicas das revistas e análises do conteúdo dos textos científicos nelas publicados); e 2) um Banco de Dados criado em Microsoft Access, o qual, projetado especialmente para a presente pesquisa, permitiu inventariar os títulos dos artigos e das resenhas publicados em cada periódico, o ano em que vieram a público e informações sobre a formação escolar, a trajetória profissional e outros vínculos sociais dos autores (família, educação religiosa, militância política, entre outros) ${ }^{15}$. O próximo passo da pesquisa caracterizou-se justamente por uma

\footnotetext{
${ }^{15} \mathrm{O}$ autor expressa aqui toda sua gratidão para com Eduardo Dimitrov, fundamental para a montagem do Banco de Dados.
} 
análise relacional (comparativa) do material acima referido. Verificou-se então se era possível reconstruir um ou mais eventuais padrões na circulação de helenistas, de latinistas e de sociólogos no conjunto das revistas.

O primeiro capítulo, "A revista dos sociólogos e os estudos greco-latinos", apresenta os resultados dessa investigação no espaço da revista dos sociólogos. Ele problematiza, em linhas gerais, a história e os vínculos institucionais do AS e de seus colaboradores, dando ênfase tanto ao lugar que os clássicos greco-latinos aí ocupavam quanto à presença direta de antiquisants.

O segundo capítulo, "As revistas dos antiquisants e a sociologia", por sua vez, aplica os mesmos procedimentos do capítulo anterior a cada uma das quatro revistas dos antiquisants. Para tanto, ele segue uma ordem cronológica, partindo do primeiro periódico fundado, o Bulletin de Correspondance Hellénique (BCH), até chegar à Revue des Études Anciennes (REA). Ao final do capítulo há ainda uma primeira conclusão da tese, voltada à análise das tensões e afinidades que estruturam não apenas as relações entre os periódicos dos antiquisants, mas também aqueles existentes entre eles e o AS.

O terceiro capítulo, "Helenistas, latinistas e sociólogos": diálogos em instituições, busca complementar os resultados antes obtidos levando a análise para além do universo das revistas. Foram então privilegiados os diálogos ocorridos em duas instituições (o Collège de France e o Musée des Antiquités Nationales) e em um dicionário enciclopédico dedicado ao mundo antigo (o Dictionnaire des Antiquités Grecques et Romaines).

$\mathrm{Na}$ "Conclusão", propõe-se, a partir dos dados discutidos, uma discussão de cunho teórico acerca da relação entre as noções de disciplina e de interdisciplinaridade no quadro das ciências humanas.

O leitor encontrará ainda dois itens ao final da tese. O primeiro, "Caderno de Imagens", concentra as imagens mencionadas ao longo do trabalho devidamente acompanhadas de notas explicativas. O segundo, intitulado "Anexo", é a transcrição da entrevista realizada em 2010 com o helenista francês Jean Bollack. Além de aspectos específicos de sua obra, discute-se aí a história das universidades francesa e alemã, bem como as relações que ele (Bollack) manteve com os cientistas sociais de sua geração, em especial Pierre Bourdieu.

Note-se, por fim, que todas as traduções dos textos originais franceses para o português apresentadas ao longo da presente tese, salvo indicação contrária, são obra e responsabilidade de seu autor. 


\section{CAPÍTULO 1}

\section{A REVISTA DOS}

SOCIÓLOGOS

E OS ESTUDOS

GRECO-

LATINOS 
capítulo inicial da presente tese discute as relações entre helenistas, latinistas e sociólogos no seio da principal revista universitária francesa dedicada à sociologia entre o final do século XIX e o início do XX, L'Année Sociologique (AS). Viu-se na introdução como os sociólogos e os antiquisants compartilharam basicamente os mesmos espaços institucionais no sistema de ensino francês, quais sejam, as Faculdades de Letras e áreas próximas a ela (as Faculdades de Direito, a École Pratique des Hautes Études e o Collège de France). Viu-se ainda que, em decorrência do predomínio da educação literária clássica no ensino secundário, os primeiros pesquisadores que reclamaram para si o rótulo de sociólogos conheciam ao menos rudimentos dos textos e das línguas antigas. Resta saber, portanto, se eles tiveram interesse em utilizar tal legado, como o fizeram e com quem dialogaram a esse respeito.

Para tanto, a análise aqui proposta se dará em duas etapas distintas. O subcapítulo 1.1, partindo de certos traços da história, do projeto epistemológico e da morfologia do AS, tratará da recepção dos trabalhos dos antiquisants nas páginas da revista, especialmente em suas resenhas. Em seguida, no subcapítulo 1.2, serão discutidas as diferentes trajetórias dos colaboradores do AS que, pessoalmente engajados na produção de conhecimento sobre o mundo antigo, fizeram aí as vezes de especialistas. 


\section{1 - O ANNÉE}

\section{SOCIOLOGIQUE}

\section{E OS ESTUDOS}

\section{GRECO-LATINOS}

Quando o primeiro volume de L'Année Sociologique (doravante, AS) veio a público em fevereiro de 1898 , os pesquisadores franceses que se reclamavam das ciências sociais eram poucos e trabalhavam isolados. Dentro do sistema de ensino superior, apenas três professores atuavam na área. Em Paris, Alfred Espinas ministrava um curso intitulado Histoire de I'Économie Sociale na Sorbonne desde 1894, ao passo que Jean Izoulet havia sido nomeado titular da cadeira de Philosophie Sociale no Collège de France em 1897. Na província, mais especificamente em Bordeaux, Émile Durkheim permanecia sozinho, acumulando desde 1887 o ensino de Pédagogie e de Sciences Sociales (tratava-se da única cadeira assim intitulada em todo o sistema universitário francês). Todas as demais autoridades no assunto - Gabriel Tarde, Charles Letourneau, René Worms, entre outros - ocupavam postos em instituições privadas de ensino e/ou atuavam como funcionários da burocracia estatal. Além disso, no plano das revistas, a única publicação destinada às ciências sociais então existente era a Revue Internationale de Sociologie, fundada e dirigida por Worms a partir de 1893. Tratava-se, porém, de um veículo desprovido de um projeto unificado de pesquisa e afastado do sistema de ensino universitário francês no que diz respeito ao recrutamento de seus colaboradores ${ }^{1}$.

\section{UMA REVISTA ATÍPICA}

Editado e distribuído anualmente por uma editora parisiense especializada nas vanguardas científicas e filosóficas que então orbitavam a universidade francesa, a Felix Alcan, o AS teve, ao longo dos quinze anos em que foi editado (1898-1913), um único diretor, Émile

\footnotetext{
${ }^{1}$ Cf. CLARK, 1973: 147-161 e, em especial, CONSOLIM, 2008.
} 
Durkheim. Oriundo de uma família judaica e nascido em Épinal, no leste da França, em 1858, o futuro patrão da "escola sociológica francesa" era fruto do que havia de mais reputado em termos de educação nacional. Não bastasse o período como aluno da École Normale Supérieure (1879-1882) e o sucesso no concurso de agrégation de filosofia (1882), ele teve ainda a oportunidade de estagiar junto a expoentes da universidade alemã (1885-1886). A ida para o exterior estava vinculada a um projeto governamental visando acompanhar e, se possível, fazer frente aos avanços das ciências sociais alemãs. Não por acaso, de volta à França, graças a um decreto ministerial, um jovem Durkheim com pouco menos de trinta anos foi empossado na Faculdade de Letras de Bordeaux, primeiro como charge de cours (1887) e, alguns anos depois de seu doutorado, como professor titular (1896). Até o lançamento do AS, ele havia publicado três livros importantes (De la Division du Travail Social, Les Règles de la Méthode Sociologique e Le Suicide), os quais Ihe garantiram, ao lado de algumas polêmicas, um renome considerável ${ }^{2}$.

Mas nem só do diretor vive uma revista. Um dos dados que torna mais singular a empresa do AS é a montagem de sua equipe e a definição de um programa mínimo de pesquisa. Diante de um cenário de institucionalização precária e, por conseguinte, da falta de profissionais capacitados a atuar na área, foram necessários dois anos de costuras e negociações para que fossem definidos os colaboradores do primeiro volume da revista. Destes, apenas três já tinham postos na universidade, Célestin Bouglé, Emmanuel Lévy e o próprio Durkheim, o mais velho e o único titular do trio. Havia ainda um colaborador que já possuía o título de doutor, Gaston Richard, cuja idade regulava a de com Durkheim, bem como oito jovens cuja agrégation fora obtida há pouco (dentre eles, Henri Hubert, Marcel Mauss, Paul Lapie, Paul Fauconnet e François Simiand). Três fatos correlatos contribuíram para que as assimetrias existentes em termos de idades e de vínculos institucionais fossem associadas a um grau de coesão pouco comum às outras revistas de época ${ }^{3}$. Em primeiro lugar, do ponto de vista morfológico, os membros da equipe do AS possuíam todos um perfil universitário, marcado pela obtenção do certificado de agrégation e pela passagem por importantes universidades ou grandes écoles. Em seguida, em um plano afetivo, as relações entre os membros iniciais do grupo foram reforçadas por laços de amizade - ou de parentesco no caso de Mauss e de Durkheim - mais ou menos intensos conforme o caso. Por fim, despontaram também entre eles afinidades no plano político. Simiand, Hubert, Mauss, Durkheim, Fauconnet, Bouglé, Lapie, todos atuaram publicamente em favor da revisão do processo do

\footnotetext{
${ }^{2}$ FOURNIER, 2007: 105-328.

3 A literatura sobre o tema é considerável. Destaco, entre textos hoje clássicos e trabalhos mais recentes, KARADY, 1973, 1976 e 1979, BESNARD, 1979a, MUCHIELLI, 1998 e 2001, bem como FOURNIER, 2007.
} 
Capitão Dreyfus, assim como estiveram próximos, como militantes ou simpatizantes, dos quadros dirigentes do momento socialista francês. A expansão do grupo não implicou um rompimento com esse padrão de relações inicialmente delineado.

A comparação de tal grupo original com aquele que animou o último volume da primeira série do AS, publicado sob a direção de Durkheim em 1913, reforça essas impressões iniciais. Afinal, dos onze fundadores, seis continuavam a participar da revista ${ }^{4}$. Destes, cinco eram professores em Paris (Durkheim, Bouglé, Simiand, Mauss e Hubert) e apenas um exercia suas atividades na província (Paul Fauconnet). Ao lado deles, figuraram então outros vinte e dois colaboradores, envolvendo desde professores do Collège de France e da Sorbonne (respectivamente Antoine Meillet e Albert Demangeon), até alunos dos membros mais antigos (Henri Beuchat, Jean Marx, Henri Jeanmaire, Georges Davy, entre outros). Ao que tudo indica, a adesão ao AS não comprometeu, ao menos não no referido intervalo (1898-1913), nem a ascensão universitária da carreira dos sociólogos nem o interesse dos jovens quanto à nova ciência.

Em termos programáticos, os objetivos declarados do AS eram, a princípio, modestos. No prefácio do primeiro volume, eles foram apresentados sucintamente nos seguintes termos (AS, 1898: i $)^{5}$ :

O Année Sociologique não tem por objetivo único, nem mesmo por principal, apresentar um quadro anual do estado no qual se encontra a literatura propriamente sociológica. Assim delimitada, a tarefa seria restrita demais e de medíocre utilidade, pois os trabalhos desse gênero são ainda muito pouco numerosos para que um órgão bibliográfico especial seja necessário aos pesquisadores. Nós acreditamos, porém, que os sociólogos precisam urgentemente de informes regulares sobre as pesquisas feitas nas ciências especiais, história do direito, dos costumes, das religiões, estatística moral, ciências econômicas, etc., porque aí se encontram os materiais com os quais a sociologia deve ser construída. Responder a essa necessidade, tal é, antes de tudo, a finalidade da presente publicação.

Tratava-se, portanto, de constituir uma arena pública, um espaço onde os trabalhos de todas as tendências, sobre os mais variados domínios, pudessem ser discutidos e comparados. Para tanto, a publicação foi subdividida em duas partes. A primeira era reservada a artigos de fôlego (mémoires originaux), um meio de colocar em prática e à prova o ofício de sociólogo. A segunda (analyses), por sua vez, reunia duas outras modalidades de texto: resenhas (comptesrendus), textos que poderiam variar de meia a vinte páginas discutindo um livro ou um

\footnotetext{
${ }^{4}$ Paul Lapie e Dominique Parodi, no entanto, continuavam a ter laços com o grupo. Apesar de nada escrever para o volume de 1913, o nome deste figura entre os colaboradores da revista em sua folha de rosto, o que permite pensar que ele pode ter escrito resenhas sem as ter assinado.

${ }^{5}$ Veja-se ainda, para uma versão completa em português, DURKHEIM, 2007.
} 
conjunto coerente de livros, e notícias (notices), contendo a simples referência bibliográfica da obra, por vezes acrescida de um breve comentário. As resenhas e as notícias não estavam dispostas aleatoriamente na revista: elas eram ordenadas segundo as subdivisões da sociologia, tal qual os durkheimianos as concebiam ${ }^{6}$.

Entre 1898 e 1907, o formato e a periodicidade originais foram mantidos. A partir de 1908, contudo, o AS se tornou tri-anual, abandonando a publicação das mémoires originaux (que passaram a sair na forma de livros ligados a uma coleção dirigida por Durkheim na editora Alcan e intitulada Travaux de l'Année Sociologique). Dois volumes do AS foram publicados nesse formato novo, um em 1910 e outro em 1913, até que a mobilização geral de grande parte dos quadros da revista em decorrência da eclosão da Primeira Guerra Mundial inviabilizou a continuidade da revista. Uma segunda série só aparecerá mais tarde, em meados da década de 1920.

Cumpre, por fim, destacar que todo esse arranjo, seja no plano do perfil dos colaboradores seja no plano da forma e da periodicidade, faz do AS uma revista atípica entre suas contemporâneas. Afinal, nenhuma publicação consultada durante a pesquisa que culminou com a presente tese apresentou as mesmas características: a coesão do grupo, a exclusividade das contribuições (restritas apenas ao grupo) e o investimento nas resenhas ${ }^{7}$.

\section{POR UM COMPARATISMO RADICAL}

Além de apresentar aos cientistas sociais franceses os mais abrangentes informes bibliográficos, os sociólogos trabalhando sob a direção de Durkheim alimentavam outro projeto intelectual, este mais ambicioso. De modo a ter uma visão mais abrangente e completa dos fenômenos sociais, eles almejavam levar o comparatismo o mais longe possível. Mauss conta no texto autobiográfico que redigiu por ocasião de sua derradeira e vitoriosa campanha ao Collège de France, em 1930, uma anedota interessante nesse sentido: ele e Hubert, visando enriquecer suas pesquisas coletivas no âmbito da sociologia religiosa, haviam simplesmente decidido dividir o mundo entre eles. Enquanto este deveria se ocupar dos povos primitivos e antigos da Europa, aquele trataria das sociedades africanas, americanas, asiáticas e da Oceania (MAUSS, 1979). O problema todo dizia respeito à articulação necessária entre o todo e as partes, o geral e o particular. Dirigindo-se especificamente aos historiadores, Durkheim, no prefácio do volume inaugural do AS, afirmou (AS, 1898: ii-iii):

\footnotetext{
${ }^{6}$ Cf., na sequência, o item De Algumas Formas Sociológicas de Classificação.

${ }^{7}$ Isso se tornará mais claro ao longo do capítulo dois, quando as revistas dos antiquisants serão tratadas com maiores detalhes.
} 
A história só pode ser uma ciência na medida que explica e não pode explicar senão comparando. Mesmo a simples descrição é impraticável de outra maneira: não se descreve bem um fato único ou do qual se possuem raros exemplos porque ele não é bem observado. Por tal razão, Fustel de Coulanges, a despeito de seu profundo conhecimento das coisas históricas, enganou-se sobre a natureza da gens, na qual ele viu apenas uma vasta família de agnatos, o que ocorreu porque ele ignorava casos etnográficos análogos a esse tipo familiar. 0 verdadeiro sacer romano é bem difícil de ser percebido e sobretudo compreendido se não se aproxima dele o tabu polinésio. Os exemplos que nós poderíamos fornecer são inumeráveis. É pois servir à causa da história ajudar o historiador a superar seu ponto de vista ordinário, a estender seu olhar para além do país e do período que ele se propõe mais especialmente a estudar, bem como a se preocupar com questões gerais que originam os fatos particulares por ele observados. Ora, se a história compara, ela se torna indistinta da sociologia. Por outro lado, a sociologia não somente não pode se privar da história, como ela tem mesmo necessidade de historiadores que sejam ao mesmo tempo sociólogos. Enquanto ela tiver de se introduzir como estrangeiro no domínio histórico para aí apreender, em alguma medida, os fatos que a interessam, ela poderá fazer aí apenas incursões bastante rasas ${ }^{8}$.

Mas um comparatismo radical, capaz de esclarecer um fato romano a partir de um fato polinésio, para ser eficiente, tem de ser rigorosamente controlado do ponto de vista do fenômeno estudado e do método adotado. Ao historiador que coleciona facetas de uma única sociedade sem jamais se interessar por fatos análogos em outras, os sociólogos durkheimianos não opuseram o diletante interessado em todas as sociedades ao mesmo tempo. Em uma resenha do livro The Mistic Rose, de Ernest Crawley, a critica do patrão do AS evoca justamente nesse ponto (AS, 1903: 352):

Esta obra apresenta no mais alto grau as qualidades e os defeitos que podem servir para caracterizar a escola de antropologia religiosa. Encontram-se aí seguramente ideias interessantes (...). Mas faltam ao método, em um nível raro, crítica e discernimento. Para provar uma proposição, o não hesita em aproximar de forma confusa fatos emprestados de sociedades as mais heterogêneas. Todos os continentes são percorridos sem ordem, sem distinção; os documentos do folclore europeu, aqueles que se relacionam às sociedades australianas, ao Egito, à China, etc., são continuamente colocados sob um mesmo plano. Disso resulta que a impressão que se extrai desse turbilhão de fatos é, ela própria, confusa e instável. Ao mesmo tempo, a extrema facilidade com a qual são por vezes aceitas, sem exame prévio, todas as informações que podem servir para confirmar as teses enunciadas compromete a autoridade das conclusões. Por fim, as teorias propostas para dar conta dos fatos são de um simplismo verdadeiramente intrépido.

Defendeu-se no AS, portanto, um compromisso entre um programa de pesquisa conjunto e a erudição do especialista. Esta deveria estar a serviço daquele. Com efeito, um dos traços marcantes da revista, algo determinante para o sucesso da empresa intelectual de Durkheim e

\footnotetext{
${ }^{8}$ Veja-se também, para uma reflexão muito similar, a resenha que Durkheim publicou em AS, 1903: 123125.
} 
de seus membros, foi a divisão do trabalho de pesquisa. Na ausência de instituições aptas a disciplinar os discípulos da nova ciência, inculcando neles preceitos minimamente compartilhados, a própria publicação foi transformada em centro de treinamento: o que se manifesta na escolha das resenhas e na participação, para além da revista, em projetos de pesquisa comuns.

É importante reter tal especificidade do AS, pois ela é determinante para que se possa compreender por que chaves os trabalhos de helenistas e latinistas chamaram a atenção dos sociólogos. Assim sendo, antes de explorar esse diálogo direto com o saber produzido por antiquisants, é salutar entender como, nos termos dos sociólogos, se dava essa divisão interna do trabalho de pesquisa.

\section{DE ALGUMAS FORMAS SOCIOLÓGICAS DE CLASSIFICAÇÃO}

Tendo se destacado por trazer à tona o problema da relação entre a organização social e as formas de classificação, a equipe do AS não pôde se furtar à prática de explicitar a origem e o significado das categorias manejadas por eles. Tarefa tanto mais importante quanto mais recente a ciência. Os doze quadros dispostos ao final do presente subcapítulo (de 1.1.1 a 1.1.12) permitem visualizar o que muda e o que permanece na organização da revista. Nota-se aí, em primeiro lugar, a continuidade absoluta no que tange as grandes seções da revista (as quais deveriam encarnar as grandes seções da disciplina): Sociologie Générale, Sociologie Religieuse, Sociologie Juridique et Morale, Sociologie Criminelle, Sociologie Économique e Divers. As justificativas desse arranjo eram precárias e bastante ambíguas, como ilustra uma passagem do texto co-escrito por Mauss e Fauconnet para a Grande Encyclopédie em 1901 (MAUSS, 1983c: 175):

\footnotetext{
A sociologia adota e transforma em suas as grandes divisões, já percebidas pelas diversas ciências comparadas das instituições das quais ela pretende ser a herdeira: ciência do direito, das religiões, economia política, etc. Desse ponto de vista, ela se divide facilmente em sociologias especiais. Mas, ao adotar tal repartição, ela não segue servilmente as classificações usuais que são, em sua maioria, de origem empírica ou prática, como, por exemplo, aquelas da ciência do direito. Em especial, ela não estabelece entre os fatos essas rígidas fronteiras que existem normalmente entre as diversas ciências especiais. O sociólogo que estuda os fatos jurídicos e morais deve, com frequência, para compreendê-los, associá-los aos fenômenos religiosos. $\mathrm{O}$ que estuda a propriedade deve considerar esse fenômeno sob seu duplo aspecto jurídico e econômico, enquanto esses dois lados do mesmo fato são comumente estudados por pesquisadores diferentes.
}

Na prática, essas divisões remetiam às divisões "tribais" dos próprios sociólogos. No primeiro volume da revista, por exemplo, cada seção tem um coordenador geral: Bouglé está associado 
à Sociologie Générale; Mauss e Hubert, à Sociologie Religieuse; Durkheim, Lapie e Emmanuel Lévy à Sociologie Morale et Juridique; Richard, à Sociologie Criminelle; Simiand à Sociologie Économique; e a seção intitulada Divers aparece como um espaço compartilhado. Durkheim, por certo, pairava por todos os campos, mas intervindo, ao menos de início, pouco. São três as mudanças significativas ocorridas nesse espaço: 1) a estabilização da seção Divers a partir de 1902 (com as subdivisões Sociologie Esthétique, Language e Technologie, cada uma com seus patrões respectivos), 2) o aparecimento de uma nova seção intitulada Morphologie Sociale já em 1899 (dominada a princípio por Durkheim e, depois, por Halbwachs), bem como 3) a estagnação e o esvaziamento da seção relativa à Sociologie Criminelle, cujo principal responsável rompe com a escola sociológica francesa em $1907^{9}$.

Mas se o que domina as grandes seções do AS é a estabilidade, o mesmo não pode ser dito de das subseções de cada uma delas. Sinal de vitalidade da produção dos sociólogos, as categorias mudam aí com bastante frequência, não sendo raro o responsável pela seção apresentar a cada volume da revista uma nota de esclarecimento ${ }^{10}$. São três as seções com o maior número de subdivisões: Sociologie Religieuse, Sociologie Morale et Juridique e Sociologie Économique. Elas apresentaram constantes modificações em sua estrutura, assim como acolheram a maior parte das resenhas publicadas na revista. Não seria exagero dizer que elas constituíram o carro-chefe da revista e, por conseguinte, expressam as áreas de predileção dos primeiros sociólogos.

Tendo isso em mente, é interessante agora verificar a acolhida que foi dada aos estudos greco-latinos nas páginas do AS.

\section{ONde Colocar Pausânias?}

Em uma carta datada provavelmente de primeiro de janeiro de 1899, Durkheim escreveu a seu sobrinho: "eu coloco o Pausânias em meio aos 'Ritos Populares'. Isso te convém?" (DURKHEIM, 1998: 189). O livro ao qual o diretor do AS fazia então referência era Pausanias's Description of Greece, publicado na Inglaterra por ninguém menos que o antropólogo James Frazer. Hubert, o autor da resenha (AS, 1899: 229-233), a despeito de algumas reservas de método, elogiou o autor, "que se sabia ser tanto helenista quanto etnólogo", enfatizando o quanto tal obra "será para os sociólogos um repertório cômodo de

\footnotetext{
${ }^{9}$ Sobre Richard e seu conflito com o grupo, veja-se PICKERING, 1979, bem como o subcapítulo 2.4 da presente tese (a parte relativa aos ataques de Richard aos sociólogos durkheimianos na Revue des Études Anciennes).

${ }^{10}$ Simiand chega a publicar um capítulo de livro sobre a questão. Veja-se, a esse respeito, SIMIAND, 1912: 153-177.
} 
antiguidade grega, esclarecida pela etnologia"11. Quanto à questão de Durkheim, não deixa de ser interessante constatar que a resenha foi publicada em outra subdivisão da seção de Sociologie Religieuse. Ao invés de Mythes, Légendes, Croyances Populaires, quem a acolheu foi Cultes en Général, plus spécialement agraires. Mas se esse foi o destino do Pausânias de Frazer, quais foram os dos outros livros relacionados a Grécia e Roma antigas?

Os quadros apresentados nas páginas que se seguem acompanham ano a ano a produção de resenhas de livros relacionados ao mundo greco-latino no seio do AS (Quadros 1.1.1 a 1.1.12) $)^{12}$. Eles indicam a seção e a subseção em que o texto foi publicado, bem como o autor da resenha (se ele não foi indicado na revista, o quadro apresenta, acompanhado de um ponto de interrogação, os nomes dos responsáveis da subseção). As notícias, simples referências bibliográficas ou notas menores, foram descartadas da análise por não desenvolverem uma discussão crítica acerca do livro mencionado. Por fim, poder-se-á ainda verificar, em números absolutos e relativos, o peso desses estudos específicos no conjunto e em cada seção maior do AS.

O que se depreende desses dados, em um plano mais geral, é que as resenhas relacionadas à Grécia e Roma antigas ocupam um espaço relativamente pequeno, mas constante, no AS. A porcentagem desses textos varia de 5,84\% (1901) a 12,17\% (1913), sem que sejam constatadas grandes variações abruptas. Outro dado interessante a ser discutido é a autoria dos textos. O que se vê nos quadros é o envolvimento da grande maioria dos membros da equipe do AS nessas questões. Por certo, existem assimetrias quanto à distribuição dos textos. Henri Hubert, por exemplo, foi, de longe, o mais próximo desses estudos ${ }^{13}$. Destacamse nessa incumbência também um jurista interessado na história do direito antigo, Paul Huvelin, bem como, nos derradeiros volumes do AS, o helenista Louis Gernet. Ainda assim, com variações consideráveis entre eles, Mauss, Durkheim, H. Bourgin, Simiand, Fauconnet, É. Lévy e Richard fizeram o mesmo. Eis aí um indício bastante forte do peso desses estudos no conjunto do sistema de ensino francês. A despeito de muitos não atuarem profissionalmente como antiquisants, eles dispunham do interesse e dos elementos necessários para realizar a crítica das obras.

\footnotetext{
${ }^{11}$ Sobre Frazer e suas relações com os helenistas ingleses, veja-se ACKERMAN, 2002.

${ }^{12}$ É difícil separar os trabalhos relativos à Antiguidade greco-latina daqueles dedicados à Antiguidade Cristã. Em todo caso, optou-se aqui por sinalizar os trabalhos que, tratando da origem da Igreja ou dos cultos cristão, os situem em relação ao ambiente social, político e religioso do mundo antigo. Todos os trabalhos centrados exclusivamente na doutrina crista não foram assim considerados. 0 mesmo vale para a Antiguidade Oriental.

13 Trata-se, afinal, de um sociólogo agrégé d’histoire, cuja atuação profissional o levou a flertar continuamente com os helenistas e latinistas. Veja-se, sobre isso, o subcapítulo 1.2 da presente tese.
} 
Quadro 1.1.1 - A presença da antiguidade greco-latina em L'Année Sociologique (compte-rendus/resenhas - 1898).

\begin{tabular}{|c|c|c|c|c|}
\hline $\begin{array}{l}\text { SEÇÃO DE L'ANNÉE } \\
\text { SOCIOLOGIQUE }\end{array}$ & $\begin{array}{l}\text { RESENHAS POR } \\
\text { SEÇÃO ( } N=100 \%)\end{array}$ & $\begin{array}{l}\text { RESENHAS RELATIVAS AO } \\
\text { MUNDO GRECO-LATINO (N/\%) }\end{array}$ & SUBSEÇÕES DE L'ANNÉE SOCIOLOGIQUE & $\begin{array}{l}\text { TíTULO DAS OBRAS RESENHADAS RELATIVAS AO MUNDO GRECO-LATINO/ } \\
\text { AUTOR DA RESENHA }\end{array}$ \\
\hline \multirow{3}{*}{$\begin{array}{l}\text { SOCIOLOGIE } \\
\text { GÉNÉRALE }\end{array}$} & \multirow{3}{*}{13} & \multirow{3}{*}{$0(0 \%)$} & SOCIOLOGIE PHILOSOPHIQUE & \\
\hline & & & SOCIOLOGIE BIOLOGIQUE & \\
\hline & & & SOCIOLOGIE PSYCHOLOGIQUE ET SPÉCIFIQUE & \\
\hline \multirow{8}{*}{$\begin{array}{l}\text { SOCIOLOGIE } \\
\text { RELIGIEUSE }\end{array}$} & \multirow{8}{*}{18} & \multirow{8}{*}{$4(22,22 \%)$} & TRAITÉS GÉNÉRAUX, PHILOSOPHIE, MÉTHODE & \\
\hline & & & RELIGIONS PRIMITIVES EN GÉNÉRAL & \\
\hline & & & CULTE DOMESTIQUE & DE MARCHI. II culto privato di Roma Antica (Mauss) \\
\hline & & & CROYANCES ET PRATIQUES CONCERNANT LES MORTS & PERCY GARDNER. Sculptured Tombs of Hellas (Mauss) \\
\hline & & & CULTES POPULAIRES EN GÉNÉRAL & \\
\hline & & & LE RITUEL & MAGANI. L'Antica Liturgia romana (Mauss) \\
\hline & & & MYTHES & HARTLAND. The Legend of Perseus (Mauss/ Hubert) \\
\hline & & & ORGANISATION DU CULTE. MONACHISME. & \\
\hline \multirow{8}{*}{$\begin{array}{l}\text { SOCIOLOGIE } \\
\text { MORALE ET } \\
\text { JURIDIQUE }\end{array}$} & \multirow{8}{*}{29} & \multirow{8}{*}{$1(3,45 \%)$} & THÉORIES GÉNÉRALES SUR LE DROIT ET LA MORALE & \\
\hline & & & ÉTUDES OBJECTIVES SUR LES MOEURS & \\
\hline & & & LA FAMILLE & LEIST. Alt-Arisches Jus civile (Durkheim) \\
\hline & & & LE MARIAGE & \\
\hline & & & LA PEINE & \\
\hline & & & L'ORGANISATION SOCIALE & \\
\hline & & & LE DROIT DE PROPRIÉTÉ & \\
\hline & & & DIVERS & \\
\hline \multirow{2}{*}{$\begin{array}{l}\text { SOCIOLOGIE } \\
\text { CRIMINELLE }\end{array}$} & \multirow[t]{2}{*}{18} & \multirow[t]{2}{*}{$0(0 \%)$} & LA STATISTIQUE MORALE & \\
\hline & & & L'ANTHROPOLOGIE CRIMINELLE & \\
\hline \multirow{4}{*}{$\begin{array}{l}\text { SOCIOLOGIE } \\
\text { ÉCONOMIQUE }\end{array}$} & \multirow{4}{*}{19} & \multirow{4}{*}{$0(0 \%)$} & THÉORIES ÉCONOMIQUES & \\
\hline & & & LES GROUPEMENTS PROFESSIONNELS & \\
\hline & & & HISTOIRE DU TRAVAIL & \\
\hline & & & L'ÉVOLUTION COMMERCIALE & \\
\hline \multirow{4}{*}{ DIVERS } & \multirow{3}{*}{6} & \multirow{3}{*}{$1(16,67 \%)$} & L'ANTHROPO-SOCIOLOGIE & \\
\hline & & & LA SOCIO-GÉOGRAPHIE & \\
\hline & & & QUESTIONS DE DÉMOGRAPHIE & OTTO SEECK. Die Statistik in der alten Geschichte (...) (Fauconnet) \\
\hline & 83 & $6(7,23 \%)$ & & \\
\hline
\end{tabular}


Quadro 1.1.2 - A presença da antiguidade greco-latina em L'Année Sociologique (compte-rendus/resenhas - 1899).

\begin{tabular}{|c|c|c|c|c|}
\hline $\begin{array}{l}\text { SEÇÃO DE L'ANNÉE } \\
\text { SOCIOLOGIQUE }\end{array}$ & $\begin{array}{l}\text { RESENHAS POR } \\
\text { SEÇÃO (N=100\%) }\end{array}$ & $\begin{array}{l}\text { RESENHAS RELATIVAS AO } \\
\text { MUNDO GRECO-LATINO (N/\%) }\end{array}$ & SUBSEÇÕES DE L'ANNÉE SOCIOLOGIQUE & $\begin{array}{l}\text { TíTULO DAS OBRAS RESENHADAS RELATIVAS AO MUNDO GRECO-LATINO/ } \\
\text { AUTOR DA RESENHA }\end{array}$ \\
\hline \multirow{3}{*}{$\begin{array}{l}\text { SOCIOLOGIE } \\
\text { GÉNÉRALE }\end{array}$} & \multirow{3}{*}{12} & \multirow{3}{*}{ ( } & MÉTHODOLOGIE & \\
\hline & & & PHILOSOPHIE SOCIALE & \\
\hline & & & DIVERS & \\
\hline \multirow{9}{*}{$\begin{array}{l}\text { SOCIOLOGIE } \\
\text { RELIGIEUSE }\end{array}$} & \multirow{9}{*}{29} & \multirow{9}{*}{$7(24,13 \%)$} & TRAITÉS GÉNÉRAUX & \\
\hline & & & RELIGIONS PRIMITIVES EN GÉNÉRAL & \\
\hline & & & MAGIE, SORCELLERIE ET SUPERTITIONS POPULAIRES & \\
\hline & & & CROYANCES ET RITES RELATIFS AUX MORTS & ROHDE. Psyche (Hubert/Mauss?) \\
\hline & & & CULTES EN GÉNÉRAL, PLUS SPÉCIALEMENT AGRAIRES & FRAZER. Pausania's description of Greece (Hubert) \\
\hline & & & MYTHES, LÉGENDES, CROYANCES POPULAIRES & $\begin{array}{l}\text { GRUPPE. Griechische Mythologie und Religionsfeschichte (Hubert) } \\
\text { USENER. Der Stoff der griechischen Epos (Hubert) } \\
\text { USENER. Gottliche Synonymie (Hubert) }\end{array}$ \\
\hline & & & LE RITUEL (SACRIFICES, PRIÈRES, MYSTÈRES) & $\begin{array}{l}\text { MAGALI. L'antica Liturgia Romana (Mauss) } \\
\text { DUCHESNE. Origines du culte chrétien (Mauss) }\end{array}$ \\
\hline & & & LES INSTITUTIONS MONACALES ET ASCÉTIQUES & \\
\hline & & & ÉTUDES DIVERSES SUR LES GRANDES RELIGIONS & \\
\hline \multirow{10}{*}{$\begin{array}{l}\text { SOCIOLOGIE } \\
\text { MORALE ET } \\
\text { JURIDIQUE }\end{array}$} & \multirow{10}{*}{33} & \multirow{10}{*}{$3(9,09 \%)$} & GÉNÉRALITÉS & \\
\hline & & & MOEURS SELON L'HABITAT & \\
\hline & & & MORALITÉ SEXUELLE. LA FEMME & \\
\hline & & & LA FAMILLE & $\begin{array}{l}\text { LEFAS. L'adoption testamentaire à Rome (Durkheim) } \\
\text { CORNIL. Contribution à l'étude de la 'patria potestas' (Durkheim) }\end{array}$ \\
\hline & & & LE MARIAGE & \\
\hline & & & LE DROIT DE PROPRIÉTÉ & \\
\hline & & & LE DROIT PÉNAL & \\
\hline & & & LA RESPONSABILITÉ & GIRARD. Manuel élémentaire de droit romain (Fauconnet) \\
\hline & & & ORGANISATION SOCIALE ET POLITIQUE & \\
\hline & & & DIVERS & \\
\hline \multirow{3}{*}{$\begin{array}{l}\text { SOCIOLOGIE } \\
\text { CRIMINELLE }\end{array}$} & \multirow{3}{*}{11} & \multirow{3}{*}{$1(9,09 \%)$} & $\begin{array}{l}\text { SOCIOLOGIE CRIMINELLE ET STATISTIQUE MORALE } \\
\end{array}$ & DUPOUY. La prostitution dans l'antiquité (Richard) \\
\hline & & & $\begin{array}{l}\text { PSYCHIATRIE ET L'ANTHROPOLOGIE CRIMINELLE } \\
\end{array}$ & \\
\hline & & & DIVERS & \\
\hline \multirow{4}{*}{$\begin{array}{l}\text { SOCIOLOGIE } \\
\text { ÉCONOMIQUE }\end{array}$} & \multirow{4}{*}{13} & \multirow{4}{*}{$1(7,69 \%)$} & CONCEPTION DE LA SCIENCE ÉCONOMIQUE & \\
\hline & & & ÉCONOMIE DES PEUPLES PRIMITIFS & \\
\hline & & & ANTIQUITÉ CLASSIQUE ET MOYEN ÂGE OCCIDENTAL & ADLER. Die socialreform im Altertum (Simiand) \\
\hline & & & ÉCONOMIE MODERNE ET OCCIDENTALE & \\
\hline \multirow{4}{*}{$\begin{array}{l}\text { MORPHOLOGIE } \\
\text { SOCIALE }\end{array}$} & \multirow{4}{*}{7} & \multirow{4}{*}{$0(0 \%)$} & MORPHOLOGIE GÉNÉRALE & \\
\hline & & & MASSE ET DENSITÉ SOCIALE & \\
\hline & & & LES GROUPES URBAINS ET LEUR ÉVOLUTION & \\
\hline & & & DIVERS & \\
\hline \multirow{3}{*}{ DIVERS } & \multirow{3}{*}{7} & \multirow{3}{*}{$0(0 \%)$} & ÉTHOLOGIE COLLECTIVE & \\
\hline & & & QUESTIONS DE MÉTHODOLOGIE STATISTIQUE & \\
\hline & & & L'ANTHROPOSOCIOLOGIE & \\
\hline & 112 & $12(10,71 \%)$ & & \\
\hline
\end{tabular}


Quadro 1.1.3 - A presença da antiguidade greco-latina em L'Année Sociologique (compte-rendus/resenhas - 1900).

\begin{tabular}{|c|c|c|c|c|}
\hline $\begin{array}{l}\text { SEÇÃO DE L'ANNÉE } \\
\text { SOCIOLOGIQUE }\end{array}$ & $\begin{array}{l}\text { RESENHAS POR } \\
\text { SEÇÃO ( } N=100 \%)\end{array}$ & $\begin{array}{l}\text { RESENHAS RELATIVAS AO } \\
\text { MUNDO GRECO-LATINO (N/\%) }\end{array}$ & SUBSEÇÕES DE L'ANNÉE SOCIOLOGIQUE & $\begin{array}{l}\text { TíTULO DAS OBRAS RESENHADAS RELATIVAS AO MUNDO GRECO-LATINO/ } \\
\text { AUTOR DA RESENHA }\end{array}$ \\
\hline \multirow{4}{*}{$\begin{array}{l}\text { SOCIOLOGIE } \\
\text { GÉNÉRALE }\end{array}$} & \multirow{4}{*}{14} & \multirow{4}{*}{$0(0 \%)$} & CONCEPTIONS GÉNÉRALES ET MÉTHODOLOGIE & \\
\hline & & & CIVILISATION ET PROGRÈS & \\
\hline & & & PERSONNALITÉ INDIVIDUELLE ET COLLECTIVE & \\
\hline & & & QUESTIONS DIVERSES & \\
\hline \multirow{7}{*}{$\begin{array}{l}\text { SOCIOLOGIE } \\
\text { RELIGIEUSE }\end{array}$} & \multirow{7}{*}{39} & \multirow{7}{*}{$4(10,26 \%)$} & TRAITÉ GÉNÉRAUX, MÉTHODE & \\
\hline & & & PHÉNOMĖNES RELIGIEUX ÉLÉMENTAIRES & $\begin{array}{l}\text { ARBOIS DE JUBAINVILLE. La civilisation des Celtes et celle de l'épopée } \\
\text { homérique (Hubert) }\end{array}$ \\
\hline & & & CROYANCES ET RITES RELATIFS AUX MORTS & \\
\hline & & & CULTES EN GÉNÉRAL, PLUS SPÉCIALEMENT AGRAIRES & MOMMSEN. Feste der Stadt Athen in Alterthum (Hubert) \\
\hline & & & TRADITIONS ET CROYANCES & $\begin{array}{l}\text { GILBERT. Griechische Goetterlehre in ihren Grundzuegen dargestellt } \\
\text { (Hubert) }\end{array}$ \\
\hline & & & RITUEL & \\
\hline & & & ÉTUDES DIVERSES SUR LES GRANDES RELIGIONS & BURCKHARDT. Griechische Kulturgeschichte (vol. 2) (Stickney) \\
\hline \multirow{10}{*}{$\begin{array}{l}\text { SOCIOLOGIE } \\
\text { MORALE ET } \\
\text { JURIDIQUE }\end{array}$} & \multirow{10}{*}{38} & \multirow{10}{*}{$4(10,53 \%)$} & GÉNÉRALITÉS, PHILOSOPHIE & \\
\hline & & & ORGANISATION POLITIQUE ET SOCIALE & $\begin{array}{l}\text { WILBRANDT. Die politische und sociale Bedeutung der attischen } \\
\text { Geschlechter vor Solon (Durkheim); } \\
\text { BURCKHARDT. Griechische Kulturgeschichte (vol. 1) (Stickney) }\end{array}$ \\
\hline & & & LA FAMILLE & \\
\hline & & & LE MARIAGE, LA CONDITION DE LA FEMME & \\
\hline & & & LE DROIT DE PROPRIÉTÉ & \\
\hline & & & LE CONTRAT & \\
\hline & & & LE DROIT PÉNAL & FERRINI. Diritto penale romano (Isidore Lévy/Fauconnet ?) \\
\hline & & & LA RESPONSABILITÉ & \\
\hline & & & LA PROCEDURE & DI MARZO. Storia della procedura criminale romana (Fauconnet) \\
\hline & & & QUESTIONS DIVERSES & \\
\hline \multirow{5}{*}{$\begin{array}{l}\text { SOCIOLOGIE } \\
\text { CRIMINELLE }\end{array}$} & \multirow{5}{*}{17} & \multirow{5}{*}{$0(0 \%)$} & GÉNÉRALITÉ ET MÉTHODOLOGIE & \\
\hline & & & CRIMINALITÉ GÉNÉRALE SELON LES PAYS & \\
\hline & & & FACTEURS DIVERS DE LA CRIMINALITÉ GÉNÉRALE & \\
\hline & & & FORMES SPÉCIALES DE LA CRIMINALITÉ & \\
\hline & & & L'ANTHROPOLOGIE CRIMINELLE & \\
\hline \multirow{6}{*}{$\begin{array}{l}\text { SOCIOLOGIE } \\
\text { ÉCONOMIQUE }\end{array}$} & \multirow{6}{*}{17} & \multirow{6}{*}{$1(5,88 \%)$} & GÉNÉRALITÉS, MÉTHODOLOGIE & \\
\hline & & & REGIMES ÉCONOMIQUES & \\
\hline & & & ÉCONOMIE GÉNÉRALE, DISTRIBUTION & $\begin{array}{l}\text { BILLETER. Geschichte der Zinsfusses im griechischen, römischen Altertum bis } \\
\text { auf Justinian (Simiand) }\end{array}$ \\
\hline & & & ÉCONOMIE SPÉCIALES & \\
\hline & & & ÉCONOMIE NATIONALES ET ÉCONOMIES LOCALES & \\
\hline & & & THÉORIES SOCIALES, SOCIALISME & \\
\hline \multirow{4}{*}{$\begin{array}{l}\text { MORPHOLOGIE } \\
\text { SOCIALE }\end{array}$} & \multirow{4}{*}{6} & \multirow{4}{*}{$0(0 \%)$} & LES MIGRATIONS HUMAINES & \\
\hline & & & MASSE, DENSITÉ SOCIALE; LEURS CAUSES & \\
\hline & & & GROUPEMENTS RURAUX ET GROUPEMENTS URBAINS & \\
\hline & & & LE MÉNAGE ET SON HABITAT & \\
\hline \multirow[t]{3}{*}{ DIVERS } & \multirow[b]{2}{*}{7} & \multirow[b]{2}{*}{$0(0 \%)$} & SOCIOLOGIE ESTHÉTIQUE & \\
\hline & & & L'ANTHROPOSOCIOLOGIE & \\
\hline & 138 & $9(6,52 \%)$ & & \\
\hline
\end{tabular}


Quadro 1.1.4 - A presença da antiguidade greco-latina em L'Année Sociologique (compte-rendus/resenhas - 1901).

\begin{tabular}{|c|c|c|c|c|}
\hline $\begin{array}{l}\text { SEÇÃO DE L'ANNÉE } \\
\text { SOCIOLOGIQUE }\end{array}$ & $\begin{array}{l}\text { RESENHAS POR } \\
\text { SEÇÃO (N=100\%) }\end{array}$ & $\begin{array}{l}\text { RESENHAS RELATIVAS AO } \\
\text { MUNDO GRECO-LATINO (N/\%) }\end{array}$ & SUBSEÇÕES DE L'ANNÉE SOCIOLOGIQUE & $\begin{array}{l}\text { TíTULO DAS OBRAS RESENHADAS RELATIVAS AO MUNDO GRECO-LATINO/ } \\
\text { AUTOR DA RESENHA }\end{array}$ \\
\hline \multirow{5}{*}{$\begin{array}{l}\text { SOCIOLOGIE } \\
\text { GÉNÉRALE }\end{array}$} & \multirow{5}{*}{16} & \multirow{5}{*}{$0(0 \%)$} & MÉTHODOLOGIE, CONCEPTIONS GÉN. DE LA SCIENCE & \\
\hline & & & ÉTUDES D'ENSEMBLE SUR L'ÉVOLUTION SOCIALE & \\
\hline & & & LA MENTALITÉ DES GROUPES & \\
\hline & & & ANTHROPOLOGIE ET SOCIOLOGIE & \\
\hline & & & HISTOIRE DES DOCTRINES SOCIOLOGIQUES & \\
\hline \multirow{8}{*}{$\begin{array}{l}\text { SOCIOLOGIE } \\
\text { RELIGIEUSE }\end{array}$} & \multirow{8}{*}{47} & \multirow{8}{*}{$5(10,64 \%)$} & CONCEPTIONS GÉNÉRALES & \\
\hline & & & PHÉNOMĖNES RELIGIEUX ÉLÉMENTAIRES & \\
\hline & & & LA MAGIE & BOUCHÉ-LECLERQ. L'astrologie grecque (Hubert) \\
\hline & & & CROYANCE ET RITES RELATIFS AUX MORTS & \\
\hline & & & LES SOCIÉTÉS RELIGIEUSES ET LEUR ORGANISATION & ALLIN. Race and religion; Hellenistic theology (...) (Hubert) \\
\hline & & & LE RITUEL & FOWLER. The Roman Festivals of the Republic (Hubert) \\
\hline & & & LES REPRÉSENTATIONS RELIGIEUSES & \\
\hline & & & ÉTUDES DIVERSES SUR LES GRANDES RELIGIONS & $\begin{array}{l}\text { AUST. Die Religion der Römer (Hubert) } \\
\text { CUMONT. Textes relatifs aux mystères de Mithra (Hubert) }\end{array}$ \\
\hline \multirow{8}{*}{$\begin{array}{l}\text { SOCIOLOGIE } \\
\text { JURIDIQUE ET } \\
\text { MORALE }\end{array}$} & \multirow{8}{*}{34} & \multirow{8}{*}{$2(5,88 \%)$} & CONSIDÉRATIONS GÉNÉRALES & \\
\hline & & & ORGANISATION SOCIALE ET POLITIQUE & LIEBENAM. Staedteverwaltung im Roemischen Kaiserreiche (Durkheim) \\
\hline & & & ORGANISATION DOMESTIQUE & \\
\hline & & & LE DROIT DE PROPRIÉTÉ & \\
\hline & & & LE DROIT CONTRACTUEL & \\
\hline & & & LE DROIT CRIMINEL & MOMMSEN. Roemisches Strafrecht (Fauconnet) \\
\hline & & & ÉTUDES D’ENSEMBLE & \\
\hline & & & DE DIVERSES NOTIONS MORALES ET JURIDIQUES & \\
\hline \multirow{8}{*}{$\begin{array}{l}\text { SOCIOLOGIE } \\
\text { CRIMINELLE ET } \\
\text { STATISTIQUE } \\
\text { MORALE }\end{array}$} & \multirow{8}{*}{15} & \multirow{8}{*}{$0(0 \%)$} & $\begin{array}{l}\text { STATISTIQUE DE LA VIE DOMESTIQUE ET CONJUGALE } \\
\end{array}$ & \\
\hline & & & $\begin{array}{l}\text { STATISTIQUE DE LA MORALITÉ SEXUELLE } \\
\end{array}$ & \\
\hline & & & DE LA MORALITÉ ET DE LA CRIMINALITÉ EN GÉNÉRAL & \\
\hline & & & FACTEURS DIVERS DE LA CRIMINALITÉ & \\
\hline & & & FORMES SPÉCIALES DE LA CRIMINALITÉ & \\
\hline & & & LES ASSOCIATIONS DE MALFAITEURS & \\
\hline & & & FONCTIONNEMENT DU SYSTÈME REPRESSIF & \\
\hline & & & LA FOLIE COMME FAIT SOCIAL & \\
\hline \multirow{10}{*}{$\begin{array}{l}\text { SOCIOLOGIE } \\
\text { ÉCONOMIQUE }\end{array}$} & \multirow{10}{*}{15} & \multirow{10}{*}{$0(0 \%)$} & ÉTUDES GÉNÉRALES, MÉTHODOLOGIE & \\
\hline & & & SYSTÈMES ÉCONOMIQUES & \\
\hline & & & RÉGIME DE LA PRODUCTION & \\
\hline & & & FORMES DE LA PRODUCTION ET DU COMMERCE & \\
\hline & & & CLASSES ÉCONOMIQUES & \\
\hline & & & ÉLÉMENTS DE LA RÉPARTITION & \\
\hline & & & ASSOCIATIONS PROFESSIONNELES & \\
\hline & & & ÉCONOMIES SPÉCIALES & \\
\hline & & & POLITIQUE ÉCONOMIQUE & \\
\hline & & & THÉORIES SOCIALES, SOCIALISME & \\
\hline \multirow{3}{*}{$\begin{array}{l}\text { MORPHOLOGIE } \\
\text { SOCIALE }\end{array}$} & \multirow{3}{*}{4} & \multirow{3}{*}{$1(25 \%)$} & LA BASE GÉOGRAPHIQUE DES SOCIÉTÉS & \\
\hline & & & DE LA POPULATION EN GÉNÉRAL & \\
\hline & & & LES GROUPEMENTS URBAINS & $\begin{array}{l}\text { KORNEMANN. Zur Stadtentstehung in den ehemals keltischen und } \\
\text { germanischen Gebieten des Roemerreichs (Durkheim) }\end{array}$ \\
\hline \multirow[t]{3}{*}{ DIVERS } & \multirow[b]{2}{*}{6} & \multirow{2}{*}{$0(0 \%)$} & SOCIOLOGIE ESTHÉTIQUE & \\
\hline & & & TECHNOLOGIE & \\
\hline & 137 & $8(5,84 \%)$ & & \\
\hline
\end{tabular}


Quadro 1.1.5 - A presença da antiguidade greco-latina em L'Année Sociologique (compte-rendus/resenhas - 1902).

\begin{tabular}{|c|c|c|c|c|}
\hline $\begin{array}{l}\text { SEÇÃO DE L'ANNÉE } \\
\text { SOCIOLOGIQUE }\end{array}$ & $\begin{array}{l}\text { RESENHAS POR } \\
\text { SEÇÃO ( } N=100 \%)\end{array}$ & $\begin{array}{l}\text { RESENHAS RELATIVAS AO } \\
\text { MUNDO GRECO-LATINO (N/\%) }\end{array}$ & SUBSEÇÕES DE L'ANNÉE SOCIOLOGIQUE & $\begin{array}{l}\text { TíTULO DAS OBRAS RESENHADAS RELATIVAS AO MUNDO GRECO-LATINO/ } \\
\text { AUTOR DA RESENHA }\end{array}$ \\
\hline \multirow{6}{*}{$\begin{array}{l}\text { SOCIOLOGIE } \\
\text { GÉNÉRALE }\end{array}$} & \multirow{6}{*}{17} & \multirow{6}{*}{$1(5,88 \%)$} & OBJET ET MÉTHODE DE LA SOCIOLOGIE & \\
\hline & & & PHILOSOPHIE SOCIALE, THÉORIES GÉNÉRALES & \\
\hline & & & LA MENTALITÉ DES GROUPES & \\
\hline & & & CIVILISATION EN GÉNÉRAL ET TYPES DE CIVILISATION & RIDGEWAY. The Early Age of Greece (...) (Hubert) \\
\hline & & & ÉTHOLOGIE COLLECTIVE & \\
\hline & & & LE MILIEU SOCIAL ET LA RACE & \\
\hline \multirow{8}{*}{$\begin{array}{l}\text { SOCIOLOGIE } \\
\text { RELIGIEUSE }\end{array}$} & \multirow{8}{*}{36} & \multirow{8}{*}{$4(11,11 \%)$} & CONCEPTIONS GÉNÉRALES, MÉTHODOLOGIE & \\
\hline & & & FORMES ÉLÉMENTAIRES DE LA VIE RELIGIEUSE & \\
\hline & & & LA MAGIE & \\
\hline & & & CROYANCE ET RITES CONCERNANT LES MORTS & \\
\hline & & & LE RITUEL & SAINT-CLAIR. Myths of Greece (...) (Hubert) \\
\hline & & & LES REPRÉSENTATIONS RELIGIEUSES & $\begin{array}{l}\text { NEGRIOLI. Dei Genii presso I Romani (Hubert) } \\
\text { de VISSER. De Graecorum diis non referentibus speciem humanam (Mauss) }\end{array}$ \\
\hline & & & LA SOCIÉTÉ RELIGIEUSE & MICHIELS. L'origine de l'Episcopat (Mauss) \\
\hline & & & ÉTUDES D'ENSEMBLE SUR LES GRANDES RELIGIONS & \\
\hline \multirow{8}{*}{$\begin{array}{l}\text { SOCIOLOGIE } \\
\text { JURIDIQUE ET } \\
\text { MORALE }\end{array}$} & \multirow{8}{*}{35} & \multirow{8}{*}{$1(2,85 \%)$} & CONSIDÉRATIONS GÉNÉRALES & \\
\hline & & & ORGANISATION SOCIALE EN GÉNÉRAL & \\
\hline & & & ORGANISATION POLITIQUE & \\
\hline & & & L'ORGANISATION DOMESTIQUE & LAMBERT. La Tradition romaine sur les formes du testament (...) (Durkheim) \\
\hline & & & LE DROIT DE PROPRIÉTÉ & \\
\hline & & & LE DROIT CONTRACTUEL & \\
\hline & & & LE DROIT CRIMINEL & \\
\hline & & & LA PROCEDURE, LES EFFETS DU JUGEMENT & \\
\hline \multirow{6}{*}{$\begin{array}{l}\text { SOCIOLOGIE } \\
\text { CRIMINELLE ET } \\
\text { STATISTIQUE } \\
\text { MORALE }\end{array}$} & \multirow{6}{*}{11} & \multirow{6}{*}{$0(0 \%)$} & STATISTIQUE DE LA VIE DOMESTIQUE & \\
\hline & & & LA CRIMINALITÉ GÉNÉRALE DANS LES DIFFÉRENTS PAYS & \\
\hline & & & FACTEURS DIVERS DE LA CRIMINALITÉ GÉNÉRALE & \\
\hline & & & FORMES SPÉCIALES DE LA CRIMINALITÉ & \\
\hline & & & MILIEUX CRIMINOGÈNES & \\
\hline & & & FONCTIONNEMENT DU SYSTĖME REPRESSIF & \\
\hline \multirow{8}{*}{$\begin{array}{l}\text { SOCIOLOGIE } \\
\text { ÉCONOMIQUE }\end{array}$} & \multirow{8}{*}{18} & \multirow{8}{*}{$3(16,67 \%)$} & MÉTHODOLOGIE, PROBLĖMES GÉNÉRAUX & \\
\hline & & & SYSTÈMES ÉCONOMIQUES & $\begin{array}{l}\text { FRANCOTTE. L'industrie dans la Grèce ancienne (H. Bourgin) } \\
\text { GUIRAUD. La main-d'oeuvre industrielle dans l'ancienne Grèce (H. Bourgin) }\end{array}$ \\
\hline & & & REGIME DE LA PRODUCTION & \\
\hline & & & FORMES DE LA PRODUCTION & \\
\hline & & & ÉLÉMENTS DE LA RÉPARTITION & \\
\hline & & & CLASSES ÉCONOMIQUES & GUIRAUD. La main-d'oeuvre industrielle dans l'ancienne Grèce (H. Bourgin) \\
\hline & & & ASSOCIATIONS PROFESSIONNELES & \\
\hline & & & ÉCONOMIES SPÉCIALES & \\
\hline \multirow{3}{*}{$\begin{array}{l}\text { MORPHOLOGIE } \\
\text { SOCIALE }\end{array}$} & \multirow{3}{*}{4} & \multirow{3}{*}{$0(0 \%)$} & LA BASE GÉOGRAPHIQUE DES SOCIÉTÉS & \\
\hline & & & DE LA POPULATION EN GÉNÉRAL & \\
\hline & & & LES GROUPEMENTS URBAINS ET RURAUX & \\
\hline \multirow{5}{*}{ DIVERS } & \multirow{4}{*}{6} & \multirow{4}{*}{$2(33,33 \%)$} & SOCIOLOGIE ESTHÉTIQUE & $\begin{array}{l}\text { LOEWY. Die Naturwiedergabe in der aelteren griechischen Kunst (Hubert) } \\
\text { OUVRÉ. Les formes littéraires de la pensée grecque (Hubert) }\end{array}$ \\
\hline & & & TECHNOLOGIE & \\
\hline & & & LE LANGAGE & \\
\hline & & & LA GUERRE & \\
\hline & 127 & $11(8,66 \%)$ & & \\
\hline
\end{tabular}


Quadro 1.1.6 - A presença da antiguidade greco-latina em L'Année Sociologique (compte-rendus/resenhas - 1903) (continua na página seguinte).

\begin{tabular}{|c|c|c|c|c|}
\hline $\begin{array}{l}\text { SEÇÃO DE L'ANNÉE } \\
\text { SOCIOLOGIQUE }\end{array}$ & $\begin{array}{l}\text { RESENHAS POR } \\
\text { SEÇÃO ( } N=100 \%)\end{array}$ & $\begin{array}{l}\text { RESENHAS RELATIVAS AO } \\
\text { MUNDO GRECO-LATINO (N/\%) }\end{array}$ & SUBSEÇÕES DE L'ANNÉE SOCIOLOGIQUE & $\begin{array}{l}\text { TíTULO DAS OBRAS RESENHADAS RELATIVAS AO MUNDO GRECO-LATINO/ } \\
\text { AUTOR DA RESENHA }\end{array}$ \\
\hline \multirow{5}{*}{$\begin{array}{l}\text { SOCIOLOGIE } \\
\text { GÉNÉRALE }\end{array}$} & \multirow{5}{*}{29} & \multirow{5}{*}{$1(3,45 \%)$} & OBJET ET MÉTHODE DE LA SOCIOLOGIE & \\
\hline & & & PHILOSOPHIE SOCIALE, THÉORIES GÉNÉRALES & \\
\hline & & & MENTALITÉ DES GROUPES ET ÉTHOLOGIE COLLECTIVE & \\
\hline & & & CIVILISATION EN GÉNÉRALE ET TYPES DE CIVILISATION & GALLOWAY KELLER. Homeric Society (Hubert) \\
\hline & & & HISTOIRE DE LA SOCIOLOGIE & \\
\hline \multirow{8}{*}{$\begin{array}{l}\text { SOCIOLOGIE } \\
\text { RELIGIEUSE }\end{array}$} & \multirow{8}{*}{58} & \multirow{8}{*}{$9(15,52 \%)$} & CONCEPTIONS GÉNÉRALES, MÉTHODOLOGIE & \\
\hline & & & FORMES ÉLÉMENTAIRES DE LA VIE RELIGIEUSE & \\
\hline & & & LA MAGIE & \\
\hline & & & CROYANCE ET RITES CONCERNANT LES MORTS & \\
\hline & & & LE RITUEL & $\begin{array}{l}\text { USENER. Milch und Honig (Hubert) } \\
\text { EVANS. The mycenean tree and pillar cult (...) (Hubert) }\end{array}$ \\
\hline & & & REPRÉSENTATIONS RELIGIEUSES & $\begin{array}{l}\text { ROSCHER. Ephialtes (...) (Hubert) } \\
\text { WISSOWA. Religion und Cultus der Römer (Hubert) } \\
\text { WINTERNITZ. Die Flutsagen des Altertums und der Naturvölker (Mauss) } \\
\text { GRUPPE. Griechische Mythologie und Religionsgeschichte (Hubert/Mauss) } \\
\text { HANNIG. De Pegaso (Hubert) } \\
\text { BÉRARD. Les Phéniciens et l'Odyssée (Hubert/Mauss) }\end{array}$ \\
\hline & & & LA SOCIÉTÉ RELIGIEUSE & \\
\hline & & & ÉTUDES D’ENSEMBLE SUR LES GRANDES RELIGIONS & WISSOWA. Religion und Cultus der Römer (Hubert) ( $2^{\mathrm{a}}$ resenha) \\
\hline \multirow{10}{*}{$\begin{array}{l}\text { SOCIOLOGIE } \\
\text { JURIDIQUE ET } \\
\text { MORALE }\end{array}$} & \multirow{10}{*}{58} & \multirow{10}{*}{$12(20,69 \%)$} & THÉORIES GÉNÉRALES SUR LA MORALE ET LE DROIT & $\begin{array}{l}\text { BONFAUTE. La progressiva diversificazione del diritto publico e privato } \\
\text { (Durkheim) }\end{array}$ \\
\hline & & & SYSTÈMES JURIDIQUES & DARESTE. - Nouvelles études d'histoire du droit. (Fauconnet) \\
\hline & & & ORGANISATION SOCIALE & SZANTO. Die Griechischen Phylen (...) (Durkheim) \\
\hline & & & ORGANISATION DOMESTIQUE & $\begin{array}{l}\text { ESMEIN. Les coutumes primitives dans les écrits des mythologues grecs et } \\
\text { romains (Durkheim) }\end{array}$ \\
\hline & & & L'ORGANISATION POLITIQUE & FRANCOTTE. Formation des villes (...) dans la Grèce ancienne (Durkheim) \\
\hline & & & LE DROIT DE PROPRIÉTÉ & $\begin{array}{l}\text { PININSKI. Begriff (...) des Eigenthumsrechts nach römischen Recht (É. Lévy) } \\
\text { MANGANO. Sulle forme primitive della proprieta fondiaria in Roma (É. Lévy) }\end{array}$ \\
\hline & & & DROIT DES OBLIGATIONS ET DROIT CONTRACTUEL & $\begin{array}{l}\text { HUVELIN. Les tablettes magiques et le droit romain (Durkheim) } \\
\text { MITTEIS. Ueber das Nexum (Huvelin) } \\
\text { DE MEDIO. Contributo alla storia del contratto di società in Roma (Huvelin) }\end{array}$ \\
\hline & & & LE DROIT CRIMINEL & MESSA. Dell'Infamia secondo il dirito romano (Fauconnet) \\
\hline & & & L'ORGANISATION JUDICIAIRE & GIRARD. Histoire de l'organisation judiciaire des Romains (Fauconnet) \\
\hline & & & DIVERSES PRATIQUES JURIDIQUES ET MORALES & \\
\hline \multirow{5}{*}{$\begin{array}{l}\text { SOCIOLOGIE } \\
\text { CRIMINELLE ET } \\
\text { STATISTIQUE } \\
\text { MORALE }\end{array}$} & \multirow{5}{*}{28} & \multirow{5}{*}{$0(0 \%)$} & STATISTIQUE DE LA VIE DOMESTIQUE & \\
\hline & & & LA CRIMINALITÉ GÉNÉRALE DANS LES DIFFÉRENTS PAYS & \\
\hline & & & FACTEURS DIVERS DE LA CRIMINALITÉ GÉNÉRALE & \\
\hline & & & LE SUICIDE & \\
\hline & & & FONCTIONNEMENT DU SYSTĖME REPRESSIF & \\
\hline \multirow{9}{*}{$\begin{array}{l}\text { SOCIOLOGIE } \\
\text { ÉCONOMIQUE }\end{array}$} & \multirow{9}{*}{32} & \multirow{9}{*}{$0(0 \%)$} & ÉTUDES GÉNÉRALES & \\
\hline & & & SYSTÈMES ÉCONOMIQUES & \\
\hline & & & RÉGIME DE LA PRODUCTION & \\
\hline & & & FORMES DE LA PRODUCTION & \\
\hline & & & ÉLÉMENTS DE LA RÉPARTITION & \\
\hline & & & CLASSES ÉCONOMIQUES & \\
\hline & & & ASSOCIATIONS PROFESSIONNELES & \\
\hline & & & ACTION DE L'ÉTAT SUR LA VIE ÉCONOMIQUE & \\
\hline & & & ÉCONOMIES SPÉCIALES, AGRAIRE, INDUSTRIALLE, ETC. & \\
\hline
\end{tabular}




\begin{tabular}{|c|c|c|c|c|}
\hline \multirow{4}{*}{$\begin{array}{l}\text { MORPHOLOGIE } \\
\text { SOCIALE }\end{array}$} & \multirow{4}{*}{14} & \multirow{4}{*}{$2(12,86 \%)$} & LES BASES GÉOGRAPHIQUES DE LA VIE SOCIALE & \\
\hline & & & DE LA POPULATION EN GÉNÉRAL & \\
\hline & & & LES GROUPEMENTS URBAINS & JULLIAN. Notes gallo-romaines (Durkheim) \\
\hline & & & L'HABITATION & de BEYLIÉ. L'habitation byzantine (Is. Lévy) \\
\hline \multirow{5}{*}{ DIVERS } & \multirow{4}{*}{9} & \multirow{4}{*}{$2(22,22 \%)$} & L’ESTHÉTIQUE & \\
\hline & & & TECHNOLOGIE & \\
\hline & & & LINGUISTIQUE & $\begin{array}{l}\text { MEYER-LÜBKE. Einführung in das tudium der romanischen } \\
\text { Sprachwissenschaft. (Meillet) } \\
\text { THUMB. Die griechische Sprache im Zeitalter des Hellenismus (Meillet) }\end{array}$ \\
\hline & & & LE SOCIALISME & \\
\hline & 230 & $26(11,30 \%)$ & & \\
\hline
\end{tabular}


Quadro 1.1.7 - A presença da antiguidade greco-latina em L'Année Sociologique (compte-rendus/resenhas - 1904) (continua na página seguinte).

\begin{tabular}{|c|c|c|c|c|}
\hline $\begin{array}{l}\text { SEÇÃO DE L'ANNÉE } \\
\text { SOCIOLOGIQUE }\end{array}$ & $\begin{array}{l}\text { RESENHAS POR } \\
\text { SEÇÃO ( } N=100 \%)\end{array}$ & $\begin{array}{l}\text { RESENHAS RELATIVAS AO } \\
\text { MUNDO GRECO-LATINO (N/\%) }\end{array}$ & SUBSEÇÕES DE L'ANNÉE SOCIOLOGIQUE & $\begin{array}{l}\text { TíTULO DAS OBRAS RESENHADAS RELATIVAS AO MUNDO GRECO-LATINO/ } \\
\text { AUTOR DA RESENHA }\end{array}$ \\
\hline \multirow{4}{*}{$\begin{array}{l}\text { SOCIOLOGIE } \\
\text { GÉNÉRALE }\end{array}$} & \multirow{4}{*}{36} & \multirow{4}{*}{$1(2,78 \%)$} & MÉTHODOLOGIE & \\
\hline & & & THÉORIES GÉNÉRALES, PHILOSOPHIE SOCIALE & \\
\hline & & & MENTALITÉ DES GROUPES ET ÉTHOLOGIE COLLECTIVE & BURCKHARDT. Griechische Kulturgeschichte, t. IV (Hubert) \\
\hline & & & TYPES DE CIVILISATION & \\
\hline \multirow{9}{*}{$\begin{array}{l}\text { SOCIOLOGIE } \\
\text { RELIGIEUSE }\end{array}$} & \multirow{9}{*}{64} & \multirow{9}{*}{$9(14,06 \%)$} & PHILOSOPHIE RELIGIEUSE, CONCEPTIONS GÉNÉRALES & \\
\hline & & & SYSTÈMES RELIGIEUX GÉNÉRAUX & JENTSCH. Hellenentum und Christentum (Hubert) \\
\hline & & & SYSTĖMES RELIGIEUX DES GROUPES SÉCONDAIRES & DE MARCHI. II Culto Privato di Roma Antica (vol. II) (Mauss) \\
\hline & & & CROYANCE ET PRATIQUES POPULAIRES INORGANISÈES & \\
\hline & & & LA MAGIE & \\
\hline & & & CROYANCES CONCERNANT LES MORTS & \\
\hline & & & LE RITUEL & ROUSE. Greek Votive offerings (Mauss) \\
\hline & & & LES REPRÉSENTATIONS RELIGIEUSES & $\begin{array}{l}\text { USENER. Dreiheit (...) (Mauss) } \\
\text { MAASS. Die Tagesgötter in Rom und den Provinzen (Hubert) } \\
\text { S. REINACH. La mort d'Orphée (Hubert) } \\
\text { S. REINACH. Sisyphe aux enfers et quelques autres damnés (Hubert) }\end{array}$ \\
\hline & & & LES SOCIÉTÉS RELIGIEUSES ET LEUR ORGANISATION & $\begin{array}{l}\text { PREUSCHEN. - Mönchtum und Sarapiskult (Hubert) } \\
\text { HARNACK. Die Mission und Ausbreitung des Christentums in den ersten drei } \\
\text { Jahrhunderten (Hubert). }\end{array}$ \\
\hline \multirow{9}{*}{$\begin{array}{l}\text { SOCIOLOGIE } \\
\text { JURIDIQUE ET } \\
\text { MORALE }\end{array}$} & \multirow{9}{*}{63} & \multirow{9}{*}{$7(11,11 \%)$} & THÉORIES GÉNÉRALES SUR LE DROIT ET LA MORALE & \\
\hline & & & SYSTĖME JURIDIQUE & CUQ. Les institutions juridiques der Romains. T. II. (Huvelin) \\
\hline & & & L'ORGANISATION SOCIALE & $\begin{array}{l}\text { USENER. Ueber vergleichende Sitten- und Rechtsgeschichte (Mauss) } \\
\text { OBERZINER. Origine della plebe romana (Durkheim) }\end{array}$ \\
\hline & & & L'ORGANISATION DOMESTIQUE & $\begin{array}{l}\text { STOCKAR. Ueber den Entzug der väterlichen Gewalt im römischen Recht } \\
\text { (Durkheim) }\end{array}$ \\
\hline & & & L'ORGANISATION POLITIQUE & \\
\hline & & & LE DROIT DE PROPRIÉTÉ & \\
\hline & & & LE DROIT DES OBLIGATIONS ET DROIT CONTRACTUEL & $\begin{array}{l}\text { BEKER. Ueber die Objekte und die Kraft der Schuldverhältnisse - Nachtrag } \\
\text { zur Lehre von Nexum (...) (Huvelin) } \\
\text { ROSTOWZEW (M.). - Geschichte der Staatspach in der römischen Kaiserzeit } \\
\text { bis Diokletian (Huvelin) }\end{array}$ \\
\hline & & & LE DROIT PÉNAL & WENGER. Der Eid in den grieschischen Papyrusurkunden (...) (Huvelin) \\
\hline & & & DIVERSES NOTIONS MORALES OU JURIDIQUES & \\
\hline \multirow{8}{*}{$\begin{array}{l}\text { SOCIOLOGIE } \\
\text { CRIMINELLE ET } \\
\text { STATISTIQUE } \\
\text { MORALE }\end{array}$} & \multirow{8}{*}{23} & \multirow{8}{*}{$0(0 \%)$} & MÉTHODOLOGIE DE LA STATISTIQUE MORALE & \\
\hline & & & STATISTIQUE DE LA VIE DOMESTIQUE & \\
\hline & & & DU CRIME ET DU CRIMINEL EN GÉNÉRAL & \\
\hline & & & CRIMINALITÉ COLLECTIVE & \\
\hline & & & CRIMINALITÉ DANS LES DIFFÉRENTS PAYS & \\
\hline & & & FORMES DIVERSES DE LA CRIMINALITÉ & \\
\hline & & & LA CRIMINALITÉ JUVÉNILE & \\
\hline & & & LE FONCTIONNEMENT DU SYSTĖME RÉPRESSIF & \\
\hline \multirow{8}{*}{$\begin{array}{l}\text { SOCIOLOGIE } \\
\text { ÉCONOMIQUE }\end{array}$} & \multirow{8}{*}{32} & \multirow{8}{*}{$0(0 \%)$} & ÉTUDES GÉNÉRALES & \\
\hline & & & SYSTĖMES ÉCONOMIQUES & \\
\hline & & & RÉGIME DE LA PRODUCTION & \\
\hline & & & FORMES DE LA PRODUCTION & \\
\hline & & & ÉLÉMENTS DE LA RÉPARTITION & \\
\hline & & & CLASSES ÉCONOMIQUES & \\
\hline & & & ACTION DE L'ÉTAT SUR LA VIE ÉCONOMIQUE & \\
\hline & & & ÉCONOMIES SPÉCIALES & \\
\hline
\end{tabular}




\begin{tabular}{|c|c|c|c|c|}
\hline \multirow{3}{*}{$\begin{array}{l}\text { MORPHOLOGIE } \\
\text { SOCIALE }\end{array}$} & \multirow{3}{*}{14} & \multirow{3}{*}{$0(0 \%)$} & MORPHOLOGIE GÉNÉRALE & \\
\hline & & & LA POPULATION EN GÉNÉRAL & \\
\hline & & & LES GROUPEMENTS URBAINS & \\
\hline \multirow{5}{*}{ DIVERS } & \multirow{4}{*}{8} & \multirow{4}{*}{$2(25 \%)$} & SOCIOLOGIE ESTHÉTIQUE & $\begin{array}{l}\text { STICKNEY. Les sentences dans la poésie grecque d'Homère à Euripide } \\
\text { (Hubert) }\end{array}$ \\
\hline & & & LINGUISTIQUE & $\begin{array}{l}\text { MEILLET. Introduction à l'étude comparative des langues indo-européennes } \\
\text { (Meillet) }\end{array}$ \\
\hline & & & TECHNOLOGIE & \\
\hline & & & L'ÉDUCATION & \\
\hline & 240 & $19(7,92 \%)$ & & \\
\hline
\end{tabular}


Quadro 1.1.8 - A presença da antiguidade greco-latina em L'Année Sociologique (compte-rendus/resenhas - 1905) (continua na página seguinte).

\begin{tabular}{|c|c|c|c|c|}
\hline $\begin{array}{l}\text { SEÇÃO DE L'ANNÉE } \\
\text { SOCIOLOGIQUE }\end{array}$ & $\begin{array}{l}\text { RESENHAS POR } \\
\text { SEÇÃO ( } N=100 \%)\end{array}$ & $\begin{array}{l}\text { RESENHAS RELATIVAS AO } \\
\text { MUNDO GRECO-LATINO (N/\%) }\end{array}$ & SUBSEÇÕES DE L'ANNÉE SOCIOLOGIQUE & $\begin{array}{l}\text { TíTULO DAS OBRAS RESENHADAS RELATIVAS AO MUNDO GRECO-LATINO/ } \\
\text { AUTOR DA RESENHA }\end{array}$ \\
\hline \multirow{7}{*}{$\begin{array}{l}\text { SOCIOLOGIE } \\
\text { GÉNÉRALE }\end{array}$} & \multirow{7}{*}{32} & \multirow{7}{*}{$0(0 \%)$} & MÉTHODOLOGIE & \\
\hline & & & DIVISIONS DE LA SOCIOLOGIE & \\
\hline & & & PHILOSOPHIE SOCIALE, THÉORIES GÉNÉRALES & \\
\hline & & & L'INDIVIDU ET LA SOCIÉTÉ & \\
\hline & & & PSYCHOLOGIE DES GROUPES, ÉTHOLOGIE COLLECTIVE & \\
\hline & & & CIVILISATION EN GÉNÉRAL ET TYPES DE CIVILISATION & \\
\hline & & & HISTOIRE DES DOCTRINES & \\
\hline \multirow{10}{*}{$\begin{array}{l}\text { SOCIOLOGIE } \\
\text { RELIGIEUSE }\end{array}$} & \multirow{10}{*}{69} & \multirow{10}{*}{$11(15,94 \%)$} & PHILOSOPHIE RELIGIEUSE, CONCEPTIONS GÉNÉRALES & \\
\hline & & & SYSTÈMES RELIGIEUX & $\begin{array}{l}\text { RENEL. Les Enseignes. Cultes Militaires de Rome (Mauss) } \\
\text { J. HARRISON. Prolegomena to the Study of Greek Religion (Hubert) } \\
\text { GRUPPE. Griechische Mythologie und Religionsgeschichte (Hubert) } \\
\text { WISSOWA. Gesammelte Abhandlungen zur romischen Religions und } \\
\text { Staatsgeschichte (Hubert) }\end{array}$ \\
\hline & & & SYSTĖMES RELIGIEUX DES GROUPES SÉCONDAIRES & \\
\hline & & & CULTES SPÉCIAUX & HEPDING. Attis, seine Mythen und sein Kult (Hubert) \\
\hline & & & CROYANCE ET PRATIQUES DITES POPULAIRES & \\
\hline & & & LA MAGIE & DIETERICH. Eine Mithrasliturgie (...) (Hubert) \\
\hline & & & CROYANCES ET RITES CONCERNANT LES MORTS & \\
\hline & & & LE RITUEL & LEJAY. Le sabbat juif et les poètes latins (...) (Hubert) \\
\hline & & & LES REPRÉSENTATIONS RELIGIEUSES & $\begin{array}{l}\text { CAIRD. The Evolution of Theology in the Greek Philosophers (Mauss) } \\
\text { REITZENSEIN. Poimandres (Hubert) } \\
\text { KARO. Altkretische Kultustatten (Hubert) }\end{array}$ \\
\hline & & & OBJETS ET LIEUX DE CULTE & $\begin{array}{l}\text { FARNELL. Sociological Hypotheses concerning the position of women in } \\
\text { ancient Religion (Mauss) }\end{array}$ \\
\hline \multirow{8}{*}{$\begin{array}{l}\text { SOCIOLOGIE } \\
\text { JURIDIQUE ET } \\
\text { MORALE }\end{array}$} & \multirow{8}{*}{53} & \multirow{8}{*}{$11(20,74 \%)$} & THÉORIES GÉNÉRALES SUR LE DROIT ET LA MORALE & BONUCCI. La legge comune nel pensiero greco (Fauconnet/Parodi?) \\
\hline & & & SYSTĖME JURIDIQUE & \\
\hline & & & L'ORGANISATION POLITIQUE & \\
\hline & & & L'ORGANISATION DOMESTIQUE & $\begin{array}{l}\text { NIETZOLD. Die Ehe in Aegypten zur ptolemäisch-römischen Zeit (Durkheim) } \\
\text { RUGGIERO. Studi papirologici sul matrimonio e sul divorcio nell'egitto greco- } \\
\text { romano (Durkheim) }\end{array}$ \\
\hline & & & LE DROIT DE PROPRIÉTÉ & \\
\hline & & & $\begin{array}{l}\text { LE DROIT DES OBLIGATIONS, DROIT CONTRACTUEL, } \\
\text { DROIT COMMERCIAL }\end{array}$ & $\begin{array}{l}\text { PEROZZI. Le obbligazione romane (Huvelin) } \\
\text { SCHLOSSMANN. Altrömisches Schuldrecht und Schuldverfahren (Huvelin) } \\
\text { BEASLEY. Le cautionnement dans I'ancien droit grec (Huvelin) } \\
\text { SCHLOSSMANN. - Zur Geschichte des römischen Kaufs (Huvelin) }\end{array}$ \\
\hline & & & LE DROIT PÉNAL & $\begin{array}{l}\text { USTERI. Aechtungung Verbannung im griechischen Rech (Durkheim) } \\
\text { GLOTZ. La solidarité de la famille dans le droit criminel en Grèce (Durkheim) } \\
\text { HUVELIN. La notion de I' 'Injuria' dans le très ancien droit romain (Durkheim } \\
\text { GLOTZ. L'ordalie dans la Grèce primitive (Durkheim) }\end{array}$ \\
\hline & & & LE DROIT INTERNATIONAL & \\
\hline \multirow{7}{*}{$\begin{array}{l}\text { SOCIOLOGIE } \\
\text { CRIMINELLE ET } \\
\text { STATISTIQUE } \\
\text { MORALE }\end{array}$} & \multirow{7}{*}{18} & \multirow{7}{*}{$0(0 \%)$} & $\begin{array}{l}\text { LA MORALITÉ CONJUGALE ET DOMESTIQUE, LA } \\
\text { MORALITÉ DANS LES RETATIONS CIVILES }\end{array}$ & \\
\hline & & & DE LA CRIMINOLOGIE EN GÉNÉRAL & \\
\hline & & & LA CRIMINALITÉ SELON LES PAYS & \\
\hline & & & CRIMINALITÉ COLLECTIVE & \\
\hline & & & FORMES DIVERSES DE LA CRIMINALITÉ & \\
\hline & & & CRIMINALITÉ ET FACTEUR ÉCONOMIQUE & \\
\hline & & & ENFANCE ET CRIMINALITÉ & \\
\hline
\end{tabular}




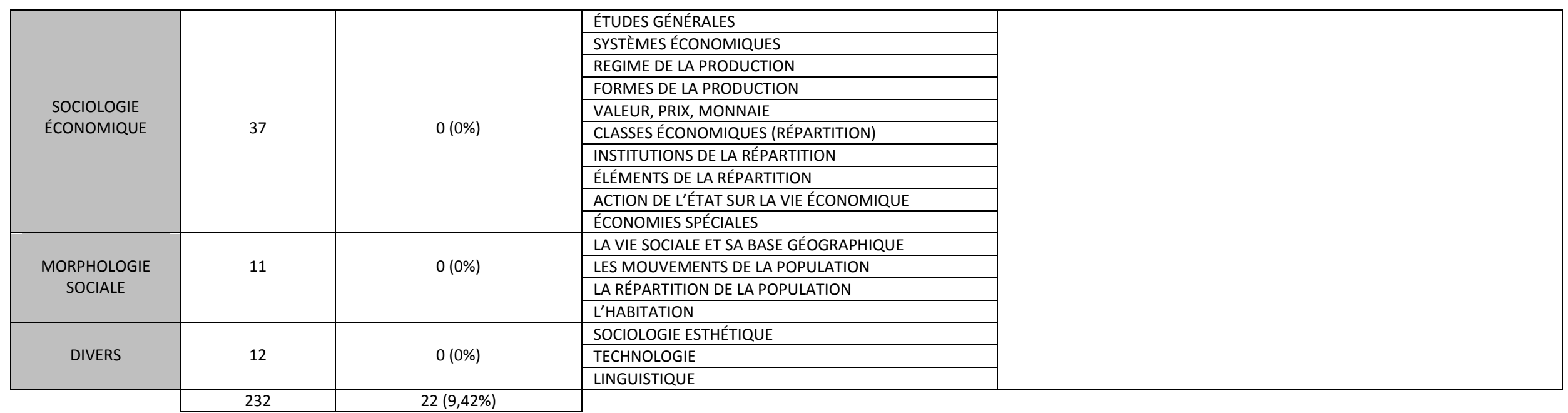


Quadro 1.1.9 - A presença da antiguidade greco-latina em L'Année Sociologique (compte-rendus/resenhas - 1906) (continua na página seguinte).

\begin{tabular}{|c|c|c|c|c|}
\hline $\begin{array}{l}\text { SEÇÃO DE L'ANNÉE } \\
\text { SOCIOLOGIQUE }\end{array}$ & $\begin{array}{l}\text { RESENHAS POR } \\
\text { SEÇÃO ( } N=100 \%)\end{array}$ & $\begin{array}{l}\text { RESENHAS RELATIVAS AO } \\
\text { MUNDO GRECO-LATINO (N/\%) }\end{array}$ & SUBSEÇÕES DE L'ANNÉE SOCIOLOGIQUE & $\begin{array}{l}\text { TíTULO DAS OBRAS RESENHADAS RELATIVAS AO MUNDO GRECO-LATINO/ } \\
\text { AUTOR DA RESENHA }\end{array}$ \\
\hline \multirow{5}{*}{$\begin{array}{l}\text { SOCIOLOGIE } \\
\text { GÉNÉRALE }\end{array}$} & \multirow{5}{*}{30} & \multirow{5}{*}{$0(0 \%)$} & MÉTHODOLOGIE. & \\
\hline & & & PHILOSOPHIE SOCIALE, THÉORIES GÉNÉRALES & \\
\hline & & & PSYCHOLOGIE DES GROUPES & \\
\hline & & & TYPES DE CIVILISATION & \\
\hline & & & RACES ET SOCIÉTÉS & \\
\hline \multirow{9}{*}{$\begin{array}{l}\text { SOCIOLOGIE } \\
\text { RELIGIEUSE }\end{array}$} & \multirow{9}{*}{89} & \multirow{9}{*}{$11(12,36 \%)$} & PHILOSOPHIE RELIGIEUSE. CONCEPTIONS GÉNÉRALES & S. REINACH. Cultes, Mythes et Religions. T. I. (Hubert) \\
\hline & & & SYSTÈMES RELIGIEUX & \\
\hline & & & CULTES SPÉCIAUX & P. FOUCART. Le culte de Dionysos en Attique (Hubert) \\
\hline & & & CROYANCE ET PRATIQUES DITES POPULAIRES & \\
\hline & & & LA MAGIE & $\begin{array}{l}\text { AUDOLLENT. Defixionum tabellae (Hubert) } \\
\text { GRENIER. Nouvelles tabellae defixionis de Sousse (...) (Hubert) }\end{array}$ \\
\hline & & & CROYANCES ET RITES CONCERNANT LES MORTS & \\
\hline & & & LE RITUEL & USENER. Die heilige Handlung (Gelly) \\
\hline & & & LES REPRESENTATIONS RELIGIEUSES & $\begin{array}{l}\text { DIETERICH. Mutter Erde. Ein Versuch über Volksreligion (Mauss) } \\
\text { GOMPERZ. Die Lebensauffassung der Griechischen Philosophen und das } \\
\text { ideal der inneren Freiheit (Hertz) } \\
\text { COOK. The European Sky-God (Hubert) } \\
\text { P. GIRARD. Ajax, fils de Télamon (Hubert) } \\
\text { LUCIUS. Die Anfänge der Heiligen Kultus in der christlichen Kirche (Hubert) } \\
\text { DECHARME. La critique des traditions religieuses chez les Grecs, des origines } \\
\text { au temps de Plutarque (Hubert) }\end{array}$ \\
\hline & & & LES SOCIÉTÉS RELIGIEUSES & \\
\hline \multirow{8}{*}{$\begin{array}{l}\text { SOCIOLOGIE } \\
\text { JURIDIQUE ET } \\
\text { MORALE }\end{array}$} & \multirow{8}{*}{55} & \multirow{8}{*}{$8(14,55 \%)$} & MORALE ET DROIT EN GÉNÉRAL & ANTONUCCI. II concetto della giustizia nel mondo greco (Lapie?) \\
\hline & & & SYSTĖMES JURIDIQUES ET MORAUX & WENBER. Römische und antike Rechtsgeschichte (Fauconnet) \\
\hline & & & ORGANISATION SOCIALE & \\
\hline & & & ORGANISATION POLITIQUE & \\
\hline & & & ORGANISATION DOMESTIQUE & \\
\hline & & & LE DROIT DE PROPRIÉTÉ & GUIRAUD. La propriété primitive à Rome (Durkheim) \\
\hline & & & $\begin{array}{l}\text { LE DROIT DES OBLIGATIONS, DROIT CONTRACTUEL, } \\
\text { DROIT COMMERCIAL }\end{array}$ & $\begin{array}{l}\text { SCHLOSSMANN. In jure cessio und Mancipatio (...) (Huvelin) } \\
\text { SENN. Le nexum, conrat de prêt du très ancien droit romain (...) (Huvelin) } \\
\text { MANIGK. Zur Geschichte der römischen Hypothek (Huvelin) }\end{array}$ \\
\hline & & & LE DROIT PÉNAL & $\begin{array}{l}\text { MOMMSEN (org). Zum ältesten Strafrecht der Kulturvölker (Durkheim) } \\
\text { LEHMANN. Ueber die Vermögensstrafen des römischen Rechts (Fauconnet) }\end{array}$ \\
\hline \multirow{5}{*}{$\begin{array}{l}\text { SOCIOLOGIE } \\
\text { CRIMINELLE ET } \\
\text { STATISTIQUE } \\
\text { MORALE }\end{array}$} & \multirow{5}{*}{9} & \multirow{5}{*}{$0(0 \%)$} & LE FONCTIONNEMENT DES INSTITUTIONS POLITIQUES & \\
\hline & & & FONCTIONNEMENT DES INSTITUTIONS DOMESTIQUES & \\
\hline & & & LA CRIMINALITÉ EN GÉNÉRAL & \\
\hline & & & FORMES SPÉCIALES DE LA CRIMINALITÉ & \\
\hline & & & FONCTIONNEMENT DU SYSTÈME RÉPRESSIF & \\
\hline \multirow{10}{*}{$\begin{array}{l}\text { SOCIOLOGIE } \\
\text { ÉCONOMIQUE }\end{array}$} & \multirow{10}{*}{38} & \multirow{10}{*}{$1(2,63 \%)$} & TRAITÉS. ÉTUDES GÉNÉRALES & GUIRAUD. Études économiques sur l'antiquité (Simiand) \\
\hline & & & SYSTĖMES ÉCONOMIQUES & \\
\hline & & & RÉGIME DE LA PRODUCTION & \\
\hline & & & FORMES DE LA PRODUCTION & \\
\hline & & & VALEUR, PRIX, MONNAIE & \\
\hline & & & CLASSES ÉCONOMIQUES & \\
\hline & & & INSTITUTIONS DE LA RÉPARTITION & \\
\hline & & & ÉLÉMENTS DE LA RÉPARTITION & \\
\hline & & & ACTION DE L'ÉTAT SUR LA VIE ÉCONOMIQUE & \\
\hline & & & ÉCONOMIES SPÉCIALES & \\
\hline
\end{tabular}




\begin{tabular}{|c|c|c|c|c|}
\hline \multirow{6}{*}{$\begin{array}{l}\text { MORPHOLOGIE } \\
\text { SOCIALE }\end{array}$} & \multirow{6}{*}{11} & \multirow{6}{*}{$0(0 \%)$} & BASES GÉOGRAPHIQUES DE LA VIE SOCIALE & \\
\hline & & & MOUVEMENT DE LA POPULATION EN GÉNÉRAL & \\
\hline & & & RÉPARTITION DE LA POPULATION & \\
\hline & & & LES PHÉNOMÈNES DE MIGRATION & \\
\hline & & & LES VILLES ET LES CAMPAGNES & \\
\hline & & & L'EXPANSION DES GROUPES SOCIAUX SUR LE SOL & \\
\hline \multirow{4}{*}{ DIVERS } & \multirow{3}{*}{11} & \multirow{3}{*}{$2(18,18 \%)$} & SOCIOLOGIE ESTHÉTIQUE & \\
\hline & & & TECHNOLOGIE & $\begin{array}{l}\text { BEILEN. Der Pflug und das Pflügen bei den Römern und in vorgeschichtlicher } \\
\text { Zeit (Beuchat) }\end{array}$ \\
\hline & & & LINGUISTIQUE & $\begin{array}{l}\text { GILLIÉRON et MONGIN. Étude de geographie linguistique. Scier, dans la } \\
\text { Gaule romane (Meillet) }\end{array}$ \\
\hline & 243 & $22(9,05 \%)$ & & \\
\hline
\end{tabular}


Quadro 1.1.10 - A presença da antiguidade greco-latina em L'Année Sociologique (compte-rendus/resenhas - 1907) (continua na página seguinte).

\begin{tabular}{|c|c|c|c|c|}
\hline SEÇÃO DE L'ANNÉE & RESENHAS POR & RESENHAS RELATIVAS AO & SUBSEÇÕES DE L'ANNÉE SOCIOLOGIQUE & TÍTULO DAS OBRAS RESENHADAS RELATIVAS AO MUNDO GRECO-LATINO/ \\
\hline SOCIOLOGIQUE & SEÇÃO (N=100\%) & MUNDO GRECO-LATINO (N/\%) & & AUTOR DA RESENHA \\
\hline \multirow{6}{*}{$\begin{array}{l}\text { SOCIOLOGIE } \\
\text { GÉNÉRALE }\end{array}$} & \multirow{6}{*}{28} & \multirow{6}{*}{$1(3,57 \%)$} & CONCEPTION GÉNÉRALE. MÉTHODOLOGIE & \\
\hline & & & TRAITÉS GÉNÉRAUX & \\
\hline & & & QUESTIONS GÉNÉRALES DIVERSES & \\
\hline & & & PSYCHOLOGIE DES GROUPES & \\
\hline & & & ÉTHOLOGIE COLLECTIVE, TYPES DE CIVILISATION & HELMOLT. Weltgeschichte. T. V. Sudosteuropa und Osteuropa (Fauconnet) \\
\hline & & & LA QUESTION DE LA RACE & \\
\hline \multirow{9}{*}{$\begin{array}{l}\text { SOCIOLOGIE } \\
\text { RELIGIEUSE }\end{array}$} & \multirow{9}{*}{65} & \multirow{9}{*}{$6(9,23 \%)$} & PHILOSOPHIE RELIGIEUSE. CONCEPTIONS GÉNÉRALES & S. REINACH. Cultes, Mythes et Religions. T. II. (Hubert) \\
\hline & & & SYSTĖMES RELIGIEUX & \\
\hline & & & SYSTÈMES RELIGIEUX DES GROUPES SECONDAIRES & \\
\hline & & & CULTES SPÉCIAUX & FRAZER. Adonis, Attis, Osiris (Mauss) \\
\hline & & & CROYANCE ET PRATIQUES DITES POPULAIRES & \\
\hline & & & LA MAGIE & \\
\hline & & & CROYANCES ET RITES CONCERNANT LES MORTS & \\
\hline & & & LE RITUEL & \\
\hline & & & LES REPRÉSENTATIONS RELIGIEUSES & $\begin{array}{l}\text { ROSCHER. Die Sieben und Neunzahl im Kultus der Griechen (Hubert) } \\
\text { COOK. The European Sky-God (Mauss) } \\
\text { GRUPPE. Griechische Mythologie und Religionsgeschichte (Hubert) } \\
\text { OTTO. Priester und Tempel im Hellenistischen Aegypten (Mauss) }\end{array}$ \\
\hline \multirow{12}{*}{$\begin{array}{l}\text { SOCIOLOGIE } \\
\text { JURIDIQUE ET } \\
\text { MORALE }\end{array}$} & \multirow{12}{*}{51} & \multirow{12}{*}{$6(11,76 \%)$} & MÉTHODOLOGIE & \\
\hline & & & LE DROIT ET LA MORALE EN GÉNÉRAL & BRUGI. I diritto greco classico e la sociologia (Durkheim ?) \\
\hline & & & SUR L'ÉVOLUTION GÉNÉRALE DES IDÉES MORALES & \\
\hline & & & SYSTÈMES JURIDIQUES ET MORAUX & \\
\hline & & & ORGANISATION SOCIALE & \\
\hline & & & L'ORGANISATION POLITIQUE & FRAZER. Lectures on the early history of the Kingship (Durkheim) \\
\hline & & & L'ORGANISATION DOMESTIQUE & \\
\hline & & & LE DROIT DE PROPRIÉTÉ & BRINI L'obbligazione nel diritto romano (Huvelin) \\
\hline & & & LE DROIT DES OBLIGATIONS, DROIT CONTRACTUEL & $\begin{array}{l}\text { SWOBODA. Beiträge zur griechischen Rechtsgeschichte (Huvelin) } \\
\text { CHLOSSMANN). Praescriptiones und praescripta verba. Wider die } \\
\text { Schriftformel des römischen Formularprozesses (Huvelin) }\end{array}$ \\
\hline & & & LE DROIT PÉNAL & GLOTZ. Études sociales et juridiques sur l'antiquité grecque (Fauconnet) \\
\hline & & & LA RESPONSABILITÉ CRIMINELLE & \\
\hline & & & MORALE ET DROIT INTERNATIONAL & \\
\hline \multirow{5}{*}{$\begin{array}{l}\text { SOCIOLOGIE } \\
\text { CRIMINELLE ET } \\
\text { STATISTIQUE } \\
\text { MORALE }\end{array}$} & \multirow{5}{*}{9} & \multirow{5}{*}{$0(0 \%)$} & FACTEURS SOCIAUX DE LA CRIMINALITÉ & \\
\hline & & & LA CRIMINALITÉ SUIVANT L'AGE ET LE SEXE & \\
\hline & & & QUELQUES FORMES PARTICULIÈRES DE CRIMINALITÉ & \\
\hline & & & LE SUICIDE & \\
\hline & & & LE SYSTÈME PÉNITENTIAIRE & \\
\hline
\end{tabular}




\begin{tabular}{|c|c|c|c|c|}
\hline \multirow{8}{*}{$\begin{array}{c}\text { SOCIOLOGIE } \\
\text { ÉCONOMIQUE }\end{array}$} & \multirow{8}{*}{42} & \multirow{8}{*}{$1(2,38 \%)$} & ÉTUDES GÉNÉRALES. TRAITÉS & \\
\hline & & & ESPËCES DE LA PRODUCTION & \multirow{10}{*}{ SALVIOLI. Le capitalisme dans le monde antique (Simiand) } \\
\hline & & & FORMES DE LA PRODUCTION & \\
\hline & & & VALEUR, PRIX, MONNAIE & \\
\hline & & & INSTITUTIONS DE LA RÉPARTITION & \\
\hline & & & ÉLÉMENTS DE LA RÉPARTITION & \\
\hline & & & ACTION DE L'ÉTAT SUR LA VIE ÉCONOMIQUE & \\
\hline & & & ÉCONOMIES SPÉCIALES & \\
\hline $\begin{array}{l}\text { MORPHOLOGIE } \\
\text { SOCIALE }\end{array}$ & 10 & $0(0 \%)$ & LES MOUVEMENTS MIGRATOIRES & \\
\hline \multirow{4}{*}{ DIVERS } & \multirow{3}{*}{9} & \multirow{3}{*}{$1(11,11 \%)$} & SOCIOLOGIE ESTHÉTIQUE & \\
\hline & & & TECHNOLOGIE & \\
\hline & & & LE LANGAGE & SCHULZE. Zur Geschichte lateinischer Eigennamen (Meillet) \\
\hline & 214 & $15(7,01 \%)$ & & \\
\hline
\end{tabular}


Quadro 1.1.11 - A presença da antiguidade greco-latina em L'Année Sociologique (compte-rendus/resenhas - 1910) (continua na página seguinte).

\begin{tabular}{|c|c|c|c|c|}
\hline $\begin{array}{l}\text { SEÇÃO DE L'ANNÉE } \\
\text { SOCIOLOGIQUE }\end{array}$ & $\begin{array}{l}\text { RESENHAS POR } \\
\text { SEÇÃO ( } N=100 \%)\end{array}$ & $\begin{array}{l}\text { RESENHAS RELATIVAS AO } \\
\text { MUNDO GRECO-LATINO (N/\%) }\end{array}$ & SUBSEÇÕES DE L'ANNÉE SOCIOLOGIQUE & $\begin{array}{l}\text { TÍTULO DAS OBRAS RESENHADAS RELATIVAS AO MUNDO GRECO-LATINO/ } \\
\text { AUTOR DA RESENHA }\end{array}$ \\
\hline \multirow{6}{*}{$\begin{array}{l}\text { SOCIOLOGIE } \\
\text { GÉNÉRALE }\end{array}$} & \multirow{6}{*}{ son } & \multirow{6}{*}{$1(5,56 \%)$} & CONCEPTION GÉNÉRALE. MÉTHODOLOGIE & \\
\hline & & & TRAITÉS GÉNÉRAUX, PHILOSOPHIE SOCIALE & MEYER. Geschichte des Altertums, $2^{E}$ Auflage (Durkheim) \\
\hline & & & QUESTIONS GÉNÉRALES DIVERSES & \\
\hline & & & PSYCHOLOGIE DES GROUPES & \\
\hline & & & CONDITIONS SOCIOLOGIQUES DE LA CONNAISSANCE & \\
\hline & & & ETHNOGRAPHIE, HISTOIRE ET SOCIOLOGIE & \\
\hline \multirow{12}{*}{$\begin{array}{l}\text { SOCIOLOGIE } \\
\text { RELIGIEUSE }\end{array}$} & \multirow{12}{*}{61} & \multirow{12}{*}{$8(13,11 \%)$} & TRAITÉS GÉNÉRAUX, PHILOSOPHIE RELIGIEUSE & \\
\hline & & & SYSTÈMES RELIGIEUX DES SOCIÉTÉS INFÉRIEURES & \\
\hline & & & SYSTÈMES RELIGIEUX NATIONAUX & $\begin{array}{l}\text { TOUTAIN. Les Cultes païens dans l'Empire romain (Hubert) } \\
\text { CUMONT. Les religions orientales dans le paganisme romain (Hubert) }\end{array}$ \\
\hline & & & SYSTĖMES RELIGIEUX UNIVERSALISTES & \\
\hline & & & SYSTĖMES RELIGIEUX DES GROUPES SECONDAIRES & \\
\hline & & & CULTES SPÉCIAUX & \\
\hline & & & CROYANCE ET PRATIQUES DITES POPULAIRES & \\
\hline & & & CROYANCES ET RITES CONCERNANT LES MORTS & \\
\hline & & & LA MAGIE & $\begin{array}{l}\text { DE JONG. Das antike Mysterienwesen in religionsgeschichtlicher, } \\
\text { ethnologischer und psychologischer Beleuchtung (Hubert) }\end{array}$ \\
\hline & & & LE RITUEL & SCHMIDT. Geburtstag im Altertum (Hubert) \\
\hline & & & LES REPRÉSENTATIONS RELIGIEUSES & $\begin{array}{l}\text { ROSCHER. Enneadische Studien (Hubert) } \\
\text { CUMONT. Le mysticisme astral dans l'antiquité (Hubert) } \\
\text { FARNELL. The cults of the Greek States (Hubert) } \\
\text { FRIEDLAENDER. Herakles (Hubert) }\end{array}$ \\
\hline & & & LES SOCIÉTÉS RELIGIEUSES & \\
\hline \multirow{11}{*}{$\begin{array}{l}\text { SOCIOLOGIE } \\
\text { JURIDIQUE ET } \\
\text { MORALE }\end{array}$} & \multirow{11}{*}{58} & \multirow{11}{*}{$13(22,41 \%)$} & DU DROIT ET LA MORALE EN GÉNÉRAL & \\
\hline & & & $\begin{array}{lllll}\text { ORIGINES REIGIEUSES DES IDÉES MORALES } & \text { ET } \\
\text { JURIDIQUES } & & & & \\
\end{array}$ & $\begin{array}{l}\text { HIRZEL. Themis, Dike und Verwandtes. Ein Beitrag zur Geschichte der } \\
\text { Rechtsidee bei den Griechen (David) }\end{array}$ \\
\hline & & & SYSTĖMES JURIDIQUES ET MORAUX & $\begin{array}{l}\text { DARESTE. Nouvelles études d'histoire du droit (Fauconnet) } \\
\text { JONES. Greek Morality in relation to Institutions (Gernet) } \\
\text { A. CROISET. Les démocraties antiques (Gernet) }\end{array}$ \\
\hline & & & L'ORGANISATION DOMESTIQUE ET MATRIMONIALE & $\begin{array}{l}\text { LAUNSPACH. State and Family in early Rome (Durkheim) } \\
\text { ERDMANN. Die Entwicklung der Testierfreiheit im roemischen Recht (Davy) } \\
\text { OBRIST. Essai sur les Origines du testament romain (Durkheim) }\end{array}$ \\
\hline & & & ORGANISATION DES GROUPES SECONDAIRES & \\
\hline & & & ORGANISATION POLITIQUE & $\begin{array}{l}\text { FRANCOTTE. La Polis grecque (Gernet) } \\
\text { CARCOPINO. Histoire de l'ostracisme athénien (...) (Gernet) }\end{array}$ \\
\hline & & & LE DROIT DE PROPRIÉTÉ & \\
\hline & & & DROIT CONTRACTUEL, DROIT COMMERCIAL & $\begin{array}{l}\text { PARTSCH. Griechisches Bürgschaftsrecht (Huvelin) } \\
\text { BERTOLINI. Appunti didattici di diritto romano (Huvelin) } \\
\text { PFLUGER. Nexum und Mancipium (...) (Huvelin) } \\
\text { FLINIAUX. Le vadimonium (Huvelin) }\end{array}$ \\
\hline & & & DROIT PÉNAL ET RESPONSABILITÉ & \\
\hline & & & LA PROCÉDURE & \\
\hline & & & MORALE INTERNATIONAL & \\
\hline
\end{tabular}




\begin{tabular}{|c|c|c|c|c|}
\hline \multirow{7}{*}{$\begin{array}{l}\text { SOCIOLOGIE } \\
\text { CRIMINELLE ET } \\
\text { STATISTIQUE } \\
\text { MORALE }\end{array}$} & \multirow{7}{*}{15} & \multirow{7}{*}{$0(0 \%)$} & NUPTIALITÉ ET DIVORCES & \\
\hline & & & DE LA CRIMINALITÉ EN GÉNÉRAL & \\
\hline & & & LA CRIMINALITÉ SUIVANT LES PAYS & \\
\hline & & & LA CRIMINALITÉ SUIVANT L'ÂGE ET SEXE & \\
\hline & & & FACTEURS DIVERS DE LA CRIMINALITÉ & \\
\hline & & & TYPES DIVERS DE DÉLITS ET DE DÉLINQUANTS & \\
\hline & & & LE SUICIDE & \\
\hline \multirow{11}{*}{$\begin{array}{l}\text { SOCIOLOGIE } \\
\text { ÉCONOMIQUE }\end{array}$} & \multirow{11}{*}{69} & \multirow{11}{*}{$3(4,35 \%)$} & ÉTUDES GÉNÉRALES. TRAITÉS & $\begin{array}{l}\text { RIEZLER. Ueber Finanzen und Monopole im alten Griechenland (Gernet) } \\
\text { GERNET. L'approvisionnement d'Athènes en blé au } V^{\mathrm{e}} \text { et au } V^{\mathrm{e}} \text { siècles } \\
\text { (Simiand) } \\
\text { OLIVER. Roman economic conditions to the close of the Republic (Gernet) }\end{array}$ \\
\hline & & & SYSTĖMES ÉCONOMIQUES & \\
\hline & & & ESPÈCES DE LA PRODUCTION & \\
\hline & & & RÉGIME DE LA PRODUCTION & \\
\hline & & & FORMES DE LA PRODUCTION & \\
\hline & & & VALEUR, PRIX, MONNAIE & \\
\hline & & & CLASSES ÉCONOMIQUES & \\
\hline & & & INSTITUTIONS DE LA RÉPARTITION & \\
\hline & & & ÉTATS ET ÉLÉMENTS DE LA RÉPARTITION & \\
\hline & & & RELATIONS ENTRE LES PHÉNOMĖNES ÉCONOMIQUES & \\
\hline & & & ÉCONOMIES SPÉCIALES & \\
\hline \multirow{4}{*}{$\begin{array}{l}\text { MORPHOLOGIE } \\
\text { SOCIALE }\end{array}$} & \multirow{4}{*}{10} & \multirow{4}{*}{$0(0 \%)$} & BASES GÉOGRAPHIQUES DE LA VIE SOCIALE & \\
\hline & & & DE LA POPULATION EN GÉNÉRAL & \\
\hline & & & MOUVEMENTS MIGRATOIRES & \\
\hline & & & GROUPEMENTS RURAUX ET URBAINS & \\
\hline \multirow{4}{*}{ DIVERS } & \multirow{3}{*}{7} & \multirow{3}{*}{$2(28,57 \%)$} & SOCIOLOGIE ESTHÉTIQUE & MURRAY. The Rise of the Greek Epic (...) (Lafitte) \\
\hline & & & LE LANGAGE & ERNOUT. Les éléments dialectaux du vocabulaire latin (Meillet) \\
\hline & & & TECHNOLOGIE & \\
\hline & 238 & $27(11,34 \%)$ & & \\
\hline
\end{tabular}


Quadro 1.1.12 - A presença da antiguidade greco-latina em L'Année Sociologique (compte-rendus/resenhas - 1913) (continua na página seguinte).

\begin{tabular}{|c|c|c|c|c|}
\hline $\begin{array}{l}\text { SEÇÃO DE L'ANNÉE } \\
\text { SOCIOLOGIQUE }\end{array}$ & $\begin{array}{l}\text { RESENHAS POR } \\
\text { SEÇÃO (N=100\%) }\end{array}$ & $\begin{array}{c}\text { RESENHAS RELATIVAS AO } \\
\text { MUNDO GRECO-LATINO (N/\%) }\end{array}$ & SUBSEÇÕES DE L'ANNÉE SOCIOLOGIQUE & $\begin{array}{l}\text { TÍTULO DAS OBRAS RESENHADAS RELATIVAS AO MUNDO GRECO-LATINO/ } \\
\text { AUTOR DA RESENHA }\end{array}$ \\
\hline \multirow{5}{*}{$\begin{array}{l}\text { SOCIOLOGIE } \\
\text { GÉNÉRALE }\end{array}$} & \multirow{5}{*}{ s 1} & \multirow{5}{*}{$2(7,41 \%)$} & CONCEPTION GÉNÉRALE. MÉTHODOLOGIE & \\
\hline & & & TRAITÉS GÉNÉRAUX. QUESTIONS GÉNÉRALES DIVERSES & \\
\hline & & & PSYCHOLOGIE COLLECTIVE & \\
\hline & & & CONDITIONS SOCIOLOGIQUES DE LA CONNAISSANCE & CORNFORD. From Religion to Philosophy (David) \\
\hline & & & CIVILISATION ET TYPES DE CIVILISATION & MORGAN. Les premières civilisations. (...) (Marx) \\
\hline \multirow{13}{*}{$\begin{array}{l}\text { SOCIOLOGIE } \\
\text { RELIGIEUSE }\end{array}$} & \multirow{13}{*}{92} & \multirow{13}{*}{$19(20,65 \%)$} & PHILOSOPHIE RELIGIEUSE & S. REINACH. Cultes, Mythes et Religions, tome IV (Hubert) \\
\hline & & & SYSTÈMES RELIGIEUX DES SOCIÉTÉS INFÉRIEURES & \\
\hline & & & SYSTĖMES RELIGIEUX NATIONAUX & $\begin{array}{l}\text { FARNELL. The Cults of the Greek States, tome V (Hubert) } \\
\text { DOMASZEWSKI. Abhandlungen zur römischen Religion (Hubert) }\end{array}$ \\
\hline & & & SYSTÈMES RELIGIEUX UNIVERSALISTES & \\
\hline & & & SYSTĖMES RELIGIEUX DES GROUPES SECONDAIRES & \\
\hline & & & CULTES SPÉCIAUX & REITZENSTEIN. Die hellenistischen Mysterienreligionen (Hubert) \\
\hline & & & CROYANCE ET PRATIQUES DITES POPULAIRES & LAWSON. Modern greek folklore and ancient greek religion (Marx) \\
\hline & & & CROYANCES ET RITES CONCERNANT LES MORTS & EITREM. Hermes und die Toten (Roussel) \\
\hline & & & LA MAGIE & \\
\hline & & & LE RITUEL & $\begin{array}{l}\text { STENGEL. Opfergebräuche der Griechen (Hubert) } \\
\text { KIRCHER. Die Sakrale Bedeutung des Weines im Altertum (Hubert) } \\
\text { HECKENBACH. De nuditate sacra sacrisque vinculis (Marx) } \\
\text { WAECHTER. Reinheitsvorschriften im griechischen Kult (...) (Reynier) }\end{array}$ \\
\hline & & & OBJETS ET LIEUX DE CULTE & $\begin{array}{l}\text { NISSEN. Orientation. Studien zur Geschichte der Religion. III (Mauss) } \\
\text { PFISTER. Der Reliquienkult im Altertum (Marx) } \\
\text { PLEY. De lanae in antiquorum ritibus usu (Reynier) }\end{array}$ \\
\hline & & & LES REPRÉSENTATIONS RELIGIEUSES & $\begin{array}{l}\text { HARRISON. Themis. A Study of the Social Origins of Greek Religion (David) } \\
\text { EISLER. Weltenmantel und Himmelszelt (Laskine?) } \\
\text { ROSCHER. Die Tessarakontaden und Tessarakontadenlehren (...) (Hubert) } \\
\text { LEUZE. Die römische Jahrzhälung (Hubert) } \\
\text { BERTHOLD. Die Unverwundbarkeit (...) der Griechen (Marx) }\end{array}$ \\
\hline & & & LES SOCIÉTÉS RELIGIEUSES & DUCHESNE. Histoire ancienne de l'Église (Mauss) \\
\hline \multirow{9}{*}{$\begin{array}{l}\text { SOCIOLOGIE } \\
\text { JURIDIQUE ET } \\
\text { MORALE }\end{array}$} & \multirow{9}{*}{70} & \multirow{9}{*}{$20(28,57 \%)$} & DE LA MORALE ET DU DROIT EN GÉNÉRAL & P. GIRARD. Mélanges de Droit romain (É. Lévy?) \\
\hline & & & SYSTÈMES JURIDIQUES & FERGUSON. Hellenistic Athens (Roussel) \\
\hline & & & L'ORGANISATION DOMESTIQUE ET MATRIMONIALE & $\begin{array}{l}\text { BLUMNER. Die römischen Privataltertümer (Davy) } \\
\text { DEMISCH. Die Schuldenerbfolge im attischen Recht(Gernet) } \\
\text { BRUCH. Die Schenkung auf den Todesfall im griechischen Recht (Gernet) } \\
\text { EUBECKER. Die Mitgift in rechtsvergleichen der Darstellung (Durkheim) } \\
\text { BRAUNSTEIN. Die politische Wirksamkeit der griechischen Frau (Gernet) }\end{array}$ \\
\hline & & & L'ORGANISATION DES GROUPES SECONDAIRES & $\begin{array}{l}\text { G. BLOCH. La plèbe romaine (Durkheim) } \\
\text { POLAND. Geschichte des griechischen Vereinswesens (Roussel?) }\end{array}$ \\
\hline & & & ORGANISATION POLITIQUE & $\begin{array}{l}\text { WILAMOWITZ-MOELLENDORF . Staat Gesellschaft der Griechen (...) (Davy) } \\
\text { ROSENBERG. Untersuchungen zur römischen Zenturienverfassung (Davy) } \\
\text { FRANCOTTE. Mélanges de droit public grec (Gernet) }\end{array}$ \\
\hline & & & DROIT CONTRACTUEL, DROIT DES OBLIGATIONS & $\begin{array}{l}\text { EISELE. Zum Streit um das Nexum (...) (Huvelin) } \\
\text { CALOGIROU. Die arrha im Vermögensrecht (...) (Huvelin) } \\
\text { PACCHIONI. Concetto e origini dell'obligation romana (...) (Huvelin) } \\
\text { WEISS. Pfandrechtliche Untersuchungen (Davy) }\end{array}$ \\
\hline & & & LE DROIT PÉNAL & HIRZEL. Die Strafe der Steinigung (Fauconnet) \\
\hline & & & L'ORGANISATION JUDICIAIRE ET LA PROCÉDURE & $\begin{array}{l}\text { HITZIG. Die Herkunft des Schwurgerichts im römischen Strafprozess (Davy?) } \\
\text { H. LÉVY-BRUHL. Le témoignage instrumentaire en droit romain (Gernet?) }\end{array}$ \\
\hline & & & LE DROIT INTERNATIONAL & PHILLIPSON. International law and custom of ancient Greece (...) (Huvelin) \\
\hline
\end{tabular}




\begin{tabular}{|c|c|c|c|c|}
\hline \multirow{7}{*}{$\begin{array}{l}\text { SOCIOLOGIE } \\
\text { CRIMINELLE ET } \\
\text { STATISTIQUE } \\
\text { MORALE }\end{array}$} & \multirow{7}{*}{15} & \multirow{7}{*}{$0(0 \%)$} & DE LA STATISTIQUE MORALE EN GÉNÉRAL & \\
\hline & & & NUPTIALITÉ. DIVORCES & \\
\hline & & & DE LA CRIMINALITÉ EN GÉNÉRAL & \\
\hline & & & LA CRIMINALITÉ SUIVANT LES PAYS & \\
\hline & & & LA CRIMINALITÉ SUIVANT L'ÂGE ET SEXE & \\
\hline & & & $\begin{array}{l}\text { FORMES DIVERSES DE LA CRIMINALITÉ } \\
\end{array}$ & \\
\hline & & & LE SYSTÈME RÉPRESSIF & \\
\hline \multirow{12}{*}{$\begin{array}{l}\text { SOCIOLOGIE } \\
\text { ÉCONOMIQUE }\end{array}$} & \multirow{12}{*}{123} & \multirow{12}{*}{$0(0 \%)$} & ÉTUDES GÉNÉRALES. MÉTHODE & \\
\hline & & & SYSTĖMES ÉCONOMIQUES & \\
\hline & & & ESPÈCES DE LA PRODUCTION & \\
\hline & & & RÉGIME DE LA PRODUCTION & \\
\hline & & & FORMES DE LA PRODUCTION & \\
\hline & & & VALEUR, MONNAIE, PRIX, ÉLÉMENTS DU PRIX & \\
\hline & & & CLASSES ÉCONOMIQUES (DE RÉPARTITION) & \\
\hline & & & ORGANES DE LA RÉPARTITION & \\
\hline & & & MORPHOLOGIE DE LA RÉPARTITION & \\
\hline & & & ÉLÉMENTS DE LA RÉPARTITION & \\
\hline & & & $\begin{array}{l}\text { RAPPORTS ENTRE LES PHÈNOMÈNES ÉCONOMIQUES } \\
\text { ET LES PHÉNOMĖNES SOCIAUX D'AUTRES CATÉGORIES }\end{array}$ & \\
\hline & & & $\begin{array}{l}\text { ÉCONOMIES SPÉCIALES, AGRICOLE, COMMERCIALE, } \\
\text { INDUSTRIELLE }\end{array}$ & \\
\hline \multirow{5}{*}{$\begin{array}{l}\text { MORPHOLOGIE } \\
\text { SOCIALE }\end{array}$} & \multirow{5}{*}{9} & \multirow{5}{*}{$0(0 \%)$} & BASES GÉOGRAPHIQUES DE LA VIE SOCIALE & \\
\hline & & & DE LA POPULATION EN GÉNÉRAL & \\
\hline & & & MOUVEMENTS MIGRATOIRES & \\
\hline & & & GROUPEMENTS RURAUX ET URBAINS & \\
\hline & & & LA MAISON & \\
\hline \multirow[t]{4}{*}{ DIVERS } & \multirow[t]{3}{*}{9} & \multirow[t]{3}{*}{$1(11,11 \%)$} & SOCIOLOGIE ESTHÉTIQUE & $\begin{array}{l}\text { RIDGEWAY. The origin of tragedy with special reference to the Greek } \\
\text { Tragedians (Hubert) }\end{array}$ \\
\hline & & & LE LANGAGE & \\
\hline & & & TECHNOLOGIE & \\
\hline & 345 & $42(12,17 \%)$ & & \\
\hline
\end{tabular}


Passando agora às subdivisões do AS, constata-se uma grande concentração das resenhas de livros sobre Grécia e Roma antigas em duas seções específicas da revista: Sociologie Religieuse e Sociologie Morale et Juridique ${ }^{14}$. Se no conjunto do AS a presença dos trabalhos relacionados à Antiguidade clássica oscilava entre 5,84\% a 12,17\%, nesses dois casos ela raramente caiu abaixo dos $10 \%$, chegando a atingir em alguns volumes $28 \%$. Tal distribuição não deixa de ser natural em função dos objetos das outras seções. Afinal, Sociologie Générale tratava de questões de fundo epistemológico, para as quais os estudos greco-romanos podiam contribuir de forma apenas marginal. Sociologie Criminelle, por sua vez, privilegiava o tratamento estatístico de dados fornecidos por nações modernas. Em Sociologie Économique, por fim, as resenhas sobre o tema tinham sua importância diluída em meio à grande quantidade de textos acolhidos na seção.

Mas quais as implicações de tal padrão? É preciso destacar aqui que as partes do AS onde os estudos greco-latinos se destacaram eram justamente aquelas coordenadas por Mauss, Hubert e Durkheim. Ou seja, o diretor e três dos principais colaboradores da revista dos sociólogos buscaram diretamente em Grécia e Roma Antigas material para avançar em suas pesquisas. Não haveria, de fato, como ser diferente. Em um cenário no qual relatos precisos e confiáveis sobre a organização política, econômica, social e religiosa de outros povos eram difíceis de serem obtidos, as fontes antigas e os trabalhos sobre elas se tornavam indispensáveis, ainda mais em um amplo registro comparatista ${ }^{15}$. Além disso, esses primeiros sociólogos universitários franceses dispunham, graças às suas formações, da capacidade de criticar os estudos greco-latinos não apenas de um ponto de vista metodológico, mas também junto às séries documentais mobilizadas. Não custa insistir que eles, embora não fossem, em sua maioria, helenistas e latinistas, haviam sido iniciados no estudo das línguas e literaturas clássicas desde os tempos de colégio. Pode-se assim afirmar que, no plano geral da nova ciência, desconsiderando por ora o peso dos clássicos na viabilização das carreiras de um ou outro sociólogo, o interesse por Grécia e Roma antigas residia precisamente nesse ponto.

Mas quem foram os antiquisants cujos trabalhos interessaram os sociólogos? Uma rápida análise dos quadros anteriores aponta para o peso da universidade alemã nessas questões. Isso não impediu, contudo, que alguns dos mais renomados especialistas franceses tenham também sido acionados. O helenista e arqueólogo Salomon Reinach foi simplesmente

\footnotetext{
${ }^{14}$ A seção Divers poderia igualmente figurar aqui, mas seu peso relativo é pequeno e a presença dos estudos greco-latinos só aumentou graças às atuações pontuais de Meillet, no domínio da linguística, e de Hubert, quanto às artes e à tecnologia dos antigos.

${ }^{15}$ A etnologia universitária, como lembra Karady, estava ainda em vias de ser plenamente constituída (cf. KARADY, 1988).
} 
um dos autores mais resenhados pela equipe do AS (em especial, por Henri Hubert) ${ }^{16}$. Já Camille Jullian, latinista reconvertido às antiguidades nacionais, teve dois de seus estudos sobre a organização urbana e política dos antigos gauleses discutidos por Durkheim ${ }^{17}$. E os exemplos poderiam ser aqui multiplicados: as teses de Paul Foucart sobre os mitos de Eleusis; os estudos de Louis Duchesne sobre os primórdios da religião cristã; o trabalho de Gustave Bloch sobre a plebe romana; os artigos acerca dos mitos gregos por Paul Girard; os livros de Franz Cumont abordando o culto de Mitra; edições críticas de inscrições mágicas feitas por membros as Écoles Françaises de Rome e d'Athènes; inúmeros tratados sobre a história do direito romano. Da perspectiva sociológica, tudo parecia interessante.

Muito embora os sociólogos durkheimianos tenham privilegiado a produção dos trabalhos de maior fôlego dos antiquisants franceses em suas resenhas, eles não deixaram de acordar um constante interesse pela produção das revistas especializadas nos estudos grecolatinos. De todas elas, a mais acionada foi a Revue des Études Grecques (REG). Seus artigos foram resenhados, referenciados ou simplesmente citados dez vezes ${ }^{18}$. Ela foi seguida, com base nos mesmos critérios, pela Revue des Études Anciennes (REA), cujos textos foram mencionados três vezes ${ }^{19}$, os Mélanges d'Archéologie et d'Histoire (MAH), com duas citações ${ }^{20}$, e o Bulletin de Correspondance Hellénique (BCH), com apenas uma alusão localizada ${ }^{21}$. Não há como explicar essa assimetria constatada sem uma análise da história e da morfologia das revistas dos antiquisants. Ela não é, no entanto, fortuita, como se quer mostrar ao longo do presente estudo.

Antes mesmo de passar ao estudo dessas revistas, cumpre observar mais detidamente quem foram os membros da equipe do AS que mais se empenharam em construir pontes entre a sociologia e os estudos greco-latinos.

\footnotetext{
${ }^{16}$ Essas referências serão listadas e discutidas mais adiante, no subcapítulo 3.2 da presente tese.

17 Este observou virtudes no trabalho do colega, mas não deixou de assinalar também deslizes conceituais (a confusão em torno do funcionamento de um "clã", por exemplo). Cf., para tanto, AS, 1902: 575 (uma breve notícia) e 1903: 552 (resenha). Ambas foram escritas logo após Durkheim deixar a Faculdade de Letras de Bordeaux, onde ele lecionava ao lado de Jullian. Sobre a relação entre os dois homens, veja-se o subcapítulo 2.4 da presente tese.

${ }^{18}$ AS, 1902: 268 e 601; 1903: 258; 1904: 280 e 647; 1905: 638; 1906: 237; 1913: 261 e 195.

${ }^{19}$ Além das referências fornecidas na nota 17, ver AS, 1904: 262.

${ }^{20}$ AS, 1906: 235; e 1907: 340.

${ }^{21}$ AS, 1905: 343.
} 


\section{2 - OS COLABORADORES}

\section{ANTIQUISANTS DE}

\section{L'ANNÉE}

\section{SOCIOLOGIQUE}

“Eu parabenizo o fato de você [Pierre Roussel] ser um bom e um exato epigrafista. Essa é a boa escola e sem dúvida o único caminho que leva a resultados seguros. Ainda assim, estou certo de que você se colocará os problemas em termos diferentes e os atacará com um espírito outro que a maioria dos puros 'historiadores da antiguidade'".

Robert Hertz

(Trecho de carta endereçada a Pierre Roussel, datada de 22 de junho de 1907. Cf. HERTZ, 1999)

Uma equipe tão heterogênea como a que animava o AS, ao menos no que tange a suas atividades de pesquisa, não prescindiu da presença de antiquisants franceses em suas fileiras. Ao longo dos doze volumes que compõem a primeira série da revista, a participação de tais profissionais foi constante, compreendendo dois momentos distintos. Entre 1898 e 1907, destacaram-se nesse papel colaboradores como Henri Hubert, Antoine Meillet e Paul Huvelin. Embora não se tratassem de helenistas e latinistas stricto sensu, eles haviam sido incentivados, em função de suas trajetórias intelectuais e institucionais, a expandir seus conhecimentos escolares sobre a Antiguidade Clássica. Tal postura implicou não apenas o contato permanente com os antiquisants, mas também a produção de conhecimento original nos domínios de estudos desses profissionais, em particular no tocante à epigrafia, à arqueologia, à linguística, à religião e ao direito antigos. Ao lado desse trio, nos dois últimos volumes do AS, constituiu-se outro, este formado por Louis Gernet, Pierre Roussel e Henri Jeanmaire, todos pesquisadores em início de carreira. Sacramentou-se então a adesão dos especialistas dos estudos grecolatinos ao projeto sociológico.

O propósito do presente subcapítulo é discorrer sobre a especificidade desses dois momentos, dando ênfase ao que, na trajetória dos referidos pesquisadores, remeteu ao diálogo entre as ciências sociais e a produção de conhecimento sobre os Antigos.

\section{ENTRE AMIZADES E COMPARATISMOS}

Até fins da primeira década do século $X X$, as interações entre os sociólogos durkheimianos e o domínio dos estudos greco-latinos passaram por dois expedientes. 0 
primeiro vinha na forma difusa das relações afetivas existentes entre os portadores desses saberes, o que geralmente traziam a reboque trocas intelectuais mais ou menos constantes. $\mathrm{O}$ caso de Durkheim é paradigmático nessa direção. O diretor do AS, conhecido em público como o "patrão" da escola sociológica francesa, tinha entre seus melhores amigos, desde o período em que foi professor em Bordeaux, dois estudiosos da filosofia antiga, Octave Hamelin e Georges Rodier. Os três se engajaram lado a lado por ocasião do Affaire Dreyfus, assim como se auxiliaram quando o assunto era a progressão institucional de suas carreiras ${ }^{1}$. As colaborações intelectuais entre eles, por sua vez, apareceram tanto de forma direta, via citações à obra alheia, quanto indiretas, por meio de sugestões para que os alunos de uns frequentassem os cursos dos outros ${ }^{2}$. Sabe-se ainda que amizades similares marcaram outros membros importantes da equipe original do AS, tais como Henri Hubert e Robert Hertz. E é muito provável que os demais sociólogos tenham vivido situações similares, uma vez que eles haviam partilhado, enquanto alunos e professores, os bancos das mesmas escolas e universidades com antiquisants.

Para além das relações afetivas, o que não exclui a possibilidade de influências e encorajamentos daí advindos, alguns dos primeiros pesquisadores ligados ao AS produziram, sem terem atuado institucionalmente como latinistas ou helenistas, conhecimento na área dos estudos greco-latinos. O mais antigo deles, ao menos no que concerne à adesão ao projeto científico encabeçado por Durkheim, foi Henri Hubert. Nascido na Paris de 1872, no seio de uma família católica de comerciantes abastados, à qual também pertenceu o historiador da arte Paul Vitry, ele recebeu a melhor educação letrada então disponível. Aluno do prestigioso Liceu Louis-le-Grand desde os dez anos de idade, Hubert aí obteve o primeiro lugar em version grecque no concours général. A vida de écolier prosseguiu com a admissão na École Normale Supérieure (ENS) em 1892, onde ele travou contato, entre seus colegas, com indivíduos que viriam a ser importantes antiquisants como Paul Perdrizet e Paul Jouguet, ambos da promoção

\footnotetext{
${ }^{1}$ Sobre a atuação conjunta no Affaire Dreyfus, veja-se a compilação de informações feita por Marcel Fournier em sua biografia de Durkheim (FOURNIER, 2007: 235-375). Veja-se também a correspondência entre Durkheim e Hamelin (tal como publicada em DURKHEIM, 1975b), bem como as referências a Rodier nas cartas que Durkheim endereçou a Salomon Reinach (BENTHIEN, 2010).

${ }^{2}$ Aproveitando-se da relação assimétrica que ele manteve com os membros mais jovens da equipe do AS, sobretudo os pretendentes ao título de agrégé de philosophie, Durkheim os incitou a seguir os cursos de Hamelin e Rodier. Marcel Mauss travou contato com os dois em Bordeaux. Já Robert Hertz e Antoine Bianconi tiveram aulas em Paris apenas com Hamelin (uma vez que Rodier só obteve um posto na capital francesa em 1908). Já quanto às referências ao trabalho alheio, elas foram particularmente marcantes entre Durkheim e Hamelin. Este, por exemplo, faz uma longa discussão sobre a importância da sociologia para o estudo da história da filosofia em seu curso, publicado postumamente, sobre Aristóteles (HAMELIN, 1931). Aquele, por sua vez, se vale da tese de Hamelin em sua Opus Magna-cf. DURKHEIM, 1912: 13 (nota 1).
} 
de 1890, ou ainda Charles Fossey, futuro assiriólogo e colaborador marginal dos sociólogos, membro da promoção seguinte. Como professores, o ensino dos clássicos ficava então a cargo de ninguém menos que Gustave Bloch (histoire) e Paul Girard (grec), dois antiquisants que se mostraram na sequência não apenas afinados com os sociólogos quanto a algumas de suas manifestações públicas (o Affaire Dreyfus), mas que também produziram trabalhos próximos às ciências sociais ${ }^{3}$. Nesse primeiro momento de sua formação Hubert parecia bastante interessado na história da Grécia Antiga, publicando, antes mesmo de sair da ENS, um artigo sobre duas inscrições epigráficas gregas provenientes da Ásia Menor na prestigiosa Revue Archéologique $^{4}$. Em 1895, ao mesmo tempo em que obteve o terceiro lugar no exame nacional de agrégation d'histoire et géographie, iniciou estudos sobre o oriente antigo na EPHE. Foi nesse ambiente que ele conheceu, um ano mais tarde, Marcel Mauss, passando a integrar a equipe que já se organizava em torno do projeto de uma revista especializada em sociologia. Hubert também militou ao lado de vários membros dessa equipe por ocasião do Affaire Dreyfus, quando foi signatário da terceira petição dos "intelectuais". Os primeiros postos no sistema de ensino e pesquisa francês, os quais ele manteve até o final de sua vida, apareceram logo depois: um no Musée des Antiquités de Saint-Germain-en-Laye (MAN), onde ele entrou attaché libre (1898) e progrediu ao cargo de conservateur adjoint (1910); e o outro como maître de conférence na seção de ciências religiosas da EPHE ( $V^{a}$ seção), assumido por ele em 1901. Hubert ainda lecionou na École du Louvre a partir de 1906, ocupando, como suplente de Salomon Reinach, a cadeira intitulada Archéologie Nationale.

O interesse crescente por antigas religiões do Oriente Médio, sobre as quais ele pretendia escrever uma tese de doutorado, não implicou a distância em relação aos estudos greco-latinos. Viu-se nas tabelas apresentadas no subcapítulo anterior como Hubert foi, no contexto do AS, aquele que resenhou o maior número de textos e livros vinculados a essas temáticas. Mas esse interesse não se fez presente apenas nas páginas impressas editadas por sociólogos: dois verbetes seus sobre as práticas religiosas gregas (Kirèné e Magia) foram publicados no início do século XX no Dictionnaire des Antiquités Grecques et Romaines, então dirigido por Edmond Saglio e Edmond Pottier ${ }^{5}$. Além disso, nas vitrines sob sua responsabilidade no MAN, havia um número considerável de objetos antigos provenientes da

\footnotetext{
${ }^{3}$ Ambos, aliás, tiveram livros e artigos seus resenhados no AS. Veja-se a resenha que o próprio Hubert fez de um artigo de Girard sobre o mito de Ajax (AS, 1906: 282) e a resenha que Durkheim fez de um texto de Bloch sobre a origem e a organização da plebe romana (AS, 1913: 441-443).

${ }^{4}$ Cf. RA, 1894/1: 308-314.

${ }^{5}$ Para uma análise desses textos específicos, veja-se o subcapítulo 3.3 da presente tese, dedicado ao referido dicionário.
} 
Península itálica e grega, sobretudo na sala de Arqueologia Comparada ${ }^{6}$. Por fim, no que diz respeito exclusivamente aos vínculos institucionais, Hubert se tornou membro ordinário da Association pour l'Encouragement des Études Grecques en France (AEEG) bastante cedo, ainda em $1898^{7}$.

Importa salientar que essas investidas no domínio dos estudos greco-latinos vinham atreladas a um plano de carreira na área, uma vez que tal diálogo fortalecia sua posição e promovia a circulação de seu nome no sistema de ensino francês. Ainda assim, havia aí também um interesse intelectual, oriundo da importância que Hubert dava ao comparatismo no âmbito de seus estudos sobre a arqueologia e a dimensão social das práticas religiosas. Prolongar e aprimorar o conhecimento escolar que ele havia acumulado sobre o grego e o latim permitiu-lhe ampliar o escopo de fenômenos disponíveis à observação, como atesta o amplo uso que ele fez de vestígios literários e materiais antigos em seus estudos sobre o sacrifício e sobre a magia, ambos publicados em parceria com Marcel Mauss (AS, 1899: 29-137 e 1904: 1-145). O mesmo poderia ser dito de muitos de seus textos sobre a religião e a arqueologia celta (Hubert, 1925). A acreditar ainda nas palavras de Mauss, os povos da Europa - gregos, latinos, celtas e germânicos - compreendiam o quinhão de Hubert na divisão que ambos fizeram para fins de estudo dos povos do mundo ${ }^{8}$. Se seus trabalhos posteriores 0 levaram a privilegiar cada vez mais os povos do norte da Europa, isso não foi feito à revelia dos demais. Tal como sugere a alocução do presidente da AEEG por ocasião da morte de Hubert: "ele [Hubert] atravessou o helenismo para chegar ao celtismo" (REG, 1927: LXIII).

Outro membro da equipe do AS que se fez presente no terreno dos antiquisants foi Antoine Meillet. Seis anos mais velho que Hubert, ele cursou praticamente todo o ensino secundário longe de Paris, em Moulins, seguindo para a capital apenas às vésperas de ingressar na universidade, quando esteve matriculado como aluno externo no Liceu Louis-leGrand. Seguiu-se então o bem-sucedido ingresso na Faculdade de Letras de Paris (1885). Uma vez nessa instituição, mas também frequentando cursos no Collège de France e na EPHE, Meillet travou contato com os grandes filólogos e linguistas em atividade na França, tais como Louis Havet, James e Arsène Darmesteter, Sylvain Lévi, Ferdinand de Saussure e Michel Bréal. Bolsista de agrégation, ele obteve em 1889 o primeiro lugar no exame nacional de grammaire,

\footnotetext{
${ }^{6}$ Sobre essa sala e o trabalho de Hubert no referido museu, veja-se o subcapítulo 3.2 da presente tese.

${ }^{7}$ Não deixa de ser interessante observar que Hubert se apresentava em L'Année Sociologique e na AEEG de maneiras diferentes. Nesta, ele aparece apenas em seu posto no Musée des Antiquités Nationales, ao passo que naquele o posto referido é o da EPHE.

${ }^{8}$ MAUSS, 1979. A ele, Mauss, caberiam os povos primitivos das Américas, da África, da Ásia e da Oceania.
} 
o que the abriu as portas da EPHE como suplente de Saussure na cadeira de Grammaire Comparée, onde foi efetivado dois anos mais tarde. Ainda em 1891, ele partiu, como bolsista do governo francês para uma missão científica no Cáucaso, durante a qual estudou as línguas eslavas e o armeniano moderno. Trata-se do início da carreira de quem viria a ser o mais prestigiado comparatista no domínio do indo-europeu na França até a década de 1930.

Com efeito, a ascensão de Meillet foi extremamente rápida e não parece ter conhecido contratempos. Ele se tornou doutor em 1897, discutindo tanto o emprego do acusativo e do genitivo no antigo eslavo (sua tese principal) quanto o significado da raiz indo-européia *men(tese secundária). Como professor, antes e depois do doutorado, acumulou também as cadeiras de iraniano antigo na EPHE (1894), em decorrência do falecimento de James Darmesteter, e a de armeniano na École des Langues Orientales (1902). A grande consagração de sua trajetória veio cedo, com a eleição para o Collège de France em 1906, substituindo o recém-aposentado Michel Bréal como professor de Grammaire Comparée ${ }^{9}$. Ele ainda se tornou mais tarde membro efetivo da Académie des Inscriptions et Belles-Lettres (1924) e presidente da IV seção da EPHE (1925), além de ter acumulado uma série de prêmios e doutorados honoris causa dentro e fora da França.

Enquanto linguista interessado na família indo-européia, Meillet não podia simplesmente negligenciar os estudos greco-latinos. Sua estratégia, porém, ao menos nos primeiros anos de carreira, foi investir em línguas indo-européias pouco conhecidas, fazendoas dialogar com os ramos mais tradicionais e prestigiosos dessa família (o que compreendia, além dos troncos latino e grego, o indo-iraniano). Foi sobretudo após sua entrada no Collège de France que seus trabalhos passaram a dar uma atenção especial às línguas do Mediterrâneo Antigo. Institucionalmente, ele se tornou membro da Association pour l'Encouragement des Études Grecques en France (AEEG) em 1908, da qual viria a ser presidente durante a Primeira Guerra Mundial e em cuja revista publicou um bom número de artigos, como se verá mais adiante na presente tese. Já quanto a seus trabalhos científicos mais importantes na área, ele publicou dois livros que se propõem a reconstituir a história social dos antigos gregos e latinos por intermédio de suas línguas. Aperçu d'une Histoire de la Langue Grecque e Esquisse d'une Histoire de la Langue Latine, publicados respectivamente em 1913 e 1928, não só marcaram época, como continuam a conhecer, até o início do século XXI, novas edições e reimpressões. As duas línguas já ocupavam um lugar importante em duas obras anteriores, embora estas não

\footnotetext{
${ }^{9}$ Para mais detalhes sobre a eleição de Meillet no Collège de France, veja-se o item 3.1 da presente tese.
} 
se centrassem nas relações entre língua e sociedade, Les Dialectes Indo-Européens (1908) e Introduction à l'Étude Comparative des Langues Indo-Européennes $(1903)^{10}$.

O contato de Meillet com os sociólogos teve início após o ingresso de Isidore Lévy, Marcel Mauss e Henri Hubert na EPHE, nos últimos anos do século XIX e nos primeiros do XX. O clima era favorável a tal encontro em vários sentidos. Durante o Affaire Dreyfus, Meillet tomou o partido dos dreyfusards, como boa parte dos sociólogos. Além disso, do ponto de vista epistemológico, após ter flertado com a teoria da imitação tardeana, ele encontrou na definição de "fato social" de Durkheim um meio de fazer progredir a linguística. Com efeito, partindo do princípio que a língua tem também uma existência autônoma aos indivíduos, Meillet elaborou toda uma explicação sociológica para dar conta de sua dimensão histórica. A partir de 1902, ele colaborou em todos os números do AS com resenhas e com longas notas que faziam um balanço do estado atual da linguística na subseção da revista que lhe fora destinada ${ }^{11}$. Seu texto conceitual e metodologicamente mais importante publicado no AS foi a memória Comment les Mots Changent de Sens (AS, 1906: 1-38). O centro da argumentação recaía nesse caso no conceito de emprunt (empréstimo), o qual postulava que os indivíduos participam ao mesmo tempo de diversos grupos sociais, cada qual com um vocabulário próprio atrelado à dinâmica das relações ali existente. O crucial, para Meillet, era acompanhar a trajetória de idas e vindas de palavras entre as fronteiras desses grupos, modificando as dinâmicas existentes anteriormente (acrescentando novas palavras, mas também modificando o sentido que elas podiam vir a ter no novo contexto). Como as palavras não circulam sem as pessoas, na base da linguística geral de Meillet estava assentada sobre uma linguística histórica sociologicamente informada ${ }^{12}$. É importante destacar ainda que, tal como ocorria com Hubert no registro da sociologia religiosa e da arqueologia, esse trabalho histórico era apenas possível graças à comparação entre diferentes línguas ou diferentes registros de uma mesma língua. Tratava-se de uma maneira bastante eficaz e por vezes a única possível de definir se uma palavra é natural ou veio por meio de importações.

E aqui o contato entre sociólogos e linguistas durou: para além das relações diretas entre Meillet e os membros da equipe do $\mathrm{AS}^{13}$, Joseph Vendryes, um de seus primeiros

\footnotetext{
${ }^{10}$ Ainda assim, esse livro traz discussões importantes do ponto de vista sociológico em seu capítulo final, intitulado Vocabulaire. Cf. MEILLET, 1903: 344-370.

11 Trata-se da subseção Le Langage ou Linguistique, situada na última seção do AS, Divers, criada também em 1902.

${ }^{12}$ Sobre o texto citado de Meillet, cf. BENTHIEN, 2011. Já quanto ao fundamento epistemológico de sua obra, veja-se VENDRYES, 1937, BERGOUNIOUX, 2006 e SWIGGERS, 2009.

${ }^{13}$ No Fonds Antoine Meillet, depositado nos arquivos do IMEC-Caen, constam cartas recebidas por ele de Robert Hertz (MLT 12.111), Émile Durkheim (MLT 12.70), Jean Marx (MLT 13.45), André Piganiol (MLT 13.79), Marcel Granet (12.99). No Fonds Mauss-Hubert, pertencente à mesma instituição, foram consultadas cartas enviadas por Meillet a Henri Hubert (MAS 50).
} 
orientandos, era também bastante próximo aos durkheimianos, trabalhando lado a lado com Henri Hubert no que se refere aos antigos celtas ${ }^{14}$. Ao menos em um plano de continuidade teórica, o mesmo pode ser afirmado quanto a dois discípulos seus mais jovens, Émile Benveniste e Pierre Chantraine.

Ora, foi como linguista-sociólogo que Meillet procurou intervir no espaço dos antiquisants. Seu conceito de emprunt foi amplamente utilizado para tornar compreensível a origem dos dialetos gregos e o desenvolvimento histórico do "grego comum", bem como, no campo latino, para entender as transformações do latim a partir da expansão romana ${ }^{15}$. Ainda assim, por certo, havia limites para sua explicação, uma vez que os dados sobre a circulação de pessoas nem sempre eram confiáveis ou mesmo existentes para períodos remotos da história. Em todo caso, mesmo quando existia tal lacuna de informação, argumentava Meillet, era preciso ao menos supor a existência desses circuitos para explicar a singularidade de uma língua ou de um dialeto ${ }^{16}$.

O terceiro e último colaborador do AS que, sem ser exatamente um antiquisant, investiu nos estudos greco-latinos foi Paul Huvelin. Nascido em 1873, ele não se formou, como Hubert e Meillet, no universo da Faculdade de Letras de Paris e da École Normale Supérieure, mas sim na Faculdade de Direito. Segundo Frédéric Audren, Huvelin se especializou cedo em uma área carente na universidade francesa, qual seja, a história do direito comercial (AUDREN, 2001). Duas conquistas marcaram sua entrada no sistema de ensino francês. Em 1897, ele defendeu uma tese intitulada Essai Historique sur le Droit des Marchés et des Foires, na qual a comparação entre os direitos comerciais greco-romano, medieval e moderno permitia problematizar a especificidade e a autonomia de legislações historicamente dadas frente aos arranjos sociais que as engendraram ${ }^{17}$. Dois anos mais tarde, ele ainda obteve o primeiro lugar na agrégation de droit (seção histoire du droit), o que the permitiu na sequência assumir postos universitários em Aix-en-Provence e, mais tarde, em Lyon (aqui, de fato, ocupando uma cadeira intitulada Droit Romain).

Sem entrar agora em detalhes quanto a seu trabalho de pesquisa, cabe aqui apontar para a importância dos dados jurídicos provenientes de Grécia e Roma Antigas ${ }^{18}$. Huvelin certamente dominava o grego e o latim desde o ensino secundário, uma vez que tais línguas

\footnotetext{
${ }^{14}$ Vendryes também manteve as posições teóricas de Meillet. Cf., por exemplo, VENDRYES, 1968.

${ }^{15}$ Veja-se MEILLET, 1913 e 1928.

${ }^{16}$ Para uma ilustração desse tipo de dificuldade, veja-se o artigo que Meillet publicou em 1908 na Revue des Études Grecques, intitulado La Place du Pamphylien parmi les Dialects Grecs (REG, 1908: 413-425).

${ }^{17}$ Huvelin considerou mesmo os povos então chamados "primitivos" em suas relações com os demais. Ele chega mesmo a se valer de exemplos provenientes dos índios do Brasil. Cf. HUVELIN, 1897: 338-346.

${ }^{18}$ Veja-se, a esse respeito, o subcapítulo 3.3 da presente tese.
} 
eram obrigatórias para os exames dos quais dependiam a obtenção de certificados em direito. A atuação no terreno da história do direito tornou necessários estudos adicionais. O diálogo direto com os antiquisants já data de sua tese, quando Adhémar Esmein, um dos mais renomados estudiosos do direito romano, professor da Faculdade de Direito de Paris e da EPHE, tomou parte em seu júri de defesa. Na sequência, Huvelin publicou textos sobre a dimensão religiosa do antigo direito penal romano ${ }^{19}$, comentou um decreto comercial grego recém-encontrado ${ }^{20}$, bem como produziu uma série de dez verbetes no Dictionnaire des Antiquités Grecques et Romaines, os quais tratavam tanto de história do direito comercial grego quanto de noções específicas do direito penal e comercial romano.

A adesão ao projeto editorial e científico encabeçado por Durkheim se deu em 1903, em meio a esse seu pesado investimento nos estudos greco-latinos. Sabe-se que os primeiros contatos com os durkheimianos foram intermediados por Emmanuel Lévy, colega de Huvelin na Faculdade de Direito de Lyon. Sabe-se também que as primeiras cartas trocadas entre ele e Mauss datam já de $1899^{21}$. Uma análise das resenhas que ele escreveu para AS e de sua única memória aí publicada dão mostras de que seu recrutamento valorizava o uso e a crítica positiva dos modelos sociológicos para a discussão dos dados provenientes da Antiguidade Clássica ${ }^{22}$. Ainda durante a Primeira Guerra Mundial, Huvelin voltou ao tema do comércio dos antigos para, discutindo a Segunda Guerra Púnica, espelhar a situação moderna, também ela "uma guerra de usura" (HUVELIN, 1917). Após o conflito, contudo, ele mesclou a carreira de professor universitário com a de político, lançando-se para a disputa de cargos públicos em Lyon com um sucesso apenas relativo. Ele falecerá subitamente na sequência, em 1925.

Mas o que concluir a respeito dessas três trajetórias bastante diferentes? Há algo em comum entre elas que permita caracterizar um momento específico da relação entre antiquisants e sociólogos? Ora, as adesões de Hubert, Meillet e Huvelin à equipe do AS remetem ao momento heróico da inserção institucional da sociologia no sistema de ensino francês, período marcado por combates e alianças dentro da universidade, nas várias áreas afetadas pela ascensão da nova disciplina (sobretudo os saberes acolhidos nas Faculdades de Letras e de Direito, na EPHE e no Collège de France). As diferentes trajetórias desses três profissionais ilustram como a adesão ao projeto sociológico durkheimiano só foi possível

\footnotetext{
${ }^{19}$ HUVELIN, 1903 e 1907.

${ }^{20} \mathrm{BCH}, 1907:$ 46-93 (Sobre esse texto, veja-se o subcapítulo 2.1 da presente tese).

${ }^{21}$ Arquivos do IMEC-Caen, Fonds Mauss-Hubert, caixa MAS 6.40. A transcrição dessas cartas está também disponível em AUDREN, 2001.

${ }^{22}$ Veja-se, em particular, sua memória intitulada Magie et Droit Individuel (AS, 1907: 1-47). A listagem das resenhas de Huvelin de livros que tratavam do mundo antigo pode ser encontrada nas tabelas discutidas no subcapítulo anterior.
} 
mediante a atuação concomitante em outros espaços institucionais, de cuja legitimidade eles não deixaram de se apropriar. Afinal, como seguir uma trajetória de sociólogo se ela não existia, ao menos não em um plano formal? Era assim preciso inventar partindo do que já existia, convencendo os colegas da valia e da importância da sociologia para auxiliar suas próprias atividades. Para Hubert, a história e a pré-história europeias. Para Meillet, a linguística a partir do estudo das famílias de linguas indo-europeias. Para Huvelin, o direito comercial e penal a partir de uma perspectiva histórica. Em todos esses casos, tanto os exemplos vindos de Grécia e Roma Antigas quanto as discussões historiográficas que tais "civilizações" suscitavam tiveram papel central. Hubert, Meillet e Huvelin apresentaram uma atitude ambígua frente à ortodoxia universitária, caminhando com e contra ela, subvertendoa, mas sem deixar de se apropriar de elementos que elas ofereciam. Certamente não se tratava, aos olhos de seus contemporâneos, de especialistas de domínios claramente definidos - seria, aliás, uma ilusão retrospectiva rotulá-los em definitivo segundo o que se produziu depois deles, mas também graças a eles. À medida que eles conseguiam, por caminhos mais ou menos tortuosos, atingir uma segurança institucional, bem como tinham, com maior ou menor sucesso, sua autoridade publicamente reconhecida, esses três colaboradores do AS se destacaram como indivíduos aptos a fazer as ideias sociológicas circularem, assim como capazes de alimentar a sociologia com outras ideias. As pontes que eles estabeleceram com estudos greco-latinos, estragéticos intelectual e institucionalmente, não podem assim ser desconsideradas. Elas ilustram, em verdade, a velha estratégia do Cavalo de Troia. E que indício melhor do sucesso dos sociólogos durkheimianos que o fato de se observar, ainda na primeira série do AS, o ingresso de pesquisadores que, seguindo a carreira de helenistas, deixaram-se seduzir por, assim como se apoiaram em, uma sociologia já conhecida e, em certa medida, reconhecida na universidade?

\section{A ADESÃO DE JOVENS ESPECIALISTAS}

A partir do décimo primeiro volume do AS, lançado em 1910, passaram a figurar entre seus colaboradores alguns jovens antiquisants. Louis Gernet foi o primeiro a cerrar fileiras com os sociólogos em 1910, seguido, em 1913, por Pierre Roussel e Henri Jeanmaire. Antes de discutir aqui sobre as diferenças e similitudes entre suas trajetórias, cumpre sublinhar dois pontos mais gerais. Em primeiro lugar, esse novo período das relações entre especialistas no mundo greco-romano e sociólogos não se deu em substituição ao que se via antes. Hubert, Huvelin e Meillet continuaram produzindo conhecimento no domínio dos antiquisants, assim 
como o fizeram, em menor escala, outros colaboradores do $\mathrm{AS}^{23}$. O segundo ponto, central para presente tese, diz respeito à adesão assimétrica de latinistas e helenistas. Com efeito, a despeito da existência de alguns (poucos) latinistas simpáticos aos trabalhos dos sociólogos, nenhum deles participará da primeira série do $\mathrm{AS}^{24}$. Mas ainda é cedo para propor uma explicação de tal fenômeno. Por ora, o importante é atentar para as especificidades das trajetórias de cada um dos três helenistas supramencionados.

Nascido em 1882, Louis Gernet entrou em contato com os sociólogos graças a sua atividade de militante socialista, particularmente intensa durante sua estada na prestigiosa École Normale Supérieure. Membro da promoção 1902, sabe-se que ele participou com dois futuros integrantes da equipe do AS, Robert Hertz, seu veterano, e Marcel Granet, seu calouro, da experiência editorial dos Cahiers du Socialisme ${ }^{25}$. Não tardou muito e, no ano seguinte, Gernet foi transformado em colaborador regular de Notes Critiques: Sciences Sociales, revista de resenhas publicada sob a direção de François Simiand entre 1900 e 1906. A transferência da referida publicação para o AS foi questão de tempo ${ }^{26}$. A saída da ENS se deu em grande estilo, com a obtenção do primeiro lugar nacional no exame de agrégation de grammaire.

Seria natural, tendo em vista a carreira de antiquisant, que Gernet se apresentasse para estagiar na École Française d'Athènes (EFA). Tratava-se, afinal, da via régia dos helenistas, pois, como se verá em detalhes ao longo do subcapítulo 2.1, ela dava aos jovens pesquisadores a oportunidade de trabalhar na prática, com documentos epigráficos inéditos e em sítios arqueológicos inexplorados, a história da Grécia Antiga. Edmond Pottier, um antigo "ateniense" e então professor na École du Louvre, chegou a sugerir em 1905 o nome de Gernet, ao lado dos de Jean Hatzfeld e de Pierre Roussel, como ex-alunos promissores a quem as vagas da EFA deveriam ser destinadas ${ }^{27}$. Ainda assim, ao contrário dos colegas

\footnotetext{
${ }^{23}$ Gaston Richard, Marcel Mauss e Charles Fossey, em particular, chegaram a publicar textos nas revistas especializadas nos estudos greco-latinos, como se verá ao longo da presente tese.

24 Iniciada em 1925, a segunda série da revista, por sua vez, terá entre os seus um historiador da Roma Antiga (André Piganiol), bem como alguém que, como Huvelin, estudou o direito romano ao lado de outros temas (Henry Lévy-Bruhl).

${ }^{25}$ Cf. GERNET, 1983: 403-420. A militância política, aliás, permaneceu em Gernet após os tempos de escola. As duas cartas mais antigas dele encontradas nos arquivos consultados ao longo da presente pesquisa remetem justamente a isso. Em uma carta endereçada a Mauss e certamente escrita antes da Primeira Guerra Mundial, Gernet pede ao "cher camarade" que o ajude a difundir um novo jornal socialista (cf., nos arquivos do IMEC-Caen, cota MAS 5.12, a carta datada "lundi soir"). A Salomon Reinach, em 1909, Gernet pede a assinatura de uma petição (cf., no Fonds Salomon Reinach da Bibliothèque Méjanes, a boîte 72).

${ }^{26}$ Notes Critiques: Sciences Sociales tinha autonomia diante do AS, ainda que muitos de seus colaboradores estivessem também nele presentes. Próximas em vários sentidos, as revistas serão como que fundidas em 1907 (cf., FOURNIER, 2007: 457-459).

${ }^{27}$ Apud. VALENTI, 1996: 164.
} 
mencionados, a ida para o exterior não se concretizou. Teria sido isso fruto de algum impedimento de ordem pessoal? Ou, por outro lado, tratar-se-ia simplesmente de um mau desempenho no processo seletivo? Não há como afirmar nada a partir da bibliografia e dos arquivos consultados ao longo da presente pesquisa. O fato é que, a partir de 1907, Gernet obteve uma bolsa da Fondation Thiers. Durante três anos, ele pôde então frequentar cursos na EPHE, na Sorbonne e no Collège de France, bem como iniciar, sob a orientação de Gustave Glotz, a pesquisa sobre a história do pensamento jurídico grego que se transformará mais tarde em sua tese de doutorado (GERNET, 2001).

O contato com Glotz foi central nos primeiros anos de sua trajetória. Com efeito, além de partilharem uma formação com o mesmo handicap (ambos não foram membros da EFA) e os mesmos focos de interesses originais (o que inclui a sociologia), aquele era uma personalidade em ascensão no campo do helenismo. Depois de um longo tempo como professor de liceu, Glotz acabara então de assumir uma cátedra na Sorbonne e a direção da prestigiosa Revue des Études Grecques (REG), da qual Gernet será um dos maiores colaboradores às vésperas da Primeira Guerra Mundial ${ }^{28}$. Além da produção científica, o orientando de Glotz atuou na revista como secretário de redação em 1907 e, no ano seguinte, tornou-se membro ordinário da instituição que a editava, a já mencionada AEEG. Além disso, entre 1910, quando teve fim sua bolsa da Fondation Thiers, e 1919, quando ocorreu a desmobilização geral, Gernet gozou ainda de uma posição privilegiada na capital. Afinal, enquanto muitos de seus colegas estavam ou nas trincheiras ou em liceus provinciais, ele trabalhou em Paris como professor do liceu preparatório para as Grandes Écoles militares, o Prytanée do Boulevard Gambetta. Com o término do conflito, Gernet passou enfim ao ensino superior, sendo nomeado professor da Faculdade de Letras de Alger, da qual veio a se tornar doyen (diretor), e onde permaneceu até 1948. De lá ele voltou a Paris para o ocupar seu último e prestigiado posto na recém-criada $\mathrm{VI}^{\mathrm{a}}$ seção da EPHE.

Nos dois últimos volumes da primeira série do AS, o jovem helenista em início de carreira assinou nada menos que dez resenhas, embora muito provavelmente ele tenha escrito ao menos uma ou duas a mais ${ }^{29}$. Desse total de autoria comprovada, oito diziam respeito a livros sobre a vida econômica, religiosa e jurídica da Grécia Antiga, uma tratava exclusivamente da economia da Roma Antiga e outra discutia o direito antigo comparando

\footnotetext{
${ }^{28}$ Glotz e as contribuições de Gernet à REG serão discutidas em detalhes no subcapítulo 2.3 da presente tese.

${ }^{29}$ No volume lançado em 1913, a subseção "I'organisation judiciaire et la procédure" da terceira seção do AS, "sociologie morale et juridique", o indica como responsável, sem que nenhuma assinatura apareça em quatro das cinco resenhas aí publicadas. Duas, aliás, tratavam do direito romano.
} 
gregos e romanos ${ }^{30}$. A partir de então, Gernet jamais perdeu o contato com os sociólogos. Ele escreveu para as outras séries posteriores do AS, assim como esteve presente no Institut Sociologique, criado no entreguerras. No terreno dos antiquisants, por sua vez, ele fez as vezes de um verdadeiro militante da escola sociológica francesa. Como se verá no próximo capítulo da presente tese, foram poucos os seus artigos publicados antes de 1920 que não trouxeram seja aplicações dos modelos evolucionistas durkheimianos para explicar a história do direito antigo, seja simples citações pontuais.

Pierre Roussel, por sua vez, era um ano mais velho que Gernet. Proveniente de uma família de pequenos funcionários instalada em Nancy, Roussel fez aí boa parte de seus estudos secundários, partindo para Paris, onde frequentou o Liceu Henri IV, apenas mais tarde, a fim de se preparar para o concurso de admissão da ENS. Sétimo colocado nesse concurso, ele integrou a promoção de 1901, na qual se destacou por seus investimentos nos estudos gregos, bem como por seu engajamento junto ao movimento socialista organizado em torno de Lucien Herr. A obtenção do quarto lugar na agrégation de lettres em 1904 lhe valeu um ano suplementar de permanência na escola para, em seguida, embarcar por um longo período de cinco anos no exterior, como membro efetivo da École Française d'Athènes. De volta à França, Roussel foi acolhido como uma promessa entre os antiquisants, recebendo tratamento diferenciado nas revistas especializadas (além de escrever inúmeros artigos e resenhas, assumiu a redação do prestigioso Bulletin Épigraphique da Revue des Études Grecques). Sem chegar realmente a ser mobilizado em 1914, ele foi em seguida colocado na reserva e convidado para assumir o cargo de professor no liceu Janson-de-Sailly, aí permanecendo até 1918. Tendo defendido nesse ínterim sua tese sobre a Délos antiga (1916a e 1916b), ele logrou obter então o posto de maître de conférence de langue et littérature grecques em Bordeaux. Eis aí o início de sua promissora carreira no ensino superior. No ano seguinte, uma vez finda a guerra, uma nova nomeação, dessa vez para a recém-fundada e já prestigiosa universidade de Strasbourg. O desenvolvimento posterior de sua carreira é dos mais bem-sucedidos de sua geração, envolvendo a direção da École Française d'Athènes (1925-1935), a nomeação na Sorbonne (1936) e o ingresso na Académie des Inscriptions et Belles-Lettres (1937). A partir de 1913, ele passou também a figurar como membro ordinário da Association pour I'Encouragement des Études Grecques en France.

\footnotetext{
${ }^{30}$ Cf., no que tange à Grécia Antiga, AS, 1910: 330-331, 331-334, 402-404, 404-406 e 559-562, bem como AS, 1913: 421-422, 438-439 e 454-456. A única resenha sua sobre Roma Antiga foi publicada em AS, 1910: 563-564. Já quanto ao estudo de direito comparado, cf. AS, 1913: 422-423.
} 
Graças às cartas que Roussel recebeu do amigo Robert Hertz, antigo colega da ENS e da militância socialista, sabe-se detalhes de como se deu seu recrutamento por parte dos sociólogos (HERTZ, 1999). Tal correspondência teve início em 1905, logo após a ida de Roussel para Atenas. Nela, Hertz incentiva o amigo a tomar partido junto aos sociólogos, entendendo que ele poderia se beneficiar intelectualmente com a nova ciência, sobretudo no campo que enão Ihe interessava, a saber, a mitologia comparada. O convite formal veio na carta datada de quatro de julho de 1910:

Falaste em ficar em Paris por algum tempo; se for possível, o faça. És feito para a produção científica. Todos os que te conhecem estimam e respeitam tua inteligência. Tens ao mesmo tempo a precisão minuciosa, o rigor, a penetração e o espírito sensível. Essas são justamente as qualidades que são necessárias para fazer belas e boas coisas no domínio que sempre te atraiu: a formação dos mitos gregos e sua utilização pela literatura. A maior parte das pessoas que se ocupam desses estudos são ou ridículos [cuistres], ou puros arqueólogos, ou amadores. Quando estiveres francamente ligado a um trabalho com a vontade de ir até o final, tenho confiança em ti, farás algo de excelente e frutuoso. Teu lugar no Année está reservado e tenho certeza que Durkheim ficará contente com a tua colaboração. Será preciso que o vejas e que converses com ele quando retornares; tuas ideias Ihe interessarão bastante e sua conversa é sempre estimulante e sugestiva. Encontrarás aqui a atmosfera de simpatia e de interesse comuns que é indispensável a todos nós.

Alguns anos antes, contudo, Hertz já concebia um trabalho em conjunto com seu antigo colega de escola:

Eu vou mesmo te surpreender ao te dizer que, por vezes, sinto o desejo de voltar ao grego e estudar algumas noções meio religiosas meio morais cuja expressão (refletida) eu encontrei entre os filólosos de meu mestre Hamelin. Eu creio que há algo a fazer nessa direção, e se isso me tenta é porque a etnografia comparada nos dá, após um certo tempo, o desejo de estudar os fatos mais diretamente perceptíveis e inteligíveis, mais "explícitos" pela consciência mesma das pessoas que os viveram (...). E o grego é, para mim, a língua mais fácil de aprender ou reaprender. Nós estaríamos assim menos distantes do que tu talvez imagines. Eu voltarei a falar contigo desse projeto caso ele se precise (...).

De fato, tal colaboração se concretizou mais tarde. Às vésperas da Primeira Guerra Mundial, Hertz confiou a primeira versão de uma monografia sua ainda inédita sobre a figura mitológica da deusa Atena a seu colega, pedindo que ele a revisasse e a preservasse. Considerado hoje perdido, tal manuscrito parece ter sido entregue por Roussel a Durkheim, que faz referência a ele no necrológio que escreveu de Hertz (DURKHEIM, 1975a: 439-445).

No tocante à sua produção dentro do AS, Roussel escreveu apenas três breves resenhas, todas para o último volume da revista e todas relacionadas aos estudos gregos (AS, 1913: 206, 405 e 443-445). Fora desse espaço, contudo, ele fez as vezes de sociólogo militante. 
Nos artigos e resenhas que ele escreveu para as duas principais revistas dos antiquisants, a Revue des Études Grecques e a Revue des Études Anciennes, os trabalhos de Mauss, Hubert, Durkheim, Hertz, Jeanmaire e Gernet foram citados e suas teses discutidas ${ }^{31}$. Tal papel de ponta de lança dos sociólogos se manteve ao longo das décadas seguintes, ainda que enfraquecido pela própria trajetória de Roussel, a qual o encaminhou cada vez mais para a epigrafia e o levou a passar longos anos a trabalho em Atenas. Ainda assim, ele participou das iniciativas dos sociólogos nas demais séries do AS, bem como se tornou próximo de Halbwachs enquanto ambos estavam em Strasbourg (HALBWACHS, 1999). Raymond Lantier, antigo aluno de Henri Hubert e seu sucessor no MAN, não deixou de comentar esse vínculo entre Roussel e os sociólogos no necrológio que dedicou ao helenista (LANTIER, 1949: 33-34).

Dos três colaboradores do AS especialistas no mundo greco-romano, Henri Jeanmaire foi o mais jovem e, sem dúvida, o mais singular. Nascido na Paris de 1884 , ele logrou a ingressar na École Normale Supérieure em 1905, sem ter, portanto, tido como colegas Louis Gernet e Pierre Roussel. Após quatro anos, ele obteve apenas o sétimo lugar no concurso de agrégation d'histoire et de géographie. $\mathrm{O}$ resultado apenas mediano inviabilizava a ida que havia feito Roussel à École Française d'Athènes. Restou-lhe então, munido do título, ser empossado como professor no liceu de Besançon, lá permanecendo por dois anos. Seguiramse então uma bolsa de estágio em Leipzig, na Alemanha (1911-1912), e um período de pesquisas na EPHE (1912-1913), onde ele foi aluno de Marcel Mauss e de Henri Hubert.

As cartas de Jeanmaire encontradas nos arquivos explorados ao longo da presente pesquisa nada esclarecem sobre o primeiro contato entre ele e os durkheimianos ${ }^{32}$. Georges Davy, seu colega na ENS e na EPHE, pode ter tido um papel central quanto a isso, ou então a aproximação inicial pode ter tido origem nos vínculos entre os sociólogos e a militância socialista bem instalada na Rue d'Ulm. Louis Gernet, muito mais tarde, já na década de 1960, confessou que tomou conhecimento da existência de Jeanmaire apenas em 1913 e indiretamente, lendo um artigo por ele produzido ${ }^{33}$. Em todo caso, importa aqui destacar o impacto dessa aproximação em termos de método e de campos de interesse.

\footnotetext{
${ }^{31}$ Veja-se, a esse respeito, os subcapítulos 2.3 e 2.4 da presente tese.

32 Foram encontradas cinco cartas de Jeanmaire durante a pesquisa, quatro pertencentes ao Fonds Mauss-Hubert depositado no IMEC-Caen e uma integrada aos dossiês de correspondência do MAN. As primeiras tinham por destinatário Mauss, com quem Jeanmaire discute tanto questões ligadas à sua participação nas revistas e instituições dos sociólogos (Institut Sociologique ou a segunda série do AS) quanto questões pessoais (felicitações pelo casamento de Mauss). A última, datada de 1922 e endereçada a Salomon Reinach, diz respeito ao artigo que Jeanmaire estava em vias de publicar na Revue Archéologique sobre a política religiosa de Marco Antônio e de Cleópatra (RA, 1924/1: 241-261).

${ }^{33}$ Cf. BCH, 1960: XXXVI-XL (reimpresso em GERNET, 1983: 397-401).
} 
Ainda bastante jovem quando eclodiu a Primeira Guerra Mundial, Jeanmaire não pôde se mostrar como o especialista na religião antiga - grega em particular - que ele revelou ser mais tarde. Ele sequer consta, até 1920, da lista de membros da Association pour I'Encouragement des Études Grecques en France, em cuja revista, no entanto, publicou seu único grande artigo do período, La Cryptie Lacédémonienne (REG, 1913: 121-150). No AS, sua participação teve início apenas em 1913, no último número da primeira série. Em números, ele escreveu apenas três resenhas (AS, 1913: 222-224, 225-226 e 821-826). O curioso, no entanto, é que os livros analisados dizem respeito à Grécia Antiga apenas indiretamente, ao ponto de não terem sido assinalados nas tabelas de resenhas do subcapítulo anterior. Em dois casos, a discussão diz respeito à religião cristã primitiva, seja focando a vida do apóstolo Paulo, seja o papel do exorcismo ritual que precedia o batismo nos primeiros séculos do cristianismo (AS, 1913: 222-224 e 225-226). No terceiro, o trabalho trata da geografia da Palestina, o que implicava a referência a episódios ocorridos na Antiguidade (AS, 1913: 821-826). O que mais chama atenção, em todo caso, é a abertura do autor quanto a outros temas que não aqueles aos quais ele dedicou a maior parte de sua carreira futura. Mais tarde Jeanmaire obteve um posto na $V^{a}$ seção da $E P H E$, de onde manteve sua colaboração com as iniciativas editoriais e científicas dos sociólogos.

$\mathrm{O}$ que dizer acerca das três trajetórias acima apresentadas? Em primeiro lugar, elas ilustram como o recrutamento de jovens sociólogos passava por uma série de expedientes outros que não apenas o puramente intelectual. Gernet e Roussel, sobretudo, se aproximaram deles via expedientes afetivos, contraídos ao longo de suas estadas na ENS ou de sua militância junto ao movimento socialista jauresiano. Em segundo lugar, elas reforçam a tese de Victor Karady acerca do caráter "elitista" desse recrutamento (KARADY, 1979). No caso específico desses representantes de um saber por si só já extremamente prestigioso como o helenismo, eles passaram pela ENS e tiveram, na sequência, carreiras universitárias bem-sucedidas. Por fim, tais trajetórias mostram o amplo leque de temas interesses desses jovens. Eles trataram de áreas cujo interesse era partilhado por sociólogos e antiquisants, como a religião, o direito e a organização social da Grécia Antiga.

Importa destacar, contudo, a existência de certas assimetrias entre os três. Todos, sem exceção, colheram os frutos do reconhecimento público que a sociologia gozava na década de 1910 para, ao contribuir com os estudos greco-latinos, fazer avançar suas carreiras. Ainda assim, tratava-se de um saber que tinha adversários e cujo prestígio declinou aos poucos ao longo das décadas de 1920 e 1930 (cf. HEILBRON, 1985). Ora, Pierre Roussel, por ter tido a chance de estagiar na EFA, dedicando-se assim a fundo a ciências como a epigrafia e a 
arqueologia antigas, acabou se revelando o mais versátil dos três, o que significa aqui o menos dependente das ciências sociais para suas atividades profissionais. Por certo, a afirmação feita assim pode parecer vaga, pois não esclarece muito sobre como funcionava o "mercado de competências" à época existente. Essa assimetria será evocada mais adiante na presente tese e esclarecida à luz das representações que as publicações especializadas apresentam das áreas por elas concernidas. 


\section{CAPÍTULO 2}

\section{AS REVISTAS}

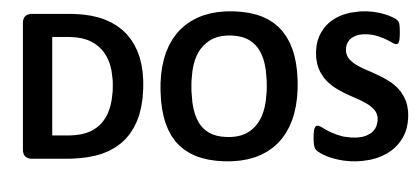

ANTIQUISANTS

E A

SOCIOLOGIA 
segundo capítulo da presente tese trata de três temas correlatos, a saber, a especificidade das publicações especializadas nos estudos greco-latinos entre fins do século XIX e inícios do XX, a recepção acordada à escola sociológica francesa em cada uma dessas revistas, bem como os investimentos em termos de publicação aí realizados por sociólogos próximos a Durkheim. Viu-se no capítulo anterior como os colaboradores da primeira série de L'Année Sociologique não ignoraram Grécia e Roma Antigas. Ainda que a presença de especialistas, helenistas em particular, só tenha se feito sentir em suas fileiras a partir de 1910, não havia como escapar de um conhecimento que Ihes fora duplamente imposto. Por um lado, tal imposição vinha do ensino secundário de então, onde a língua, a história e a literatura greco-latinas eram indispensáveis; por outro, uma vez dentro das universidades e das écoles, os durkheimianos tinham de se ater ao peso nada desprezível dos antiquisants na produção científica e na vida burocrática dessas instituições. Mas isso não é tudo: em suas pesquisas, diante da carência de informes precisos e seguros sobre outros povos e épocas, eles se valeram de bom grado seja de textos e de vestígios materiais dos Antigos seja de trabalhos a eles dedicados. Por mais paradoxal que possa parecer, a autonomia epistemológica e institucional de uma nova ciência não se torna defensável sem o diálogo com a produção de outros saberes e sem a simpatia de seus portadores. Já se viu aqui como, por parte dos sociólogos, se procurou construir pontes com o mundo dos antiquisants. Trata-se de um lado da moeda. Resta saber agora se e como os próprios antiquisants responderam a essas iniciativas.

Antes de prosseguir com a análise, contudo, é preciso desmistificar a categoria "antiquisant". Por mais que se possa utilizar tal palavra para se referir a um grupo específico de universitários, disso não decorre a total e completa homogeneidade de seus membros. Ao menos no que concerne o período aqui tratado - e seria hoje diferente? -, nem todos os antiquisants partilhavam exatamente a mesma concepção de suas atividades. Wittgenstein, ao tratar dos "jogos de linguagem", lembrava que a carga semântica de uma categoria equivale sempre a todos os sentidos que ela pode assumir nos contextos em que é evocada. Nada mais verdadeiro. Tratar-se-á aqui, porém, de dar um passo adiante, mostrando como essa carga semântica era também influenciada e limitada por arranjos sociais, os quais sugerem, ao menos em determinados momentos, padrões claramente identificáveis. Assim sendo, o modo 
como os antiquisants franceses estiveram organizados em revistas distintas e as justificativas de várias ordens que eles lançaram para encampar seus projetos editoriais e científicos, por mais conflitantes e contraditórias que possam parecer, constituem o cerne do presente capítulo.

Já se utilizou na presente tese o conceito bourdieusiano de "campo" para tratar de disciplinas em cujo cerne se encontram linhas de força que permitem aos seus portadores se aproximarem ou se diferenciarem, por vezes radicalmente, uns dos outros. Esse conceito será aqui mais uma vez empregado, mas agora para tratar do universo das revistas dos antiquisants. Tendo em vista que tais publicações fornecem uma expressão direta e concreta, ainda que parcial, das regras da arte que caracterizavam a produção dos estudos greco-latinos, elas não podem nem devem ser entendidas separadamente. Por suas histórias, morfologias e estribos institucionais, elas se aproximaram e se afastaram umas das outras, permitindo entrever tensões e afinidades eletivas atuando aí de maneira sistemática. A própria acolhida diferenciada reservada à sociologia e aos sociólogos durkheimianos em cada um desses espaços esteve ligada à lógica das relações que as uniam e as separavam. Houve aí, portanto, um campo, o qual foi construído e reconstruído à medida que novas publicações seguiam surgindo e modificando o peso e o lugar de cada uma delas. Essa é, ao menos, uma das teses que se quer aqui avançar.

Para expor as linhas de força que caracterizaram as relações entre tais revistas especializadas se optou aqui por um estudo monográfico de cada uma delas. De início, importa saber em que circunstâncias elas foram criadas, que pessoas e instituições animaram inicialmente esses empreendimentos, bem como as modificações na composições de seus quadros de colaboradores ao longo do tempo. Uma vez isso devidamente esclarecido, será então o momento de cruzar a especificidade das publicações com a recepção da sociologia e a presença dos sociólogos durkheimianos em suas páginas.

A sequência de apresentação dessas revistas obedece aqui à ordem cronológica com que elas foram aparecendo. Desse modo, a mais antiga revista especializada nos estudos greco-latinos, intitulada Bulletin de Correspondance Hellénique e fundada em 1877, será apresentada antes das demais. A ela se seguirão as análises dos Mélanges d'Histoire et d'Archéologie (1881), da Revue des Études Grecques (1888) e da Revue des Études Anciennes $(1899)^{1}$. Tal procedimento tem a vantagem de promover ativamente, à medida que a discussão

\footnotetext{
${ }^{1}$ Não custa relembrar que a Revue des Études Latines (1923) não será considerada em função de sua fundação tardia, a qual a impediu de conviver com a primeira série do AS. Já quanto à Revue Archéologique, várias vezes referenciada ao longo do presente capítulo, Grécia e Roma Antigas ocupavam nela um lugar importante, mas não exclusivo (os antiquisants tinham de conviver lá com americanistas, orientalistas, especialistas na pré-história europeia, entre outros).
} 
avança, a comparação. Com efeito, ele permite recapitular a cada passo como a estrutura e as justificativas epistemológicas já apresentatas no contexto de uma revista já estudada foram consideradas por suas "concorrentes" em meio a estratégias mais ou menos declaradas de diferenciação. Ao final do capítulo, o leitor ainda encontrará uma breve conclusão, na qual as tensões paulatinamente desveladas serão resumidas, conformando assim uma primeira conclusão, esta mais específica, da presente tese. 


\section{1 - O BULLETIN DE}

\section{CORRESPONDANCE}

\section{HELLÉNIQUE}

"O melhor agrégé é apenas a esperança de um bom ateniense." Georges Radet (RADET, 1901)

A criação do Bulletin de Correspondance Hellénique (BCH) em 1877 lançou a pedra fundamental do que mais tarde seria o campo dos periódicos franceses voltados aos estudos greco-latinos. Além do mais, ele figurou entre as primeiras publicações ao mesmo tempo especializadas em uma disciplina (o helenismo) e acopladas ao sistema de ensino superior (via École Française d'Athènes). No caso específico do $\mathrm{BCH}$, esse duplo vínculo atendia a propósitos precisos: a formação de pesquisadores de ponta, bem como a divulgação de documentos até então inéditos.

Até as décadas de 1870 e 1880, como já foi mencionado na introdução da presente tese, a pesquisa e a formação de pesquisadores estiveram por demais atreladas à dinâmica das academias e dos salões. Nesse ínterim, as Faculdades de Letras funcionavam apenas como instâncias preparatórias para os futuros quadros de professores do ensino secundário e, em menor grau, de burocratas do estado. Pouco antes do advento da Terceira República, contudo, teve início um movimento reformista que ganhou força com o passar do tempo, o qual almejava transformar a universidade em uma instância também apta a produzir conhecimento científico original.

A École Française d'Athènes (EFA), instituição responsável pela publicação do $\mathrm{BCH}$, não escapou da onda reformista. Ela, que já acolhia para estágios em Atenas jovens agrégés desde 1846, passou a privilegiar cada vez mais o trabalho de campo de seus membros, o que incluía, em especial, estudos práticos sobre a epigrafia e a arqueologia gregas. $\mathrm{O} B C H$ surgiu diretamente atrelado a esse esforço de profissionalização, tornando-se uma publicação importante para quem almejasse seguir carreira de helenista na França e estar a par das últimas descobertas.

Diante desse cenário, o objetivo do presente subcapítulo é duplo. Em primeiro lugar, ele almeja apresentar a EFA e o $\mathrm{BCH}$, situando-os no sistema de ensino francês. Uma vez isso 
feito, será o caso de discutir tanto como a sociologia durkheimiana apareceu nas páginas dessa revista quanto quais colaboradores do Année Sociologique (AS) por aí eventualmente transitaram.

\section{A ÉCOLE FRANÇAISE D'ATHÈNES}

Das instituições de ensino e pesquisa francesas instaladas no exterior, a EFA foi, de longe, a mais antiga. Criada por um decreto real em 11 de setembro de 1846, ela serviu, direta ou indiretamente, de ponta de lança para o posterior estabelecimento da École Française de Rome (1875), das Écoles Supérieures d'Alger (1879), do Institut Français d'Archéologie Orientale (1881) e do Institut des Hautes Études Hispaniques (1909). Nesse sentido, a EFA inaugurou uma nova fase da atuação da França no Mediterrâneo: se antes tal presença se fazia sentir por meio de ocupações militares (o que ocorreu no Egito em 1798 e na Argélia em 1830) e de missões temporárias artístico-diplomáticas (tal como a que visitou o Marrocos em 1832), agora se almejava, de modo permanente, fazer ciência fora das fronteiras nacionais ${ }^{1}$.

A situação política da Grécia Moderna, marcada pela guerra de independência contra o Império Turco desde o início da década de 1820, favoreceu em muito as pretensões francesas. O rei Charles X, em 1827, já havia dado provas disso ao enviar ao Peloponeso, contra os otomanos, um corpo de expedicionários acompanhado de artistas e cientistas. Nas décadas seguintes, com o reconhecimento internacional da autonomia política grega em 1832, um novo incentivo veio da corrida das grandes potências europeias à região, em particular Rússia, Inglaterra e, bem mais tarde, Alemanha. Em que zona de influência o novo país se colocaria? $\mathrm{Na}$ dúvida, era recomendável intensificar a presença francesa no local, buscando criar e fortalecer os laços entre os dois países. O prestígio dos estudos sobre a Grécia Antiga no sistema educacional francês forneceu um excelente pretexto.

Os primeiros regimentos da nova instituição foram bastante vagos quanto a seus reais propósitos. No decreto de sua fundação, falou-se em "uma Escola francesa de aperfeiçoamento para o estudo da língua, da história e das antiguidades gregas em Atenas", a qual seria destinada exclusivamente "aos alunos da École Normale Supérieure, agrégés das classes de humanidades, história ou filosofia". Tratava-se, portanto, de uma instituição inicialmente voltada às matérias dos liceus e formada por futuros professores/funcionários do estado francês. Destacava-se ainda a atuação da escola como centro cultural e diplomático, disposto a difundir os ideais franceses entre as elites gregas. Por uma clara guinada pró-ciência da EFA ter-se-ia de esperar até a década de 1870, quando outros institutos estrangeiros

\footnotetext{
${ }^{1}$ Veja-se, sobre esses "institutos imperiais" da Terceira República, CHARLE, 2004.
} 
(alemães, americanos e ingleses) começaram a se instalar em Atenas e métodos arqueológicos já bem consolidados passaram a ditar a nova vocação da instituição².

Mas ficam então as perguntas: quem foram os membros da EFA? Como lograram eles obter tal posto? Em que consistiam suas atividades? E, por fim, qual o impacto desse estágio no exterior em suas carreiras? Em se tratando de uma instituição atrelada ao sistema de ensino, era natural que seu recrutamento estivesse atrelado àqueles que almejassem seguir uma carreira ligada à docência e à pesquisa. Já se mencionou antes como, no ano de fundação da escola, poderiam apenas ser candidatos os normalianos bem-sucedidos na obtenção da agrégation, justamente aquele concurso que garantia a seus detentores uma posição no sistema de ensino. Quatro anos mais tarde, contudo, a obrigatoriedade da passagem pela École Normale Supérieure (ENS) caiu, mantendo-se como única exigência o título de agrégé. Tal decisão se manteve inalterada até o final do período aqui tratado ${ }^{3}$.

Uma vez obtido o certificado nacional, era preciso ainda enfrentar um processo seletivo. Embora nos primeiros anos de existência da EFA a escolha dos futuros membros tenha sido apanágio exclusivo do ministro da instrução pública, a partir de 1850 foi estabelecido um teste específico envolvendo conhecimentos de língua, história e literatura da Grécia Antiga, além de rudimentos de grego moderno ${ }^{4}$. Quem elaborava as provas e as corrigia eram os integrantes da Académie des Inscriptions et Belles-Lettres, a mesma instituição que, por meio de relatórios e trabalhos publicados, avaliava as atividades científicas da escola e de seus membros. Devidamente dotados da nota desse exame, bem como de uma carta de motivação, de um curriculum vitae atualizado e de cartas de recomendação, os candidatos passavam a depender apenas da decisão do diretor da EFA e do número de vagas disponíveis. Aprovados, eles passavam a ser "atenienses".

Esses novos membros, os quais tinham suas despesas de viagens custeadas e recebiam remuneração como funcionários regulares do estado, partiam então por um período de estágio que durava normalmente três anos. Ainda assim, existiram estadas mais longas ou mais curtas, o que dependia tanto dos interesses dos membros e do diretor da EFA quanto do aval positivo da Académie des Inscriptions et Belles-Lettres. Em Atenas, suas atividades seguiam o planejamento da instituição. Sobretudo a partir de fins da década de 1860, o ano de

\footnotetext{
${ }^{2}$ Cf. RADET, 1901 e VALENTI, 2006A. Valenti, contudo, chama atenção para uma "primeira orientação científica" da EFA já na década de 1850. Sem que representasse a corrente dominante na escola, argumenta a autora, o trabalho arqueológico de Ernest Beulé sobre a Acrópole testemunharia esse fato.

${ }^{3}$ Segundo Catherine Valenti (1996), tal medida não surtiu efeito imediato e, na prática, até 1891, apenas um não normaliano ingressou na EFA. A taxa mudaria na sequência, em função das políticas de recrutamento dos novos diretores (Théophile Homole, Maurice Holleaux e Gustave Fougères). Segundo essa autora, entre 1891 e 1923, 45\% dos membros da EFA passou então a ser de não normalianos.

${ }^{4}$ Para mais detalhes acerca das transformações nas provas, cf. VALENTI, 2006A: 87-90.
} 
estágio se dividia em duas fases distintas. Os "atenienses" despendiam a maior parte do verão, da primavera e do outono em missões de prospecção ou em campanhas de escavação. Na Grécia continental, nas ilhas gregas ou mesmo em outros países banhados pelo mediterrâneo oriental (os domínios otomanos na Ásia Menor e no Oriente Médio e o Egito), eles visitavam museus, recolhiam in loco documentos e elaboravam seus relatórios de campo. O retorno a Atenas, nos demais períodos do ano, era utilizado para estudar a fundo as descobertas do período anterior a partir do contato com a bibliografia disponível nas bibliotecas locais e do diálogo com especialistas, sejam eles o diretor da EFA, os universitários gregos ou membros das demais missões científicas internacionais. Tal fluxo ideal de atividades foi, no entanto, constantemente atrapalhado por problemas diplomáticos e/ou orçamentários (novas guerras com os turcos, atrasos no repasse das verbas, entre outros).

Para quem conseguisse suportar os longos períodos longe da terra natal e ainda aproveitar as condições de trabalho locais, tarefas nada fáceis, a EFA se revelava um caminho promissor a ser seguido. Com efeito, na medida em que setores voltados à pesquisa original puderam se consolidar minimamente na universidade francesa a partir de fins da década de 1860, o estágio em Atenas forneceu a melhor alternativa para quem quisesse, almejando atuar com pesquisas, escapar de imediato ao ensino secundário. Desde a fundação da EFA, o estado francês procurou seduzir os candidatos ao manter em suspenso a posição docente que eles ocupariam graças ao sucesso no exame de agrégation. Ainda assim, com a forte expansão universitária nas décadas de 1870 e 1880, muitos de seus membros obtiveram diretamente, ao deixar Atenas, postos na universidade. Em 1905, diante de um mercado já bastante saturado, o governo lhes concedeu ainda mais um incentivo: além da manutenção da vaga, promoção proporcional ao período de permanência no exterior (ou seja, mesmo que nomeados para dar aulas em liceus, eles assumiriam turmas mais avançadas). Desse modo, enquanto seus concorrentes aos postos no sistema de ensino tinham de dividir seu tempo entre a sala de aula e a pesquisa, os membros da EFA se dedicavam em tempo integral, enquanto estivessem em Atenas, à derradeira atividade. De quebra, eles eram incentivados a transformar seus trabalhos em tema de tese. As condições, quanto a isso, eram as melhores possíveis: as séries documentais eram invariavelmente inéditas e todo trabalho científico produzido sobre elas relatórios e artigos - adiantava significativamente a redação do manuscrito final. $O$ efeito não poderia ser outro: os "atenienses" doutoravam-se mais rápido. Como os postos efetivos no ensino superior, à exceção da EPHE e do Collège de France, eram reservados a doutores, tratava-se de uma vantagem nada negligenciável. Por fim, seus membros ainda gozavam do privilégio de ter contatos com alguns expoentes internacionais do helenismo, bem como fortaleciam os laços que os ligavam a seus colegas de escola. 


\section{"ATENIENSE": MAIS QUE UM SIMPLES RÓTULO, UMA CORPORAÇÃO DE LETRADOS}

Findo o período de estágio no exterior, os membros da EFA tinham de deixar Atenas. Isso não significava, contudo, que Atenas os deixasse. Com efeito, a herança da EFA se manifestava de inúmeras formas ao longo de suas trajetórias. Por um lado, ela se fazia sentir na aprendizagem de novos métodos científicos e conteúdos eruditos; por outro, acompanhava os antigos membros da EFA por intermédio das amizades (ou inimizades) lá contraídas. Mas a passagem pela EFA implicava também, e sobretudo, o ingresso em uma influente corporação de letrados.

Tal corporação existiu de modo informal e parece ter atuado ativamente quando o assunto era o avanço nas carreiras dos colegas antiquisants. Em uma carta inédita, datada de 1897 e pertencente ao Fonds Marcel Mauss do Institut Mémoires de l'Édition Contemporaine (cota MAS 3.67), o sobrinho de Durkheim fez alusão ao lobby institucional dos atenienses a Henri Hubert (o sublinhado consta no original):

Eu escrevi apenas uma curta carta a [Isidore] Lévy, para desejar-Ihe uma boa viagem. Na verdade, eu tinha pouco a the dizer. Eu tenho, aliás, para ele, informações muito ruins relativas a Bordeaux. Os Atenienses são terrivelmente fortes. Parece-me que não se poderá impedir o Foucart, saudado por todos, de chegar lá, ao menos que se recuse o princípio mesmo da cadeira e se proponha uma outra. Eu não tenho coragem de falar nestes termos a Lévy. Enfim, o que fazer?

Marcel Mauss se refere aqui à rede de solidariedade que ligava Paul Foucart, o pai do orientalista Georges Foucart, a professores da Faculdade de Letras de Bordeaux, antigos membros da EFA (em especial, a Georges Radet e a Pierre Paris). A eleição para a cadeira foi mantida e, no pleito, Foucart filho foi eleito com ampla maioria.

Outro indício nessa direção vem da correspondência entre Gustave Glotz e Salomon Reinach. Ao pleitear assento na Académie des Inscriptions et Belles-Lettres, em carta inédita datada de 2 de março de 1919, Glotz pediu ajuda ao colega nos seguintes termos (caixa 72 , em Correspondances de Salomon Reinach, depositadas na Bibliothèque Méjanes):

Até o momento eu não apresentei minha candidatura. Mas acabo de encontrar por acaso Girard, que me disse que os Atenienses vão deliberar por estes dias para optar definitivamente entre mim e Fougères. Se o senhor acreditar ser útil intervir a meu favor, eu vos serei grato.

Na ocasião, nem Glotz nem Fougères, ambos então professores da Faculdade de Letras de Paris, foram eleitos. Isso, no entanto, não tardou a acontecer. Aquele, então diretor da Revue des Études Grecques, teve sucesso no ano seguinte. Já este, antigo ateniense e ex-diretor da EFA (1913-1919), esperou até 1923.

Independente do sucesso ou do fracasso dessas iniciativas, a movimentação políticoinstitucional dos atenienses mostra tanto o quão conscientes eles eram de sua posição privilegiada no sistema de ensino francês como sua disposição em manter tal posição. Conhecido além do círculo de iniciados, o rótulo "ateniense" possuía, portanto, mais que um conteúdo simplesmente honorífico. 
Com o passar dos anos, visando expandir sua influência nacional e internacionalmente, a EFA ampliou seu recrutamento. A partir de 1880, além dos membros efetivos, ela passou a contar também com "membros livres", ou seja, membros enviados a Atenas para missões específicas a pedido da Académie des Inscriptions et Belles-Lettres. Até 1920, contudo, apenas quatro jovens foram enviados a Atenas nessa condição: Georges Barrilleau (1880), Arthur Engel (1881), Ludovic Beauchet (1895) e Adolphe-Joseph Reinach (1908). Seus vínculos com a escola foram, em geral, limitados. O único que aí permaneceu praticamente quatro anos foi Adolphe Reinach, muito provavelmente em função de sua notável capacidade de trabalho no domínio da epigrafia e por ter dois tios, Salomon e Théodore Reinach, entre os mais ilustres antiquisants franceses. A outra modalidade possível de entrada na EFA era reservada aos não franceses. Até 1920, foram identificados dezoito casos de "membros estrangeiros", os quais provinham da Bélgica (dez), Dinamarca (quatro), Suíça (dois), Holanda (um) e Suécia (um). Tal política de recrutamento internacional sugere a preocupação do governo francês em expandir suas zonas de influência também no âmbito universitário.

\section{Criação e estrutura do BCH}

O aparecimento do $\mathrm{BCH}$ é inseparável da atuação de Albert Dumont como diretor da EFA entre os anos de 1875 e 1878. Georges Radet e Catherine Valenti, os dois historiadores dessa instituição, fazendo coro com os testemunhos de época, concordam em situar aí a ruptura definitiva entre a escola "literária" do passado e a "científica" do futuro 5 . Mas quem foi Dumont e que transformações engendrou na EFA? Nascido na Scey-sur-Saône em 1842, ele havia pertencido à geração de alunos que assistiu às primeiras tentativas de modernização do sistema de ensino francês. Aluno na École Normale Supérieure e agrégé d'histoire et géographie em 1864, ele embarcou no mesmo ano para Atenas como membro efetivo da EFA, lá permanecendo por três anos. Dumont teve então a oportunidade, rara à época, de trabalhar com o que se chamaria hoje de "cultura material". Embora as iniciativas da própria escola fossem ainda tímidas nessa direção, ele se engajou junto a autoridades gregas na catalogação de quantidades significativas de cerâmica e de inscrições epigráficas antigas. No necrológio escrito em 1884 por um ex-membro e futuro diretor da EFA, Théophile Homolle, descreveu-se do seguinte modo a transformação de seus temas de predileção ( $\mathrm{BCH}, 1884$ : ii-iii):

O sr. Dumont começou, como se faz costumeiramente, pelos projetos os mais vastos; ao que parece, ele não sonhou com menos que uma história do Helenismo: suas notas provam que ele abordou todas as partes do tema, lendo de todos os lados um pouco ao sabor das

\footnotetext{
${ }^{5}$ Cf., para além da bibliografia citada na nota dois, VALENTI, 2002.
} 
circunstâncias, reunindo as informações as mais diversas. Mas ele não tardou a perceber que os problemas se mostravam em todos os temas, que todas as questões estavam para serem respondidas e que era necessário limitar seus estudos para os tornar mais eficazes e novos; ele compreendeu que as fontes não haviam sido nem esgotadas, nem todas utilizadas, e que se podia descobrir um pouco de verdade até nos vestígios mais humildes e aparentemente mais desprezáveis da antiguidade. A necessidade da precisão e da claridade o conduziram assim das generalidades da história ao detalhe da epigrafia e da arqueologia figurada.

Ou seja, ele encarnou, individual e prematuramente, a transformação que deveria mais tarde tocar toda a escola.

Os trabalhos que Dumont desenvolveu em sua estada em Antenas sobre a epigrafia, a cerâmica e os monumentos do neolítico gregos o tornaram conhecido dos patrões do helenismo situados em Paris. Em 1868, logo após seu retorno à França, a Académie des Inscriptions et Belles-Lettres o enviou em mais uma missão, dessa vez para o Egito e para várias regiões então sob o domínio otomano (Síria, Trácia e a capital do Império), onde ele deveria coletar indícios materiais da antiga presença grega. Após um ano de viagens, seguiu-se um período de consolidação de sua carreira: ele defendeu então sua tese principal sobre a cronologia e a sucessão dos arcontes atenienses, na qual cruzou documentos de origens diferentes (literárias e epigráficas) para datar com a maior precisão possível mais de trezentos anos de história grega (DUMONT, 1870). Seguiram-se novas missões ao exterior (dessa vez aos Balcãns), bem como trabalhos sobre cerâmicas e a participação ativa em várias revistas de época (em particular, a Revue Archéologique, o Journal des Savants e a Gazette des BeauxArts). Foi então que, com apenas 31 anos de idade, ele foi convidado para se tornar o subdiretor da seção romana da École Française d'Athènes.

Em função da longa distância que separava a França da Grécia, os membros da EFA se viam encorajados a passar de alguns meses a um ano em Roma. Tratava-se de um período de "aclimatação" ao clima mediterrânico. Mas tal antena, compartilhada por antiquisants de vários países, não tinha qualquer autonomia e, após a derrota para a Prússia em 1870, as instalações voltadas à arqueologia foram fechadas aos franceses. Ou seja, em resumo, era preciso tudo refazer. A escolha de Dumont é um bom indício do prestígio que ele gozava junto a seus colegas mais velhos. Outro indício igualmente significativo é o objetivo de sua missão: estabelecer a curto prazo uma escola independente de arqueologia em Roma. Não se trata agora de discutir em detalhes a fundação da École Française de Roma (EFR), sobre a qual se falará mais adiante na presente tese (subcapítulo 2.2). O que importa destacar aqui é o fato de Dumont se ver na situação de administrador de uma unidade cada vez mais autônoma, com "membros livres" desde 1873 e "efetivos" a partir de 1875. Era preciso, portanto, criar boas condições institucionais (estatutos e vínculos com outras instituições) e materiais (sede, 
alojamentos e biblioteca) de trabalho. Uma vez a tarefa concluída, o estado francês the concedeu uma clara promoção: assumir e modernizar a escola da qual ele havia sido membro. Entre 1875 e 1878, Dumont voltou a Atenas, mas agora como diretor.

Dentre suas realizações na EFA, a mais significativa foi certamente a criação do Institut de Correspondance Hellénique logo em seu primeiro ano. Catherine Valenti apresenta tal feito como símbolo não apenas da "virada científica" da escola, mas também da competição entre os franceses e o Deutsches Archäologisches Institut, fundado em 1874 (VALENTI, 2006a: 6268). Tal competição esteve, porém, longe de ser apenas científica. No necrológio de Dumont antes referenciado, Théophile Homolle esclareceu que as elites locais e nacionais gregas haviam se organizado em várias sociedades eruditas, as quais, em seus pequenos boletins, apresentavam o resultado de achados arqueológicos e epigráficos, muitas vezes realizados sem qualquer cuidado profissional ( $\mathrm{BCH}, 1884: \mathrm{xv}-\mathrm{xvii})$. Atento a esse movimento e disposto a tirar vantagens dele, Dumont estabeleceu no seio da EFA o Institut de Correspondance Hellénique, capaz de congregar os universitários franceses e as elites gregas. No início da primavera, entre princípios de março e meados de maio de cada ano, os membros dessa instituição, formados sobretudo por arqueólogos amadores e profissionais gregos, aos quais se associavam os membros da escola, reuniam-se quinzenalmente em Atenas para apresentar e discutir seus achados. A ideia, portanto, era coordenar uma série de esforços antes isolados e promover sua profissionalização. Divulgar esses resultados na forma de uma revista especializada surgiu como uma das decorrências mais imediatas dessa iniciativa.

O primeiro volume do Bulletin de Correspondance Hellénique $(\mathrm{BCH})$ apareceu já em 1877. Ao que tudo indica, ele foi publicado anualmente, tendo como editoras e difusoras a parisiense Ernest Thorin $^{6}$ e a ateniense $\Pi E T P O Z$ חEPPHZ EK $\triangle O T H \Sigma$. Sua organização interna era bastante simples e não se alterou significativamente com o passar dos anos: ao lado dos artigos e das raras resenhas, estas em sua maioria voltadas aos trabalhos de antigos membros da escola, havia uma parte voltada aos informes e aos resumos das comunicações apresentadas no Institut de Correspondance Hellénique. A sofisticação da revista estava, contudo, em seu índice de matérias. Teve-se o cuidado de apontar nessa seção, ao final de cada volume, os temas de interesse de cada texto. Em 1877, o conteúdo da revista foi dividido da seguinte forma: 1) "escavações e viagens"; 2) "arqueologia figurada" (esse item subdividido em "esculturas", "objetos em ouro", "prata", "bronzes", "chumbos", "vidros", "pedras gravadas", "terra-cotas e vasos pintados", "numismática", "pintura" e "museus"); 3) "epigrafia"; 4) "filologia"; 5) "crítica histórica"; 6) "bibliografia"; e 7) "comunicações e

\footnotetext{
${ }^{6}$ Tal editora mudou seu nome em 1896 para Fontemoing \& Cie, continuando a editar o BCH.
} 
correspondências". Como se pode constatar, os quatro primeiros itens estavam ligados diretamente às atividades ditas "científicas" da escola: as escavações e expedições, as inscrições e os objetos encontrados. Eis aí a vocação da revista mais uma vez explicitada: apresentar documentos originais inéditos. Comprovam ainda isso o fato de haver inicialmente muito pouco espaço para textos de síntese (em geral enquadrados em "crítica histórica") e também a função dos demais itens, os quais diziam respeito ou às resenhas ou à parte científico-administrativa do Institut de Correspondance Hellénique.

Com o passar dos anos, esse panorama foi sendo complexificado. A direção das transformações perpetuou, contudo, a ambição inicial da revista. Tratou-se, no mais das vezes, de discriminar as áreas de proveniência dos achados ou de acrescentar novos itens e subitens ("geografia", "topografia", "arquitetura"). Houve, no entanto, duas mudanças significativas. A primeira foi a criação de um campo intitulado "mitologia". Ele surgiu pela primeira vez em 1883, voltando a aparecer em 1895, dessa vez para ficar. Sob tal rubrica, por vezes apresentada também como "religião", foram publicados tanto textos específicos sobre objetos de culto como artigos mais gerais sobre as práticas religiosas antigas. A outra inovação importante é a transformação do item cinco original, "crítica histórica", em algo intitulado "história e instituição", já em 1891. Com efeito, ao carregar tal nome, ele passou a integrar discussões jurídico-institucionais nos ensaios de fundo histórico. Eram essas as duas categorias que permitiram, até fins da Primeira Guerra, textos de maior fôlego.

É importante manter em mente tal estrutura, justamente porque ela explicita as formas classificatórias com as quais os próprios helenistas então subdividiam suas áreas de atuação e davam sentido às suas instituições. Por certo, o BCH não foi criado, como será mais tarde a Revue des Études Grecques, para dar conta de todas as facetas do helenismo ${ }^{7}$. Atrelado a uma instituição de ensino e de pesquisa, além da divulgação de material inédito, ele visava tão somente dar espaço ao fruto do treinamento de boa parte dos futuros helenistas franceses. Ainda assim, foram precisamente essas formas de classificação impressas na revista que, dentro de certos limites, permitiram o diálogo entre o saber dos helenistas e aqueles oriundos de outras disciplinas.

Antes de verificar como se deu o diálogo específico entre helenistas e sociólogos, cumpre ainda entender a morfologia do $\mathrm{BCH}$. Afinal, quem, da fundação da revista até o período do imediato pós-Primeira Guerra Mundial, esteve aí presente? Quais constantes e transformações podem ser identificadas nesse intervalo? São justamente essas indagações que serão enfrentadas nas páginas que se seguem.

\footnotetext{
${ }^{7}$ Para uma análise do que seria esse helenismo, veja-se, no subcapítulo 2.3 da presente tese, o item "O helenismo é um humanismo".
} 


\section{OS DIRETORES DA EFA: UM PERFIL CIENTIFICAMENTE PROGRESSISTA}

Até o fim da Primeira Guerra Mundial, Dumont foi sucedido como diretor da EFA por quatro helenistas dos mais gabaritados: Paul Foucart (1836-1926), Théophile Homolle (18481925), Maurice Holleaux (1861-1932) e Gustave Fougères (1863-1927). Eles tinham em comum o fato de terem integrado tanto a École Normale Supérieure quanto a EFA. Além do mais, os quatro representaram, em suas respectivas épocas, posições cientificamente progressistas.

Foucart ficou à frente da escola entre 1878 e 1890 . Tendo defendido uma tese sobre as associações religiosas na Atenas Clássica (1873) e sendo então titular da cadeira de Épigraphie et Antiquités Grecques no Collège de France (1876), ele era o nome mais gabaritado para assumir a antiga posição de Dumont. É bem verdade que sua gestão não acrescentou grandes feitos à escola. A maior parte de seus membros era enviada para missões pontuais em sítios pequenos e médios. Salomon Reinach, que estagiou na EFA nesses mesmos anos, foi bastante crítico e irônico quando se referiu ao seu ex-diretor. Além de descrevê-lo como alguém sem iniciativa, enfatizou seus conservadorismos políticos e morais (RA, 1926/1: 67-73):

Sacrificar o paganismo ao cristianismo foi uma das preocupações de sua exegese. Não que sua fé fosse profunda, pois ele era o menos místico dos homens $e$ ignorava completamente a teologia; mas ele tinha horror a toda heresia, a todo não-conformismo, em particular quanto ao livre pensamento em religião $e$ em política.

Ainda que não de todo justa, a crítica de Reinach é reveladora. Foucart, mesmo representando um dos expoentes do helenismo francês nos anos $1870-80$, viu seus trabalhos serem colocados em questão pelas novas gerações. A velocidade das mudanças era grande demais. Mas ele soube, ao menos, consolidar as reformas instauradas por Dumont, colocando-as ao alcance de toda uma geração de helenistas.

Na sequência, a direção de Homolle coincidiu com as grandes escavações realizadas pela EFA. Ele, doutor desde 1884 e suplente de Foucart no Collège de France, foi convidado para assumir a tarefa em 1890, aí permanecendo por quatorze anos. Graças à partilha dos sítios gregos entre as potências europeias, os franceses fizeram valer seu direito de explorar Delos, Delfos, Tasos e Argos. O trabalho foi imenso e a EFA, graças à iniciativa de Homolle, reviu as normas do recrutamento interno, enfraquecendo o predomínio dos normalianos, bem como passando a aceitar "membros estrangeiros" (VALENTI, 1996). Seu sucesso junto à escola the rendeu a nomeação futura como diretor da École du Louvre e dos museus nacionais (1904-1911), ao que se seguiu um novo ano em Atenas (1912) e, por fim, a direção da Bibliothèque Nationale.

Já Holleaux e Fougères, os sucessores de Homolle, pertenciam à mesma geração. Mais que isso, eles encarnaram os ideais científicos e políticos da "Nouvelle Sorbonne", da qual ambos fizeram parte como professores titulares. Tratavam-se, afinal, de um epigrafista e de um arqueólogo de renomes já consolidados, ambos dreyfusards. Na EFA, suas gestões foram marcadas pela manutenção dos trabalhos nos grandes sítios arqueológicos e pela ampliação dos quadros da instituição. Na gestão Fougères, porém, a guerra cobrou seu preço, esvaziando a EFA por quatro longos anos. 


\section{PadRões de ReCRUtAMENTO}

$\mathrm{O} \mathrm{BCH}$ apresenta um padrão de recrutamento que, em linhas gerais, se manteve com poucas variações ao longo do intervalo aqui estudado (1877-1920). É salutar reconhecer a existência de três grupos de colaboradores aí presentes: os "atenienses", ou seja, aqueles que estagiam ou estagiaram na EFA; os franceses sem vínculos com a instituição; e os estrangeiros.

O primeiro grupo, o dos "atenienses", constiuiu o núcleo duro da revista. Apenas em seus dois primeiros anos, quando o número de gregos suplantou os demais, bem como durante a Guerra de 1914 e 1918, eles não representaram ao menos metade do total de colaboradores (veja-se as tabelas 2.1.1, 2.1.2, 2.1 .3 e 2.1.4). Tal grupo dividia-se, contudo, em quatro subgrupos, cujas especificidades cumpre aqui observar. Parte significativa do material impresso no BCH vinha dos trabalhos desenvolvidos por "membros efetivos" da EFA. Tratavase de jovens helenistas, geralmente entre os 20 e os 25 anos de idade, os quais apresentavam publicamente suas primeiras pesquisas com materiais epigráficos e arqueológicos inéditos. $\mathrm{Na}$ mesma situação, mas com vínculos institucionais diferentes, estavam os "membros livres" e os "membros estrangeiros". Sua presença no $\mathrm{BCH}$ foi, porém, tardia e de pouco impacto se comparada à dos "membros efetivos". Por fim, houve um quarto subgrupo, o dos "antigos membros efetivos". A importância desse subgrupo tendeu a crescer com o passar dos anos, indicando justamente o aumento do número de antigos membros da EFA ligados à pequisa nos domínios do helenismo (ou seja, é um bom indicador da viabilização e do crescimento da área). Apenas uma observação sobre o perfil dos indivíduos que podem ser assim caracterizados: embora muitos deles tenham escrito como helenistas consagrados, a maioria dos "antigos membros efetivos" era composta por "atenienses" cujo estágio havia recémterminado. De volta a França, eles se deparavam com os preparativos de suas teses e, até o momento da defesa, publicavam regularmente no $\mathrm{BCH}$ suas conclusões sobre o material recolhido na Grécia. Uma vez findo o doutorado, suas intervenções na revista tendiam a desaparecer ou a se tornar esparsas. Outras publicações, especializadas ou não, justamente por privilegiarem textos de síntese, passavam então a serem por eles visadas.

O segundo grupo, o dos franceses sem vínculos anteriores com a EFA, é morfologicamente mais homogêneo. Eles sim representam expoentes do helenismo que, em função de suas especialidades, foram convidados a auxiliar no tratamento de um ou outro material recém-descoberto. Henri Weil e Théodore Reinach, por exemplo, foram requisitados com frequência ao longo da década de 1890 quando o tema era a música antiga ${ }^{8}$.

\footnotetext{
${ }^{8}$ Cf. BCH, 1893: 561-568, 569-583 e 584-610; BCH, 1894: 345-362 e 363-389; BCH 1895: 393-418; e, por fim, $\mathrm{BCH}, 1897:$ 510-513.
} 
Quadro 2.1.1 - Padrões de recrutamento - autores de artigos (BCH, 1877-1887). ${ }^{9}$

\begin{tabular}{|c|c|c|c|c|c|c|c|c|c|c|c|}
\hline $\begin{array}{l}\text { VÍNCULO INSTITUCIONAL DOS AUTORES (articles de } \\
\text { fonds)/ANO }\end{array}$ & 1877 & 1878 & 1879 & 1880 & 1881 & 1882 & 1883 & 1884 & 1885 & 1886 & 1887 \\
\hline Membro efetivo da EFA (incluindo diretor) & $18,52 \%$ & $23,33 \%$ & $31,58 \%$ & $20,83 \%$ & $21,74 \%$ & $31,81 \%$ & $24 \%$ & $26,92 \%$ & $35 \%$ & $37,5 \%$ & $33,33 \%$ \\
\hline Membro livre da EFA & $0 \%$ & $0 \%$ & $0 \%$ & $0 \%$ & $0 \%$ & $4,54 \%$ & $0 \%$ & $3,85 \%$ & $0 \%$ & $0 \%$ & $0 \%$ \\
\hline Membro estrangeiro da EFA & $0 \%$ & $0 \%$ & $0 \%$ & $0 \%$ & $0 \%$ & $0 \%$ & $0 \%$ & $0 \%$ & $0 \%$ & $0 \%$ & $0 \%$ \\
\hline Professor/pesquisador antigo membro efetivo da EFA & $18,52 \%$ & $13,33 \%$ & $31,58 \%$ & $37,5 \%$ & $34,78 \%$ & $22,73 \%$ & $28 \%$ & $42,31 \%$ & $35 \%$ & $43,75 \%$ & $33,33 \%$ \\
\hline Pesquisador francês sem vínculo anterior com a EFA & $11,11 \%$ & $16,67 \%$ & $5,26 \%$ & $12,5 \%$ & $8,70 \%$ & $9,09 \%$ & $12 \%$ & $3,85 \%$ & $10 \%$ & $6,25 \%$ & $13,33 \%$ \\
\hline Colaborador estrangeiro (Alemão) & $0 \%$ & $0 \%$ & $0 \%$ & $0 \%$ & $0 \%$ & $0 \%$ & $0 \%$ & $0 \%$ & $0 \%$ & $0 \%$ & $0 \%$ \\
\hline Colaborador estrangeiro (Britânico) & $0 \%$ & $0 \%$ & $0 \%$ & $0 \%$ & $0 \%$ & $4,54 \%$ & $4 \%$ & $0 \%$ & $0 \%$ & $0 \%$ & $0 \%$ \\
\hline Colaborador estrangeiro (Belga) & $0 \%$ & $0 \%$ & $0 \%$ & $0 \%$ & $0 \%$ & $0 \%$ & $0 \%$ & $0 \%$ & $0 \%$ & $0 \%$ & $0 \%$ \\
\hline Colaborador estrangeiro (Suíço) & $0 \%$ & $0 \%$ & $0 \%$ & $0 \%$ & $0 \%$ & $0 \%$ & $0 \%$ & $0 \%$ & $0 \%$ & $0 \%$ & $0 \%$ \\
\hline Colaborador estrangeiro (Grego) & $48,15 \%$ & $40 \%$ & $26,32 \%$ & $25 \%$ & $26,08 \%$ & $4,54 \%$ & $12 \%$ & $11,54 \%$ & $5 \%$ & $12,5 \%$ & $13,33 \%$ \\
\hline Colaborador estrangeiro (Outro) & $0 \%$ & $0 \%$ & $0 \%$ & $0 \%$ & $0 \%$ & $4,54 \%$ & $0 \%$ & $0 \%$ & $0 \%$ & $0 \%$ & $0 \%$ \\
\hline Colaborador não identificado & $3,70 \%$ & $6,67 \%$ & $5,26 \%$ & $4,17 \%$ & $8,70 \%$ & $18,19 \%$ & $20 \%$ & $11,54 \%$ & $15 \%$ & $0 \%$ & $6,67 \%$ \\
\hline Total de colaboradores por ano $(\mathrm{N}=100 \%)$ & 27 & 30 & 19 & 24 & 23 & 22 & 25 & 26 & 20 & 16 & 15 \\
\hline
\end{tabular}

\footnotetext{
${ }^{9}$ Na elaboração das tabelas 2.1.1, 2.1.2, 2.1.3 e 2.1.4 desconsiderou-se a quantidade de textos por colaborador. O método adotado consistiu em acompanhar, ano a ano, quem escrevia para o BCH e qual era então seu vínculo institucional. Se o vínculo para o ano em questão não pôde ser recuperado, preferiu-se então incorporar o autor à categoria "não identificado".
} 
Quadro 2.1.2 - Padrões de recrutamento - autores de artigos (BCH, 1888-1898).

\begin{tabular}{|c|c|c|c|c|c|c|c|c|c|c|c|}
\hline \multirow{2}{*}{$\begin{array}{l}\text { VÍNCULO INSTITUCIONAL DOS AUTORES (articles de } \\
\text { fonds)/ANO }\end{array}$} & 1888 & 1889 & 1890 & 1891 & 1892 & 1893 & 1894 & 1895 & 1896 & 1897 & 1898 \\
\hline & & & & & & & & & & & \\
\hline Membro efetivo da EFA (incluindo diretor) & $30 \%$ & $27,27 \%$ & $15 \%$ & $19,05 \%$ & $12 \%$ & $19,23 \%$ & $14,29 \%$ & $22,22 \%$ & $14,29 \%$ & $18,75 \%$ & $21,43 \%$ \\
\hline Membro livre da EFA & $0 \%$ & $0 \%$ & $0 \%$ & $0 \%$ & $0 \%$ & $0 \%$ & $0 \%$ & $0 \%$ & $0 \%$ & $0 \%$ & $0 \%$ \\
\hline Membro estrangeiro da EFA & $0 \%$ & $0 \%$ & $0 \%$ & $0 \%$ & $0 \%$ & $0 \%$ & $0 \%$ & $0 \%$ & $0 \%$ & $0 \%$ & $0 \%$ \\
\hline Professor/pesquisador antigo membro efetivo da EFA & $35 \%$ & $54,55 \%$ & $60 \%$ & $61,90 \%$ & $48 \%$ & $50 \%$ & $42,86 \%$ & $44,44 \%$ & $42,85 \%$ & $50 \%$ & $50 \%$ \\
\hline Pesquisador francês sem vínculo anterior com a EFA & $5 \%$ & $4,54 \%$ & $0 \%$ & $4,76 \%$ & $0 \%$ & $11,54 \%$ & $10,71 \%$ & $5,56 \%$ & $14,29 \%$ & $6,25 \%$ & $0 \%$ \\
\hline Colaborador estrangeiro (Alemão) & $0 \%$ & $0 \%$ & $0 \%$ & $0 \%$ & $0 \%$ & $3,85 \%$ & $3,57 \%$ & $5,56 \%$ & $4,76 \%$ & $0 \%$ & $14,29 \%$ \\
\hline Colaborador estrangeiro (Britânico) & $5 \%$ & $0 \%$ & $5 \%$ & $0 \%$ & $0 \%$ & $0 \%$ & $7,14 \%$ & $0 \%$ & $0 \%$ & $0 \%$ & $7,14 \%$ \\
\hline Colaborador estrangeiro (Belga) & $0 \%$ & $0 \%$ & $0 \%$ & $0 \%$ & $0 \%$ & $0 \%$ & $0 \%$ & $0 \%$ & $0 \%$ & $0 \%$ & $0 \%$ \\
\hline Colaborador estrangeiro (Suíço) & $0 \%$ & $0 \%$ & $0 \%$ & $0 \%$ & $0 \%$ & $0 \%$ & $0 \%$ & $0 \%$ & $0 \%$ & $0 \%$ & $0 \%$ \\
\hline Colaborador estrangeiro (Grego) & $15 \%$ & $13,64 \%$ & $15 \%$ & $14,29 \%$ & $20 \%$ & $15,38 \%$ & $17,86 \%$ & $16,67 \%$ & $9,52 \%$ & $0 \%$ & $0 \%$ \\
\hline Colaborador estrangeiro (Outro) & $0 \%$ & $0 \%$ & $0 \%$ & $0 \%$ & $0 \%$ & $0 \%$ & $0 \%$ & $5,56 \%$ & $0 \%$ & $6,25 \%$ & $0 \%$ \\
\hline Colaborador não identificado & $10 \%$ & $0 \%$ & $5 \%$ & $0 \%$ & $20 \%$ & $0 \%$ & $3,57 \%$ & $0 \%$ & $14,29 \%$ & $18,75 \%$ & $7,14 \%$ \\
\hline Total de colaboradores por ano ( $\mathrm{N}=100 \%)$ & 20 & 22 & 20 & 21 & 25 & 26 & 28 & 18 & 21 & 16 & 14 \\
\hline
\end{tabular}


Quadro 2.1.3 - Padrões de recrutamento - autores de artigos (BCH, 1899-1909).

\begin{tabular}{|c|c|c|c|c|c|c|c|c|c|c|c|}
\hline $\begin{array}{l}\text { VÍNCULO INSTITUCIONAL DOS AUTORES (articles de } \\
\text { fonds)/ANO }\end{array}$ & 1899 & 1900 & 1901 & 1902 & 1903 & 1904 & 1905 & 1906 & 1907 & 1908 & 1909 \\
\hline Membro efetivo da EFA (incluindo diretor) & $28,57 \%$ & $20 \%$ & $22,22 \%$ & $28,57 \%$ & $20 \%$ & $20 \%$ & $14,29 \%$ & $11,11 \%$ & $16,67 \%$ & $11,76 \%$ & $18,18 \%$ \\
\hline Membro livre da EFA & $0 \%$ & $0 \%$ & $0 \%$ & $0 \%$ & $0 \%$ & $0 \%$ & $0 \%$ & $0 \%$ & $0 \%$ & $0 \%$ & $0 \%$ \\
\hline Membro estrangeiro da EFA & $0 \%$ & $0 \%$ & $22,22 \%$ & $21,43 \%$ & $20 \%$ & $13,33 \%$ & $21,42 \%$ & $5,56 \%$ & $11,11 \%$ & $5,88 \%$ & $0 \%$ \\
\hline Professor/pesquisador antigo membro efetivo da EFA & $50 \%$ & $45 \%$ & $33,33 \%$ & $42,86 \%$ & $40 \%$ & $40 \%$ & $28,57 \%$ & $50 \%$ & $44,44 \%$ & $23,53 \%$ & $18,18 \%$ \\
\hline Pesquisador francês sem vínculo anterior com a EFA & $0 \%$ & $5 \%$ & $0 \%$ & $0 \%$ & $0 \%$ & $6,67 \%$ & $7,14 \%$ & $5,56 \%$ & $5,56 \%$ & $17,65 \%$ & $18,18 \%$ \\
\hline Colaborador estrangeiro (Alemão) & $0 \%$ & $5 \%$ & $0 \%$ & $0 \%$ & $0 \%$ & $0 \%$ & $7,14 \%$ & $0 \%$ & $0 \%$ & $5,88 \%$ & $9,09 \%$ \\
\hline Colaborador estrangeiro (Britânico) & $0 \%$ & $10 \%$ & $0 \%$ & $0 \%$ & $0 \%$ & $0 \%$ & $0 \%$ & $0 \%$ & $0 \%$ & $0 \%$ & $0 \%$ \\
\hline Colaborador estrangeiro (Belga) & $0 \%$ & $0 \%$ & $0 \%$ & $0 \%$ & $0 \%$ & $0 \%$ & $0 \%$ & $5,56 \%$ & $0 \%$ & $0 \%$ & $9.09 \%$ \\
\hline Colaborador estrangeiro (Suíço) & $0 \%$ & $0 \%$ & $0 \%$ & $0 \%$ & $0 \%$ & $0 \%$ & $0 \%$ & $0 \%$ & $0 \%$ & $5,88 \%$ & $0 \%$ \\
\hline Colaborador estrangeiro (Grego) & $14,29 \%$ & $5 \%$ & $0 \%$ & $7,14 \%$ & $13,33 \%$ & $6,67 \%$ & $7,14 \%$ & $11,11 \%$ & $11,11 \%$ & $5,88 \%$ & $18,18 \%$ \\
\hline Colaborador estrangeiro (Outro) & $0 \%$ & $0 \%$ & $0 \%$ & $0 \%$ & $0 \%$ & $0 \%$ & $0 \%$ & $5,56 \%$ & $5,56 \%$ & $11,76 \%$ & $9,09 \%$ \\
\hline Colaborador não identificado & $7,14 \%$ & $10 \%$ & $22,22 \%$ & $0 \%$ & $6,67 \%$ & $13,33 \%$ & $14,29 \%$ & $5,56 \%$ & $5,56 \%$ & $11,76 \%$ & $0 \%$ \\
\hline Total de colaboradores por ano ( $\mathrm{N}=100 \%)$ & 14 & 20 & 9 & 14 & 15 & 15 & 14 & 18 & 18 & 17 & 11 \\
\hline
\end{tabular}


Quadro 2.1.4 - Padrões de recrutamento - autores de artigos ( $\mathrm{BCH}, 1910-1920)$

\begin{tabular}{|l|l|l|l|l|l|l|l|l|l|} 
VÍNCULO INSTITUCIONAL DOS AUTORES (articles de & 1910 & 1911 & 1912 & 1913 & 1914 & 1915 & 1916 & $1917^{10}$ & 1920
\end{tabular}

\section{fonds)/ANO}

\begin{tabular}{|c|c|c|c|c|c|c|c|c|c|}
\hline Membro efetivo da EFA (incluindo diretor) & $23,53 \%$ & $23,09 \%$ & $16,67 \%$ & $25 \%$ & $8,33 \%$ & $0 \%$ & $0 \%$ & $0 \%$ & $0 \%$ \\
\hline Membro livre da EFA & $5,88 \%$ & $0 \%$ & $5,56 \%$ & $0 \%$ & $0 \%$ & $0 \%$ & $0 \%$ & $0 \%$ & $0 \%$ \\
\hline Membro estrangeiro da EFA & $0 \%$ & $0 \%$ & $0 \%$ & $8,33 \%$ & $8,33 \%$ & $0 \%$ & $0 \%$ & $0 \%$ & $0 \%$ \\
\hline Professor/pesquisador antigo membro efetivo da EFA & $29,41 \%$ & $30,77 \%$ & $44,44 \%$ & $16,67 \%$ & $75 \%$ & $70 \%$ & $55,55 \%$ & $0 \%$ & $35,71 \%$ \\
\hline Pesquisador francês sem vínculo anterior com a EFA & $5,88 \%$ & $7,69 \%$ & $0 \%$ & $0 \%$ & $0 \%$ & $0 \%$ & $22,22 \%$ & $100 \%$ & $21,43 \%$ \\
\hline Colaborador estrangeiro (Alemão) & $11,76 \%$ & $0 \%$ & $5,56 \%$ & $0 \%$ & $0 \%$ & $0 \%$ & $0 \%$ & $0 \%$ & $0 \%$ \\
\hline Colaborador estrangeiro (Britânico) & $0 \%$ & $0 \%$ & $0 \%$ & $0 \%$ & $0 \%$ & $0 \%$ & $11,11 \%$ & $0 \%$ & $0 \%$ \\
\hline Colaborador estrangeiro (Belga) & $0 \%$ & $0 \%$ & $0 \%$ & $0 \%$ & $8,33 \%$ & $10 \%$ & $11,11 \%$ & $0 \%$ & $0 \%$ \\
\hline Colaborador estrangeiro (Suíço) & $0 \%$ & $0 \%$ & $0 \%$ & $0 \%$ & $0 \%$ & $0 \%$ & $0 \%$ & $0 \%$ & $0 \%$ \\
\hline Colaborador estrangeiro (Grego) & $11,76 \%$ & $23,09 \%$ & $22,22 \%$ & $0 \%$ & $0 \%$ & $0 \%$ & $0 \%$ & $0 \%$ & $14,29 \%$ \\
\hline Colaborador estrangeiro (Outro) & $5,88 \%$ & $7,69 \%$ & $5,56 \%$ & $25 \%$ & $0 \%$ & $0 \%$ & $0 \%$ & $0 \%$ & $14,29 \%$ \\
\hline Colaborador não identificado & $5,88 \%$ & $7,69 \%$ & $0 \%$ & $25 \%$ & $0 \%$ & $20 \%$ & $0 \%$ & $0 \%$ & $14,29 \%$ \\
\hline Total de colaboradores por ano $(\mathrm{N}=100 \%)$ & 17 & 13 & 18 & 12 & 12 & 10 & 9 & 1 & 14 \\
\hline
\end{tabular}

\footnotetext{
${ }^{10}$ Entre 1917 e 1919, o BCH foi colocado ao serviço do Exército Francês do Oriente. Alistado nas forças francesas, o chartista Léon Rey (1887-1954) se encarregou então de redigir um único volume relativo aos anos 1917, 1918 e 1919, o qual resumiu as atividades da EFA e do departamento de arqueologia do exército francês durante a Primeira Guerra Mundial.
} 
O mesmo valeu para Gustave Glotz quando o assunto tangenciou tópicos mais amplos da história política e econômica da Grécia Antiga ${ }^{11}$, ou para Paul Huvelin, em questões relativas ao direito comercial em Délos ${ }^{12}$. E tais casos poderiam ser ainda multiplicados (o filósofo Ernst Renan, o epigrafista René Cagnat, o numismata Ernst Babelon, entre tantos outros). Sua presença constante nas páginas da $\mathrm{BCH}$ dá uma boa medida do prestígio da publicação e, a reboque, dos temas relativos ao helenismo no interior da própria universidade francesa.

Por fim, o grupo relativo aos estrangeiros foi marcado por uma grande heterogeneidade. Destacaram-se em seu interior os gregos. Como foi dito antes, entre eles havia tanto amadores quanto pesquisadores renomados, tais como Panagiotis Cavvadias e Georges Sotiriadis, ambos professores universitários em Atenas. O núcleo que os congregava era o Institut de Correspondance Hellénique. Além de indivíduos dessa nacionalidade, publicaram no $\mathrm{BCH}$ com alguma frequência os membros das outras missões científicas internacionais: alemães, ingleses e, em menor grau, norte-americanos. Suas presenças oscilaram ao sabor das relações diplomáticas e científicas entre os países. Os helenistas alemães, por exemplo, estiveram ausentes dos treze primeiros anos do $\mathrm{BCH}$ : não bastasse a recente guerra com a Prússia, houve ainda a polêmica em torno do abandono dos sítios arqueológicos franceses, denunciada por ninguém menos que Henrich Schliemann, o descobridor de Troia ${ }^{13}$. Três anos após seu falecimento os ânimos pareceram mais calmos e finalmente os alemães publicaram com relativa constância, ao menos até 1912, às vésperas da Primeira Guerra Mundial. Quanto aos demais estrangeiros, chama atenção o fato de os belgas e suíços terem contribuído pouco e tardiamente. Sua presença não deixa, porém, de ser reveladora. Afinal, ela é um reflexo direto da abertura da escola aos integrantes desses países em um cenário de crescente tensão internacional.

Diante da frequência de publicação de todos esses grupos, pode-se depreender algumas tendências mais gerais do $\mathrm{BCH}$. Por exemplo, a despeito de ser a EFA a mais antiga das escolas arqueológicas estrangeiras instaladas na Grécia, seu periódico só se tornou mesmo aberto a expoentes de outras potências europeias a partir de 1890, ou seja, a partir da exploração sistemática dos grandes sítios arqueológicos sob responsabilidade francesa (gestão Homolle). Outro indício na mesma direção foi o recrutamento de "membros estrangeiros", iniciado em 1900.

\footnotetext{
${ }^{11}$ Veja-se BCH, 1908: 271-278; 1909: 526-546; 1920: 362-366.

${ }^{12} \mathrm{BCH}, 1907$ : 46-93. Em se tratando de um colaborador do AS, esse texto será discutido em detalhes mais adiante.

${ }^{13}$ A resposta dos "atenienses" veio da pena de um ex-membro da EFA, Gustave Fougères $(\mathrm{BCH}, 1890$ : 271-275). Talvez não por acaso o diretor da EFA, Paul Foucart, tenha sido substituído em meio à crise por Théophile Homolle.
} 
Além disso, as tabelas acima assinalam bem dois fenômenos que se mantiveram sempre constantes: o caráter pedagógico do $\mathrm{BCH}$ e o corporativismo subjacente à instituição que o produz. Tratava-se assim de uma revista dominada por "jovens", o que no contexto da presente pesquisa significa pesquisadores em início de carreira. Se a EFA disponibiliza o treinamento específico, epigráfico e arqueológico, a partir do contato direto com a documentação antiga, o BCH abre espaço para que tudo isso ganhe forma científica (artigos e ensaios), garantindo ainda sua circulação entre os pares. É notável que nenhum outro agrégé não membro da escola tenha publicado aí. É também notável que a presença de não membros franceses seja relativamente pequena se restrita a expoentes já consolidados do helenismo e, quando a ocasião reclamava, do latinismo. Não há como separar, portanto, a revista da instituição que a edita: o BCH é o braço impresso da EFA.

Mas sendo ela uma revista de "jovens", até que ponto a sociologia durkheimiana pode se fazer aí presente? Afinal, não se pode esquecer que durante os trinta e um primeiros anos do $\mathrm{BCH}$ sequer existia L'Année Sociologique e cadeiras de sociologia na França. Houve tempo para que os trabalhos desses sociólogos alcançassem os membros da escola? E mais, teriam membros seus aderido à empresa sociológica?

\section{A recepção da sociologia no Bulletin de CoRRespondanCe Hellénique (1898-1920)}

Privilegiando, em detrimento de grandes ensaios interpretativos, a divulgação de documentos originais, o $\mathrm{BCH}$ diminuiu consideravelmente a porta de acesso à sociologia durkheimiana. Afinal, uma ciência recém-estabelecida e com quadros reduzidos não estava em condições de propor avanços imediatos em arqueologia e, sobretudo, em epigrafia. Ou seja, os membros da EFA pareciam poder prescindir da sociologia para traduzir inscrições e descrever objetos extraídos dos sítios arqueológicos gregos $^{14}$. Ainda assim, como foi visto antes, existiram seções do $\mathrm{BCH}$ aptas a acolherem textos mais alentados, em especial aquelas intituladas "mitologia" (ou "religião") e "história e instituição". Foi precisamente nesses espaços que o diálogo foi viável.

Tratou-se, porém, de um diálogo breve se pensado em termos diretos. De 1898 a 1920, apenas três referências foram feitas por não-sociólogos aos trabalhos de colaboradores do AS. Às vésperas da Primeira Grande Guerra, Henri Hubert teve seu verbete Magia escrito para o Dictionnaire des Antiquités Grecques et Romaines (doravante DAGR) citado por um antigo membro da EFA, o então bolsista do Institut des Hautes-Études Hispaniques, René

\footnotetext{
${ }^{14} \mathrm{O}$ caso da arqueologia é, de fato, mais complexo, pois Henri Hubert e alguns de seus alunos atuaram na área, discutindo, em particular, o contexto galo-romano. Veja-se, sobre isso, o subcapítulo 3.2 da presente tese.
} 
Vallois (BCH, 1914: 250-271). Em um texto intitulado APAI, partindo de uma estela encontrada em Délos, o autor discutiu a carga religiosa da legislação em torno das imprecações nas cidades gregas. Para além de Hubert, Pierre Roussel foi também referenciado como alguém a quem Vallois recorreu pessoalmente. Por fim, o autor ainda se valeu do trabalho de James Frazer e de uma helenista britânica bastante próxima aos sociólogos durkheimianos, Jane Harrison.

Outra citação direta ao trabalho de um sociólogo durkheimiano ocorreu dois anos mais cedo. George Seure, outro antigo membro da EFA, publicou na revista da escola o catálogo dos lapidários pertencentes a um colecionador grego, Anastásio Stamoulis. Todos os objetos eram provenientes do norte da Grécia (Trácia) e o catálogo, que não se restringia apenas a uma descrição das peças, discutia-as com algum nível de detalhamento (BCH, 1912: 534-641). Em duas ocasiões, páginas 557 e 614, Seure se valeu do verbete Negotiator, escrito pelo jurista e sociólogo Paul Huvelin para o mesmo dicionário em que Hubert havia publicado o seu Magia. O tema das inscrições, as práticas comerciais e/ou determinados comerciantes antigos, reclamava um suporte bibliográfico como esse, mais geral.

É interessante notar que, nesses dois casos, as referências vieram de "atenienses" que já haviam deixado a escola. Isso significa que ambos estavam em uma fase mais avançada de seus trabalhos de pesquisa, podendo agregar à tradução de inscrições antigas comentários mais aprofundados. É revelante também a origem das citações. O DAGR era uma enciclopédia da Antiguidade greco-latina que visava fornecer uma base para a discussão de temas pontuais (deuses, ritos, localidades, utensílios variados, entre outros) ${ }^{15}$. O público-alvo era, portanto, o dos antiquisants. Não se pode assim estranhar que os textos dos colaboradores do AS aí impressos tenham sido justamente aqueles que chegaram às mãos dos helenistas em início de carreira. Por fim, vale ainda destacar os temas dos artigos: as relações entre leis e religião na Grécia Antiga.

A terceira citação opera em um registro similar. Em 1913, Charles Avezou e Charles Picard, dois membros efetivos da EFA em fim de estágio, discutiram inscrições epigráficas encontradas na costa da Trácia ( $\mathrm{BCH}, 1913$ : 84-154). Uma dessas inscrições, na qual se enumeram as honrarias e as obrigações dadas a um negociante romano, fazia menção ao comércio do trigo. Os autores então citaram um dos primeiros trabalhos publicados do helenista-sociólogo Louis Gernet (1909), o capítulo de livro intitulado L'approvisionnement d'Athènes en blé au $V^{e}$ et au $I V^{e}$ siècles, para atestar a importância da referida atividade. A citação é importante não apenas pelas intuições sociológicas que tal texto contém, mas

\footnotetext{
${ }^{15}$ Para mais detalhes sobre o DAGR, cf. o subcapítulo 3.3 da presente tese.
} 
também, e sobretudo, por indicar o reconhecimeno de jovens pares de sua autoridade na área. Com efeito, ao contrário de Huvelin e Hubert, Gernet seguiu desde cedo a trajetória de antiquisant $^{16}$.

Além das alusões diretas, toda uma literatura familiar ou próxima aos sociólogos esteve presente nas páginas do $\mathrm{BCH}$. Os nomes de James Frazer e Jane Harrison foram já mencionados acima em um artigo específico. A revista da EFA chegou mesmo a publicar um artigo dessa helenista inglesa sobre os usos rituais do Ônfalos de Delfos (BCH, 1900: 154-126), o único texto seu nas revistas dos antiquisants franceses antes da Guerra. Do mesmo modo, o $\mathrm{BCH}$ registrou um número considerável de alusões a Frazer e a outro antropólogo britânico, William Robertson Smith ${ }^{17}$. Entre os franceses, autores como Salomon Reinach e Paul Perdrizet, ambos antigos membros da EFA e helenistas próximos aos durkheimianos, também aí discutiram aspectos da religiosidade dos antigos gregos ${ }^{18}$.

Desse modo, não se poderia dizer que a escola sociológica francesa, bem como outros ramos das ciências sociais praticados à época (em particular a antropologia britânica), tenham sigo negligenciados no $\mathrm{BCH}$. Dado o foco da publicação, é mesmo um sinal bastante positivo a simples alusão a trabalhos nela inspirados, pois indicam a convergência de interesses quanto a certos temas e abordagens. Ter-se-á de esperar por periódicos destinados aos "velhos", aos helenistas já consolidados, para que essa modalidade de diálogo seja explicitada em termos de alianças ou de tensões, sejam elas epistemológicas e/ou institucionais.

Há, contudo, outros indícios da presença da sociologia durkheimiana no $\mathrm{BCH}$ : a participação direta. De fato, como será visto na sequência, os portadores de tal saber também atuaram aí como colaboradores.

\section{Os sociólogos no BULLetin de CoRRespondanCE HeLléNIQUe}

Apenas dois membros da equipe de AS ostentaram em seus currículos a prestigiosa passagem pela EFA: Charles Fossey e Pierre Roussel. O primeiro deles aí esteve entre 1894 e 1897, antes mesmo da criação da revista dirigida por Émile Durkheim. Tal estágio no exterior foi, porém, crucial para sua trajetória. Uma vez em Atenas, Fossey foi incumbido de missões na

\footnotetext{
${ }^{16}$ É importante lembrar que o referido texto de Gernet foi publicado em uma coletânea publicada em homenagem a um dos poucos latinistas próximos aos sociólogos, Gustave Bloch. Uma resenha sobre ele, bastante elogiosa, foi publicada por François Simiand em L'Année Sociologique (cf. AS, 1910: 563).

17 Destaco o uso que Paul Perdrizet faz dos dois autores em BCH, 1911: 108-119, bem como as discussões de Avezou e Picard em BCH, 1914: 38-62.

${ }^{18}$ Veja-se, entre outros, os textos de Salomon Reinach sobre os deuses Ártemis e Pã, respectivamente em BCH, 1906: 150-160 e BCH, 1907: 1-19. Quanto a Perdrizet, veja-se o texto que ele dedica a Hermes $(\mathrm{BCH}, 1903: 300-313)$, bem como o terceiro artigo que ele dedica às representações em alto relevo da deusa Nêmesis (BCH, 1914: 89-100).
} 
Síria em nome da escola, situação que lhe permitiu entrar pela primeira vez em contato direto com as antigas civilizações do Oriente Médio, às quais ele dedicou o restante de sua carreira de pesquisador ${ }^{19}$. Tal reconversão, da qual Fossey não foi o único exemplo entre os "atenienses", permitiu-Ihe embarcar para mais um estágio de dois anos no Institut Français $d^{\prime}$ Archéologie Orientale (1897-1899), onde ele se iniciou definitivamente na assiriologia ${ }^{20}$. Foi no retorno a França, quando logrou obter uma posição na $V^{a}$ seção da EPHE (encarregado de um curso livre intitulado Religion Babylonienne), que ele travou contato, por intermédio de Henri Hubert, Isidore Lévy e Marcel Mauss, com a sociologia ${ }^{21}$.

O caso de Pierre Roussel é diferente. Não bastasse o seu estágio na EFA ter sido posterior e maior se comparado ao de Fossey (1905-1911), ele representou para Roussel o início da carreira de helenista. Foi com a experiência adquirida lá que ele se tornou um dos maiores epigrafistas franceses no período entreguerras, ocupando, além de uma cátedra na Sorbonne, o posto de diretor da EFA entre 1925 e 1936. Além do mais, Roussel manteve contato com os durkheimianos durante sua estada em Atenas, bem como escreveu ao BCH um artigo no mesmo ano em que iniciou sua colaboração para o AS (1913).

Em todo caso, o lugar dado à nova ciência em seus trabalhos ligados a EFA foi mínimo. Dos quinze textos que ele aí escreveu até 1920, a grande maioria apresentou ou o resultado de escavações ${ }^{22}$ ou a edição crítica de novas inscrições descobertas ${ }^{23}$. Todo esse material arqueológico e epigráfico trabalhado provinha da ilha de Délos, o sítio ao qual ele dedicou sua tese, Les cultes égyptiens à Délos du Ille au ler siècle av. J.-C., defendida em meio à Primeira Guerra Mundial (ROUSSEL, 1916b). O artigo publicado no BCH após ele ter deixado a escola e aderido ao AS, Le Sénatus-Consulte de Délos, remete já a um estado avançado desse trabalho (BCH, 1913: 310-322). O autor aí discute o impacto da dominação romana em Délos no tocante à administração dos cultos públicos provenientes do Egito (antes sob tutela de instituições implementadas pelos atenienses). Nele, porém, não é o culto em si (em especial o de Serápis) que é objeto de discussão, mas sim as suas bases jurídicas e sociais (propriedade dos templos, magistrados responsáveis pela administração pública do culto, entre outros). 0 único

\footnotetext{
${ }^{19} \mathrm{No} \mathrm{BCH}$ ele publicou três artigos, todos relatos de viagens à Síria. $\mathrm{Cf}$. $\mathrm{BCH}, 1895$ : 303-306; $\mathrm{BCH}$ : 1897 : 39-65 e 66-91 (o último em coautoria com Paul Perdrizet).

${ }^{20}$ Veja-se, por exemplo, a trajetória de Pierre Jouguet, o qual partiu do helenismo para se dedicar ao Egito Antigo (antes e após a conquista macedônica).

${ }^{21}$ Para mais detalhes sobre a trajetória de Fossey, veja-se o subcapítulo 3.1 da presente tese.

${ }^{22}$ Veja-se, BCH, 1909: 472-522 e 1910: 355-423 (ambos em coautoria com Jean Hatzfeld).

${ }^{23}$ Cf. BCH, 1907: 421-470; 1908: 303-444; 1909: 443-444; 1910: 110-115 e 424; 1911: 423-432, 433-440 e 441-455; 1912: 436-438.
} 
colaborador do AS citado no artigo foi o orientalista Isidore Lévy, o qual havia publicado anos antes um texto sobre as possíveis origens do culto ao deus Serápis ${ }^{24}$.

$\mathrm{O}$ terceiro e último sociólogo presente nas páginas do $\mathrm{BCH}$ durante o intervalo aqui estudado foi Paul Huvelin. Ao contrário de Fossey e Roussel, ele jamais foi membro da EFA e sua presença na revista se deve tão somente a sua especialidade. Em 1907, portando quatro anos após sua adesão à equipe do AS, ele foi convidado pelo então diretor da EFA, Maurice Holleaux, para redigir em companhia de um membro da escola em seu último ano de estágio, Enzio Schulhof, um artigo acerca de uma lei comercial praticamente intacta recém-encontrada em Délos.

Mas por que o recrutamento de Huvelin? O fato é que ele havia se doutorado dez anos antes com uma tese sobre o direito comercial da Antiguidade greco-latina à Europa Moderna (HUVELIN, 1897). Na mesma linha de pesquisas, mantendo também um amplo viés comparativo, ele já havia escrito até então nove verbetes sobre a história das práticas comerciais e legais para o DAGR, dedicando-se sobretudo à Grécia Antiga. Sua escolha como colaborador pontual do $\mathrm{BCH}$ era, portanto, bastante natural.

O texto publicado intitula-se Fouilles de Délos exécutées aux frais de M. Le Duc de Loubat (1905): inscriptions, loi réglant la vente du bois et du charbon à Délos e ele é subdividido em seis partes (BCH, 1907: 46-93). Na primeira delas, trata-se de apresentar a transcrição e a tradução da inscrição antiga. A segunda parte, por sua vez, investe na datação da peça, o que é feito a partir do cruzamento de dados relativos ao seu vocabulário, à história do sítio arqueológico onde foi encontrada e ao estilo ou grafia de certas letras nela utilizadas. As três partes seguintes discutem o significado e as implicações econômico-sociais da lei, atentando para suas divisões internas (diretos comerciais e as penas previstas em casos de infração). Por fim, os autores propõem um balanço do valor documental do objeto. Tendo em vista a natureza de cada uma dessas discussões, é muito provável que Schulhof tenha se ocupado das duas partes iniciais do texto, deixando assim a Huvelin as discussões propriamente jurídicas.

Chama atenção nas derradeiras partes do artigo as intuições sociólogicas que os guiam. Por exemplo, em se tratando do único decreto completo à época conhecido regulando práticas comerciais envolvendo carvão e madeira, Huvelin explora-o a partir de um viés comparativo. A raridade desse tipo de documentação foi então compensada por outros suportes documentais gregos (textos de Platão e Ateneu), bem como por legislações

\footnotetext{
${ }^{24}$ A citação ocorre em BCH, 1913:312. Roussel grafou, contudo, o nome de Lévy de forma errada (que aparece como "Léwy"), bem como errou o número da página à qual seu texto faz alusão (no artigo está escrito " 281 , note 11 ", quando o correto seria " 286 , note 11 "). Quanto ao texto de Lévy em questão, cf. RHR, 1909: 285-298.
} 
provenientes de outras experiências societárias (o direito comercial romano ou aquele proveniente do medievo europeu). Huvelin busca assim mostrar como não há nada na lei antiga que sugira medidas protecionistas do estado. O que estava em questão ali era basicamente o direito dos consumidores ou, em outros termos, o preço justo para os consumidores. A legislação de Délos, em consonância com o que se conhecia das experiências no Mediterrâneo e do Ocidente Medieval, obrigava os importadores a utilizar as balanças públicas, forçando igualmente a fixação prévia dos preços antes da venda e a venda direta das mercadorias, sem intermediários. Tais medidas impediam assim que o comerciante pudesse gerar especulações a partir de seus produtos. Para Huvelin, esse conjunto de práticas traduziria "ideias que eram correntes na Grécia, como em todos os meios dificilmente separáveis da economia agrícola". Ele ainda discute certos privilégios para comerciantes capazes de se fazer representar legalmente na ilha, bem como as diferentes medidas punitivas em caso de violação das leis.

Finda a discussão sobre a atuação dos sociólogos durkheimianos no $\mathrm{BCH}$, resta ainda fazer um balanço provisório do diálogo que eles aí estabeleceram. Ora, sua presença direta e indireta na revista da EFA, ainda que pequena, é um excelente termômetro para se medir o sucesso relativo da sociologia na universidade francesa quando aos modernismos então em voga no campo de helenismo. Não é de se estranhar que o $\mathrm{BCH}$, voltado prioritariamente para a divulgação de material arqueológico e epigráfico original, bem como ao treinamento de jovens helenistas, tenha cedido espaço para teorias mais gerais acerca do funcionamento das práticas religiosas e jurídicas provenientes da equipe do AS. Afinal, ele foi um dos primeiros periódicos ao mesmo tempo científicos e ligados ao sistema de ensino, o que não lhe permitia negligenciar totalmente o que se produzia de novo na universidade.

Do mesmo modo, é bastante compreensível que certos sociólogos durkheimianos tenham compreendido as benesses de se frequentar um espaço tão reputado e tradicional como o da EFA e de contribuir com seu boletim. Como o público interessado pela nova documentação aí periodicamente publicada era grande dentro e fora da França, tratava-se de uma vitrine interessante. 


\section{$2.2-O S$}

\section{MÉLANGES}

\section{D'ARCHÉOLOGIE}

ET D'HISTOIRE

\begin{abstract}
"Assim se esvaía muito rápido, rápido demais, nossos trabalhos e nossos dias: jovens arqueólogos ocupados com suas eruditas memórias e escavações, nas quais eles aprendiam na prática as difíceis técnicas, medievalistas atrelados cada um a um registro pontifical sem prejudicar seus trabalhos pessoais, historiadores do humanismo e dos tempos modernos, todos colaboradores privilegiados dos Mélanges (cuja reputação estava nessa época já solidamente estabelecida), nós nos esforçávamos para nos tornarmos dignos de nossos predecessores, os Jullian, os Nolhac, os Diehl, os Gsell, os Prou e os Bertaux, sem esquecer o próprio abade Duchesne, que desde o início nos mostrou o caminho".
\end{abstract}

Charles Samaran

(SAMARAN, 1979: 135-136)

Com o lançamento do primeiro número do periódico Mélanges d’Archéologie et d'Histoire (MAH) em 1881, pode-se finalmente falar em um campo de publicações universitárias especializadas nos estudos da Antiguidade greco-romana. Embora o latim e o grego representassem, ao lado do francês, as línguas dominantes no ensino secundário, havia entre elas, ao menos desde o início do século XIX, uma clara assimetria: esta língua ocupava aí um espaço muito menor que aquela ${ }^{1}$. Os estudos latinos, além de representar o catolicismo francês, funcionavam tal qual uma "barreira", como diria Edmond Goblot, no tocante aos processos seletivos ligados às profissões liberais e à alta burocracia estatal. Não obstante, quando considerado o ensino universitário e a pesquisa científica, foram os estudos gregos que saíram na frente na segunda metade do século XIX, modernizando seus quadros e fundindo o ensino literário de então às perspectivas científicas advindas de outras disciplinas (a arqueologia, a epigrafia e assim por diante). O aparecimento dos MAH aponta, em conformidade com a tendência reformista da Terceira República, para a primeira tentativa de realizar uma similar profissionalização no campo dos latinistas. A tarefa não era nada fácil e várias tradições nacionais, tanto religiosas quanto laicas, colaboraram para imprimir a ela características singulares. Tais particularidades foram assim expressão de tensões e de afinidades eletivas antes existentes, mas também produtoras de novas modalidades de relações.

Colado ao exemplo do $\mathrm{BCH}$, os $\mathrm{MAH}$ foram criados no seio de uma escola de especialização francesa situada no exterior, a École Française de Rome (EFR). Fundada apenas

\footnotetext{
${ }^{1}$ Cf., sobre a predominância histórica do latim sobre o grego, WAQUET, 1998: 17-31.
} 
em 1873, tal instituição seguiu os paços de sua "irmã mais velha", a EFA, unindo demandas próprias ao sistema de ensino francês com a produção de cientistas de ponta, no presente caso, latinistas, medievalistas e historiadores da Europa pós-Renascimento. Os MAH se apresentaram como o braço impresso da nova escola, atuando na divulgação de documentação inédita, bem como no auxílio à formação de especialistas.

O objetivo do presente subcapítulo é apresentar a EFR e sua revista, mostrando se e como elas acolheram os trabalhos advindos da escola sociológica francesa.

\section{A ÉCOLE FRANÇAISE DE ROME}

Desde a segunda metade do século XVII, quando foi fundada a Académie de France à Rome, a corte dos Bourbons tinha por hábito enviar a cada ano artistas e técnicos para estadas que variavam de seis a dezoito meses na Itália. Já estava em questão o estudo metódico do classicismo, sobretudo no que dizia respeito à escultura e à arquitetura antigas. Ainda assim, teve-se de esperar até 1829 para que o primeiro ancestral direto da EFR aí aparecesse. Diante dos progressos da arqueologia nas primeiras décadas do século XIX e da vitalidade de suas universidades, a Prússia liderou um esforço internacional para fundar em Roma o Instituto di Corrispondenza Archeologica, cuja sede encontrou um espaço altamente prestigioso junto ao Capitólio. Os sucessivos regimes de governo franceses, tenham sido eles monarquias, repúblicas ou impérios, aderiram à iniciativa, enviando para estágios ou missões pontuais na referida instituição estudiosos das antiguidades greco-latinas.

Com a intensificação das tensões internacionais na década de 1860, planos envolvendo a fundação de uma instituição totalmente nacional dedicada à arqueologia começaram a ganhar força ainda durante o Segundo Império. A derrota para a Prússia em 1870 e a germanização do Instituto di Corrispondenza Archeologica, o qual passou a se chamar Deutsches Archäologisches Institut, acabou tornando imperativo o projeto. Para viabilizar a iniciativa, o governo da Terceira República se escorou então na École Française d'Athènes, a qual não apenas serviu de modelo para a EFR, como também lhe emprestou grande parte de seus primeiros quadros e recursos.

Um decreto assinado em 25 de março de 1873 instituiu, sob a direção do helenista Albert Dumont, a Section Romaine de l'École Française d'Athènes, abrigada junto ao Palácio Farnèse, o mesmo edifício onde se localizava a embaixada da França na Itália. Composta apenas por dois "membros livres" em seu primeiro ano, Louis Duchesne e Eugène Müntz, tal instituição tinha por objetivo principal acolher os "atenienses" para um período de aclimatação ao clima mediterrânico, além de lhes proporcionar um primeiro contato prático 
com a arqueologia. Ela também permitia àqueles que desejassem se dedicar aos estudos latinos permanecerem mais tempo no local antes de partir a Atenas².

Mas a missão de Dumont não consistia somente em instalar uma simples antena da EFA na Península Itálica. A curto prazo, tratava-se mesmo de fundar uma escola arqueológica independente. Os decretos de 26 de novembro e 28 de dezembro de 1874 deram mais um passo nessa direção: além de nomear dois outros "membros livres", Léon Clédat e Berthold Zeller, eles a tornaram uma instituição nominalmente autônoma. A Section Romaine de l'École Française d'Athènes passou assim a se chamar École Archéologique de Rome, tendo ainda por diretor o helenista Albert Dumont. Por fim, após mais um ano de atividades preparatórias reformas nas instalações, acordos com as autoridades italianas e eclesiásticas, entre outras -, a instituição ganhou o mesmo estatuto que a EFA. Surgiu assim, em 20 de novembro de 1875, a École Française de Rome, agora dirigida por Auguste Geffroy, um pesquisador mais afinado com os estudos latinos.

Tal mudança de estatuto implicou uma transformação na morfologia da escola. A partir desse momento, ao lado dos poucos "membros livres" já atuantes, passaram a ser nomeados a cada ano "membros efetivos", os quais poderiam permanecer em Roma entre um e quatro anos como funcionários-pesquisadores do governo francês. Para se tornar um "romano", o processo seletivo era muito semelhante ao praticado no interior da EFA. O fundamental era obter um bom resultado no exame de agrégation, sendo igualmente necessários um curriculum alentado e cartas de recomendações de expoentes das áreas contempladas na escola. Não parecem ter existido, contudo, testes seletivos especiais, muito provavelmente em função do amplo leque de recrutamento da EFR. De fato, em contraposição ao que ocorria em Atenas, a nova escola não recebia apenas antiquisants, mas também jovens pesquisadores interessados em estudar a história medieval e moderna da Europa, em geral provenientes da École Normale Supérieure (ENS), da École des Chartes e/ou da École Pratique des Hautes Études (EPHE).

A definição desse escopo de interesses esteve ligada a circunstâncias políticas e infraestruturais que marcaram a fundação da escola. O governo francês e a Igreja Católica haviam mantido uma relação de proximidade ao longo do Segundo Império. Não se pode esquecer que, nesse ínterim, Napoleão III havia enviado tropas para proteger os territórios papais

\footnotetext{
${ }^{2}$ A situação do "ateniense" Gustave Bloch é paradigmática quanto a isso. Nascido no seio de uma família judaica em Estrasburgo, filho de um professor primário, Bloch passou em primeiro lugar no exame de admissão da École Normale Supérieure (1868), obtendo também o primeiro lugar na agrégation de lettres, três anos mais tarde. Sua carreira de sucesso, iniciada na EFA, o levou na sequência das universidades provinciais para a Sorbonne, onde ocupou a cadeira intitulada Histoire Romaine a partir de 1904. Bloch também foi um ativista pró-Dreyfus na virada dos séculos XIX e XX.
} 
ameaçados por partidários da unificação da Itália. Novamente aqui a guerra contra a Prússia teve um papel fundamental, pois, na eminência da derrota francesa, todos esses soldados tiveram de ser retirados às pressas. Aproveitando-se a ocasião, os nacionalistas italianos finalmente anexaram o centro-oeste da Itália, confiscando os domínios da Igreja e dando início ao que o papa Pio IX chamou de o "cativeiro do Vaticano". Em decorrência desse conjunto de episódios, cujas implicações negativas aos olhos dos italianos foram ainda intensificadas pela corrida colonialista das velhas e novas potências europeias ao norte da África, as relações diplomáticas entre França e Itália foram inauguradas em um clima particularmente tenso. A carta que Camille Jullian, integrante da sexta promoção da escola, escreveu à família em 6 de maio de 1881 faz menção ao clima de hostilidade que ele encontrou ao chegar a Roma:

\footnotetext{
Vocês devem entender que a questão de Túnis nos apaixona, que esses rumores de guerra, de conquista, de vitória nos entusiasmam. Sente-se patriota quando se vive, como nós, longe da pátria e em meio a uma população estrangeira e hostil! Todos os nossos desejos, todos os nossos votos são para a entrada imediata das tropas francesas em Túnis. Se os que nos governam soubessem como nós somos julgados e amados aqui, eles se apressariam em aproveitar, com um golpe de mestre, da ocasião que nos é oferecida pela impotência atual dos italianos (JULLIAN, 1936: 120).
}

As consequências práticas disso para a EFR foram duas. Por um lado, graças à criação de uma legislação italiana rígida quanto ao patrimônio histórico e arqueológico nacional, os franceses viram o trabalho junto aos grandes e médios sítios ser dificultado; por outro, os canais existentes com as autoridades católicas favoreceram o acesso a um acervo bibliográfico e documental único, a Biblioteca do Vaticano. Não por acaso, como também testemunham as cartas de Jullian, boa parte das atividades dos primeiros membros antiquisants da escola consistia em longos períodos de estudos nessa e em outras bibliotecas, pontuados por uma ou outra ida a campo. Considerando esse cenário particular, as autoridades políticas e universitárias francesas optaram por enviar, ao lado de pretendentes a arqueólogos, arquivistas-historiadores provenientes de outras instituições (as já mencionadas École des Chartes e a EPHE). Além disso, visando contornar a escassez de terrenos disponíveis à arqueologia, elas patrocinaram, sob os auspícios da EFR, a abertura de novas frentes de escavações no Norte da África, as quais consumiram a partir de meados da década de 1880 boa parte dos antiquisants da escola.

A complexidade das circunstâncias tornava ainda mais estratégica a figura do diretor da instituição. Afinal, ele tinha de conciliar o treinamento científico de seus subordinados com a atuação diplomática junto aos representantes dos governos do Vaticano e da Itália. Compreende-se assim melhor a nomeação de Auguste Geffroy. Com efeito, sem ser 
exatamente um especialista em Roma Antiga, ele conjugava uma profunda fé católica, bemvinda aos olhos da Igreja, com um declarado amor patriótico, crucial para um regime que acabara de se instalar mediante uma derrota militar.

Nascido na Paris de 1820 no seio de uma família ligada ao exército e ao comércio, Geffroy teve à sua disposição a melhor educação literária da época. Em 1840, ingressou na École Normale Supérieure, da qual saiu agrégé d'histoire et géographie em 1845. Os sete primeiros anos de sua carreira, em meio aos quais se doutorou com uma tese sobre Milton (1848), foram marcados por sua atuação em diversos liceus provinciais (Dijon e ClermontFerrant) e parisienses (Louis-le-Grand). Seguiram-se sua nomeação como chargé de cours d'histoire e, depois, professor na Faculdade de Letras de Bordeaux, bem como sucessivas missões aos países escandinavos, sobre os quais ele publicou várias obras ao longo dos anos 1850. A ida a Paris se deu uma década mais tarde, sucessivamente como professor na ENS (1862) e na Sorbonne (1864). Sua primeira grande obra sobre a Antiguidade, um estudo sobre as relações entre os romanos e os bárbaros a partir da obra de Tácito, data de 1874, mesmo ano em que foi eleito membro não da Académie des Inscriptions et Belles-Lettres, baluarte dos estudos arqueológicos e greco-latinos, mas sim da Académie des Sciences Morales et Politique. Em 1875, ele foi nomeado diretor da EFR, cargo que manteve até fins de 1882, vindo ainda a ocupar a mesma função entre 1888 e 1895. Diante desse background, seu papel na EFR foi

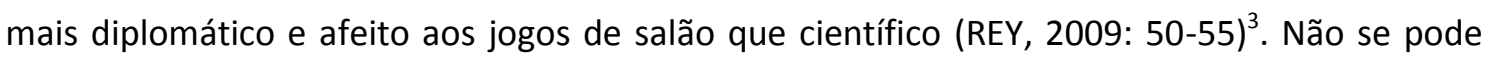
esquecer, porém, que o contexto tornava esta atividade dependente daquelas.

No tocante às suas realizações, a principal herança da gestão de Geffroy foi a criação, seguindo o exemplo vindo de Atenas, de uma revista voltada à divulgação das atividades científicas da escola. Administrada por ele apenas em seus dois primeiros números, os MAH se mantiveram como a única revista que privilegiou os estudos sobre Roma Antiga até a década de 1920. Antes de discutir o perfil dos colaboradores da publicação e o perfil de seus diretores, é salutar compreender sua estrutura interna e periodicidade.

\section{A estrutura dos MAH}

Publicado regularmente pela EFR a partir de 1881, os Mélanges d'Archéologie et d'Histoire (MAH) foram editados ao mesmo tempo em Roma e em Paris. Do lado francês, a tarefa coube à mesma editora responsável pelo $\mathrm{BCH}$, a Ernest Thorin (mais tarde renomeada

\footnotetext{
${ }^{3}$ Veja-se também o necrológio de Geffroy assinado por Louis Duchesne, seu sucessor na escola em MAH, 1895: 141-153.
} 
Fontemoing \& (ie). Do lado italiano, o nome que aparecia nos volumes era o da editora Spithöver. Ambas também se ocupavam da difusão e da venda das revistas.

Se houve uma novidade significativa inaugurada pelos $M A H$, esta dizia respeito à sua periodicidade. Para dinamizar a circulação de sua revista, a EFR optou por publicar, ao lado de um volume anual, pequenos fascículos antecipando seus conteúdos. Ainda assim, como as bibliotecas atuais não conservaram a revista sob esse formato e como não há nada dentro dela que explicite o intervalo no qual eles vinham a público, é necessário fazer suposições a partir de outros dados. Além de uma breve nota que anuncia a existência desses fascículos no $\mathrm{BCH}$ (1881: 328), um forte indício se encontra no próprio arranjo de artigos e resenhas apresentado no sumário de cada volume anual, o qual sugere a existência de três ou quatro blocos independentes de texto. Tratar-se-ia, portanto, de uma publicação tri ou quadrimestral. Dentro do intervalo aqui privilegiado, 1881-1920, os únicos episódios constatados de mudança de periodicidade coincidiram com o esvaziamento da escola durante a Primeira Guerra Mundial. Com praticamente todos os seus "membros efetivos" mobilizados entre 1916 e 1919, a EFR transformou então sua revista em uma publicação bianual, retomando o antigo formado na sequência, em 1920.

Em termos de estrutura interna, no entanto, o referido periódico manteve o que havia de mais simples no $\mathrm{BCH}$ : seu sumário faz apenas a distinção entre artigos, resenhas (cuja presença não era constante) e necrológios (de antigos membros da EFR ou, algo mais raro, de personalidades próximas a ela). Note-se ainda que nem tudo do $\mathrm{BCH}$ foi preservado: é o caso, em especial, do complexo índice temático que dinamizava a leitura desse periódico. Isso se deveu, em parte, ao leque mais amplo dos temas tratados nos MAH, não apenas ligados ao estudo de Roma Antiga ${ }^{4}$. Mas é também certo que isso tenha se dado em função da incapacidade técnica e diplomática da instituição de apresentar a mesma diversidade de materiais originais que sua irmã ateniense. A única inovação perceptível quanto ao material impresso teve, aliás, um fundo corporativo, pois cada volume anual trazia arrolados o nome de todos os membros atuais e antigos da escola, dando ênfase às posições institucionais ocupadas pelos últimos.

\section{EDMOND LE BLANT E LOUIS DUCHESNE}

Os limites técnicos e diplomáticos que nortearam a atividade científica impressa nas páginas dos MAH remetem mais uma vez às atuações dos diretores da publicação, justamente os profissionais responsáveis por guiar a formação e o trabalho dos membros da EFR. Já se

\footnotetext{
${ }^{4}$ A separação entre os antiquisants, os medievalistas e os historiadores dos tempos modernos só ocorreu próximo ao centenário da escola, em 1975.
} 
evocou aqui o fato de Auguste Geffroy ter tido uma formação literária, ligada apenas de forma marginal aos estudos latinos. Evocou-se ainda sua posição de católico convicto e as benesses que isso trouxe nas negociações da escola para obter acesso aos acervos sob o controle do Vaticano, em especial sua biblioteca.

Ora, a despeito do sucesso "diplomático" de Geffroy e de seu patriotismo, sua posição em Roma foi se tornando cada vez mais insustentável aos olhos dos políticos franceses. A consolidação do novo regime republicano ao longo da década de $1880 \mathrm{se}$ fez, entre outras coisas, em favor da modernização das universidades, uma modernização que reclamava não só os rigores da ciência, como também a luta contra as ingerências da Igreja Católica na educação. Em suma, almejava-se construir um sistema de ensino laico e capaz de produzir conhecimentos científicos originais (MAYEUR, 2004: 581-635). Alguém como Geffroy, nesse contexto, tinha tudo para parecer suspeito, seja por sua fé, seja por sua formação.

A solução encontrada para tal impasse veio por meio de um decreto assinado no dia 26 de dezembro de 1882, o qual substituiu Geffroy por Edmond Le Blant. Nascido no seio de uma família católica parisiense em 1818 e jurista de formação, o segundo diretor da EFR havia se tornado um especialista em epigrafia e arqueologia latina sem passar pela universidade. Bastante familiarizado com o latim desde seus tempos de escola, ele iniciou sua atividade erudita em paralelo às funções que desempenhava como advogado e como funcionário do Ministério das Finanças, ainda na década de 1840. Ao longo dos próximos trinta anos, aproveitando todo seu tempo livre em viagens de prospecção e assistindo cursos na Sorbonne, ele foi conquistando o reconhecimento dos colegas. André Pératé, no necrológio de Le Blant escrito para a Revue Archéologique (RA, 1897/2:1-7), esclarece dois pontos centrais de sua trajetória ${ }^{5}$. O primeiro deles diz respeito aos vínculos criados entre o latinista francês e o mais renomado arqueólogo italiano do século XIX, Giovanni Battista de Rossi. Ambos travaram contato pela primeira vez em fins da década de 1840 e este inspirou aquele quanto aos seus temas de predileção: as antiguidades dos primeiros tempos do cristianismo. Privilegiando a região da antiga Gália romana, dos séculos IV ao VIII d.C., Le Blant produziu os primeiros grandes catálogos de inscrições e sarcófagos cristãos publicados na França. O segundo ponto esclarecedor que o necrológio escrito por Pératé traz à tona é o viés polêmico desses trabalhos: mesmo sendo católico convicto, Le Blant desafiou a Igreja Católica em seu próprio terreno, mostrando inúmeras continuidades pagãs nos resquícios da nova religião, bem como uma história heterodoxa de sua penetração no atual território francês. Sua obra letrada foi coroada em 1867, quando ocorreu sua eleição para membro efetivo da Académie des

\footnotetext{
${ }^{5}$ Veja-se também o necrológio publicado por Héron de Villefosse em MAH, 1897: 492-502.
} 
Inscriptions et Belles-Lettres. Tendo, portanto, a experiência de terreno no campo de atuação da EFR, gozando do reconhecimento dos pares e mantendo uma postura crítica/independente da história oficial da Igreja Católica, Le Blant parecia cumprir todos os requisitos para cumprir as atribuições de diretor da EFR, seu primeiro cargo permanente no sistema de ensino francês.

Sua permanência em Roma foi, no entanto, breve. Em fins de 1888, totalizando pouco menos de seis anos à frente da escola, ele teve de ser substituído em função de um duplo fracasso, político e científico. Habituado ao trabalho individual e sem o hábito docente necessário à posição de diretor, Le Blant falhou no campo da diplomacia ao não conseguir expandir os espaços abertos às atividades dos "romanos". No campo científico, os problemas vieram de seu conhecimento reduzido do solo italiano, uma vez que sua atuação havia se dado até então exclusivamente na Gália romana. André Pératé, comentando sobre o período em que Le Blant permaneceu em Roma, sentenciou: "ele permaneceu lá como um erudito em alguma medida solitário e sem dúvida ele se equivocou ao forçar sua natureza" (RA, 1897: 5. Itálico não consta no original). Diante de um tal cenário, Auguste Geffroy foi reconvocado para assumir a escola por mais seis anos e meio, de dezembro de 1888 a fevereiro de 1895 . Mas situação só se alterou sensivelmente quando Louis Duchesne recebeu o convite do governo francês para assumir a posição de Geoffroy, o que ele fez ininterruptamente até 1922. Tratase, portanto, do diretor mais longevo e mais importante para o período que interessa à presente tese. Mas quem foi ele e que novidades trouxe para a EFR e para os MAH?

Nascido em 1843, Louis Duchesne compartilhava com Geffroy e Le Blant a fé católica, mas se distinguia deles na forma como a vivia, uma vez que pertencia aos quadros letrados da própria Igreja ${ }^{6}$. Criado com mais cinco irmãos no seio de uma família humilde de província, órfão de pai (pescador) desde muito cedo, ele iniciou seus estudos no colégio local (SaintCharles), completando-os no seminário de Saint-Brieuc. Afim de aprimorar seus estudos, Duchesne seguiu para Roma entre 1864 e 1865. No Colegio Romano travou contato com alguns dos expoentes da história e da arqueologia dos primórdios do cristianismo, tais como o já mencionado De Rossi e o abade d'Hulst. Ordenado padre pela diocese de Rennes em 1867 e tomado de entusiasmo pela possibilidade de se associar a esses estudos, ele se inscreveu quatro anos mais tarde nos cursos de epigrafia e de paleografia antigas na EPHE. Os contatos aí nutridos com os especialistas franceses no tema lhe renderam a nomeação como "membro livre" da Section Romaine de l'École Française d'Athènes em 1873.

Louis Duchesne viu a EFR nascer de dentro. Ele aí permaneceu por três anos, participando não apenas de escavações e trabalhos em bibliotecas na Península Itálica, mas

\footnotetext{
${ }^{6}$ Há uma extensa biografia sobre Louis Duchesne. Para maiores detalhes sobre sua trajetória, veja-se, em especial, WACHÉ, 1992.
} 
também acompanhando "membros efetivos" da École Française d'Athènes, e em particular o arqueólogo Maxime Collignon, em uma série de escavações na Ásia Menor ${ }^{7}$. O período no exterior foi também utilizado para a preparação de sua tese, Étude sur le Liber Pontificalis, defendida logo na sequência, em 1877. A boa acolhida desse trabalho nos meios universitários Ihe garantiu postos tanto na EPHE, primeiro como maître de conférence e mais tarde como directeur d'études, quanto no Institut Catholique. Outro indício desse sucesso veio da eleição para o posto de membro efetivo da Académie des Inscriptions et Belles-Lettres em 1888.

Pode-se assim dizer que a própria trajetória intelectual de Duchesne, a qual soube combinar com rara felicidade a inserção no seio da Igreja Apostólica Romana com o reconhecimento dos integrantes da universidade laica, dentro e fora da França, fornece a chave explicativa para sua nomeação e longevidade à frente da EFR. Uma vez lá, ele modernizou o contato com a arqueologia dos "romanos" antiquisants e aprofundou os acervos documentais visitados pelo conjunto de membros da instituição ${ }^{8}$. Outra marca importante de sua gestão, como será visto posteriormente, foi a transformação dos MAH em um veículo de divulgação de trabalhos sobre a história institucional da Igreja Católica.

Mas tudo isso não implicou, bem entendido, a ausência de dificuldades ao longo de seus anos como diretor da escola. O episódio mais significativo nesse sentido é a crise "modernista" de inícios do século XX. Diante da radicalização das posições entre os republicanos franceses e as autoridades eclesiásticas, culminando com a lei de separação do Estado e da Igreja que passou a ter vigência em 1906, Duchesne encontrou-se em uma posição delicada, buscando pregar uma fé devidamente esclarecida e orientada pela ciência. Seus ensinamentos pouco ortodoxos, nos quais se defendia a origem não apostólica das igrejas gaulesas, foram proibidos no Institut Catholique. Um de seus alunos e amigos, Alfred Loisy, foi excomungado 9 . Além disso, sua tese foi ameaçada de ir para o Index, obrigando o autor a incorporar modificações nas futuras edições (CHOLVY; HILAIRE: 151-159).

Cedendo às demandas da Igreja, Duchesne conseguiu manter essa sua estratégica posição entre vários mundos. Aos olhos dos membros da escola, como testemunha Charles Samaran, ele era o "melhor historiador francês dos primeiros séculos da Igreja, o que the valeu um renome internacional" (SAMARAN, 1979: 125). Para Salomon Reinach, o rigor científico de

\footnotetext{
${ }^{7}$ São testemunhos desse período uma série de artigos que Duchesne publicou no periódico da EFA. Cf. BCH, 1877: 332-337 e 361-376 (com Collignon); 1878: 289-299; 1879: 144-146 e 478-482; 1880: 195205; 1881: 316-318; 1883: 230-246; 1887: 311-317.

${ }^{8}$ Veja-se REY, 2009: 50-55. Duchesne também envolveu outros autores de destaque nos estudos sobre o mundo antigo na orientação do trabalho de seus pupilos. É o que testemunham as cartas entre ele e De Rossi (SAINT-ROCH, 1995).

${ }^{9}$ Sobre Alfred Loisy, veja-se o subcapítulo 3.1 da presente tese, na qual se discute sua eleição ao Collège de France.
} 
Duchesne era o que mais se destacava: "o gabinete de trabalho de Duchesne no palácio Farnese era adornado de dois grandes retratos, o de Erasmo e o de Mommsen. Na história da erudição, ele terá seu lugar não longe desses dois gigantes, e também bem próximo de seu par J.-B. de Rossi, do qual ele escreveu um dia: 'é a ele que eu devo minha vocação científica, seus escritos me salvaram'” (RA, 1922/2: 158-176).

Uma vez discutido o perfil dos três diretores da EFR - Geffroy, Le Blant e Duchesne -, é chegado o momento de abordar a morfologia da revista editada por essa instituição. Afinal, quais grupos tinham acesso a ela? E há mais: existiram variações sensíveis na intensidade de suas contribuições ao longo dos anos?

\section{PADRÕES DE RECRUTAMENTO}

O padrão de recrutamento constatado nos Mélanges d'Archéologie et d'Histoire lembra muito, em suas linhas mais gerais, aquele já apresentado no contexto do BCH. Nos dois casos, três grupos podem ser aí identificados: os "romanos", ou seja, os atuais e antigos membros da EFR; os professores/pesquisadores franceses sem vínculos anteriores com a instituição; e, por fim, os estrangeiros. Diferenças significativas saltam aos olhos, contudo, ao se discorrer sobre as especificidades de cada um deles.

Os "romanos", tal como os "atenienses" no BCH, constituíram o epicentro dos MAH (veja-se as tabelas 2.2.1, 2.2.2, 2.2.3 e 2.2.4). Apenas em dois anos, 1891 e 1915, tal grupo não representou ao menos metade de todos os colaboradores da revista. Mas aqui, essa categoria se apresentava de forma ligeiramente diferente. Em primeiro lugar, não existiram "membros estrangeiros" na EFR durante todo o período aqui estudado, assim como os "membros livres" tiveram apenas existência nos primeiros anos da escola, o que não lhes permitiu deixar marcas na revista. Além disso, contrastando com o padrão encontrado no $\mathrm{BCH}$, aqui foram os "membros efetivos" que constituíram o subgrupo mais representativo. Eles aí publicaram seus primeiros trabalhos científicos, em geral edições críticas de documentos impressos inéditos encontrados na Biblioteca do Vaticano ou em outros arquivos, bem como relatórios de escavações e análises de objetos provenientes de museus e das demais escolas de arqueologia internacionais instaladas em Roma. Ora, o predomínio inicial dos "membros efetivos" é bastante natural, uma vez que a escola era relativamente recente e que não havia muitos "antigos membros" a serem acionados ao longo da década de 1880. O curioso é constatar que o número desses ex-membros não aumentou com o passar do tempo. Ele teve apenas um pico que coincidiu com a segunda direção de Geffroy (1888-1895), mantendo-se geralmente abaixo do percentual de contribuições dos "membros efetivos". 
Quadro 2.2.1 - Padrões de recrutamento - autores de artigos (MAH, 1881-1887) ${ }^{10}$.

\begin{tabular}{|c|c|c|c|c|c|c|c|}
\hline VÍNCULO INSTITUCIONAL DOS AUTORES (articles de fonds)/ANO & 1881 & 1882 & 1883 & 1884 & 1885 & 1886 & 1887 \\
\hline Membro efetivo da EFR (incluindo diretor) & $66,67 \%$ & $29,41 \%$ & $66,67 \%$ & $58,33 \%$ & $40 \%$ & $35 \%$ & $43,75 \%$ \\
\hline Membro livre da EFR & $0 \%$ & $0 \%$ & $0 \%$ & $0 \%$ & $0 \%$ & $0 \%$ & $0 \%$ \\
\hline Professor/pesquisador antigo membro da EFR & $25 \%$ & $37,5 \%$ & $33,33 \%$ & $41,66 \%$ & $30 \%$ & $45 \%$ & $37,50 \%$ \\
\hline Professor/pesquisador sem vínculo anterior com a EFR & $8,33 \%$ & $11,76 \%$ & $0 \%$ & $0 \%$ & $5 \%$ & $10 \%$ & $12,50 \%$ \\
\hline Colaborador estrangeiro (Alemão) & $0 \%$ & $0 \%$ & $0 \%$ & $0 \%$ & $0 \%$ & $0 \%$ & $0 \%$ \\
\hline Colaborador estrangeiro (Britânico) & $0 \%$ & $5,88 \%$ & $0 \%$ & $0 \%$ & $0 \%$ & $0 \%$ & $0 \%$ \\
\hline Colaborador estrangeiro (Belga) & $0 \%$ & $0 \%$ & $0 \%$ & $0 \%$ & $0 \%$ & $0 \%$ & $0 \%$ \\
\hline Colaborador estrangeiro (Suíço) & $0 \%$ & $0 \%$ & $0 \%$ & $0 \%$ & $0 \%$ & $0 \%$ & $0 \%$ \\
\hline Colaborador estrangeiro (Italiano) & $0 \%$ & $11,76 \%$ & $0 \%$ & $0 \%$ & $10 \%$ & $0 \%$ & $0 \%$ \\
\hline Colaborador estrangeiro (Outro) & $0 \%$ & $0 \%$ & $0 \%$ & $0 \%$ & $0 \%$ & $0 \%$ & $0 \%$ \\
\hline Colaborador não identificado & $0 \%$ & $5,88 \%$ & $8,33 \%$ & $0 \%$ & $5 \%$ & $10 \%$ & $6,25 \%$ \\
\hline Total de colaboradores por ano $(\mathrm{N}=100 \%)$ & 12 & 17 & 12 & 12 & 20 & 20 & 16 \\
\hline
\end{tabular}

\footnotetext{
${ }^{10} \mathrm{Na}$ elaboração dos quadros 2.2.1 $2.2 .2,2.2 .3$ e 2.2.4 desconsiderou-se a quantidade de textos por colaborador. O método adotado consistiu em acompanhar, ano a ano, quem escrevia para os MAH e qual era então seu vínculo institucional. Se o vínculo para o ano em questão não pode ser recuperado, preferiu-se então incorporar o autor à categoria "não identificado".
} 
Quadro 2.2.2 - Padrões de recrutamento - autores de artigos (MAH, 1888-1898).

\begin{tabular}{|c|c|c|c|c|c|c|c|c|c|c|c|}
\hline $\begin{array}{l}\text { VÍNCULO INSTITUCIONAL DOS AUTORES (articles de } \\
\text { fonds)/ANO }\end{array}$ & 1888 & 1889 & 1890 & 1891 & 1892 & 1893 & 1894 & 1895 & 1896 & 1897 & 1898 \\
\hline Membro ffetivo da EFR (incluindo diretor) & $31,58 \%$ & $38,89 \%$ & $12,50 \%$ & $20 \%$ & $33,33 \%$ & $30,77 \%$ & $27,27 \%$ & $29,57 \%$ & $38,46 \%$ & $61,54 \%$ & $42,86 \%$ \\
\hline Membro livre da EFR & $0 \%$ & $0 \%$ & $0 \%$ & $0 \%$ & $0 \%$ & $0 \%$ & $0 \%$ & $0 \%$ & $0 \%$ & $0 \%$ & $0 \%$ \\
\hline Professor/pesquisador antigo membro da EFR & $42,10 \%$ & $33,33 \%$ & $62,50 \%$ & $26,67 \%$ & $50 \%$ & $38,46 \%$ & $55,56 \%$ & $42,86 \%$ & $38,46 \%$ & $30,77 \%$ & $35,71 \%$ \\
\hline Professor/pesquisador sem vínculo anterior com a EFR & $10,53 \%$ & $5,56 \%$ & $25 \%$ & $26,67 \%$ & $8,33 \%$ & $23,08 \%$ & $9,09 \%$ & $7,14 \%$ & $7,69 \%$ & $7,69 \%$ & $0 \%$ \\
\hline Colaborador estrangeiro (Alemão) & $0 \%$ & $5,56 \%$ & $0 \%$ & $0 \%$ & $0 \%$ & $7,69 \%$ & $0 \%$ & $0 \%$ & $0 \%$ & $0 \%$ & $0 \%$ \\
\hline Colaborador estrangeiro (Britânico) & $0 \%$ & $0 \%$ & $0 \%$ & $0 \%$ & $0 \%$ & $0 \%$ & $0 \%$ & $0 \%$ & $0 \%$ & $0 \%$ & $0 \%$ \\
\hline Colaborador estrangeiro (Belga) & $0 \%$ & $0 \%$ & $0 \%$ & $0 \%$ & $0 \%$ & $0 \%$ & $0 \%$ & $7,14 \%$ & $0 \%$ & $0 \%$ & $0 \%$ \\
\hline Colaborador estrangeiro (Suíço) & $0 \%$ & $0 \%$ & $0 \%$ & $0 \%$ & $0 \%$ & $0 \%$ & $0 \%$ & $0 \%$ & $0 \%$ & $0 \%$ & $0 \%$ \\
\hline Colaborador estrangeiro (Italiano) & $10,53 \%$ & $5,56 \%$ & $0 \%$ & $6,67 \%$ & $0 \%$ & $0 \%$ & $0 \%$ & $0 \%$ & $0 \%$ & $0 \%$ & $0 \%$ \\
\hline Colaborador estrangeiro (Outro) & $0 \%$ & $0 \%$ & $0 \%$ & $0 \%$ & $0 \%$ & $0 \%$ & $0 \%$ & $0 \%$ & $0 \%$ & $0 \%$ & $0 \%$ \\
\hline Colaborador não identificado & $5,26 \%$ & $11,11 \%$ & $0 \%$ & $20 \%$ & $8,33 \%$ & $0 \%$ & $9,09 \%$ & $14,29 \%$ & $15,38 \%$ & $0 \%$ & $21,43 \%$ \\
\hline Total de colaboradores por ano $(\mathrm{N}=100 \%)$ & 19 & 18 & 16 & 15 & 12 & 13 & 11 & 14 & 13 & 13 & 14 \\
\hline
\end{tabular}


Quadro 2.2.3 - Padrões de recrutamento - autores de artigos (MAH, 1899-1909).

\begin{tabular}{|c|c|c|c|c|c|c|c|c|c|c|c|}
\hline $\begin{array}{l}\text { VÍNCULO INSTITUCIONAL DOS AUTORES (articles de } \\
\text { fonds)/ANO }\end{array}$ & 1899 & 1900 & 1901 & 1902 & 1903 & 1904 & 1905 & 1906 & 1907 & 1908 & 1909 \\
\hline Membro efetivo da EFR (incluindo diretor) & $72,73 \%$ & $64,29 \%$ & $50 \%$ & $81,82 \%$ & $50 \%$ & $66,67 \%$ & $50 \%$ & $37,50 \%$ & $46,67 \%$ & $66,67 \%$ & $53,33 \%$ \\
\hline Membro livre da EFR & $0 \%$ & $0 \%$ & $0 \%$ & $0 \%$ & $0 \%$ & $0 \%$ & $0 \%$ & $0 \%$ & $0 \%$ & $0 \%$ & $0 \%$ \\
\hline Professor/pesquisador antigo membro da EFR & $18,18 \%$ & $21,43 \%$ & $33,34 \%$ & $18,18 \%$ & $30 \%$ & $16,67 \%$ & $14,29 \%$ & $25 \%$ & $26,67 \%$ & $8,33 \%$ & $13,33 \%$ \\
\hline Professor/pesquisador sem vínculo anterior com a EFR & $9,09 \%$ & $7,14 \%$ & $0 \%$ & $0 \%$ & $0 \%$ & $8,33 \%$ & $21,43 \%$ & $0 \%$ & $6,67 \%$ & $8,33 \%$ & $13,33 \%$ \\
\hline Colaborador estrangeiro (Alemão) & $0 \%$ & $0 \%$ & $0 \%$ & $0 \%$ & $0 \%$ & $0 \%$ & $0 \%$ & $0 \%$ & $0 \%$ & $0 \%$ & $0 \%$ \\
\hline Colaborador estrangeiro (Britânico) & $0 \%$ & $0 \%$ & $8,33 \%$ & $0 \%$ & $10 \%$ & $0 \%$ & $7,14 \%$ & $6,25 \%$ & $0 \%$ & $0 \%$ & $0 \%$ \\
\hline Colaborador estrangeiro (Belga) & $0 \%$ & $0 \%$ & $0 \%$ & $0 \%$ & $0 \%$ & $0 \%$ & $0 \%$ & $0 \%$ & $0 \%$ & $0 \%$ & $0 \%$ \\
\hline Colaborador estrangeiro (Suíço) & $0 \%$ & $0 \%$ & $0 \%$ & $0 \%$ & $0 \%$ & $0 \%$ & $0 \%$ & $0 \%$ & $0 \%$ & $0 \%$ & $0 \%$ \\
\hline Colaborador estrangeiro (Italiano) & $0 \%$ & $0 \%$ & $0 \%$ & $0 \%$ & $0 \%$ & $0 \%$ & $0 \%$ & $6,25 \%$ & $6,67 \%$ & $0 \%$ & $6,67 \%$ \\
\hline Colaborador estrangeiro (Outro) & $0 \%$ & $0 \%$ & $0 \%$ & $0 \%$ & $0 \%$ & $0 \%$ & $0 \%$ & $0 \%$ & $0 \%$ & $0 \%$ & $0 \%$ \\
\hline Colaborador não identificado & $0 \%$ & $7,14 \%$ & $8,33 \%$ & $0 \%$ & $10 \%$ & $8,33 \%$ & $7,14 \%$ & $25 \%$ & $13,33 \%$ & $16,67 \%$ & $13,33 \%$ \\
\hline Total de colaboradores por ano ( $\mathrm{N}=100 \%)$ & 11 & 14 & 12 & 11 & 10 & 12 & 14 & 16 & 15 & 12 & 15 \\
\hline
\end{tabular}


Quadro 2.2.4 - Padrões de recrutamento - autores de artigos (MAH, 1910-1920).

\begin{tabular}{|c|c|c|c|c|c|c|c|c|c|}
\hline $\begin{array}{l}\text { VÍNCULO INSTITUCIONAL DOS AUTORES (articles de } \\
\text { fonds)/ANO }\end{array}$ & 1910 & 1911 & 1912 & 1913 & 1914 & 1915 & $\begin{array}{c}1916 \\
1917^{11}\end{array}$ & $\begin{array}{l}1918 \\
1919\end{array}$ & 1920 \\
\hline Membro efetivo da EFR (incluindo diretor) & $61,54 \%$ & $43,75 \%$ & $66,67 \%$ & $63,64 \%$ & $66,67 \%$ & $44,44 \%$ & $33,33 \%$ & $30 \%$ & $60 \%$ \\
\hline Membro livre da EFR & $0 \%$ & $0 \%$ & $0 \%$ & $0 \%$ & $0 \%$ & $0 \%$ & $0 \%$ & $0 \%$ & $0 \%$ \\
\hline Professor/pesquisador antigo membro da EFR & $7,69 \%$ & $25 \%$ & $16,67 \%$ & $18,18 \%$ & $11,11 \%$ & $0 \%$ & $33,33 \%$ & $30 \%$ & $20 \%$ \\
\hline Professor/pesquisador sem vínculo anterior com a EFR & $7,69 \%$ & $6,25 \%$ & $16,67 \%$ & $0 \%$ & $0 \%$ & $0 \%$ & $0 \%$ & $0 \%$ & $0 \%$ \\
\hline Colaborador estrangeiro (Alemão) & $0 \%$ & $0 \%$ & $0 \%$ & $0 \%$ & $0 \%$ & $0 \%$ & $0 \%$ & $0 \%$ & $0 \%$ \\
\hline Colaborador estrangeiro (Britânico) & $0 \%$ & $0 \%$ & $0 \%$ & $0 \%$ & $0 \%$ & $0 \%$ & $0 \%$ & $0 \%$ & $0 \%$ \\
\hline Colaborador estrangeiro (Belga) & $0 \%$ & $0 \%$ & $0 \%$ & $0 \%$ & $0 \%$ & $11,11 \%$ & $0 \%$ & $10 \%$ & $0 \%$ \\
\hline Colaborador estrangeiro (Suíço) & $0 \%$ & $0 \%$ & $0 \%$ & $0 \%$ & $0 \%$ & $0 \%$ & $0 \%$ & $0 \%$ & $0 \%$ \\
\hline Colaborador estrangeiro (Italiano) & $15,38 \%$ & $0 \%$ & $0 \%$ & $0 \%$ & $22,22 \%$ & $22,22 \%$ & $33,33 \%$ & $10 \%$ & $20 \%$ \\
\hline Colaborador estrangeiro (Outro) & $0 \%$ & $0 \%$ & $0 \%$ & $0 \%$ & $0 \%$ & $0 \%$ & $0 \%$ & $0 \%$ & $0 \%$ \\
\hline Colaborador não identificado & $7,69 \%$ & $25 \%$ & $0 \%$ & $18,18 \%$ & $0 \%$ & $22,22 \%$ & $0 \%$ & $20 \%$ & $0 \%$ \\
\hline Total de colaboradores por ano ( $\mathrm{N}=100 \%)$ & 13 & 16 & 12 & 11 & 9 & 9 & 6 & 10 & 10 \\
\hline
\end{tabular}

\footnotetext{
${ }^{11}$ Entre 1916 e 1919, devido à escassez de seus membros e às dificuldades oriundas da guerra, os MAH tornam-se bianuais. Em 1920 , o antigo formato foi retomado.
} 
O segundo grupo, o dos franceses sem vínculos anteriores com a EFR, era formado sobretudo por especialistas em temas relacionados aos trabalhos da escola ${ }^{12}$. No caso dos antiquisants, por exemplo, Réné Cagnat, após sua eleição ao Collège de France, tratou de inscrições epigráficas oriundas do Norte da África ${ }^{13}$. O professor de arqueologia na Sorbonne e "ateniense" Maxime Collignon, por seu turno, apresentou aí suas conclusões sobre uma escultura antiga pertencente a um colecionador privado italiano ${ }^{14}$. Além dos especialistas no Mundo Antigo, estiveram também presentes nas páginas dos MAH arquivistas e juristas franceses, tais como Léopold Delisle, então administrador da Bibliothèque Nationale de France, ${ }^{15}$ e Adhémar Esmein, professor na EPHE e na Faculdade de Direito de Paris ${ }^{16}$. Ainda assim, o subgrupo mais atuante no período aqui priviegiado foi outro. Graças aos interesses e aos contatos de Louis Duchesne, estiveram aí presentes os especialistas na história do cristianismo primitivo e/ou simplesmente eruditos pertencentes à Igreja. Dentre eles, quem mais se sobressaiu foi Pierre Battiffol, escrevendo um total de cinco artigos de temáticas variadas para a revista da $\mathrm{EFR}^{17}$. Nascido na Toulouse de 1861, ele foi aluno de Duchesne em Paris, além de professor na EPHE (1885) e cofundador da Revue Biblique (1892) ${ }^{18}$.

Em terceiro e último lugar, o grupo dos pesquisadores estrangeiros era composto de indivíduos pertencentes tanto às demais escolas arqueológicas situadas em Roma como aos círculos dos diretores da escola. Em se tratando de um grupo bastante heterogêneo, destacaram-se nele os colaboradores italianos. Como ocorria com os gregos no $\mathrm{BCH}$, a revista da EFR reunia igualmente arqueólogos de maior ou menor renome, tais como Giovanni de Rossi, Orazio Marucchi, Rodolfo Lanciani, Giacommo Lumbroso e Pietro Fedele, bem como um jovem estudante de antropologia como Fábio Frasseto. Para além deles, contudo, a presença de outros estrangeiros é por demais ocasional. O único alemão identificado que colaborou com a revista da EFR foi Wolfgang Heilbig, helenista radicado em Roma. Do lado inglês, quem se destacou foi Thomas Ashby Junior, o qual assumiu em 1906 a direção da British School. Por fim, o único belga aí presente foi Franz Cumont, bem conhecido dos universitários e eruditos franceses, presente na EFR durante seu refúgio na Itália entre 1914-1918.

\footnotetext{
12 Os únicos casos que fogem à regra são o dos poucos membros da EFA, tais como Charles Avezou e Charles Picard, que escreveram aos MAH enquanto ainda estavam em Atenas. Em todo caso, o dado é interessante por marcar uma assimetria entre as duas instituições, pois nenhum membro da EFR teve a mesma oportunidade.

${ }^{13} \mathrm{MAH}, 1887:$ 258-267 e 1891: 314-322.

${ }^{14} \mathrm{MAH}, 1890: 118-122$.

${ }^{15} \mathrm{MAH}, 1884$ : 3-8; e 1886: 239-250.

${ }^{16} \mathrm{MAH}, 1885$ : 223-242; 1886: 416-428; e 1888: 426-436. Não deixa de ser interessante o fato de Esmein apenas colaborar com os MAH durante a gestão Le Blant, de quem ele era genro.

${ }^{17} \mathrm{MAH}, 1885$ : 358-376; 1887: 419-431; 1888: 297-308; 1889: 28-48; e 1890: 98-111.

${ }^{18}$ Veja-se seu necrológio assinado por Salomon Reinach em RA, 1929/1: 372-3.
} 
O conjunto de informações acima apresentado é interessante e sugestivo, sobretudo se comparado com aquele já extraído do $\mathrm{BCH}^{19}$. Ele atesta, afinal, que as duas revistas, MAH e $\mathrm{BCH}$, devem ser consideradas publicações de "jovens", de pesquisadores em formação ou em início de carreira. Isso não significa, bem entendido, a ausência de nomes consagrados. Ocorre apenas que a presença desses nomes é percentualmente pequena, servindo como indício do prestígio e dos círculos de sociabilidade da instituição responsável pela publicação das revistas. Chama atenção, contudo, a maior "juventude" da revista dos "romanos" frente à dos "atenienses". De fato, ela retirava o grosso de suas contribuições de seus próprios "membros efetivos". Atuaram na origem dessa tendência dois fatores diferentes, embora complementares. Em primeiro lugar, como já mencionado antes, o número de ex-membros era necessariamente menor na EFR que na EFA em função da recente fundação daquela escola. Em segundo lugar, isso sugere um prestígio científico menor quanto aos temas tratados por "romanos". No caso específico dos latinistas, em sua maioria oriundos da ENS ou da EPHE, eles se deparavam com um apoio institucional menor que o reservado aos helenistas. Não bastasse o intervalo temporal existente entre a criação da EFA e da EFR, não existia para eles algo análogo à Association pour l'Encouragement des Études Grecques en France, criada já em $1867^{20}$. Do mesmo modo, no plano universitário, os antiquisants "romanos" tinham de enfrentar a dura concorrência dos "atenienses", familiarizados com o ensino literário do latim e, como isso já não bastasse, formados segundo métodos científicos mais modernos (arqueologia e epigrafia) ${ }^{21}$.

Outro dado relevante, esse relativo à atuação de estrangeiros colaboradores na revista da EFR, reforça ainda mais a assimetria entre ela e $\mathrm{O} \mathrm{BCH}$. Trata-se de indício que deixa transparecer o quanto o grau de internacionalização dos MAH era então significativamente menor que o apresentado por sua homóloga ateniense. A raríssima presença de integrantes das outras duas maiores universidades europeias, a inglesa e a alemã, não deixa dúvidas quanto a isso. Do mesmo modo, a influência considerável que a universidade francesa exercia em determinados países, tais como a Bélgica e a Suíça, não se traduziu aqui em contribuições constantes. Por fim, a presença significativa dos italianos precisa também ser relativizada, pois, além de ser menor que a dos gregos no $\mathrm{BCH}$, esteve presa a um círculo muito restrito (De

\footnotetext{
${ }^{19}$ Veja-se o subcapítulo 2.1 da presente tese.

${ }^{20}$ Sobre a referida associação, veja-se o próximo capítulo da presente tese.

${ }^{21}$ Por outros motivos, a mesma situação vale para os integrantes da EFR que não eram latinistas, em especial aqueles oriundos da École des Chartes. Afinal, ligada ao estado francês como uma Grande École, tal instituição geralmente encaminhava seus ex-membros a uma carreira de administração de arquivos, onde a atividade científica vinha combinada a (e minimizada por) demandas burocráticas consideráveis.
} 
Rossi, seus alunos e colaboradores). E o que dizer da ausência de "membros estrangeiros" nos quadros da escola?

Longe de traduzir um isolamento da França no cenário intelectual europeu - porque se fosse esse o caso, uma tendência parecida teria sido constatada no contexto da EFA -, tal tendência aponta para o interesse estruturalmente menor das vanguardas científicas francesas quanto ao mundo latino, por demais associado ao catolicismo e a certas tradições retóricas nacionais. Esse mesmo conjunto de tensões e oposições foi vivido, ainda que de formas diferentes, em todas as grandes universidades de então (França, Alemanha, Inglaterra). Grosso modo, ele dependia tanto do maior ou menor peso da tradição revisionista protestante, um fator decisivo de impulso para a criação da filologia moderna, como da especificidade histórica da montagem de cada um dos sistemas de ensino (o peso institucional dos clássicos grecolatinos, o recrutamento dos alunos e dos professores, o acesso que esse sistema dava à burocracia estatal e às profissões liberais, entre outros) ${ }^{22}$.

Mas por que tal assimetria entre MAH e BCH deve ser aqui considerada? Ora, ela ajuda a compreender, ao menos em parte, o silêncio que aí foi reservado aos durkheimianos, mesmo quando alguns deles atuaram como "membros efetivos" da EFR. É dessa recepção, ou da ausência dela, que se tratará a seguir.

\section{A RECEPÇÃo dA SOCIOLOGIA NOS MÉLANGES D'ARCHÉOLOGIE ET D'HISTOIRE (1898-1920)}

A escola sociológica francesa encontrou aqui, tal como ocorreu nas páginas do $\mathrm{BCH}$, um espaço de ação reduzido. Em se tratando de uma revista visando o treinamento de futuros pesquisadores, nem todos antiquisants, grande parte de seus textos trazia a público edições de manuscritos inéditos, bem como apresentações de objetos e de inscrições epigráficas encontradas em escavações ou em acervos de museus/coleções locais. Por certo, tal ciência poderia se infiltrar em artigos mais alentados, de síntese, visando fornecer novas chaves analíticas para tratar de um ou outro tema relacionado aos estudos latinos. O intrigante, no caso específico dos MAH, é a completa ausência de referências aos trabalhos dos integrantes da equipe do AS. Tal fato é ainda mais intrigante uma vez que os durkheimianos citaram e resenharam, como foi visto no subcapítulo 1.1, contribuições publicadas na revista da EFR.

Uma explicação para tal fenômeno reside no plano secundário que a referida publicação dedicava aos campos de investigação mais caros aos sociólogos, a saber, a religião,

\footnotetext{
${ }^{22}$ A presente tese não tem condições de discutir tais contextos particulares com a devida atenção. Remeto, para uma primeira visão geral das particularidades dos sistemas de ensino francês, britânico e alemão, às discussões publicadas em The Rise of Modern Educational System (MÜLLER; RINGER; SIMON, 1989), bem como à entrevista que realizei com Jean Bollack (veja-se o anexo da presente tese).
} 
o direito e, em menor escala, a economia. Não que possíveis pontes não existissem. Por exemplo, um número significativo de trabalhos sobre cultos pagãos e cristãos na Antiguidade foi publicado nos MAH, mas os autores aos quais se fazia então menção eram, salvo raras exceções, Ernest Renan, Salomon Reinach e Franz Cumont ${ }^{23}$. Tratavam-se de figuras bem conhecidas dos antiquisants franceses, mas que estavam longe de representar a totalidade de correntes trabalhando sobre a religião. As abordagens mais comuns no que tange à religião antiga eram duas: ou a descrição/transcrição, acompanhada de comentários, de inscrições ou lugares de culto antigos; ou a história institucional da Igreja Católica, tal como praticada por ninguém menos que o diretor da escola, Louis Duchesne. O mesmo silêncio se impôs ainda quanto às demais dimensões da vida social caras aos sociólogos, a jurídica e a econômica. No caso específico dos juristas, a maior parte dos textos de maior fôlego sobre o direito romano vieram da pena de Adhémar Esmein e foram publicados muito antes do lançamento do $\mathrm{AS}^{24}$. Já quanto aos pesquisadores interessados na história econômica do mundo antigo, os diálogos ocasionais se travaram mais com os historiadores e sociólogos alemães ${ }^{25}$.

Outra possível explicação para a ausência de diálogo vem da falta de engajamento dos próprios durkheimianos. É bem verdade que nenhum latinista participou da equipe que animou a primeira série do AS. O jurista Paul Huvelin foi quem mais se aproximou desse domínio com seus trabalhos sobre as relações entre direito e religião na Roma Antiga, mas sem sensibilizar os colaboradores dos $\mathrm{MAH}$, algo que ele havia conseguido no contexto do $\mathrm{BCH}$ e da EFR. Ter-se-ia assim de esperar pela segunda séria da revista dos sociólogos para que um dos latinistas provenientes dos antigos quadros da EFR, André Piganiol, cerrasse fileiras com eles.

As duas explicações não são, porém, excludentes. O problema todo remete, mais uma vez, à posição estrutural do latim no sistema de ensino francês. Tudo se passa como se a abertura menor dos estudos latinos às novidades científicas inibisse, ao menos até a Primeira Guerra Mundial, o aparecimento de vanguardas organizadas na área. Os diálogos com a sociologia marcaram assim os escritos de um ou outro latinista isolado, em particular Gustave Bloch e Camille Jullian. Nesses casos, porém, os diálogos positivos e negativos ocorreram mais tarde, transparecendo apenas em um ou outro de seus escritos ${ }^{26}$.

\footnotetext{
${ }^{23}$ Veja-se, por exemplo, MAH, 1902: 23-68; 1909: 239-268 e 1920: 63-143.

${ }^{24} \mathrm{Cf}$. os textos citados na nota 16.

${ }^{25}$ No âmbito dos MAH, por exemplo, Max Weber, em função de seus trabalhos sobre a propriedade rural em Roma, foi citado já em 1905 por Jérôme Carcopino. Veja-se MAH, 1905: 33. Nas páginas do AS, Weber teve seu nome mencionado pela primeira vez apenas um ano mais tarde (AS, 1906: 471).

${ }^{26}$ Quanto às relações, pontuadas de episódios conflituosos, entre Jullian e os sociólogos durkheimianos, veja-se os subcapítulos 2.4 e 3.1 da presente tese.
} 


\section{OS SOCIÓLOGOS NOS MÉLANGES D'ARCHÉOLOGIE ET D'HISTOIRE}

Dois pesquisadores ligados ao AS tiveram suas trajetórias marcadas pela passagem na EFR - e, consequentemente, pela contribuição aos MAH. Ainda assim, o que só reforça o que acaba de ser afirmado, nenhum deles possuía a formação ou seguiu carreira de latinista.

Em ordem cronológica, o primeiro sociólogo a estagiar em Roma foi Georges Bourgin. Nascido na Nevers de 1879, ele ingressou na EFR por intermédio da École des Chartes. Bourgin permaneceu em Roma apenas um ano, chegando no segundo semestre de 1903 e partindo em meados de 1904. Sua contribuição ao AS teve início no ano seguinte ao de seu retorno à França, ainda que os primeiros contatos com os sociólogos tenham sido certamente anteriores a essa data. Seu irmão mais velho, Hubert Bourgin, já integrava a equipe do AS desde 1901. Ele também pode ter tido contato com Marcel Mauss e Henri Hubert nas salas de aula e nos corredores da EPHE, por ele frequentados no momento em que os dois sociólogos aí iniciavam suas atividades docentes (1901-1903).

Suas atividades em Roma se concentraram em pesquisas junto à biblioteca do Vaticano, mapeando manuscritos que vão do início do século XV ao início do XIX. Na revista da escola, até 1920, ele publicou um total de oito artigos, todos apresentando ao público letrado textos raros seguidos de comentários. O primeiro deles, Un document sur la Bibliothèque de Sainte-Croix de Jérusalem en 1810 (MAH, 1904: 13-16), é típico nessa direção. Trata-se da transcrição de um manuscrito italiano datado do início do século XIX no qual se discrimina em detalhes o acervo de uma importante biblioteca católica em Jerusalém, incorporada pelo Vaticano em 1875. Embora alguns de seus artigos tratem dos quadros da Igreja Católica (MAH, 1904: 277-319), ou ainda da história regional de Midi francês (MAH, 1904: 35-64), a maior parte deles evoca episódios ocorridos na França e na Itália durante o Império napoleônico. Em Pour deux sonnets (1813), por exemplo, Bourgin apresenta ao público poemas satíricos compostos por um prelado expulso de Roma por ter se recusado a pregar sermões exigidos por autoridades francesas (BCH, 1908: 337-339). E os exemplos nessa direção poderiam ser ainda multiplicados ${ }^{27}$. Se houve alguma influência da sociologia nesses textos, ela não é explicitada pelo autor.

O retorno rápido de Georges Bourgin à França se deveu a um posto vacante nos Archives Nationales, o qual the foi ofertado ainda em 1904. Uma vez instalado em Paris, ele iniciou sua colaboração com o grupo do AS, do qual não mais se distanciou. Bourgin também esteve ligado, como seu irmão e muitos de seus colegas sociólogos, às correntes socialistas próximas de Jean Jaurès, Léon Blum e Lucien Herr (FRANÇOIS, 1959).

${ }^{27} \mathrm{MAH}, 1905:$ 97-105; 1906, 117-142; 1907: 311-322; 1913: 365-478. 
O outro durkheimiano que frequentou a EFR como "membro efetivo" foi Jean Marx. Nascido em Paris, cinco anos depois de Georges Bourgin, ele seguiu o mesmo caminho de seu precursor em Roma: a EPHE e a École des Chartes (1909-1912). Foi na primeira instituição que ele travou contato com Mauss, Hubert e um antigo aluno de Meillet muito próximo aos sociólogos, Joseph Vendryes. As cartas que Marx enviou aos sociólogos, conservadas nos Fonds Mauss-Hubert e Meillet do Institut Mémoires de l'Édition Contemporaine (IMEC), mostram o quanto ele já estava próximo deles antes mesmo de partir para a Itália. Em julho de 1912, ele endereçou uma carta a Mauss para Ihe pedir dicas de Londres, onde realizaria um estágio com recursos da EPHE na British Library $^{28}$. Sua contribuição ao AS teve início logo depois do retorno da Inglaterra, como testemunha a carta de 29 de agosto do mesmo ano, na qual questiona Hubert sobre os livros que the serão endereçados para a preparação de resenhas $^{29}$. Por fim, em outubro de 1912, poucos dias antes de partir para a Itália, Marx aceitou trabalhar com Hubert em paralelo às suas atividades na EFR acerca de um ciclo mitológico celta. Em suas palavras:

Eu refleti bastante sobre nossa conversa ocorrida no mês de julho e eu reconheço estar muito tentado pela perspectiva de um trabalho ao vosso lado e sob vossa direção. Mas, por outro lado, será praticamente impossível para mim assumir como tema de um trabalho de Roma um tema pré-histórico, e eu não poderei trabalhar sobre esse domínio, por agora, que paralelamente. É verdade que não há talvez urgência no caso, pois eu estarei retido no exterior ao menos por dois anos. Em todo caso, eu não saberia vos dizer o quanto fiquei sensibilizado com vossa confiança e com vossa simpatia: permita-me dizer que eu vos sou muito grato.

Eu espero continuar meu trabalho sobre Finn na Itália, ao lado de minhas tarefas de medievalista propriamente dito. Eu estou levando para lá livros e algo para exercitar o irlandês. Talvez eu tenha o prazer de vos encontrar em Roma nesse inverno ou nessa primavera. Em todo caso, caso não tenhais retornado a Paris até o fim do mês, eu vos encontrarei sem dúvida quando eu mesmo retornar à França, sem dúvida no final de janeiro ${ }^{30}$.

Em sua estada em Roma, interrompida em 1915 pela Primeira Guerra Mundial, Jean Marx trabalhou sobretudo com arquivos relativos ao medievo italiano. Na revista da EFR ele publicou apenas dois artigos. O primeiro deles, Les Registres de Bannis à Pérouse au XIII Siècle, discute "detalhes interessantes da vida privada de uma grande cidade da Itália central" a partir dos registros de ostracismo de uma comuna italiana (MAH, 1914: 369-381). O segundo texto,

\footnotetext{
${ }^{28}$ Cf. as cartas datadas de 10 de julho e de 14 de julho de 1912, pertencentes aos arquivos do IMECCaen, Fonds Mauss-Hubert (MAS 8.71).

${ }^{29}$ Veja-se a referida carta nos arquivos IMEC-Caen, Fonds Mauss-Hubert (MAS 50). Vale lembrar que a maior parte das resenhas destinadas a Marx dizia respeito à religião grega, tal como mostra a tabela 1.1.12, apresentada no subcapítulo 1.1 da presente tese.

${ }^{30}$ Carta data de 10 de outubro, certamente postada em 1912. Cf., nos arquivos IMEC-Caen, Fonds Mauss-Hubert (MAS 50).
} 
Quatre Documents relatifs à Guillaume D'Estouteville, reproduz registros escritos em latim que esclarecem a passagem do cardeal Guillaume d'Estouteville, arcebisbo de Rouen, na Roma de metade do século XV. Ainda que naquele artigo se discuta aspectos da sociedade medieval italiana, nenhuma alusão explícita à sociologia é feita.

Note-se ainda que o vínculo com a EFR e o período em Roma não fez com que Jean Marx perdesse o contato com os sociólogos. Poupado das trincheiras, ele permaneceu na Itália até o final da Guerra atuando junto ao serviço diplomático francês. Como a esposa (alemã) e o filho de Henri Hubert aí permaneceram durante o conflito, Marx pode visitá-los e enviou relatos desses encontros ao seu orientador ${ }^{31}$. Mesmo defendendo na sequência uma tese sobre a organização do estado pontificial nos séculos XII e XIII, Marx dedicou boa parte de sua produção intelectual ao estudo das mitologias celta e germânica. Anos depois, já como especialista nesses temas, ele pôde substituir Hubert na EPHE, primeiro como suplente (19241927) e, após a morte deste, como professor efetivo. Em paralelo às suas atividades docentes, ele ainda ocupou um posto permanente no Ministère des Affaires Étrangères.

Embora não se tratasse de antiquisants, a presença de Jean Marx e de Georges Bourgin nas páginas dos MAH ilustram a dificuldade de se realizar nos quadros da EFR um trabalho em sintonia com a agenda dos sociólogos durkheimianos. Ambos já mantinham, direta ou indiretamente, contato com o grupo em torno do AS e, no entanto, não puderam transferir essas relações e os interesses que elas supõem para o solo italiano (ao menos não de maneira direta, como ilustra o caso de Marx). É bem verdade que os temas de suas pesquisas romanas os ajudaram pouco quanto a isso.

Uma acolhida completamente diferente foi reservada aos sociólogos no seio da Association pour l'Encouragement des Études Grecques en France e de sua revista, a Revue des Études Grecques. É isso se será discutido no próximo subcapítulo.

\footnotetext{
${ }^{31}$ É o que testemunham as cartas de Marx endereçadas a Hubert e datadas de 20 de abril e de 9 de junho de 1915. Veja-se, nos arquivos IMEC-Caen, Fonds Mauss-Hubert (MAS 50).
} 


\section{$2.3-A$}

\section{REVUE}

\section{DES}

\section{ÉTUDES}

\section{GRECQUES}

“Na realidade, nós não podemos nos enganar quanto à necessidade do progresso. No geral, no domínio da ciência ou da crítica, a imobilidade não é possível. Elas vivem apenas graças a uma renovação perpétua de sua matéria e de suas formas, sendo necessário que os órgãos com os quais elas se comunicam com o público estejam em condições de segui-las. A Associação, no campo específico que escolheu, não escapa a esta lei. Ela arriscaria manter-se aquém de sua tarefa se mantivesse intactos seus primeiros esforços. Quais não são hoje, de fato, a atividade e a abrangência dos estudos e dos trabalhos que se relacionam à Grécia? E qual é hoje o significado da palavra helenismo, a qual resume em si os objetivos múltiplos de nossas ocupações?

O helenismo é a tradição piedosa e viva do passado, é o espírito da Grécia Antiga preservado por sua literatura e por suas artes, animando a Grécia Moderna, garantindo a ela seu lugar no mundo e iluminando todas as nações civilizadas; é o laço de reconhecimento que as une a ela; é o sentimento que suscita esforços cada vez mais ativos, seja para descobrir e compreender os restos da antiguidade helênica, seja para propagar o conhecimento de sua língua, de sua história e de sua civilização."

Jules Girard

(A Nos Lecteurs, em REG, 1888, p. 3-4)

O lançamento da Revue des Études Grecques (REG) em 1888 afetou profundamente o campo dos periódicos voltados aos estudos greco-latinos, dando-lhe nova orientação. O que se via até então era a simples distinção entre helenistas, colaboradores do $\mathrm{BCH}$, e latinistas, reunidos em torno do MAH. Além do mais, como tais espaços priorizavam tanto o treinamento das futuras gerações de especialistas quanto a divulgação de documentos arqueológicos e epigráficos inéditos, os pesquisadores já estabelecidos se viam obrigados a divulgar seus trabalhos em publicações não especializadas.

A simples presença da REG nesse cenário teve dois efeitos imediatos. Por um lado, reforçou as diferenças preexistentes entre helenistas e latinistas, evidenciando mais uma vez a primazia daqueles quanto aos novos métodos de divulgar e fazer ciência. Por outro, inaugurou não apenas o primeiro espaço dirigido aos antiquisants profissionais, como também o primeiro dirigido por eles. Ao dispor de um comitê científico e de diretores reputados, a REG apareceu aos olhos de seus contemporâneos como uma instância privilegiada de consagração, o que lhe valeu um prestígio ímpar.

Mas para se compreender o peso e a especificidade da REG é preciso atentar ainda para sua incomum ancoragem institucional. Ela não foi concebida, como ocorreu com o $\mathrm{BCH}$ e o MAH, para ser o veículo de comunicação de um braço avançado do sistema de ensino francês no exterior. Tampouco se tratou da iniciativa de um grupo restrito e coeso de 
professores provinciais, como será o caso da Revue des Études Anciennes (REA), criada onze anos mais tarde. Existia sim, por trás da REG, uma instituição sediada em Paris, cuja influência, constituída no encontro de agendas políticas, humanísticas e universitárias, fez-se sentir ao longo de toda a Terceira República francesa: a Association pour l'Encouragement des Études Grecques en France (AEEG).

O presente subcapítulo visa apresentar em detalhes as especificidades da REG para, problematizando-as, explicar os motivos que levaram essa publicação a acolher, em geral de modo positivo, as contribuições de pesquisadores ligados à "escola sociológica francesa".

\section{UMA INSTITUIÇÃO DE ELITE}

Enquanto corria o ano de 1867, Alexandre Bertrand (1820-1902) se ocupava da direção do recém-criado Musée des Antiquités Nationales. Victor Duruy (1811-1894), por seu turno, atuava como ministre de l'instruction publique de Napoleão III. Já quanto a Ambroise Firmin Didot (1790-1876), ele administrava uma das mais renomadas e antigas tipografias francesas. Em paralelo às ocupações que os caracterizavam, esses três homens de idade e de interesses distintos congregaram esforços para então fundar, com a concurso de quarenta e sete outros notáveis, a $A E E G^{1}$.

A princípio, a vocação da nova instituição era pedagógica. Em seu estatuto, logo no primeiro artigo, lê-se o seguinte: "a Associação encoraja a propagação dos melhores métodos e a publicação dos livros mais úteis para o estudo da língua e da literatura gregas. Ela concede quanto a isto medalhas e recompensas". Estabeleceu-se, para dar conta das tarefas administrativas da instituição, uma direção formada por cinco membros eleitos anualmente para as funções de presidente, vice-presidente, tesoureiro, secretário e arquivista. A única regra a ser observada sobre tal composição dizia respeito ao cargo máximo: o vice-presidente deveria suceder ao presidente, ao passo que este não poderia exercer qualquer atribuição na direção da instituição no período imediatamente posterior ao de seu mandato. Quanto às suas atividades científicas, também ao longo de um ano, um comitê formado por vinte e um membros se responsabilizava por deliberar acerca das "medalhas e recompensas". Várias

\footnotetext{
${ }^{1}$ A lista completa dos fundadores da associação inclui ainda Charles Alexandre, Charles Beulé, Michel Bréal, Charles Brunet de Presle, Emile Burnouf, Antoine Campaux, Alexis Chassang, Charles Daremberg, o barão Jérôme David, Felix Dehèque, Théodore Delyannis, Frédéric Dübner, Émile Egger, Gustave d'Eichthal, Charles Gidel, Jules Girard, Saint-Marc Girardin, A. M. Goumy, Joseph-Daniel Guigniaut, Louis Havet, Léon Heuzey, Louis-Henri Hignard, Karl Hillebrand, Charles Jourdain, Gabriel-Marie Legouvé, Charles Lévêque, Adrien de Longpérier, Alfred Maury, Constantin Mélas, Emmanuel Miller, Joseph Naudet, Henri Patin, Georges Perrot, Félix Ravaisson, Ernest Renan, Léon Renier, Léon Thénon, Charles Thurot, J. Valettas, Abel-François Villemain, A. Vincent, Henry Waddington, Henri Weil, Carle Wescher e o barão Jean Joseph Antoine Marie de Witte.
} 
modalidades de encorajamentos passaram então a ser distribuídas aos futuros e atuais helenistas, abarcando alunos do secundário (alvos dos prêmios de versão grega e de retórica), professores e eruditos (alvos, entre outros, do prêmio Zographos).

Para sustentar tal aparato científico-burocrático, a AEEG dependia da cotização de seus associados, os quais poderiam ser pessoas físicas ou jurídicas (bancos, editoras e instituições de ensino). O artigo 10 de seu estatuto previa duas modalidades de vínculo: enquanto o membro ordinário deveria pagar a cota mínima estabelecida em assembleia, qualquer um que fornecesse uma quantia no mínimo superior a dez vezes esse valor receberia o título de "membro doador". A AEEG nasceu grande, pois, em 1867, ela contava já com 440 associados, dos quais 12 eram doadores ${ }^{2}$. Em 1888, quando a REG começou a ser publicada, o número de doadores passou a 213, de um total de 682 membros (REG, 1888: xliv-|xiii). Ao final da Primeira Guerra Mundial, mesmo após enormes perdas em suas fileiras, esses números se mantiveram altos, somando 486 membros e, entre eles, 134 doadores (REG, 1920: xvii-xxxv).

Se o tamanho da AEEG, por si só, impressiona, não menos excepcional era a qualidade de seus membros. Entre os pesquisadores franceses, além de praticamente todos os helenistas, aderiram a ela latinistas (René Cagnat, Gustave Bloch), filósofos (Ernst Renan), orientalistas (Gaston Maspero, Émile Sénart), antropólogos (Émile Boutmy), geógrafos (Paul Vidal de Lablache) e, inclusive, pesquisadores ligados a L'Année Sociologique (Antoine Meillet, Henri Hubert, Pierre Roussel, Louis Gernet e Isidore Lévy). Também se fizeram aí representar a École Normale Supérieure, a École des Langues Orientales Vivantes e uma série de agremiações estudantis de liceus e de colégios particulares. Algo similar se deu no plano internacional: Alphonse Willems e Franz Cumont na Bélgica; Jules Nicole e Waldemar Deonna na Suíça; Henry Sayce na Inglaterra; Heinrich Schliemann, Gustave Hirschfeld e Karl Krumbacher na Alemanha; Demétrius Bikelas, Panagiotis Cavvadias e Andréas Andréadès na Grécia. A filiação desses e de outros estrangeiros de maior ou menor renome permitiu que a associação se tornasse um espaço verdadeiramente europeu de discussão e de circulação de ideias.

Mas nem só de uma agenda universitária vivia a AEEG. Parte considerável de sua força provinha mesmo da capacidade de mobilizar contatos e recursos outros. Devido ao prestígio das antigas língua e literatura gregas em fins do século XIX e inícios do XX, não era raro que letrados não universitários, mundanos abastados e políticos se interessassem em ver seus nomes atrelados a ela. Até 1920, a AEEG contou entre seus associados com dois presidentes, Armand Fallières e Raymond Poincaré, bem como com ministros, senadores e deputados, dentre os quais se destacam Victor Duruy, Louis Liard, Théodore Reinach, Victor Bérard e Louis

\footnotetext{
${ }^{2}$ Veja-se o Annuaire de l'Association pour l'Encouragement des Études Grecques en France, 1868: 13-28.
} 
Passy. No mais, dotando a AEEG de ares proustianos, estiveram ligados a ela membros das famílias Rothschild e Bilbesco, um escritor como Anatole France, um crítico literário como Charles Sainte-Beuve, bem como diversos magistrados e comerciantes.

Outra marca indelével da AEEG, esta com duradouras consequências para sua morfologia, foi o lobby favorável ao moderno estado grego que ela exerceu dentro e fora da França. Desde inícios da década de 1820, quando teve início a longa guerra de independência grega contra o domínio otomano, muitos franceses de formação humanística uniram-se para defender o renascimento da nação que, acreditavam eles, havia legado ao Ocidente suas inclinações filosóficas, políticas e espirituais. Alguns dos futuros fundadores da AEEG atuaram nesse sentido já em 1824, por ocasião do estabelecimento do Comité Philellène de Paris. Outros foram decisivos para a fundação da École Française d'Athènes um pouco mais tarde, em 1846. A experiência acumulada no contato constante e direto com as elites gregas rendeu frutos para a AEEG. De fato, instituições e professores universitários da nova nação ingressaram nela com entusiasmo. Ainda assim, tal como no caso francês, a adesão da sociedade grega foi além do terreno puramente científico. Um exame das listas de seus membros entre 1867 e 1920 revela que ela contou com o apoio de um rei grego (George I), do Banco Nacional da Grécia, bem como de personagens influentes nos cenários político, econômico e letrado locais (ministros, senadores, deputados, comerciantes, escritores, entre outros).

Para atender um público tão heterogêneo, a AEEG não só promoveu encontros periódicos, como também desenvolveu uma eficiente rede de comunicação interna. Como previsto no artigo dezenove de seu estatuto, uma vez por ano, a princípio na primeira sextafeira após a Páscoa, os membros afiliados recebiam por correio o convite e os informes relativos à assembleia geral da associação, durante a qual seriam eleitos os novos integrantes de seu comitê científico e de sua direção. Nesses encontros, realizados na sede da instituição em Paris, as contas da entidade eram tornadas públicas, bem como se escutava o discurso do presidente e as divulgações dos trabalhos premiados. Outra modalidade de reunião, esta mensal e ocorrida em uma sala cedida pela École des Beaux-Arts, era voltada à discussão de trabalhos científicos e à apresentação de novos membros. Não menos importantes eram as políticas de comunicação da instituição: desde sua fundação, a AEEG dispunha de um invejável caderno de endereços, disponibilizado aos seus por meio de um anuário impresso, no qual igualmente se encontravam artigos, ensaios, traduções e os resumos de todas as atividades da instituição. Esse formato de publicação subsistiu até fins de 1888 , quando foi modernizado e adaptado a um público mais amplo. É a passagem de tal anuário à REG que será discutida a seguir. 


\section{A AEEG E O SISTEMA DE ENSINO FRANCÊS: UMA POSIÇÃO ABERTA ÀS REFORMAS}

Em uma época marcada por reformas educacionais, a AEEG não se furtou à tarefa de encorajar os estudos gregos. Mas como e em que direções isso se deu?

Acompanhando os discursos dos presidentes da associação, as atas de seus encontros e os artigos publicados em seu anuário ou revista, percebe-se que o tema da reforma ganhou destaque em fins do século XIX. Em um primeiro momento, a situação alemã, marcada por uma redução significativa do espaço da língua grega no secundário, orientou as discussões. Quem trouxe o tema à tona foi Théodore Reinach, então diretor da REG. Em um dos encontros mensais da associação, ele se posicionou quanto ao sentido das reformas e às posições dos colegas do outro lado do Reno:

"O que é interessante para ser estudado é todo o desenvolvimento histórico e moral do pensamento grego, aí incluindo a ciência, o direito e a própria teologia. Ao invés de fazer do grego o objeto de um ensino puramente estético, é preciso torná-lo a base o caminho para todos os estudos, tanto do religioso, como do científico. É preciso renunciar ao purismo ático e fazer com que os alunos percorram todos os domínios deste vasto campo chamado helenismo." (REG, 1900: 506)

Os debates tornaram-se mais acalorados na sequência, quando a própria estrutura do ensino francês foi modificada em 1902. Restringiu-se nessa ocasião o ensino obrigatório do grego aos segundo e terceiro anos do ensino médio. Além do mais, ele foi desvinculado do latim quanto ao acesso à maioria das profissões liberais, passando a ser indispensável apenas aos que desejassem seguir uma carreira docente na área de letras.

Dentro da associação, quanto a isso, duas posturas diferentes se fizeram notar. Houve quem se sentisse atacado pelas reformas, vendo nelas o declínio da tradição humanística francesa. Mas também houve quem enxergasse aí algo de positivo. Salomon Reinach, discursando como presidente da AEEG em 1903, falou em "não confundir o estudo do grego, que é um meio, com o do pensamento grego, que é um fim". Segundo ele, os estudantes franceses ganhariam se, ao invés de aprenderem o grego, pudessem dispor de livros que transmitissem fiel e criticamente as ideias dos antigos (REG, 1903: xixii). Em 1909, o então presidente Théophille Homolle voltou ao tema. Mesmo lamentando a escassez de alunos de grego nas escolas, insistiu no ganho em profissionalismo. Ele afirmou que tal constatação era o "fim de uma ilusão" e pediu para que, diante de novos sacrifícios, "a letra fosse abandonada, não o espírito” (REG, 1909: xviii-xxii). Opinião similar aparece no relatório que a $A E E G$ encomendou junto ao Ministère de I'Instruction Publique, o qual foi redigido por Louis Liard e divulgado naquele mesmo ano: se houve perdas de alunos no pós-1902, ganhou-se em qualidade (REG, 1909: 257-275).

Mesmo levando em conta a posição contrária à reforma de muitos membros da $A E E G$, argumentos pró-modernização do sistema de educação tiveram a simpatia de seus dirigentes. Eles estavam dispostos a perder terreno no ensino da língua se isso fosse compensado por uma maior divulgação do helenismo e um maior profissionalismo dos estudantes remanescentes. 


\section{DO ANUÁRIO À REVISTA}

Em 1868, logo após o estabelecimento da AEEG, teve início a publicação do Annuaire de l'Association pour l'Encouragement des Études Grecques en France. Duas editoras, ambas parisienses, trabalharam para sua impressão: Ad. Lainé et J. Havard e A. Durand et Pedrone. A distribuição, contudo, ficava a cargo da própria $A E E G$, a qual encaminhava os exemplares a seus membros por correio.

Durante os vinte anos em que foi editado, o anuário não sofreu reestruturações maiores. Quanto à forma, ele comportava duas partes, uma administrativa, relativa à questões internas da associação, e outra científica. Na primeira encontravam-se o estatuto, a lista completa de membros (com endereço para correspondência e ocupação atual de cada um deles), o discurso do presidente, bem como relatórios sobre as contas da AEEG e os prêmios por ela distribuídos. A segunda parte, por seu turno, compreendia o item "memórias e notícias", espaço aberto aos textos dos colaboradores, e o item "bibliografia", no qual uma seleção das publicações do ano anterior passíveis de interessar aos helenistas era listada.

Mas se a forma se manteve estável, o tamanho do anuário não cessou de aumentar. Em 1868, ele contava com pouco menos de cem páginas. Um ano depois, a barreira das duzentas páginas havia sido ultrapassada. Na segunda metada da década de 1880, por fim, alguns de seus derradeiros volumes chegaram a ter mais de quatrocentas páginas. Eis aí um forte indício da expansão do sistema universitário francês, a qual também não deixou de exercer sobre a AEEG pressão em várias direções. Com efeito, havia, antes de mais nada, a necessidade de dinamizar a circulação dos trabalhos impressos em seu anuário, uma vez que seus concorrentes diretos vinham a público em intervalos menores, seja semestral, quadrimestral ou trimestralmente. Some-se a isso a necessidade de expandir o leque de leitores: o anuário da AEEG circulava apenas entre seus membros e instituições ou pessoas jurídicas para as quais a associação destinava certa cota de exemplares. Era preciso, portanto, adaptar sua estrutura e periodicidade para atender às demandas de um mercado editorial em expansão. As razões que levaram ao aparecimento da REG em 1888 estão aí.

No primeiro número da nova revista, o helenista Jules Girard, professor da Sorbonne e presidente em exercício da AEEG, contentou-se em assinalar a "necessidade do progresso" e a "renovação de matérias e de formas" (REG, 1888: 3). Resta saber, contudo, o que mudou e o que permaneceu no processo de transição. Uma primeira mudança sensível veio da parte do novo editor, o qual também se ocupou da distribuição da revista para vendas em livrarias. Estrategicamente tornado membro da AEEG em 1887, Ernest Leroux, então em evidência por publicar toda uma série de boletins do Institut de France e de universidades francesas, assimiu a tarefa até sua morte, a qual coincide com o final da Grande Guerra. Nos anos que se 
seguiram ao conflito, mesmo com a criação da Presses Universitaires de France em decorrência da fusão da Leroux, da Félix Alcan (a editora de l'Année Sociologique) e da Rieder, a REG continuou carregando o nome do antigo editor.

Outra mudança considerável se deu no plano formal. Desde sua fundação, a nova revista privilegiou as questões científicas, reduzindo o espaço destinado às questões internas da associação. Operou-se então uma divisão mais refinada quanto ao caráter dos textos nela impressos. Por exemplo, no que antes constituía o bloco "memórias e notícias", a REG passou a discriminar "artigos", "variedades" e "crônicas". Se a seção de artigo não requer maiores explicações, por "variedades" deve-se entender informações sobre eventos, falecimentos e premiações. As "crônicas", por seu turno, eram boletins escritos por um ou mais pesquisadores visando a sintetizar os derradeiros avanços de suas especialidades. Entre $1893 \mathrm{e}$ 1920, a REG contou com três boletins: o epigráfico, o arqueológico e o papirológico ${ }^{3}$. Por fim, a parte antes intitulada "bibliografia" foi devidamente complexificada: além de apresentar a listagem anual do que se produziu nos diversos ramos do helenismo, ela passou a comportar resenhas críticas das obras endereçadas à associação.

E quanto à periodicidade? Ora, em conformidade com as publicações mais modernas, a AEEG optou por lançar a cada ano quatro ou excepcionalmente cinco volumes contendo algo entre cem e duzentas páginas. Embora o número de volumes tenha sido mais regular, o tempo que os separava variou. Em geral, eles apareceram a cada trimestre, ainda que alguns volumes tenham contemplado intervalos de dois, quatro ou mesmo seis meses. Como a paginação era contínua entre um e outro exemplar, ao final de cada ano os membros da AEEG poderiam obter um único exemplar em capa dura com tudo o que foi impresso. Nesse sentido, o velho anuário pôde continuar existindo em paralelo aos volumes avulsos.

Uma última novidade que importa destacar é a institucionalização de um conselho de publicação e da função de diretor. Tais pessoas deveriam necessariamente ser membros da AEEG, cabendo a elas responder pela excelência científica da revista. Além do diretor, todos os antigos presidentes da associação possuíam assento no referido conselho, assim como outros dois ou três membros eleitos por seus renomes em alguma área específica de saber. Entre 1888 e 1920, apenas dois homens exerceram a função de diretor da REG: Théodore Reinach e

\footnotetext{
3 o "boletim epigráfico" foi, dos três, o mais antigo e regular. Entre 1893 e 1902 ele esteve sob responsabilidade de Théodore Reinach, ao qual se seguiram Émile Bourguet (1903 e 1908), AdolpheJoseph Reinach (1904-1912), Pierre Roussel (1913-1920) e Georges Nicole (1916-1917). Já o "boletim arqueológico" surgiu em 1894, tendo Charles Diehl como primeiro redator. Ocuparam-se dele depois Henri Lechat (1895-1902), André de Ridder (1902-1918) e o suíço Waldemar Deonna (o qual dividiu com de Ridder essa incumbência a partir de 1916). Quanto ao boletim "boletim papirológico", ele apareceu somente em cinco anos e ainda assim de modo descontínuo (1901, 1902, 1903, 1905 e 1914). Em todas essas ocasiões, Seymour de Ricci esteve por trás de sua publicação.
} 
Gustave Glotz. Salvo em nove semestres passados entre 1907 e 1908, período de transição entre as duas gestões, eles cumpriram suas funções sem quaisquer auxílios ${ }^{4}$. Antes mesmo de examinar o significado da expressão "helenismo" que define o conteúdo da revista, ou de discutir a morfologia de seus colaboradores, cumpre isolar aqui o perfil e o impacto de cada um deles na referida publicação.

\section{DOIS DIRETORES}

A direção da REG coube, de início, a Théodore Reinach. Dois fatores tornam hoje essa nomeação intrigante. Em primeiro lugar, Théodore estava longe de ser um antiquisant consagrado em 1888. Tratava-se, em verdade, de um jovem de 28 anos de idade, apenas no início de sua carreira como pesquisador. Além disso, ele havia trilhado uma formação atípica se comparada à dos grandes helenistas de sua geração, não tendo sido nem aluno da École Normale Supérieure (ENS) nem membro da École Française d'Athènes (EFA). Mas o que, então, tornou-o apto a assumir esse papel que ele desempenhou por vinte anos? Uma resposta a tal questão deve ser procurada em sua própria trajetória profissional e em seu círculo familiar.

Nascido nos arredores de Paris, em Saint-Germain-en-Laye, Théodore foi o mais novo dos três filhos do banqueiro alemão Hermann Reinach (1814-1899), instalado na França em 1843 e naturalizado francês um ano depois. Escorado por um casamento vantajoso com Julia Büding, proveniente de uma família de banqueiros alemães, e tendo realizado uma carreira comercial de sucesso, a qual incluiu missões diplomáticas oficiais na Península Ibérica, Hermann logrou fazer de sua casa um espaço frequentado por personalidades como Adolphe Thiers e Ernest Renan. Esses contatos com os mundos político e letrado, associados à fortuna da família, foram mais tarde mobilizados para promover as carreiras dos filhos ${ }^{5}$.

Joseph Reinach (1856-1821), o varão, tornou-se um dos maiores publicistas da Terceira República. Graduado na Faculdade de Direito de Paris, ele foi direcionado, primeiro por Thiers e depois por Léon Gambetta, para o mundo da política e da grande imprensa. Diretor, por indicação direta de Gambetta, do jornal La République Française a partir de 1882, ele foi eleito para o primeiro de seus quatro mandatos não consecutivos de deputado nacional em 1889. Joseph destacou-se ainda por ocasião do Affaire Dreyfus, quando assumiu a defesa processual do capitão acusado, ajudou a fundar a Ligue des Droits de l'Homme et du Citoyen e atuou nos

\footnotetext{
4 Entre o segundo semestre de 1906 e o terceiro de 1907, Jules Petit-Jean aparece como "gerente" da REG ao lado de Théodore Reinach. No quarto semestre de 1907, o mesmo Petit-Jean transforma-se em "secretário" de Gustavo Glotz. O exemplar da REG que circulou no primeiro trimestre de 1908 trouxe Albert Cuny nessa função de "secretário", sendo sucedido nos dois volumes seguintes por Louis Gernet. Difícil saber ao certo em que consistiam as atribuições desses cargos sem cruzar as correspondências dos envolvidos.

${ }^{5}$ Sobre Hermann Reinach, veja-se a nota publicada em BASCH; ESPAGNE; LECLANT, 2008: 15-16.
} 
jornais cotidianos em favor da causa. Dos três irmãos, ele foi o último a aderir a AEEG, justo no momento em que a REG estava sendo criada.

Quanto a Salomon Reinach (1858-1932), o filho do meio, ele trilhou a via régia dos universitários. Educado no Liceu Fontaine, depois rebatisado Condorcet, obteve seis prêmios de primeiro lugar no concours général, ingressando mais tarde em primeiro lugar na ENS, de onde saiu agrégé de grammaire (em 1879, também em primeiro lugar). Na sequência, Salomon obteve um posto na EFA e participou da abertura da frente de escavações francesas no norte da África. Embora tenha se revelado um polígrafo, escrevendo sobre filosofia, filolofia, história da arte, gramática e história, ele seguiu institucionalmente a carreira de arqueólogo, estando ligado desde meados da década de 1880 à École du Louvre, ao Musée des Antiquités Nationales (do qual foi nomeado diretor em 1902) e à Revue Archéologique (da qual se tornou codiretor a partir de 1903) ${ }^{6}$. Na vida pública, destacou-se também como dreyfusard. Dos membros de sua família, ele foi o primeiro a ingressar na AEEG (1878), vindo a ser seu presidente entre 1902 e 1903.

Experimentando desde cedo um ambiente de intensa emulação em casa, o caçula Théodore (1860-1928), à sua maneira, combinou elementos das trajetórias de seus irmãos. Cursando também o Liceu Fontaine, ele superou Salomon ao conquistar em três anos consecutivos dezoito prêmios de primeiro lugar no concours général, feito que, lembram os necrológios a ele dedicados, renderam-Ihe a fama nacional de "prodígio"7. Quanto aos seus estudos superiores, Théodore seguiu os passos de Joseph, cursando direito em Paris. Ao ofício de advogado, contudo, agregou a atividade de pesquisador e de artista (tradutor e compositor). Em 1880, tendo então apenas vinte anos, publicou uma tradução comentada do Hamlet, de Shakespeare, e uma memória jurídica intitulada De l'extinction des privilèges et hypothèques $^{8}$. Quatro anos depois, lançou pela Hachette uma história do povo judeu, discutindo o período que abarca a dispersão judaica sob o domínio romano e o presente do autor (REINACH, Th., 1884). Em 1885, por fim, obteve seu primeiro doutorado, em direito,

\footnotetext{
${ }^{6}$ A trajetória de Salomon Reinach será discutida com mais detalhes no item 3.2 da presente tese.

${ }^{7}$ Veja-se GLOTZ, 1928 e JAMOT, 1928. E tal fama atravessou gerações: em uma passagem polêmica de suas memórias, o escritor Julien Benda se referiu ao sucesso escolar dos irmãos Reinach como um dos alimentos do antissemitismo francês. A passagem diz o seguinte: "O que toda uma burguesia judaica mostrava então como modelo aos seus filhos eram os três irmãos Reinach, os quais acabavam de obter todos os prêmios no concours général. Bem natural em seres aos quais se acaba de dar a liberdade (...), esta pressa dos judeus em mostrar 'quem eles eram' - a se encaminhar às escolas do governo, nas quais eles entravam frequentemente em primeiro lugar, e ao Conselho de Estado - terá sido uma das causas principais de suas futuras infelicidades, das quais o Caso Dreyfus deveria ser o símbolo mais claro. 0 triunfo dos Reinachs no concours général me parece uma das fontes essenciais do antissemitismo, tal como ele deveria aparecer quinze anos mais tarde. Que os judeus se dessem conta ou não, tais sucessos eram sentidos por outros franceses como um ato de violência" (BENDA, 1936: 42-43).

${ }^{8}$ REINACH, Th., 1880 e SHAKESPEARE, 1880.
} 
defedendo uma tese sobre o dispositivo legal do estádio de sítio em Roma Antiga e na França Moderna (REINACH, Th., 1885).

Foi nesse momento preciso que a trajetória de Théodore se orientou para os estudos gregos. Tornado membro da AEEG em 1884, ele iniciou em seguida estudos de história antiga e de filologia, dessa vez na École Pratique des Hautes Études e sob supervisão de Henri Weil, helenista judeu-alemão radicado na França ${ }^{9}$. Decorrem dessa nova fase seus primeiros trabalhos voltados à numismática antiga - Les Monnaies Juives (1887) e Trois Royaumes de I'Asie Mineure (1888) -, bem como o início da pesquisa de doutorado, na qual ele reconstituiu, a partir de diversos suportes documentais (epigráficos, numismáticos e literários), a história de Mitríades Eupator, o rei do Ponto. Embora a tese só tenha sido defendida na Sorbonne em 1890, é possível inferir que, diante de tal cenário, o nome de Théodore deveria soar bem aos ouvidos dos membros mais velhos e influentes dentro da AEEG. Jovem, com uma incrível disciplina de trabalho atestada desde os tempos de colégio, versado em vários idiomas, rico e dotado de contatos importantes em diversas esferas sociais: a aposta dificilmente poderia ser mais segura. E, de fato, ela surtiu efeitos positivos para a associação.

Uma vez elevado ao posto de diretor da REG, Théodore ocupou rapidamente o centro dos estudos gregos, destacando-se também na abertura de novos campos de trabalho. Ele estabeleceu de pronto relações com a EFA, publicando no $\mathrm{BCH}$ e trabalhando lado a lado com a referida instituição na análise dos materiais arqueológicos por ela encontrados ${ }^{10}$. Quanto a isto, Théodore se notabilizou por examinar os primeiros grandes conjuntos relativamente completos de notações musicais da antiguidade, os então recém-descobertos hinos délficos a Apolo $^{11}$. O diretor da REG ainda atuou em favor da EFA para ampliar os sítios arqueológicos franceses no oriente, em particular no território sob domínio otomano. Some-se a essas atividades a atuação como docente livre, ou seja, sem vínculo efetivo, em instituições como a Faculdade de Letras de Paris (curso de numismática antiga entre 1894-97 e em 1901) e a École Libre de Sciences Sociales. Antes de desvincular-se de seu cargo na REG, Théodore assumiu ainda a direção da Gazette des Beaux-Arts em 1906, bem como publicou traduções de obras gregas ainda inéditas em francês de Plutarco (1900) e de Aristóteles (1891).

\footnotetext{
9 Henri Weil (1818-1909) foi também um dos fundadores da AEEG. Veja-se, sobre ele, a longa homenagem publicada na REG (1909: 373-385) e a notícia, assinada por Salomon Reinach, na RA (1909/2: 459).

10 Entre 1888 e 1920, Théodore Reinach publicou quatorze artigos no BCH. Seus temas principais versavam sobre inscrições encontradas em escavações, adaptações modernas das partituras musicais antigas de Delfos e o sistema financeiro antigo. Veja-se BCH, 1890: 571-545; 1893: $34-39$ e 584-610; 1894: 363-389; 1896: 251-256 e 523-548; 1900: 324-328; 1904: 5-19; 1905: 257-258; 1906: 46-51; 1908: 499-513; 1909: 547; 1910: 429-431 e 431-432.

${ }^{11}$ Théodore Reinach, com a ajuda de Gabriel Fauré, ainda orquestrou e executou o primeiro deles. Sobre o papel da musicologia em sua trajetória, veja-se BASCH; ESPAGNE; LECLANT, 2008: 165-176.
} 


\section{A VILLA KÉRYLOS}

A Grécia Antiga, para um helenista como Théodore Reinach, não foi apenas objeto de estudo, mas um modus vivendi. Entre 1902 e 1908, no intervalo que compreende seus últimos anos como diretor da REG e o início de sua carreira política, ele construiu em Beaulieu-surMer, nos arredores de Nice, um palacete inspirado na antiguidade: a Villa Kérylos, cujo nome designa em grego a andorinha do mar.

O cumprimento da tarefa coube a Emmanuel Pontremoli (1865-1956), arquiteto acadêmico bastante próximo aos antiquisants. Oriundo de uma família judaica de Nice, Pontremoli partiu a Paris para estudar na École de Beaux-Arts (1883). Laureado com o prêmio de Roma em 1890, ele obteve uma bolsa para completar sua formação no exterior. Após um breve período em Roma, seguiu para Grécia, onde tomou parte nas escavações que a EFA coordenava em diversos sítios arqueológicos, com destaque para Delfos. Nesse contexto, coube a ele investigar e reconstituir o plano urbano das ruínas e a forma das edificações. Já de volta a França, Pontremoli atuava como arquiteto do Observatoire de Paris quando recebeu o convite de Th. Reinach.

Produzida em meio a um diálogo intenso entre artista e encomendante, no qual não parecem ter existido quaisquer restrições orçamentárias, a Villa Kérylos fundiu o que então se imaginava ser a típica residência aristocrática grega e o conforto moderno. A fachada branca e os dois andares construídos em torno de um átrio aberto lembravam as casas de veraneio que, desde a descoberta de Pompeia, haviam sido encontradas por todo o Mediterrâneo. Além disso, graças às escavações em Délos, o início do século XIX havia revelado detalhes quanto ao interior dessas moradias (cf. VIAN DES RIVES, 2002: 79-87).

Em Beaulieu-sur-Mer, os cômodos, o mobiliário, os mosaicos no chão e as pinturas nas paredes são ou reproduções diretas de modelos antigos ou realizações neles inspiradas. Logo na entrada (thyrôreion), o visitante se depara com uma sala de banho à sua esquerda e, à direita, com o átrio. Dessa peça é possível entrar na biblioteca, na sala de recepção (andron) e em uma anticâmara que serve de vestíbulo (amphityros). Pode-se, por fim, da anticâmara, ter acesso às demais partes da casa: a sala de refeições (triklinos) e os quartos da família, localizados no segundo andar (vejam-se as figuras 2.3.1, 2.3.2, 2.3.3, 2.3.4 e 2.3.5).

Até sua morte, em 1928, Reinach utilizou o local em curtas temporadas, em geral no auge do inverno. Além de descançar, ele ali recebia diversas personalidades. Beaulieu-sur-Mer, aliás, era um dos balneários mais procurados pela alta sociedade francesa da Belle Époque. Entre os que possuíam villas nos arredores encontravam-se o engenheiro Gustave Eiffel e o banqueiro de origem judaica Maurice Ephrussi.

Mais que uma réplica histórica, o palacete construído por Reinach e Pontremoli evoca assim traços das famílias judaicas engajadas no mundo das finanças e no mundo das letras (e do helenismo, em particular). Em um cenário no qual o antissemitismo se fazia cada vez mais presente, a villa representou ao mesmo tempo um desejo de integração e um emblema de eleição, ambas via expedientes intelectuais. 
Na REG, Théodore se fez um diretor presente, publicando nada menos que cinquenta artigos entre 1888 e 1907. Seu maior feito, porém, foi ter sabido administrar a situação híbrida em que viviam os estudos gregos na virada do século. Com efeito, por mais que a expansão da universidade e a divisão trabalho entre as diferentes faculdades e escolas estivessem avançadas, a presença de especialistas "livres" (funcionários públicos ou simplesmente letrados abastados) e de sociedades eruditas, mais ou menos independentes do sistema educativo, ainda se fazia sentir. Théodore soube manter esses laços, acolhendo na revista as contribuições de helenistas não provenientes das Faculdades de Letras e da ENS. Nos quadros 2.3.1, 2.3.2 e 2.3.4, apresentados mais à frente, pode-se ver como estão presentes na REG chartistas, um antigo aluno da École Polytéchinque e até mesmo um erudito sem vínculos com a universidade. Só alguém com uma formação multifacetada como a sua, situada entre as antigas e novas formas de produção de conhecimento, estaria em condições de realizar tal façanha.

O fim do período de Reinach à frente da REG coincide com mais um redirecionamento em sua trajetória: a carreira política. As polêmicas da vida pública não the eram completamente estranhas, tendo visto seu engajamento, em conjunto com o dos irmãos, no Affaire Dreyfus. A partir de 1906, porém, ele se lançou por duas vezes candidato ao posto de deputado nacional, comemorando sucessos nas duas legislaturas (1906-1910 e 1910-1914). Nesse período, as principais atividades de Théodore se concentraram no campo da cultura e da educação (JOLY, 1960: 2816). E quanto a AEEG e a REG? Elas, como o restante de vida intelectual, não foram deixadas de lado. Théodore foi eleito presidente da AEEG entre 1907 e 1908, escrevendo mais sete artigos para a REG até 1919. O reconhecimento de sua obra por parte da Académie des Inscriptions et Belles Lettres veio em 1909, quando foi eleito membro livre. Após a guerra, em 1924, ele finalmente ocupou seu primeiro posto fixo no sistema de ensino, a cadeira de Numismatique Ancienne no Collège de France. Até sua morte, ocorrida quatro anos mais tarde, lançou um livro condensando suas investigações sobre a música antiga e aventurou-se na esfera do teatro ${ }^{12}$.

Mas quem foi o sucessor de Reinach e quais transformações sua gestão operou na REG? Nascido em uma família de pequenos comerciantes judeus alsacianos, Gustave Glotz (1862-1935) vivenciou de perto, ainda criança, o desfecho traumático da guerra francoprussiana. Em 1872, por decisão paterna, a família optou pela cidadania francesa, deixando a Alsácia para refazer a vida em Paris. Sem dispor de grandes recursos financeiros e contatos,

\footnotetext{
${ }^{12}$ Sobre os sucessos e dificuldades de Reinach como escritor de roteiros teatrais, veja-se o episódio relatado em CHARLE, 2008 (em especial, no capítulo 9).
} 
Glotz deveu o essencial de sua formação às instituições republicanas. Aluno nos Liceus SaintLouis e Louis-le-Grand, ele ingressou na ENS em 1882 com um louvável segundo lugar. Três anos mais tarde, a despeito da boa colocação no exame nacional de agregation d'histoire et géographie (terceiro lugar), o que Ihe permitiria disputar uma vaga na EFA, ele acabou optando por permanecer na França e iniciar imediatamente carreira como professor no ensino secundário. Ao primeiro posto no liceu de Angoulême (1885-1886) sucederam-se posições análogas em Nancy (1886-1892) e em Vanves (1892-1897), na periferia de Paris. A entrada na capital se deu em grande estilo: entre 1897 e 1907, ele voltou a frequentar o liceu Louis-leGrand, mas agora como professor. Seu ingresso na AEEG se deu em 1895, quando ele ainda lecionava em Vanves.

E quanto à sua produção intelectual? De início, ela foi dedicada à docência. Sem ter escrito um artigo sequer para as revistas especializadas nos estudos greco-latinos até 1900, Glotz publicou seu primeiro livro em 1897: Lectures Historiques, rédigées conformément aux programmes officiels pour la classe de cinquième (enseignement classique) et pour la classe de sixième (enseignement moderne). Tratava-se de um volume produzido para compor a coleção didática então organizada por Gabriel Monod e editada pela Alcan. Em uma resenha publicada na REG, Théodore Reinach elogiou o autor por elaborar "um belo pequeno livro que forma o útil complemento de todo curso de história grega" (REG, 1898: 112-113).

O retorno a Paris, o que supõe uma maior proximidade com as melhores bibliotecas e instituições de pesquisa, permitiu a Glotz não apenas se inteirar da produção de ponta em sua área, mas também iniciar o doutorado. O tema: as relações entre as formas jurídicas e as crenças religiosas na Grécia Antiga. Como não havia participado das grandes escavações realizadas pela EFA, tampouco se especializado em epigrafia, Glotz voltou-se para as ciências sociais então em voga, em particular aquelas praticadas pela antropologia inglesa e pela escola sociológica francesa, para propor uma leitura renovada dos textos literários antigos. Em 1904, contando com a participação de Émile Durkheim em sua banca examinadora, apresentou as teses La solidarité de la famille dans le droit criminel en Grèce (tese principal) e L'Ordalie dans la Grèce primitive (tese secundária) ${ }^{13}$. As duas foram publicadas de imediato e a AEEG coroou seu autor no ano seguinte com o prêmio Zographos, o mais significativo oferecido pela instituição $^{14}$. Em 1906, na mesma linha de abordagem, ele ainda publicou a coletânea de

${ }^{13}$ GLOTZ, 1904a e 1904b. A reação de Durkheim, na ocasião, foi bastante positiva. Ele saudou o candidato por mostrar como entre a história e a sociologia não existem "fronteiras impermeáveis", criticando-o apenas quanto à amplitude de seu comparativismo, por vezes imprudente. Tal arguição foi publicada em DURKHEIM, 1975a: 241-243.

${ }^{14}$ A REG publicou duas resenhas elogiosas sobre o fundo, mas crítica quanto aos detalhes, das teses de Glotz. Quem redigiu a resenha da grande tese foi Adolphe Reinach, sobrinho de Théodore (REG, 1905: 
ensaios Études Sociales et Juridiques sur l'Antiquité Classique. Desse modo, seu nome começou a se fazer notar entre os grandes helenistas franceses ${ }^{15}$.

Outro fator que impulsionou a carreira de Glotz foi sua atuação, em consonância com a elite letrada judaica implicada no helenismo, como dreyfusard. Sabe-se, graças à sua correspondência ativa, que seus primeiros contatos com os irmãos Reinach remontam aos anos imediatamente anteriores ao Affaire Dreyfus. A primeira carta endereçada por ele a Salomon data de 1895: trata-se de uma correspondência profissional, na qual Glotz requisitou junto ao colega informes bibliográficos acerca de um verbete que ele deveria então escrever para o Dictionnaire des Antiquités Grecques et Romaines (DAGR) ${ }^{16}$. Logo depois, contudo, surgiram as manifestações públicas em torno das irregularidades do processo. O futuro diretor da REG esteve então ao lado dos irmãos Reinach, de Gustave Bloch e de outros tantos antiquisants católicos ou protestantes (Émile Bourget, Paul Havet, Gustave Fougères, Maxime Collignon, Paul Mazon, Maurice Holleaux, Paul Girard, entre outros) ${ }^{17}$. Tal episódio extra universitário certamente fortaleceu os laços entre eles.

Sobre seu papel na revista, os quatorze anos da gestão Glotz foram marcados por continuidades e rupturas. Por um lado, como seu antecessor, ele se esforçou por manter o vínculo com a EFA, publicando em seu boletim e auxiliando em seus projetos ${ }^{18}$. Por outro lado, contudo, imprimiu à REG um perfil mais homogêneo e mais próximo ao seu. Como será visto adiante (quadros 2.3.2, 2.3.3, 2.3.5 e 2.3.6), os colaboradores formados nas faculdades de letras e na ENS tornaram-se então muito mais importantes que os demais. Glotz também soube valorizar o espaço das ciências sociais na REG, abrindo-a a sociólogos como Alfred Espinas e a colaboradores de l'Année Sociologique. Outro traço marcante de sua gestão foi o período atribulado que viveu a AEEG em decorrência da Guerra de 1914-18. Muitos membros da associação morreram dentro e fora das trincheiras, assim como as doações antes vultuosas minguaram. Nesse ínterim, Glotz teve o mérito de manter a revista ativa e, na medida do possível, periodicizada. Por fim, coube a ele também a organização do volume especial em

136-140). Esse texto será discutido em detalhes mais adiante. A resenha da "pequena tese" de Glotz, por seu turno, veio do próprio diretor da REG (1904: 383-4).

${ }^{15}$ Além dos livros, Glotz publicou dois artigos na revista: REG, 1900:137-157 e 1903: 143-153.

${ }^{16}$ Encontrei um total de trinta cartas de Gustave Glotz a S. Reinach nos dossiês de correspondência do Musée d'Archéologie Nationale e nos arquivos Correspondances de Salomon Reinach depositados na Bibliothèque Méjanes, todas relativas ao período que vai de 1895 a 1922. Sobre a carta em questão, na qual Glotz se desculpa por abordar assim um colega que ele não conhece pessoalmente, ela pertence ao primeiro desses arquivos e data de 21 de junho de 1895. Veja-se, sobre o Dictionnaire des Antiquités Grecques et Romaines, o item 3.3 da presente tese.

17 Para um apanhado bastante geral da atuação dos classicistas franceses no contexto do Affaire Dreyfus, cf. BLANCHET, 2004: 29-48.

${ }^{18}$ Glotz interveio no BCH como historiador em três ocasiões: BCH, 1908: 271-278; 1909: 526-546; 1920: 362-366. 
comemoração ao cinquentenário da AEEG (1867-1917), uma amostra de força da associação e da ciência francesa que reuniu, em 1919, quarenta e sete renomados especialistas de toda a Europa (com exceção, por certo, dos alemães) ${ }^{19}$.

O papel de diretor da REG fez bem à trajetória profissional de Glotz. No mesmo ano em que assumiu esse encargo, ele foi nomeado chargé de cours de história grega na Faculdade de Letras de Paris, sendo promovido a professor titular em 1913. A eleição para tornar-se membro efetivo da Académie des Inscriptions et Belles-Lettres veio em 1920, logo após a guerra, mesmo ano em que publicou sua história econômica da Grécia Antiga (GLOTZ, 1920). Esse seria o primeiro de uma série de trabalhos de síntese histórica que ele, já um reconhecido patrão do helenismo francês, lançou nos quinze anos após ter deixado a direção da REG ${ }^{20}$.

\section{O HELENISMO É UM HUMANISMO}

Viu-se até agora o quanto renomados diretores e o excepcional lastro institucional fornecido pela AEEG apartaram a REG das demais revistas francesas especializadas em Grécia e Roma Antigas. Mas isso não é tudo: outro elemento que emprestou seu carisma à publicação foi o campo de estudos do qual ela se quis representante. Eis aí um tema explicitado de forma recorrente na REG, cujas linhas mais gerais cumpre aqui isolar e compreender. Qual era, afinal, o significado do termo "helenismo" no contexto da revista?

No dia 5 de maio de 1892, em um banquete realizado em homenagem aos vinte e cinco anos da AEEG, seu presidente, o filósofo Ernest Renan, abordou tal questão em um eloquente discurso (REG, 1892: iii-iv):

Há na história um milagre, Senhores (eu chamo milagre o que ocorre apenas uma vez), é a Grécia Antiga. Sim, cerca de quinhentos anos antes de J.-C., terminou de se desenhar na humanidade uma espécie de civilização tão perfeita, tão completa, que tudo o que a precedeu entrou na sombra. Era de fato o nascimento da razão e da liberdade. 0 cidadão, o homem livre, fazia sua aparição nas coisas humanas. A nobreza, a dignidade simples deste homem novo obrigava a baixar os olhos tudo o que até então havia parecido real e majestoso. A moral, fundada sobre a razão, se afirmou, na sua verdade eterna, sem mistura de fiç̧ões sobrenaturais. A verdade sobre os deuses e a natureza foi quase toda descoberta. $\mathrm{O}$ homem, livre dos tolos terrores de sua infância, começou a almejar com calma seu destino. A ciência, o que quer dizer a verdadeira filosofia, foi fundada. $O$ sistema mecânico do mundo foi, em certos momentos, vislumbrado; os homens não souberam permanecer no mesmo patamar; mas, no final das contas, o princípio foi encontrado. Copérnico, Galileu e Newton apenas tiraram consequências de uma ordem de ideias que tirava da terra sua posição central e fazia entrever o infinito do universo.

E na arte, oh céus! Que fecondidade! Que mundo de deuses e de deusas! Que celeste revolução! A Grécia inventou a beleza, como ela havia inventado a razão. 0 Oriente havia feito

\footnotetext{
${ }^{19}$ Sobre a gestão Glotz, veja-se a homenagem publicada na própria REG (REG, 1935: 207-209).

${ }^{20}$ Entre outros, GLOTZ, 1923 e 1928.
} 
estátuas antes dela; como um certo Oriente antes dela, ela havia encontrado meios de suportar a contínua intervenção dos deuses. Mas só a Grécia descobriu a estabilidade das leis da natureza; só a Grécia descobriu o segredo do bom e do verdadeiro, a regra, o ideal. A partir de então nada mais será preciso fazer que colocar-se como seu aprendiz; é o que Roma fará, é o que fará a Renascença, é o que farão, após cada declínio rumo à barbárie, os autores das Renascenças futuras.

Esta hora decisiva da história da humanidade é aquela que vocês estudam, Senhores.

Treze anos mais tarde, no momento em que deixava a presidência da associação, Paul Girard tinha certamente em mente a reatualização da prece renaniana diante da Acrópole ao proferir as seguintes palavras (REG, 1905: xi-xii):

Não houve, Senhores, milagre grego; o milagre é, pois, algo que não se explica e o gênio grego não é inexplicável. Mas houve um povo felizmente muito bem dotado, que se destacou em tudo, um povo que criou a ciência e a filosofia, a liberdade intelectual e a liberdade política, a beleza artística e a beleza literária, um povo todo imbuído do amor à pátria, do espírito de justiça e dos princípios das humanidades, um povo, enfim, do qual emana, diretamente ou não, quase toda a civilização moderna. Não é natural que esta raça de elite excite ao mais alto grau nossa curiosidade e não será um signo de barbárie se ela nos viesse a ser de súbito indiferente? Não vos parece que ela é ao menos tão digna de interesse que esses selvagens da idade da pedra ou da idade do bronze, dos quais a antropologia descobre piedosamente os mais humildes vestígios? Não somos nós, em todo caso, que seremos tentados a considerar o estudo da Grécia como uma espécie de luxo tornado incompatível com as preocupações utilitárias de uma democracia laboriosa. Nós estimamos que nada é mais instrutivo que a evolução de um povo que teve no mundo um lugar tão belo.

Milagrosa porque única ou não milagrosa porque, em sua unicidade, explicável. A despeito da carga semântica que cada um deles atribuiu ao termo "milagre", Renan e Girard reproduziram, quanto ao essencial, os mesmos tópoi discursivos. Ambos concordariam em emprestar à Grécia Antiga toda uma série de notáveis atributos: a origem das ciências (ou da Razão), das artes (ou da Beleza) e do livre pensar na esfera pública (ou da Cidadania e da Política). Diante disso, quem poderia rivalizar com ela? Certamente não a Roma Antiga ou a Renascença, posto que essas etapas posteriores da história humana apenas souberam se apropriar dos helenos para fins próprios; tampouco seria o caso dos selvagens, cujo legados se traduzem em raros e "humildes" vestígios. Aos olhos desses presidentes da AEEG, como modelo ou fonte de inspiração, a Grécia pairava soberana sobre todas as nações e épocas.

Tal ajuizamento poderá encontrar maior ou menor simpatia fora dos círculos dos helenistas e, ainda assim, enquanto ato, ele revela um traço típico daqueles que se dedicam ao estudo de sociedades ou de recortes cronológico-espaciais específicos. Com efeito, não há nada mais comum a tais especialistas que a tentativa de convencimento, de si mesmo e dos outros, do inestimável valor de sua especialidade. Quando isso acontece, problemas de cunho 
metodológico e epistemológico tendem a ocupar, quando muito, um plano secundário. E há mais: tudo se passa como se a qualidade dos objetos pesquisados fosse, tal qual a magia na definição proposta por Mauss e Hubert, contagiosa. Ela se confunde com o analista, emprestando a ele algo de sua aura.

Mas não se trata aqui, ao menos não por hora, de enfrentar o problema da hierarquia social dos objetos analisados por cientistas sociais. Importa sim, sem que seja necessário apresentar em detalhes a complexa história dos estudos gregos na França ${ }^{21}$, destacar os argumentos com os quais os próprios colaboradores da REG buscaram enobrecer e justificar sua atividade. $O$ fato é que, para eles, o helenismo não derivava sua legitimidade nem do papel ocupado pela Grécia na história deste ou daquele povo específico, nem por ela trazer em si prefigurações de fenômenos típicos da modernidade (a democracia, o capitalismo, a globalização e o que mais se quiser). A Grécia Antiga merecia ser estudada porque ela foi a única a inventar ou a primeira a descobrir bens que são, por definição, sempre os mesmos. Ou seja, em outras palavras, o que há nela de particular é sua universalidade.

$\mathrm{Na}$ França de fins do século XIX e inícios do XX, em meio ao processo de consolidação da universidade e do estado laicos, a definição dessa universalidade esteve longe de ser neutra ou desinteressada. Os estudos gregos foram então associados, talvez mais que qualquer outro saber, aos valores do humanismo clássico. Eles passaram a dizer respeito ao advento e aos meios de conservação da Razão e da Beleza em uma esfera propriamente humana. Tal formulação mobilizava uma filosofia da história, a qual permitiu aos helenistas se distinguir dos colegas com os quais eles tradicionalmente dividiam espaço nas faculdades de letras e nos liceus, os latinistas e os orientalistas. Nesse cenário, os orientalistas se mostravam muito reféns do passado bíblico, da afirmação ou da refutação das verdades do antigo e do novo testamento. Os latinistas, por seu turno, a despeito de seu reinado no sistema de ensino, permaneciam atrelados às ideias, em geral combinadas, de império e de cristandade. Os helenistas, por fim, pareciam defender um modelo de civilização mais arejado. Vale dizer: o universalismo intelectual e estético que eles ofereciam, justamente porque liberto a priori de componentes judaico-cristãos, adaptava-se melhor às bandeiras da Terceira República. Ao menos era essa a imagem que boa parte da cúpula da AEEG procurou apresentar.

Nobre, a tarefa do helenista não era nada simples. Para dar conta da complexidade do objeto Grécia, os colaboradores da REG assumiram a necessidade de uma divisão do trabalho, a qual abarcava certo número de disciplinas e de suportes documentais. Mas quais? Ora, a Bibliographie Annuelle des Études Grecques, publicada com raras interrupções desde o

\footnotetext{
${ }^{21}$ Veja-se, quanto a isto, AVLAMI, 2000.
} 
lançamento da revista até 1912, justo por ser em sua seção que as subdivisões do helenismo foram explicitadas de forma mais clara, ajuda a compreender como esse campo do conhecimento se transformou ${ }^{22}$. Em 1888, a produção intelectual relativa aos estudos gregos foi apresentada por meio de nove eixos temáticos: 1) Religião - Filosofia - Direito Instituições; 2) História - Cronologia - Geografia; 3) Arqueologia - Numismática - Epigrafia Ciência Antiga; 4) Gramática - Linguística; 5) Música - Ritmo - Métrica; 6) Filologia - História Literária - Paleografia; 7) Autores gregos antigos; 8) Autores diversos - Anônimos; 9) Neohelênica (REG, 1888: 402-461). Essa estrutura manteve-se bastante instável ao longo dos próximos cinco anos: itens antigos foram desmembrados, novos apareceram e a ordem da lista foi modificada. A partir de 1893, a Bibliographie adquiriu sua forma definitiva, a qual foi mais tarde apenas corrigida ou modernizada em um ou outro ponto. Ela apresentou então dezesseis eixos temáticos na seguinte sequência: 1) Generalidades - Ensino do Grego - Coletâneas Biografias de Eruditos; 2) História literária em geral; 3) Filosofia; 4) Ciências Exatas e Naturais Medicina; 5) Autores Gregos; 6) Epigrafia; 7) Paleografia; 8) Gramática - Retórica - Lexicografia - Pronunciação; 9) Métrica - Música; 10) História - Geografia; 11) Religião - Culto - Mitologia; 12) Antiguidades ${ }^{23}$; 13) Arte e Arqueologia Figurada - Escavações; 14) Metrologia Numismática - Calendário; 15) Bizâncio; 16) Neo-helênica (REG, 1893: 410-478).

$\mathrm{O}$ que se pode inferer de tal estrutura? Um primeiro ponto que interessa à presente tese é como a referida bibliografia se revela uma construção tipicamente francesa. Ela atrela, afinal, demandas provenientes do sistema de ensino secundário (grande parte de suas seções tem nomes de testes no exame de agrégation) a novidades em termos de levantamento documental (epigrafia, paleografia, numismática). Outro ponto sensível é a inexistência de categorias autônomas para dar conta das ciências sociais então praticadas na universidade. Tal ausência não impediu, contudo, que elas conquistassem seu espaço infiltradas em rubricas tradicionais (religião, gramática ou antiguidades). Nada mais natural: em seu âmago simpáticos à ciência em geral, os helenistas que publicavam na REG não podiam dispensar instrumentos adicionais de conhecimento - com a condição, bem entendido, que eles não dessacralizassem seu objeto de estudo (ele próprio uma encarnação primordial, entre outras coisas, da ciência).

Antes de abordar as vias de acesso da sociologia e da equipe de L'Année Sociologique na REG, cumpre discutir quem eram exatamente os especialistas por trás dessa revista.

\footnotetext{
${ }^{22}$ A tarefa coube a Charles-Émile Ruelle (1833-1912), antigo chartista e administrador da Bibliothèque Sainte-Geneviève. Sócio da AEEG desde 1869, ele já escrevia esse item para o anuário da associação desde 1873. Na REG, apenas em 1894 e em 1895, provavelmente por motivos de saúde, a Bibliographie des Études Grecques não foi publicada. Ninguém assumiu a tarefa após sua morte, ocorrida em 1912. Sobre Charles Ruelle, veja-se o breve necrológio de autoria de Salomon Reinach em RA, 1912/2: 424.

${ }^{23}$ Esse item será mais tarde intitulado "Antiguidades - Instituições - Direito", explicitando melhor sua função.
} 


\section{PADRÕES DE RECRUTAMENTO}

Entre 1888 e 1920, o recrutamento da REG pouco se alterou, o que sugere a manutenção de sua posição de destaque nos âmbitos nacional e internacional. Tal constância não implicou, contudo, imobilismo. A forte expansão do sistema universitário francês a partir da década de 1880 tendeu a elevar o número de postos dedicados aos estudos gregos nas províncias, tornando mais frequentes as contribuições de professores daí provenientes. Além disso, a crescente tensão entre as potências europeias no período que antecedeu a Primeira Grande Guerra teve seu impacto na quantidade e na procedência dos artigos produzidos por colegas estrangeiros. São justamente esses e outros padrões observáveis na morfologia dos trinta primeiros anos da REG que serão agora discutidos.

No que diz respeito aos vínculos institucionais de seus colaboradores, como se pode observar nos quadros 2.3.1, 2.3.2 e 2.3.3, sobressaíram-se os detentores de postos na capital. Mesmo quando a categoria "professores de faculdades provinciais" surge como a mais representativa individualmente, o somatório das posições parisienses se sobrepõe a ela em todos os anos, salvo em 1897 e em 1914. Trata-se de uma tendência bastante natural se considerada a sintonia da REG com a estrutura altamente hierárquica e centralizadora do sistema educacional francês.

A Sorbonne e o Collège de France se destacaram quanto ao número de colaboradores fornecidos à revista. Foram raros os anos em que os professores desses vértices do sistema de ensino deixaram de contribuir. Em 1908, eles chegaram a estar por trás de aproximadamente metade de todos os textos publicados. Ainda no contexto parisiense, chama atenção a presença de helenistas ligados a outras instituições mais especializadas, tais como o Musée des Antiquités Nationales, o Musée du Louvre, a École Pratique des Hautes Études, a École Normale Supérieure, a Bibliothèque Sainte-Geneviève e a Bibliothèque Nationale. Já quanto aos liceus e colégios da capital, justo aqueles que serviam de antessala às faculdades e escolas mais renomadas, o número de colaboradores foi pequeno, embora tenha crescido com o passar dos anos. Por fim, um quarto subgrupo oriundo de Paris foi composto por patrões e promessas de outras disciplinas. Até 1920, foram nela publicados textos esporádicos de quatro orientalistas (Jules Oppert, James Darmesteter, Sylvain Lévi e Isidore Lévy) e de um cientista social (Alfred Espinas) ${ }^{24}$. Os linguistas Michel Bréal, Antoine Meillet e Joseph Vendryes fizeram-se

\footnotetext{
${ }^{24}$ Desses cinco pesquisadores, quatro publicaram apenas um texto na REG. Sylvain Lévi, ainda como maître de conférence na EPHE, tratou das relações entre a Índia e a Grécia Antiga a partir de testemunhos epigráficos e literários indianos (REG, 1891: 24-45). O professor do Collège de France James Darmesteter, por seu turno, procurou datar um trecho do novo Zend-Avesta identificando Alexandre como um dos nomes referidos no texto (REG, 1892: 189-196). O assiriólogo Jules Oppert, também professor no Collège de France, discutiu questões relativas ao calendário grego (REG, 1903: 5-
} 
igualmente presentes, ainda que seus interesses particulares, centrados nos diversos ramos linguísticos do indo-europeu, os tenham incentivado a frequentar a REG com maior assiduidade que seus colegas não helenistas ${ }^{25}$.

Se Paris fez-se representar na REG a partir de pesquisadores consagrados, da Província vieram os que almejavam conquistar um lugar ao sol. Não seria, afinal, o simples fato de ter um artigo nela impresso, fazendo seu nome circular ao lado dos grandes pesquisadores parisienses, um signo de eleição? Entre 1888 e 1920, muitos dos futuros expoentes do helenismo francês passaram pela REG no início de suas carreiras, quando ocupavam posições provinciais. Maurice Croiset, Maurice Holleaux, Émile Bourguet, Pierre Roussel ilustram bem esse fenômeno: todos escreveram para a REG antes de assumirem suas respectivas cátedras no Collège de France e na Sorbonne. Outros, como Philippe-Ernest Legrand, Félix Dürrbach e Paul Perdrizet, a despeito de seus investimentos por vezes consideráveis em termos de publicação, não tiveram o mesmo destino: os três terminaram suas carreiras como professores de língua, literatura e história antigas longe da capital, respectivamente em Lyon, Toulouse e Estrasburgo. Não cabe discutir aqui as causas e consequências desses (in)sucessos. Cumpre sim sublinhar que os colaboradores provinciais da REG formaram uma categoria mais homogênea que a dos parisienses. Com efeito, não existiram entre eles especialistas de outras disciplinas: tratava-se apenas de universitários engajados nos estudos gregos, o que reforça mais uma vez o lugar da REG como instância privilegiada de reconhecimento e de seleção nessa área específica do saber.

A posição central da REG no cenário francês e europeu transparece ainda, e sobretudo, na quantidade e na qualidade dos estrangeiros que aceitaram colaborar com ela. A atuação da AEEG em favor dos interesses da Grécia surtiu efeitos quanto aos artigos impressos em sua

17). Já o sociólogo Alfred Espinas, professor na Sorbonne, abordou o espaço dedicado às relações econômicas no conjunto da obra platônica (REG, 1914: 105-129 e 236-255). Isidore Lévy, por fim, foi autor de quatro artigos. Nos três primeiros, escritos enquanto o autor ainda era bolsista da Fondation Thiers ou chargé de cours na EPHE, discutiu-se a vida municipal na Ásia Menor sob o Império Romano (REG, 1895: 203-255; 1899: 255-289; 1901: 350-371). No último, já efetivado na EPHE, discutiu alguns problemas de transcrição de um hino grego e dedicado a divindades orientais (REG, 1913: 262).

${ }^{25}$ Michel Bréal foi um dos membros fundadores da AEEG e publicou um total de oito artigos na revista da associação (REG, 1890: 125-130; 1899: 116 e 300-304; 1901: 113-121; 1902: 1-10; 1908: 113-118; 1909: 231-233; 1911: 1-4). Antoine Meillet, como se verá mais tarde, também esteve intensamente envolvido com a AEEG, da qual se tornou sócio em 1908 e presidente durante a Primeira Guerra Mundial. Na REG, ele publicou quatro artigos (REG, 1908: 413-425; 1916: 259-274; 1918: 277-314; 1919: 384-387). Dos três linguistas, Vendryes foi o único que não trabalhou intensivamente com o grego, tendo se especializado no ramo céltico das línguas indo-europeias. Ainda assim, ele foi membro da AEEG desde 1903, publicando na REG um artigo (REG, 1919: 495-503) e inúmeras resenhas (comptes-rendus). 
revista. Os professores gregos mais renomados, os quais detinham, aliás, um poder nada negligenciável quanto ao acesso aos sítios arqueológicos e arquivos locais, representaram a presença internacional mais constante na REG. É o caso, entre outros, do arqueólogo Panagiotis Cavvadias, do jurista Andréas Andréadès e do médico Georges Costomiris, professores na Universidade de Atenas ${ }^{26}$.

A REG se notabilizou também por ser uma ponte direta com os dois outros maiores polos universitários europeus, o alemão e o britânico. Quanto aos colegas do outro lado do Reno, a colaboração seguiu esporádica até atingir um pico entre 1903 e 1907, quando foram publicados textos do papirologista Wilhelm Crönert, do bizantinista Karl Krumbacher e a tradução de um texto de Goethe ${ }^{27}$. Na sequência, porém, com o acirramento das tensões entre França e Alemanha, o diálogo direto cessou. Da Grã-Bretanha, as colaborações foram mais intensas nos primeiros anos da REG, tornando-se esporádicas entre 1898 e 1920 . O orientalista Archibald Henry Sayce, professor de assiriologia em Oxford, foi quem, do outro lado do Canal da Mancha, mais colaborou com a revista francesa ${ }^{28}$.

Para além da Alemanha, da Grã-Bretanha e da Grécia, a REG contou ainda com a participação ativa de professores vindos de países com regiões francófonas: a Bélgica e a Suíça. Tal presença se explica, em parte, pela competição entre as potências europeias quanto à expansão de suas zonas de influência intelectual. Nomes de peso como os de Franz Cumont, professor em Gand, e Waldemar Deonna, diretor do Musée d'Art et d'Histoire de Genebra, tiveram parte de suas formações na França e jamais perderam o contato com o país. Mas havia ainda outra razão estratégica, importante quando se tratava dos suíços: eles foram os únicos em condição de servir de intermediários entre os professores franceses e alemães imediatamente antes e durante a Guerra de $14-18^{29}$. Por fim, quanto aos demais estrangeiros, foram identificados como colaboradores três italianos (Giorgio Castellani, Francesco Garofalo e Francesco Pellati), dois holandeses (Dirk Hesseling e Conrad Kuiper), um búlgaro (Gawril Kazarow), um polonês (Charles Hadaczek) e um austríaco (Karl Wessely).

\footnotetext{
${ }^{26}$ Cavvadias, arqueólogo grego responsável pela exploração sistemática da Acrópole de Atenas, publicou na revista um texto sobre estátuas gregas recém-descobertas (REG, 1901:122-126). Andréadès, por seu turno, discutiu na REG tanto as finanças da Grécia Moderna (REG, 1910: 131-183; 1912: 427-460), quanto aquelas da Grécia Homérica (REG, 1915: 377-416). Georges Costomiris, por fim, dedicou suas pesquisas à medicina antiga. Ele publicou na REG um extenso levantamento dos manuscritos relativos ao tema, de Hipócrates até o século XIV d.C., existentes em toda a Europa (REG, 1889: 343-383; 1890: 145-179; 1891: 97-110; 1892: 61-72; 1897: 405-445).

${ }^{27}$ Sobre esses textos em especial, cf. REG, 1903: 1-4, 193-197 e 246-275; 1904: 12-17; 1907: 358-363.

${ }^{28}$ Embora tenha ocupado a cátedra de assiriologia em Oxford de 1891 a 1919, os artigos encaminhados para a REG tratam das relações entre a Grécia e o Egito Antigos. Veja-se, a esse respeito, REG, 1888: 311-317; 1890: 131-144; 1891: 46-57; 1894: 284-304.

${ }^{29}$ Veja-se um testemunho direto disso na carta que Waldemar Deonna endereça a Salomon Reinach, datada de 13 de agosto de 1916 (cf. os dossiês de correspondência do Musée d'Archéologie Nationale).
} 
Quadro 2.3.1 - Padrões de recrutamento - autores de artigos (REG, 1888-1898). ${ }^{30}$

\begin{tabular}{|c|c|c|c|c|c|c|c|c|c|c|c|}
\hline $\begin{array}{l}\text { VÍNCULO INSTITUCIONAL DOS AUTORES (articles de } \\
\text { fonds)/ANO }\end{array}$ & 1888 & 1889 & 1890 & 1891 & 1892 & 1893 & 1894 & 1895 & 1896 & 1897 & 1898 \\
\hline Professor do Collège de France (Paris) & $0 \%$ & $0 \%$ & $13,33 \%$ & $0 \%$ & $6,25 \%$ & $6,67 \%$ & $10,53 \%$ & $0 \%$ & $7,69 \%$ & $0 \%$ & $0 \%$ \\
\hline Professor das Faculdades de Letras/Direito de Paris & $14,29 \%$ & $14,29 \%$ & $6,67 \%$ & $15,38 \%$ & $6,25 \%$ & $6,67 \%$ & $5,26 \%$ & $8,33 \%$ & $0 \%$ & $0 \%$ & $8,33 \%$ \\
\hline Professor de Liceu parisiense & $7,14 \%$ & $0 \%$ & $0 \%$ & $0 \%$ & $0 \%$ & $0 \%$ & $0 \%$ & $0 \%$ & $0 \%$ & $0 \%$ & $0 \%$ \\
\hline Professor/pesquisador em Paris (EPHE, ENS, Museus) & $42,86 \%$ & $35,71 \%$ & $20 \%$ & $23,08 \%$ & $31,25 \%$ & $20 \%$ & $26,32 \%$ & $25 \%$ & $15,38 \%$ & $23,08 \%$ & $25 \%$ \\
\hline Professor de Faculdade de Letras/Direito provincial & $7,14 \%$ & $7,14 \%$ & $0 \%$ & $0 \%$ & $6,25 \%$ & $20 \%$ & $15,79 \%$ & $16,67 \%$ & $15,38 \%$ & $30,77 \%$ & $8,33 \%$ \\
\hline Professor de Liceu de província & $0 \%$ & $0 \%$ & $0 \%$ & $0 \%$ & $0 \%$ & $0 \%$ & $0 \%$ & $0 \%$ & $0 \%$ & $7,69 \%$ & $0 \%$ \\
\hline Pesquisador sem posto fixo em liceus ou universidades & $14,29 \%$ & $7,14 \%$ & $13,33 \%$ & $23,08 \%$ & $12,50 \%$ & $26,67 \%$ & $15,79 \%$ & $25 \%$ & $30,77 \%$ & $23,08 \%$ & $25 \%$ \\
\hline Colaborador francês sem diploma universitário (erudito) & $0 \%$ & $0 \%$ & $0 \%$ & $0 \%$ & $6,25 \%$ & $0 \%$ & $0 \%$ & $0 \%$ & $0 \%$ & $0 \%$ & $0 \%$ \\
\hline Colaborador estrangeiro (Alemão) & $0 \%$ & $0 \%$ & $6,67 \%$ & $0 \%$ & $0 \%$ & $0 \%$ & $0 \%$ & $0 \%$ & $0 \%$ & $0 \%$ & $0 \%$ \\
\hline Colaborador estrangeiro (Britânico) & $7,14 \%$ & $7,14 \%$ & $6,67 \%$ & $7,69 \%$ & $0 \%$ & $6,67 \%$ & $5,26 \%$ & $0 \%$ & $7,69 \%$ & $0 \%$ & $0 \%$ \\
\hline Colaborador estrangeiro (Belga) & $0 \%$ & $0 \%$ & $0 \%$ & $0 \%$ & $0 \%$ & $0 \%$ & $0 \%$ & $0 \%$ & $0 \%$ & $0 \%$ & $0 \%$ \\
\hline Colaborador estrangeiro (Suíço) & $0 \%$ & $0 \%$ & $0 \%$ & $0 \%$ & $0 \%$ & $0 \%$ & $5,26 \%$ & $8,33 \%$ & $0 \%$ & $0 \%$ & $0 \%$ \\
\hline Colaborador estrangeiro (Grego) & $7,14 \%$ & $14,29 \%$ & $13,33 \%$ & $7,69 \%$ & $6,25 \%$ & $6,67 \%$ & $0 \%$ & $0 \%$ & $0 \%$ & $7,69 \%$ & $16,67 \%$ \\
\hline Colaborador estrangeiro (Outro) & $0 \%$ & $0 \%$ & $6,67 \%$ & $0 \%$ & $6,25 \%$ & $0 \%$ & $0 \%$ & $0 \%$ & $7,69 \%$ & $0 \%$ & $0 \%$ \\
\hline Colaborador não identificado & $0 \%$ & $14,29 \%$ & $13,33 \%$ & $23,08 \%$ & $18,75 \%$ & $6,67 \%$ & $15,79 \%$ & $16,67 \%$ & $15,38 \%$ & $7,69 \%$ & $16,67 \%$ \\
\hline Total de colaboradores por ano ( $\mathrm{N}=100 \%)$ & 14 & 14 & 15 & 13 & 16 & 15 & 19 & 12 & 13 & 13 & 12 \\
\hline
\end{tabular}

${ }^{30} \mathrm{Na}$ elaboração das tabelas 2.3.1, 2.3.2 e 2.3.3 desconsiderou-se a quantidade de textos por colaborador. O método adotado consistiu em acompanhar, ano a ano, quem escrevia para a REG e qual era então seu vínculo institucional. Se o vínculo para o ano em questão não pode ser recuperado, preferiu-se então incorporar o autor à categoria "não identificado". Quanto aos "agrégés sem posto em liceus ou universidades", podem ser tanto bolsistas do governo francês em formação no exterior quanto especialistas renomados então ocupados com atribuições burocráticas ou políticas. 
Quadro 2.3.2 - Padrões de recrutamento - autores de artigos (REG, 1899-1909).

\begin{tabular}{|c|c|c|c|c|c|c|c|c|c|c|c|}
\hline $\begin{array}{l}\text { VÍNCULO INSTITUCIONAL DOS AUTORES (articles de } \\
\text { fonds)/ANO }\end{array}$ & 1899 & 1900 & 1901 & 1902 & 1903 & 1904 & 1905 & 1906 & 1907 & 1908 & 1909 \\
\hline Professor do Collège de France (Paris) & $5,88 \%$ & $0 \%$ & $6,67 \%$ & $7,69 \%$ & $11,11 \%$ & $7,14 \%$ & $0 \%$ & $0 \%$ & $0 \%$ & $21,43 \%$ & $20 \%$ \\
\hline Professor das Faculdades de Letras/Direito de Paris & $11,76 \%$ & $0 \%$ & $13,33 \%$ & $0 \%$ & $11,11 \%$ & $14,29 \%$ & $7,69 \%$ & $0 \%$ & $16,67 \%$ & $21,43 \%$ & $6,67 \%$ \\
\hline Professor de Liceu parisiense & $11,76 \%$ & $6,67 \%$ & $0 \%$ & $0 \%$ & $5,56 \%$ & $0 \%$ & $0 \%$ & $0 \%$ & $0 \%$ & $7,14 \%$ & $0 \%$ \\
\hline Professor/pesquisador em Paris (EPHE, ENS, Museus) & $29,41 \%$ & $40 \%$ & $33,33 \%$ & $30,77 \%$ & $11,11 \%$ & $14,29 \%$ & $23,08 \%$ & $50 \%$ & $25 \%$ & $14,29 \%$ & $13,33 \%$ \\
\hline Professor de Faculdade de Letras/Direito provincial & $17,65 \%$ & $20 \%$ & $20 \%$ & $15,38 \%$ & $16,67 \%$ & $21,43 \%$ & $15,38 \%$ & $20 \%$ & $8,33 \%$ & $7,14 \%$ & $13,33 \%$ \\
\hline Professor de Liceu de província & $0 \%$ & $0 \%$ & $0 \%$ & $7,69 \%$ & $0 \%$ & $0 \%$ & $7,69 \%$ & $0 \%$ & $0 \%$ & $7,14 \%$ & $6,67 \%$ \\
\hline Pesquisador sem posto fixo em liceus ou universidades & $11,76 \%$ & $6,67 \%$ & $6,67 \%$ & $15,38 \%$ & $11,11 \%$ & $14,29 \%$ & $23,08 \%$ & $20 \%$ & $0 \%$ & $14,29 \%$ & $20 \%$ \\
\hline Colaborador francês sem diploma universitário (erudito) & $0 \%$ & $0 \%$ & $0 \%$ & $0 \%$ & $0 \%$ & $0 \%$ & $0 \%$ & $0 \%$ & $0 \%$ & $0 \%$ & $0 \%$ \\
\hline Colaborador estrangeiro (Alemão) & $0 \%$ & $6,67 \%$ & $0 \%$ & $0 \%$ & $16,67 \%$ & $7,14 \%$ & $0 \%$ & $0 \%$ & $8,33 \%$ & $0 \%$ & $0 \%$ \\
\hline Colaborador estrangeiro (Britânico) & $0 \%$ & $0 \%$ & $0 \%$ & $0 \%$ & $0 \%$ & $0 \%$ & $7,69 \%$ & $0 \%$ & $8,33 \%$ & $0 \%$ & $0 \%$ \\
\hline Colaborador estrangeiro (Belga) & $0 \%$ & $0 \%$ & $6,67 \%$ & $7,69 \%$ & $5,56 \%$ & $7,14 \%$ & $0 \%$ & $10 \%$ & $0 \%$ & $0 \%$ & $0 \%$ \\
\hline Colaborador estrangeiro (Suíço) & $0 \%$ & $0 \%$ & $0 \%$ & $0 \%$ & $0 \%$ & $7,14 \%$ & $7,69 \%$ & $0 \%$ & $8,33 \%$ & $0 \%$ & $0 \%$ \\
\hline Colaborador estrangeiro (Grego) & $5,88 \%$ & $6,67 \%$ & $13,33 \%$ & $7,69 \%$ & $5,56 \%$ & $7,14 \%$ & $0 \%$ & $0 \%$ & $8,33 \%$ & $0 \%$ & $13,33 \%$ \\
\hline Colaborador estrangeiro (Outro) & $0 \%$ & $6,67 \%$ & $0 \%$ & $0 \%$ & $0 \%$ & $0 \%$ & $0 \%$ & $0 \%$ & $8,33 \%$ & $0 \%$ & $0 \%$ \\
\hline Colaborador não identificado & $5,88 \%$ & $6,67 \%$ & $0 \%$ & $7,69 \%$ & $5,56 \%$ & $0 \%$ & $7,69 \%$ & $0 \%$ & $16,67 \%$ & $7,14 \%$ & $6,67 \%$ \\
\hline Total de colaboradores por ano $(\mathrm{N}=100 \%)$ & 17 & 15 & 15 & 13 & 18 & 14 & 13 & 10 & 12 & 14 & 15 \\
\hline
\end{tabular}


Quadro 2.3.3 - Padrões de recrutamento - autores de artigos (REG, 1910-1920).

\begin{tabular}{|c|c|c|c|c|c|c|c|c|c|c|c|}
\hline $\begin{array}{l}\text { VÍNCULO INSTITUCIONAL DOS AUTORES (articles de } \\
\text { fonds)/ANO }\end{array}$ & 1910 & 1911 & 1912 & 1913 & 1914 & 1915 & 1916 & 1917 & 1918 & 1919 & 1920 \\
\hline Professor do Collège de France (Paris) & $0 \%$ & $10 \%$ & $11,11 \%$ & $0 \%$ & $0 \%$ & $6,25 \%$ & $6,67 \%$ & $0 \%$ & $7,14 \%$ & $10,64 \%$ & $0 \%$ \\
\hline Professor das Faculdades de Letras/Direito de Paris & $18,18 \%$ & $0 \%$ & $11,11 \%$ & $14,29 \%$ & $15,38 \%$ & $6,25 \%$ & $20 \%$ & $22,22 \%$ & $7,14 \%$ & $25,53 \%$ & $33,33 \%$ \\
\hline Professor de Liceu parisiense & $9,09 \%$ & $0 \%$ & $11,11 \%$ & $7,14 \%$ & $0 \%$ & $18,75 \%$ & $6,67 \%$ & $22,22 \%$ & $14,29 \%$ & $2,13 \%$ & $16,67 \%$ \\
\hline Professor/pesquisador em Paris (EPHE, ENS, Museus) & $9,09 \%$ & $10 \%$ & $11,11 \%$ & $21,43 \%$ & $7,69 \%$ & $18,75 \%$ & $13,33 \%$ & $11,11 \%$ & $7,14 \%$ & $23,40 \%$ & $16,67 \%$ \\
\hline Professor de Faculdade de Letras/Direito provincial & $18,18 \%$ & $10 \%$ & $11,11 \%$ & $7,14 \%$ & $38,46 \%$ & $6,25 \%$ & $0 \%$ & $33,33 \%$ & $14,29 \%$ & $10,64 \%$ & $16,67 \%$ \\
\hline Professor de Liceu de província & $0 \%$ & $20 \%$ & $0 \%$ & $0 \%$ & $0 \%$ & $6,25 \%$ & $13,33 \%$ & $11,11 \%$ & $7,14 \%$ & $0 \%$ & $0 \%$ \\
\hline Pesquisador sem posto fixo em liceus ou universidades & $0 \%$ & $10 \%$ & $0 \%$ & $7,14 \%$ & $7,69 \%$ & $6,25 \%$ & $13,33 \%$ & $0 \%$ & $7,14 \%$ & $2,13 \%$ & $0 \%$ \\
\hline Colaborador francês sem diploma universitário (erudito) & $0 \%$ & $0 \%$ & $0 \%$ & $0 \%$ & $0 \%$ & $0 \%$ & $0 \%$ & $0 \%$ & $0 \%$ & $0 \%$ & $0 \%$ \\
\hline Colaborador estrangeiro (Alemão) & $0 \%$ & $0 \%$ & $0 \%$ & $0 \%$ & $0 \%$ & $0 \%$ & $0 \%$ & $0 \%$ & $0 \%$ & $0 \%$ & $0 \%$ \\
\hline Colaborador estrangeiro (Britânico) & $0 \%$ & $0 \%$ & $0 \%$ & $0 \%$ & $7,69 \%$ & $0 \%$ & $0 \%$ & $0 \%$ & $0 \%$ & $2,13 \%$ & $0 \%$ \\
\hline Colaborador estrangeiro (Belga) & $0 \%$ & $0 \%$ & $0 \%$ & $0 \%$ & $0 \%$ & $0 \%$ & $0 \%$ & $0 \%$ & $14,29 \%$ & $6,38 \%$ & $0 \%$ \\
\hline Colaborador estrangeiro (Suíço) & $9,09 \%$ & $0 \%$ & $0 \%$ & $7,14 \%$ & $7,69 \%$ & $6,25 \%$ & $13,33 \%$ & $0 \%$ & $14,29 \%$ & $2,13 \%$ & $16,67 \%$ \\
\hline Colaborador estrangeiro (Grego) & $18,18 \%$ & $0 \%$ & $22,22 \%$ & $7,14 \%$ & $0 \%$ & $18,75 \%$ & $0 \%$ & $0 \%$ & $7,14 \%$ & $0 \%$ & $0 \%$ \\
\hline Colaborador estrangeiro (Outro) & $9,09 \%$ & $0 \%$ & $11,11 \%$ & $14,29 \%$ & $0 \%$ & $0 \%$ & $13,33 \%$ & $0 \%$ & $0 \%$ & $8,51 \%$ & $0 \%$ \\
\hline Colaborador não identificado & $9,09 \%$ & $40 \%$ & $11,11 \%$ & $14,29 \%$ & $15,38 \%$ & $6,25 \%$ & $0 \%$ & $0 \%$ & $0 \%$ & $6,38 \%$ & $0 \%$ \\
\hline Total de colaboradores por ano $(\mathrm{N}=100 \%)$ & 11 & 10 & 9 & 14 & 13 & 16 & 15 & 9 & 14 & 47 & 6 \\
\hline
\end{tabular}


Duas últimas observações sobre os vínculos institucionais dos colaboradores da REG. A primeira diz respeito ao "pesquisador sem posto em liceus ou universidades". A porcentagem elevada daqueles que foram enquadrados em tal categoria, sobretudo entre 1888 e 1906, pode dar a impressão de que a revista acolheu muitos novatos. Nada mais equivocado. Embora alguns jovens tenham conseguido, de fato, nela publicar, essas altas taxas remetem a especialistas reconhecidos que ocupavam posições fora da universidade. Impossível não mencionar aqui os casos de Théodore Reinach e de Paul Tannery, dois dos maiores habitués da REG. Enquanto este permaneceu atrelado ora à docência (cursos livres na Faculdade de Ciências de Paris e suplência no Collège de France), ora à burocracia estatal (Ministério das Finanças), ora aos negócios (indústria do tabaco), aquele alternou postos provisórios em várias instituições parisienses com a função de deputado, vindo a assumir uma cadeira no sistema de ensino apenas na década de 1920, no Collège de France. Tal situação não impediu que ambos se dedicassem com afinco aos estudos gregos. Tannery, por exemplo, em fins do século XIX e inícios do XX, era considerado um dos mais competentes historiadores da ciência na França, tendo trabalhos de peso sobre os matemáticos gregos e sobre Descartes ${ }^{31}$.

A segunda observação remete à relativa ausência dos "eruditos". Mesmo tendo sido criada e mantida com a ajuda de indivíduos desprovidos de credenciais universitárias, a AEEG soube restringir o espaço aberto a eles em sua revista. Levando em consideração o recorte temporal aqui observado, o único autor que pôde ser assim identificado foi Fernand de Mély. Não se tratava, porém, de um savant qualquer. Membro da Société des Antiquaires e com contatos no mundo universitário, de Mély produziu estudos sobre uma gama variada de temas: lapidários antigos, relíquias cristãs, cerâmica chinesa e igrejas medievais ${ }^{32}$. Seu único texto publicado na REG discutiu um tratado que Aristóteles teria supostamente escrito sobre as propriedades dos minerais (REG, 1894: 181-191). É provável, contudo, que a porcentagem desses "eruditos" tenha sido maior do que o indicado nos quadros acima apresentados. Muitos dos autores sobre os quais não foi possível encontrar informações foram provavelmente ou pesquisadores desconectados da universidade ou então estrangeiros. De todo o modo, mesmo considerando essa possibilidade, o número de "eruditos" seria sempre muito inferior ao de professores e pesquisadores universitários.

\footnotetext{
31 Tannery (1843-1904) chegou a ser indicado por seus colegas para ocupar o posto de professor no Collège de France em 1903, mas viu sua vaga ser destinada a Grégoire Wyrouboff por uma decisão governamental (sobre os procedimentos eleitorais do Collège de France, ver o item 3.1 da presente tese). Por ocasião de sua morte, a REG publicou um breve necrológio (REG, 1904: 393-395). Mais informações sobre Tannery podem ser ainda encontradas em Favoro (1905), Duhem (1905) e Milhaud (1906).

${ }^{32}$ Uma notícia contendo maiores detalhes sobre a vida e os trabalhos de Fernand de Mély foi publicada por Raymond Lantier na Revue Archéologique (cf. RA, 1935: 87-89).
} 
Se o vínculo institucional dos colaboradores permite, por si só, compreender melhor a dinâmica interna da REG, dados de outra natureza ajudam a expandir e a complementar essa análise. Nos quadros apresentados nas próximas páginas (2.3.4, 2.3.5 e 2.3.6), encontram-se informações detalhadas sobre a carreira profissional (escolas frequentadas, diplomas obtidos e postos ocupados) e o background pessoal (educação religiosa, militância por ocasião do Affaire Dreyfus e situação familiar) dos autores que mais publicaram nela em três intervalos: 18991906, 1907-1913 e 1914-1920. Além de apresentar com maior nitidez o perfil dominante da revista, tal expediente cumpre aqui a uma função comparatista: ele servirá mais tarde para precisar as afinidades e diferenças entre a REG, o AS e a REA.

O primeiro intervalo, 1899-1906, caracterizou-se pela profunda reforma do sistema de ensino, pela radical separação entre Igreja e Estado e por ter sido nele que se desenrolou o Affaire Dreyfus. Tais fenômenos afetaram a relação entre os professores/pesquisadores universitários, suscitando tensões e associações que não se explicam por chaves puramente intelectuais. Nesse ínterim, é interessante notar que a REG, dirigida então por Théodore Reinach, foi marcada por uma importante presença de judeus e de dreyfusards declarados entre seus principais colaboradores. Entre os estrangeiros, apenas um grego ganhou destaque, ao qual se somaram dois professores de faculdades provinciais (Philippe-Ernest Legrand e Maurice Holleaux), dois pesquisadores parisienses (Henri Weil e Henry Omont) e outros dois renomados especialistas sem vínculo docente estável (Théodore Reinach e Paul Tannery). Outro detalhe é a diversidade de formações dos franceses: um chartista, um politécnico, um formado nas universidades alemãs e dois alunos da ENS (os quais eram, aliás, os mais jovens). Esses seis pesquisadores, sozinhos, foram então responsáveis por $41,3 \%$ dos artigos publicados, o que sugere uma notável concentração (com destaque para o diretor da revista, autor de nada menos que $14 \%$ do total).

O segundo intervalo, 1907-1913, o qual compreende os anos que antecederam a Primeira Guerra Mundial, foi marcado internamente pelo início da gestão de Gustave Glotz. A concentração de artigos antes encontrada passa a não ter mais a mesma intensidade: foram agora necessários 17 autores para cobrir $46,2 \%$ do total de textos publicados, o que implica um menor número de artigos por autor. Além disso, constata-se uma maior homogeneidade na formação dos principais colaboradores: os antigos alunos da ENS se sobressaíram aos demais, seguidos por antigos alunos das Faculdades de Letras francesas. Por fim, os detentores de posições em Paris ganharam um espaço maior que as demais categorias institucionais. Mas como nem só de rupturas viveu a REG, o número de antiquisants judeus e de dreyfusards continuou nela elevado. Entre os estrangeiros, a única diferença deve-se à presença de um suíço, Waldemar Deonna, ao lado de dois pesquisadores gregos. 
Quadro 2.3.4 - REG - 1899-1906. Frequência de publicação, trajetória pessoal e institucional.

\begin{tabular}{|c|c|c|c|c|c|c|c|c|}
\hline NOME & $\begin{array}{l}\text { ARTIGOS } \\
\text { (N) }\end{array}$ & $\begin{array}{c}\text { ARTIGOS } \\
(\%)\end{array}$ & $\begin{array}{l}\text { ESTUDO } \\
\text { SUPERIOR }\end{array}$ & AGRÉGATION & CARGOS E TÍTULOS ACADÊMICOS & $\begin{array}{l}\text { FILIAÇÃO } \\
\text { RELIGIOSA }\end{array}$ & $\begin{array}{l}\text { AFFAIRE } \\
\text { DREYFUS }\end{array}$ & BACKGROUD FALIMIAR \\
\hline $\begin{array}{l}\text { Théodore } \\
\text { REINACH }\end{array}$ & 20 & $14 \%$ & $\begin{array}{l}\text { Faculté de } \\
\text { droit-Paris }\end{array}$ & Sem agregação & $\begin{array}{l}\text { Docteur-en-droit (1885). } \\
\text { Diretor de Revue des Études Grecques (1888-1906). } \\
\text { Docteur-ès-lettres (1890). } \\
\text { Oferece cursos livres de numismática antiga na Faculdade de } \\
\text { letras de Paris (1894-97 e 1901). } \\
\text { Diretor da Gazette de Beaux Arts (1906). }\end{array}$ & Judeu & Dreyfusard & $\begin{array}{l}\text { De Saint-Germain-en- } \\
\text { Laye. Pai e mãe } \\
\text { envolvidos com o } \\
\text { mundo das altas } \\
\text { finanças. Esposa filha de } \\
\text { banqueiros. } \\
\end{array}$ \\
\hline $\begin{array}{c}\text { Paul } \\
\text { TANNERY }\end{array}$ & 7 & $4,9 \%$ & $\begin{array}{l}\text { E. Poly. } \\
\text { (prom. } \\
1861-?)\end{array}$ & Sem agregação & $\begin{array}{l}\text { Oferece cursos livres de História da Aritméica na Faculdade de } \\
\text { Ciências de Paris (1884-1885). } \\
\text { Suplente de Charles Lévèque no Collège de France (1892-1897). } \\
\text { Diretor de Manufaturas de Tabaco (?). } \\
\text { Membro do Institut (1903). }\end{array}$ & Católico & & $\begin{array}{l}\text { De Mantes.Irmão } \\
\text { normaliano, matemático } \\
\text { e dreyfusard (Jules } \\
\text { Tannery). }\end{array}$ \\
\hline $\begin{array}{c}\text { Maurice } \\
\text { HOLLEAUX }\end{array}$ & 7 & $4,9 \%$ & $\begin{array}{l}\text { Ens-lettres } \\
\text { (prom. 1879- } \\
8^{\text {eme }} \text { ) }\end{array}$ & $\begin{array}{l}\text { Hist/géo } \\
\left(1882-1^{\text {er }}\right)\end{array}$ & $\begin{array}{l}\text { Membro da École Française d'Athène (1882-5). } \\
\text { Chargé de cours na Faculdade de letras de Bordeaux (1886-1888). } \\
\text { Chargé de cours na Faculdade de letras de Lyon (1888-1904). } \\
\text { Diretor da École Française d'Athènes (1904). }\end{array}$ & Católico & Dreyfusard & $\begin{array}{c}\text { De Chateau-Thierry. Pai } \\
\text { engenheiro. Casa-se } \\
\text { com filha de engenheiro } \\
(1890) . \\
\end{array}$ \\
\hline $\begin{array}{l}\text { Alexandre-E. } \\
\text { CONDOLÉON }\end{array}$ & 7 & $4,9 \%$ & & & & & & Grego. \\
\hline $\begin{array}{l}\text { Henri } \\
\text { WEIL }\end{array}$ & 6 & $4,2 \%$ & $\begin{array}{l}\text { Universidades } \\
\text { de Bonn, } \\
\text { Berlin e } \\
\text { Leipzig }\end{array}$ & Lettres (1848-?) & $\begin{array}{l}\text { Docteur-ès-lettres (1845). } \\
\text { Professeur na Faculdade de letras de Strasbourg (1846-9). } \\
\text { Professor na Faculdade de letras de Besançon (1849-1876). } \\
\text { Correspondente (1866) e membro efetivo (1882) da Académie des } \\
\text { Inscriptions et Belles Lettres. } \\
\text { Membro Fundador da AEEG (1867). } \\
\text { Maître de conférence na École normale Supérieure e, ao mesmo } \\
\text { tempo, diretor-adjoint na École pratique des Hautes-Études } \\
(1876-1891) .\end{array}$ & Judeu & & $\begin{array}{l}\text { De Frankfurt } \\
\text { (Alemanha). Naturaliza- } \\
\text { se francês após estudos.. }\end{array}$ \\
\hline $\begin{array}{l}\text { Henry } \\
\text { OMONT }\end{array}$ & 6 & $4,2 \%$ & $\begin{array}{l}\text { E. Chartes } \\
\text { (prom. 1877- } \\
11^{\text {eme }} \text { ) }\end{array}$ & Sem agregação & $\begin{array}{l}\text { Bibliotecário na Bibliothèque National - setor de manuscritos } \\
\text { (1881-1933). } \\
\text { Membro efetivo da Académie des Inscriptions (1900). }\end{array}$ & & & De Evreux. \\
\hline $\begin{array}{l}\text { Phillipe-Ernest } \\
\text { LEGRAND }\end{array}$ & 6 & $4,2 \%$ & $\begin{array}{l}\text { Ens-lettres } \\
\text { (prom. 1885- } \\
\quad 8^{\text {eme }} \text { ) }\end{array}$ & Lettres $\left(1888-1^{\mathrm{er}}\right)$ & $\begin{array}{l}\text { Membro da École Française d'Athènes (1888-90). } \\
\text { Maître de conférence e professeur na Faculté de Lettres de Lyon } \\
\text { (1894). } \\
\text { Docteur-ès-lettres (1899). }\end{array}$ & & & De Sainte-Doulchard. \\
\hline
\end{tabular}


Quadro 2.3.5 - REG - 1907-1913. Frequência de publicação, trajetória pessoal e institucional.

\begin{tabular}{|c|c|c|c|c|c|c|c|c|}
\hline NOME & $\begin{array}{l}\text { ARTIGOS } \\
(\mathrm{N})\end{array}$ & $\begin{array}{l}\text { ARTIGOS } \\
(\%)\end{array}$ & $\begin{array}{l}\text { ESTUDO } \\
\text { SUPERIOR }\end{array}$ & AGRÉGATION & CADEIRAS E TíTULOS ACADÊMICOS & $\begin{array}{l}\text { FILIAÇÃO } \\
\text { RELIGIOSA }\end{array}$ & $\begin{array}{l}\text { AFFAIRE } \\
\text { DREYFUS }\end{array}$ & BACKGROUND FAMILIAR \\
\hline $\begin{array}{l}\text { Francisque } \\
\text { GREIF }\end{array}$ & 4 & $4,4 \%$ & & & $\begin{array}{l}\text { Professor no Conservatoire de Musique (?). } \\
\text { Conseiller à la Cour d'Appel em Nîmes (?). }\end{array}$ & & & \\
\hline $\begin{array}{l}\text { Waldemar } \\
\text { DEONNA }\end{array}$ & 4 & $4,4 \%$ & & & $\begin{array}{l}\text { Membro estrangeiro na École Française d'Athènes (1903-7). } \\
\text { Conservador no Musée de Génève (?). }\end{array}$ & & & $\begin{array}{c}\text { Suíço } \\
\text { Pai diplomata. }\end{array}$ \\
\hline $\begin{array}{l}\text { Théodore } \\
\text { REINACH }\end{array}$ & 3 & $3,3 \%$ & $\begin{array}{l}\text { Faculté de } \\
\text { Droit-Paris }\end{array}$ & Sem agregação & $\begin{array}{l}\text { Docteur-en-droit (1885). } \\
\text { Diretor de Revue des Études Grecques (1888-1906). } \\
\text { Docteur-ès-lettres (1890). } \\
\text { Oferece cursos livres de numismática antiga na Faculdade de } \\
\text { letras de Paris (1894-97 e 1901). } \\
\text { Diretor da Gazette de Beaux Arts (1906). } \\
\text { Deputado pela Savoie (gauche radicale - entre 1906-1914). }\end{array}$ & Judeu & Dreyfusard & $\begin{array}{l}\text { De Saint-Germain-en- } \\
\text { Laye. Pai e mãe } \\
\text { envolvidos com o } \\
\text { mundo das altas } \\
\text { finanças. Esposa filha de } \\
\text { banqueiros. }\end{array}$ \\
\hline $\begin{array}{l}\text { René } \\
\text { PICHON }\end{array}$ & 3 & $3,3 \%$ & $\begin{array}{l}\text { Ens-lettres } \\
\text { (prom. 1888- } \\
3^{\text {eme }} \text { ) }\end{array}$ & $\begin{array}{l}\text { Lettres (1891- } \\
\quad 3^{\text {eme }} \text { ) }\end{array}$ & $\begin{array}{l}\text { Docteur-ès-lettres (1903). } \\
\text { Professor no Liceu Henri IV (1907- ?). }\end{array}$ & & & De Mans. \\
\hline $\begin{array}{l}\text { Phillipe-Ernest } \\
\text { LEGRAND }\end{array}$ & 3 & $3,3 \%$ & $\begin{array}{l}\text { Ens-lettres } \\
\text { (prom. 1885- } \\
8^{\text {eme }} \text { ) }\end{array}$ & Lettres $\left(1888-1^{\mathrm{er}}\right)$ & $\begin{array}{l}\text { Membro da École Française d'Athènes (1888-90). } \\
\text { Maître de conférence e professeur na Faculté de Lettres de Lyon } \\
\text { (1894). } \\
\text { Docteur-ès-lettres (1899). }\end{array}$ & & & De Sainte-Doulchard \\
\hline $\begin{array}{l}\text { Michel } \\
\text { BRÉAL }\end{array}$ & 3 & $3,3 \%$ & $\begin{array}{l}\text { Ens-lettres } \\
\text { (prom. 1852- } \\
\text { ?) }\end{array}$ & Lettres (1857- ?) & $\begin{array}{l}\text { Professor de Grammaire Comparée no Collège de France (1866). } \\
\text { Membro fundador da AEEG (1867). } \\
\text { Fundador e diretor da École des Hautes Études (1868). } \\
\text { Membro da Académie des Inscriptions et Belles Lettres (1875). } \\
\text { Inspecteur générale pour l'enseignement supérieur (1879-1888). }\end{array}$ & Judeu & & $\begin{array}{l}\text { De Landau (Alemanha). } \\
\text { Pai advogado de origem } \\
\text { francesa. Mãe alemã. }\end{array}$ \\
\hline $\begin{array}{l}\text { Pierre } \\
\text { WALTZ }\end{array}$ & 2 & $2,2 \%$ & $\begin{array}{l}\text { Faculté de } \\
\text { Lettres- } \\
\text { Bordeaux }\end{array}$ & $\begin{array}{l}\text { Grammaire (1898- } \\
\left.2^{\text {ème }}\right)\end{array}$ & $\begin{array}{l}\text { Professor no Liceu de Bordeaux (1906 ?). } \\
\text { Docteur-ès-lettres (1906). } \\
\text { Professor na Faculté de lettres de Clermont-Ferrand (1907). }\end{array}$ & & & De Lyon. \\
\hline $\begin{array}{l}\text { George } \\
\text { SEURES }\end{array}$ & 2 & $2,2 \%$ & $\begin{array}{l}\text { Ens-lettres } \\
\text { (prom. 1894- } \\
\left.15^{\text {eme }}\right)\end{array}$ & $\begin{array}{l}\text { Lettres (1897- } \\
\left.\quad 8^{\text {eme }}\right)\end{array}$ & $\begin{array}{l}\text { Membro da École Française d'Athène ( 1898-1901). } \\
\text { Professor no Liceu de Chartres (1904). } \\
\text { Professeur de première no Liceu Saint-Louis (1907). }\end{array}$ & & & \\
\hline $\begin{array}{l}\text { Salomon } \\
\text { REINACH }\end{array}$ & 2 & $2,2 \%$ & $\begin{array}{l}\text { Ens-lettres } \\
\text { (prom. 1876- } \\
1^{\text {er }} \text { ) }\end{array}$ & $\begin{array}{l}\text { Grammaire }(1879 \\
\left.-1^{\mathrm{er}}\right)\end{array}$ & $\begin{array}{l}\text { Attaché libre e, depois, conservateur no Musée de Saint-Germain- } \\
\text { en-Laye (1885). Suplente e, depois, professor titular na École du } \\
\text { Louvre (1890-190?). } \\
\text { Membro da Académie des Inscriptions et Belles Lettres (1896). } \\
\text { Codiretor da Revue Archéologique (1903). }\end{array}$ & Judeu & Dreyfusard & $\begin{array}{l}\text { De Saint-Germain-en- } \\
\text { Laye. Pai e mãe } \\
\text { envolvidos com o } \\
\text { mundo das altas } \\
\text { finanças. Esposa médica. }\end{array}$ \\
\hline $\begin{array}{l}\text { Adolphe-J. } \\
\text { REINACH }\end{array}$ & 2 & $2,2 \%$ & $\begin{array}{l}\text { Fac. de } \\
\text { Lettres de } \\
\text { Paris. EPHE. }\end{array}$ & $\begin{array}{l}\text { Hist/géo } \\
\text { (1909-?) }\end{array}$ & $\begin{array}{l}\text { Membro da École Française d'Athènes (1909-11). } \\
\text { Suplente na EPHE (1912 ?). }\end{array}$ & Judeu & & $\begin{array}{l}\text { De Paris. Pai era Joseph } \\
\text { Reinach, advogado e } \\
\text { homem político. }\end{array}$ \\
\hline
\end{tabular}




\begin{tabular}{|c|c|c|c|c|c|c|c|c|}
\hline $\begin{array}{l}\text { Étienne } \\
\text { MICHON }\end{array}$ & 2 & $2,2 \%$ & $\begin{array}{l}\text { Ens-lettres } \\
\text { (prom. 1884- } \\
\text { ?) }\end{array}$ & $\begin{array}{l}\text { Lettres (1887- } \\
\left.5^{\text {emee }}\right)\end{array}$ & $\begin{array}{l}\text { Membro da École française de Rome (1887-9). } \\
\text { Docteur-ès-lettres (?). } \\
\text { Conservador adjunto no Louvre (1899). }\end{array}$ & Católico & & $\begin{array}{l}\text { De Marly-sous-Issy. Pai } \\
\text { doutor em medicina e } \\
\text { em letras. }\end{array}$ \\
\hline $\begin{array}{l}\text { Louis } \\
\text { MÉRIDIER }\end{array}$ & 2 & $2,2 \%$ & $\begin{array}{l}\text { Fac. de } \\
\text { Lettres de } \\
\text { Paris. EPHE. }\end{array}$ & $\begin{array}{l}\text { Lettres (1901- } \\
\text { 12ème) }\end{array}$ & $\begin{array}{l}\text { Professor no Liceu de Pontivy (1902-1904). } \\
\text { Professor no Liceu de Sens (1904-8). } \\
\text { Docteur-ès-lettres (1906). } \\
\text { Maître de conférences na Faculdade de letras de Montpellier } \\
\text { (1908-20). } \\
\text { Maître de conférence na Faculdade de letras de Paris em } \\
\text { Versailles (1920). }\end{array}$ & & & $\begin{array}{c}\text { De Saint-Eloy-les-Mines. } \\
\text { Pai engenheiro. }\end{array}$ \\
\hline $\begin{array}{l}\text { Gustave } \\
\text { GLOTZ }\end{array}$ & 2 & $2,2 \%$ & $\begin{array}{l}\text { Ens-lettres } \\
\left(1882-2^{\text {eme }}\right)\end{array}$ & $\begin{array}{l}\text { Hist/géo } \\
\left(1885-3^{\text {ème }}\right)\end{array}$ & $\begin{array}{l}\text { Professor no Liceu d'Angoulême (1885-6). } \\
\text { Professor no Liceu de Nancy (1886-92). } \\
\text { Professor no Liceu Michelet (Vanves) (1892-7). } \\
\text { Professor no Liceu Louis-le-Grand (1897-1907). } \\
\text { Docteur ès lettres (1904). } \\
\text { Chargé de cours e, depois, professeur d'histoire grecque à la } \\
\text { Faculdade de Letras de Paris (1907). }\end{array}$ & Judeu & Dreyfusard & $\begin{array}{l}\text { De Hagenau. Pai } \\
\text { negociante. Casado com } \\
\text { filha de negociantes }\end{array}$ \\
\hline $\begin{array}{l}\text { Paul } \\
\text { GIRARD }\end{array}$ & 2 & $2,2 \%$ & $\begin{array}{l}\text { Ens-lettres } \\
\left(1872-1^{\text {er }}\right)\end{array}$ & Lettres $\left(1875-1^{\mathrm{er}}\right)$ & $\begin{array}{l}\text { Membro da Ecole française d'Athènes (1875-1878). } \\
\text { Maître de conférence e, depois, Chargé de cours à la Faculdade de } \\
\text { Letras de Toulouse (1879). Maître de conférences à la Faculdade } \\
\text { de Letras de Paris et Professor no Liceu Fénelon (1883). } \\
\text { Maître de conférences na Ens (1893) Professeur de langue et } \\
\text { littérature grecques na Faculté de Lettres de Paris (1904-1922). } \\
\text { Membro da Académie des inscriptions (1908). }\end{array}$ & Católico & Dreyfusard & $\begin{array}{l}\text { De Paris. Pai era inspetor } \\
\text { geral de instrução } \\
\text { pública. Esposa: Marie } \\
\text { Martha, filha de um } \\
\text { professor da faculdade } \\
\text { de letras de Paris. }\end{array}$ \\
\hline $\begin{array}{l}\text { Maurice } \\
\text { CROIZET }\end{array}$ & 2 & $2,2 \%$ & $\begin{array}{l}\text { Ens-lettres } \\
\text { (1865-?) }\end{array}$ & Lettres (1868- ?) & $\begin{array}{l}\text { Docteur-ès-lettres (1874). } \\
\text { Professor na Faculté de Lettres de Montpellier (1876). } \\
\text { Maître de Confêrences na ENS (1891). } \\
\text { Titular da cadeira Langue et Littérature Grecques no CF (1893- } \\
\text { 1930). } \\
\text { Membro da Académie des Inscriptions (1902). } \\
\text { Administrador do CF (1911-29). }\end{array}$ & Católico & & $\begin{array}{l}\text { De Paris. Pai normaliano, } \\
\text { agrégé de lettres e } \\
\text { professor no Liceu Saint- } \\
\text { Louis. Tinha um irmão } \\
\text { professor universitário } \\
\text { na Sorbonne (Alfred } \\
\text { Croizet). }\end{array}$ \\
\hline $\begin{array}{c}\text { Jean-C. } \\
\text { BOYATIZIDÈS }\end{array}$ & 2 & $2,2 \%$ & & & & & & Grego. \\
\hline $\begin{array}{c}\text { Andrèas } \\
\text { ANDRÉADÈs }\end{array}$ & 2 & $2,2 \%$ & & & $\begin{array}{l}\text { Professor na Universidade de Atenas (?) } \\
\text { Reitor da Faculdade de Direito de Atenas (?). } \\
\text { Correspondente do Institut de France (?). }\end{array}$ & Ortodoxo & & Grego. \\
\hline
\end{tabular}


Quadro 2.3.6 - REG - 1914-1920. Frequência de publicação, trajetória pessoal e institucional.

\begin{tabular}{|c|c|c|c|c|c|c|c|c|}
\hline NOME & $\begin{array}{l}\text { ARTIGOS } \\
\text { (N) }\end{array}$ & $\begin{array}{l}\text { ARTIGOS } \\
(\%)\end{array}$ & $\begin{array}{l}\text { ESTUDO } \\
\text { SUPERIOR }\end{array}$ & AGREGAÇÃO & CARGOS E TÍTULOS ACADÊMICOS & $\begin{array}{l}\text { FILIAÇÃO } \\
\text { RELIGIOSA }\end{array}$ & $\begin{array}{l}\text { AFFAIRE } \\
\text { DREYFUS }\end{array}$ & FAMÍLIA \\
\hline $\begin{array}{l}\text { Gustave } \\
\text { GLOTZ }\end{array}$ & 6 & $4,8 \%$ & $\begin{array}{l}\text { Ens - lettres } \\
\left(1882-2^{\text {ème }}\right)\end{array}$ & $\begin{array}{l}\text { Hist/géo } \\
\left(1885-3^{\text {ème }}\right)\end{array}$ & $\begin{array}{l}\text { Professor no Liceu d'Angoulême (1885-6). } \\
\text { Professor no Liceu de Nancy (1886-92). } \\
\text { Professor no Liceu Michelet (Vanves) (1892-7). } \\
\text { Professor no Liceu Louis-le-Grand (1897-1907). } \\
\text { Docteur-ès-lettres (1904). Chargé de cours e, depois, professeur } \\
\text { d'histoire grecque na Faculdade de letras de Paris (1907). } \\
\text { Membro da Académie des Inscriptions (1920). }\end{array}$ & Judeu & Dreyfusard & $\begin{array}{l}\text { De Hagenau. Pai } \\
\text { negociante. Casado com } \\
\text { filha de negociantes. }\end{array}$ \\
\hline $\begin{array}{l}\text { Waldemar } \\
\text { DEONNA }\end{array}$ & 6 & $4,8 \%$ & & & $\begin{array}{l}\text { Membro estrangeiro à l'École Française d'Athènes (1903-7). } \\
\text { Conservador no Musée de Génève ( ?). }\end{array}$ & & & $\begin{array}{c}\text { Suíço. } \\
\text { Pai diplomata. }\end{array}$ \\
\hline $\begin{array}{l}\text { Louis } \\
\text { GERNET }\end{array}$ & 6 & $4,8 \%$ & $\begin{array}{c}\text { Ens - lettres } \\
(1902-?)\end{array}$ & $\begin{array}{c}\text { Grammaire } \\
\left(1905-1^{\text {er }}\right)\end{array}$ & $\begin{array}{l}\text { Bolsista do Institut Thiers (1908). } \\
\text { Professor no Prytanée (1910). } \\
\text { Docteur-ès-Lettres (1917). }\end{array}$ & & & Militância socialista. \\
\hline $\begin{array}{l}\text { Théodore } \\
\text { REINACH }\end{array}$ & 4 & $3,2 \%$ & $\begin{array}{l}\text { Faculté de } \\
\text { droit-Paris }\end{array}$ & Sem agregação & $\begin{array}{l}\text { Docteur-en-droit (1885). } \\
\text { Docteur-ès-lettres (1890). } \\
\text { Oferece cursos livres de numismática antiga na Faculdade de } \\
\text { Letras de Paris (1894-97 e 1901). } \\
\text { Diretor da Gazette de Beaux Arts (1906). }\end{array}$ & Judeu & Dreyfusard & $\begin{array}{l}\text { De Saint-Germain. Pai e } \\
\text { mãe envolvidos com o } \\
\text { mundo das altas } \\
\text { finanças. Esposa filha de } \\
\text { banqueiros. }\end{array}$ \\
\hline $\begin{array}{l}\text { Maurice } \\
\text { HOLLEAUX }\end{array}$ & 4 & $3,2 \%$ & $\begin{array}{l}\text { Ens - lettres } \\
\left(1879-8^{\text {ème }}\right)\end{array}$ & $\begin{array}{l}\text { Hist/géo } \\
\left(1882-1^{\text {er }}\right)\end{array}$ & $\begin{array}{l}\text { Membre da École Française d'Athène (1882-5). } \\
\text { Chargé de cours na Faculdade de letras de Bordeaux (1886-1888). } \\
\text { Chargé de cours na Faculdade de letras de Lyon (1888-1904). } \\
\text { Diretor da École Française d'Athènes (1904). } \\
\text { Chargé de cours na Faculdade de letras de Paris (1912). }\end{array}$ & Católico & Dreyfusard & $\begin{array}{l}\text { De Chateau-Thierry. Pai } \\
\text { engenheiro. Casa-se } \\
\text { com filha de engenheiro } \\
\text { (1890). }\end{array}$ \\
\hline $\begin{array}{c}\text { Paul } \\
\text { CLOCHÉ }\end{array}$ & 4 & $3,2 \%$ & $\begin{array}{c}\text { Ens - lettres } \\
\text { (1902-?) }\end{array}$ & $\begin{array}{c}\text { His/géo } \\
\left(1906-12^{\text {ème }}\right)\end{array}$ & $\begin{array}{l}\text { Docteur-ès-lettres ( ?). Professor no Liceu de Douai (1910). } \\
\text { Chargé de cours na Faculdade de letras de Besançon (1918). }\end{array}$ & & & \\
\hline $\begin{array}{l}\text { Pierre } \\
\text { ROUSSEL }\end{array}$ & 3 & $2,4 \%$ & $\begin{array}{l}\text { Ens - lettres } \\
\text { (prom. 1901- } \\
\quad 7^{\text {eme }} \text { ) }\end{array}$ & $\begin{array}{l}\text { Lettres } \\
\left(1904-4^{\text {ème }}\right)\end{array}$ & $\begin{array}{l}\text { Membro da École Française d'Athène (1905). Professor no liceu } \\
\text { Janson-de-Sailly (1915). Docteur-ès-lettres (1916). } \\
\text { Maître de conférence de langue et littérature grecque em } \\
\text { Bordeaux (1918). Professor na Faculdade de Letras de Strasbourg } \\
\text { (1919). }\end{array}$ & & & $\begin{array}{l}\text { De Nancy. Militância } \\
\text { socialista. }\end{array}$ \\
\hline $\begin{array}{l}\text { Salomon } \\
\text { REINACH }\end{array}$ & 3 & $2,4 \%$ & $\begin{array}{l}\text { Ens - lettres } \\
\text { (prom. 1876- } \\
\left.\quad 1^{\text {er }}\right)\end{array}$ & $\begin{array}{l}\text { Grammaire }(1879 \\
\left.-1^{\text {er }}\right)\end{array}$ & $\begin{array}{l}\text { Attaché libre e, depois, conservador no Musée de Saint-Germain- } \\
\text { en-Laye (1885). Suplente e, depois, professor titular na École du } \\
\text { Louvre (1890-190?). } \\
\text { Membro da Académie des Inscriptions et Belles Lettres (1896). } \\
\text { Codiretor da Revue Archéologique (1903). }\end{array}$ & Judeu & Dreyfusard & $\begin{array}{l}\text { De Saint-Germain-en- } \\
\text { Laye. Pai e mãe } \\
\text { envolvidos com o } \\
\text { mundo das altas } \\
\text { finanças. Esposa médica. }\end{array}$ \\
\hline $\begin{array}{l}\text { Antoine } \\
\text { MEILLET }\end{array}$ & 3 & $2,4 \%$ & $\begin{array}{l}\text { Faculté de } \\
\text { Lettres de } \\
\text { Paris }\end{array}$ & $\begin{array}{c}\text { Grammaire }(1889 \\
\left.-1^{\mathrm{er}}\right)\end{array}$ & $\begin{array}{l}\text { Suplente e, depois, maître de conférences na EPHE (1889). } \\
\text { Suplente de Bréal no Collège de France (1899-1900). } \\
\text { Professor de armeniano na École des Langues Orientales (1902-6). } \\
\text { Professeur de Grammaire Comparée au Collège de France (1906). }\end{array}$ & Católico & Dreyfusard & $\begin{array}{l}\text { De Moulins. Pai era } \\
\text { funcionário público. }\end{array}$ \\
\hline
\end{tabular}


O terceiro e último intervalo, 1914-1920, marcado pela guerra, traz um cenário próximo ao do período anterior. Como a REG congregava os patrões do helenismo francês, o afluxo de jovens universitários em direção às trincheiras, os quais só puderam voltar aos seus antigos afazeres com a desmobilização geral de 1919, pouco afetou o perfil de seus principais colaboradores. Dos nove autores que mais escreveram para a revista, responsáveis por $31,2 \%$ de seus artigos, cinco ocupavam postos na capital (Glotz, Gernet, Holleaux, Reinach, Meillet). 0 predomínio dos antigos dreyfusard foi então quase absoluto, mantendo-se forte também a presença de professores judeus. Entre os estrangeiros, embora gregos, belgas e britânicos tenham continuado a enviar seus textos, o único que se destacou quanto ao volume publicado foi, mais uma vez, o arqueólogo e historiador da arte suíço Waldemar Deonna.

O que se pode dizer desse conjunto? Ora, ele permite contrastar nitidamente a situação da REG com a do $\mathrm{BCH}$ e do $\mathrm{MAH}$. Tendo por suporte a tradição do anuário da AEEG, ela surgiu no cenário das revistas dos antiquisants como uma instância dominante. Era esse o espaço que os antiquisants consagrados buscavam para apresentar ao público universitário suas pesquisas originais. Era também para lá que os recém-saídos da École Française d'Athènes e da École Française de Rome orientavam seus investimentos em termos de publicação. Tratava-se, portanto, de uma revista de "adultos", de pesquisadores já consagrados ou em busca da consagração, em comparação com aquelas destinadas aos "jovens", aos helenistas e latinistas em formação ou recém-formados. Uma competição entre os "adultos" só se fez sentir a partir de 1899, com o aparecimento da Revue des Études Anciennes (REA). Ainda assim, como se verá no próximo subcapítulo, isso jamais colocou em risco a posição dominante da REG.

Quanto à sociologia praticada em torno do AS, vários fatores levaram a REG a acolhê-la bem. Houve, em primeiro lugar, uma aproximação em termos de plano de carreira: os pesquisadores próximos a Durkheim, muitos deles familiarizados com o grego antigo desde a mais tenra idade, travaram suas lutas no espaço institucional das faculdades de letras, justo onde os helenistas detinham considerável prestígio intelectual. Não era raro, como já visto no primeiro capítulo da presente tese, que os sociólogos se utilizassem dos seus conhecimentos acerca dos antigos para fins de pesquisa. A contrapartida dos helenistas vinha na forma de interesse científico e de suporte institucional. Houve, em segundo lugar, bandeiras políticas comuns, especialmente no que se refere ao Affaire Dreyfus. Entre os anos 1899 e 1920, grande parte dos dirigentes e dos principais colaboradores da REG foi marcada por essa luta, para a qual encontraram aliados nos colaboradores do AS. Houve, por fim, a sociabilidade típica dos letrados de origem judaica, marcante tanto para os patrões do helenismo quanto para o 
patrão dos sociólogos. É bem verdade que a recepção da sociologia despertou desconfianças e até mesmo hostilidade por parte de alguns membros da AEEG. Ainda assim, as afinidades eletivas existentes entre sociólogos e alguns dos mais destacados helenistas os convidaram, no mais das vezes, a um diálogo positivo. São os registros desse diálogo que serão explorados nas páginas que se seguem.

\section{A ReCEPÇÃo dA SOCIOLOGIa NA REVUE des ÉtUdes GRECQUes (1898-1920)}

Logo nos primeiros anos de publicação do AS, pessoas ligadas a essa revista estiveram presentes direta ou indiretamente na REG. Isidore Lévy aí escreveu, entre 1899 e 1901, dois artigos sobre as transformações das municipalidades gregas da Ásia Menor sob a dominação romana, os quais serão discutidos mais tarde (REG, 1899: 255-289 e 1901: 350-371). Além disso, os nomes de Henri Hubert e de Antoine Meillet foram mencionados em artigos ou resenhas. O primeiro viu um antigo artigo seu sobre duas inscrições epigráficas gregas provenientes da Ásia Menor (RA, 1894/1: 308-314) e seu verbete Magia, publicado no Dictionnaire des Antiquités Grecques et Romaines (DAGR), serem citados em 1902 e $1903^{33}$. Já Meillet foi evocado como alguém dotado de um "método rigoroso" na resenha de um livro sobre etimologias de palavras gregas e latinas (REG, 1902: 168). Em nenhuma dessas ocasiões, porém, a sociologia foi evocada ou discutida diretamente. Isso mudará na sequência.

A primeira menção a tal disciplina e a L'Année Sociologique na REG veio da pena de seu diretor, Théodore Reinach. No volume publicado no segundo trimestre de 1904, ele dedicou uma elogiosa resenha à tradução, coordenada por Henri Hubert e Isidore Lévy, do Manuel d'Histoire des Religions de Chantepie de la Saussaye. É sobretudo o texto introdutório de quarenta e oito páginas, no qual Hubert defendeu diante do público universitário francês o método sociológico, que chamou a atenção do helenista (REG, 1904: 278-279):

\footnotetext{
Os tradutores franceses não procuraram 'atualizar' a obra de Chantepie; eles se deram ao trabalho de completar (e ainda aqui com parcimônia) as indicações bibliográficas, de suprimir erros ou superficialidades, de acrescentar aqui e ali notas corretivas, geralmente judiciosas e discretas (...). Nós não deixaremos este volume sem recomendar, em particular, a leitura da substancial Introdução que aí foi inserida pelo Sr. Hubert. Há lá, em uma ordem um pouco caprichosa, toda uma série de perspectivas sugestivas que completam e corrigem em vários pontos o Manual e definem felizmente o estado atual de certos problemas limites da história religiosa. O Sr. H. faz aí da noção do sagrado em particular (da qual ele já havia tratado em seu estudo do sacrifício, escrito em colaboração com o Sr. Mauss) uma análise penetrante. Não é de se espantar que um dos principais redatores de L'Année Sociologique interprete a religião de modo a valorizar a sociologia, e que a religião dos selvagens com seus totens, seus tabus, suas iniciações bizarras aí se sobressaia à religião individualista e moralizante do século XX. Mas
}

\footnotetext{
${ }^{33}$ Cf. REG, 1902: 311 e REG, 1903: 43 (nota 1). Sobre o DAGR, veja-se o item 3.3 da presente tese.
} 
subsistem tantos elementos primitivos inconscientes na crença e nas práticas dos mais civilizados que não há mal algum em insistir de tempos em tempos sobre esta hereditariedade e, como o diz o Sr. H., 'afastar os galhos para entrever a raiz'

Tal passagem interessa aqui por duas razões: ao mesmo tempo que a sociologia e os sociólogos tiveram seus méritos reconhecidos no âmbito dos estudos gregos, eles viram a eficácia de sua ação ser localizada a um terreno bastante específico, o do primitivo/selvagem. Em se tratando de religião, o principal mérito da sociologia foi, segundo Théodore Reinach, ter chamado atenção para suas origens arcaicas (dos quais são exemplos vários ritos coletivos) e, por extensão, para aquilo que, desse substrato original, mantém-se de forma inconsciente em contextos mais "civilizados".

Percepção muito parecida foi apresentada um ano mais tarde por Adolphe-Joseph Reinach, sobrinho de Théodore. A publicação em livro da tese principal de Gustave Glotz, La Solidarité de la Famille dans le Droit Criminel en Grèce, forneceu a ocasião para tal manifestação. Na longa e positiva resenha que produziu sobre a obra, ele destacou tanto a abrangência do tema tratado por Glotz, capaz de interessar a todo o indivíduo preocupado com a "história da sociedade humana", como a escolha metodológica acertada, "o melhor da doutrina dos princípios éticos e da sociologia" (REG, 1905: 136-140). O segundo elogio é melhor compreendido à luz do primeiro. Para Adolphe Reinach, esse era um trabalho sobre "a história da passagem do direito das gens ao da cidade antiga", ou seja, a análise da transformação do direito punitivo vivido nos termos de uma vendetta coletiva ao direito compensatório pautado em responsabilidades individuais. Coube à sociologia, neste caso, fornecer três explicações: a dos princípios que regem o direito primitivo, prenhe de preceitos mágico-religiosos, a do processo de sua decadência e, por fim, a dos indícios de sua sobrevivência em períodos posteriores (a lei de Gortina, por exemplo). A resenha aponta ainda para o valor da comparação e os limites dessa operação analítica. Glotz, diz o resenhista, teria se valido do direito comparado para explicar, por analogia, certas práticas dos antigos. Tal procedimento pareceu a Adolphe apropriado apenas quando dizia respeito aos períodos mais recuados da história. Problemas tendiam a surgir, no entanto, ao se colocar no mesmo plano a Grécia dos séculos V e IV a.C. e os povos primitivos. O sobrinho de Théodore aproveitou então para reafirmar a natureza única do objeto de estudo dos helenistas: "de todas as Nações, a Hélade foi a primeira a substituir a justiça familiar, que é por inteira vingança, pela justiça social, que é por inteira bondade [bienveillance]; o ódio entre os homens por amor; à frente da Hélade está Atenas, a qual, superando-a, resume suas aspirações".

As duas resenhas são paradigmáticas em mais de um sentido quanto se trata de compreender a acolhida reservada à sociologia na REG. Por um lado, elas mostram como tal 
disciplina emergente na universidade francesa adquiriu, mais cedo do que muitos estariam ainda hoje dispostos a admitir, cidadania no vasto campo do helenismo. Por outro lado, porém, explicitam o pedágio a ser pago, qual seja: a sociologia deveria auxiliar os especialistas a identificar e a depurar tudo o que, no caso atípico da Grécia Antiga, destocasse de seu ideal. Ou seja, dito de outro modo, ela tornaria possível explicar o que nos primórdios da Grécia e ao longo de sua história ou não era Grécia ou ainda não o era por completo. Tratava-se, assim, de uma ciência interessante por suas virtudes purificadoras.

Um terceiro elemento que as resenhas dos Reinach têm o mérito de identificar são subdivisões do helenismo potencialmente suscetíveis ao diálogo com os sociólogos. Deixadas por hora de lado as numerosas remissões que os próprios colaboradores do AS fizeram a si mesmos na REG, constatou-se que as alusões aos trabalhos da escola sociológica francesa ocorreram sobretudo nos campos dos estudos relativos à religião e, em segundo plano, ao direito grego ${ }^{34}$. No intervalo entre 1898 e 1920, o verbete Magia, de autoria de Henri Hubert, foi o mais acionado dos textos sociológicos. Além da citação de 1903 acima mencionada, Paul Perdrizet se valeu dele para estudar a numerologia relativa à evocação de deuses helênicos um ano mais tarde (REG, 1904: 350-360). Em 1905, foi a vez de Paul Girard utilizá-lo para tratar de certos aspectos do heroísmo mítico de Ajax (REG, 1905: 1-75). Waldemar Deonna, por fim, cita-o dois anos mais tarde em seu estudo sobre amuletos mágicos encontrados em Tasos (REG, 1907: 365-382). É provável que o sucesso do referido texto, mesmo após a publicação do longo ensaio sobre a magia que Hubert redigiu com Mauss em 1904, tenha se dado graças ao seu suporte, o DAGR, um dicionário especializado no mundo antigo. Isso não implicou, porém, a ausência de circulação de L'Année Sociologique entre os antiquisants. A memória sobre o sacrifício aí publicada por Mauss e Hubert em 1899, Essaie sur la Nature et la Fonction du Sacrifice, apareceu referenciada em duas ocasiões ${ }^{35}$. Esse também foi o caso do texto de Paul Huvelin, Magie et Droit Individuel, publicado no AS em 1907 e citado por Waldemar Deonna em um dos volumes da REG publicado logo após a Grande Guerra (REG, 1920: 291-238). Ainda no campo da sociologia religiosa, a pequena tese defendida em 1916 por Pierre Roussel, na qual ele discutiu a presença dos cultos egípcios em Delos, foi premiada pela AEEG com o prêmio Zographos e passou a ser referência quanto aos hibridismos religiosos do período helenístico ${ }^{36}$.

\footnotetext{
${ }^{34}$ O que condiz, é bom lembrar, com os conteúdos das seções do AS mais atinadas com a produção dos helenistas (sociologie religieuse e sociologie morale et juridique). Veja-se o item 1.1 da presente tese.

${ }^{35}$ Além do já mencionado texto de Perdrizet publicado em 1904, Waldemar Deonna utilizou-o em suas investigações sobre a origem da representação de monstros na Antiguidade (REG, 1915: 288-349).

${ }^{36}$ A tese chama-se Les cultes égyptiens à Délos du IIle au ler siècle av. J.-C (ROUSSEL, 1916b). Sobre a recepção do trabalho, veja-se, em especial, o texto de Gustave Glotz sobre as festas ptolomaicas em
} 
Para além dos temas relacionados à religião e ao direito, a linguística de inspiração sociológica fez sucesso na REG. Antoine Meillet teve duas edições de uma mesma obra sua, Introduction à l'Étude Comparative des Langues Indo-Européennes, resenhadas (REG, 1904: 134-6 e 1912: 476-7). Jules Bloch, o autor do primeiro desses textos, não economizou elogios ao colaborador do AS. Foram dois os pontos destacados por ele. Em primeiro lugar, Meillet revolucionou a linguística em termos de método. De fato, ele não quis restabelecer por completo uma língua original, o indo-europeu, em termos gramaticais. Seu intuito era antes o de comparar os componentes das várias línguas derivadas do indo-europeu para isolar o que foi possível constatar nelas em termos de mudanças e continuidades. Isolados esses pontos, aí sim o analista recorreu à história e à dinâmica da sociedade para buscar explicações. Ainda segundo Bloch, outra contribuição notável da obra de Meillet seria a desvinculação das noções de língua e de raça. A resenha mais recente, de Pierre Boudreaux, consideravelmente menor, apenas elogia algumas modificações no capítulo metodológico da obra, as quais o teriam deixado mais claro e sistemático. Mas as melhores provas da reputação desse linguistasociólogo entre os helenistas da REG são as alusões a ele, invariavelmente como figura de autoridade, em artigos, resenhas e na Biographie Annuelle des Études Grecques. Nos dois primeiros casos, excluindo mais uma vez as citações feitas por outros colaboradores do AS que aí publicaram, Meillet foi acionado dezoito vezes entre 1904 e $1920^{37}$. Já quanto à bibliografia anual, ele foi o único pesquisador ligado aos sociólogos a figurar aí seis vezes ${ }^{38}$. Em todo caso, o que há de particular na apreensão de sua obra é que ela jamais foi atrelada na REG nominalmente à sociológica, mas sim à linguística, à filologia e à gramática. Isso não significa, contudo, que os helenistas tenham estado indiferentes quanto aos desdobramentos sociohistóricos de seus resultados e métodos.

Embora o conjunto dessas alusões apontem para uma acolhida positiva da produção intelectual dos colaboradores do AS na seio da REG, ruídos e tensões também se fizeram sentir. Duas resenhas tardias, publicadas respectivamente em 1918 e em 1920, testemunham que nem todos os colaboradores da revista viam com bons olhos as possíveis contribuições da sociologia. A primeira delas, a mais direta e agressiva, foi assinada por Aimé Puech, professor

honra a Adonis, discutidas a partir de um papiro contendo detalhes sobre os rituais (REG, 1920: 169222).

${ }^{37}$ As citações que encontrei de Meillet na REG são, da mais antiga à mais recente: REG, 1902: 168; 1904: 484-485; 1906: 62; 1907: 106; 1909: 339; 1910: 74 e 230; 1912: 210, 462 e 483; 1913: 103-105; 1914: 74-79, 80, 235 (nota 3), 333 e 349; 1917: 317 (nota 3); 1918: 373.

${ }^{38}$ Em ordem cronológica: REG, 1904: 447; 1905: 457; 1906: 457; 1907: 464; 1909: 436 e 1910: 444. Apenas Isidore Lévy e Paul Huvelin tiveram seus trabalhos incluídos nessa parte da revista, dos quais localizei, no intervalo entre 1898 e 1912, apenas uma referência para cada um - cf. REG, 1903: 470 (Is. Lévy) e 1909: 444 (Huvelin). 
de língua e literatura gregas na Sorbonne (REG, 1918: 103-105). O livro em questão era a tese principal de Louis Gernet, Recherches sur le Développement de la Pensée Juridique et Morale en Grèce, defendida e publicada em 1917. Para Puech, Gernet feria as leis da história ao defender um raciocínio "tautológico", segundo o qual teria sido a coletividade a responsável por fundar uma primeira ordem jurídica na Grécia. A ideia condutora não era, contudo, muito diferente daquela defendida por Glotz anos antes, mas não foram as ideias desse autor que foram atacadas, e sim a importância declarada da inspiração durkheimiana na obra ${ }^{39}$. Puech associou Gernet à "escola sociológica", criticando o que ele entendia ser o ponto central do livro com o seguinte argumento: "tudo é obra do pensamento coletivo, trabalhando, não se sabe como, sob o impulso de sentimentos intensos. Nem os grandes eventos históricos, nem mesmo as grandes mudanças econômicas influenciaram seriamente, em algum momento, este trabalho misterioso. A ação dos grandes espíritos não é considerada".

A segunda resenha crítica à sociologia, essa muito mais discreta, foi escrita por Jules Toutain, maître de conférence na quinta seção da EPHE, a de ciências religiosas, mesmo local onde trabalhavam Hubert e Mauss. O livro discutido foi a tese de doutorado do latinista André Piganiol, Essai sur les Origines de Rome, assumidamente influenciada pelas ideias de Durkheim e dos sociólogos próximos a ele ${ }^{40}$. Embora elogie o recém-doutor por sua "erudição" e seu "talento dos mais brilhantes", o que suscitou as primeiras ressalvas foi o método investigativo adotado no trabalho:

O método é aquele que consiste em explicar a origem obscura dos povos e das cidades da antiguidade clássica por comparações emprestadas de civilizações pouco civilizadas da África e da Oceania. Para explicar esse método, os savants que o aplicam não hesitam em afirmar que os Gregos, os Latinos e os Orientais passaram pelo estágio de desenvolvimento no qual essas tribos estão hoje paradas e que ao observar essas tribos se têm sob os olhos instituições sociais, econômicas e religiosas totalmente análogas às instituições de Roma e Grécia Primitivas. Eis aí uma pura hipótese, não demostrada e indemonstrável.

Mas isso não é tudo. Toutain se opõe ainda a Piganiol quanto à ideia de que a oposição entre patrícios e plebeus nasceu em decorrência de uma tensão quase universal entre povos pastores e agricultores. Trata-se, segundo ele, de uma hipótese "diletante", a qual não

\footnotetext{
${ }^{39}$ O próprio Gernet, no final de seu prefácio, assume a dívida para com os dois autores: "No que diz respeito às bases de nosso ensaio, é fácil perceber que ele não poderia ter sido feito sem a grande obra do Sr. Glotz. Quanto à inspiração geral, dizê-lo é quase supérfluo agora: nós a devemos aos escritos do Sr. Durkheim e de sua escola" (GERNET, 2001: 16).

${ }^{40}$ Como já mencionado nos capítulos anteriores, Piganiol se tornou o primeiro latinista a colaborar com o AS, mas isso teve início apenas na segunda série da revista. Professor do liceu de Chambéry entre 1916-1917, ele contou em sua banca com a participação de Antoine Meillet (veja-se, a esse respeito, a carta de Piganiol a Meillet, pertencente aos arquivos Antoine Meillet depositados no Institut Mémoire de l'Édition Contemporaine, MLT 13.79, datada de 30 de dezembro de 1916).
} 
encontra nenhum fundamento em indícios arqueológicos (a resenha discute a esse respeito certos monumentos votivos). Ao final de seu texto, ele afirmou: "é muito lamentável ver tanto talento, tanta coragem e tanta dedicação ao trabalho desviados do verdadeiro método histórico". Todas as críticas à equipe do AS ficaram, no entanto, subentendidas: Toutain enumerou o pecado, mas não os pecadores.

É preciso relativizar, contudo, a importância desses textos. Ricardo Di Donato, no pósfácio da coletânea de textos de Gernet por ele organizada, referiu-se à resenha de Puech como uma "recusa total de linguagem e de método", prova de que "o helenismo não admitia a sociologia em seu domínio espiritual" (GERNET, 1983: 409). Ora, como foi aqui visto, essa foi a primeira e única alusão direta negativa à sociologia durante todo o período compreendido entre a fundação do AS e o final da Guerra de 1914-1918 . Cabe também questionar o quanto Puech, a despeito de seu vínculo com a cadeira de língua e literatura gregas na Faculdade de Letras de Paris, deve ou não ser considerado o representante por excelência do helenismo francês de inícios do século XX. Sócio da AEEG a partir de 1892, ele publicou apenas dois artigos na REG até 1920 e, ao contrário de muito de seus colegas tanto da Nouvelle Sorbonne quanto da elite do helenismo francês, declarou-se antidreyfusard ${ }^{41}$. Tratava-se ainda de um especialista de literatura, ao melhor estilo retórico característico da "velha" Sorbonne. A mesma questão deve ser aplicada a Jules Toutain, a quem Mauss identificou em correspondência como "reacionário" ${ }^{42}$. Latinista reconvertido ao estudo da religião pagã na antiga Gália, Toutain aderiu a AEEG somente em 1914, não escrevendo sequer um artigo na revista da associação até 1920 . Quanto ao papel dessas críticas para as carreiras dos então jovens Gernet e Piganiol, é bom lembrar que elas não impediram que ambos, após longos anos passados em faculdades provinciais e diante de um cenário cada vez mais competitivo, chegassem a Paris durante a década de 1940 (o primeiro na EPHE e o segundo no Collège de France).

E quanto aos concorrentes diretos da escola sociológica francesa nos estudos sobre a religião antiga? É bem verdade que os artigos publicados na REG fizeram referência a outros especialistas europeus então em evidência, tais como Max Müller, Wilhem Wundt, Biron Jevons, Robertson Smith e, em especial, o antropólogo britânico James Frazer ${ }^{43}$. Ainda assim, muitos dos textos nos quais eles foram citados também continham alusões a Hubert, Huvelin e

\footnotetext{
${ }^{41}$ Sobre os artigos de Aimé Puech, cf. REG, 1910: 255-275 e REG, 1919: 415-428.

42 Apud FOURNIER, 1994: 328.

${ }^{43}$ No que diz respeito à presença de Frazer na REG, de longe a mais significativa, recolhi onze citações. Veja-se, quanto aos artigos nos quais isso ocorre, REG, 1904: 350-360; 1906: 335-358; 1907: 112; 1911: 105-151; 1914: 59-69; 1915: 288-349; 1916: 275-280; 1918: 19-82; 1919: 339-358 e 433-442; 1920: 169222.
} 
Mauss, ou a alguém próximo a Durkheim como Lucien Lévy-Bruhl. Outro dado interessante é o silêncio dos helenistas quanto aos concorrentes locais da "escola sociológica". Nenhuma alusão foi encontrada seja a Gabriel Tarde, seja a Jean Izoulet, seja a Gaston Richard (pós1910). Esse conjunto sugere que os durkheimianos conseguiram se firmar, ao menos no campo dos estudos religiosos e do direito primitivo, como referências não negligenciáveis.

Em todo caso, o diferencial dos sociólogos quanto a seus concorrentes no contexto específico da REG foi sua participação na revista ${ }^{44}$. Como se verá no próximo item, eles puderam demarcar seu espaço por intermédio de um número expressivo de artigos e de resenhas. Eis aí, em verdade, a evidência maior da aceitação da sociologia no "domínio espiritual" do helenismo.

\section{OS SOCIólogos NA REVUE DES ÉTUDES GRECQUES (1898-1920)}

A acolhida em geral positiva reservada à sociologia foi acompanhada na REG por uma intensa colaboração direta. Dos pesquisadores associados à primeira série do AS, cinco se fizeram aí presentes até o final do período aqui privilegiado ${ }^{45}$. Foram eles o linguista Antoine Meillet, o orientalista Isidore Lévy e os helenistas Pierre Roussel, Henri Jeanmaire e Louis Gernet $^{46}$.

A atuação dos membros da equipe do AS na REG se deu em dois planos distintos: um administrativo (no seio da AEEG e da própria revista) e outro científico (por meio de artigos, boletins e resenhas). Quanto ao primeiro desses planos, Meillet exerceu um papel nada negligenciável. Embora filiado tardiamente à associação, apenas em 1908, ele atuou no intervalo entre 1910 e 1912 como membro do comitê da associação, sendo eleito "segundo vice-presidente" no segundo semestre de 1914, função que o levou a ser nomeado "vicepresidente" um ano depois e "presidente" em 1916 ${ }^{47}$. Em 1917, por mais três anos, ele voltou a atuar no comitê da associação. Louis Gernet, por seu vez, ocupou por dois trimestres a função de "secretário de redação" do início da direção de Gustave Glotz na REG. Tal fato

\footnotetext{
${ }^{44}$ Veja-se sobre isso o quadro 2.3.6 apresentado anteriormente, no qual três sociólogos - Antoine Meillet, Pierre Roussel e Louis Gernet - figuram entre os nove maiores colaboradores da REG para o período 1914-1920.

${ }^{45}$ Seis se considerarmos também o artigo aí publicado por Marcel Mauss em 1921, o qual será discutido em separado ao final deste subcapítulo.

${ }^{46}$ Embora tenha sido o primeiro sociólogo a tornar-se membro da AEEG em 1898, Henri Hubert não exerceu nenhuma função na associação, tampouco publicou algo em sua revista.

${ }^{47}$ Enquanto presidente, Meillet pronunciou um discurso na assembléia geral da associação. Publicado naquele mesmo ano, ele reflete o momento dramático da Primeira Guerra. Três foram os temas abordados: a impossibilidade de se comemorar o cinquentenário da associação em meio ao conflito e às sérias restrições orçamentárias que a Guerra impõe, as homenagens póstumas aos membros e aos filhos de membros mortos em batalha e, por fim, a crítica da postura do governo grego, até então em paz com a Alemanha e com o Império Austro-Húngaro (REG, 1917: xi-xvi).
} 
ocorreu em meados de 1908, justo no momento em que ele havia se tornado membro da AEEG.

No que tange às contribuições científicas durante o período aqui tratado, elas compreendem um total de trinta e dois textos divididos em nove resenhas (comptes-rendus), dezessete artigos e seis boletins epigráficos publicados na seguinte ordem cronológica:

- 1899: Um artigo de Is. Lévy (REG, 1899: 255-289).

- 1901: Um artigo de Is. Lévy (REG, 1901: 350-371).

- 1908: Uma resenha de Gernet; uma resenha e um artigo de Meillet (REG, 1908: 380 381, 388-389 e 413-425).

- 1909: Três resenhas e um artigo de Gernet (REG, 1909: 13-32, 340, 353 e 358-359).

- 1910: Um resenha de Gernet (REG, 1910: 85).

- 1913: Um artigo de Jeanmaire, um artigo de Is. Lévy e um boletim de Roussel (REG, 1913: 121-150, 262 e 441-487).

- 1914: Um boletim de Roussel (REG, 1914: 441-477).

- 1915: Um artigo e um boletim de Roussel (REG, 1915: 234-250 e 446-475).

- 1916: Um artigo de Meillet, um artigo de Gernet, um artigo e um boletim de Roussel (REG, 1916: 259-274, 383-403 e 435-456).

- 1917: Dois artigos de Gernet, uma resenha e um boletim de Roussel (REG, 1917: 181$183,214-215,249-293,363-383$ e 407-415).

- 1918: Um artigo de Gernet e outro de Meillet (REG, 1918: 185-196 e 277-314).

- 1919: Um artigo de Meillet e outro de Roussel (REG, 1919: 384-387 e 482-489).

- 1920: Uma resenha de Meillet, um boletim de Roussel, uma resenha e dois artigos de Gernet (REG, 1920: 97-100, 113-114 123-169, 249-290 e 403-432).

Levando em conta o volume de textos, o longo período que eles cobrem e sua diversidade temática, optou-se aqui por tratar em separado a produção de cada autor. Será possível assim averiguar quem se valeu do trabalho dos demais colaboradores do AS, bem como o uso que faz das intuições e dos métodos sociológicos.

Dos quatro artigos que o orientalista Isidore Lévy escreveu para a REG entre 1895 e $1913^{48}$, apenas o mais antigo foi publicado antes de sua adesão à equipe do AS, ocorrida em 1899. Desse conjunto, os três primeiros textos formam um só bloco e trazem o mesmo título:

${ }^{48}$ Veja-se REG, 1895: 203-250; 1899: 255-289; 1901: 350-371 e 1913: 262. 
Études sur la Vie Municipale en Asie Mineure sous les Antonins. O autor se propôs a apresentar aí um panorama das transformações institucionais nas cidades helenizadas da Ásia Menor durante o século II d.C., sob a dominação do Império Romano. Tal região, afinal, possuía estruturas jurídicas e administrativas próprias já há muitos séculos, o que permitia refletir, nas palavras de Lévy, sobre as "graves alterações na função pública" em função de um expediente de "conquista". O texto se estrutura a partir da sucessão das instituições tratadas (assembleia, tribunais, arquivos municipais, força policial, entre outras), intercalando às considerações de ordem puramente formal discussões sócio-históricas. Com efeito, Lévy procura demonstrar como as eventuais transformações na organização das cidades não dependeram apenas do poder central/imperial, mas também do perfil de quem exercia os cargos no seio da administração pública local. Foram duas as suas conclusões mais gerais (ou seja, desconsiderando aqui as variações constatadas entre cidades): no âmbito municipal, a noção de cidadania antiga foi se enfraquecendo e cedendo espaço para uma plutocracia, na qual pouco importava a nacionalidade, o sexo e a idade. Mesmo indivíduos mortos e divindades, por meio de doações de famílias ou templos, puderam ocupar certos cargos. Por tais expedientes, se favoreceu a criação de dinastias de magistrados pertencentes aos mesmos grupos de notáveis locais - um processo que, segundo o autor, pode ser comparado ao advento do episcopado na Igreja Católica. No âmbito central, por outro lado, a administração imperial aparecia como uma instância pouco disposta a intervir na administração local, a qual, em sua autonomia relativa, era considerada mais como um sustentáculo do sistema que como um potencial concorrente.

Destoando desses longos textos, o mesmo autor ainda publicou na REG um breve artigo em 1913, intitulado KАРПОКРАТН $\Sigma$. Nele, partindo do vínculo entre Horus e os cultos agrários, algo manifesto na etimologia popular, Lévy propôs a correção da transcrição do nome das divindades evocadas em um hino grego recém-encontrado dedicado a Isis. Em todo caso, seja nesse artigo, seja naqueles, o mais importante é sublinhar aqui a facilidade com que esse colaborador do AS, fundindo a história dos povos do "oriente antigo" com a do helenismo, resolveu problemas técnicos (de transcrição) ou narrou uma história institucional recorrendo a expedientes comparativos e sociológicos.

Como Isidore Lévy, Antoine Meillet atuou na REG em função de sua especialidade disciplinar: no caso, a linguística. Sua colaboração à REG não foi, contudo, marcada por debates de cunho epistemológico ou metodológico, tal como as que se deu entre ele e os demais colaboradores do AS. Meillet privilegiou em seus textos voltados aos helenistas 
investigações pontuais sobre a língua grega antiga (ainda que em geral associadas a alguma questão relativa à linguística indo-europeia).

O primeiro artigo que ele aí publicou, La Place du Pamphylien parmi les Dialects Grecs, é paradigmático nesse sentido (REG, 1908: 413-425). Com ele, Meillet almejava complementar a classificação dos dialetos gregos proposta por um linguista norte-americano, Carl Darling Buck. O referido autor havia dividido os dialetos gregos em três grandes grupos: o ocidental (compreendendo o dórico e os demais dialetos do noroeste grego), o oriental (composto pelo jônico e pelo ático) e o árcade-cipriota. Desses, os dois primeiros se apresentavam como conjuntos bastante coerentes do ponto de vista linguístico, ao passo que o terceiro reunia os dialetos dos prováveis remanescentes dos primeiros gregos a habitar a Hélade, repletos de arcaísmos e, portanto, mais próximos do que deveria ser a matriz original do "grego comum". Mas então onde situar o panfiliano, dialeto falado no sul da Ásia Menor? Logo no princípio do artigo, Meillet procurou aproximá-lo do grupo árcade-cipriota, mostrando suas semelhanças quanto ao infinitivo, particípio, certos fechamentos vocálicos e expressões. E aqui mesmo as diferenças se mostraram reveladoras, pois em tudo em que o panfiliano não reproduzia dos demais dialetos do grupo, estes dialetos também não concordavam entre si (quanto ao dativo plural, a composição de certas palavras, entre outros). Na sequência, Meillet atacou os partidários da tese que aproximava o panfiliano do dórico, julgando-a superficial (embora ele não descarte a possibilidade de cohabitação de populações falantes de dialetos árcadecipriotas e dóricos como uma explicação da origem do panfiliano). Ao final do texto, o autor ainda explicitou as principais vantagens de tal estudo. Em primeiro lugar, ele ajudaria a expandir a compreensão da língua comum que originou os dialetos constatados em épocas históricas. Além disso, como o panfiliano se manteve como forma dialetal mesmo após o advento da koiné, a língua franca grega criada a partir do século IV a.C., ele ajudaria a explicar certas perplexidades dos gregos do continente europeu frente à língua de seus "parentes" asiáticos. Tratava-se assim, em resumo, de um dos estudos preparatórios de Meillet para a história da língua grega que ele publicou cinco anos mais tarde (MEILLET, 1913).

Os demais artigos de Meillet a REG seguem o mesmo padrão. Em De Quelques Faits Grammaticaux, ele abordou a história do singular infinitivo grego, de certas formas verbais e do dativo plural no dialeto ático (REG, 1916: 259-274). Em seguida, com Sur une Édition Linguistique d'Homère, propôs a estrutura de uma edição crítica da obra de Homero, voltada aos estudiosos do texto antigo (REG, 1918: 277-314). Por fim, seu último e menor artigo, Le Nom de Calypso et la Formation Désidérative, elucidou a formação particular do nome de uma divindade (REG, 1919: 384-387). 
E quanto às suas resenhas? Ora, nessa seção da REG, Meillet forneceu ainda mais provas de seu amplo conhecimento não apenas da língua grega, como da literatura acadêmica internacional produzida sobre o tema. Por exemplo, ele apresentou ao público francês uma coletânea de ensaios de um helenista-filólogo russo até então ignorado na França (REG, 1908: 388-389). Em outra ocasião, comentando o artigo de um linguista francês sobre o "siracusano", dialeto dórico falado na Sicília, inseriu digressões sobre os raros vestígios materiais relativos à língua e a dificuldade de reconstituir sua forma original a partir de manuscritos alterados por sucessivas gerações de copistas (REG, 1920: 113-114).

Embora não tenha citado outro colaborador do AS em nenhum de seus textos publicados na REG, Meillet não deixou de se valer de expedientes centrais em sua linguística sócio-histórica, sobretudo da ideia do "emprunt" (ou "empréstimo"). Tal conceito, o qual supunha a circulação de palavras entre diferentes grupos sociais como algo central para explicar a ampliação e a transformação do campo semântico das palavras de uma língua, foi acionado três vezes nos artigos de 1908 e de 1916 para avançar hipóteses sobre o desenvolvimento da língua grega ${ }^{49}$.

Além de um orientalista e de um linguista, helenistas próximos à sociologia também colaboraram com a REG. Dentre eles encontrava-se Pierre Roussel, o qual esteve aí constantemente presente a partir da véspera da Primeira Guerra Mundial. Suas contribuições para a REG foram então voltadas tanto à epigrafia, ciência que ele passou a dominar como poucos ao longo dos anos que passou como membro e pesquisador ligado a EFA, quanto ao estudo da mitologia grega. No primeiro caso, a sociologia tinha, quando muito, uma influência secundária. No segundo, ela dominava a cena ${ }^{50}$.

Os trabalhos de Roussel publicados na REG sobre epigrafia consistiram, quanto ao essencial, nos seis boletins de sua autoria ${ }^{51}$. Tratava-se de textos extensos, nos quais o autor passava em revista as novas descobertas de inscrições observando suas regiões de procedência, bem como novas discussões em torno do material já conhecido. Longe de ser um simples apanhado ou lista, Roussel também se posicionava quanto aos achados e polêmicas, avaliando o quanto isso acrescentava realmente algo ao que já se sabia. As únicas alusões indiretas à sociologia vinham aí das indicações que Roussel fez em um de seus boletins a um

\footnotetext{
${ }^{49}$ Sobre esse conceito de Meillet, veja-se, a bibliografia já citada no subcapítulo 1.2 da presente tese.

${ }^{50}$ A única resenha de Roussel que identifiquei na REG (1917: 214-215) foge a essa dicotomia. Ela trata de um estudo de Paul Cloché, tributário dos textos antigos, sobre a instituição da democracia grega em 403 a.C.

${ }^{51}$ Além dos boletins, Roussel publicou na REG ainda um breve artigo com temática epigráfica (cf. REG, 1916: 181-183).
} 
artigo de Gernet sobre as leis de Gortina, texto que será discutido logo mais, e de seus próprios estudos sobre os cultos egípcios em Delos (REG, 1917: 411 e 420-1).

Seus outros artigos podem ser lidos como aplicações da sociologia na análise de motivos mitológicos presentes em poemas épicos e tragédias gregas. Em Le rôle d'Achille dans I'Iphigénie à Aulis, por exemplo, Roussel destacou a importância da temática do sacrifício da filha de Agamêmnon como chave para a trama (REG, 1915: 234-250). Valendo-se do ensaio de Hubert e Mauss sobre o tema, ele apontou para a importância do consentimento de duas das vítimas de líder dos aqueus (a mulher imolada, Ifigênia, e o chefe guerreiro envolvido em uma falsa promessa de casamento, Aquiles) para a resolução da trama ${ }^{52}$. O segundo artigo, Astyanax, apresentou uma discussão similar (REG, 1919: 482-489). Nesse artigo, contudo, o autor não se restringiu a uma obra ou autor específico, mas sim ao tema da manifestação da heroicidade ou da divindade por meio de sua descendência. Casos como o de Astíanax, filho de Heitor, e de Telêmaco, filho de Odisseu, herdeiros dos atributos de seus pais, foram então evocados para mais tarde passar ao tema dos deuses-criança, em geral associados à proteção das comunidades.

Nesses dois últimos casos, Roussel não se contentou em citar os trabalhos impressos em L'Année Sociologique, sobretudo quanto à temática do casamento e da família, bem como um autor próximo aos sociólogos como Arnold van Gennep. Ele valeu-se igualmente dos helenistas britânicos, Jane Harrison e Gilbert Murray, à época bastante influenciados pela sociologia de Durkheim e de sua escola.

Mas Roussel não foi o único helenista presente na revista da AEEG. Henri Jeanmaire, no mesmo ano em que aderiu ao AS, 1913, publicou na REG seu primeiro artigo, o único durante o intervalo aqui investigado. Ainda assim, La Cryptie Lacédémonienne fundiu exemplarmente os interesses da sociologia e dos estudos greco-latinos (REG, 1913: 121-150). Nele, Jeanmaire rediscutiu a "criptia", rito descrito em detalhes por Plutarco e comentado en passant por outros autores antigos. Tratava-se, segundo tais relatos, de um período no qual os jovens espartanos se mantinham nas margens da comunidade, vivendo furtivamente durante o dia e tendo a obrigação de assassinar os hilotas (escravos) que encontrassem após o entardecer. A maior parte da historiografia havia ignorado até então esses aspectos

\footnotetext{
${ }^{52}$ No que tange às tragédias euripidianas, Roussel apresentou ainda no dia 11 e janeiro de 1917, em um dos encontros mensais da AEEG, uma comunicação sobre as Fenícias. Um resumo dessa apresentação foi impressa em REG, 1917: iii-iv. Para o desenvolvimento posterior dessas discussões, veja-se também: 1) o artigo intitulado Médée et le meurtre de ses enfants (REA, 1920: 151-171), o qual será discutido no subcapítulo 3.4 e 2) o artigo Le thème du sacrifice volontaire dans la tragédie d'Euripide, publicado em 1922 na Revue Belge de Philologie et d'Histoire (ROUSSEL, 1922).
} 
considerados por demais pitorescos ou inconsistentes da "criptia", tomando-a como um simples exercício preparatório para a vida militar espartana. Para Jeanmaire, contudo, o referido fenômeno era não só mais complexo como perfeitamente integrado às demais instituições do país. E há mais: "ela [a criptia] é apenas uma espécie de fenômenos universalmente presentes, na qual não há nada que não seja conforme aos dados gerais que possuímos sobre o caráter e a psicologia do homem em sociedade". Ou seja, a chave para sua compreensão não residia somente na leitura correta dos textos antigos, mas também no método comparativo.

A primeira parte do texto versa sobre a organização social lacedemônia. Para o autor, os filólogos modernos erraram ao tentar compreendê-la supondo como ponto de partida as divisões dos homens em classes econômicas e de status, bem como exagerando o papel da consaguinidade. Em Esparta, teriam sido os grupos distintos por sexo e por idade que se impuseram aos demais. Valendo-se de autores teóricos conhecidos dos sociólogos, em especial Henrich Schurtz e Hutton Webster, Jeanmaire sustentou que em sociedades assim concebidas: 1) os homens adultos constituem verdadeiras sociedades secretas, cujo emblema é geralmente uma casa comunitária; e 2) os jovens só podem ingressar nestas sociedades após um período de iniciação. O texto ainda se vale de dados etnográficos dos aruntas, dos massais e dos zulus, para só então investigar os indícios de práticas análogas na lacedemônia: a existência de classes de idade bem definidas, a separação das crianças do convívio materno desde a mais tenra idade e, por fim, as refeições comunitárias (o equivalente espartano das "casas comunitárias").

A segunda e a terceira partes do texto investem no significado e na importância dos "sistemas de classificação por idade". Partindo de dados etnográficos, Jeanmaire apontou para as semelhanças entre Esparta e outras sociedades - os aruntas e os kwakiutls - quanto ao papel dos ritos de iniciação na promoção de uma gerontocracia. O que se segue é a descrição da especificidade desses ritos, os quais supõem períodos de maior ou menor isolamento, em geral em lugares ermos e nas fronteiras da tribo, pontuados por atos de violência extrema. A "criptia" se encaixava com perfeição nas comparações promovidas por Jeanmaire e ele não hesitou em apresentá-la como a derradeira fase da iniciação lacedemônia, responsável por investir o antigo jovem do estatuto de adulto.

Na partes quatro e cinco do texto, o autor voltou ao tema da preparação militar, privilegiado pela historiografia moderna. Para ele, a modalidade de rito do qual a "criptia" fez parte inculcava nos indivíduos os valores da "mentalidade coletiva". Tendo sido a atividade guerreira orientada, na Lacedemônia, para o combate coletivo e diurno, a caça noturna aos escravos em nada se assemelhava a ela. Não haveria, portanto, como fazer derivar uma da 
outra, pois os traços básicos de suas organizações eram opostos. O derramamento de sangue hilota surgia então como uma modalidade, certamente extremada, de rito de iniciação. Para reforçar sua hipótese, o autor ainda recorre, ao final do texto, a casos análogos relatados em etnografias sobre a Melanésia.

Louis Gernet, em seu discurso presidencial na assembleia anual da AEEG, quase cinquenta anos mais tarde, ao elogiar o texto, não deixou de situar seu autor no campo da “antropologia inglesa" (GERNET, 1983: 399). De fato, Jeanmaire, que aí não referencia ninguém da equipe do AS, valeu-se dos trabalhos dos britânicos James Frazer, Alfred William Howitt e Baldwin Spencer. Ainda assim, ele também citou autores alemães (Henrich Schurtz, Karl Bücher e Hermann Usener) e americanos (Hutton Webster). Em todo caso, para além do jogo das citações, o que chama atenção é a preocupação do autor com os "sistemas de classificação" e com "mentalidade coletiva", temas absolutamente centrais para a empresa durkheimiana. Cumpre ainda destacar que, publicado às vésperas da Guerra de 14-18, esse texto pouco circulou entre os helenistas até 1920. As únicas referências encontradas vieram da parte de Louis Gernet, o qual se valeu dele em dois de seus artigos ${ }^{53}$.

Mas se Gernet situou Jeanmaire em outro ramo das ciências sociais, isso se deve, ao menos em parte, à declarada militância pró-sociologia que ele próprio desempenhou entre os helenistas no início do século $X X^{54}$. Dentre os colaboradores do AS, foi ele quem mais escreveu artigos e resenhas para a REG, sendo raro um texto seu sem alusões diretas a essa ciência. Ilustram bem tal situação os dois primeiros textos que Gernet aí publicou. Na resenha de 1908, por exemplo, ao discutir os resultados de um artigo dedicado à competência dos juízes públicos em Atenas, ele criticou a incapacidade do autor de esclarecer a "origem histórica" do fenômeno, bem como de mostrar suas "funções sociais" (REG, 1908: 380-381). Na mesma direção, $A Y \Theta E N T H \Sigma$, seu primeiro artigo, discutiu os significados que tal palavra grega assumiu ao longo dos séculos V a IV a.C. (REG, 1909: 13-32). Partindo das diferentes traduções que os comentadores atribuíram a ela ("assassino", "suicida" ou "aquele que mata um parente"), Gernet isolou aí os contextos jurídicos e "literários" nos quais aưtévTnS foi originalmente utilizada, mostrando como nem todas as traduções modernas procediam (em especial, a de "suicida"). Mas sua reflexão não se restringiu no campo semântico: ele quis, em

\footnotetext{
${ }^{53}$ REG, 1917: 281 (nota 4) e 1920: 160-161 (nota 3).

${ }^{54}$ É salutar não esquecer, contudo, que a fala de Gernet ocorreu em um momento de revalorização das ciências sociais sob a égide do estruturalismo, o qual implicou uma disputa tanto do legado da escola sociológica francesa quanto do bom uso (ou leitura) a ser feita dos trabalhos de tal escola. Remeto aqui a análise de Lygia Sigaud sobre o estado de cenário intelectual francês pós-1945 a partir das apropriações do Ensaio sobre o Dom, de Marcel Mauss (SIGAUD, 1999).
} 
verdade, pesquisar sobre "as representações coletivas" e as ordens sociais que as tornaram possíveis. Daí sua ênfase no fundo religioso que ligava primitivamente a culpabilidade individual à coletividade familiar, bem como no enfraquecimento progressivo do direito penal grego em prol de um direito de restituição, tal como já preconizara Durkheim em seu De la Division du Travail Social.

Com exceção de uma resenha publicada em 1910, na qual Gernet tratou da religião grega por meio de certos ritos mortuários (REG, 1910: 85), as demais intervenções de Gernet na REG seguiram o mesmo padrão acima delineado, mantendo-se atreladas à esfera do direito - ou, para ser mais preciso, à confluência entre o direito primitivo e a religião. Seus seis artigos publicados na sequência trataram ou de legislações e episódios jurídicos específicos ou buscaram definir os princípios gerais de certas práticas jurídicas (o contrato e o testamento).

Em Observations sur la Loi de Gortyne, Gernet discutiu o significado das leis relativas ao estupro nesse que era considerado um dos mais arcaicos códigos de direito gregos (REG, 1916: 383-403). O propósito das primeiras seções do artigo era, através de um exame minucioso do texto antigo, mostrar como não existia então uma lei específica para o estupro, como queriam alguns comentadores. De fato, longe de reconhecer em tal crime a violação dos direitos universais dos indivíduos, a lei de Gortina o associava à ideia do rapto e/ou do adultério. A segunda parte do texto procurou precisar, a partir do que foi discutido antes, o "estado jurídico" representado pela legislação em questão. Valendo-se do direito comparado, Gernet inferiu que tal querela se resolvia no contexto grego no âmbito do direito interfamiliar (entendendo aqui família como $\gamma^{\prime} \varepsilon$ vos, ou seja, como comunidade organizada em torno de um pater familias). O estupro tendia assim a ser pensado como a suspensão da paz entre grupos extensos, cuja gravidade dependeria unicamente do status (cidadão, estrangeiro ou escravo) e do estado civil (casado ou solteiro) da pessoa agredida.

Os dois textos homônimos publicados um ano depois, Hypothèses sur le Contrat Primitif en Grèce, foram mais ousados (REG, 1917: 249-293 e 363-383). No centro da discussão

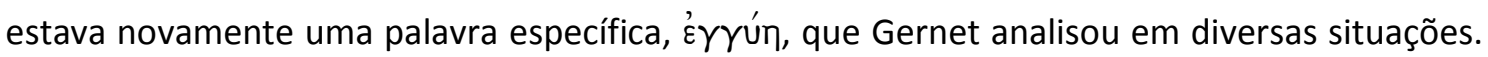
Mas qual eram seus significados? Na cena homérica em que Hefesto cobra de Possêidon uma garantia para que Ares lhe pague o preço do adultério cometido contra ele (Odisseia, VIII, 351), o autor chamou atenção para o uso dessa palavra para expressar garantia em uma complexa negociação. Mais uma vez se tratava aqui de um direito que engaja não apenas o delinquente enquanto indivíduo (Ares), mas também sua família (em nome da qual fala Possêidon). Gernet acompanhou, em seguida, os usos de Éryún quando aplicada ao contexto do casamento. Os indícios sugerem, nesse caso, uma continuidade do direito interfamiliar, para o qual o 
casamento só faz sentido como acordo entre coletividades ${ }^{55}$. Valendo-se ainda dos resultados acumulados pela "sociologia do casamento" e do estudo sobre as polaridades religiosas de Robert Hertz (1909), ele buscou mostrar como o contrato grego original supunha a crença religiosa na força da coletividade ${ }^{56}$. Desse modo, ao final do segundo artigo, Gernet apontou para a insuficiência das teorias individualistas do contrato, as quais desconsiderariam "a realidade moral que sustenta o pensamento". Tudo se passa como se sempre houvesse uma sociedade suposta em qualquer acordo, importando apenas explicar como ela está organizada e como essa organização transparece nas categorias com as quais seus membros explicam o mundo.

Note sur les Parents de Démosthène (REG, 1918: 185-196) e as duas partes de La Création du Testament (REG, 1920: 123-168 e 249-290), por fim, enfrentaram o problema dessa forma específica de contrato que é o testamento. Afinal, como se transmitiram os bens dentro na Grécia Antiga? Qual era a margem de manobra de quem lega seus bens? Quais as possíveis linhas de sucessão (via ágnatos, cognatos ou terceiros sem quaisquer laços de parentesco)? Mais uma vez Gernet se valeu da sociologia para mostrar os arcaísmos dos antigos helenos nessa matéria. Suas observações sobre a lei de sucessão testamentária de Sólon, a qual fornece a substância para os dois últimos textos, fornecem um bom exemplo disso. Nelas, se procurou relativizar o lado reformista do legislador ateniense. Para muitos dos contemporâneos de Gernet, a lei de Sólon representaria a luta bem-sucedida, em nome da política moderna, contra as formas de organização arcaicas, ligadas às famílias estendidas (o Y'́vos). Elas teriam colocado pela primeira vez à disposição de quem lega a propriedade o direito de escolher um sucessor. Para o helenista-sociólogo, contudo, tal ajuizamento não considerava que essa escolha fosse limitada em muitos aspectos, dependendo sobretudo das condições de sucessão (condição civil de quem lega e a existência ou não de herdeiros consanguíneos). Essas limitações, diferentes das antigas, ganhavam sentido em função dos rearranjos das estruturas familiares, as quais se modificaram com o passar dos séculos. Ao que parece, Sólon teria, segundo Gernet, tentado atender a essas novas demandas, flexibilizando certas convenções, mas instituindo outras. Não se quis assim de opor um testamento puramente coletivo (o do regime do Yévos, anterior a Sólon) a um puramente individualista (posterior a Sólon). Nas palavras do autor (REG, 1920: 287-288):

\footnotetext{
${ }^{55}$ Ainda que, bem entendido, essas unidades tenham variado e perdido força ao longo da antiga história grega.

${ }^{56}$ Há aqui uma interessante discussão em torno das teses de Huvelin (1908) sobre o papel da magia no contrato primitivo. Gernet tende a ser um durkheimiano mais ortodoxo ao ver na magia uma decorrência da religião. Assim, tudo o que, quanto aos direitos individuais, Huvelin atrelava ao ritual mágico-individual, Gernet derivava da religião coletiva. Ao acreditar nas palavras de Mauss, ele e Hubert jamais se convenceram totalmente da leitura de seu tio (MAUSS, 1979: 227-229).
} 
Desse modo, a inovação legislativa pode ser considerada sob dos pontos de vista: de um lado, nós vemos o grupo familiar se concentrar e, tendo se tornado um novo ente jurídico, é para ele que a liberdade aparece. Por outro lado, nós vemos o indivíduo se tornar mais autônomo, e, liberto de uma tutela, é sobre ele que a organização se funda. Eis aí duas faces de um mesmo fenômeno: é supondo um status que a lei confere um direito.

Vale dizer: os processos de transmissão de bens devem ser compreendidos na Atenas clássica em função do aparecimento de novos grupos sociais (famílias mais "concentradas" ou "menos extensas"), aos quais se tornam presentes por meio dos indivíduos, de seus direitos e obrigações. Mais uma vez a chave de leitura sociológica (e histórica) foi aqui determinante em suas ponderações.

Finda a apresentação dos textos dos sociólogos na REG, é importante explicar o conjunto dos dados recolhidos. Afinal, por que esses autores específicos? E mais: por que essa frequência de intervenções? Um primeiro elemento a ser observado a esse respeito é o encaixe da presença dos sociólogos com os padrões de recrutamento da REG. Três deles Roussel, Jeanmaire e Gernet -, todos antigos alunos da École Normale, seguiam então a carreira de helenistas e era natural que buscassem construir na principal revista da área um espaço.

Roussel, o mais velho do grupo, nascido em 1881, tinha a vantagem nada desprezível de ter sido membro da EFA (1905-1908), permanecendo em Atenas um período suplementar como pesquisador. Foi nesse longo estágio no exterior que ele adquiriu o prestígio de bom epigrafista, podendo dedicar-se in loco aos progressos na área. Com pouco mais de trinta anos ao voltar a França, ele era uma aposta segura para a direção da REG, a qual lhe atribuiu a redação dos boletins epigráficos aí publicados. As portas da revista estavam, enfim, abertas. Gernet, por sua vez, apenas um ano mais novo, teve de se contentar em seguir cursos mais especializados na própria Paris, recebendo depois de sua agrégation de lettres em 1905 uma bolsa da Fundação Thiers. Mas o handicap de títulos foi, no seu caso, compensado pelas relações sociais ${ }^{57}$. Ao menos no início de sua carreira, ele esteve muito próximo de Gustave Glotz, trabalhando com temas inspirados na obra desse helenista já consolidado e atuando ao seu lado na administração da REG. Jeanmaire, por fim, era o mais novo dos quatro. Nascido em 1884 e agrégé d'histoire et de géographie apenas em 1909, ele também não havia usufruído o privilégio de ser membro da EFA. Era normal que seus primeiros textos só viessem a público no início da década seguinte, algo adiado ainda mais pela eclosão da Primeira Grande Guerra. A

\footnotetext{
${ }^{57}$ Veja-se também o subcapítulo 1.2 da presente tese.
} 
presença contínua dos três helenistas a partir de 1908, em especial de Roussel e de Gernet, explica-se assim em função de suas entradas no mercado de trabalho.

E quanto a Antoine Meillet e Isidore Lévy? A presença do primeiro já foi comentada antes (veja-se padrões de recrutamento). A REG, enquanto revista de uma certa elite universitária engajada no helenismo, buscava também a presença de grandes especialistas em outras disciplinas em suas páginas. Meillet, em 1908, já era professor do Collège de France e, seguramente, o maior linguista francês em atividade. Seu interesse por línguas antigas, derivadas do indo-europeu, tornou o encontro com a REG e com a AEEG inevitável.

O caso de Isidore Lévy é um pouco diferente. Ele ainda não era o grande patrão dos estudos sobre a Antiguidade Oriental que se tornará mais tarde. Em verdade, quando ele publicou seu primeiro texto na REG em 1895, contava apenas com vinte e quatro anos, tendo recém passado o exame de agrégation. Além do mais, bolsista da fundação Thiers desde o ano anterior, ele já se dirigia aos estudos judaicos e egípcios, aos quais, por certo, ele combinava os gregos. Se seu nome já estava solidificado em 1913, data de seu último texto na REG no período aqui estudado, a situação era bem diferente duas décadas antes. É salutar lembrar ainda que a REG não tinha, como foi visto antes, o hábito de recrutar autores tão jovens.

Nesse caso, a única explicação plausível vem dos contatos sociais, em especial dentro dos círculos de universitários normalianos e judeus. Em uma carta não datada, mas provavelmente escrita em 1898, Henri Hubert revelou a Mauss que seu patrão no Musée des Antiquités Nationales, Salomon Reinach, "estimava infinitamente" Lévy ${ }^{58}$. É muito provável que a encomenda para a série de seus primeiros textos na REG tenha passado por aí, explicando, a reboque, a precocidade com que este colaborador do AS aí publicou.

Outro elemento que essa série permite tratar são as simpatias e resistências à sociologia entre os helenistas. Ao contrário da impressão deixada pela simples leitura das resenhas de Puech e Toutain, viu-se como uma abordagem sociologicamente orientada encontrou espaço na REG, seja no campo da linguística, seja no campo dos estudos relativos à religião e ao direito primitivos. Não por acaso, com apenas duas exceções, 1911 e 1912, todos os volumes da revista publicados a partir de 1908 trouxeram artigos de colaboradores do AS. Isso prova, ao menos, que a nova ciência poderia ser percebida como algo interessante no campo do helenismo, ainda que em chaves específicas. Jovens especialistas, afinal, buscaram também viabilizar suas carreiras a partir de tal aliança. A presença de um artigo de Marcel Mauss na REG, em 1921, sugere que essa simpatia mútua se manteve, ao menos por mais algum tempo.

\footnotetext{
${ }^{58}$ Carta não datada. Arquivos do IMEC-Caen, Fonds Mauss-Hubert (MAS 49).
} 


\section{UMA FORMA ANTIGA DE CONTRATO ENTRE OS TRÁCIOS: MAUSS NA REG}

Em 1921, ao publicar um artigo na REG, Mauss se uniu ao seleto grupo de colaboradores do AS até então formado por Is. Lévy, Meillet, Roussel, Gernet e Jeanmaire (REG, 1921: 388397). Nesse texto, ele apresentou aos helenistas o primeiro indício que encontrou do fenômeno do "potlatch" no domínio indo-europeu.

Dos trácios, habitantes do limite norte do antiga Hélade, vinha o indício em questão. Quanto ao "potlatch", tratava-se de um "sistema de prestações totais" que regulava a circulação de bens em certas sociedades, fenômeno particularmente recorrente entre os nativos da Polinésia e da América do Norte (aos quais se deve o termo). Tal sistema implicava grandes coletividades em verdadeiras alianças, em geral seladas por meio de banquetes e matrimônios. Além disto, o "potlatch" se caracterizava por uma gratuidade aparente, a qual supunha a usura, e por seu caráter agonístico, capaz de hierarquizar famílias e clãs presentes.

Para provar sua tese, Mauss mobilizou três textos antigos. Em um primeiro momento, valendo-se de Xenofonte (Anabase, VII) e de Tucídides (II, 97), isolou o fenômeno dos banquetes trácios, mostrando como a lógica do "potlatch" se fez neles presente. Em seguida, discutiu a passagem relativa à descrição de um casamento trácio na comédia Protesilaus, datada do século III a.C. e de autoria de Anaxandrides.

Chama aí atenção a destreza com que Mauss faz as vezes de helenista. Ele demonstra grande domínio dos textos antigos, ao ponto de discutir termos específicos empregados por suas fontes, ou ainda de traduzir do próprio punho trechos longos de Xenofonte e de Anaxandrides.
Igualmente intrigante, contudo, é como Mauss reiterou, aqui e ali, sensos comuns de seus leitores helenistas. Assim, por exemplo, ao tratar de Tucídides, disse que sua descrição dos fatos era "aqui, como sempre, clara e precisa". Além disso, em meio aos dados etnográficos extraídos de Xenofonte, elogiou a construção do relato, "muito pitoresto e muito bem escrito". Por fim, quanto à relação dos próprios helenos com esses ritos arcaicos, afirmou: "sente-se bem que os gregos não compreendem os usos que, espertos, eles foram os primeiros a abandonar". Ele ainda se valeu de uma conhecida passagem da llíada, a frustrada troca de armas entre Glauco e Diomedes, para reforçar essa imagem de uma Grécia Antiga liberta de arcaísmos.

Em uma carta escrita no dia dezesseis de março de 1923 e pertencente aos arquivos do Institut Mémoires de l'Édition Contemporaine, Louis Gernet comentou com as seguintes palavras a iniciativa do mestre e amigo: "você deveria escrever mais para a Revue des Études Grecques. Isto não faria mal aos helenistas supondo que se possa perturbar um sono que não é nem mesmo dogmático" (MAS 5.12).

Dogmático ou não, nos anos seguintes, poucos helenistas despertaram para seguir a via aberta por Mauss. Gernet explorou a temática em alguns de seus textos posteriores, sobretudo em La notion mythique de valeur en Grèce (1982: 93-137) e Frairies antiques (REG, 1928: 313-359). O mesmo fez Moses Finley em The World of Odysseus, um de seus primeiros trabalhos (2002). Nos dois casos, porém, os costumes antes tidos como "primitivos", pertencentes às margens da Grécia Antiga, invadiram seu centro. 


\section{$2.4-A$}

\section{REVUE}

DES

ÉTUDES
"Nem exclusivismo, nem esnobismo, tal é a fórmula que nos parece deve regular as energias provinciais. Alguns dentre nós se creem perdidos se, ao publicar um livro, os curiosos não lerem sobre a capa o nome de um editor parisiense. Eles se enganam e tal superstição da capital fecha seus olhos às vantagens que eles encontrarão ao tomar lugar junto à nossa Biblioteca. Mas o espírito contrário - o espírito chauvinista - não é menos irritante. Não confundamos, por favor, este espírito chauvinista com o patriotismo da terra natal, tão legítimo, tão generoso, tão fecundo quanto outros sentimentos de família."

Georges Radet

(Avant-propos, cf. REA, 1899: 6)

“Eu não serei desmentido pelo Sr. Georges Radet, diretor, para a antiguidade clássica, da Revue des Études Anciennes que é publicada em Bordeaux, se eu dissesse que a colaboração de Henri Lechat, sob a forma das Notes archéologiques, é um dos principais títulos desta publicação, a única impressa na província que, talvez, rivalize com seus primogênitos e concorrentes parisienses."

Paul Jamot

(JAMOT, 1926: 17, grifos meus)

\section{ANCIENNES}

Antes do aparecimento da Revue des Études Anciennes (REA) em 1899, o campo das publicações especializadas nos estudos greco-latinos se restringia aos três periódicos até aqui analisados: o $\mathrm{BCH}$, O MAH e a REG. De um lado, os espaços voltados prioritariamente aos "jovens", os quais estavam sendo treinados para se tornarem os futuros grandes antiquisants franceses (o BCH e o MAH); de outro, o lugar dos "velhos", daqueles que, procurando manter ou acumular certo prestígio, haviam já iniciado carreira (a REG). O envelhecimento natural no campo se caracterizava, portanto, pela migração dos dois primeiros periódicos ao terceiro.

Outra característica desse cenário pré-1899 era o monopólio parisiense. Na capital se encontravam os editores das revistas e era a partir de lá que elas eram distribuídas. Paris concentrava também os mais significativos debates ligados ao tema, por intermédio de instituições como a Association pour l'Encouragement des Études Grecques en France e a Académie des Inscriptions et Belles-Lettres, bem como as facudades e escolas das quais provinha, ou nas quais havia estudado, a maioria de seus colaboradores. Estar em contato com a capital era uma obrigação para quem quisesse produzir na área; ter uma posição lá, uma significativa vantagem.

Mas eis que, com o surgimento da REA, tanto as antigas oposições estruturantes desse cenário foram complexificadas quanto novas foram criadas. Veja-se, por exemplo, o binômio jovens $\mathrm{x}$ velhos. Durante o período analisado na presente tese, a REA foi dirigida por um grupo 
bastante coeso de professores, o qual concentrava aí, e não na prestigiosa REG, seus investimentos em termos de publicação. Tal fato permite explicitar, senão um rompimento, ao menos uma forte tensão no interior da comunidade dos antiquisants franceses (a qual certamente reverberou nos mecanismos de recrutamento até então vigentes, fornecendo opções à via tradicional de envelhecimento no campo). Além disso, a REA inaugurou na esfera dos periódicos universitários especializados em Grécia e Roma Antigas a oposição Paris x Província. Os membros de sua equipe inicial, embora tenham todos estudado na capital, exerceram parte considerável de suas atividades docentes na Província. De lá provinham também seu editor e a maioria de seus colaboradores. E há mais: há o próprio esforço em se redefinir o valor desse território, antes uma mera passagem ou antessala de Paris. A Província passou a ter então toda uma dignidade própria, a qual deveria ser defendida sobretudo contra o que Georges Radet denominou "a superstição da capital".

O propósito do presente subcapítulo é explorar variáveis que permitam explicar como foi possível essa transformação estrutural operada pela REA, atentando igualmente para a recepção que nessa revista se reservou à sociologia defendida em outra publicação da mesma época, o Année Sociologique.

\section{ANTECEDENTES INSTITUCIONAIS E A CARACTERIZAÇÃO DE UMA EQUIPE}

A criação da REA torna-se mais facilmente compreensível se inserida na história da expansão do sistema universitário francês. Desde ao menos os derradeiros anos do Segundo Império, sobretudo em função da cada vez mais evidente superioridade científica alemã, falava-se em revitalizar as Faculdades de Letras Provinciais, até aquele momento reduzidas à tarefa de formar professores para atender a demandas locais. A derrota militar para a Prússia em 1870 só fez acelerar o processo, o que incluiu um progressivo aumento das verbas e dos postos de ensino por todo o país. Queria-se com isso criar novos polos de produção de conhecimento científico original, bem como garantir os meios de divulgação e de discussão de seus resultados. Foi em tal contexto que a temática dos periódicos provinciais se impôs.

Um dos primeiros esforços nessa direção se deu com a criação dos Annales de la Faculté des Lettres de Bordeaux em 1879. Concebidos por Louis Liard e Auguste Couat, ilustres representantes das elites letradas reformistas dos primórdios da Terceira República, neles eram impressos anualmente tanto trabalhos científicos dos professores quanto a prestação de contas das atividades docentes e burocráticas da instituição (cursos ofertados, resumos de defesas, resultado de exames locais). A ideia inovadora chamou atenção de outras faculdades, as quais foram aos poucos aderindo ao veículo já existente: Toulouse em primeiro lugar (1882), seguida de Aix-en-Provence e Montpellier (1895). 
Ao final desse processo de fusões, os Annales originais acabaram se tornando outro periódico, o qual bem poderia ser considerado o ancestral imediato da REA, a Revue des Universités du Midi (RUM). Mais que um simples órgão federativo, a RUM inaugurou e consolidou mudanças de escopo considerável, cujo impacto sobreviveu aos quatro anos de sua existência (1895-98). Merecem destaque nesse sentido as "modernizações" de periodicidade e de forma, bem como os novos patrocinadores e editores. Nela, quanto à forma, os artigos passaram a ser classificados segundo o período da história ao qual eles se referiam (Antiquité ou Moyen Âge et Temps Modernes). Além disso, foram também criadas seções próprias para boletins regionais, comunicações de toda ordem e resenhas de livros ou teses. Quanto à periodicidade, optou-se por publicar um número a cada três meses, dinamizando assim a divulgação das atividades provinciais (os volumes anuais comportavam desse modo quatro números). Por fim, atuando conforme o desejo de um de seus patrocinadores locais (o Conseil Municipal de Bordeaux), a RUM não renovou o contrato com o editor parisiense dos Annales (Leroux - o mesmo da REG), passando a contar com os serviços de um provincial (Feret \& Fils).

Mas a grande novidade da RUM estava mesmo na equipe que a animava. Se considerados apenas os autores de textos relativos ao Mundo Antigo, já se encontravam lá os futuros responsáveis pela criação da REA. O núcleo estava situado em Bordeaux, com Henri de la Ville de Mirmont, Pierre Paris, Camille Jullian e Georges Radet, sendo este o diretor-geral da revista. Eles contavam ainda com uma importante colaboração vinda de Aix-en-Provence, a de Michel Clerc. Tratava-se de um grupo bastante jovem (nenhum de seus membros tinha mais de 40 anos em 1898), compostos por agrégés de letras ou de história, e cujos históricos escolares indicam a passagem por algumas das mais renomadas instituições francesas ligadas aos estudos greco-latinos (a École Normale Supérieure, a École Française d'Athènes e a École Française de Rome).

Isso não significa, por certo, que nela se tenha publicado somente a produção intelectual dessas pessoas. A RUM contou ainda com a participação de autores mais experientes (Auguste Couat), de estrangeiros de maior ou menor prestígio (o arqueólogo escocês William Mitchell Ramsay e o antiquário grego Aristote Fontrier), ou mesmo com a de outros jovens professores de província (Georges Rodier, Maurice Holleaux, Paul Perdrizet, para evocar apenas alguns nomes). Isso sem levar em conta os não-antiquisants. Chamam atenção, no entanto, o peso e a constância da presença daqueles indivíduos. Foram eles que lutaram para imprimir à revista um perfil próprio, recrutando colaboradores e explorando temáticas compatíveis com ele. A transformação de RUM em REA é uma etapa desse processo, sendo mesmo indissociável de suas ambições científicas e institucionais. 
Novas posições se consolidam: a crítica dos dominantes e sua resposta (1895)

A organização de um pequeno grupo de antiquisants em torno da RUM não passou desapercebida pela instância dominante no campo das revistas especializadas nos estudos greco-latinos, a REG. Quem emitiu uma opinião sobre a "concorrente" foi o próprio diretor da revista, Théodore Reinach.

O pretexto para tal manifestação surgiu da crônica que Georges Radet publicou logo no primeiro número da RUM, L'Invention de la Monnaie (RUM, 1895: 116-121). Nela, entre outras coisas, o autor insinuou que Reinach havia se apossado de ideias desenvolvidas por ele, Radet, sem lhe reconhecer os devidos créditos (em especial, no tocante ao comércio marítimo no Mediterrâneo Oriental).

A resposta veio na forma de uma nota breve e mordaz, estrategicamente colocada ao final da resenha que Théodore Reinach escrevera acerca de outro artigo publicado na RUM (REG, 1895: 159-160). Nesse texto, o autor criticou Radet por este se vangloriar da paternidade de certas "verdades elementares" e aproveitou a deixa para definir o lugar da RUM nos seguintes termos:

"A revista de onde se extraiu esta excelente memória subsititui os Annales da Faculdade de Bordeaux e, creio eu, uma outra publicação similar; é já um progresso, mas me parece que os compêndios desse gênero, ao mesmo tempo vastos pelo programa e estreitos pela redação, são uma aplicação equivocada do princípio de descentralização universitária. A verdadeira descentralização consiste em abrir com liberalidade nossas revistas especializadas aos trabalhos de professores de província e não a inumar estes trabalhos em saladas de frutas locais onde os especialistas não os irão procurar em meio a tantas coisas indiferentes".

Radet, por seu turno, respondeu à crítica dos dominantes naquele mesmo ano (RUM, 1895: 345-346):

"O brilhante e fogoso diretor da Revue des Études Grecques não ama as revistas provinciais. Ele reserva suas preferências aos compêndios onde ele é mestre ou onde ele pode trazer o auxílio de sua ciência, que é vasta, aos seus colaboradores provinciais. Para ele, a verdadeira descentralização consiste em dirigir a Paris todos os trabalhos da província. O próprio Sr. Brunetière não estaria talvez muito satisfeito com esta definição inesperada. É difícil ver como artigos enviados de Toulouse ou Marselha, de Montpellier ou Bordeaux, a periódicos parisienses contribuirão para o desenvolvimento intelectual das cidades nas quais eles foram elaborados. $O$ inverso se compreende melhor. Paris é povoada de provinciais que não guardaram uma má lembrança da província. Paris é mesmo povoada de parisienses que, por serem de tão pura raça parisiense como o Sr. Th. Reinach, não são contudo hostis à nossa iniciativa. A Sorbonne, menos orgulhosa que nosso espirituoso contraditor, não nos despreza e nós acolhemos bem as páginas que ela não hesita em 'inumar' aqui.

Aliás, com o progresso do tempo e o aumento de recursos, nós não perdemos a esperança de dividir nossa "Salada de Frutas" em um certo número de sessões homogêneas onde os especialistas encontrarão apenas memórias de mesma natureza. Sem dúvida, nossa publicação, qual seja ela, jamais terá o brilho daquela que o Sr. Th. Reinach tornou tão próspera e onde ele nos oferece uma hospitalidade generosa". 
Mas qual o propósito da criação de uma nova revista? Já no derradeiro volume da RUM se anunciou que esta seria dividida em duas: a Revue des Études Anciennes e a Revue des Lettres Françaises et Étrangères, cada uma com sua "fisionomia própria" (RUM, 1898: 362). No ano seguinte, a cisão foi justificada por Georges Radet como uma decorrência da "lei moderna da divisão do trabalho", a qual teria por efeito a "união pela especialização" (REA, 1899: 1-6). Ele, cujo posto de diretor foi mantido com o fim da RUM, sugeria com tal formulação que cada Faculdade de Letras do Midi publicasse um periódico especializado associado às atividades privilegiadas por seu corpo docente. Segundo tal proposta, Bordeaux ficaria encarregada do estratégico domínio da "erudição greco-latina", herança dos Annales originais. Com efeito, em se tratando de uma área de grande prestígio dentro e fora da França, a tendência era que isso colocasse a Faculdade de Letras de Bordeaux no mapa da filologia clássica. Entretanto, advertiu Radet, só isso não bastava: era preciso também enfatizar os interesses e o caráter do local no qual a nova revista estava sendo produzida. Em se tratando de uma "coletânea meridional", a história das regiões meridionais (o sul da França e adjacências) deveria encontrar aí o merecido destaque.

A análise das formas de classificação explicitadas na tábua de matéria da REA aponta para a medida com que os temas mais "universais" se articulavam nela com os "particulares". No item Articles de Fond, por exemplo, instituiu-se desde o início a tripartição Orient Grec, Monde Latin e Antiquités Nationales, sendo a terceira seção aquela na qual se integravam as temáticas clássicas e regionais. Similar divisão se impôs ainda, embora posteriormente, ao item Bibliographie ${ }^{1}$. Além do mais, foram igualmente criados um item reservado às crônicas, onde se discutiram os mais variados temas, e o Bulletin Hispanique, o qual acompanhou a revista em seus três primeiros anos de vida ${ }^{2}$. Por fim, é importante sublinhar que a nova revista incorporou todo o aparato técnico necessário às grandes discussões arqueológicas, epigráficas e filológicas do período, instituindo desde 1899 seções específicas nas quais poderiam ser impressos desenhos, fotos e mapas indispensáveis ao bom entendimento de seus artigos.

\footnotetext{
${ }^{1}$ Isso porque foi apenas em 1911 que as resenhas pararam de ser dispostas em um bloco único para conhecerem o seguinte arranjo: 1) Orient Grec, 2) Monde Latin, 3) Préhistoire et Antiquités Nationales e 4) Antiquités Chrétiennes. Ainda assim, se comparados aos Articles de Fond, a Bibliographie teve uma estrutura mais instável. Entre 1911 e 1920, novos domínios foram criados (Ethnographie et Linguistique em 1919), bem como os antigos sofreram variações - assim, ao invés de Antiquités Chrétiennes, surgem Monde Chrétien et Bizantin (1915) e Monde Chrétien et Arabe (1920). Isso sem mencionar os volumes em que certas seções ou não aparecem ou não são mantidas.

${ }^{2}$ O Bulletin Hispanique permanece integrado à REA até 1901. Em 1902 ele ganha estatuto de seção nos Articles de Fond, desaparecendo no ano seguinte. Sua criação é fruto tanto da importância das descobertas arqueológicas na Espanha, como do papel de Bordeaux e da equipe da REA em tal domínio (com destaque para Pierre Paris). Não por acaso, o Bulletin Hispanique tornou-se nesses mesmos anos um periódico independente (e, como a REA, até hoje existente).
} 
Tal estruturação sugere que a equipe envolvida com a REA se esforçava para produzir certa diferença, algo como uma marca registrada, em um cenário ainda bastante restrito de publicações. Cientificamente, seus integrantes se valeram da formação de antiquisants de que dispunham para relacioná-la a questões regionais e, a partir daí, nacionais (isso enquanto as outras revistas tendiam a valorizar os grandes temas universais, dos quais decorrem a própria ideia de legado greco-latino). Institucionalmente, eles se esforçaram por promover alianças com as mais diversas forças regionais. Assim, a editoração provincial foi mantida com a criação da REA (ainda por intermédio de Feret et Fils), o mesmo valendo para muitos de seus patrocionadores (as faculdades provinciais, o Conseil Général de la Gironde e o Conseil Municipal de Bordeaux). Já quanto aos colaboradores, como será visto adiante, destacam-se tanto professores de província quanto diversas modalidades de eruditos locais.

Similar investimento não poderia se sustentar sem a dedicação e o espírito combativo das pessoas que o empreenderam. Michel Clerc, Henri de la Ville de Mirmont, Pierre Paris, Camille Jullian e Georges Radet, tal como os integrantes de certas vanguardas artísticas e científicas do período (entre elas a dos sociólogos), viram-se impelidos a concentrar sua presença nos espaços criados por eles (RUM e REA), saindo de lá apenas eventualmente e, em geral, para fortalecer sua posição ignorar grupo.

Um dado capaz de confirmar a pertinência da caracterização de tais indivíduos como equipe ou grupo provém dos números absoluto e relativo de artigos publicados por eles no conjunto das revistas dedicadas aos estudos greco-latinos ${ }^{3}$. Entre 1895 e 1898, Clerc, de la Ville de Mirmont, Paris e Jullian atuaram exclusivamente na RUM. Juntos, eles contribuíram com seis artigos, $20 \%$ de tudo o que foi nela publicado. A exceção que confirma a regra é Radet. Ele publicou nesses mesmos quatro anos um só artigo no $\mathrm{BCH}$, o equivalente a 1,02\% de toda a produção deste periódico. Em compensação, ele foi o de longe maior colaborador da RUM, publicando sozinho o mesmo número de artigos que todos os seus colegas. Desse modo, como grupo/equipe, os cinco antiquisants foram responsáveis por nada menos que $40 \%$ da produção da RUM.

Para o intervalo seguinte, situado entre 1899 e 1920, no qual a RUM transformou-se em REA, constata-se uma tendência similar. De la Ville de Mirmont, Clerc e Radet publicaram um total de quatro artigos na REG, os quais, somados, totalizam pouco mais de $1 \%$ da produção deste periódico para o referido período. Em compensação, ao lado de Jullian e de Paris, eles redigiram cento e vinte e um artigos na REA, totalizando $21,17 \%$ de tudo o que nela

\footnotetext{
${ }^{3}$ Por certo, a produção desses autores não se resumiu a artigos científicos, pois, sobretudo na RUM e na REA, eles foram responsáveis pela redação de boletins diversos e resenhas.
} 
foi publicado. O destaque nesse caso é Jullian, o qual produziu setenta textos, mais da metade do saldo total do grupo.

Embora os dados acima dispostos - associados ao fato de serem os pesquisadores aos quais eles se referem todos jovens, formados nas melhores escolas francesas e professores de universidades provinciais - permitam falar de um grupo, eles pouco ou nada esclarecem sobre como tal associação foi possível. Afinal, existiam outros indivíduos com perfis parecidos e que, no entanto, não aderiram institucional e cientificamente ao mesmo projeto editorial. Para responder a tal questão, antes mesmo de aprofundar a análise da revista, é preciso resgatar e confrontar as biografias de seus principais animadores, problematizando em que medida elas apontam para a aquisição de certas disposições comuns.

\section{O GRUPO ANTES DO GRUPO I (UMA FORMAÇÃO DE ELITE)}

Ao se comparar as trajetórias dos membros da equipe inicial da REA, o local e a data de seus nascimentos são elementos que se destacam. Todos eram, afinal, de origem provincial e nascidos em fins da década de 1850. Mas se a data foi um provável fator de união, permitindo caracterizá-los como pertencentes a uma mesma "geração", o mesmo já não pode ser dito do local. O fato é que eles provinham de regiões distantes umas das outras: Georges Radet nasceu no nordeste da França (Chesley, Champagne-Ardenne); Michel Clerc, no leste (Chalonsur-Saône, Bourgogne); Henri de la Ville de Mirmont, no sudoeste (Bordeaux, Aquitaine); Pierre Paris, no sul (Rodez, Midi-Pyrénées); Camille Jullian, por fim, no sudeste (Marselha, Provence-Alpes-Côte d'Azur). Some-se a isso uma significativa diversidade de origens sociais: dentre os três indivíduos cuja profissão paterna foi identificada há um filho de banqueiro (Jullian), um filho de pequeno funcionário público (Radet) e um descendente da nobreza togada (de la Ville de Mirmont).

Ainda assim, havia um fator capaz de nuançar as eventuais diferenças preexistentes entre eles, transformando-as até em força adicional de integração: a passagem pela École Normale Supérieure (ENS). É difícil avançar quaisquer hipóteses sobre a constituição das elites letradas francesas ao longo dos séculos XIX e XX sem considerar tal instituição, espaço de treinamento ao mesmo tempo social e intelectual. Sua principal marca distintiva, acentuada no decorrer da Terceira República, era o vínculo com o Estado, do qual os alunos eram considerados funcionários. Além do mais, contrastando com uma Universidade onde deveriam encontrar acolhida todos os que desejassem levar seus estudos ao nível superior, a ENS e as demais Grandes Écoles (a École des Chartes, a École Polytechnique, a École des Mines, entre outras) promoviam anualmente concursos de ingresso com alto grau de dificuldade e para um 
número muito reduzido de vagas. A contrapartida das dificuldades vinha na forma de significativas compensações, sejam elas de ordem material (como, por exemplo, o fato dos anos de estudo contarem para o tempo de aposentadoria), ou de ordem intelectual (os professores da ENS estarem invariavelmente entre os mais conceituados de suas respectivas áreas).

Outra importante vantagem dos normalianos provinha dos vínculos estabelecidos entre eles ao longo dos três anos que lá passavam. Apesar de a ENS ser uma das principais instituições autorizadas a "distinguir" alguém no mundo dos estudos literários franceses, ela integrava os membros das elites em um momento de relativa indistinção (o período da juventude). Assim, a despeito do passado e do futuro de cada aluno, esse era o lugar no qual afloravam entre eles solidariedades e conflitos cuja influência tendia a se perpetuar. Dito de outro modo: saber se colocar aí diante dos potenciais concorrentes e daqueles que se ocupariam mais tarde das mais distintas atribuições no seio da sociedade francesa poderia fazer toda a diferença na hora de viabilizar uma carreira, seja ela científica, literária ou burocrática ${ }^{4}$.

O primeiro contato entre os fundadores da REA seguramente se deu em tal ambiente. Todos, sem exceção, viveram a mesma experiência de deixar suas províncias de origem ou para se prepararem para o concurso da ENS nos mais renomados liceus de Paris (sobretudo Louis-le-Grand) ou para lá ingressarem diretamente. Três deles - Michel Clerc, Henri de la Ville de Mirmont e Camille Jullian - foram aceitos ao mesmo tempo, integrando a promoção de letras de 1877. Dois anos depois, na mesma promoção de Durkheim, entrou Pierre Paris. Georges Radet, por seu turno, foi o último a ser admitido, em 1881. Se é difícil precisar o grau e a intensidade das relações estabelecidas entre eles no período de preparação para o concurso de admissão e na própria ENS, não há dúvidas de que, direta ou indiretamente, eles passaram a se conhecer.

\footnotetext{
${ }^{4}$ Ao analisar o estado do sistema de ensino francês em fins da década de 1960, Pierre Bourdieu insistiu no fato de a École Normale Supérieure proporcionar uma chave privilegiada tanto para o domínio da ciência "pura" (espaço de um capital propriamente intelectual), quanto para os da ciência "aplicada" e da arte (nos quais se destacam ora um capital de relações sociais, ora outras modalidades específicas de capital). O poder dos grandes normalianos consiste, assim, na capacidade de fazer convergir, independente do teor de seus investimentos, capitais de naturezas diferentes. Eles conhecem os integrantes das elites e estão familiarizados com as diversas ocupações que as caracterizam (BOURDIEU, 1984: 55-167). Jean-Pierre Faguer, estudando o sistema educacional francês nas décadas de 1950 e 1960, sublinhou ainda a importância dos cursos preparatórios para a ENS (os khâgnes e hypokhâgnes) como antecipação desse processo de acumulação de capitais (FAGUER, 1995). Embora tais resultados remetam a um período posterior ao aqui analisado, parece-me que eles revelam certas invariantes estruturais que acompanham o sistema de ensino francês desde os primórdios da Terceira República. Indicações nessa direção podem ser igualmente encontradas nos trabalhos de Fritz Ringer sobre os sistemas educacionais europeus (em particular, RINGER, 1992: 55-75).
} 


\section{Três retratos de normalianos por Salomon Reinach: a REA antes da REA}

Entre julho de 1877 e setembro de 1878, quando ainda integrava o quadro de alunos da ENS, Salomon Reinach registrou em um caderno várias descrições de seus colegas. Inédito até 1994, tal documento foi organizado levando em conta os anos das promoções e os indivíduos que as compunham. Nele, Reinach avaliou os defeitos e as virtudes de seus contemporâneos, descreveu os grupos aos quais eles pertenciam e chegou mesmo a narrar eventos pitorescos ocorridos enquanto esteve na escola.

Nascido nos arredores de Paris, Reinach teve como pai um banqueiro judeu bastante integrado às elites letradas francesas de fins do Segundo Império e inícios da Terceira República. Foi nesse ambiente que ele e seus dois irmãos, dentre os quais se encontrava o caçula Théodore, cresceram. Salomon entrou na ENS como cacique (primeiro colocado) da promoção de letras de 1876, ganhando cedo a fama de prodígio. Após passar pela École Française d'Athènes, obteve um posto no Musée des Antiquités Nationales de Saint-Germain-en-Laye (1885) e a direção de uma das mais antigas e prestigiadas revistas francesas, a Revue Archéologique (1903). Some-se a isso sua inserção precoce em instituições centrais como a Association pour l'Encouragement des Études Grecques en France (1878) e a Académie des Inscriptions et Belles-Lettres (1896). Como antiquisant, manteve-se sempre mais próximo do espaço dominante da REG, publicando vez por outra na REA (são 16 artigos contra 3 até 1920).
$O$ interesse nos retratos de Reinach reside nesse ponto. Embora tenha uma origem social e uma trajetória acadêmica distintas das que caracterizam os principais colaboradores da REA, ele os conheceu na ENS. Suas descrições de Henri de la Ville de Mirmont, Camille Jullian e Michel Clerc podem assim fornecer pistas acerca de tensões e rivalidades características não só desse período de formação, mas de todo o cenário posterior dos estudos greco-latinos.

Seguem abaixo os retratos elaborados por Reinach dos três normalianos supracitados, futuros integrantes da equipe da REA (REINACH, S., 1994: 205-208):

"De la Ville de Miremont [sic.], dito Le Pic, ser obsceno, pé torto, vangloria-se de descender de Henrique III, senão pelas mulheres, ao menos por um amante. Dito isto, de espírito e de algum talento."

"Jullian, marselhês doutrinário, entrou cacique de história e com uma dispensa de idade graças à proteção entusiasta de Desjardins. No primeiro dia, ele veio até mim no dormitório e me fez uma declaração, dizendo que queria absolutamente ser meu amigo. Nós jamais fomos íntimos, mas eu prestei serviços a ele, sobretudo no momento de uma doença semelhante a um começo de tifo que o obrigou a partir para Marselha. Dupuy, que o chamava de o Inseto, prevenia-me a seu respeito. É um bom menino cujas ideias são ainda pouco claras. Ligações com Lévy $e$ Rébelliau."

"Clère [sic.], imbecil cabeça-oca. Eu não o conheço." 
No terceiro e derradeiro ano de permanência na ENS, os cinco se prepararam, como os demais alunos, para a agrégation. Três deles optaram por histoire et géographie (Clerc, Jullian e Radet) e dois por lettres (de la Ville de Mirmont e Paris). Tais exames, nos quais todos tiveram sucesso, tornavam possível começar a carreira docente em um liceu, ou ainda ir para o exterior como bolsista do governo francês, o que dependia basicamente do número de vagas ofertadas e do resultado nos exames. Clerc, Paris e Radet seguiram para a École Française d'Athènes, enquanto Jullian permaneceu dois anos na École Française de Rome e um terceiro na Universidade de Berlim. Foi nesses espaços que os quatro receberam o melhor treinamento filológico, arqueológico e epigráfico da época. De la Ville de Mirmont, por seu turno, foi nomeado professor de língua e de literatura latina em um liceu de província, na Pau (Béarn) de 1880. É a partir desse ponto que se torna mais fácil precisar as relações entre eles.

Graças à correspondência mantida entre Jullian e seus pais durante sua estada no exterior, descobre-se que as relações entre Clerc, de la Ville de Mirmont e ele próprio não só já existiam no período da ENS como se mantêm depois. No caso de Clerc, Jullian celebrou em fins de 1880 a chegada desse "camarada" a Roma, o qual deveria cumprir lá um estágio de dois meses e meio antes de assumir seu posto na École Française d'Athènes. Ele informou a seus pais que Clerc deveria Ihes fazer uma visita antes de partir para a Itália e o descreveu nos seguintes termos: "trata-se de um rapaz que eu conheci bem durante meus três anos de Escola e ao qual se pode certamente confiar. Ele é muito franco e alegre." (JULLIAN, 1936: 38). De la Ville de Mirmont também foi mencionado por Jullian. Em suas cartas, ele fala de um convite que teria recebido no início de 1881 para contribuir com a Revue Bordelaise, jornal que o antigo colega normaliano ajudava a coordenar ${ }^{5}$.

Quanto à tríade de "atenienses" do futuro grupo, as informações são mais escassas. Clerc e Paris foram contemporâneos na École Française d'Athènes, quando este era recémchegado e aquele já veterano (em 1882). A mesma relação se repetiu dois anos mais tarde, mas agora envolvendo Paris e Radet. Nesse caso, porém, há registros de que ambos atuaram juntos. Entre 1885 e 1891, eles publicaram oito artigos em coautoria no $\mathrm{BCH}$, nos quais traduzem e comentam o material epigráfico recolhido em vários sítios arqueológicos gregos ${ }^{6}$.

\footnotetext{
${ }^{5}$ A referência a de la Ville de Mirmont ocorre na carta XVI, de 21 de janeiro de 1881 (cf. JULLIAN, 1936). Ela não é, no entanto, explícita e quem identifica de la Ville de Mirmont é o editor do volume, Paul Courteault. Ainda assim, o informante é confiável. Sucessor de Jullian em Bordeaux (1905), Courteault estava familiarizado com os expedientes do grupo e tornou-se ele próprio um colaborador assíduo da REA. Pude folhear alguns números da Revue Bordelaise na Bibliothèque Nationale, mas sem conseguir identificar o referido texto de Jullian nesta publicação. Além do precário estado de conservação de alguns números, dificultando seu manuseio, os artigos sobre temas greco-latinos, até onde pude constatar, eram assinados por pseudônimos.

${ }^{6}$ Cf. BCH, 1885: 433-436; BCH, 1886: 148-161 e 500-514; BCH, 1887: 63-70; BCH, 1889: 342-345 e 486497; $\mathrm{BCH}, 1890$ : 587-589; BCH, 1891: 571-608.
} 
Quadro 2.4.1 - Trajetória escolar e background familiar dos fundadores da REA.

\begin{tabular}{|c|c|c|c|c|c|}
\hline $\begin{array}{c}\text { Nome } \\
\text { (Ano de nascimento) }\end{array}$ & $\begin{array}{c}\text { Preparatório } \\
\text { para a ENS }\end{array}$ & $\begin{array}{l}\text { ENS-lettres } \\
\text { promoção }\end{array}$ & Agrégation & $\begin{array}{l}\text { Estágio no } \\
\text { exterior }\end{array}$ & $\begin{array}{c}\text { Background } \\
\text { familiar }\end{array}$ \\
\hline $\begin{array}{c}\text { Michel CLERC } \\
\text { (1857) }\end{array}$ & (?) & $\begin{array}{c}1877 \\
\left(3^{\circ} \text { lugar }\right)\end{array}$ & $\begin{array}{l}\text { Hist/géo - } 1880 \\
\left.\text { ( } 3^{\circ} \text { lugar }\right)\end{array}$ & $\begin{array}{c}\text { École } \\
\text { Française } \\
\text { d'Athènes }\end{array}$ & $\begin{array}{l}\text { De Chalôn- } \\
\text { sur-Saone. }\end{array}$ \\
\hline $\begin{array}{c}\text { Henri DE LA VILLE DE } \\
\text { MIRMONT } \\
\text { (1858) }\end{array}$ & (?) & $\begin{array}{c}1877 \\
\text { (19 lugar) }\end{array}$ & $\begin{array}{l}\text { Lettres }-1880 \\
\qquad\left(5^{\circ} \text { lugar }\right)\end{array}$ & & $\begin{array}{l}\text { De Bordeaux. } \\
\text { De família } \\
\text { aristocrática. }\end{array}$ \\
\hline $\begin{array}{c}\text { Camille JULLIAN } \\
\text { (1859) }\end{array}$ & $\begin{array}{l}\text { Liceu de } \\
\text { Marselha }\end{array}$ & $\begin{array}{c}1877 \\
\left(15^{\circ} \text { lugar }\right)\end{array}$ & $\begin{array}{l}\text { Hist/géo - } 1880 \\
\text { (1ºlugar })\end{array}$ & $\begin{array}{c}\text { École } \\
\text { Française de } \\
\text { Rome e } \\
\text { Univ. de } \\
\text { Berlim }\end{array}$ & $\begin{array}{l}\text { De Marselha. } \\
\text { Pai banqueiro } \\
\text { e mãe filha de } \\
\text { proprietários. }\end{array}$ \\
\hline $\begin{array}{c}\text { Pierre PARIS } \\
\text { (1859) }\end{array}$ & $\begin{array}{l}\text { Liceu Louis- } \\
\text { le-Grand }\end{array}$ & $\begin{array}{c}1879 \\
\left(21^{\circ} \text { lugar }\right)\end{array}$ & $\begin{array}{l}\text { Lettres }-1882 \\
\text { (10 lugar) }\end{array}$ & $\begin{array}{c}\text { École } \\
\text { Française } \\
\text { d'Athènes }\end{array}$ & De Rodez. \\
\hline $\begin{array}{c}\text { Georges RADET } \\
(1859)\end{array}$ & $\begin{array}{l}\text { Liceu Louis- } \\
\text { le-Grand }\end{array}$ & $\begin{array}{c}1881 \\
\left(14^{\circ} \text { lugar }\right)\end{array}$ & $\begin{array}{c}\text { Hist/géo - } 1884 \\
\text { (?) }\end{array}$ & $\begin{array}{c}\text { École } \\
\text { Française } \\
\text { d'Athènes }\end{array}$ & $\begin{array}{l}\text { De Chesley. } \\
\text { Pai "receveur } \\
\text { des postes". }\end{array}$ \\
\hline
\end{tabular}

Nascidos na província, mas educados em Paris e no exterior, os integrantes da equipe da REA compartilharam muito de uma juventude em comum. Quando finalmente ingressaram no mundo "adulto" da docência universitária em Bordeaux e em Aix-en-Provence, já existiam entre eles laços bem consolidados. Resta explicar como e por que eles convergiram também no projeto coletivo de uma revista.

\section{O GRUPO ANTES DO GRUPO II (REORIENTAÇÃO E CONVERGÊNCIA)}

Para além de uma formação envolvendo basicamente os mesmos espaços de sociabilidade - a École Normale Supérieure, a École Française de Rome e a École Francaise $d^{\prime}$ Athènes -, o que emprestou maior coerência à equipe inicial da REA foi a necessidade de uma reorientação, mais ou menos radical conforme o caso, das estratégias de inserção acadêmica de seus membros. Isso pode ser constatado a partir da seguinte regularidade: embora tenham trilhado o caminho régio para o estudo de alguns dos mais valorizados objetos no âmbito das Faculdades de Letras (aqueles associados à Grécia e à Roma clássicas), todos se viram forçados em determinado momento a direcionar seus esforços seja para a exploração de 
temas a princípio menos nobres (o que implicava um investimento considerável em sua reabilitação), seja para a diversificação de suas áreas de atuação (em especial, via cargos políticos e/ou postos na alta burocracia universitária).

A despeito das diferentes variáveis que possam ter tido influência em cada caso, há aqui um dado estrutural capaz de dar coerência a todo o cenário: esses indivíduos tinham a sensação de pertencer a uma elite para a qual o acesso a Paris, o que incluía as posições centrais do sistema de ensino, estava comprometido. Um testemunho disso nos foi legado por Camille Jullian, de longe o mais precoce e mais bem-sucedido do grupo, o qual escreveu a seus pais, não sem alguma revolta, em setembro de 1883:

\footnotetext{
Eu tenho uma bela cadeira em Poitiers. Ela talvez não seja definitiva: uma cadeira análoga está vaga em Bordeaux e outra em Dijon. Mas por que não permanecer com Poitiers? Eis aí uma questão resolvida, pois eu não poderia esperar Paris. Paris está reservada aos doutores. Faltam, é bem verdade, três meses para eu defender minha tese (graças a negligência habitual do Sr. Geoffroy, que guardou minha tese, com visto e assinada, dois meses na gaveta!), mas são precisamente esses meses nos quais as nomeações são feitas (JULLIAN, 1936: 370-1, itálico no original).
}

Mas só a titulação, valorizada na passagem, já não era mais suficiente. Jullian, cuja tese defendida no ano seguinte fará dele um dos mais jovens doutores da Terceira República (apenas 24 anos!), terá de esperar ainda duas décadas para ocupar um espaço na capital. Algo semelhante aconteceu a Michel Clerc, Pierre Paris, Georges Radet e Henri de la Ville de Mirmont: todos iniciaram suas carreiras docentes em liceus e faculdades provinciais, aí permanecendo mesmo após terem defendido seus respectivos doutorados.

A impossibilidade de se ter acesso imediato aos postos de maior prestígio é bastante compreensível, sobretudo se considerarmos o sentido e o ritmo da expansão do sistema de ensino francês. Partindo dos dados fornecidos por Terry Nichols Clark, é possível constatar entre 1865 e 1878 um aumento considerável do número absoluto e relativo de cadeiras ligadas aos estudos greco-latinos nas Faculdades de Letras, tanto na capital quanto no interior (veja-se o quadro abaixo). A ampliação inicial dessas áreas era natural e inevitável, uma vez que qualquer expansão da totalidade do sistema tinha de se ater ao fato de que o latim e o grego formavam um de seus principais alicerces. Ainda assim, nos vinte anos seguintes (18791898), justamente quando os membros da REA iniciavam suas carreiras, o mercado parisiense parece estar saturado e o crescimento se mantém somente nas províncias. Diante dessa restrição de oferta para uma demanda cada vez maior de professores capacitados, o valor atrelado às cadeiras centrais tendia a aumentar e, com ele, as exigências para se chegar até lá. 
Quadro 2.4.2 - Número absoluto e relativo de cadeiras associadas aos estudos greco-latinos nas

Faculdades de Letras francesas (1865-1928) ${ }^{7}$.

\begin{tabular}{|c|c|c|c|c|c|c|c|c|}
\hline & \multicolumn{2}{|c|}{1865} & \multicolumn{2}{|c|}{1878} & \multicolumn{2}{|c|}{1898} & \multicolumn{2}{|c|}{1928} \\
\hline $\begin{array}{l}\text { Fac. de Letras } \\
\text { Provinciais }\end{array}$ & $\begin{array}{c}15 \\
\text { (de 75) }\end{array}$ & $20 \%$ & $\begin{array}{c}22 \\
\text { (de 82) }\end{array}$ & $27 \%$ & $\begin{array}{c}34 \\
\text { (de 115) }\end{array}$ & $30 \%$ & $\begin{array}{c}45 \\
\text { (de 165) }\end{array}$ & $27 \%$ \\
\hline $\begin{array}{l}\text { Fac. de Letras de } \\
\text { Paris }\end{array}$ & $\begin{array}{c}4 \\
\text { (de 11) }\end{array}$ & $36 \%$ & $\begin{array}{c}5 \\
\text { (de 13) }\end{array}$ & $38 \%$ & $\begin{array}{c}5 \\
\text { (de 22) }\end{array}$ & $26 \%$ & $\begin{array}{c}5 \\
\text { (de 47) }\end{array}$ & $11 \%$ \\
\hline
\end{tabular}

O crescimento estrutural da Universidade e a diminuição relativa do espaço dedicado aos estudos greco-latinos na capital caminharam ainda em paralelo a outra tendência de época: a complexificação da divisão do trabalho científico. Com efeito, as especializações estavam na ordem do dia e o impacto disso nas Faculdades de Letras foi duplo. Por um lado, os saberes tradicionais passaram a dividir seu espaço com disciplinas novas (dentre as quais se encontrava a sociologia). Por outro lado, as cadeiras já institucionalizadas foram sendo aos poucos segmentadas, o que respondia ora a critérios cronológico-espaciais, ora a classificações pautadas na série documental tratada pelo pesquisador (epigrafia, arqueologia, entre outras). Em tal contexto, saber optar por uma especialização, ou mudar de área quando uma circunstância favorável se apresentasse, poderia garantir o sucesso de uma carreira.

As trajetórias dos indivíduos que compõem a equipe inicial da REA, todos iniciando suas atividades profissionais na década de 1880, ilustram perfeitamente tais circunstâncias, especialmente porque apontam para reações criativas e coletivas às dificuldades então enfrentadas. Pode-se, para verificar isso, cruzar os percursos profissionais não lineares dos "atenienses" do referido grupo: Michel Clerc, Pierre Paris e Georges Radet - Camille Jullian, o único "romano" entre eles, teve uma trajetória parecida, mas seu caso será discutido em separado mais adiante.

Como já indicado antes, após uma passagem pela École Normale Supérieure, os três foram contemplados, em função de suas aprovações no exame de agrégation, com bolsas do governo francês para aperfeiçoarem seus conhecimentos na École Française d'Athènes. Uma vez lá, eles passaram a integrar as equipes de arqueologia desta instituição e tiveram a chance tanto de explorar fontes inéditas como de se integar ao ambiente cosmopolita da capital grega, frequentado por eminentes representantes das elites letradas locais e internacionais ${ }^{8}$. A

\footnotetext{
7 Cf. CLARK, 1973: 60-65. Tais números, embora possam ser indicativos do processo, comportam imprecisões. O autor criou tipologias que nem sempre correspondem aos nomes e funções das cadeiras existentes. Além disso, não atentou para divisões importantes à presente pesquisa (ao tratar, por exemplo, das cadeiras de filosofia, Clark não distingue das demais aquelas dedicadas aos Antigos).

${ }^{8}$ Sobre a EFA, veja-se o subcapítulo 2.1 da presente tese.
} 
ida ao exterior tinha, portanto, o efeito de integrá-los ainda muito jovens às vanguardas do helenismo, o que, levando-se em conta o prestígio da área, sugeria um início de carreira bastante promissor.

Uma vez de volta a França, já como professores, os três procuraram se manter atrelados às suas áreas de formação. Um primeiro indício com o qual se pode verificar isso são as cadeiras que eles passaram a ocupar. Clerc foi nomeado em 1883 Maître de conférences d'Histoire Ancienne et Archéologie na Faculdade de Letras de Aix-Marselha. Paris, por seu turno, assumiu em 1885 a cadeira de Antiquités grecques et latines na Faculdade de Letras de Bordeaux, também como Maître de conférences. Já Radet, o último a ser empossado, lecionou História no Liceu de Argel em 1887, sendo promovido um ano depois ao cargo de Maître de Conférence d'Histoire Ancienne, dessa vez em Bordeaux.

Outros indicadores dessa continuidade inicial são o tema de suas teses francesas e a adesão à Association pour l'Encouragement des Études Grecques en France (AEEG). Quanto ao primeiro ponto, Clerc obteve em 1893 o título de doutor com um estudo sobre os estrangeiros na Atenas clássica (os metecos), o qual Ihe rendeu no ano seguinte o prêmio Zographos, o mais importante distribuído anualmente pela AEEG (CLERC, 1893a). Já Paris, em 1891, apresentou como tese uma monografia sobre o sítio arquelógico de Elatéia, explorado sistematicamente por ele durante sua estada na Grécia (PARIS, 1892). Radet, por fim, discutindo a relação entre os gregos e os lídios nos séculos VII e VI a.C, obteve o mesmo título em 1893, sendo também agraciado com o prêmio Zographos daquele ano (RADET, 1893). No que diz respeito à AEEG, o órgão oficial do helenismo na França, Clerc, Paris e Radet filiaram-se a ela respetivamente em 1893,1894 e 1890.

É precisamente ao final desse ciclo de defesas e de filiações às instituições centrais ou seja, a partir de meados da década de 1890 - que começa a se desenhar uma clara reorientação na trajetória dos três. Tomemos como primeiro caso a ser analisado o de Michel Clerc. Sabe-se que, ao menos desde 1893, ele passou a ministrar cursos sobre a história da Provence na Antiguidade (o que, importante destacar, estava longe de envolver apenas a temática da presença grega na região francesa) $)^{9}$. Apenas dois anos mais tarde, tal mudança de foco foi mesmo oficializada: Clerc assumiu, na condição de professor titular, a recém-criada Chaire départamentale d'Histoire de Provence, bem como passou a dirigir o Musée Borély, uma instituição vinculada à Faculdade de Letras de Aix-Marselha e especializada em coleções arqueológicas de procedência local.

\footnotetext{
${ }^{9} \mathrm{O}$ primeiro indício que encontrei a esse respeito foi CLERC, 1893b.
} 
A ênfase no "regional" em detrimento dos temas "clássicos" fez-se igualmente sentir no âmbito de sua produção acadêmica. Dos vinte artigos publicados por Clerc nos periódicos especializados nos estudos greco-latinos entre 1895 e 1920, a maioria tratou de inscrições, monumentos e outras modalidades de objetos encontrados nos (ou relativos aos) sítios arqueológicos da França meridional ${ }^{10}$. Mesmo quando vez por outra escreveu ensaios de maior fôlego sobre a Grécia Antiga, ele discutiu questões centrais para a história da Provence, com especial destaque para a origem e a especificidade da migração focéia rumo ao Mediterrâneo Ocidental $^{11}$. Não por acaso, Aquae Sextiae, sua opus magnum, é um extenso estudo monográfico sobre a fundação e a história da cidade de Aix-en-Provence ${ }^{12}$.

O esforço de diferenciação de Clerc foi percebido e recompensado pelas instituições centrais, embora se deva considerar igualmente o sucesso do grupo ao qual ele pertenceu como um dos fatores decisivos para isso. Sua eleição para o posto de correspondant da Académie des Inscriptions et Belles-Lettres ocorreu em 1909. Pouco tempo depois, durante a Primeira Guerra, ele ainda obteve o posto de doyen (diretor) da Faculdade de Letras de AixMarselha. A duplicidade de sua carreira não deixou de ser assinalada por ocasião de sua morte. Quem o fez foi Salomon Reinach, no prestigiado espaço da Revue Archéologique: "por vezes um pouco indolente, [Clerc] deixa a reputação de um bom erudito que rendeu serviços notáveis à ciência helênica e à arqueologia da Provence" (RA, 1931/2: 317-318).

Mas a conversão à história e à arqueologia regionais estava longe de representar uma solução estritamente individual ao aumento de competitividade no interior das Faculdades de Letras. É o que sugere, ao menos, a análise da trajetória de Pierre Paris. Também nesse caso vê-se a busca da consagração de uma carreira a partir do investimento intelectual em um domínio até então pouco explorado e certamente menos prestigioso que o greco-latino: a arte ibérica. De acordo com uma nota biográfica recente, o ponto de inflexão da carreira de Paris pode ser situado nas duas viagens que ele fez à Espanha, entre 1895 e $1897^{13}$. Nessas ocasiões, chefiando missões arqueológicas de seu país, ele participou da descoberta e intermediou a transferência para museus franceses de peças que, por suas características singulares,

\footnotetext{
${ }^{10}$ Sobre tal faceta de sua produção, veja-se REA, 1903: 196; REA, 1904: 145-148; REA, 1908: 342-346; REA, 1909: 49-52 e 53-68; REA, 1912: 189 e 190-2; REA, 1913: 189-190; REA, 1914: 71-74, 75-78, 79-80, 81-82, 407 e 408-409; REA, 1916: 55-56; e REA, 1918: 47-52.

${ }^{11}$ Cf., sobre isso, REA, 1905: 329-356; e REG, 1905: 143-158. Desses seus textos propriamente históricos, apenas um não foi dedicado à questão. Nele, o autor expande a problemática de sua tese, comparando o estatuto dos estrangeiros em Atenas ao de outras localidades gregas (RUM, 1898: 1-32, 153-180, 249275).

${ }^{12}$ CLERC, 1973. Trata-se de um fac-símile da edição original publicada em 1916.

${ }^{13}$ Cf. ROUILLARD, 2009. Agradeço a Pierre Rouillard não só a comunicação deste e de outros textos de sua autoria, como também as dúvidas que ele gentilmente dispersou sobre Pierre Paris e a história de seu campo de estudos na França.
} 
suscitaram calorosos debates. Foi justamente o interesse cada vez maior por tais objetos, em grande medida alimentado pelo próprio Paris, que tornou viável a mudança de especialidade ${ }^{14}$. Por certo, isso não significou o abandono completo do antigo métier. Como Clerc, ele poderia mantê-lo em segundo plano, utilizando o que aprendeu como helenista para estabelecer um padrão de comparação e, sobretudo, de explicação para o que encontrou na arte Ibérica.

O sucesso da reconversão de Paris pode ser avaliado pela rapidez com que sua carreira avançou. Já em 1898, ele foi nomeado diretor da École des Beaux-Arts de Bordeaux, função que exerceu até 1913. Um ano mais tarde, na recém-fundada REA, criou-se uma seção para tratar exclusivamente da arqueologia e da arte ibéricas (o já referido Bulletin Hispanique), a qual ganhou status de periódico independente logo depois. O reconhecimento institucional da plena autonomia de seu campo de estudos chegou, no entanto, em 1909, quando ele passou a dirigir a recém-fundada École des Hautes Études Hispaniques. Por seus serviços à ciência francesa, Paris foi recebido como membro efetivo na Académie des Inscriptions et BellesLettres em 1920 e, nos últimos anos de sua vida, assumiu cargos de diretor de instituições francesas na Espanha (o Institut Français de Madrid em 1926 e a Casa Velázquez em 1928).

No que diz respeito à sua produção, os sete artigos que ele publicou nas revistas dos antiquisants (apenas RUM e REA) apontam para a nova área de atuação. Neles, Paris se limitou a apresentar inscrições e objetos antigos encontrados em sítios arqueológicos ou expostos em museus espanhóis ${ }^{15}$. O mesmo vale para seus livros: a maioria foi dedicada à arte ibérica ${ }^{16}$, embora ele tenha eventualmente abordado os temas clássicos de sua formação e a história da pintura espanhola, da pré-história a Goya ${ }^{17}$.

Chega-se, por fim, à trajetória de Georges Radet. Se comparada às de Clerc e Paris, marcadas por profundas mudanças na esfera propriamente intelectual do trabalho acadêmico (a dedicação a um novo objeto), a sua ganha contornos particulares, ainda que relacionados aos de seus colegas. Isso se deve ao fato de, sem lançar mão dos temas de sua formação, Radet privilegiar desde cedo uma carreira burocrática. Enquanto professor, ele se manteve sempre atrelado à Chaire d'Histoire Ancienne. Ainda assim, suas outras atribuições não cessaram de crescer. Em 1895, ele assumiu a direção da recém-criada Revue des Universités du Midi, a qual ele ajudará a transformar na sequência em Revue des Études Anciennes. Quatro

\footnotetext{
${ }^{14}$ Sobre o crescente interesse na arte ibérica e seu reflexo institucional à época, veja-se ROUILLARD, 1997: 1-15 (Introduction et Histoire de la Collection Ibérique du Louvre).

${ }^{15}$ Cf. RUM, 1896: 393-398; REA, 1902: 55-61; REA, 1902: 245-257; REA, 1903: 15-18, 388; REA, 1910 : 152-153; e REA, 1916 : 27-30. Paris ainda publicou, entre 1899 e 1901, várias notas próximas a estas na seção da REA intitulada Bulletin Hispanique. Tais textos não foram referenciados aqui.

${ }^{16}$ Em especial, PARIS, 1903-4 (em dois volumes).

${ }^{17}$ Ele volta aos temas de sua formação em PARIS e ROQUES, 1909. Quanto aos estudos sobre a pintura espanhola, veja-se PARIS: 1928a e 1928b.
} 
anos mais tarde, em um episódio cujas implicações tratarei mais adiante, o Affaire Stäpfer, Radet obteve o posto de doyen (diretor) da Faculdade de Letras de Bordeaux. Note-se ainda que ele se manteve à frente da Faculdade por vinte anos e ocupou a função de diretor-geral da REA até sua morte, em 1941 (Jullian o auxiliou nessa função, atuando como diretor da seção dedicada às "Antiguidades Nacionais"). Nesse ínterim, Radet foi eleito correspondant da Académie des Inscriptions et Belles-Lettres (1904) e integrou uma série de comitês governamentais sobre a educação superior.

A análise dos textos produzidos por ele entre 1895 e 1920 também sugere uma atuação mais voltada para a viabilização de sua carreira burocrática do que para a consagração como helenista. É notável, nesse sentido, a distribuição dos vinte e dois artigos que publicou nas revistas dedicadas aos estudos greco-latinos: com exceção de um único texto tardio veiculado no espaço dominante da REG, seus investimentos foram todos feitos na RUM e na REA. Quanto ao conteúdo desses trabalhos, seu tema continuou a ser a relação entre a Grécia e o Oriente já explorada em sua tese. Ainda assim, Radet colaborou de tempos em tempos com as investigações dos colegas, sejam elas ligadas à migração dos foceus para o Mediterrâneo Ocidental ou às antiguidades da Espanha ${ }^{18}$.

Outro dado importante sobre a produção de Radet é que, além de helenista, ele se fez conhecido como historiador da École Française d'Athènes. Em sua principal publicação sobre o tema, ele comparou os antigos membros da escola a figuras míticas (há um capítulo intitulado "A Geração dos Argonautas") e insistiu em sua progressiva profissionalização - da qual ele era, bem entendido, um dos produtos (RADET, 1901). Desse modo, ao fazer o elogio de uma instituição altamente prestigiosa à qual ele havia pertencido, Radet ativava redes de solidariedade que envolviam tanto algumas das mais influentes personalidades da Universidade (dentre as quais se encontravam os antigos membros da instituição analisada e as pessoas próximas a eles) quanto jovens promessas no campo dos estudos helênicos.

Um último elemento a ser aqui destacado é a importância de Radet para a consolidação da equipe da REA. Foi ele quem, na economia interna do grupo, centralizou as questões institucionais associadas aos esforços de seus integrantes. Sua atuação foi crucial para a criação da École des Hautes Études Hispaniques e da Casa Velázquez, ou mesmo para a independência do Bulletin Hispanique e para o crescimento contínuo dos recursos da própria REA. É assim que, distintas na forma, suas ações se integraram às dos colegas.

Os pontos em comum revelados pela análise cruzada dessas três trajetórias indicam algo que não pode ser traduzido nem por uma simples coincidência, nem por um estratagema

\footnotetext{
${ }^{18}$ Sobre tal faceta de sua produção, cf. REA, 1903: 327-328; REA, 1908: 249; e REA, 1910: 281-283.
} 
definido a priori por parte dos fundadores da REA. Antes, é possível perceber neles a incorporação gradativa de um modo de apreender e de se relacionar com o mundo acadêmico (ou ainda, em termos bourdieusianos, a constituição de um habitus compartilhado). Durante suas formações, Michel Clerc, Pierre Paris e Georges Radet haviam aprendido a cultuar os clássicos greco-latinos como emblemas de uma elite letrada à qual eles se sentiam predestinados a pertencer. E tudo parecia reforçar isso: a educação recebida na ENS, a ida para o exterior, o início de suas carreiras. O próximo passo teria de ser a consagração na capital, pois esse era o apanágio do professor de "grande envergadura", o qual não poderia "escapar ao seu destino"19. Mas eis que o destino tardava a chegar, ou dava sinais de escapar por entre os dedos dos supostos eleitos.

A situação material e o ambiente intelectual das faculdades provinciais, ainda muito precários em fins do século XIX, certamente agravaram tal sensação. Como, afinal, manter-se atrelado às discussões de ponta em suas prestigiosas áreas de formações quando as melhores bibliotecas e os mais dinâmicos espaços de debate estavam na capital? Como acrescentar-lhes algo se as verbas necessárias para o trabalho nos principais sítios arqueológicos e para os demais estágios no exterior dependiam em grande parte de instituições parisienses nas quais eles tinham pouca voz? Diante desse cenário extremamente hierarquizado, no qual estar distante de Paris parecia implicar um ostracismo, três alternativas se apresentavam aos jovens professores de província: ou se aceitava permanecer em uma posição menor, ou se pagava do próprio bolso o custo de se manter atrelado aos temas centrais (o que envolvia deslocamentos constantes para estudos e eventos), ou se mudava a área de atuação tendo em vista alguma eventual ascenção não convencional.

Foi a derradeira opção que uniu esses indivíduos em torno REA, emprestando-lhes uma identidade. Assim, se as posições centrais estavam cada vez mais fechadas em função da expansão da Universidade, foi preciso inventar um modo de conquistá-las a partir do espaço marginal que eles ocupavam. Por certo, a história e a arqueologia regionais poderiam fornecer o material necessário para viabilizar tal empreendimento, pois aí, de fato, o que eles haviam aprendido como antiquisants poderia ser utilizado na produção de trabalhos inovadores. A dificuldade, porém, continuava a ser o relativo desprestígio de tais áreas diante dos temas "universais" sobre os quais o sistema de ensino francês havia sido montado. A solução para tal dilema, no plano intelectual, mas também no institucional, foi a invenção de uma nova síntese. Com as "Antiguidades Nacionais", Paris finalmente pôde ser conquistada a partir da província.

\footnotetext{
${ }^{19}$ Essas são algumas das expressões com as quais Aimé Puech justifica o fato de Camille Jullian ter deixado a província para ocupar uma posição em Paris (PUECH, 1935).
} 
Destoando dos demais fundadores da REA, Henri de la Ville de Mirmont não teve a carreira marcada por reconversões maiores, o que requer ponderação. Por que, afinal, teria ele investido tanto nessa publicação? Duas variáveis aparecem aqui como decisivas: os vínculos com sua terra natal e sua inclinação "literária".

Nascido em 1858 no seio da aristocracia católica de Bordeaux, De la Ville de Mirmont teve uma educação de elite. Normaliano, ele integrou a promoção de Clerc e Jullian (1877), prestando três anos mais tarde a agrégation de lettres, na qual obteve um respeitável quinto lugar. Não obstante, a chance de estudar no exterior ou não Ihe foi ofertada ou não o seduziu. Em todo caso, ele iniciou logo na seqüência a carreira docente, a qual se passaria toda no sudoeste da França. Seu primeiro posto foi no Liceu de Pau (1880-3), de onde ele partiu para se tornar Maître de Conférence e, depois, Professeur de Langue et Littérature Latines na Faculdade de Letras da cidade onde nasceu (1883-1923). Além disso, De la Ville de Mirmont escreveu para jornais locais e participou do serviço de instrução pública da prefeitura de Bordeaux.

O grosso de sua produção foi dedicada à literatura e à retórica antigas. Tradutor de Cícero e comentador de vários prosadores e poetas, ele defendeu uma tese sobre o papel dos deuses no épico de Apolônio Ródio e em Virgílio (1894). Dos dezenove artigos que escreveu nas revistas dedicadas aos estudos greco-latinos até 1920, a maioria tratou da vida e da obra de escritores. Não obstante, explorou também temas análogos aos dos colegas, como atesta a série de quatro textos seus sobre a astrologia galo-romana (REA,
1902: 115-111; REA, 1903: 255-293; REA, 1906 : 128-164; e REA, 1907: 69-82, 155-171).

Mas o envolvimento com a literatura ia além da profissão. Sua esposa, Sophie Malan, foi uma escritora de relativo sucesso. A mesma ocupação seduziu também um de seus filhos, Jean de la Ville de Mirmont. Apesar da curta carreira, abreviada pela morte nas trincheiras, Jean foi considerado uma jovem promessa, sendo mesmo laureado postumamente pela Académie Française. O desaparecimento precoce do filho abalou muito o casal, o qual se dedicou depois a publicar suas cartas e biografia. É a partir de tais fontes que se pode apreender algo do ambiente familiar (DE LA VILLE DE MIRMONT, J., 1917 e DE LA VILLE DE MIRMONT, Mme., 1935). Note-se que as referências às temáticas greco-latinas são aí usuais, povoando tanto o que o jovem Jean viu no conflito (a "eterna luta dos bárbaros contra o Ocidente"), como suas memórias (as temporadas na propriedade da família em Royan, chamada Les Argonautes, ou ainda a relação com os amigos antiquisants do pai, Paris e Jullian).

Embora tal faceta "literária e provincial" tenha afetado a atividade de Henri De la Ville de Mirmont, afastando-o de fontes não textuais e limitando reconversões similares às dos colegas, ela o sensibilizou à temática da REA. De fato, se abordagens literárias como a sua encontravam ainda ecos em Paris, tratava-se de uma tendência criticada na Nouvelle Sorbonne. Não parece assim fortuito o retrato que Radet registrou do amigo: "um latinista de raça”, "figura original e íntegra, no estilo destes eruditos do século XVI que lhe eram tão familiares e com os quais ele sentia afinidades eletivas" (REA, 1923: 403-404). 


\section{O TOdo e AS PARTES}

O investimento em novas disciplinas é um modo bastante comum de se firmar posição em mercados universitários em franca expansão. Se bem-sucedido, ele engendra espaços relativamente autônomos, nos quais experts se reconhecem e se fazem reconhecer como tais. Ao menos de início, motivados pela promessa de um ambiente mais livre, ou seja, desprovido de grandes concorrências e tradições previamente estabelecidas, os defensores desses saberes se veem forçados a migrar de áreas bem institucionalizadas para aventurar-se em vias heterodoxas de consagração. Os usos das "Antiguidades Nacionais" por parte dos indivíduos reunidos em torno da REA remetem invariavelmente a processos análogos.

A referida expressão já havia sido cunhada, contudo, antes do fin-de-siècle. Seja para evocar a ideia de antiquariato, o que remetia às suas raízes etimológicas, seja como sinônimo de arqueologia do território francês, falou-se em "Antiguidades Nacionais" desde ao menos o Antigo Regime. Em 1776, por exemplo, Louis XVI se valeu de uma variante sua para compor o terceiro princípio diretor da então recém-reformada Académie des Inscriptions et BellesLettres, qual seja: "ela esclarecerá os títulos, diplomas e antiguidades da história da França e das outras Nações, principalmente aquelas cujos interesses e os eventos estão ou foram combinados com aqueles da França" (apud GRELL, 1995: 114). No século seguinte, em 1862, foi-Ihe ainda concedida outra ancoragem institucional com a criação do Musée des Antiquités Nationales de Saint-Germain-en-Laye, cujo acervo abrigava coleções arqueológicas francesas que se estendiam da pré-história ao medievo. Tratava-se, nesse caso, de uma iniciativa de Napoleão III, interessado tanto em responder aos avanços da ciência prussiana quanto em reverter para si os lucros simbólicos das escavações em Alésia, derradeiro bastião da resistência gaulesa aos romanos.

Os sentidos fixados pelo tempo não foram propriamente desconsiderados quando "Antiguidades Nacionais" apareceu em 1899 como título de uma das seções de artigos da REA. Ainda assim, para além deles, o velho rótulo passou a designar também um amplo e inovador programa de pesquisa. Mas do que tratava tal programa? Antes de tudo, importa aqui sublinhar que às "Antiguidades Nacionais" foi associado um duplo objeto: a história regional e a nacional. A lição proferida por Clerc ao assumir a Chaire départementale d'histoire de Provence é bastante esclarecedora quanto à relação que se pretendia estabelecer entre essas duas esferas. Na ocasião, ele lançou ao seu auditório as seguintes perguntas: "não é a história detalhada das províncias e das cidades a base indispensável da história nacional? Não é vão tentar a síntese da história da França enquanto não se tiver para a sustentar uma massa compacta de monografias locais?" (CLERC, 1895: 8). Queria-se, portanto, chegar ao Todo (a “história nacional"), a partir de suas partes (a "história das províncias e das cidades"). 
Outra marca distintiva das "Antiguidades Nacionais" foi a fusão desse seu duplo objeto à temática das "origens". Por certo, pensar nesses termos não era exatamente uma novidade, sobretudo ao se considerar que Grécia e Roma Antigas ostentavam então a fama de serem o berço do Ocidente e dos universais a ele vinculados (a invenção da razão, das artes e das ciências). A questão, no entanto, era que as nações europeias não possuíam apenas raízes greco-latinas. Daí as ressalvas da equipe inicial da REA aos grandes marcos cronológicos que organizavam o ensino nas Faculdades de Letras francesas (Antiguidade, Idade Média e Tempos Modernos): não obstante sua validade, eles eram excessivamente gerais quando se tratava das especificidades locais. A solução proposta com as "Antiguidades Nacionais" passava por estudos minuciosos das regiões de uma Nação, o que deveria ser feito desde seu mais remoto passado. Era preciso, pois, inventariar quais povos haviam habitado cada localidade, suas crenças, hábitos e relações com vizinhos, bem como a dinâmica histórica de tudo isso. Não por acaso, um dos gêneros mais praticados entre os principais colaboradores da REA foi o estudo monográfico de cidades e de regiões, cujo paradigma havia sido estabelecido com um dos trabalhos pioneiros de Jullian sobre Bordeaux (1895). Some-se a isso toda uma gama de investigações pontuais (com destaque para a religião e a política), bem como a descrição crítica de materiais arqueológicos e epigráficos recém-descobertos. Se a história nacional deveria ser construída a partir de algum lugar, acreditava-se na REA que seria esse o ponto.

Mas o grande trunfo da disciplina coroada por um tal programa era mesmo sua disposição a englobar métodos e resultados provenientes de outros saberes para dar-Ihes uma orientação própria. Desse modo, toda uma gama de ciências novas poderia ser mobilizada caso oferecesse instrumentos para a reconstrução da história de regiões e, por extensão, de Nações $^{20}$. O mesmo valia para os mais tradicionais estudos célticos, germânicos e grecolatinos: cada um deles, à sua maneira, elucidava aspectos da formação dos Estados europeus. Em suma, não se queria simplesmente instituir um novo espaço disciplinar contra aquilo que já existia. O que se propunha era, de fato, uma encruzilhada de saberes, na qual os diversos especialistas poderiam se sentir à vontade para contribuir com a construção do edifício da história nacional. Por certo, tal esforço coletivo requeria artífices responsáveis pela síntese e

\footnotetext{
${ }^{20}$ É novamente Michel Clerc quem, antes mesmo da criação da REA, anuncia de forma exemplar quais saberes diziam respeito à história que ele almejava praticar: "é preciso recorrer aos conhecimentos especiais da geologia e da antropologia, mas infelizmente essas ciências estão ainda longe de estabelecer seus resultados definitivos. (...) É à linguística que é preciso recorrer para determinar com alguma probabilidade, por intermédio dos nomes dos lugares, a área geográfica habitada por esses povos; à arqueologia, para reconstituir ao menos em linhas gerais sua maneira de viver. (...) É sobretudo graças à epigrafia, ciência também muito recente, mas já absolutamente segura de seus métodos e resultados, que nós poderemos reconstituir a imagem da Marselha grega e da Provence romana" (CLERC, 1893b: 8-10. Itálicos no original).
} 
era neste momento que os pesquisadores voltados às "Antiguidades Nacionais" entravam em cena, ao mesmo tempo auxiliando na confecção das partes e colando-as umas às outras.

\section{A DAMA DE ELCHE: EMBLEMA DE UM GRUPO, MOTIVO DE LUTAS}

Quem quer que folheie um dos volumes da REA encontrará em seu frontispício, entre 1899 e 1914, a reprodução da célebre Dama de Elche (figuras 2.4 .1 e 2.4.2). Similar recurso gráfico, inusual nas demais revistas dedicadas aos estudos greco-latinos do período, nada tinha de fortuito. Com efeito, ele estava lá para evocar a unidade temática e os primeiros sucessos do grupo reunido em torno do referido periódico.

A relação entre os colaboradores da REA e a Dama é tão antiga quanto sua descoberta. Quando ela veio à tona nos arredores da Elche de 1897, no sul da Espanha, foi um jovem professor universitário francês quem primeiro a examinou: tratava-se de ninguém menos que Pierre Paris, então encarregado de uma missão arqueológica na região. Perplexo com o estilo e seguro da autenticidade da peça, ele negociou sua compra e transferência para o Louvre.

Os elogios à iniciativa do arqueólogo foram unânimes e à descoberta seguiram-se intensos debates (cf., para uma primeira síntese, REG, 1899: 211-219). Queria-se saber, por exemplo, se tal peça possuía um estilo clássico ou arcaico. Além disto, discutia-se o peso dos traços orientais nela presentes: seriam eles sinal de atraso, ou de algum ethos particular? Entre "Carmem" e "Salambô", a Dama de Elche acabou se impondo como um desafio à História da Arte praticada naquele momento.

Dois dos fundadores da REA atuaram diretamente nas discussões sobre a peça. 0 próprio Paris, por um lado, defendeu a tese da influência micênica sobre a arte ibérica, a qual teria moldado o estilo da região entre o séc. XV a.C. e a conquista romana (ROUILLARD, 1996). Assim, a Dama de Elche, apesar de seguramente datada entre 460 e 440 a.C., deveria ser tomada como arcaica nos termos da arte grega. Tal estilo teria se mantido estagnado e adquirido feições próprias em função das particularidades étnicas e históricas da Península Ibérica.

Jullian, por seu turno, investiu em outra direção (REA, 1903: 317-327). Para ele, a estátua seria expressão da presença grega, mais precisamente foceia, na região. Mesmo sabendo que a expansão de Cartago havia desbancado a talassocracia dos foceus quando a Dama foi produzida, ele defendeu a tese de que sua influência ainda se fazia sentir por meio de rotas comerciais. Tratava-se, provavelmente, da obraprima de algum artesão foceu que atendia a comendatários locais.

Contrastando com as abordagens acima mencionadas, nas quais a história regional é um dos principais elementos acionados na explicação da escultura antiga, Théodore Reinach manteve sua análise restrita a questões estilísticas. Para ele, diretor da Revue des Études Grecques, os traços orientais da Dama não suscitavam maiores questões. Afinal, nada deveria obscurecer o fato de ela ser "uma Carmem que Temístocles poderia ter conhecido" (REG, 1898: 39-60). O desejo de integrá-la ao seu domínio de estudo, atendo-se ao que havia nela de puramente grego, guiava, assim, a leitura de Th. Reinach. 
Uma análise do número de artigos publicados em cada uma das áreas temáticas acolhidas pela REA, entre 1899 e 1920, indica como a nova disciplina foi rapidamente alçada à posição de carro-chefe da publicação. Como se pode verificar no quadro abaixo, se houve um período inicial marcado por fortes oscilações, no qual as "Antiguidades Nacionais" passaram a competir com os estudos gregos e latinos em termos de número de artigos publicados, não menos da metade dos textos apareceu integrado a esse rótulo a partir de 1906.

Quadro 2.4.3 - Números absoluto e relativo de artigos (articles de fond) por área temática da REA.

\begin{tabular}{|c|c|c|c|c|c|c|c|}
\hline ANO & $\begin{array}{c}\text { N. TOTAL DE ARTIGOS } \\
\text { PUBLICADOS }\end{array}$ & & $\begin{array}{l}\text { NT GREC } \\
\text { BS/\%) }\end{array}$ & & $\begin{array}{l}\text { DE LATIN } \\
3 \text { S/\%) }\end{array}$ & & $\begin{array}{c}\text { ANTIQUITÉS } \\
\text { NATIONALES } \\
(A B S / \%)\end{array}$ \\
\hline 1899 & 11 & 8 & $72,7 \%$ & 2 & $18,2 \%$ & 1 & $9,1 \%$ \\
\hline 1900 & 12 & 5 & $41,7 \%$ & 5 & $41,7 \%$ & 2 & $16,7 \%$ \\
\hline 1901 & 10 & 6 & $60 \%$ & 3 & $30 \%$ & 1 & $10 \%$ \\
\hline 1902 & $27(*)$ & 10 & $37 \%$ & 3 & $11,1 \%$ & 11 & $40,7 \%$ \\
\hline 1903 & $25\left(^{*}\right)$ & 7 & $28 \%$ & 2 & $8 \%$ & 12 & $48 \%$ \\
\hline 1904 & 20 & 9 & $45 \%$ & 6 & $30 \%$ & 5 & $25 \%$ \\
\hline 1905 & 25 & 8 & $32 \%$ & 5 & $20 \%$ & 12 & $48 \%$ \\
\hline 1906 & 30 & 7 & $23,3 \%$ & 3 & $10 \%$ & 20 & $66,7 \%$ \\
\hline 1907 & 39 & 11 & $28,2 \%$ & 1 & $2,6 \%$ & 27 & $69,2 \%$ \\
\hline 1908 & 28 & 12 & $42,9 \%$ & 2 & $7,1 \%$ & 14 & $50 \%$ \\
\hline 1909 & 21 & 8 & $38,1 \%$ & 2 & $9,5 \%$ & 11 & $52,4 \%$ \\
\hline 1910 & 35 & 8 & $22,9 \%$ & 1 & $2,9 \%$ & 26 & $74,2 \%$ \\
\hline 1911 & 36 & 10 & $27,8 \%$ & 3 & $8,3 \%$ & 23 & $63,9 \%$ \\
\hline 1912 & 39 & 14 & $35,9 \%$ & 1 & $2,6 \%$ & 24 & $61,5 \%$ \\
\hline 1913 & 45 & 13 & $28,9 \%$ & 6 & $13,3 \%$ & 26 & $57,8 \%$ \\
\hline 1914 & 40 & 13 & $32,5 \%$ & 3 & $7,5 \%$ & 24 & $60 \%$ \\
\hline 1915 & 18 & 5 & $27,8 \%$ & 4 & $22,2 \%$ & 9 & $50 \%$ \\
\hline 1916 & 21 & 3 & $14,3 \%$ & 5 & $23,8 \%$ & 13 & $61,9 \%$ \\
\hline 1917 & 18 & 3 & $16,7 \%$ & 5 & $27,8 \%$ & 10 & $55,5 \%$ \\
\hline 1918 & 26 & 7 & $26,9 \%$ & 2 & $7,7 \%$ & 17 & $65,4 \%$ \\
\hline 1919 & 26 & 6 & $23,1 \%$ & 3 & $11,5 \%$ & 17 & $65,4 \%$ \\
\hline 1920 & 19 & 5 & $26,3 \%$ & 2 & $10,5 \%$ & 12 & $63,2 \%$ \\
\hline
\end{tabular}

(*) Há, entre 1902 e 1903, uma seção de artigos intitulada "Péninsule Hispanique". Eis a razão de o total de artigos não bater com o número publicado nas três demais seções (Orient Grec, Monde Latin e Antiquités Nationales) nesses anos. 
Mesmo considerando-se o destaque que as "Antiguidades Nacionais" receberam no interior da REA, é importante destacar que isso jamais implicou uma forma qualquer de monopólio. A despeito das especificidades da nova disciplina, em especial a interdisciplinaridade dirigida ao problema da origem de regiões e de nações, ela foi também defendida como um braço especial dos estudos sobre o Mundo Antigo. Certamente havia uma razão que tornava indesejável, ou mesmo impensável, sua emancipação total, a saber: a particularidade de sua institucionalização no seio do sistema de ensino francês.

Com exceção da cadeira de Histoire et Antiquités Nationales criada para Camille Jullian no Collège de France de 1905, as "Antiguidades Nacionais" não conquistaram postos nos ensinos médio e superior para tratar exclusivamente de seus conteúdos, nem originaram exames aptos a direcionar desde cedo estudantes para eles. Um dos efeitos imediatos disso foi a imposição de limites quanto à atuação profissional de seus entusiastas. Como será visto mais adiante, muitos permaneceram vinculados às cadeiras voltadas à Grécia e à Roma antigas, embora outros tenham conseguido conquistar novos e importantes nichos tanto nas cadeiras universitárias de história e de literatura regionais como nos postos de conservador de museus provinciais. Efeitos desses limites se fizeram sentir igualmente no recrutamento do grupo: a maioria dos colaboradores franceses e universitários da REA, até 1920, possuía uma formação de latinista ou de helenista. De fato, sendo estas duas das áreas centrais nas Faculdades de Letras, era natural que o interessado em se tornar professor ou pesquisador se sentisse compelido a partir daí para então se voltar a outras questões e objetos. Vale lembrar que para os fundadores da REA a situação foi exatamente esta: as "Antiguidades Nacionais" surgiram após os estudos greco-latinos. Para seus herdeiros, o cenário manteve-se praticamente inalterado.

Mas tal ancoragem institucional estava longe de implicar tão somente desvantagens para a nova disciplina. Poder-se-ia dizer que, ao atrelar as "Antiguidades Nacionais" à Grécia e à Roma Antigas, seus especialistas mantiveram-se próximos a um dos principais pilares do sistema educacional francês. Além disso, estava em questão toda a revitalização de uma tradição. Com efeito, diante da ausência de instituições aptas a formar outras modalidades de especialistas ao longo do século XIX, latinistas e helenistas de carreira haviam se ocupado do estudo da Gália e das origens germânicas da França. Na geração imediatamente anterior àquela dos fundadores da REA, o exemplo vinha de um dos mais ilustres representantes da elite universitária, Fustel de Coulanges ${ }^{21}$. Entre os contemporâneos que não aderiram totalmente à proposta da revista, Salomon Reinach e Gustave Bloch dedicaram-se, com maior

\footnotetext{
${ }^{21}$ Cf., entre outros, COULANGES, 1874; 1885; 1891a e 1891b.
} 
ou menor empenho, a questões similares ${ }^{22}$. Deste modo, o grupo em torno da REA, ao tornar o que era uma variante estruturalmente possível na carreira de latinistas e de helenistas um objeto de contenda, afirmando uma ruptura com o caráter descentralizado e desordenado que tais estudos possuíam até então, procurou tomar posse de um espaço já existente e de relativo prestígio, potencializando-o.

Outra vantagem nada desprezível dos vínculos com os estudos greco-latinos provinha do fato de um certo uso deles ter sido utilizado para justificar o aparecimento da REA. A nova revista, afinal, queria-se contrária a certos modernismos parisienses, os quais, nesses campos específicos do saber, relegavam o local e o nacional a um plano menor, tudo em função de valores abstratos e universalistas. Tratava-se assim de um capítulo da reação contra a Nouvelle Sorbonne, uma Sorbonne "germanizada" que ameaçava padrões já consagrados de trajetórias ao fazer com que latinistas e helenistas perdessem espaço para saberes cujas epistemologias não se subordinavam necessariamente às suas ${ }^{23}$. Canalizar as "energias provinciais" contra tais modernismos, em defesa dos "autênticos" estudos greco-latinos franceses, era assim um ato ao mesmo tempo científico e patriótico. Sobre isso, como registrou o latinista William Seston, Georges Radet costumava dizer (REA, 1941: 6-7):

Não tendo Lutécia tido um papel de primeiro plano na história de nossas origens, é na província, acreditava ele [Radet], que se está melhor situado para compreender a vida antiga de nosso país. Enfim, ao aproximar os estudos que a concernem e aqueles que tratam do Oriente antigo, da Grécia e de Roma, Radet afirmava que a isolar seria se arriscar a compreender mal sua originalidade, pois a vida de nosso país na época céltica e galo-romana é apenas um aspecto da vida antiga que nele permanece.

"Se queremos que tudo continue, é preciso antes que tudo mude". A máxima pela qual tornou-se célebre o protagonista do romance de Giuseppe Tomasi di Lampedusa ilustra bem os efeitos e as lógicas dos investimentos sociais dos fundadores da REA. Como membros de elites, nesse caso universitárias, que se sentem ameaçadas de rebaixamento, eles inventaram uma proposição capaz de frear outras proposições concorrentes. Afinal, nada na síntese das "Antiguidades Nacionais" colocava em questão a antiga estrutura do sistema de ensino, até porque Grécia e Roma Antigas permaneciam no centro de formação e dos espaços de

\footnotetext{
${ }^{22}$ Em função de seu cargo de conservador do Musée des Antiquités Nationales, Salomon Reinach dedicou-se, sobretudo, à arqueologia galo-romana. Destaco aqui, entre tantos outros de seus trabalhos, REINACH, 1889, 1890 e 1895. Já o latinista Gustave Bloch publicou um importante estudo sobre a história da Gália (BLOCH, 1901).

${ }^{23} \mathrm{Um}$ momento de tensão particularmente instrutivo entre essas epistemologias que se manifestavam dentro e fora da Universidade foi a Comissão Ribot, a qual ouviu professores e personalidades a fim de propor uma reforma para o sistema de ensino. Tal Comissão foi decisiva para a flexibilização dos padrões de ingresso na vida universitária francesa, tornando opcionais as provas de latim e grego em 1902. Uma instigante análise disso pode ser encontrada em RINGER (1992: 114-126, 141-195).
} 
sociabilidade dos representantes da nova disciplina. Nesse sentido, tratava-se de uma inovação de aporte estruturalmente conservador.

\section{CAMille JulLian, PATRONo e PATRÃo}

Se, nesse empreendimento coletivo que abarca a criação de uma revista e de uma disciplina, fosse necessário destacar um nome e um evento-chave, não se poderia evocar outros que não o de Camille Jullian e sua primeira tentativa de ingresso no Collège de France. No dia 13 de dezembro de 1886, motivado por uma série de sucessos em sua recém-iniciada carreira, Jullian endereçou ao administrador dessa instituição uma carta apresentando sua candidatura $^{24}$. O jovem latinista, então com 27 anos, possuía já um respeitável currículo. No que diz respeito à sua trajetória acadêmica, além de ter sido aluno da ENS, membro da École Française de Rome e estagiário de Mommsen na Universidade de Berlim, ele ministrava há alguns anos cursos na Faculdade de Letras de Bordeaux. Quanto à sua produção, além das teses, Jullian havia publicado livros e memórias, bem como um número considerável de artigos nas mais importantes revistas científicas francesas (os Mélanges d'Archéologie et Histoire, a Revue Archéologique, a Revue Philologique, a Revue Historique, entre outras).

A cadeira ambicionada por ele era a de Epigraphie et d'Antiquités Romaines, cujo titular, Ernst Desjardins, seu antigo professor em Paris, havia falecido. Para a infelicidade de Jullian, contudo, apareceram outros três pretendentes ao mesmo posto, Gustave Bloch (18481923), Jean-Baptiste Mispoulet (1849-1917) e René Cagnat (1852-1937), todos mais velhos e bastante qualificados. O primeiro, Bloch, havia sido normaliano e membro da École Française de Rome no momento em que esta se separava de sua matriz ateniense. Sua tese, defendida em 1883, discutia as origens do senado romano e sua produção posterior, restrita a artigos, mantinha-se atrelada ao estudo das instituições políticas de Roma. Bloch era, naquele momento, professor de Antiquités Grecques et Latines na Faculdade de Letras de Lyon. JeanBaptiste Mispoulet, por seu turno, era o mais desfavorecido em termos de títulos e de publicações. Sem jamais ter sido aluno da ENS, ele devia sua formação aos cursos de Rénier e de Desjardins que acompanhara no Collège de France e na EPHE. A produção que acumulava até o momento poderia ser encontrada basicamente no Bulletin Critique, embora possuísse um livro (sobre as instituições de Roma) e uma memória (sobre o senado romano) laureados respectivamente pela Académie des Sciences Morales et Politiques e pela Académie des Inscriptions et Belles-Lettres. A despeito desses trunfos, Mispoulet não contava com grau de doutor e, por conseguinte, mantinha-se às margens da Universidade (sua atuação na área

\footnotetext{
${ }^{24}$ Cf. Arquivos do Collège de France, na pasta Assemblée du 16 janvier 1887, o documento código g-IVe-32a.
} 
limitava-se a cursos para auditores livres oferecidos na Sorbonne). René Cagnat, por fim, destacava-se de seus concorrentes em mais de um quesito. Embora não tenha passado pela École Française de Rome, esse antigo normaliano esteve envolvido desde cedo com a epigrafia latina. Após ter defendido em 1880 um doutorado sobre as milícias municipais e provinciais no Império Romano, ele foi encarregado pelo governo francês da nova frente de escavações que se abria na Tunísia. Para além da experiência de campo e das publicações que isso lhe rendeu diretamente, Cagnat foi convidado na mesma época para ser diretor de um dos suplementos, o relativo a África, da Corpus Inscriptionum Latinarum, a monumental coleção dirigida por Mommsen. O prestígio conquistado nesses primeiros anos de atividade foram ainda aumentados com a publicação do livro que mais o tornou conhecido, seu Cours élémentaire d'épigraphie latine (1886). Entre uma e outra de suas missões arqueológicas no exterior, Cagnat atuava como professor na Faculdade de Letras de Douai.

Pouco mais de um mês após Jullian ter escrito sua carta, no dia 16 de janeiro de 1887, os integrantes do Collège de France se reuniram, como reza o regulamento da casa, para deliberar acerca do sucessor de Desjardins ${ }^{25}$. Seguindo os registro da ata dessa assembleia, constata-se que, após a apresentação dos quatro candidatos, o professor de Histoire de la Littérature Latine, Gaston Boissier, pediu a palavra para desenhar aos colegas um resumo do quadro que se Ihes apresentava. Para ele, causava certo embaraço ter diante de si "quatro candidatos muito recomendáveis". Não obstante, como alguns pareciam-lhe mais recomendáveis que outros, ele tratou logo de descartar dois nomes: o de Bloch e o de Mispoulet. Do primeiro, reconheceu o "espírito vigoroso", "de primeira ordem", mas criticou os fatos de seus trabalhos serem pouco numerosos e, o que era ainda mais comprometedor, apenas marginalmente ligados à epigrafia. Do segundo, limitou-se a dizer que "sua memória coroada pela Academia não é inteiramente de primeira mão". Já entre os outros dois, Jullian e Cagnat, Boissier pareceu hesitar. Seguiu-se então uma breve exposição de suas produções, da qual se inferiu que Jullian deveria aparecer como o segundo e Cagnat como o primeiro a ser indicado pelo colegiado para o crivo do ministro da Instrução Pública (o qual, por via de regra, deveria respeitar a ordem definida pela assembleia). Além de Boissier, outros dois professores se manifestaram: enquanto Louis Havet, titular da cadeira de Philologie Latine, concordou com as considerações do colega, Jacques Flash, professor de Histoire des Législations Comparée, quis "completar a exposição dos títulos do Sr. Bloch".

Uma vez aberta a votação, quanto ao primeiro nome a ser indicado, Cagnat obteve uma maioria de dezoito votos, seguido de longe por Bloch, com apenas oito. Jullian apareceu

\footnotetext{
${ }^{25}$ Cf. Arquivos do Collège de France, na pasta Assemblée du 16 janvier 1887, o documento código g-IVe-32k.
} 
em terceiro lugar com três votos e ninguém optou por Mispoulet. Não obstante, quando se passou para a votação do segundo nome, aqueles que haviam votado em Cagnat optaram em sua maioria por Jullian. Foram, ao total, dezessete votos para ele, seguidos de onze para Bloch e um para Mispoulet. Resultado final: Cagnat ganhou a eleição e Jullian voltou para Bordeaux com um louvável, mas frustrante, segundo lugar.

A crônica desse fracasso suscita importantes questões para quem almeja compreender a dinâmica de funcionamento da REA. Ela fornece, por um lado, subsídios para apartar o nome de Jullian do coletivo constituído em torno da referida publicação. Tratava-se, afinal, do único de seus fundadores disposto a (e em condições de) obter um posto no Collège de France, o que reclama explicações. Por outro lado, tal crônica permite acompanhar o momento preciso em que a carreira de latinista de Jullian deu uma guinada decisiva em direção às "Antiguidades Nacionais", com as quais, de fato, ele viria a conquistar Paris dezessete anos mais tarde.

Quanto ao primeiro ponto, as especificidades de Jullian no interior da REA, é salutar atentar para o que se poderia chamar de um legado familiar duplamente vantajoso. Enquanto seus colegas provinham de famílias católicas mais ou menos remediadas, ele, nascido na Marselha de 1859, foi o único filho homem de um casal que tinha por pai, de quem herdara nome e sobrenome, um abastado banqueiro provincial e por mãe, Marie Rouvière, uma descendente de proprietários fundiários. Some-se a isso, fato indissociável do anterior, a pertença de ambos, pai e mãe, à fina flor dos protestantes vaudois franceses.

Os vínculos com a elite protestante abastada parecem ter marcado Jullian, sensibilizando-o a um cenário no qual essa sua condição resvalava com frequência nos modos à época disponíveis de se fazer ciência e política. Ele cresceu, efetivamente, sob um regime, o da Terceira República, marcado por intensos conflitos de classe (a Comuna de Paris, as primeiras grandes greves de trabalhadores e a fundação da SFIO) e de fundo político-religioso (a laicização do Estado francês e o Affaire Dreyfus). Não por acaso, essas questões guiaram sua interpretação do mundo e, em particular, suas estratégias de inserção em universos letrados.

Vê-se um exemplo de como Jullian esteve atento ao que se passava ao seu redor quando, em novembro de 1880 , ele escreveu a seus pais comentando a suspensão de um professor da ENS por suposto envolvimento com congregações religiosas: "eu fiquei muito surpreso ao ver o nome do Sr. Ollé-Laprune envolvido com política; ele é doce demais para fazer o que the condenam. Sua demissão é uma revogação. Eu sei que ele é um católico convicto, mas muito tolerante; a prova é que ele nos ama muito, a [Henry] Michel e a mim, e que ele me recomendou com vigor ao Sr. Geffroy, seu primo" (JULLIAN, 1936: 26-7). Pode-se dizer o mesmo de suas observações acerca da carreira do próprio Geffroy. Jullian especulou 
sobre o futuro do diretor da École Française de Rome em uma carta de outubro de 1881. Nela, suspeitava que, em função de seu "clericalismo", o qual "não o deixa muito bem em Paris", Geffroy perderia seu posto (JULLIAN, 1936: 164-5) ${ }^{26}$.

Jullian teve, contudo, o faro suficientemente aguçado para perceber que o vínculo religioso não era em si mesmo uma desvantagem. No período de sua formação, é interessante observar como ele se valeu de redes protestantes para fortalecer sua posição na Universidade. Em maio de 1880, ele escreveu de Paris a sua mãe para contar-Ihe do encontro com Jules Bonnet, um dos fundadors da Société de l'histoire du protestantisme français e diretor do Boletim dessa instituição (JULLIAN, 1936: 2-3):

Ele é muito rico, a julgar por suas relações e as numerosas viagens que fez; ele é amigo de Mignet, dos Orléans e amigo muito íntimo de seu camarada de École [Normale Supérieure], o Sr. Geffroy, diretor da École de Rome. Não poderia ele me recomendar? O Sr. Bonnet me prometeu (...) Eu espero que papai fique contente com este encontro que eu havia procurado, já há bastante tempo, fazer e que eu enfim fiz.

Ora, este senhor fora também colega de seu pai nos tempos de liceu e, de fato, abriu-lhe inúmeras portas durante o período em que permaneceu na Itália e na Alemanha. Graças a ele, Jullian foi acolhido por fiéis estrangeiros, frequentou bibliotecas de acesso restrito e recebeu encomendas de textos sobre a história de sua Igreja que o tornaram conhecido no meio.

Outro apadrinhamento importante proveniente dos círculos protestantes veio da parte de Gabriel Monod. Diretor da Revue Historique, ele acolheu desde cedo as contribuições de Jullian, primeiro sob a forma de resenhas e, finalmente, dando-Ihe a direção de uma seção da revista dedicada à Roma Antiga (trata-se do item Travaux sur l'antiquité romaine, publicado com alguma regularidade entre 1893 e 1908). Nas cartas de Jullian endereçadas a seus pais, fala-se com entusiasmo das encomendas de Monod, bem como dos contatos estabelecidos a partir dele (JULLIAN, 1936: 72, 165, 273-4).

Mas não se deve confundir o uso dessas redes de influência com alguma forma de militância religiosa. Embora jamais tenha deixado de assumir publicamente seu credo, Jullian reconheceu que a transferência desse trunfo para a Universidade tinha uma eficácia limitada. Assim, na sedução de letrados católicos ou judeus, ele se valeu das outras modalidades de capitais de que dispunha, em particular o prestígio intelectual.

Com efeito, Jullian soube cultivar a fama de prodígio desde o período de sua formação. Após brilhantes estudos no Liceu de Marselha, ele foi aprovado no exame de admissão da ENS com uma idade inferior à permitida (17 anos, quando o mínimo era 18), tendo mesmo de

\footnotetext{
${ }^{26}$ Jullian não se enganou quanto a isso. De fato, em fins de 1882, Edmond Le Blant acabou sendo nomeado o novo diretor da Instituição. Veja-se o subcapítulo 2.2 a esse respeito.
} 
contar com a anuência do então diretor da instituição (Ernst Desjardins) para realizar sua matrícula. Uma vez lá, ao final do triennium normaliano, ele obteve o primeiro lugar na agrégation de histoire et géographie, embarcando na sequência para Roma e Berlim como um dos mais jovens bolsistas do Estado francês. Terminando esses estágios, Jullian defendeu, com apenas 24 anos, suas teses, das quais uma (a latina) discutia a organização da Casa Imperial nos tempos de Augusto, enquanto a outra (a francesa) tratava das transformações políticas da Itália durante o governo dos primeiros imperadores romanos. Antes mesmo de sua aprovação no exame, contudo, ele já havia passado a integrar o corpo docente da Faculdade de Letras de Bordeaux. Até 1887, Jullian ocupou sucessivamente as cadeiras de Histoire Ancienne (a partir de 1883, como Chargé de Cours Complémentaire), Antiquité Grecques et Latines (a partir de 1885, como suplente do titular), bem como acumulou Antiquités Latines e Histoire de Bordeaux et de la Région du Sud-Ouest (ambas, como Maître de Conférence, a partir de 1886, sendo esta para o público local e aquela para as turmas preparatórias da agrégation).

Nesse ínterim, Jullian optou por se estabelecer como latinista. É bem verdade que, em certo momento, ele chegou a titubear quanto ao tema preciso de suas pesquisas: a frente arqueológica aberta no Norte da África soava promissora ${ }^{27}$. Ainda assim, foram temáticas mais tradicionais e valorizadas (os primórdios do Império) que o conquistaram. Sua produção ao longo da década de 1880 confirma esse fato: ela trata da história de Roma e de epigrafia latina ${ }^{28}$. Por fim, quanto aos contatos sociais, Jullian soube se tornar conhecido entre os especialistas: ele travou amizade com Philippe Boissevan e Gaston Boissier, acompanhando-os em visitas a sítios históricos e a jantares (JULLIAN, 1936: 204-214), assistiu às conferências de Jean Baptiste de Rossi (JULLIAN, 1936: 180-184) e frequêntou a casa e os cursos universitários de Emil Hübner e Theodor Mommsen (JULLIAN, 1936: 271-2, 283-5). Seus futuros colegas da REA, Henri de la Ville de Mirmont, Pierre Paris, Michel Clerc e Georges Radet, estavam longe de dispor de tantos contatos e de tamanho prestígio intelectual em fins da década de 1880.

Mas a concentração de consideráveis recursos, aos quais certamente se somavam grandes esperanças, não foi suficiente para garantir a ida a Paris. Teria Jullian, um dos universitários mais promissores de sua geração, perdido a oportunidade que o destino the

\footnotetext{
27 JULLIAN, 1936: 119-120. A clarividência de Jullian é, também nesse ponto, espantosa. De fato, as descobertas do Norte da África acabaram por reforçar o lugar dos estudos greco-latinos em meio à expansão do Sistema de Ensino francês. René Cagnat, como foi visto, conquistou sua cadeira no Collège de France graças à atuação na região. Na mesma instituição, em 1912, Stéphane Gsell (1864-1932) foi eleito o primeiro professor de Histoire de l'Afrique du Nord (ou seja, em termos mais explícitos, a cadeira de História Antiga da África do Norte).

${ }^{28}$ Para suas teses, cf. JULLIAN, 1883 e 1884a. Quanto à epigrafia, destaco aqui Étude d'épigraphie bordelaise. Les bordelais dans l'armée romaine (1884b), Notes d'Épigraphie (1886) e o primeiro dos dois volumes dedicados às inscrições latinas de Bordeaux (1887).
} 
reservara? Estaria ele fadado a permanecer indefinidamente em uma posição subalterna na Província? Em 1902, na mensagem de felicitação endereçada a um Durkheim recém-admitido na Sorbonne, a ferida continuava aberta. Embora tenha se perdido a carta original de Jullian, na resposta a ela encontra-se o seguinte consolo: "Vês pelo meu caso que as coisas terminam por se arranjar, pois era mais difícil encontrar um lugar em Paris para mim, que para ti" (DURKHEIM, 1982: 3). E quando, três anos depois, tudo finalmente se arranjou no Collège de France, Jullian fez questão de evocar "o sonho por demais ambicioso de uma juventude já distante", o qual acabara de se transformar em realidade (JULLIAN, 1905: 1).

O candidato derrotado de 1887 tinha, contudo, pouco em comum com o vitorioso de 1905. Enquanto um apresentou-se como latinista-epigrafista, o outro foi reconhecido como patrono da História e das Antiguidades Nacionais. Por certo, tal mudança não ocorreu subitamente, tornando necessário explicitar aqui em que pontos e com que intensidade há, desde a primeira candidatura, desvios no padrão de sua trajetória ${ }^{29}$.

Uma das mais notáveis mudanças provém do fato de Jullian voltar parte considerável de seus investimentos sociais e intelectuais para a Província - aqui, com um duplo sentido, uma Província romana (a Gália) e a Província francesa (em especial a França meridional). Os temas de seus livros fornecem bons indícios para comprovar isso. Na sequência da publicação do segundo volume das Inscriptions Romaines de Bordeaux (1890), enquanto estudioso da Antiguidade, ele redigiu uma história da Gália (1892), três estudos sobre Bordeaux (1893, 1895 e 1897a), uma biografia de Vercingetorix (1901) e um tratado sobre a religião gaulesa (1903a). O mesmo pode ser dito de seu lugar institucional: embora tenha ocupado várias cadeiras ao longo de seus primeiros anos de docência, Jullian foi efetivado em 1891 justamente como professor titular da cadeira de Histoire de Bordeaux et du Sud-ouest. E que dizer de seus contatos sociais? Enquanto o centro nevrálgico da Universidade francesa fechava-se cada vez mais aos eruditos locais, desprovidos de seus certificados, ele fez um esforço na direção contrária. A partir de 1888, ele foi aderindo sistematicamente a sociedades científicas e literárias regionais: a Académie de Bordeaux, a Académie d'Aix-en-Provence, a Société des Sciences, Lettres et Arts de Bayonne, entre outras.

No que se preservou da participação de Jullian nesses espaços, chama atenção a valorização do local e do nacional, em um registro próximo àquele de que será visto anos mais

\footnotetext{
${ }^{29}$ Seu mais recente biógrafo moderno a interpretou como "extremamente coerente" e, portanto, marcada por uma "grande continuidade" (MOTTE, 1990). Também entre seus contemporâneos não se fala em grandes rupturas. Para eles, Jullian se manteve sempre "cientista", "provincial" e "patriota" (REA, 1934: 5-24; RA, 1933: 95-6). A única exceção é Aimé Puech, o qual tratou da transformação do "Historiador de Bordeaux" em "Historiador da Gália", mas entendendo-a como uma decorrência da ida de Jullian a Paris (PUECH, 1935). Os demais necrológios consultados sequer mencionam algo que não remeta ao Jullian das "Antiguidades Nacionais" (DE MARIEN, 1934 e LYZOP, 1934).
} 
tarde nas conferências já mencionadas de Michel Clerc. Desse modo, ao ser recebido pela pela Académie de Bordeaux em 1888, ele optou por discorrer sobre a trajetória de Ausônio, um dos derradeiros poetas da Antiga Roma, natural da região. Cinco anos depois, foi sua vez de pronunciar o principal discurso do Congrès des Sociétés Savantes. Sua fala tratou então de Montesquieu, outro letrado nascido em Bordeaux. Ora, esse philosophe foi apresentado como o emblema do provincial genial, generoso e patriota, ao qual, por medo, contrapôs-se um Voltaire, escritor da Corte. Nas palavras do próprio orador (JULLIAN, 1903b: 6-7):

\begin{abstract}
Nosso Congresso, Senhores, é a revanche de Bordeaux sobre Voltaire: revanche que é também a de Montesquieu, das sociedades de província e dos estudos locais.

Pois a história local não é fofoca retrospectiva. Todos vocês, Senhores, pesquisadores apaixonados das coisas de outrora, vocês não estudam suas províncias ou suas cidades por uma vã necessidade de tagarelice erudita. (...) O que vocês amam sobretudo nos anais de suas cidades, mesmo as menores, é de ver como a história da França se passou sobre o seu solo e os seus muros. É esta história da França que é a paixão soberana de vocês; e vocês a fazem, Senhores, da boa maneira - não, como Voltaire, sob a forma de ideias vagas e narrativas muito gerais; mas, como a Academia de Montesquieu, de modo bastante preciso e concreto, estudando a terra onde os eventos foram produzidos e os homens que os dirigiram. Vocês reconstroem as cenas de tempos desaparecidos nas próprias ruas e praças que os abrigaram. A história local é talvez a única que seja uma ressurreição.
\end{abstract}

Em paralelo ao "retorno" à Província, Jullian voltou-se também ao passado de sua disciplina e, por extensão, à construção de uma genealogia intelectual. Um de seus "heróis" foi o próprio Montesquieu, editado e comentado por ele (1897b). Outros nomes dos quais eles soube se apropriar foram os dos grandes historiadores franceses do século XIX. Em um livro intitulado Extraits des Historiens du XIXe siècles. Publiés, annotés et précédés d'une introduction sur l'histoire de France, ele propõe uma retrospectiva da historiografia nacional (JULLIAN, 1897c). Após uma longa introdução, na qual ele passa em revista as correntes de ideias que guiaram os historiadores, ele apresenta excertos de suas obras. A escolha dos autores é, por si só, reveladora: ignorando as querelas revolucionárias, ele principia com um literato, Chateaubriand, passa por Thierry, Barante, Guizot, Thiers, Mignet, Michelet, Tocqueville, Quinet, Duruy, Renan, Taine, até chegar, por fim, a Fustel de Coulanges. Dentre tais nomes, aliás, foi Fustel de Coulanges quem Ihe concebeu maior notoriedade na sequência. Ao falecer em 1889, este seu antigo professor da ENS exprimiu em testamento o desejo de que Jullian terminasse e publicasse suas obras inacabadas. A partir de 1890, foram lançados volumes complementares à Histoire des Institutions Politiques de l'Ancienne France e, em 1893, as Questions Historiques, reunindo textos programáticos e metodológicos do mestre.

A descoberta das "Antiguidades Nacionais" se dá, portanto, sob esse duplo retorno à Província e ao passado disciplinar. E há mais: nela, Jullian se destaca de seus futuros colegas da 
REA tanto pela precocidade (pois estes só se aproximaram da nova área em meados da década de 1890) quanto pela capacidade de agregar valor à iniciativa. Derrotado em Paris como latinista, ele esforçou-se por voltar como algo mais que um especialista. Falando em nome da História e da tradição historiográfica nacionais, o Jullian pós-1887 quis apresentar-se, em Paris e na Província, como um novo Fustel de Coulanges.

\section{Do Patriotismo Gaulês (ou a TRADIÇão ReINVENTADA)}

Uma descrição do gabinete de Jullian em Paris revela muito do peso da herança Fustel de Coulanges em sua vida (LYZOP, 1934: 2-3):

Seus amigos e discípulos evocarão sempre com uma melancólica nostalgia seu gabinete de trabalho na rua Guynemer, no terceiro andar de um calmo imóvel, diante dos nobres horizontes de pomares e mármores do Jardim de Luxembourg. Sobre a porta deste santuário coberto de livros e de revistas, atrás de uma mesa sobrecarregada de notas e de manuscritos, sob o olhar tutelar de uma fotografia de Fustel de Coulanges, a silhueta breve e alerta do mestre se apresentava com um gesto de boas-vindas.

Mas não se deve confundir o uso da imagem de Fustel de Coulanges (e da tradição representada por ela) com uma submissão cega à sua memória. Jullian, como político e intelectual que era, na melhor tradição normaliana, soube adequar a herança recebida às circunstâncias dos novos tempos. Seu texto Du Patriotisme Gaulois é um perfeito exemplo disto. Nele, dirigindo-se a Salomon Reinach, o autor se colocou contra a tese, defendida por Fustel e seu interlocutor, da ausência de uma consciência nacional entre os gauleses. Em suas palavras:

Eu sei bem, meu caro amigo, como nosso mestre comum Fustel de Coulanges intitulou o primeiro capítulo de suas Institutions: que não existia unidade nacional entre os Gauleses. Mais de uma vez, após dez anos, fizeram-me lembrar destas linhas que eu redigi quase sobre seu ditado: "a única espécie de patriotismo que eles puderam conhecer foi o amor do pequeno Estado ao qual cada um fazia parte". Mas as escrevendo, eu fiz respeituosas reservas (...). Fustel de Coulanges estava sobretudo surpreso com as divisões que separavam os Gauleses, como esteve com as que destruíram a Grécia (RC, 1902: 373).

Insistiu-se no restante do texto na coesão cultural e linguística como indícios da consciência nacional gaulesa, argumento ainda reforçado pela suposta existência de uma unidade política céltica à época dos últimos reis de Roma. Comparações com a Grécia Antiga, como a que está nas linhas transcritas acima, são bastante frequentes. Afinal, se, mesmo com as divisões internas, os gregos tinham consciência de sua unidade, por que não a teriam os gauleses? O Império Romano também ganhou destaque, mas sobretudo como a potência externa interessada na divisão da Gália.

No momento em que um novo Império (o Alemão) parecia ameaçar os descendentes dos gauleses, a inovação diante da tradição não parece nem um pouco desinteressada. Tal tese, contudo, esteve longe de ser unânime. Além de Salomon Reinach, Henri Hubert a criticará duramente em seus futuros trabalhos (HUBERT, 2001: 541-636). 
Mas como se deu a ida de Jullian a Paris? Ora, a morte de Gabriel Tarde em 1904 abriu espaço para a entrada das "Antiguidades Nacionais" no Collège de France. Com efeito, como Henri Bergson passou a ocupar a cadeira de Tarde, Philosophie Moderne, a sua, Philosophie Grecque et Latine, tornou-se vacante ${ }^{30}$. No dia 28 de novembro de 1904, a Assembleia de professores dessa instituição decidiu, por ampla maioria, transformar a cadeira de Bergson ${ }^{31}$. De início, cinco propostas de mudanças foram colocadas em votação: Sociologie, Philosophie Générale, Histoire Générale, Pédagogie e, por fim, Antiquités Nationales. Ao final da reunião, no segundo turno das votações, configurou-se um impasse: onze votos para Sociologie, onze para Histoire e onze para Antiquités Nationales. Na Assembleia seguinte, a do dia 15 de janeiro de 1905, tanto aqueles que defendiam Histoire Générale quanto os que advogavam em nome das Antiquités Nationales reestruturam suas demandas, fazendo-as convergir em prol da criação de uma cadeira de Histoire et Antiquités Nationales ${ }^{32}$. Única em toda França, argumentaram eles, ela permitiria manter a tradição do Collège de uma cadeira geral de História (como aquela que existia para Michelet) e, ao mesmo tempo, relacionaria isso à especialidade da história regional e nacional. Enquanto a proposta em prol da Sociologie manteve os mesmos onze votos de antes, Histoire et Antiquités Nationales recebeu dezenove dos trinta e quatro disponíveis. Na Assembleia do dia 2 de abril do mesmo ano, enfim, Camille Jullian foi eleito contra Jules Toutain, o qual só havia apresentado sua candidatura para a segunda linha, por vinte nove votos contra dois ${ }^{33}$.

Após essa triunfal entrada em uma das mais prestigiosas instituições francesas, Jullian se dedicou intelectualmente à história da Gália. Entre 1908 e 1926, ele publicou nada menos que oito volumes sobre o tema, os quais cobriram o período situado entre a chegada dos gauleses ao atual território francês e o estabelecimento das monarquias germânicas na Idade Média. Institucionalmente, contudo, ele ainda acumulou progressos significativos em sua trajetória. Único de seus colegas da REA a obter um posto no Collège de France, ele foi o primeiro a ser eleito como membro efetivo da Académie des Inscriptions et Belles-Lettres, em 1908 (Pierre Paris entrará aí em 1920, enquanto Georges Radet e Michel Clerc ocuparão apenas o modesto posto de membro correspondente). Em 1924, ainda novo trunfo: Jullian foi eleito membro da Académie Française. Dois anos mais tarde é a vez de atingir o grau máximo

\footnotetext{
${ }^{30}$ Para mais detalhes sobre esse processo, veja-se, na presente tese, o subcapítulo 3.1.

${ }^{31}$ Cf. Arquivos do Collège de France, na pasta Assemblée du 28 novembre 1904, o documento G-IV-g $21 R$.

${ }^{32} \mathrm{Cf}$. Arquivos do Collège de France, na pasta Assemblée du 15 janvier 1905, o documento G-IV-g 22M.

${ }^{33}$ Cf. Arquivos do Collège de France, os documentos da pasta Assemblée du 2 avril 1905. Uma versão simplificada e heroicizada de todos esses acontecimentos foi inscrita por Georges Radet em um dos necrológios de Jullian que consultamos (REA, 1934: 9).
} 
na Legião Francesa, o de Grand Commendateur. Também nesses dois últimos casos, ele foi o único membro da REA a obter as distinções.

De latinista prodígio a um dos mais destacados historiadores de seu tempo, herdeiro de Fustel de Coulanges e patrono de uma nova especialidade, as "Antiguidades Nacionais", Jullian foi igualmente o grande patrão por trás da REA. Entre seus contemporâneos, aliás, essa era uma opinião bastante difundida. Nas notas dedicadas postumamente a ele pela Revue Archéologique, o latinista Jêrome Carcopino resumiu assim sua atuação na REA: "Jullian a havia fundado, com a colaboração de Georges Radet, em 1899, e, sob seu impulso, [ela] tornou-se um dos melhores periódicos de filologia e de arqueologia contemporâneos" (RA, 1933: 95-6). Vale dizer: nada menos que o iniciador e o maior estímulo da revista! Lucien Febvre vai ainda mais longe quando, em uma carta, vale-se da imagem de Jullian para explicar a Marc Bloch a importância de se participar ativamente da publicação que ambos então tencionavam fundar: "lembremo-nos sempre do exemplo, tão típico, da Revue des Études Anciennes, que é apenas alguma coisa porque Jullian a anima" (BLOCH; FEBVRE, 1994: 72).

Para se compreender melhor como o peso de Jullian se integra ao trabalho coletivo existente no seio da REA, serão discutidos a seguir tanto um incidente político-institucional que marcou a fundação da revista quanto seus padrões de recrutamento entre 1899 e 1920.

\section{O “INCIDENTE” STAPFER}

Ao publicar suas memórias, Charles Samaran, ex-aluno da École de Chartes e exbolsista da École Française de Rome, declarou sobre o Affaire Dreyfus: "ele envenenou literalmente a atmosfera ao jogar uns contra os outros os membros de uma mesma família, os mestres e os alunos de uma mesma escola" (SAMARAN, 1979: 113). Isso, que o autor redigiu pensando na École de Chartes, fez-se também sentir entre os professores da Faculdade de Letras de Bordeaux, justo quando alguns deles se preparavam para fundar uma nova revista. 0 ano era 1898 e as circunstâncias que envolveram o Affaire levaram ao batismo político da REA.

A questão nacional eclodiu na capital da Aquitaine por intermédio do óbito do reitor de sua Universidade, o helenista Auguste Couat. Em meio às honras fúnebres dirigidas ao falecido, acompanhadas por algumas das mais distintas autoridades universitárias, políticas e militares locais, Alfred Stapfer, professor de literatura francesa e doyen (diretor) da Faculdade de Letras, afirmou em alto e bom som a posição dreyfusard de Couat. Em seu discurso, tal como foi reproduzido pelo diário Le Temps, havia a seguinte passagem ${ }^{34}$ :

\footnotetext{
${ }^{34} \mathrm{O}$ itálico está no original. Cf., para esta e para as citações do próximo parágrafo, a notícia "Les Affaires Dreyfus-Picquart-Esterhazy: un incident aux obsèques du recteur Couat. Notre correspondant de Bordeaux nous télégraphie à la date d'hier" em Le Temps, edição de 25 de julho de 1898.
} 
Mas é preciso que se saiba que este homem [Couat], apaixonado como um santo, tomava para si, a ponto de tornar-se doente, os males e as vergonhas do país, e, se não me é permitido indicar mais claramente de que lado estava a grande alma deste nobre intelectual, digamos somente (pois este linguajar não é uma ofensa nem para um, nem para o outro partido) que a profunda ferida de seu patriotismo havia também atingido as fontes de sua vida. Senhores, a justiça se encontra por vezes eclipsada pelas nuvens da paixão. Se, hoje, nós não sabemos onde ela está, sigamos sempre os passos deste justo: nós estaremos certos de estar na verdade.

Intelectual? Stapfer poderia ter escolhido outra palavra se não quisesse mesmo revelar de que lado estava Couat. Ainda segundo o Le Temps, após o término da fala do doyen, "quase todos os professores da Faculdade presentes foram, em protesto, apertar as mãos do general Varaigne, o qual estava cercado por outros generais da divisão". Por fim, algumas horas mais tarde, "diferentes Faculdades se reuniram e enviaram ao quartel general delegados para ali testemunhar sua simpatia em relação ao exército".

Ao contrário do que o jornal dava a entender, contudo, a condenação da atitude de seu doyen não era uma unanimidade entre os membros da Faculdade de Letras de Bordeaux. Émile Durkheim, professor titular das cadeiras de Pédagogie e de Sciences Sociales, além de notório dreyfusard ${ }^{35}$, redigiu na sequência uma carta de protesto endereçada ao Le Temps. Nela, acusava-se a imprecisão da informação relativa à condenação institucional do discurso de Stapfer. Segundo Durkheim, quanto aos supostos testemunhos de simpatia da Faculdade para com o exército, "nenhuma delegação foi enviada; nem mesmo uma proposição foi feita neste sentido". Todas estas manifestações seriam, portanto, expressões de "opiniões pessoais" contrárias aos sentimentos de Stapfer, os quais, por seu turno, "são também os de muitos de nós" ${ }^{36}$.

A atitude de Durkheim definitivamente não agradou à maioria de seus colegas. Apenas dois dias após a divulgação de seu texto, o mesmo Le Temps publicou uma carta-resposta assinada por oito professores da casa ${ }^{37}$. Nela se lê:

Ao querer dissipar um equívoco, nosso Colega, Sr. Durkheim, em uma carta de retificação que ele vos encaminhou no dia 26 de julho, parece-nos criar um outro. Sobre a questão da forma, a faculdade de letras de Bordeaux foi unânime em reprovar a manifestação inoportuna de seu diretor. Sobre o fundo do debate, se, como o afirma o Sr. Durkheim, o sentimento do Sr. Stapfer "é também aquele de muitos dentre nós", aqueles que assinam abaixo, em função da

\footnotetext{
${ }^{35}$ Em fevereiro daquele mesmo ano, Durkheim e dois colegas de Faculdade, os filósofos Georges Rodier e Octave Hamelin, haviam sido acusados de pertencer a um "sindicato" dreyfusard. Veja-se a reação dos três em uma carta publicada no jornal Le Nouvelliste, edição de 5 de fevereiro de 1898.

${ }^{36}$ Cf., para a carta de Durkheim, a seção "Correspondance" em Le Temps, edição de 28 de julho de 1898.

${ }^{37}$ Veja-se a seção “Correspondance” em Le Temps, edição de 30 de julho de 1898.
} 
ausência de seus nomes junto ao seu, querem se desvincular categoricamente desta formulação, por demais generalizante.

Dentre os signatários da carta-resposta encontravam-se não menos que três dos futuros fundadores da REA (De la Ville de Mirmont, Paris e Radet), bem como dois de seus eventuais colaboradores (o iberista Cirot e o linguista Bourgiez) e outros três professores da Faculdade (De Tréverret, Gebelin e La Breton, sendo este último um membro ativo da Action Française, o partido antidrefusard por excelência). No dia três de agosto daquele mesmo ano, o geógrafo e historiador Imbart de la Tour escreveu também ao Le Temps afirmando sua adesão ao protesto dos colegas ${ }^{38}$.

Camille Jullian, embora não tenha colocado seu nome junto aos de Radet, Paris e De la Ville de Mirmont, condenou o discurso de Stapfer em termos muito parecidos aos empregados por eles. Não obstante, ele parece ter mantido sua atuação restrita aos bastidores da Universidade. O que nos permite recuperar esse fato é justamente uma carta que Durkheim endereçou a Jullian em outubro de 1898. Trata-se, nesse caso, de uma resposta ao envio de algumas brochuras e à indagação sobre seu silêncio relativo a outra carta escrita em julho, no calor dos acontecimentos. Agradecendo os textos recebidos, Durkheim explica a Jullian as razões de sua não-resposta nos seguintes termos (DURKHEIM, 1982, o sublinhado consta no original):

Em primeiro lugar, a fórmula com a qual me anunciaste a tua adesão declarando que Stapfer, $\underline{0}$ qual acabava de ser suspenso, havia incorrido "na reprovação da faculdade". Ora, não me parece nem generoso, nem conforme às nossas tradições universitárias censurar assim um colega que acabava de ser punido administrativamente. Um apelo contrário não tinha o direito de empregar termos parecidos. Isto porque jamais uma fórmula falando de reprovação reuniu a totalidade da faculdade. Se, naquele momento, eu não coloquei publicamente o fato, foi para não prolongar este penoso incidente.

Em segundo lugar, no que diz respeito ao debate inicial [o Caso Dreyfus], origem de toda diferença, ainda que jamais a verdade e o dever me tenham parecido mais evidentes, eu não vou ao ponto de não poder admitir que outros não pensem como eu. Eu tenho apenas a necessidade bastante natural de imaginar o que pode ter determinado meus adversários em suas opiniões. Há várias razões que me parecem muito inteligíveis. Eu compreendo sem esforço que o boulangismo clerical, o antisemitismo e o antiprotestantismo nos resistam com todas as forças, eles jogam sua derradeira cartada. - 0 espírito de corpo, a ausência de informações podem produzir os mesmos efeitos. - Enfim, eu concebo ainda que certas pessoas, intimidadas por alguma afirmação ministerial e temendo que este caso tenha consequências desconhecidas, tenham achado mais sábio esperar, ainda que, para todo espírito liberal, a questão da legalidade deve vir em primeiro lugar. Mas o teu caso não me parecia ser nenhum destes. Não tens nada em comum com o clericalismo, não vens de um ambiente militar, estavas

\footnotetext{
${ }^{38}$ Cf. a seção “Nouvelles du Jour” em Le Temps, edição de 3 de agosto de 1898.
} 
completamente informado. Destes provas disto a mim ao longo de uma conversa que eu tive então contigo. Eu estava mesmo convencido que partilhavas profundamente meu sentimento, que achavas apenas inoportuna a manifestação universitária. Eu não sou o único a quem destes essa impressão (...).

Nestas condições, tua atitude me parecia inexplicável. Tua carta não a explicava: pois te contentavas em dizer que "esta questão não te parecia solúvel por nossas reflexões pessoais", o que não é lá muito explicativo. Tal era também a opinião daqueles a quem eu a comuniquei segundo a tua autorização.

Eis porque eu não te respondi. Eu sei que, sobre esta questão, os discursos são vãos: então por que te escrever? Eu jamais pensei que nossas relações tivessem de ser suspensas em função disto. Mas eu não podia empregar nela nem a mesma liberdade de espírito, nem a mesma confiança de antes e, eu o imagino, tu também não.

Em todo caso, como se lê na carta de Durkheim, o "incidente" envolvendo o doyen provocou suficiente comoção para que medidas disciplinares recaíssem sobre ele. Isso, que já fora anunciado no Le Temps de 29 de julho, acabou sendo confirmado no dia seguinte: Stapfer encontrou-se suspenso de suas funções de doyen por tempo indeterminado. Uma vez consolidada uma maioria de professores antidreyfusard na Faculdade e isolados aqueles que poderiam lhes fazer oposição nesse campo, a próxima manobra passou a ser a ocupação do cargo deixado em aberto. É nesse ponto que Georges Radet entrou em cena. Ele, então diretor da RUM, foi indicado pela maioria de seus colegas como novo doyen, posição da qual ele se utilizará para levar adiante, entre outros projetos, aquele relativo à criação da REA.

Os desdobramentos do Affaire serviram assim para reforçar os laços entre muitos dos futuros membros da equipe da REA, dando-lhes inclusive meios institucionais para garantir as condições de seu desenvolvimento. William Seston, no necrológio de Radet, não deixou de evocar o fato, conquanto se esforçou por silenciar as precondições e as consequências disso. Com efeito, ele se limitou a dizer que:

Em uma época na qual o desenrolar de paixões partidárias torna particularmente difícil as funções que [Radet] assumia, ele deve ter sido escolhido por seus colegas graças à solidez e à elegância de seu ensino, à seu vínculo com o papel de professor sobre o qual ele jamais aceitava brincar, à sua perfeita cortesia, à sua devoção para com seus estudantes e ao seu caráter tão correto que o levava às vezes a ferir laços de amizades antigas (REA, 1941: 4).

Em uma carta datada de novembro de 1898 e endereçada a Celestin Bouglé, Durkheim manifestou opinião diferente sobre a eleição do novo doyen: "Radet é um espírito falso, falso ainda mais que o natural por seu desejo de tornar-se diretor. Oh, ambições! Não é quem tem a atitude a mais [miserável?]. Quem tem o controle é Jullian, não por sua violência, mas pela política" (DURKHEIM, 1975b: 427). 
Ora, se é possível afirmar, como se fez recentemente, que o sucesso do grupo em torno do Année Sociologique está intimamente ligado às relações sociais estabelecidas no seio da elite universitária dreyfusard (MUCCHIELLI, 1998 e 2001), ter-se-ia de admitir que o caso da REA constitui um exemplo na direção oposta. Isso, que por si só põe em questão o poder explicativo da categoria dreyfusard como garantia de sucesso, auxilia uma melhor visualização da ingerência de solidariedades e de concorrências "político-religiosas" no conjunto do sistema universitário. Dentro do campo específico dos estudos greco-latinos, é interessante constatar que a REA se diferencia claramente da REG nesse ponto. Esta contava com renomados dreyfusards entre seus dois diretores e colaboradores principais (Glotz, os irmãos Reinach, Holleaux, Girard). A REA, por seu turno, já deixa transparecer posições muito mais conservadoras, ligadas na maior parte dos casos, como declarou Durkheim à Jullian, a círculos católicos e ao "espírito de corpo". Não por acaso, em contraposição à defesa de valores universalistas dominante no espaço da REG, a REA fez do nacionalismo sua principal bandeira. Uma análise da morfologia da REA e dos processos de recrutamento nela vigentes pode esclarecer algo sobre as causas e os efeitos dessa sua "posição política", bem como sobre a consagração de modelos de trajetória já observáveis entre seus fundadores e sobre certas alianças institucionais e científicas que reforçaram o projeto. É o que se observará a seguir.

\section{PADRÕEs de RECRUTAMENTO}

Ao se acompanhar, entre 1899 e 1920, o recrutamento de colaboradores da REA, distinguem-se certas invariantes, bem como tendências marcantes em determinados períodos específicos. Por certo, para tornar tudo isso inteligível, é preciso atentar não só para as transformações do próprio campo dos estudos greco-latinos, mas também para o impacto de fatores "externos", ou seja, não propriamente universitários.

Quanto ao vínculo institucional, a invariante mais significativa da REA foi o predomínio dos professores de Província em suas fileiras. Nos primeiros anos da revista, a presença de tal grupo chegou a ser muito superior à dos demais. Certamente contribuíram para isso as demandas e rivalidades ligadas à expansão assimétrica (capital/interior) do sistema de ensino francês, bem como o engajamento de uma importante fração dos antiquisants parisienses no Affaire Dreyfus ${ }^{39}$. A seguir, contudo, o cenário vai se diversificando, embora os professores provinciais mantenham-se sempre como a categoria mais representativa. $\mathrm{O}$ arrefecimento das tensões oriundas do Affaire, bem como o avanço das carreiras e dos projetos intelectuais dos indivíduos ligados ao grupo original da REA parecem ter orientado tal fenômeno.

\footnotetext{
${ }^{39}$ Uma primeira análise desse engajamento, ainda bastante precária em função do tratamento e das lacunas de informações, pode ser encontrada em BLANCHET, 2004: 29-48.
} 
Quadro 2.4.4 - Padrões de recrutamento - autores de artigos (REA, 1899-1909) ${ }^{40}$.

\begin{tabular}{|c|c|c|c|c|c|c|c|c|c|c|c|}
\hline $\begin{array}{l}\text { VÍNCULO INSTITUCIONAL DOS AUTORES (articles de } \\
\text { fonds)/ANO }\end{array}$ & 1899 & 1900 & 1901 & 1902 & 1903 & 1904 & 1905 & 1906 & 1907 & 1908 & 1909 \\
\hline Professor do Collège de France (Paris) & $11,11 \%$ & $0 \%$ & $0 \%$ & $0 \%$ & $0 \%$ & $0 \%$ & $5,26 \%$ & $4,55 \%$ & $6,25 \%$ & $4,35 \%$ & $5,88 \%$ \\
\hline Professor das Faculdades de Letras/Direito de Paris & $0 \%$ & $0 \%$ & $0 \%$ & $4,76 \%$ & $0 \%$ & $5,26 \%$ & $0 \%$ & $4,55 \%$ & $6,25 \%$ & $0 \%$ & $5,88 \%$ \\
\hline Professor de Liceu parisiense & $0 \%$ & $0 \%$ & $0 \%$ & $0 \%$ & $0 \%$ & $5,26 \%$ & $0 \%$ & $4,55 \%$ & $0 \%$ & $4,35 \%$ & $5,88 \%$ \\
\hline Professor/pesquisador em Paris (EPHE, ENS, Museus) & $0 \%$ & $10 \%$ & $0 \%$ & $0 \%$ & $0 \%$ & $5,26 \%$ & $0 \%$ & $4,55 \%$ & $3,12 \%$ & $4,35 \%$ & $0 \%$ \\
\hline Professor de Faculdade de Letras/Direito provincial & $55,55 \%$ & $80 \%$ & $100 \%$ & $33,33 \%$ & $60 \%$ & $52,63 \%$ & $47,37 \%$ & $31,82 \%$ & $25 \%$ & $43,48 \%$ & $41,18 \%$ \\
\hline Professor de Liceu de província & $0 \%$ & $0 \%$ & $0 \%$ & $0 \%$ & $0 \%$ & $5,26 \%$ & $0 \%$ & $0 \%$ & $6,25 \%$ & $0 \%$ & $5,88 \%$ \\
\hline Pesquisador sem posto fixo em liceus ou universidades & $0 \%$ & $0 \%$ & $0 \%$ & $4,76 \%$ & $0 \%$ & $0 \%$ & $0 \%$ & $4,55 \%$ & $15,63 \%$ & $4,35 \%$ & $0 \%$ \\
\hline Colaborador francês sem diploma universitário (erudito) & $0 \%$ & $0 \%$ & $0 \%$ & $19,05 \%$ & $26,67 \%$ & $10,53 \%$ & $21,05 \%$ & $18,18 \%$ & $12,5 \%$ & $13,04 \%$ & $11,76 \%$ \\
\hline Colaborador estrangeiro (Alemão) & $0 \%$ & $0 \%$ & $0 \%$ & $4,76 \%$ & $0 \%$ & $0 \%$ & $5,26 \%$ & $0 \%$ & $0 \%$ & $4,35 \%$ & $0 \%$ \\
\hline Colaborador estrangeiro (Britânico) & $0 \%$ & $0 \%$ & $0 \%$ & $4,76 \%$ & $0 \%$ & $0 \%$ & $0 \%$ & $0 \%$ & $0 \%$ & $0 \%$ & $0 \%$ \\
\hline Colaborador estrangeiro (Belga) & $0 \%$ & $0 \%$ & $0 \%$ & $9,52 \%$ & $0 \%$ & $0 \%$ & $5,26 \%$ & $4,55 \%$ & $0 \%$ & $0 \%$ & $0 \%$ \\
\hline Colaborador estrangeiro (Suíço) & $0 \%$ & $0 \%$ & $0 \%$ & $0 \%$ & $0 \%$ & $0 \%$ & $0 \%$ & $0 \%$ & $3,12 \%$ & $13,04 \%$ & $0 \%$ \\
\hline Colaborador estrangeiro (Grego) & $11,11 \%$ & $0 \%$ & $0 \%$ & $4,76 \%$ & $6,67 \%$ & $0 \%$ & $0 \%$ & $9,09 \%$ & $3,12 \%$ & $0 \%$ & $5,88 \%$ \\
\hline Colaborador estrangeiro (Outro) & $0 \%$ & $0 \%$ & $0 \%$ & $0 \%$ & $0 \%$ & $0 \%$ & $0 \%$ & $0 \%$ & $0 \%$ & $0 \%$ & $0 \%$ \\
\hline Colaborador não identificado & $22,22 \%$ & $10 \%$ & $0 \%$ & $14,29 \%$ & $6,67 \%$ & $15,79 \%$ & $15,79 \%$ & $13,63 \%$ & $18,75 \%$ & $8,7 \%$ & $17,65 \%$ \\
\hline Total de colaboradores por ano $(\mathrm{N}=100 \%)$ & 9 & 10 & 8 & 21 & 15 & 19 & 19 & 22 & 32 & 23 & 17 \\
\hline
\end{tabular}

${ }^{40} \mathrm{Na}$ elaboração dos quadros 2.4 .4 e 2.4 .5 desconsiderou-se a quantidade de textos por colaborador. O método adotado consistiu em acompanhar, ano a ano, quem escrevia para a REA e qual era então seu vínculo institucional. Se o vínculo para o ano em questão não pode ser recuperado, preferiu-se então incorporar o autor à categoria "não identificado". Quanto aos "agrégés sem posto em liceus ou universidades", estes podem ser tanto bolsistas do governo francês em formação no exterior quanto especialistas renomados então ocupados com atribuições burocráticas ou políticas. 
Quadro 2.4.5 - Padrões de recrutamento - autores de artigos (REA, 1910-1920).

\begin{tabular}{|c|c|c|c|c|c|c|c|c|c|c|c|}
\hline $\begin{array}{l}\text { VÍNCULO INSTITUCIONAL DOS AUTORES (articles de } \\
\text { fonds)/ANO }\end{array}$ & 1910 & 1911 & 1912 & 1913 & 1914 & 1915 & 1916 & 1917 & 1918 & 1919 & 1920 \\
\hline Professor do Collège de France (Paris) & $3,57 \%$ & $6,45 \%$ & $6,06 \%$ & $7,69 \%$ & $3,33 \%$ & $22,22 \%$ & $20 \%$ & $11,76 \%$ & $9,52 \%$ & $8,70 \%$ & $23,53 \%$ \\
\hline Professor das Faculdades de Letras/Direito de Paris & $0 \%$ & $0 \%$ & $6,06 \%$ & $7,69 \%$ & $0 \%$ & $5,55 \%$ & $5 \%$ & $5,88 \%$ & $9,52 \%$ & $13,04 \%$ & $5,88 \%$ \\
\hline Professor de Liceu parisiense & $0 \%$ & $3,23 \%$ & $3,03 \%$ & $2,56 \%$ & $3,33 \%$ & $0 \%$ & $5 \%$ & $5,88 \%$ & $0 \%$ & $0 \%$ & $0 \%$ \\
\hline Professor/pesquisador em Paris (EPHE, ENS, Museus) & $10,71 \%$ & $6,45 \%$ & $9,09 \%$ & $7,69 \%$ & $10 \%$ & $5,55 \%$ & $5 \%$ & $0 \%$ & $4,76 \%$ & $13,04 \%$ & $11,76 \%$ \\
\hline Professor de Faculdade de Letras/Direito provincial & $28,57 \%$ & $29,03 \%$ & $30,30 \%$ & $41,02 \%$ & $50 \%$ & $27,78 \%$ & $30 \%$ & $35,29 \%$ & $33,33 \%$ & $17,39 \%$ & $29,41 \%$ \\
\hline Professor de Liceu de província & $3,57 \%$ & $3,23 \%$ & $6,06 \%$ & $0 \%$ & $0 \%$ & $0 \%$ & $0 \%$ & $0 \%$ & $4,76 \%$ & $0 \%$ & $5,88 \%$ \\
\hline Pesquisador sem posto fixo em liceus ou universidades & $3,57 \%$ & $3,23 \%$ & $6,06 \%$ & $2,56 \%$ & $10 \%$ & $0 \%$ & $5 \%$ & $5,88 \%$ & $0 \%$ & $0 \%$ & $5,88 \%$ \\
\hline Colaborador francês sem diploma universitário (erudito) & $25 \%$ & $32,26 \%$ & $18,18 \%$ & $7,69 \%$ & $13,33 \%$ & $16,67 \%$ & $10 \%$ & $11,76 \%$ & $9,52 \%$ & $13,04 \%$ & $0 \%$ \\
\hline Colaborador estrangeiro (Alemão) & $0 \%$ & $0 \%$ & $0 \%$ & $0 \%$ & $0 \%$ & $0 \%$ & $0 \%$ & $0 \%$ & $0 \%$ & $0 \%$ & $0 \%$ \\
\hline Colaborador estrangeiro (Britânico) & $0 \%$ & $0 \%$ & $0 \%$ & $0 \%$ & $0 \%$ & $0 \%$ & $0 \%$ & $0 \%$ & $0 \%$ & $0 \%$ & $0 \%$ \\
\hline Colaborador estrangeiro (Belga) & $0 \%$ & $0 \%$ & $0 \%$ & $0 \%$ & $0 \%$ & $0 \%$ & $0 \%$ & $5,88 \%$ & $9,52 \%$ & $0 \%$ & $0 \%$ \\
\hline Colaborador estrangeiro (Suíço) & $3,57 \%$ & $6,45 \%$ & $0 \%$ & $5,13 \%$ & $0 \%$ & $5,55 \%$ & $5 \%$ & $5,88 \%$ & $4,76 \%$ & $4,35 \%$ & $0 \%$ \\
\hline Colaborador estrangeiro (Grego) & $0 \%$ & $0 \%$ & $0 \%$ & $0 \%$ & $0 \%$ & $0 \%$ & $0 \%$ & $0 \%$ & $0 \%$ & $0 \%$ & $0 \%$ \\
\hline Colaborador estrangeiro (Outro) & $0 \%$ & $0 \%$ & $3,03 \%$ & $2,56 \%$ & $3,33 \%$ & $0 \%$ & $0 \%$ & $0 \%$ & $0 \%$ & $4,35 \%$ & $0 \%$ \\
\hline Colaborador não identificado & $17,86 \%$ & $9,68 \%$ & $12,12 \%$ & $15,38 \%$ & $6,67 \%$ & $16,67 \%$ & $15 \%$ & $11,76 \%$ & $14,29 \%$ & $17,39 \%$ & $17,65 \%$ \\
\hline Total de colaboradores por ano $(\mathrm{N}=100 \%)$ & 28 & 31 & 33 & 39 & 30 & 18 & 20 & 17 & 21 & 23 & 17 \\
\hline
\end{tabular}


A categoria "professores de faculdades provinciais" era, contudo, mais heterogênea do que o ato de sua nomeação induz a pensar. Por certo, no interior desse grupo destacavam-se os que orientaram suas carreiras para os estudos greco-latinos. Surgem aí nomes como os de Maurice Holleaux, Paul Perdrizet, Charles Dugas, Henri Lechat, entre outros. Em geral, tratavase de antigos normalianos, agrégés de histoire et géographie, de lettres e, em um grau menor, de grammaire. Os filósofos especialistas na Antiguidade também estiveram presentes, ainda que, sobretudo em função da própria dinâmica da filosofia universitária, a qual os encorajava a publicar nas revistas da área, seu número fosse bastante reduzido ${ }^{41}$. A mesma escassez pode ser constatada entre os estudiosos do direito romano: agrégés de droit e oriundos das Faculdades de Direito, eles se restringiram a Gaston May e a Édouard Cuq.

Mas nem todo professor provincial na REA era um helenista ou um latinista. Em função da interdisciplinaridade típica tanto dos estudos greco-latinos, como das "Antiguidades Nacionais", vários representantes de vanguardas disciplinares encontraram aí acolhida. Entre os linguistas, por exemplo, destacou-se Albert Cuny. Agrégé de grammaire, Cuny defendeu em 1907 uma premiada tese sobre a língua grega orientada por Antoine Meillet. Após sua entrada como Maître de Conférence na Faculdade de Letras de Bordeaux naquele mesmo ano, ele tornou-se um dos colaboradores mais atuantes da REA ${ }^{42}$. Já quanto ao campo dos estudos célticos, participaram da revista dois professores inicialmente instalados em Rennes, Georges Dottin e Joseph Loth. Por fim, cumpre notar que até mesmo a sociologia possuiu aí um representante, Gaston Richard. Sucessor de Émile Durkheim na cadeira de Science Sociale a partir de 1902, ele publicou, antes e depois de sua ruptura com o Année Sociologique, um número significativo de resenhas.

A presença maciça desses professores provinciais é um bom indicador da posição inicialmente marginal da REA no campo das publicações especializadas nos estudos grecolatinos. Aderindo ou não ao discurso contrário ao "culto de Paris", os integrantes desse grupo encontraram na revista um fórum receptivo aos seus trabalhos, espaço tanto mais atraente quanto mais livre da disputa com os grandes expoentes (parisienses) de suas respectivas áreas. Muitos eram simplesmente jovens quando escreveram para a REA e, até como um plano de ascensão de carreira, buscaram também atuar junto à mais prestigiada e tradicional REG. Maurice Holleaux, Pierre Roussel e Jérôme Carcopino podem ser apontados como modelos

\footnotetext{
${ }^{41}$ A despeito da tímida adesão, nomes de peso como Émile Bréhier e Georges Rodier escreveram à REA. Quanto à situação específica da filosofia na virada do século, cf. FABIANI, 1988: 73-101.

42 Em 22 de dezembro de 1907, Cuny escreveu a Meillet dizendo que estava "incrivelmente só" em Bordeaux. Ainda assim, na mesma carta, mencionou que encontrou receptividade da parte do diretor da REA: "eu falei com o diretor [Radet] de meu projeto (que é o vosso). Está acertado que eu farei um artigo que, se não for longo demais, aparecerá no próximo número da REA". Cf. arquivos do IMEC-Caen, Fond Meillet, pasta ML 12.59 .
} 
nessa direção ${ }^{43}$. Outro caso típico é o daqueles que, carentes de credenciais acadêmicas, ou apenas afinados com um projeto não ortodoxo de carreira, buscaram fortalecer suas posições a partir de uma adesão quase incondicional à REA, cujo autonomia e reputação se consolidavam rapidamente. Helenistas, latinistas e entusiastas das "Antiguidades Nacionais" tais como Auguste Audollent, Octave Navarre e Paul Courteault, sem mencionar os próprios idealizadores da revista, dedicaram muito pouco de suas energias às demais publicações da área ${ }^{44}$.

Um segundo importante grupo de colaboradores é o dos professores parisienses. Vêse, acompanhando os quadro acima apresentados, que a REA jamais se furtou, ao contrário do que uma leitura apressada de seu projeto intelectual levaria a supor, a contar com textos de simpatizantes instalados na Capital. O aumento significativo dessas pessoas ao longo dos anos deve ser tomado, aliás, como emblema da consolidação institucional e científica da revista.

Difícil não destacar a ida de Jullian ao Collège de France em 1905 como um marco divisório para explicar o crescimento desse número. Até então, somente cinco "parisienses" haviam aderido a REA, cada qual com apenas um artigo: Paul Foucart (professor no Collège de France), Paul Giraud (professor na Sorbonne), René Pichon (professor no liceu Henry IV), Edmond Pottier e Salomon Reinach (respectivamente, os conservadores do Musée du Louvre e do Musée des Antiquités Nationales) ${ }^{45}$. No pós-1906, o percentual da participação desse grupo

\footnotetext{
${ }^{43}$ Entre 1899 e 1920, Holleaux publicou 12 artigos na REA e 12 na REG; Roussel, 4 e 3; e, por fim, Carcopino, 1 e 1.

${ }^{44}$ Para ficarmos somente com os exemplos enumerados, considerando apenas o período aqui trabalhado: Auguste Audollent publicou 4 artigos na REA e 0 na REG; Octave Navarre, 10 e 1; e, por fim, Paul Courteault, 9 e 0. Quanto aos fundadores da REA, veja-se a tabela 2.

${ }^{45}$ A presença desses antiquisants específicos permite recuperar algumas facetas da então recémfundada publicação. Quanto a Foucart, ele havia sido o diretor de Clerc, Paris e Radet na École Française $d^{\prime}$ Athènes. O vínculo entre eles se manteve e tornou-se mesmo mais intenso por ocasião da candidatura de Georges Foucart, filho de Paul, à cadeira de Antiquités Orientales na Faculdade de Letras de Bordeaux (1898). Tal episódio marcou um primeiro embate entre o grupo da REA e os sociólogos próximos a Durkheim. Estes apoiavam o nome de Isidore Lévy para a vaga. Em março de 1898, Durkheim escreveu a seu sobrinho: “O curso será criado aparentemente com o nome de 'Antiquités orientales'. Que ele [Lévy] veja se deve se apresentar. Isto não faria nenhum mal a ele e poderia o inserir no futuro no caso da cadeira tornar-se vacante. [Paul] Foucart encontrará bem um meio de chamar seu filho a Paris. Pessoalmente, eu creio que vou me abster de votar, jusfiticando minha abstenção oralmente. E esta é a única atitude que me parece correta. Aqueles dentre os nossos colegas que deveriam nos esclarecer sobre o valor dos candidatos estão, eles já o admitiram para mim, engajados a votar por Foucart independente do concorrente. Nesses condições, como eu não posso ter uma opinião esclarecida, irei abster-me muito provavelmente. Uma outra razão para esta atitude é que, se eu votasse por I. Lévy, o qual não teria mais que alguns votos de nossos amigos, isto o atrapalhará mais do que lhe será útil: nós daríamos a impressão de responder ao nepotismo de Foucart com semitismo." (DURKHEIM, 1998: 117). Ao comentar o mesmo episódio, Mauss escreveu a Hubert enfatizando o lobby dos antigos membros da École Française d'Athènes: "Os atenienses são terrivelmente fortes. Não me parece que se possa
} 
raramente cai abaixo dos 15\%, tornando-se ainda maior com o início da Primeira Guerra. Nesse ínterim, destacam-se o próprio Jullian e seu círculo no Collège de France (René Cagnat, da cadeira de Épigraphie et Antiquités Latines; Louis Havet, de Philologie Latine; bem como Joseph Loth, de Langue et Littérature Celtiques). Maurice Holleaux, o qual, após longos anos nas faculdades provinciais, obteve em 1912 um posto na Sorbonne, foi também um colaborador regular. Outro nome que se sobressai é o de um latinista reconvertido às "Antiguidades Nacionais", Jules Toutain, maître de conférence na EPHE. Por fim, até mesmo os grandes nomes da REG se fizeram aí presentes, embora com participação tardia e discreta ${ }^{46}$.

Um terceiro grupo que, como o dos "parisienses", pode ser tomado como indício do prestígio da publicação é o dos colaboradores não franceses. Ainda assim, é preciso considerar a existência de diferentes modalidades de estrangeiros. Ao contrário da REG, cuja posição dominante no campo das revistas especializadas nos estudos greco-latinos tendia a priori a atrair a elite do helenismo europeu, a recém-fundada REA precisou construir aos poucos uma rede de colaboradores a partir dos contatos de seus fundadores. É sintomático que o estrangeiro a publicar o maior número de textos nos primeiros anos da revista tenha sido Aristote Fontrier, com o qual Radet e Paris haviam travado contato durante seus estágios em Atenas. Comerciante e arqueólogo amador nascido na Ásia Menor, Fontrier passava por um correspondente menor do $\mathrm{BCH}$, onde costumava divulgar material epigráfico. Ele jamais publicou na REG e estava longe de ter o mesmo estatuto de um Panagiotis Cavvadias ou de um Andréa Andréadès, professores universitários gregos. Na REA, Fontrier manteve-se como informante de inscrições inéditas e essa sua participação foi celebrada por ocasião de sua morte (cf. REA, 1907: 376-380). Além dele, estiveram presentes pesquisadores mais ou menos ilustres como Hermann Dessau, Berhendt Pick e Philippe Boissevan, todos contatos estabelecidos por Camille Jullian em seus estágios na Itália e na Alemanha, ou o Marquês de Cerralbo, arqueólogo espanhol próximo a Pierre Paris.

impedir o Foucart, saudado por todos, de chegar lá" (arquivos do IMEC-Caen, Fond Mauss-Hubert, pasta MAS 6.37, carta de 1897, sublinhado no original).

A presença de Reinach e Pottier se explica em outros termos. Ambos compartilhavam com os membros da REA tanto a formação de antiquisant (os dois eram antigos membros da École Française d'Athènes) quanto o posterior interesse na arqueologia e na história da Gália. Isso não significou, contudo, que suas opiniões políticas e intelectuais coincidissem. Os dois eram, além disso, muito mais ligados à REG, dirigindo também a Revue Archéologique.

Por fim, quanto a Paul Giraud, helenista especialista na história econômica da Grécia Antiga, ele publicou na REA um único texto discutindo as propriedades fundiárias em Roma, tema que a REG apenas marginalmente abordaria (REA, 1904: 221-255). E que dizer de Pichon: dominado entre os dominantes?

${ }^{46}$ Assim, por exemplo, Théodore Reinach e Gustave Glotz publicaram na REA, entre 1899 e 1920, 4 e 1 artigos respectivamente. Cf., em ordem cronológica, REA, 1906: 125-126; 1907: 1-5; 1914: 133-159; 1917: 32; 1920: 105-106. 
Com o passar dos anos, contudo, pode-se notar a padronização da presença de não franceses na REA e na REG. Isso não significa, por certo, a ausência de especificidades: a REG continuou monopolizando os grandes letrados gregos, ao passo que a REA atraía aqueles interessados na arqueologia e na história das "regiões meridionais" (o já mencionado Marques de Cerralbo, ou alguém como o padre alemão Hugo Obermaier). Em todo caso, o sub grupo que mais se destaca é aquele oriundo de países com regiões francófonas, sobretudo da Bélgica e da Suíça. Franz Cumont, professor na Universidade de Gand, e Waldemar Deonna, diretor do Musée d'Art et d'Histoire de Genebra, estiveram entre os maiores colaboradores (tanto no volume quanto na importância de artigos publicados) das duas revistas. Difícil não considerar o acirramento das tensões entre Alemanha e França, cada qual ciosa em manter também uma zona de influência letrada, como um dos elementos capazes de explicar tal propensão.

Chega-se, por fim, a um derradeiro grupo significativo no interior da REA. Comparando-se os quadros 4 e 5 com o de número 3, é possível traçar um paralelo entre a diversificação morfológica da REA e a expansão da seção de artigos intitulada "Antiguidades Nacionais". A partir de 1902, isso deu ensejo ao aparecimento de uma nova categoria de colaboradores, a dos "eruditos".

Desprovidos dos títulos indispensáveis para seguir carreira nas Faculdades de Letras (a agrégation e o doutorado), eles provinham em geral das elites provinciais, as quais patrocinavam, por meio de sociedades literárias e arqueológicas, estudos (pré-)históricos. É o caso, por exemplo, de Henri Ferrand. Advogado, mas também fotógrafo e alpinista, Ferrand foi membro de instituições como a Société des Touristes du Dauphiné, a Société Dauphinoise des Amateurs photographes e a Société d'Études des Hautes-Alpes. Na REA, ele discutiu sobretudo as prováveis rotas de Aníbal em sua travessia dos Alpes. Charles Dangibeaud enquadra-se na mesma categoria. Jurista da região de Chartres e conservador do museu local, seus interesses giravam em torno da arqueologia galo-romana. E os exemplos poderiam ser ainda multiplicados: Jules Momméja (conservador do Museu de Agen), Joseph Sautel (padre versado no estudo arqueológico da região de Avignon), Julien de Saint-Venant (membro da Société des Antiquaires du Centre), entre outros.

Esse grupo transformou-se rapidamente em uma marca distintiva da REA. Mesmo uma publicação como a Revue Archéologique, a qual dialogava com os "eruditos" quando se tratava de temas galo-romanos, hierarquizava suas contribuições. Com poucas exceções, os nãoacadêmicos tinham nela à sua disposição apenas um pequeno espaço de notas na seção Variétés. E o que dizer do $\mathrm{BCH}$, do $\mathrm{MAH}$ e da REG? Por razões que remetem ao próprio lugar institucional dessas revistas, colaboradores similares eram muito raros. Na REA, contudo, os 
nomes desses eruditos figuravam ao lado dos de antigos normalianos, doutores e professores de universidades e de liceus, o que não se revelou uma má estratégia. Com efeito, os vínculos entre as sociedades regionais e a produção científica haviam sido consideráveis ao longo da história da França e o processo de autonomização da Universidade não estava em condições de cortar todos esses laços, embora pudesse enfraquecê-los e os marginalizar (cf. THIESSE, 1991 e REVEL, 1989: 159-180). Some-se a isso o fato desses provinciais disporem de recursos consideráveis, os quais, se bem canalizados, poderiam servir aos propósitos da REA.

\section{JOSEPH DÉCHELETTE (1862-1914), UM “ERUDITO EXCEPCIONAL” A SERVIÇO DA REA}

Nascido na Roanne de 1862, no seio de uma próspera família burguesa envolvida com a produção textil desde o século XVII, Joseph Déchelette alcançou ao final da vida, sem passar pela Universidade, o reconhecimento unânime de sua competência como arqueólogo.

Caçula de seis filhos, dentre os quais três eram homens, ele foi educado em um colégio Marista, saindo de lá para atuar na firma familiar. Com efeito, a notável extensão dessa empresa e a morte de seu pai em 1888 tornavam imperativa sua presença nos negócios. Desse modo, Déchelette dedicou a maior parte de sua vida à administração de fábricas, bem como a viagens comerciais, dentro e fora da Europa.

O contato e o fascínio com a arqueologia vieram ao final de sua juventude. Em 1884, sob a influência de um tio, Jacques-Gabriel Bulliot, ele foi aceito como membro da Diana, uma associação que até hoje organiza escavações no interior da França. Lá, em um ambiente repleto de aristocratas, padres e burgueses provinciais, ele travou contato com alguns dos maiores expoentes da arqueologia regional, bem como encontrou uma companheira, Jane Bonnier.

Com o passar do tempo, Joseph Déchelette foi direcionando cada vez mais recursos (tempo e dinheiro) para seus empreendimentos científicos. Oito anos após o ingresso na Diana, ele foi nomeado conservador no Museu de Roanne (1892) e, na sequncia, tratou de investir na melhoria da sede e das coleções desta instituição. Vez por outra, conseguiu também se ausentar do trabalho ordinário nos negócios para conhecer os grandes museus e estagiar junto aos mais renomados especialistas europeus.

No início do novo século seu prestígio já estava suficientemente consolidado para que um editor parisiense (Picard), por intermédio de Salomon Reinach, lhe encomendasse um manual de arqueologia. O primeiro volume dessa obra só foi publicado, contudo, no momento em que Déchelette conseguiu delegar a outros suas responsabilidades familiares (1908). Morto nas trincheiras em 1914, ele não teve tempo de a terminar, o que não o impediu de obter o título prestigioso de correspondente da Académie des Inscriptions et Belles-Lettres já em 1911.

$\mathrm{Na}$ REA, onde publicou seis artigos de 1903 a 1912, seu nome esteve ligado ao projeto das "Antiguidades Nacionais". Erudito incomum, ele não foi simplesmente esquecido após a morte: o próprio Jullian incumbiu um de seus alunos, Albert Grenier, da tarefas de revisar e de concluir os manuscritos não publicados do autor. 
Uma vez obtida tal visão de conjunto dos vínculos institucionais dos colaboradores da REA, cumpre agora aprofundar o estudo morfológico da revista a partir da análise das pessoas que mais publicaram nela - ou seja, os mais determinantes para emprestar-lhe um perfil. Nos quadros inseridos nas próximas páginas, pode-se acompanhar em três diferentes intervalos (1899-1906, 1907-1913 e 1914-1920) quem são esses indivíduos, bem como detalhes sobre suas trajetórias acadêmicas, filiação religiosa, atuação política e background familiar.

Quanto ao primeiro intervalo, o qual justamente compreende tanto o auge e a resolução jurídica do Affaire Dreyfus quanto a ascensão institucional dos membros da REA, chama atenção o predomínio de colaboradores católicos, antidreyfusards e instalados na Província. Protestantes estão presentes em posições de destaque, mas não há aí nenhum dos antiquisants judeus habitués da REG, nem professores/pesquisadores instalados em Paris (à exceção do Camille Jullian pós-1905). Outros dados significativos vêm dos seguintes fatos: alguns "eruditos" aparecem desde já bastante integrados ao projeto da revista e, como já mencionado, o único estrangeiro entre os maiores colaboradores foi Aristote Fontrier.

No período seguinte, os anos que antecedem a Primeira Grande Guerra, o padrão delineado anteriormente mantém seus contornos mais gerais. Por certo, aparecem novos nomes, bem como evoluem os vínculos institucionais dos antigos (via, sobretudo, a Académie des Inscriptions et Belles-Lettres). Ainda assim, continuam ausentes os universitários judeus e, desconsiderando-se Jullian, os professores da capital. Mais uma vez é possível ver "eruditos" entre os maiores colaboradores e também um estrangeiro, Waldemar Deonna, o conservador de um dos mais importantes museus suíços.

Mudanças significativas aparecem, no entanto, durante os anos de Guerra. Privados dos mais jovens professores, mobilizados no conflito, há um sensível envelhecimento dos autores. Isso, associado aos trunfos já consolidados da revista, fez com que o número de "parisienses" aumentasse significativamente: eles passam agora a ser três dos nove autores mencionados (quatro se considerarmos que Bréhier é transferido de Bordeaux para a Sorbonne em 1919). Os outros são nomes ou de antigos colaboradores (de la Ville de Mirmont, Clerc e Cuny), ou de estrangeiros (Waldemar Deonna e Franz Cumont). Judeus, contudo, continuam ausentes, assim como desaparecem da lista os eruditos (o que não significa que eles desapareçam da revista).

Tendo em vista tais peculiaridades morfológicas, pode-se compreender melhor a posição muito particular que a REA ocupou no campo das publicações especializadas nos estudos greco-latinos. Ao contrário do $\mathrm{BCH}$ e do $\mathrm{MAH}$, cuja existência dependia das atividades de jovens agrégés e dos diretores das École Française d'Athènes e de Rome, a REA era uma 
Quadro 2.4.6 - REA - 1899-1906. Frequência de publicação, trajetória pessoal e institucional.

\begin{tabular}{|c|c|c|c|c|c|c|c|c|}
\hline NOME & $\begin{array}{l}\text { ARTIGOS } \\
(\mathrm{N})\end{array}$ & $\begin{array}{c}\text { ARTIGOS } \\
(\%)\end{array}$ & ESTUDOS & AGREGAÇÃO & CARGOS E TÍTULOS ACADÊMICOS & $\begin{array}{l}\text { FILIAÇÃO } \\
\text { RELIGIOSA }\end{array}$ & $\begin{array}{l}\text { AFFAIRE } \\
\text { DREYFUS }\end{array}$ & $\begin{array}{l}\text { BACKGROUND } \\
\text { FAMILIAR }\end{array}$ \\
\hline $\begin{array}{l}\text { Camille } \\
\text { JULLIAN }\end{array}$ & 29 & $18,0 \%$ & $\begin{array}{l}\text { Ens-lettres } \\
\text { (prom. 1877- } \\
\left.15^{\text {eme }}\right)\end{array}$ & $\begin{array}{l}\text { Hist/géo (1880- } \\
\text { 1er) }\end{array}$ & $\begin{array}{l}\text { Membro da École Française de Rome (1880-2). } \\
\text { Bolsista na Alemanha (1882-3) Docteur-es-lettres (1884). } \\
\text { Chargé de cours e, mais tarde, professeur na Faculté de Lettres de } \\
\text { Bordeaux (1883-1904) Membro da Académie de Bordeaux (1888). } \\
\text { Correspondente da Académie des Inscriptions (1897). } \\
\text { Professor no Collège de France (1904). }\end{array}$ & Protestante & & $\begin{array}{l}\text { De Marselha. } \\
\text { Pai banqueiro. Mãe filha } \\
\text { de proprietários. } \\
\text { Esposa filha de professor } \\
\text { de Medicina de } \\
\text { Bordeaux. }\end{array}$ \\
\hline $\begin{array}{c}\text { Paul } \\
\text { PERDRIZET }\end{array}$ & 10 & $6,2 \%$ & $\begin{array}{l}\text { Ens-lettres } \\
\text { (prom. 1890- } \\
1^{\mathrm{er}} \text { ) }\end{array}$ & $\begin{array}{l}\text { Lettres (1893- } \\
\text { 12ème) }\end{array}$ & $\begin{array}{l}\text { Membro da École Française d’Athènes (1894-1897). } \\
\text { Maître de Conférence na Faculté de Lettres de Nancy (1899). }\end{array}$ & Protestante & & $\begin{array}{l}\text { De Montbéliard. } \\
\text { Pai professor de colégio. } \\
\text { Avô paterno pastor. }\end{array}$ \\
\hline $\begin{array}{l}\text { Georges } \\
\text { GASSIES }\end{array}$ & 10 & $6,2 \%$ & & & $\begin{array}{l}\text { Vice-presidente da Société Historique et Littéraire de la Brie } \\
\text { (1897). }\end{array}$ & & & $\begin{array}{l}\text { De Meaux. Arqueólogo e } \\
\text { literato local. }\end{array}$ \\
\hline $\begin{array}{l}\text { Phillipe- } \\
\text { Ernest } \\
\text { LEGRAND }\end{array}$ & 6 & $3,7 \%$ & $\begin{array}{l}\text { Ens-lettres } \\
\text { (prom. 1885- } \\
8^{\text {eme }} \text { ) }\end{array}$ & Lettres $\left(1888-1^{\mathrm{er}}\right)$ & $\begin{array}{l}\text { Membro da École Française d'Athènes (1888-90). } \\
\text { Maître de conférence e, depois, professeur na Faculté de Lettres } \\
\text { de Lyon (1894). Docteur-es-lettres (1899). }\end{array}$ & & & De Sainte-Doulchard \\
\hline $\begin{array}{l}\text { Henri de } \\
\text { LA VILLE DE } \\
\text { MIRMONT } \\
\end{array}$ & 6 & $3,7 \%$ & $\begin{array}{c}\text { Ens-lettres } \\
\text { (prom. 1877- } \\
\left.19^{\text {eme }}\right) \\
\end{array}$ & $\begin{array}{l}\text { Lettres }(1880- \\
\left.5^{\text {eme }}\right)\end{array}$ & $\begin{array}{l}\text { Professeur no Lycée de Pau (1880). } \\
\text { Maître de conférence e, mais tarde, professeur na Faculté de } \\
\text { Lettres de Bordeaux (1883). Docteur-ès-lettres (1903). }\end{array}$ & Católico & $\begin{array}{l}\text { Antidreyfusard } \\
\text { (Affaire Stapfer) }\end{array}$ & $\begin{array}{l}\text { De Bordeaux. Membro } \\
\text { de família nobre. Político } \\
\text { local. Esposa escritora. }\end{array}$ \\
\hline $\begin{array}{l}\text { Georges } \\
\text { RADET }\end{array}$ & 5 & $3,1 \%$ & $\begin{array}{l}\text { Ens-lettres } \\
\text { (prom. . 1881- } \\
14^{\text {eme }} \text { ) }\end{array}$ & Hist/géo (1884- ?) & $\begin{array}{l}\text { Membro da École Française d'Athènes (1884-7). } \\
\text { Professeur no Lycée d'Alger (1887). } \\
\text { Maître de conférence e, mais tarde, professeur na Faculté de } \\
\text { Lettres de Bordeaux (1888). } \\
\text { Docteur-ès-lettres (1893) e diretor da REA (1899). } \\
\text { Doyen (diretor) da Faculté de Lettres de Bordeaux (1899). } \\
\text { Correspondant da Académie des Inscriptions (1904). }\end{array}$ & Católico & $\begin{array}{l}\text { Antidreyfusard } \\
\text { (Affaire Stapfer) }\end{array}$ & $\begin{array}{l}\text { De Chesley. Pai pequeno } \\
\text { funcionário de província } \\
\text { ('receveur de postes'). }\end{array}$ \\
\hline $\begin{array}{l}\text { Aristote } \\
\text { FONTRIER }\end{array}$ & 5 & $3,1 \%$ & & & & Ortodoxo & & $\begin{array}{l}\text { De Ismirna (Turquia). } \\
\text { Negociante. Arqueólogo } \\
\text { e historiador amador. }\end{array}$ \\
\hline $\begin{array}{l}\text { Pierre } \\
\text { PARIS }\end{array}$ & 4 & $2,5 \%$ & $\begin{array}{l}\text { Ens-lettres } \\
\text { (prom. 1879- } \\
21^{\text {eme }} \text { ) }\end{array}$ & $\begin{array}{l}\text { Lettres }(1882- \\
\left.10^{\text {eme }}\right)\end{array}$ & $\begin{array}{l}\text { Membro da École Française d'Athènes (1882-5). } \\
\text { Maître de conférence e, mais tarde, professeur na Faculté de } \\
\text { Lettres de Bordeaux (1885). } \\
\text { Diretor da École des Beaux-Arts de Bordeaux (1898). }\end{array}$ & Católico & $\begin{array}{l}\text { Antidreyfusard } \\
\text { (Affaire Stapfer) }\end{array}$ & De Rodez. \\
\hline $\begin{array}{c}\text { Paul } \\
\text { MASQUERAY }\end{array}$ & 4 & $2,5 \%$ & Sorbonne & $\begin{array}{c}\text { Grammaire (1887- } \\
\left.3^{\text {eme }}\right)\end{array}$ & $\begin{array}{l}\text { Docteur-ès-lettres (1895). } \\
\text { Professor na Faculté de Lettres de Bordeaux (1891). }\end{array}$ & Católico & & De Rouen. \\
\hline $\begin{array}{l}\text { Charles } \\
\text { DANGIBEAUD }\end{array}$ & 4 & $2,5 \%$ & & & $\begin{array}{l}\text { Secretário e tesoureiro da Société des Archives Historiques de la } \\
\text { Saintonge et de l'Aunis (1876). Conservador do Museu de Saintes } \\
\text { (1885). Associé correspondant national de la Société Nationale des } \\
\text { Antiquaires de France (1887). Conservador do Musée } \\
\text { archéologique (1903). Bibliotecário de Saintes (1905). }\end{array}$ & Católico & & $\begin{array}{l}\text { De Chartres. Família de } \\
\text { juristas e militares da } \\
\text { região de Saintes. } \\
\text { Arqueólogo e } \\
\text { historiador local. } \\
\end{array}$ \\
\hline
\end{tabular}


Quadro 2.4.7 - REA - 1907-1913. Frequência de publicação, trajetória pessoal e institucional.

\begin{tabular}{|c|c|c|c|c|c|c|c|c|}
\hline NOME & $\begin{array}{l}\text { ARTIGOS } \\
\text { (N) }\end{array}$ & $\begin{array}{l}\text { ARTIGOS } \\
(\%)\end{array}$ & ESTUDOS & AGRÉGATION & CARGOS E TÍTULOS ACADÊMICOS & $\begin{array}{l}\text { FILIAÇÃO } \\
\text { RELIGIOSA }\end{array}$ & $\begin{array}{l}\text { AFFAIRE } \\
\text { DREYFUS }\end{array}$ & $\begin{array}{l}\text { BACKGROUND } \\
\text { FAMILIAR }\end{array}$ \\
\hline $\begin{array}{l}\text { Camille } \\
\text { JULLIAN }\end{array}$ & 24 & $9,9 \%$ & $\begin{array}{l}\text { Ens-lettres } \\
\text { (prom. . 1877- } \\
15^{\text {eme }} \text { ) }\end{array}$ & $\begin{array}{l}\text { Hist/géo (1880- } \\
\text { 1er) }\end{array}$ & $\begin{array}{l}\text { Membro da École Française de Rome (1880-2). } \\
\text { Bolsista na Alemanha (1882-3). Docteur-es-lettres (1884). } \\
\text { Chargé de cours e, depois, professeur na Faculté de Lettres de } \\
\text { Bordeaux (1883-1904). Membro da Académie de Bordeaux (1888). } \\
\text { Professeur no Collège de France (1904). } \\
\text { Membro da Académie des Inscriptions (1908). }\end{array}$ & Protestante & & $\begin{array}{l}\text { De Marselha. } \\
\text { Pai banqueiro. Mãe filha } \\
\text { de proprietários. } \\
\text { Esposa filha de professor } \\
\text { de Medicina de } \\
\text { Bordeaux. } \\
\end{array}$ \\
\hline $\begin{array}{l}\text { Albert } \\
\text { CUNY } \\
\end{array}$ & 12 & $4,9 \%$ & $\begin{array}{l}\text { EPHE/Fac. de } \\
\text { Lettres-Paris }\end{array}$ & $\begin{array}{l}\text { Grammaire } \\
\left(1901-8^{\text {eme }}\right)\end{array}$ & $\begin{array}{l}\text { Maître de Conférences e, depois, professeur na Faculté des Lettres } \\
\text { de Bordeaux (1907) Docteur-ès-lettres (1907). }\end{array}$ & & & \\
\hline $\begin{array}{l}\text { Georges } \\
\text { RADET }\end{array}$ & 8 & $3,3 \%$ & $\begin{array}{l}\text { Ens-lettres } \\
\text { (prom. } 1881- \\
14^{\text {eme }} \text { ) }\end{array}$ & Hist/géo (1884- ?) & $\begin{array}{l}\text { Membro da École Française d'Athènes (1884-7). Professeur no } \\
\text { Lycée d'Alger (1887). Maître de conférence e, depois, professeur } \\
\text { na Faculté de Lettres de Bordeaux (1888). Docteur-ès-lettres } \\
\text { (1893). Doyen na Faculté de Lettres de Bordeaux (1899). }\end{array}$ & Católico & $\begin{array}{l}\text { Anti-dreyfusard } \\
\text { (Affaire Stapfer) }\end{array}$ & $\begin{array}{l}\text { De Chesley. Pai pequeno } \\
\text { funcionário de província } \\
\text { ('receveur de postes'). }\end{array}$ \\
\hline $\begin{array}{l}\text { Henri } \\
\text { LECHAT }\end{array}$ & 7 & $2,9 \%$ & $\begin{array}{l}\text { Ens-lettres } \\
\text { (prom. 1883- } \\
\text { ?) }\end{array}$ & Lettres (1886- ?) & $\begin{array}{l}\text { Membro da Ecole Française d'Athènes (1886-9). Charge de cours } \\
\text { na Faculté des lettres de Montpellier (1889-98). Professeur na } \\
\text { Faculté de Lettres de Lyon (1898). Correspondente da Académie } \\
\text { des Inscriptions (1906). }\end{array}$ & Católico & & De Langives-le-Forges. \\
\hline $\begin{array}{c}\text { Paul } \\
\text { COURTEAULT } \\
\end{array}$ & 7 & $2,9 \%$ & $\begin{array}{l}\text { Ens-lettres } \\
\text { (prom. 1887) }\end{array}$ & $\begin{array}{l}\text { Lettres (1890- } \\
6^{\text {eme }}\end{array}$ & $\begin{array}{l}\text { Chargé de cours e, depois, professeur na Faculté de Lettres de } \\
\text { Bordeaux (1905-?). }\end{array}$ & & & \\
\hline $\begin{array}{l}\text { Michel } \\
\text { CLERC }\end{array}$ & 7 & $2,9 \%$ & $\begin{array}{l}\text { Ens-lettres } \\
\text { (prom. 1877- } \\
3^{\text {eme }} \text { ) }\end{array}$ & $\begin{array}{l}\text { Hist/géo } \\
\left(1880-3^{\text {ème }}\right)\end{array}$ & $\begin{array}{l}\text { Membro da École française d'Athènes (1880-3). Maître de } \\
\text { conférence e, depois, professeur na Fac. des lettres d'Aix (1883) } \\
\text { Docteur-ès-lettres (1893). Conservador do Musée Bórely (1895) } \\
\text { Correspondente da Académie des Inscriptions (1909). }\end{array}$ & Católico & & De Salôn-sur-Saone. \\
\hline $\begin{array}{c}\text { Octave } \\
\text { NAVARRE } \\
\end{array}$ & 5 & $2,1 \%$ & & $\begin{array}{c}\text { Lettres (1887- } \\
\left.7^{\text {ème}}\right)\end{array}$ & $\begin{array}{l}\text { Maître de conférences e, depois, professeur à la Faculté des lettres } \\
\text { de Toulouse (1896). Docteur-ès-lettres (1900). }\end{array}$ & & & De Lessay. \\
\hline $\begin{array}{l}\text { Phillipe-Ernest } \\
\text { LEGRAND }\end{array}$ & 5 & $2,1 \%$ & $\begin{array}{l}\text { Ens-lettres } \\
\text { (prom. 1885- } \\
8^{\text {eme }} \text { ) }\end{array}$ & Lettres $\left(1888-1^{\mathrm{er}}\right)$ & $\begin{array}{l}\text { Membro da École Française d'Athènes (1888-90). Maître de conf. } \\
\text { e, depois, professeur na Faculté de Lettres de Lyon (1894). } \\
\text { Docteur-es-lettres (1899). }\end{array}$ & & & De Sainte-Doulchard \\
\hline $\begin{array}{l}\text { Henri } \\
\text { FERRAND }\end{array}$ & 5 & $2,1 \%$ & & & $\begin{array}{l}\text { Membro da Société d'Etudes des Hautes-Alpes (1893). } \\
\text { Membro da Société Dauphinoise des Amateurs photographes (?). } \\
\text { Membro da Société des Touristes du Dauphiné (?). } \\
\text { Presidente do Comité de protections des Sites Pittoresques (?). }\end{array}$ & & & $\begin{array}{l}\text { Pai médico. Advogado. } \\
\text { Fotógrafo, alpinista e } \\
\text { geógrafo local. }\end{array}$ \\
\hline $\begin{array}{l}\text { Georges } \\
\text { DOTTIN } \\
\end{array}$ & 5 & $2,1 \%$ & $\begin{array}{l}\text { Fac. de lettres } \\
\text { Rennes/Paris }\end{array}$ & $\begin{array}{c}\text { Grammaire (1890- } \\
\left.11^{\text {eme }}\right)\end{array}$ & $\begin{array}{l}\text { Docteur-ès-lettres (?). Professeur na Faculté de Lettres de Rennes } \\
\text { (1897). Doyen da Faculté de Lettres de Rennes (1910). }\end{array}$ & & & 'Gauche radicale' \\
\hline $\begin{array}{l}\text { Waldemar } \\
\text { DEONNA }\end{array}$ & 5 & $2,1 \%$ & & & $\begin{array}{l}\text { Membro estrangeiro na École Française d'Athènes (1903-7). } \\
\text { Conservador no Musée de Génève (?). }\end{array}$ & & & $\begin{array}{c}\text { (Suiço) } \\
\text { Pai diplomata. }\end{array}$ \\
\hline $\begin{array}{c}\text { Joseph } \\
\text { DÉCHELETTE }\end{array}$ & 5 & $2,1 \%$ & & & $\begin{array}{l}\text { Membro da Diana (1888). Conservador do Musée de Roanne } \\
\text { (1892). Membro da Société des Antiquaires (1893). } \\
\text { Correspondente da Académie des Inscriptions (1911). }\end{array}$ & Católico & & $\begin{array}{l}\text { De Roanne. Família do } \\
\text { ramo da indústria têxtil. } \\
\text { Arqueólogo. }\end{array}$ \\
\hline
\end{tabular}


Quadro 2.4.8 - REA - 1914-1920. Frequência de publicação, trajetória pessoal e institucional.

\begin{tabular}{|c|c|c|c|c|c|c|c|c|}
\hline NOME & $\begin{array}{l}\text { ARTIGOS } \\
\text { (N) }\end{array}$ & $\begin{array}{l}\text { ARTIGOS } \\
(\%)\end{array}$ & ESTUDOS & AGRÉGATION & CARGOS E TÍTULOS ACADÊMICOS & $\begin{array}{l}\text { FILIAÇÃO } \\
\text { RELIGIOSA }\end{array}$ & $\begin{array}{l}\text { AFFAIRE } \\
\text { DREYFUS }\end{array}$ & $\begin{array}{l}\text { BACKGROUND } \\
\text { FAMILIAR }\end{array}$ \\
\hline $\begin{array}{l}\text { Camille } \\
\text { JULLIAN }\end{array}$ & 17 & $9,8 \%$ & $\begin{array}{l}\text { Ens-lettres } \\
\text { (prom. } 1877- \\
15^{\text {eme }} \text { ) }\end{array}$ & $\begin{array}{l}\text { Hist/géo (1880- } \\
\text { 1er) }\end{array}$ & $\begin{array}{l}\text { Membro da École Française de Rome (1880-2). Bolsista na } \\
\text { Allemagne (1882-3) Docteur-es-lettres (1884). Chargé de cours e, } \\
\text { depois, professeur na Faculté de Lettres de Bordeaux (1883-1904). } \\
\text { Membro da Académie de Bordeaux (1888). Professeur no Collège } \\
\text { de France (1904). Membro da Académie des Inscriptions (1908). }\end{array}$ & Protestante & & $\begin{array}{l}\text { De Marselha. Pai } \\
\text { banqueiro. Mãe filha de } \\
\text { proprietários. Esposa } \\
\text { filha de professor de } \\
\text { Medicina de Bordeaux. }\end{array}$ \\
\hline $\begin{array}{l}\text { Michel } \\
\text { CLERC }\end{array}$ & 8 & $4,6 \%$ & $\begin{array}{l}\text { Ens-lettres } \\
\text { (prom. 1877- } \\
3^{\text {ème}} \text { ) }\end{array}$ & $\begin{array}{l}\text { Hist/géo } \\
\left(1880-3^{\text {ème }}\right)\end{array}$ & $\begin{array}{l}\text { Membro da École française d'Athènes (1880-3). Maître de } \\
\text { conférence e, depois, professeur na Fac. des lettres d'Aix (1883). } \\
\text { Docteur-ès-lettres (1893). Conservador do Musée Bórely (1895). } \\
\text { Correspondente da Académie des Inscriptions (1909). Doyen da } \\
\text { Faculté de Lettre d'Aix (1918?). }\end{array}$ & Católico & & De Chalôn-sur-Saone. \\
\hline $\begin{array}{l}\text { Maurice } \\
\text { HOLLEAUX }\end{array}$ & 7 & $4,0 \%$ & $\begin{array}{l}\text { Ens-lettres } \\
\text { (prom. 1879- } \\
8^{\text {eme }} \text { ) }\end{array}$ & $\begin{array}{l}\text { Hist/géo } \\
\left(1882-1^{\text {er }}\right)\end{array}$ & $\begin{array}{l}\text { Membro da École Française d'Athènes (1882-5). } \\
\text { Chargé de cours na Faculté des lettres de Bordeaux (1886-1888). } \\
\text { Chargé de cours na Faculté des lettres de Lyon (1888-1904). } \\
\text { Diretor da École Française d'Athènes (1904). } \\
\text { Chargé de cours complémentaire d'institutions grecques na } \\
\text { Faculté de Lettres de Paris (1912). }\end{array}$ & Católico & Dreyfusard & $\begin{array}{l}\text { De Chateau-Thierry. Pai } \\
\text { engenheiro. Casamento } \\
\text { com a filha de um } \\
\text { engenheiro (1890). }\end{array}$ \\
\hline $\begin{array}{l}\text { Waldemar } \\
\text { DEONNA }\end{array}$ & 7 & $4,0 \%$ & & & $\begin{array}{l}\text { Membro estrangeiro na École Française d'Athènes (1903-7). } \\
\text { Conservador no Musée de Génève (?). }\end{array}$ & & & $\begin{array}{c}\text { (Suiço) } \\
\text { Pai diplomata. }\end{array}$ \\
\hline $\begin{array}{l}\text { Albert } \\
\text { CUNY }\end{array}$ & 7 & $4,0 \%$ & $\begin{array}{l}\text { EPHE/Fac. de } \\
\text { Lettres-Paris }\end{array}$ & $\begin{array}{l}\text { Grammaire } \\
\left(1901-8^{\text {eme }}\right)\end{array}$ & $\begin{array}{l}\text { Maître de Conférences e, depois, professeur na Faculté des Lettres } \\
\text { de Bordeaux (1907). Docteur-ès-lettres (1907). }\end{array}$ & & & \\
\hline $\begin{array}{l}\text { Joseph } \\
\text { LOTH }\end{array}$ & 6 & $3,4 \%$ & EPHE & $\begin{array}{l}\text { Grammaire (1877- } \\
\left.8^{\text {eme }}\right)\end{array}$ & $\begin{array}{l}\text { Docteur-ès-lettres (1881). Professor no Lycée Condorcet (1882-3). } \\
\text { Professor na Université de Rennes (1883). Doyen da Faculté de } \\
\text { Rennes (1889-1910). Professor no Collège de France (1910-30). } \\
\text { Membre de l'Academie des Inscriptions (1919). }\end{array}$ & Católico & & $\begin{array}{l}\text { De Guéméné-sur-Scorff. } \\
\text { Pai artesão. Destinado } \\
\text { ao sacerdócio. }\end{array}$ \\
\hline $\begin{array}{c}\text { Henri } \\
\text { DE LA VILLE DE } \\
\text { MIRMONT }\end{array}$ & 4 & $2,3 \%$ & $\begin{array}{l}\text { Ens-lettres } \\
\text { (prom. } \\
1877-19^{\text {eme }} \text { ) }\end{array}$ & $\begin{array}{l}\text { Lettres (1880- } \\
\left.5^{\text {emee }}\right)\end{array}$ & $\begin{array}{l}\text { Professeur no Lycée de Pau (1880). } \\
\text { Maître de conférence e, mais tarde, professeur na Faculté de } \\
\text { Lettres de Bordeaux (1883). Docteur-ès-lettres (1903). }\end{array}$ & Católico & $\begin{array}{l}\text { Anti-dreyfusard } \\
\text { (Affaire Stapfer) }\end{array}$ & $\begin{array}{l}\text { De Bordeaux. Membro } \\
\text { de família nobre. Político } \\
\text { local. Esposa escritora. }\end{array}$ \\
\hline $\begin{array}{l}\text { Franz } \\
\text { CUMONT }\end{array}$ & 4 & $2,3 \%$ & $\begin{array}{l}\text { Université de } \\
\text { Grand } \\
\text { (Bélgica) }\end{array}$ & & $\begin{array}{l}\text { Docteur en Philosophie et ès Lettre (1887). } \\
\text { Bolsista em Atenas, Roma e Paris (aluno na EPHE e no Collège de } \\
\text { France) (1890-2). Professor na Université de Gand (1892-1910). } \\
\text { Conservador no Musée Cinquantenaire (1899). }\end{array}$ & & & $\begin{array}{l}\text { Nascido na Bélgica. } \\
\text { Família burguesa liberal. }\end{array}$ \\
\hline $\begin{array}{l}\text { Émile } \\
\text { BRÉHIER }\end{array}$ & 4 & $2,3 \%$ & $\begin{array}{l}\text { Bolsista na } \\
\text { Fac. de } \\
\text { Lettres de } \\
\quad \text { Paris }\end{array}$ & $\begin{array}{l}\text { Philosophie } \\
\left(1900-3^{\text {eme }}\right)\end{array}$ & $\begin{array}{l}\text { Professor no Lycée de Coutances (1900-2). Professor no Lycée de } \\
\text { Laval (1903-8). Professor no Lycée de Beauvais (1908-9). Docteur } \\
\text { ès lettres (1908). Maître de conférences na Faculté des Lettres de } \\
\text { Rennes (1909-11). Professor na Faculté des Lettres de Bordeaux } \\
\text { (1912-9). Maître de conférences d'histoire de la philosophie na } \\
\text { Faculté des Lettres de Paris (1919-23). }\end{array}$ & Católico & & $\begin{array}{l}\text { De Bar-le-Duc. Pai } \\
\text { agrégé de grammaire, } \\
\text { professor de liceu. Irmão } \\
\text { professor. }\end{array}$ \\
\hline
\end{tabular}


publicação dominada efetivamente por "adultos", helenistas e latinistas que já haviam iniciado carreira. Ainda assim, entre 1899 e 1920, esses "adultos" optaram por não se confundir com aqueles que dominavam o espaço da REG. Por certo, como já mencionado, isso não impediu a circulação de colaboradores entre as duas revistas, algo que aumentou de intensidade na medida que o próprio grupo da REA conquistou um espaço no seio da elite universitária. Mas aqui, essa pertença à elite foi justamente assegurada por uma estratégia de diferenciação, a qual se revelou em vários níveis: nas trajetórias e nas opções políticas de seus maiores colaboradores, nas agendas de investigações privilegiadas, assim como no recrutamento geral da revista.

Defensores da Província em um sistema de ensino orientado para Paris; original e predominantemente antidreyfusards, quando renomados antiquisants haviam tomado um partido diferente; católicos e protestantes em áreas nas quais letrados judeus dominavam posições-chave; interessados em fazer do nacionalismo uma ciência, quando muitos expoentes nas Faculdades de Letras apostavam em diferentes universais como base de suas atividades: se todas essas escolhas destoavam das tendências dominantes na REG, ainda que pudessem sensibilizar um ou outro grupo integrado à eclética associação responsável por tal publicação, elas colocaram a REA e o AS em rota de colisão. Por certo, havia algo em comum às duas revistas: ambas circularam nos mesmos espaços (o das Faculdades de Letras e, em menor grau, de Direito), bem como envolveram agentes similares (jovens universitários engajados em modernismos científicos). Para todo o restante, contudo, as apostas foram opostas. Não por acaso, como será visto a seguir, a recepção da sociologia na REA oscila entre a indiferença e a hostilidade declarada - no que ela se diferencia mais uma vez da REG, onde o novo saber suscita admiração e mesmo adesão, ainda que não de modo unânime. Daí a contribuição de uma análise minusciosa da REA para se esclarecer algo da resistência à sociologia na universidade fracesa: se o que se afirma aqui é verdade, tal resistência aumentou, institucional e intelectualmente, na mesma razão do progresso das carreiras dos indivíduos envolvidos com a REA e com o AS.

\section{A ReCEPÇÃo da SOCIOLOGIA NA REVUe des ÉTUdes ANCIENNES (1899-1920)}

A REA, desde sua fundação atenta às novidades científicas pertinentes para seus objetos de estudo (o Mundo Antigo e as "Antiguidades Nacionais"), preocupou-se também com as (des)valias da sociologia defendida no AS. Não são incomuns, portanto, referências aos sociólogos nos textos, bem como resenhas de livros ou artigos seus. Com o intuito de isolar os termos dessa recepção, para então verificar a existência de padrões relativos a quem faz as avaliações, como e quando o faz, optou-se na sequência por estudar cada sociólogo 
referenciado em separado. Assim, entre 1899 e 1920, Antoine Meillet, Henri Hubert, Marcel Mauss, Paul Huvelin e Émile Durkheim têm seus livros resenhados e/ou são objetos, uns mais, outros menos, de citações no corpo de artigos, crônicas e resenhas ${ }^{47}$.

Dos colaboradores regulares do AS, Antoine Meillet foi, de longe, o mais acionado na REA. Nada menos que sete de seus livros foram resenhados, assim como uma nota especial foi dedicada à aula inaugural que ele proferiu ao assumir a cadeira de Grammaire Comparée no Collège de France. Some-se a isso, por fim, uma quantidade razoável de referências em artigos e resenhas, com destaque para aquelas redigidas por Albert Cuny, seu antigo orientando.

A apreciações dos trabalhos de Meillet foi, em geral, bastante positiva. A única exceção ocorreu logo na primeira menção a seu nome na revista: trata-se do comentário relativo à sua aula inaugural. Publicado em 1906 na seção de Chroniques e intitulado Un manifeste de la nouvelle école linguistique, este texto foi escrito por Émile Bourciez, linguista (romanista) e professor em Bordeaux. Nele, criticou-se severamente a relação que Meillet julgou por bem instituir entre a linguística e a sociologia:

Para o Senhor Meillet, o que deve nos dar a chave para o desenvolvimento linguístico e o que nos permitirá formular no futuro leis não empíricas são as mudanças ocorridas na "estrutura da sociedade".

Dito de outra forma, eis aí a linguística que, sob pretexto de se renovar e de fazer um passo decisivo para frente, procura se ligar à sociologia: isto me assusta um pouco, haja visto que a sociologia é atualmente um saber que titubeia, que se debate em meio a dados vagos e imprecisos. Ninguém, com efeito, sonha em negar - e nós já o sabíamos - que deve haver uma correlação entre a evolução das línguas e as transformações sociais sofridas pelos povos que falam estas línguas (...). Mas deste ponto, querer remeter tudo à sociologia requer ainda um bom chão. (...)

De duas, uma: ou bem o método sociológico aplicado às línguas será, com uma mudança de rótulo, a continuação pura e simples das investigações histórias, ou bem isto será um não sei o que tomado das teorias de Auguste Comte e nos levará, em suma, à construções a priori, puramente lógicas. (REA, 1906: 272-3) ${ }^{48}$

\footnotetext{
${ }^{47}$ Os trabalhos de Louis Gernet e Robert Hertz foram igualmente mencionados na REA, mas por outro sociólogo, Pierre Roussel. Além destes nomes, o de Antoine Bianconni foi referenciado. Trata-se, nesse caso, de uma única e breve alusão na resenha do livro de Octave Hamelin, Le Système d'Aristote (REA, 1920: 301-303). Segundo nos informa o autor, cadernos de notas de Bianconi teriam sido usados na composição da obra póstuma de Hamelin.

${ }^{48}$ Os termos originais de Meillet que tanto pareceram ter irritado Bourciez foram os seguintes: "mas é mais importante indicar os problemas novos colocados pelo progresso da ciência que de repetir as soluções, aliás necessariamente incompletas, que receberam os antigos problemas: o dever do professor é, sobretudo aqui, mostrar mais as pesquisas a serem feitas que os resultados dos trabalhos já feitos. O século XIX foi o século da história, e os progressos que realizou a linguística ao se colocar sob o ponto de vista histórico foram admiráveis; as ciências sociais se constituem agora e a linguística deve tomar aí o lugar que a sua natureza determina. Chegou, portanto, o momento de marcar a posição dos problemas linguísticos por um ponto de vista social. Olhar para o futuro ao invés de olhar para o
} 
A defesa que Bourciez promoveu do método histórico contra a novidade da sociologia marcou, nos anos que se seguiram, mesmo as avaliações positivas do trabalho de Meillet. Com efeito, se ignorar o linguista-sociólogo tornou-se com o passar do tempo cada vez mais difícil, pois seu prestígio era considerável, os colaboradores da REA trataram de ignorar seu lado "sociológico", enfatizando outros aspectos de sua produção. Albert Cuny, por exemplo, elogiou em Meillet a reconciliação entre a linguística e a filologia ${ }^{49}$. Camille Jullian, na resenha que escreveu à terceira edição do livro Introduction à l'Étude Comparative des Langues IndoEuropéennes, também silenciou sobre a importância da sociologia para a epistomologia do autor. Em compensação, sobram elogios para o filólogo e o historiador: "não sei se alguma vez, ao abrir um livro de linguística, eu tive uma impressão tão plena (...). Mas o que quero dizer neste momento é que quem quer que se ocupe das nossas antiguidades nacionais deve lê-lo, meditá-lo e reconhecer o quanto suas soluções se adaptam bem às da história e às da filologia" (REA, 1912: 318). E mesmo quando se faz referência à tese de Meillet sobre o caráter social (externo) da linguagem, o saber referido é a história, e não a sociologia. É isso o que Paul Fournier afirmou em sua resenha de Aperçu d'une Histoire de la Langue Grecque: "tal tese [a do livro de Meillet] é que 'a linguagem não deve o princípio de seu desenvolvimento a ela mesma', mas que 'sua evolução é comandada em grande parte por fatos que the são exteriores'. De forma não menos clara que o título mesmo do livro, tal frase situada no início do prefácio indica que o gramático que o escreveu quis fazer também obra de historiador." (REA, 1913: 343-4).

A maneira mais comum com a qual se silenciou os lanços entre Meillet e a sociologia foi, contudo, a da citação técnica. Assim, sobretudo nas inúmeras resenhas que escreveu, Cuny utilizou-se da obra de seu antigo mestre para emitir juízos sobre detalhes de fonética, de declinações, entre outros ${ }^{50}$.

Entre os sociólogos citados na REA, embora numa frequência muito inferior à de Meillet, esteve Henri Hubert. Entre 1899 e 1920, ele teve dois de seus livros resenhados, bem como viu seus estudos serem referenciados. A mais antiga dessas alusões data de 1904 e devese à resenha que Georges Radet escreveu do livro cuja tradução havia sido coordenada por Hubert e Isidore Lévy, o Manuel d'Histoire des Religions de Chantepie de la Saussaye (REA: 1904: 273-5). Tal texto principia com um elogio dirigido a Lévy e a Hubert, os quais, segundo

passado é o meio de seguir o exemplo do mestre que me precedeu nesta cadeira [Michel Bréal] e de permanecer fiel ao espírito da nobre casa que me deu o privilégio de me acolher" (MEILLET, 1948: 18).

${ }^{49}$ Cf. REA: 1908, 281. Nessa sua avaliação, Cuny foi seguido anos mais tarde por Georges Radet, REA: $1913,235-6$.

${ }^{50}$ Veja-se REA, 1908: 275-7; 1909: 184-6, 207; 1910: 52 e 266; 1912: 318 e 1914: 105. 
Radet, "poderiam tê-lo escrito eles mesmos, pertencendo àqueles a quem esta ambição é permitida". Chama atenção, no entando, seu silêncio quanto ao longo texto introdutório do volume, no qual Henri Hubert faz uma defesa do método sociológico ${ }^{51}$. A única alusão à sociologia se deu mais adiante no texto, quando Radet elogia Chantepie de la Saussaye:

Desconfiando das sínteses prematuras e factíveis, ele não se serviu de nenhuma escola; ele não sofreu a tirania de nenhum sistema; ele não se decidiu exclusivamente por nenhuma das hipóteses que se multiplicam uns contra os outros, ao longo dos séculos, os espíritos curiosos das coisas religiosas, evemeristas, simbolistas, linguistas, folcloristas, etnógrafos, antropólogos, sociólogos. Seu ponto de vista foi histórico e não dogmático.

Quanto às demais referências à Hubert, quem as faz é Jullian e para discutir questões relacionadas aos estudos célticos, tema comum a ambos. É o caso, por exemplo, da resenha elogiosa dirigida ao trabalho de Hubert sobre certos padrões iconográficos e morfológicos das cerâmicas da idade do bronze e do ferro (REA: 1911, 503-504). Além do mais, o sociólogo é elogiado quanto a uma hipótese interessante sobre uma divindade céltico-germânica (REA, 1913:116, nota 1) e criticado por sua interpretação de uma estela celta em conjunto com Joseph Vendryes (REA, 1914: 101). Em todas essas circunstâncias, porém, nenhuma alusão é feita à sociologia ou ao Année Sociologique, o que sugere um padrão próximo ao já constatado no caso de Meillet.

Paul Huvelin e Marcel Mauss também foram citados na REA, mas em contextos menos significativos. Mauss, por exemplo, é por duas vezes evocado. Em um desses casos, Cuny menciona um capítulo seu escrito para os Mélanges Sylvain Lévi (REA, 1911: 474). Na outra ocasião, Jullian, ao referir-se a uma conferência de Mauss sobre o valor mágico das moedas, limitou-se a dizer que "a engenhosa teoria de Déchelette é retomada e discutida" (REA, 1919: 275). Huvelin, por seu turno, teve um de seus trabalhos sobre a magia no direito romano (no qual ele cita Mauss e Hubert) citado por um colega do direito, Gaston May. Em seu artigo, May discutiu o problema da autenticidade da lei das XII tábuas e, embora não identifique o autor como sociólogo, se apropriou sem maiores problemas de suas conclusões (REA, 1902: 201212). A segunda referência a Huvelin é bem mais tardia. Henri Lechat resenhou em 1917 um livro do sociólogo sobre a segunda guerra púnica. Interessava a Lechat destacar, contudo, os paralelismos entre a antiga guerra e o conflito que então se vivia (REA, 1917:288-289) ${ }^{52}$.

\footnotetext{
51 Théodore Reinach também resenhou este livro para a REG, com uma abordagem sensivelmente diferente (veja-se o item 2.3 da presente tese).

${ }^{52}$ Henri Lechat não se enganou quanto ao teor do texto. De fato, Huvelin parece querer fazer dele um simples panfleto de guerra. Pouquíssimos são os autores modernos citados (Jullian, Mommsen) e as
} 
A presença de Durkheim foi, por outro lado, muito mais expressiva e, na medida que seu nome dificilmente se separava da sociologia, ilustrativa das tensões entre a REA e tal ciência. Com a exceção da menção elogiosa feita por Pierre Roussel, a qual será analisada mais adiante, e de uma citação de Gaston May (REA, 1905: 6), o sociólogo e sua disciplina transformaram-se aqui em alvo de constantes críticas.

Uma parte significativa dessas reações negativas veio de um antigo colaborador do AS, Gaston Richard. Após a ruptura com o grupo devido às discordâncias entre ele e Durkheim quanto à universalidade e a importância do tabu do incesto, em 1907, Richard tornou-se um habitué da REA, publicando constantemente resenhas sobre temáticas associadas às ciências sociais (em particular, estudos sobre crenças e práticas religiosas). Duas dessas resenhas fizeram, em detrimento da sociologia, o elogio da antropologia britânica. É o caso, por exemplo, do texto de Richard sobre o livro de Ward Fowler, The religious experience of the roman people from the earliest times to the age of Augustus. Nela, Richard resumiu as teses defendidas no AS com as seguintes palavras:

Para os sociólogos provenientes de Auguste Comte e agrupados hoje em torno do Senhor Durkheim, a religião é e não pode ser nada mais que a expressão da vida coletiva. Ela é a forma espontânea, primitiva, das crenças sociais ou ela não é nada. A religião mais simples, mais sincera e menos desnaturalizada é aquela que se forma na comunidade mais rústica e menos diferenciada. A religião é, contudo, algo completamente exterior: ela consiste em ritos, em gestos destinados a manter em um certo grau de tensão suficiente o sentimento de coesão social.

Fowler estima, ao contrário, que o essencial da religião romana primitiva é um sentimento todo individual. A disciplina coletiva rígida que impõe mais tarde o Estado patrício é a causa de uma estagnação no desenvolvimento deste sentimento. 0 Jus divinum preenche temporariamente $o$ individualismo religioso, mas ele não tem razão. Da segunda guerra púnica ao desenvolvimento do cristianismo, a experiência religiosa do individuo torna-se o fator decisivo da evolução religiosa de Roma.

Sabe-se que a escola sociológica francesa utilizou-se fartamente da contribuição dos trabalhos anteriores da escola antropológica inglesa. Sem as obras de Frazer, de Robertson Smith, de Byron, de Crawley, os estudos do Senhor Durkheim sobre o Totemismo, os dos Senhores Hubert e Mauss sobre o Sacrificicio e sobre a Magia, os do Senhor Lévy-Bruhl sobre as Funções mentais das sociedades inferiores sem dúvida não teriam vindo à luz. Fowler tem portanto muito mais em vista as teorias de Frazer e de Byron Jevons que a de nossos compatriotas. Aqui ainda seu testemunho nos é dos mais preciosos (REA, 1912: 441-2).

A mesma modalidade de ataque Richard reedita cinco anos mais tarde, ao comentar a obra de René Dusaud, Introduction à l'histoire des religions. Nesse caso, o autor da resenha

comparações com outras épocas abundam no texto. Além do mais, não foram encontradas alusões a Durkheim e aos demais membros do AS (HUVELIN, 1917). 
apoia o autor do livro resenhado quanto às críticas ao caráter universal do totemismo, bem como comunga com ele a certeza de que a religião pode manifestar tanto uma consciência coletiva quanto uma individual. Durkheim não é citado aqui diretamente, mas apenas a escola sociológica francesa e suas teses, ou como as denomina o autor, seus "castelos de ventos".

O documento mais interessante quanto a Durkheim é, contudo, a longa resenha que Camille Jullian dedicou às Formas Elementares da Vida Religiosa ${ }^{53}$. De início, o patrão da REA ressalta as qualidades "filosóficas" e "literárias" do livro, seu "estilo sóbrio". Em seguida, lê na definição da sociologia que dá Dukheim no prefácio da obra, um "elogio à história". O mais interessante, contudo, é a forma como Jullian resume a tese do livro nos tons mais positivos possíveis para, então, descartá-la:

\begin{abstract}
A religião nasceu da sociedade humana, da coletividade solidária, formada por um grupo humano organizado para a eternidade. Toda sociedade tem de início uma igreja, vale dizer, uma 'comunidade moral, a qual criou, ao aplicá-lo à sua própria vida, 'um sistema de crenças e de práticas' destinadas a fortificar e perpetuar sua união. Em outros termos, o princípio religioso vem do homem, ser social, e não de fora, da impressão produzida em sua inteligência por fenômenos exteriores.

Eu direi francamente minha opinião. - Antes de mais nada, é, acredito, a teoria a mais refletida, a mais fortemente pensada que já se tentou sobre a origem das religiões, e, que se a aceite ou não, é preciso se curvar diante dela com respeito e admiração - Em seguida, eu não tenho nem a coragem, nem o desejo de a combater ou a aceitar. Nada do que nós sabemos sobre os antigos povos do Ocidente por seus monumentos e documentos a informa ou a confirma. (grifo meu)
\end{abstract}

Vê-se por essa citação como Jullian traduz a tese de Durkheim para os termos de um historiador. Ele se preocupou com "origens" e em checar se, historicamente, ela poderia ser confirmada. Ainda em outros momentos da resenha, no tocante a questões mais pontuais, o mesmo procedimento foi utilizado: por hora dados históricos são evocados para comprovar algo do raciocínio de Durkheim, por hora o que ocorre é o contrário. Em todo caso, o efeito da leitura da obra por essa chave histórica acaba transformando a defesa do método e da epistomologia sociológicas almejada por Durkheim na defesa de uma Filosofia da História, a qual supõe estágios evolutivos. Não por acaso, Jullian caracteriza o patrão do AS como "um dos mais vigorosos lógicos do nosso tempo". Sua conclusão é que a obra merece ser lida, mas apenas na medida que permite aos estudiosos do mundo antigo e das antiguidades nacionais pensar questões específicas. No mesmo volume da REA, Jullian ainda tem o cuidado de indicar

\footnotetext{
53 Essa é, em verdade, a maior resenha publicada nos primeiros vinte e um anos da história da REA, ocupando seis páginas da revista (REA, 1914: 244-250).
} 
aos interessados no livro de Durkheim a resposta crítica escrita por Alfred Loisy, seu colega no Collège de France (REA, 1914: 392).

O que se pode aventar dessa recepção da sociologia na REA é que tal saber suscita, no mais das vezes, reações críticas ou eufemismos. Vale dizer: até é possível apreciar positivamente o trabalho de um dos membros do AS, via resenhas e citações em corpo de texto. Ainda assim, em nenhum momento o ponto elogiado é atribuído a alguma virtude da sociologia enquanto ciência. O que pareceu incomodar os antiquisants reunidos em torno da REA foi, sobretudo, a pretensão da sociologia de encontrar universais a partir dos quais fosse possível refletir também sobre os particulares. A esse respeito, o próprio Durkheim já havia sentenciado no prefácio do primeiro volume do AS:

\footnotetext{
A história só pode ser uma ciência na medida que explica, e não pode explicar senão comparando. Mesmo a simples descrição é impraticável de outra maneira: não se descreve bem um fato único ou do qual se possuem raros exemplos porque ele não é bem observado. Por tal razão, Fustel de Coulanges, a despeito de seu profundo conhecimento das coisas históricas, enganou-se sobre a natureza da gens na qual ele viu apenas uma vasta família de agnatos, o que ocorreu porque ignorava casos etnográficos análogos a este tipo familiar. 0 verdadeiro caráter do sacer romano é bem difícil de ser percebido e sobretudo compreendido se não se aproxima dele o tabu polinésio (DURKHEIM, 2007: 8).
}

Ao contrário de Durkheim e dos pesquisadores próximos a ele, contudo, os membros da REA apostavam no particular como meio para se chegar ao geral. Além do mais, para eles, o comparativismo só fazia sentido entre objetos dotados da mesma dignidade histórica. Não deixa de ser sintomático a recepção calorosa reservada às outras modalidades de ciências sociais então em voga, com destaque para a antropologia inglesa. O mesmo Jullian avesso às teses dos sociólogos saudou em outras ocasiões, sem maiores constrangimentos, a obra de um Frazer (REA: 1911, 240).

\section{Os Sociólogos na REVUE DES ÉTUdES ANCIENNES (1899-1920)}

Ainda que, para o período aqui considerado, a recepção da sociologia tenha oscilado entre a indiferença e a hostilidade declarada na REA, um pequeno número de pesquisadores associados à primeira série do AS esteve aí presente. Entre eles encontram-se Gaston Richard (antes de sua ruptura com Durkheim), Antoine Meillet e Pierre Roussel.

É salutar reconhecer, contudo, que essas intervenções se deram em contextos e com intensidades diferentes, muitas vezes sem fazer menção à sociologia. Elas perfazem um total 
de quatorze textos, os quais se dividem em nove resenhas (compte-rendus), uma carta e quatro artigos publicados na seguinte ordem cronológica:

- 1905: Duas resenhas de Richard (REA, 1905: 301-304, 320-321)

- 1912: Dois artigos de Roussel (REA, 1912: 39, 377-381)

- 1914: Um artigo e uma resenha de Roussel (REA, 1914: 349-450, 463-465)

- 1915: Uma resenha de Roussel (REA, 1915: 77-78)

- 1918: Uma carta de Meillet (REA, 1918: 131-133)

- 1919: Uma resenha de Roussel (REA: 1919: 298-9)

- 1920: Um artigo e quatro resenhas de Roussel (REA, 1920: 131-132, 134-137, 138-140, 157-171, 304-306)

As resenhas de 1905 são duplamente emblemáticas, pois, no âmbito da REA, elas inauguram tanto a presença dos sociólogos vinculados ao AS como as discussões acerca da sociologia. Na primeira delas, Gaston Richard analisou a segunda edição da tradução do Código de Hamurabi por Vincent Scheil (REA, 1905: 301-304). Não se trata, porém, de uma avaliação da tradução enquanto tal, mas de um debate sobre as questões passíveis de serem suscitadas por tal documento. De início, Richard destacou que a recente descoberta arqueológica do Código deveria interessar "aos historiadores, aos juristas, aos sociólogos e talvez ainda mais aos teólogos alemães". A suposta razão desse interesse foi definida nos seguintes termos: "o direito é o aspecto mais definido da disciplina social, que é ela mesma o objeto mais definido dos estudos históricos. Ora, sabe-se qual imenso esforço foi realizado pela ciência europeia, ao longo do século XIX, para reconstituir a marcha das ideias jurídicas nas suas relações com as crenças religiosas e a civilização material". Richard então avançou a seguinte leitura da legislação babilônica: esta apontaria para um momento no qual o direito começa a se separar da religião. Tratar-se-ia, portanto, de um sistema de legislação misto, em cujo interior os "costumes mais antigos e mais bárbaros", para os quais toda injúria reclama uma vingança, estavam em vias de ser substituídos por leis aptas a instituir a paz no seio das (e nas relações entre as) unidades domésticas. Em outras palavras, tal fonte histórica sugeriria a existência de um Estado que passava a exercer progressivamente o controle sobre a aplicação de penas. Mas Richard não se contentou com tal afirmação. Para confirmá-la, ele também se utilizou do expediente da comparação, fazendo referências pontuais às legislações das antigas China e Israel. 
A segunda resenha discute o livro La Famille Celtique de Henry d'Arbois de Jubainville, professor de Langue et Littérature Celtiques no Collège de France. Richard identificou aí vícios e virtudes. Quanto às virtudes, elogiou a divisão do livro em duas partes, o que estaria "de acordo com todos os ensinamentos dos sociólogos contemporâneos". Com efeito, d'Arbois de Jubainville separou, de um lado, tudo o que está relacionado ao parentesco e, de outro, as questões relativas à sociedade conjugal. Os vícios do autor, no entanto, aparecem em decorrência da aplicação de métodos diferentes a cada uma dessas partes. Enquanto ele se valeu do direito comparado no que diz respeito ao parentesco, uma única relação de causaefeito parece determinar toda a organização conjugal. Richard protestou especialmente contra a explicação do concubinato celta, o qual aparece no livro como uma decorrência direta do descompasso, oriundo da guerra, entre o número de homens e de mulheres em idade fértil. Tal associação, reforçada por d'Arbois de Jubainville a partir de uma aproximação dos costumes celtas com o Código de Hamurabi, veria na poligamia um simples meio de manutenção do equilíbrio social. Ora, Richard destacou então que "o erro do Senhor d'Arbois consiste em reconhecer apenas um tipo de poligamia, a que coloca todas as esposas de um homem em pé de igualdade". Por fim, para corrigir esse problema, ele sugeriu uma comparação com as poligamias chinesa e semítica, derivando disso que, em sua opinião, o caso da Irlanda medieval remeteria a um estágio intermediário entre a poligamia e a monogamia estrita, pois as esposas possuíam nele estatutos diferentes.

Após sua estreia, os sociólogos vinculados ao AS desapareceram por seis anos das páginas da REA (com exceção, como já foi visto, de Richard, embora este já não estivesse mais alinhado ao programa da "escola sociológica francesa"). Nesse ínterim, consolidou-se na revista um ambiente em geral arredio às ideias provenientes da nova disciplina. Foi apenas a partir de 1912 que dois outros colaboradores do AS tiveram a chance de aí publicar, mas seus textos, com algumas importantes exceções, acabaram remetendo a saberes especializados não necessariamente sociológicos. É o caso, por exemplo, da única contribuição de Meillet (REA, 1918: 131-3). Publicada na seção Variétés, ela consiste em uma carta endereçada a Albert Cuny, o linguista oficial da REA, professor na Faculdade de Letras de Bordeaux e seu exorientando. Nela, Meillet responde às críticas que Cuny lhe havia dirigido quanto ao lugar das aspirantes sonoras indo-européias em latim ${ }^{54}$. Toda a questão gira, no entanto, em torno de fatos puramente linguísticos que, pela falta da documentação, são tratados de modo abstrato. O próprio autor explicita isso no seguinte trecho: "a substituição de aspirantes surdas por

\footnotetext{
${ }^{54}$ Veja-se, quanto a isso, REA, 1917: 255-60.
} 
aspirantes sonoras em todas as posições é um traço característico de todo o itálico: houve um momento em que o itálico ignorou toda aspirante sonora. É um desses fatos particulares que caracterizam uma língua particular, em um momento particular, sobre o qual apenas se pode encontrar uma resposta ao se conhecer as condições históricas que os determinaram". Por certo, essas condições não estavam acessíveis nem a Meillet, nem a Cuny.

Quanto à atuação de Roussel na REA, de longe a mais expressiva de um colaborador do AS nesse espaço, ela pode ser dividida em dois blocos. Destes, o primeiro diz respeito às especialidades que o consagraram em sua carreira de helenista: a história e a epigrafia gregas. Assim, em três de seus artigos, Notes sur un Décret Attique (REA, 1912: 39), Notes sur Deux Inscriptions de Thasos (REA, 1912: 377-381) e Une Inscription Funéraire de l'Égypte (REA, 1914: 349-350), Roussel acusou problemas nas reconstituições e interpretações de textos epigráficos, demonstrando ter domínio não só das particularidades dessa modalidade de documentação como das fontes literárias aptas a auxiliar sua compreensão. Algumas de suas resenhas vão na mesma direção. Em duas delas, ele tratou das monografias de eruditos alemães sobre Andros e Lesbos, nas quais se discutia a história dessas ilhas e se publicava o material, arqueológico e epigráfico, nelas encontrado (cf., respectivamente, REA, 1914: 463465 e REA, 1919: 298-299). Em outra circunstância, analisou o trabalho de um aluno de Gustave Glotz sobre o papel das "casas sagradas" na economia da Delos independente (REA, 1915: 77-78).

O segundo bloco de textos é composto por quatro resenhas e um artigo. Todos eles foram publicados em 1920 e a sociologia está aí, em maior ou menor grau, presente. Roussel interessou-se então por trabalhos relativos a outras sociedades (a babilônica e a romana), bem como por uma análise comparativa de questões ligadas à própria Grécia Antiga. Na resenha da memória Les Nouveaux Fragments du Code de Hammourabi sur le Prêt à Intérêt et les Sociétés, de Édouard Cuq (REA, 1920: 131-132), por exemplo, ele discutiu as conclusões do autor sobre as condições legais de empréstimo na Mesopotâmia, mas, ao fazê-lo, procurou estabelecer paralelos com a Hélade. O mesmo ocorreu nas notas elogiosas que dirigiu ao livro de Jean Hatzfeld, Les Trafiquants Italiens dans l'Orient Héllenique, pois interessaram-Ihe nele as novas relações sociais oriundas da presença de mercadores latinos no Mediterrâneo Oriental (REA, 1920: 138-140). Quanto aos seus comentários sobre La Loi de Hiéron et les Romains, livro de Jérôme Carcopino, Roussel tanto salientou a história da assimilação, generalização e deturpação desta lei siracusana por toda a Sicília romana como levantou dúvidas sobre sua origem egípcia. 
Há, porém, uma resenha que se destaca das demais quanto à presença da sociologia: trata-se daquela dedicada ao livro Les Mystères d'Eleusis, do helenista Paul Foucart (REA, 1920: 134-138). Desde os tempos em que era diretor da École Française d'Athènes, esse antigo desafeto dos sociólogos participou dos debates sobre os cultos da Ática. Ao longo das décadas de 1880 e 1890 , ele desenvolveu uma teoria, aprimorada no trabalho acima referido, acerca das origens egípcias dos Mistérios de Eleusis. Em seus comentários sobre a obra, Roussel procurou demonstrar a fragilidade dos dados levantados pelo autor. Assim, a tripla argumentação da tese - pautada em indícios arqueológicos que mostram trocas entre gregos e egípcios, em testemunhos literários gregos relativos ao estabelecimento de colonos egípcios em Eleusis e, por fim, nas homologias existentes entre Deméter e Isis - é descartada como absolutamente conjectural. Afinal, ela somente prova, fato amplamente aceito, que existiram relações entre o Egito e a Grécia, sem que seja possível inferir nada mais substancial a partir daí. Para além de outras discordâncias pontuais, a parte mais interessante (e irônica) da resenha provém da crítica à noção de rito defendida por Paul Foucart. Ao observar as festividades em honra a Osíris, tal como estudadas por seu filho, Georges Foucart, o helenista encontrou paralelismos na forma com que elas e os ritos de Eleusis representavam para suas respectivas comunidades o tema da renovação do ciclo da vida. Sobre isso Roussel sentenciou, fazendo referência textual à Durkheim e aos sociólogos:

No âmago da interpretação pessoal que o Senhor G. Foucart deu do drama litúrgico de Osíris, há uma concepção do rito que se encontra em muitas religiões, senão em todas. A comunidade australiana dos Warramunga representa episódios, épicos ou cômicos, da trajetória terrestre do ancestral Thalaualla: "São dramas, mas de um gênero muito particular; eles agem, ou ao menos se crê que eles ajam, sobre o curso da natureza. Quando a comemoração de Thalaualla termina, os Warramunga estão convencidos que as serpentes negras não podem deixar de crescer e de se multiplicar" (É. Durkheim, Les formes élémentaires de la vie religieuse, p. 534. $)^{55}$

Dentre os adversários de sua tese egípcia, o Senhor Paul Foucart atacou especialmente aqueles "que tentam renovar com a ajuda do folclore e da etnologia o estudo das religiões gregas". Estes são idealistas; mas constituem uma escola particularmente perigosa "pelo emprego de procedimentos intensivos de vulgarização". Ao dar um lugar, por menor que ele seja, às suas teorias, mostra-se uma lamentável fraqueza contra a qual ele pretende reagir. Várias passagens do livro do Senhor P. Foucart são de fato uma reação, ainda que um pouco brutal, contra as "aproximações superficiais" e a "fraseologia desprovida de realidade" do folclore e da etnografia. Mas indiretamente e, sem dúvida, sem se dar conta, ele abre a porta a estas inovações que ele condena. Isto porque nenhum egiptólogo, não importa o quão perspicaz ele seja, daria a interpretação que se viu do drama litúrgico de Osíris se os etnólogos, os antropólogos, ou os sociólogos - independente das diferenças que os separam - não tivessem elaborado certas teorias dos atos religiosos.

\footnotetext{
${ }^{55}$ A tradução da citação de Durkheim também é minha. Para situar tal passagem em uma edição brasileira, cf. DURKHEIM, 2000: 407.
} 
Eu não acredito que o Senhor Paul Foucart tenha dado à sua tese geral um grau maior de probabilidade; mas o emprego, embora muito limitado, que ele fez do método comparativo o levou, quase contra sua vontade, a modificar e a ampliar suas ideias ${ }^{56}$.

Mas se a sociologia restringiu-se até aqui a um instrumental a partir do qual Roussel ponderou sobre os métodos e os resultados obtidos em outros trabalhos, foi com o artigo Médée et la Meurtre de Ses Enfants que ela encontrou-se colocada à prova (REA, 1920: 157171). O helenista partiu então da seguinte questão: teria Eurípides inventado ex nihilo o tema da culpabilidade de Medeia quanto ao assassinato de seus filhos, ou teria ele trabalhado diferentes versões tradicionais da mesma história? Para responder a isso, Roussel retomou todas as diferentes versões que se conhece dos mitos relativos a Medeia, passando por Pausânias, Aristóteles, alguns escoliastas e o próprio Eurípides. Por meio de tal expediente, ele intentou provar a ambiguidade de uma série de pontos que sustentam a argumentação em prol da invenção do tema. Quanto à culpa de Medeia, apoiando-se em Louis Gernet, ele sublinhou que em todas as diferentes versões da história está em questão uma noção bastante ambígua de responsabilidade. Afinal, independente de ser ela a assassina direta de seus filhos, o destino desses permanece de qualquer modo associado ao seu. Quanto aos procedimentos utilizados para a morte das crianças nas diferentes versões do mito, citando Robert Hertz, Roussel aproximou-os dos ritos funerários e, por extensão, dos ritos ligados à preservação da vida. Também James Frazer é referenciado, uma vez que seus trabalhos trazem inventários de histórias muito semelhantes às de Medeia em registros temporais e espaciais diferentes. Em suma, como sociólogo, o autor pretendeu, sem que isso diminuísse em nada a importância de Eurípides e de sua arte, mostrar o quanto Medeia ganha em inteligibilidade se pensada a partir do diálogo com a tradição, compreendida aqui como um arranjo complexo de símbolos que as sociedades constroem e mobilizam para povoar de sentidos suas existências.

Uma vez apresentados os textos dos sociólogos na REA, é salutar procurar padrões que permitam explicar tanto a seleção dos autores como a frequência de suas intervenções. Ao se tratar dessas questões, um primeiro elemento a ser destacado é a relação de Meillet, Richard e

\footnotetext{
${ }^{56}$ Em um número anterior da REA, igualmente publicado em 1920, seu diretor-geral, Georges Radet, avaliou as teses de Foucart com um tom bem mais positivo e, por vezes, condescendente. Ao concluir sua resenha da memória Le Culte des Héros Chez les Grecs, ele afirmou o seguinte: "Um plano sólido de divisões lógicas, o gosto pelas linhas claras, uma lúcida análise a serviço de uma forte síntese, uma ciência que dispensa o detalhe insignificante, as soluções complicadas, as combinações artificiais para se ater apenas aos grandes conjuntos, uma língua precisa e plena, tais são as qualidades que recomendam esta obra. Ela foi concebida na maneira clássica de outrora, por um representante da geração à qual pertencia Fustel de Coulanges. Os partidários de uma ciência mais atormentada não deixarão de dizer que ela é datada, que é simplista demais, que aí se encontra a amarra sistemática e sem ornamento da Cidade Antiga. Isto é possível, Felix culpa!"(REA, 1920: 57-59).
} 
Roussel com os padrões de recrutamento mais gerais da revista. De fato, os três encaixam-se perfeitamente nas regularidades outrora destacadas. Meillet, por exemplo, pertencia a um grupo, o de professores do Collège de France, cada vez mais requisitado na medida que a REA foi conquistando prestígio e consolidando seu espaço institucional. Além disso, viu-se anteriormente como ele era o membro da equipe do AS mais celebrado na REA, embora se operasse aí uma estratégica separação entre o teórico da linguística (pró-sociologia) e o linguista-historiador. Não é de se estranhar, portanto, a presença desse seu texto.

No que diz respeito aos dois outros membros da equipe do AS, eles integravam o segmento junto ao qual a REA recrutou a maior parte de seus colaboradores: o de professores universitários de província. Richard havia assumido em 1902 a cadeira vacante de Durkheim em Bordeaux, ao passo que Roussel, após longos anos de formação e de trabalho junto à École Française d'Athènes (1905-12), ocupou sucessivamente cargos no Liceu de Janson-de-Sailly (1915), na Faculdade de Letras de Bordeaux (1918) e na Faculdade de Letras de Strasbourg (1919-25), chegando a Paris apenas em 1936. No interior dessa categoria ampla de "professor de província", contudo, os dois ocupam posições diferentes. Enquanto Richard interessava por ser o representante de alguma modalidade nova de ciência (uma sociologia que, para o deleite dos fundadores da REA, descobriu-se logo antidurkheimiana ${ }^{57}$ ), Roussel trilhava os rumos clássicos de um helenista, para quem a sociologia poderia ser um aliado interessante.

E como compreender a concentração de textos de Roussel entre os anos 1912 e 1920 ? Ora, certamente sua especialidade tem um grande papel aqui. É preciso, contudo, levar também em conta um dado geracional. Nascido em 1881, ele pertencia ao grupo dos mais jovens no seio da equipe do AS, iniciando sua carreira em fins da primeira década do século XX, quando participou sistematicamente de missões arqueológicas a Delos. Era natural, portanto, que seus textos começassem a aparecer nesse momento. A manutenção da produção intelectual de Roussel foi ainda favorecida em outro ponto: durante a Primeira Guerra Mundial, enquanto muitos de seus colegas deixaram as fileiras do exército com a desmobilização geral de 1919, ele foi reformado já em 1915.

O período da guerra marca, aliás, uma reavaliação da sociologia no âmbito da REA. Embora isso não signifique o término das desconfianças e das hostilidades, tudo se passa como se aqueles mais envolvidos com sua direção percebessem a fragilidade dos sociólogos, incapazes de manter a publicação de um periódico próprio e rapidamente privados de muitos de seus membros (dentre os quais encontrava-se seu próprio patrão, Durkheim). Assim, de

\footnotetext{
${ }^{57}$ Sobre as divergências teóricas que marcam tal ruptura, cf. PICKERING, 1979 e FOURNIER, 2007: 675676 e $760-762$.
} 
ciência potencialmente perigosa, a sociologia passou a ser considerada um saber domesticado, o qual ocasionalmente poderia ser acionado. Mas se trata, é bem verdade, de uma via de mão dupla. Para jovens sociólogos como Roussel, órfãos do AS, a REA fornecia um espaço nada desprezível de interlocução e de viabilização de carreira. 


\section{5 - LINHAS}

\section{DE FORÇA}

Viu-se como, ao longo do presente capítulo, as revistas especializadas nos estudos greco-latinos foram sendo constituídas na França. À medida que a análise avançou, passando de uma a outra publicação, foram sendo isolados pontos de tensão e de afinidades eletivas entre elas. Com efeito, uma revista não pode nem deve ser analisada em separado das demais, como se constituísse um universo totalmente autônomo. Graças a seus vínculos institucionais, projetos editoriais e a evolução de sua morfologia, cada uma delas afetou de modo contínuo e profundamente o "lugar" e o "peso" das demais. É chegado o momento de sintetizar as linhas de força mais importantes que, durante o período aqui analisado e com uma notável estabilidade, regularam essas influências recíprocas, conformando assim um campo das revistas especializadas nos estudos greco-latinos, no sentido bourdieusiano do termo. Além disso, a partir de tal análise, a própria revista dos sociólogos será revisitada.

\section{"JOVENS" X "VeLHOS"}

Um primeiro elemento digno de nota é a divisão das revistas em "classes de idade". Duas delas, o $\mathrm{BCH}$ e os $\mathrm{MAH}$, a despeito do fato de acolherem reconhecidos especialistas, oriundos sobretudo das redes intelectuais às quais estavam integrados seus diretores, privilegiavam os agrégés recém-saídos da universidade que estagiavam ou estagiaram em Atenas ou em Roma. Tendo em vista o interesse dos "velhos" quanto ao material aí impresso, em geral apresentações de materiais arqueológicos e epigráficos inéditos ou ainda pouco conhecidos, a passagem por uma dessas revistas auxiliava os "jovens" a promover a circulação de seus nomes, facilitando assim a construção de uma reputação. Do outro lado estavam a REG e a REA, voltadas aos profissionais já estabelecidos, desejosos, portanto, de manter ou de ampliar o renome que lhes era acordado por meio dos textos aí publicados. A migração dos primeiros periódicos aos segundos fazia assim parte de um processo natural de envelhecimento no campo.

Ainda quanto a essa dicotomia, é bastante instigante a sequência de fundação das revistas. Afinal, as que privilegiavam a colaboração dos "jovens" apareceram antes das outras. Como explicar tal fenômeno? Discorreu-se na introdução da presente tese que, ao contrário da 
sociologia, os estudos greco-latinos ingressaram na universidade francesa vindos do ensino secundário. Os antiquisants reformistas ao longo da segunda metade do século XIX, ansiando associar a pesquisa científica original com a tradição retórica e literária do secundário, viramse então diante da tarefa de produzir, em uma universidade bastante uniforme, uma divisão do trabalho intelectual mais complexa. O problema todo se resume ao seguinte: em um cenário orientado quase que exclusivamente ao secundário, era preciso construir e garantir nichos voltados à pesquisa e à formação de pesquisadores. $\mathrm{O} \mathrm{BCH}$ e os MAH ilustram tal preocupação de parte da elite universitária dos primórdios da Terceira República. Uma vez que essa formação diferenciada estivesse garantida, a tendência era que os profissionais imbuídos da nova mentalidade de professor-pesquisador almejassem continuar produzindo e divulgando suas pesquisas originais. $O$ aparecimento posterior da REG, antes um boletim interno de uma associação ligada aos antiquisants reformistas, e da REA, criada por professores em início de carreira formados nos quadros do $\mathrm{BCH}$ e do $\mathrm{MAH}$, aponta justamente para um mercado letrado que vai, aos poucos, se estabilizando e, depois, sendo inflacionado.

Outro dado interessante vem da inserção do AS nesse quadro de relações. Com efeito, a revista dirigida por Émile Durkheim não parece obedecer a uma clivagem similar. Em seus primeiros anos, ela é praticamente uma revista de "jovens". Em 1898, por exemplo, ela contava com três professores de província (Durkheim, Bouglé e E. Lévy), um doutor (Richard) e oito agrégés, com idades compatíveis com os colaboradores mais jovens do $\mathrm{BCH}$ e dos MAH. Esse cenário vai se transformando com o passar dos anos, à medida que o grupo original envelheceu, colhendo os frutos de seus trabalhos na forma de reconhecimento dos pares e ascensão da carreira. Mas isso não significa, como já foi visto no subcapítulo 1.1, que o número de pesquisadores em início de carreira decresça demais: em 1910 e 1913, eles representam pouco mais de metade de todos os colaboradores. Nesse sentido, não seria possível também designar o AS como uma revista de "velhos". Trata-se, em verdade, de uma forma mista, compatível com a situação institucional precária de uma ciência vanguardista, a qual ainda não dispunha de um sistema de treinamento (certificados e centros especializados de estudo) na universidade ${ }^{1}$.

\section{PARIS X PROVÍNCIA}

Outro elemento que, independente do primeiro, regulou a relação entre as revistas dos antiquisants foi a oposição Paris $x$ província, estabelecida com a criação da REA. Não se

\footnotetext{
${ }^{1}$ Embora não seja o interesse do presente estudo, seria interessante contrastar a idade média dos colaboradores do AS com a de outras revistas que se dedicavam então às ciências sociais, tais como a Revue Internationale de Sociologie, L'Anthropologie ou mesmo Notes Critiques: Sciences Sociales.
} 
trata aqui de nada novo ou exclusivo ao universo letrado: o processo de centralização burocrático-administrativa do Antigo Regime teve esse efeito. No sistema de ensino, constituído ao longo do século XIX, tal polaridade se expressava na concentração das Grandes Écoles, das bibliotecas e das mais prestigiosas faculdades em região parisiense. Não custa nada evocar aqui os exemplos tão típicos dos grandes heróis masculinos de Balzac, membros de obscuras famílias burguesas e aristocráticas provinciais, os quais vão necessariamente à capital para suas iniciações educacionais (faire son droit) e/ou mundanas (faire sa gloire).

Até 1899 , todas as publicações especializadas nos estudos greco-latinos expressavam os anseios de grupos de letrados instalados em Paris. A REG é um exemplo claro nessa direção, posto que editada por uma associação cuja sede e grande parte do conselho administrativo eram parisienses. O mesmo se aplica ao $\mathrm{BCH}$ e aos $\mathrm{MAH}$. As atividades das instituições que os produziam eram acompanhadas tanto pela Académie des Inscriptions et Belles-Lettres quanto por setores do governo francês, cujas sedes estavam na capital. Além disso, essas duas revistas eram editadas e difundidas também a partir daí (em paralelo às editores estrangeiras que trabalhavam com o mesmo propósito).

A REA se colocou nesse cenário como uma alternativa a isso, posto ter sido criada e gerenciada por professores instalados na Província, com editores igualmente provinciais. Ainda assim, é importante frisar que a tensão oriunda de tal oposição não teve por efeito a quebra do monopólio parisiense. Argumentou-se ao longo do subcapítulo 2.4 que a aposta na "província" enquanto entidade provida de um valor próprio permitiu a ascensão na carreira dos integrantes do grupo original envolvido com a REA. Ou seja, em outras palavras, ela abriu uma brecha para que outros reconhecimentos intelectuais passassem também, necessariamente, por Paris via Académie des Inscriptions et Belles-Lettres ou postos universitários. Eis aí um dos traços conservadores que, de um ponto de vista estrutural, marcaram o aparecimento da REA.

E quanto aos sociólogos durkheimianos? Mais uma vez, a relação deles com essa oposição central aos antiquisants não foi assim tão imediata. Em todo caso, não deixa de ser interessante evocar aqui o exemplo da REA, bastante próximo ao do AS. As duas revistas tinham, afinal, entre seus fundadores, diretores e principais colaboradores professores de província, assim como não representavam nenhuma instituição particular (a AEEG, a EFA ou a EFR). Ou seja, tratavam-se de iniciativas de pequenos grupos de vanguarda universitária. O que não significa, por outro lado, uma sintonia quanto ao conteúdo e às formas de suas atuações. A categoria "província" não teve no AS nenhuma centralidade e os esforços dos membros do grupo foram sempre dirigidos abertamente a Paris. Some-se a isso o fato de o AS possuir, ao contrário da REA, uma editora parisiense (a Alcan). 


\section{LATINISTAS X HELENISTAS}

As tensões e afinidades existentes entre latinistas e helenistas acompanharam a presente tese desde seu início. Elas têm aqui um papel central, pois, aproximando-os como portadores de um saber escolar absolutamente indispensável e, portanto, altamente prestigioso, afastaram-nos quando o assunto dizia respeito à abertura aos modernismos científicos que acompanharam a construção da universidade francesa. Tudo se passa como se, parodiando Marx, o saber histórico e institucionalmente dominante, o latim, fosse dominado por sua dominação, tendo seu desenvolvimento científico retardado por um sucesso mundano e religioso inconteste. $\mathrm{O}$ grego, por outro lado, a despeito de seu papel importante no ensino secundário, era marginal, dominado, em relação ao latim. Seus portadores tinham assim mais espaço de manobra e podiam reclamar outras tradições, sejam elas estrangeiras, religiosas ou mesmo não escolares. Nada ilustra melhor tal situação que o descompasso, assinalado no quadro 2.5.1, entre as instituições dedicadas a um ou outro domínio de estudo.

Quadro 2.5.1 - Instituições dedicadas aos estudos greco-latinos (1846-1923).

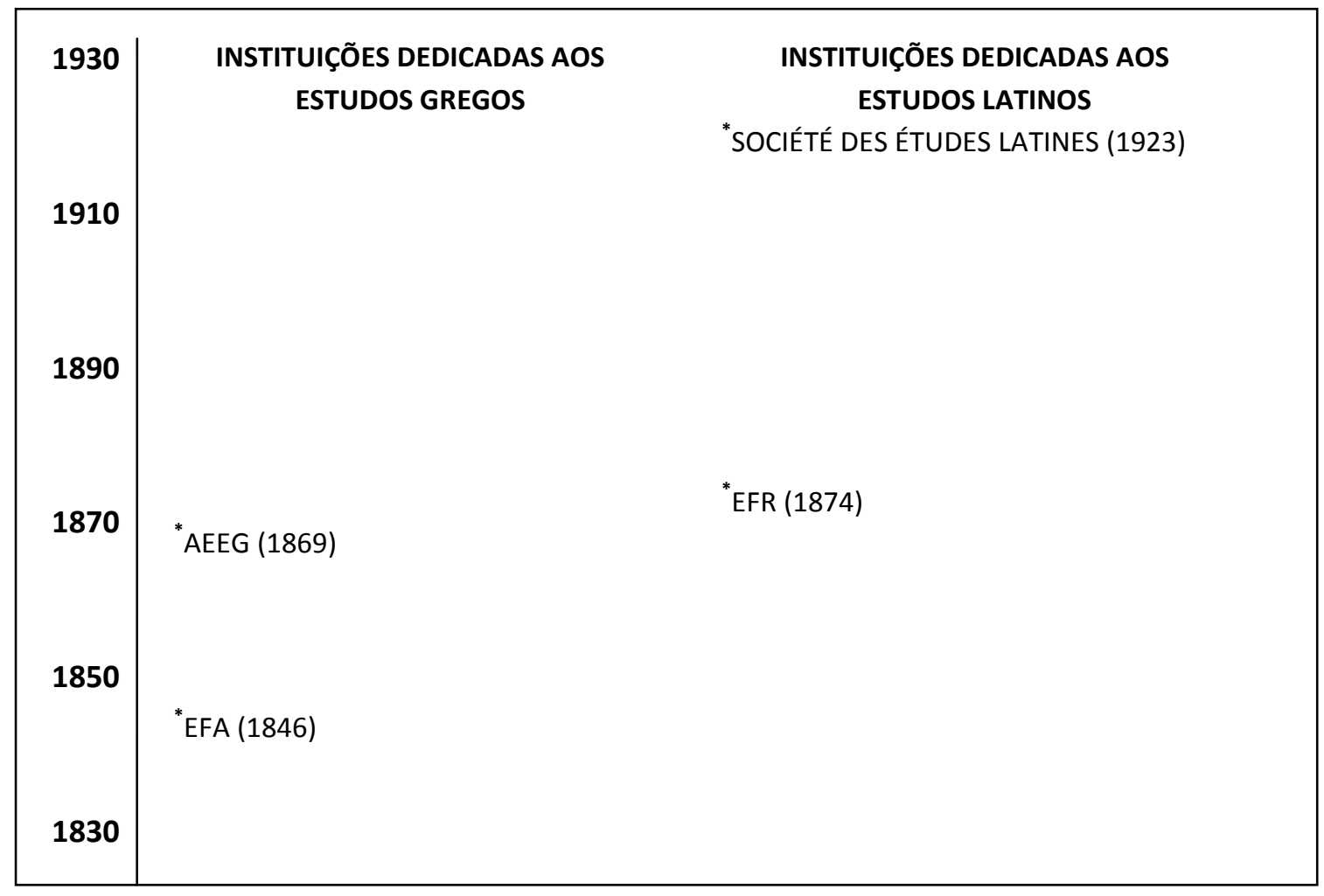

Entre a fundação da EFA e da EFR, contam-se quase trinta anos de diferença. Entre a associação dos helenistas e a dos latinistas, cinquenta e quatro. Ainda no registro das associações, é reveladora a diferença de nomes. Os helenistas agiram já em 1869 como se o saber que eles encarnavam estivesse em perigo, justificando assim o militantismo intelectual e o lobby institucional. Era preciso, afinal, encorajá-lo! Os latinistas, seguros de si, tiveram outra postura bem mais tarde, em 1923. 
Similar assimetria é visível também no campo das revistas especializadas, tal como, resumindo o que foi apresentado nos subcapítulos anteriores, assinala o quadro abaixo:

Quadro 2.5.2 - Revistas dedicadas aos estudos greco-latinos (1877-1923).

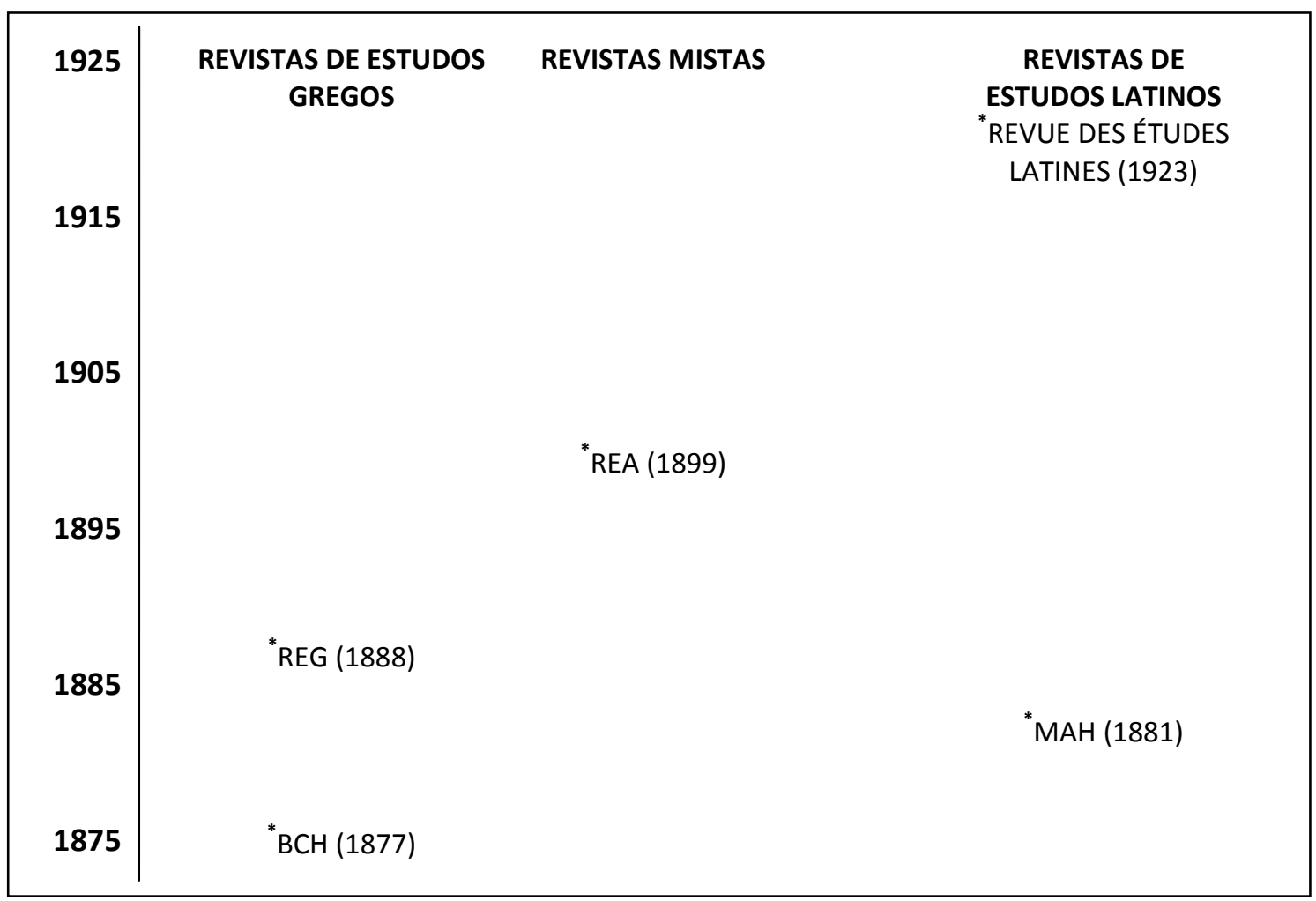

Se o $\mathrm{BCH}$ e os $\mathrm{MAH}$ aparecem em um intervalo relativamente curto, uma Revue des Études Latines só foi instituída em 1923, trinta e cinco anos depois de sua análoga no helenismo (REG) e vinte e quatro anos após uma revista "mista" como a REA.

Por fim, essas diferenças aparecem mesmo em um plano epistemológico. Os helenistas se destacaram por avançar continuamente na divisão do trabalho intelectual, a qual estava ancorada na afinidade presumida entre seu objeto e os ideais universais da ciência e das artes. Ora, nada análogo foi explicitado durante o período aqui analisado por latinistas universitários. O que não significa, por certo, a inexistência de uma base epistemológica. Nesse caso, porém, esta não foi a razão e a beleza originalmente encarnadas pelo homem grego, mas sim a fé católica e os valores mundanos da sociedade francesa leiga em termos acadêmicos. Os colaboradores do AS, por sua vez, embora concebessem os universais em termos menos desencarnados que os helenistas, uniam-se a eles quando o tema era o culto da razão e da ciência. Não parece assim fortuita a presença de helenistas e a ausência de latinistas na primeira série da revista. 


\section{PARTICULARISMOS X UNIVERSALISMOS}

As bases institucionais e epistemológicas que separaram latinistas e helenistas trazem à tona o problema da relação entre o geral e o particular, problematizado de modo explícito nas relações entre os projetos editoriais da REG e da REA. Para colocar tudo da forma mais simples e esquemática possível, poder-se-ia dizer que esta revista se queria a porta-voz de uma nação particular, cuja singularidade, expressa em termos históricos e geográficos - os contatos entre gregos, romanos e celtas em território francês -, deveria ser objeto de culto. $\mathrm{O}$ caso da REG é diferente. Também nela, é verdade, se trata de uma nação particular, a Grécia Antiga. Mas aqui, tal nação ocupa uma posição de destaque e apenas aparentemente paradoxal na história da humanidade: ela encarna com perfeição ideais que então se queriam universais (a razão e a estética, a ênfase ou o tratamento de cada um desses polos variando conforme o helenista).

Os outros universais que poderiam eventualmente ser aí evocados, o império da fé católica com seu deus transcendental e/ou o império político e militar romans, eram muito mais próximos dos estudos latinos e encontraram resistência em uma comunidade letrada definida, ao menos em parte, contra a Igreja e na qual as minorias religiosas (judeus e protestantes) ocupavam um lugar de destaque. Além do mais, a palavra "império" tinha na França do final do século XIX uma conotação política particular, remetendo às experiências com os Bonapartes, não exatamente consensuais.

Muito da acolhida reservada à sociologia durkheimiana nas duas revistas se torna compreensível nesses termos. Afinal, era no mais amplo leque comparatista possível, a princípio desencarnado de objetos dotados de valores em si mesmos, que essa nova ciência queria operar. Sua universalidade, ela a buscava na humanidade que, formada de experiências particulares, apresentava também regularidades em suas variações. Nesse sentido, a ponte com os helenistas da REG era muito mais fácil de ser construída que aquela que os levassem a dialogar com os responsáveis pela REA. Isso não significa, contudo, a ausência de tensões entre os dois lados (sociólogos do AS e helenistas da REG).

\section{DREYFUSARDS X ANTIDREYFUSARDS}

Um episódio da magnitude do Affaire, capaz de atravessar espaços diferentes da sociedade francesa, produzindo novos conflitos e solidariedades onde antes eles não existiam, revelou-se um elemento pertinente para problematizar os vínculos existentes entre as diferentes revistas aqui analisadas. À medida em que foram levantados os dados relativos aos seus principais colaboradores e às posições públicas que eles assumiram durante o Affaire, em 
especial como signatários de petições e/ou artigos em jornais, claros padrões foram se delineando. Entre os sociólogos durkheimianos, a atitude pró-Dreyfus era a regra. Na REG, tratava-se de um grupo importante, senão majoritário. A tendência se inverte quando se passa para a REA. Atento a isso, é possível presumir ou mesmo localizar redes de sociabilidade transcendendo as equipes dessas revistas, tal como aquela existente entre Salomon Reinach e Émile Durkheim, da qual são testemunhas as cartas que este enviou àquele (DURKHEIM, 2010).

\section{PADRÕES de ReLAÇÃo}

Se o analista não pode, como diria Wittgenstein, descrever a totalidade dos fatos que constitui o mundo, nada o impede de isolar certas relações existentes no mundo. Ou seja, todos os pares de oposição acima evocados não representam em absoluto uma realidade que é infinitamente mais complexa. O que eles podem fazer é apenas sinalizar a existência de tensões e afinidades entre elementos, os quais, na prática, jamais atuaram de modo absolutamente isolado. Em todo caso, um grau maior de sofisticação analítica depende da capacidade que o analista tem de cruzar o maior número possível de variáveis sem perder o controle dos nexos existentes entre elas, ou seja, de suas influências recíprocas.

No caso específico da produção de conhecimentos sobre o mundo greco-latino e sobre a sociologia na França, ao menos tal como percebido a partir dos periódicos acadêmicos aqui selecionados, várias linhas de força aparecem aí atuando, tornando inteligíveis relações entre os diferentes atores e entre os próprios periódicos. O interessante a ser observado ao final do presente capítulo é o cruzamento dos vários planos antes evocados de modo isolado. Assim, por exemplo, para evocar um dos casos mais evidentes de homologia estrutural entre esses planos, existe uma clara sintonia entre a militância durante o Affaire Dreyfus e o modo como se justifica epistemologicamente os projetos editoriais das revistas dos "velhos". Na defesa de Dreyfus estava em questão ou os direitos universais de um indivíduo ou o prestígio de uma instituição nacional (a saber, o exército). Não parece assim fortuíto o engajamento de um número grande de colaboradores do AS e de helenistas da REG - para quem esses universais são, de formas e com conteúdos diferentes, objeto de culto - em prol da revisão do julgamento do capitão.

Na página seguinte, por meio de uma análise de múltiplas correspondências, é possível dar uma expressão gráfica para o conjunto do cenário. Isso foi feito tomando como referência os colaboradores das cinco revistas entre 1905, 1906 e 1907 (ou seja, o momento do fim do Affaire Dreyfus e do acirramento de tensões entre estado e Igreja por ocasião da lei que definia a radical separação entre ambos, sobretudo no plano educacional). O eixo vertical do 
gráfico tem por base a idade cronológica dos indivíduos envolvidos, embora essa seja calibrada ao longo da análise a partir das correlações com as outras variáveis. O eixo horizontal, por seu turno, tem por polos ideais, também devidamente calibrados ao longo da análise, as diferentes posições por ocasião do Affaire Dreyfus. Foram ainda considerados os vínculos institucionais, o ambiente religioso familiar (católico, protestante ou judaico) e a circulação entre as revistas dos indivíduos estudados. Note-se ainda que foram excluídos da análise os não franceses e aqueles sobre os quais as muitas lacunas de informação inviabilizavam suas inserções na análise cruzada das variáveis².

Quadro 2.5.3 - O espaço das revistas dos helenistas, dos latinistas e dos sociólogos: correspondências (1905-7).

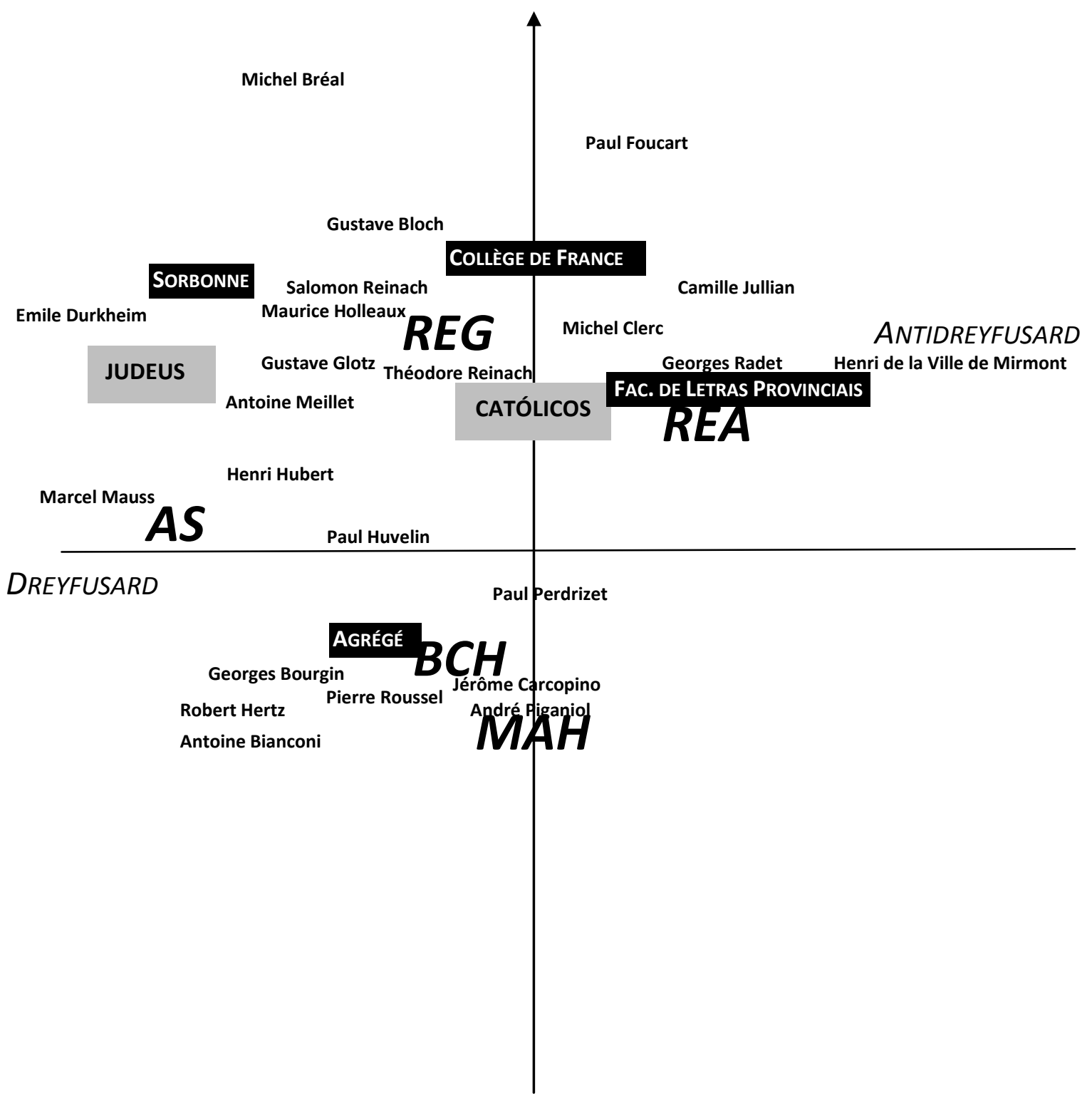

\footnotetext{
${ }^{2}$ Baseio-me aqui nos procedimentos analíticos sugeridos por Brigitte Le Roux. Cf. LE ROUX; ROUANET, 2010 e também ACKERMAN; LE ROUX; ROUANET, 2005.
} 
São dois os fatos interessantes aí apresentados. Em primeiro lugar, em função do sentido dos eixos e das demais variáveis isoladas, ele ilustra bem, no intervalo em questão, o estado das tensões e afinidades que caracterizavam o campo das revistas especializadas nos estudos greco-latinos. Vê-se aí claramente a oposição assimétrica entre a REG e a REA no que diz respeito aos antiquisants consagrados e às instituições de consagração (Sorbonne e o Collège de France), bem como a distância que as separa das revistas dos "jovens", indistintas em função da rara adesão de seus membros à causa do capitão Dreyfus (muitos deles eram então alunos das classes preparatórias ou estavam ainda na ENS).

Em paralelo a isso, ele permite ainda perceber como aí se inserem os colaboradores do AS. Um dos limites mais comuns dos trabalhos relativos à história das ciências sociais reside no seguinte ponto: eles partem em geral do pressuposto da autonomia disciplinar para reafirmar, a partir de um recorte analítico e documental muito específico, essa mesma autonomia. Se é verdade que os portadores de um mesmo saber disciplinar atuam em um espaço comum, delimitado não sem concorrências por vezes tensas nos planos institucional e epistemológico, não é menos correto afirmar que eles, em geral, também circulam em outros espaços. Afinal, nenhum especialista nasceu especialista. O processo que culmina com a definição da especialidade supõe um momento crítico, no qual indivíduos que mais tarde seguirão caminhos diferentes se encontram juntos (trata-se, por exemplo, do período da juventude). Além disso, mas também ligado aos laços aí contraídos, sempre são possíveis circuitos mais ou menos extensos mais tarde. No caso dos sociólogos durkheimianos isso é relativamente fácil de ser vislumbrado, uma vez que sua posição nova não lhes permitia uma atitude defensiva, de fechamento, para o que existia além da sociologia. Mas seria assim tão diferente hoje, quando os diferentes sistemas de ensino nacionais já contam com gerações de especialistas em cada um dos ramos das ciências sociais?

Em todo caso, para voltar aos diálogos entre os sociólogos e os antiquisants, já se constatou que, ao longo dos dois primeiros capítulos, as fronteiras entre os saberes que eles representavam não são assim tão nítidas. Houve um fluxo de ideias e de pessoas em uma e outra direção, o que foi abordado mediante as citações e as colaborações diretas (via artigos e resenhas). Uma análise cruzada de disposições mais gerais, apresentada na forma de gráfico, permite encerrar o segundo capítulo abordando e resumindo as mesmas questões a partir de outra perspectiva. 


\section{CAPÍTULO 3}

\section{HELENISTAS, \\ LATINISTAS E \\ SOCIÓLOGOS: \\ DIÁLOGOS EM \\ INSTITUIÇÕES}


terceiro e último capítulo da presente tese discute instituições francesas que, frequentadas ao mesmo tempo por helenistas, latinistas e sociólogos, permitem explorar em novos contextos os resultados até aqui apresentados. Viu-se antes como cada um dos cinco periódicos estudados - L'Année Sociologique, Bulletin de Correspondance Hellénique, Mélanges d'Archéologie et d'Histoire, Revue des Études Grecques e Revue des Études Anciennes - possuía lastros históricos, temáticos e morfológicos específicos. Discutiu-se ainda, partindo de tais lastros, as interações entre os referidos periódicos, seja na forma de autores compartilhados, seja mediante a apreciação crítica que os colaboradores de um periódico fizeram aos trabalhos publicados nas demais revistas. $\mathrm{O}$ que se depreendeu dessas análises pode ser sintetizado na forma de pares de oposição estruturais velhos $\mathrm{x}$ jovens, latinistas $\mathrm{x}$ helenistas, Paris $\mathrm{x}$ província; dreyfusard $\mathrm{x}$ antidreyfusard - , os quais permitem ao historiador atual compreender melhor tanto tensões e afinidades eletivas inerentes aos antiquisants franceses quanto aquelas que os vincularam aos colaboradores de L'Année Sociologique, e vice-versa. Tudo se passa como se tais oposições explicassem algo da lógica das redes de sociabilidade que então atravessaram instituições e disciplinas universitárias. A reboque, elas ajudam a refletir sobre os limites teóricos e práticos de uma interdisciplinaridade historicamente dada.

Tal embocadura analítica tem, no entanto, um preço. Afinal, ela passa ao largo da particularidade das diversas instituições implicadas diretamente no debate entre os sociólogos durkheimianos e os antiquisants. Isso não significa, bem entendido, que as oposições reconstruídas com a ajuda das revistas especializadas não tenham qualquer validade para além delas. Ao contrário, implica apenas reconhecer que os padrões antes delineados tendem a sofrer maiores ou menores reorientações em cenários nos quais outras variáveis também se fizeram presentes. Qual a história e as particularidades do funcionamento de cada instituição? Que lugar ocupavam elas então no sistema de ensino e pesquisa francês? Quem foram os antiquisants e os durkheimianos aí engajados? Como eles interagiram? A resposta a tais questões permite verificar se houve ou não divergências maiores diante daquilo que foi constatado nos dois primeiros capítulos, tornando a análise aqui proposta mais refinada e completa. É isso o que se tentará nas páginas que se seguem. 
A priori, todos os espaços institucionais compartilhados entre 1898 e 1920 por colaboradores de L'Année Sociologique e por aqueles provenientes de uma ou mais revistas especializadas no mundo greco-latino permitem desenvolver a questão. Poder-se-ia, por exemplo, discutir o caso da Faculdade de Letras de Paris, onde Émile Durkheim, Albert Demangeon e Célestin Bouglé conviveram com renomados antiquisants (Paul Girard, Gustave Bloch, Gustave Glotz, Aimé Puech, Maurice Holleaux, entre outros). O mesmo se aplica à EPHE, onde Marcel Mauss, Henri Hubert, Antoine Meillet, Charles Fossey e Isidore Lévy trabalharam ao lado de Henri Weil, Adhémar Esmein, Jules Toutain e Adolphe-Joseph Reinach. E os exemplos não param por aí: o Collège de France (no qual Antoine Meillet e Charles Fossey lograram ingressar), a Faculdade de Letras de Bordeaux (onde Durkheim, Gaston Richard, Paul Lapie e Pierre Roussel ocuparam cadeiras), a Faculdade de Letras de Toulouse (onde Bouglé iniciou carreira no ensino superior), a Faculdade de Direito de Lyon (à qual estiveram ligados Émmanuel Lévy e Paul Huvelin), o Musée des Antiquités Nationales (onde Henri Hubert trabalhou), e assim por diante. Não obstante, alguns desses contextos são atualmente bem conhecidos. É o que ocorre, em particular, com os espaços nos quais transitaram Durkheim e Mauss, autores cujo legado não cessou de ser retomado e/ou atacado. Mas se as Faculdades de Letras de Bordeaux e Paris, às quais se soma a EPHE, foram privilegiadas pela historiografia, o mesmo não se pode dizer das demais instituições acima mencionadas.

Pensando justamente em sanar lacunas deixadas pela historiografia, foram aqui selecionadas três instituições, muito diferentes entre si, para serem alvo de estudos de caso: o Collège de France (CF), o Musée des Antiquités Nationales de Saint-Germain-en-Laye (MAN) e o Dictionnaire des Antiquités Grecques et Romaines (DAGR).

O texto relativo ao CF (subcapítulo 3.1) investiga os sucessos e fracassos que as candidaturas dos durkheimianos aí enfrentaram, com especial destaque para a participação de helenistas e latinistas nos pleitos. Particularmente antigo e singular em sua organização, o CF representava em fins do século XIX e inícios do XX um dos ápices possíveis para as carreiras de professor e pesquisador na França. Conviviam nele os maiores expoentes de vários ramos das ciências e das artes. Daí as perguntas: como funcionava o recrutamento do CF e quais elementos, em geral e em cada eleição, mobilizaram os integrantes da casa na defesa de um ou de outro candidato? Com o intuito de responder a isso, foram mobilizadas as atas das assembleias da instituição, cartas pessoais de indivíduos envolvidos nos pleitos e memórias de antigos professores.

Na sequência, será a vez de discutir o caso do MAN (subcapítulo 3.2). Primeiro museu francês exclusivamente voltado à arqueologia nacional e européia, foi nele que Henri Hubert, um dos principais colaboradores de L'Année Sociologique, iniciou sua carreira de pesquisador e 
trabalhou lado a lado com Alexandre Bertrand e Salomon Reinach, arqueólogos e helenistas de renome. O propósito desse subcapítulo é, por um lado, compreender a importância de tal instituição não apenas para o sistema de ensino, mas também para as redes de sociabilidade intelectuais da França. Além disso, em seguida, importa saber qual o papel da sociologia na instituição e que proveito puderam os sociólogos durkheimianos tirar dela. Para tanto, além de livros e artigos impressos, foram utilizados os arquivos depositados no referido Museu (hoje renomeado Musée d'Archéologie Nationale et Domaine National de Saint-Germain-en-Laye), em especial os dossiês de correspondência da instituição e o fundo Henri Hubert.

O terceiro e último item, por sua vez, trata do maior dicionário dedicado à Antiguidade greco-latina jamais produzido na França, o DAGR (subcapítulo 3.3). Publicado ao longo de quarenta e dois anos, ele sintetizou os conhecimentos de várias gerações de latinistas e helenistas, mantendo-se por longa data como instrumento privilegiado de pesquisa e ensino dos clássicos. Para além dos dados relativos a sua história e morfologia, interessa aqui a atuação dos durkheimianos nesse empreendimento editorial. Quais sociológicos dela participaram? Sobre o que escreveram? Como se deu o processo de recrutamento e a recepção de seus textos entre os antiquisants? Para responder a tais questões serão mobilizados, além do próprio dicionário, dossiês de correspondências pertencentes ao Institut Mémoire de l'Édition Contemporaine e os arquivos do Musée d'Archéologie Nationale. 


\title{
3.1 OS DURKHEIMIANOS
}

\section{NO COLLÈGE DE FRANCE:}

\section{NOTAS SOBRE OS LIMITES}

\section{DE REPRODUÇÃO DE UM}

\section{CORPO PROFESSORAL}

\section{(1897-1918)}

\begin{abstract}
"O Ministério deve fazer alguns cortes de alinhamento nas altas copas do Ensino Superior. O Museu de História Natural, o Instituto Zoológico e o Collège de France serão metodologicamente esclarecidos. Aposentar-se-á uma dúzia de professores, de chefes de trabalhos e de naturalistas auxiliares, ou de assistentes, se você preferir. Serão atingidos todos os que tiveram o mal gosto de chegar a uma situação oficial sem ter se curvado diante dos examinadores da Sorbonne..."
\end{abstract}

Maurice Maindron (L'Arbre de Science, 1906, pp. 12-3)

Poucos são os temas mais espinhosos para a história social das ciências sociais que a reprodução dos corpos de letrados nelas engajados. Como são definidas as pessoas responsáveis por escolher seus futuros pares? Quem são os eleitos para ocupar os postos disponíveis? Quais fatores concorrem para fortalecer um ou mais nomes em detrimento de outros? Como, enfim, a posição institucional das ciências sociais se transforma ou se conserva entre uma e outra geração de pesquisadores? A lógica da produção intelectual encontra aqui 
outras lógicas, sobre as quais uma deontologia mais ou menos explícita obriga, ao menos em determinados círculos, a calar. Nada mais revelador, portanto, sobre os elementos implicados na constituição das (e na tensão entre as) formas do entendimento professoral.

Em se tratando da história da equipe constituída em torno de L'Année Sociologique, contudo, não se pode negar que os avanços foram consideráveis nos últimos quarenta anos. Tudo se passa como se o efeito eufemizador do tempo - a universidade da Quinta República francesa não é exatamente a mesma da Terceira - e o progressivo acúmulo de novos documentos permitissem hoje ter uma ideia mais precisa do que esteve em jogo na viabilização das trajetórias profissionais dos durkheimianos.

Victor Karady deu um importante passo nessa direção ao estudar comparativamente a emergência institucional das ciências sociais francesas e a composição de seus quadros originais (KARADY, 1976). No caso da sociologia, quanto aos traços marcantes de sua história, ele sublinhou a origem tardia, nas décadas de 1880-1890, e precária, tendo como primeiro representante um jovem professor, Émile Durkheim, instalado em uma universidade provincial, Bordeaux. Tratava-se também de um saber com epistemologia própria e com atuação interdisciplinar, atendendo a demandas variadas no interior das Faculdades de Letras e de Direito.

A despeito desse frágil estribo institucional, a sociologia durkheimiana conseguiu se firmar como saber autônomo, conquistando ao longo dos anos um lugar de visibilidade no sistema educacional francês. Para explicar tal sucesso relativo, Karady evocou, antes de tudo, a morfologia do grupo envolvido com a nova ciência: grande parte de seus quadros provinha das elites letradas republicanas, o que incluía a passagem pela École Normale Supérieure e/ou a obtenção dos mais prestigiosos certificados de ensino nacionais. Além do mais, longe de permanecerem dispersos, seus integrantes trabalharam coletivamente em uma revista especializada, L'Année Sociologique. Por fim, eles lograram obter postos-chave em instituições de ensino e de pesquisa da época.

Ora, se há um ponto assinalado por Karady que vem suscitando investigações constantes, trata-se justamente dos sucessos e dos fracassos institucionais dos durkheimianos ${ }^{1}$. As biografias dedicadas aos dois nomes mais célebres dessa escola, Marcel Mauss e o próprio Durkheim, esclareceram muitas das circunstâncias que marcaram suas candidaturas junto à École Pratique des Hautes Études, à Sorbonne e ao Collège de France ${ }^{2}$. 0 mesmo pode ser dito de toda uma série de estudos centrados em instituições específicas, com

\footnotetext{
${ }^{1} \mathrm{O}$ próprio Karady avançou ainda mais em suas hipóteses em um artigo produzido posteriormente. $\mathrm{Cf}$. KARADY, 1979.

${ }^{2}$ LUKES, 1973; FOURNIER, 1994 e FOURNIER, 2007.
} 
ênfase na já mencionada École Pratique des Hautes Études (doravante EPHE) ${ }^{3}$. O que se infere desses trabalhos é um cenário parisiense marcado, até 1918, por uma alta taxa de sucesso por candidatura dos durkheimianos na EPHE e na antiga, mas em plena modernização, Faculdade de Letras de Paris (a "Nouvelle Sorbonne", como então se dizia). Durkheim, Mauss, Hubert, Bouglé, Meillet, Demangeon, Moret, Lévy, Fossey, Hertz e Simiand transitaram por esses espaços. Mas eis que o cenário muda quando se considera o Collège de France (doravante $\mathrm{CF})^{4}$. Nele, apenas Meillet e Fossey lograram obter nomeações até o término da Primeira Guerra, sendo essas para cadeiras a priori não sociológicas (Grammaire Comparée e Philologie et Archéologie Assyriennes, respectivamente). Similar fracasso foi ainda mais emblemático ao se considerar o número de cadeiras relacionadas às ciências sociais criadas no período (quadro 3.1.1), bem como as candidaturas dos colaboradores de L'Année Sociologique (quadro 3.1.2).

Quadro 3.1.1 - Cadeiras nominalmente relacionadas às ciências sociais criadas no Collège de France (1897-1918).

\begin{tabular}{|l|c|}
\hline NOME DA CADEIRA & ANO DE CRIAÇÃO \\
\hline Philosophie Sociale & 1897 \\
\hline Sociologie et Sociographie Musulmane & 1902 \\
\hline Histoire du Travail & 1907 \\
\hline Études des Faits Économiques et Sociaux & 1912 \\
\hline Géographie Humaine & 1912 \\
\hline Prévoyance et Assistances Sociales & 1917 \\
\hline
\end{tabular}

Quadro 3.1.2 - Candidaturas de sociólogos durkheimianos ao Collège de France até 1918.

\begin{tabular}{|l|c|r|}
\multicolumn{1}{|c|}{ SOCIÓLOGO CANDIDATO } & ANO & CADEIRA AMBICIONADA \\
\hline Émile DURKHEIM & 1897 & Philosophie Sociale \\
\hline Antoine MEILLET & 1906 & Grammaire Comparée \\
\hline Charles FOSSEY & 1906 & Philologie et Archéologie Assyriennes \\
\hline Marcel MAUSS & 1907 & Histoire des Religions \\
\hline Marcel MAUSS & 1909 & Histoire des Religions \\
\hline François SIMIAND e Hubert BOURGIN & 1912 & Études des Faits Économiques et Sociaux \\
\hline
\end{tabular}

Diante desses dados, algumas questões se impõem: o que explica a resistência à "escola sociológica francesa" no CF, justo quando tal instituição se abria aos temas sociais? E mais: como reagiram a ela os portadores de saberes já consolidados, em especial os helenistas

\footnotetext{
${ }^{3}$ Veja-se, a esse respeito, MUCCHIELLI, 1998b; STRENSKI, 2000; e BROOKS, 2002.

${ }^{4} \mathrm{O}$ único texto específico que encontrei sobre a questão é uma nota, bastante informativa, publicada por Philippe Besnard (1979b).
} 
e os latinistas? Responder a tais perguntas é o propósito do presente subcapítulo. Mas antes de analisar contextos e fatos que marcaram as candidaturas dos colaboradores de L'Année Sociologique, discutir-se-á aqui a posição do CF no conjunto do sistema de ensino francês, as particularidades de seu recrutamento e, por fim, as linhas de força que o caracterizaram no período aqui estudado.

\section{O COLLÈGE DE FRANCE I: DISPOSIÇões HERÉTICAS}

O estudo de uma instituição requer mais que a simples análise sincrônica de sua posição em um universo específico, seja ele o estado nacional ou o mercado de alguma modalidade de bem. Sua história, entendida aqui como o conjunto tanto dos traços que marcaram sua organização interna quanto das posições que ocupou em um ou mais domínios da vida social, é outro dado crucial. De fato, também as instituições, por meio de seus funcionários e estatutos, incorporam disposições, manifestando-as com maior ou menor intensidade ao sabor das circunstâncias.

Tendo como pano de fundo a Reforma e o Renascimento, a fundação do CF é central para a explicação de características ainda hoje perceptíveis em seu funcionamento. Criado em 1530, o então chamado Collège Royal foi a expressão maior de um movimento de letrados no seio da corte de François I, o qual obteve amplo apoio do monarca. Tal movimento se destacou por sua postura crítica diante das instituições de ensino medievais ${ }^{5}$. Seus partidários queriam, por um lado, inovar em termos de conteúdo. Assim, longe de ser mais um baluarte da escolástica, o Collège Royal dedicou-se às ciências e ao estudo de línguas. Suas primeiras cadeiras foram a de grego e a de hebraico, às quais se somaram, ao longo dos séculos XVI e XVII, outras oito (árabe, siríaco, eloquência latina, filosofia antiga, matemáticas, cirurgia, medicina e direito canônico). Além das diferenças de conteúdo, foram aí implementadas inovações quanto à forma. Ao contrário das universidades, o Collège Royal não possuía turmas fixas, abrindo suas portas a todos os que desejassem acompanhar o que ali era ensinado. Do mesmo modo, ele não fornecia diplomas, nem preparava seus alunos para quaisquer tipos de exames. Em suma, trata-se da primeira instituição francesa que, via mecenato estatal, consagrou inovações importantes por iniciativa de grupos organizados de letrados, rompendo com o monopólio das corporações de ensino e da Igreja Católica ${ }^{6}$.

\footnotetext{
${ }^{5}$ Sobre o contexto mais geral desse movimento, cf. DURKHEIM, 1999: 134-260.

${ }^{6}$ Tal tendência parece constituir a principal invariante do caso francês: ao invés de reformar o cerne do sistema de ensino, opera-se a inovação a partir das margens, criando instituições cuja presença força paulatinamente um desequilíbrio do conjunto e seu subsequente rearranjo. Quanto ao Antigo Regime, veja-se GRELL, 1995: 45-143. No que se refere ao século XIX, cf. RINGER, 1992: 40-93.
} 
Ainda que a influência do CF tenha variado com o tempo, o pacto inicial com o poder central visando a uma maior autonomia intelectual e científica continuou se fazendo sentir em sua história. Por certo, o ímpeto reformista de seus primeiros anos foi, em vários momentos, arrefecido: ora os representantes estatais não se sensibilizavam com as demandas das vanguardas letradas, ora a coesão mesma dessas vanguardas vacilava, ora seu possível impacto era neutralizado pela ação de correntes ortodoxas. Sem se tornar uma instituição convencional, o CF também teve de ceder, abrigando eventualmente representantes do establishement ${ }^{7}$. O período anterior à Revolução Francesa reservou a ele, no entanto, um crescendum de prestígio. O CF surgiu aos olhos dos contemporâneos como uma alternativa ao modelo educacional em vigor no Antigo Regime. A primeira École Normale e as Écoles Centrales, enquanto experiências revolucionárias, buscaram nos saberes lá ensinados opções para um currículo em demasia carregado de latim, de literatura clássica e de retórica ${ }^{8}$.

Sem que reformas profundas e duradouras do sistema de ensino pudessem ser então realizadas, a primeira metade do século XIX, repleta de revoluções e contra-revoluções, acabou reforçando a posição central do CF para a vida intelectual da França. Nesse ínterim, ele se notabilizou mais uma vez por ser um porto seguro para pensadores autônomos e cientificamente originais. $O$ auge da instituição veio, contudo, logo em seguida, nas décadas de 1860 e 1880. Segundo Christophe Charle, sob pressão da universidade alemã, o CF se converteu em lar de maîtres à penser em vários campos novos do saber, os quais foram sendo aos poucos disseminados nas universidades (CHARLE, 1997). Marcelin Berthelot em química, Claude Bernard em medicina, Joseph Bertrand em física, Théodule Ribot em psicologia, Ernest Renan em línguas e história bíblicas, Michel Bréal em linguística; todos possuíam renome internacional e estavam afinados com o que se produzia de mais moderno Europa afora. Isso não significa que pensadores "mundanos", campeões da tradição retórica francesa, não estivessem lá representados. Ainda assim, foi àquele grupo de notáveis que os governos do Segundo Império e da Terceira República recorreram com o intuito de modernizar o sistema de ensino. Nesses tempos em que reformas eram debatidas e realizadas, a eleição para o CF passou a ser percebida como a coroação de uma trajetória bem-sucedida, amparada pelo reconhecimento dos pares e do estado.

Mas eis que nas décadas seguintes, as mais importantes para a presente tese, o CF viu sua soberania ameaçada. Para explicar tal fenômeno, deve-se considerar aqui tanto as reformas na Faculdade de Letras de Paris (a Nouvelle Sorbonne) quanto a consolidação da

\footnotetext{
${ }^{7}$ A Contra-Reforma e as guerras de religião, as quais levaram a um fortalecimento das ordens religiosas católicas dentro da França, tiveram um papel nada desprezível nessa direção, mantendo o CF por muito tempo às margens. Veja-se, para mais detalhes: QUÉNIART; LÉBRUN; VÉNARD, 1981.

${ }^{8}$ LÉON; ROCHE, 2008: 48-68.
} 
École Pratique des Hautes Études (EPHE). Fundado em 1868, esse instituto de pesquisas avançadas foi estruturado em torno de seminários especializados, os quais criaram condições para a efetiva profissionalização de várias áreas do conhecimento. Dele saíram as primeiras gerações de pesquisadores universitários em filologia, epigrafia, linguística e história da França. Por certo, dado o interesse constante do CF em disciplinas originalmente abrigadas na EPHE, era difícil que esta preservasse intactos seus quadros. Como será visto adiante, não era incomum que vários professores seus concorressem ao mesmo posto daquela instituição, atraídos por melhores salários, menor carga horária de aulas e maior prestígio. 0 papel de "celeiro" não retira, porém, seu brilho próprio, capaz de produzir concorrentes de peso e sucessores à altura dos titulares do CF.

A reforma da Faculdade de Letras de Paris, por sua vez, representou um perigo maior. Uma das mais antigas e emblemáticas instituições francesas, ela alimentou até a década de 1880 o ideal do honnête homme, o indivíduo munido de uma formação geral de cunho literário. Com esse espírito "mundano", ela atendia às demandas dos liceus e das faculdades provinciais, as quais, à medida que celebravam os mesmos valores, mantinham o sistema refém de um círculo vicioso. Diante de tal constatação, os reformistas da Terceira República optaram por atacar a estrutura a partir de cima, transformando a Sorbonne em um centro de pesquisas capaz de propor aos franceses uma nova formação e, sobretudo, uma nova moral, laica e republicana. As reformas realizadas em 1902 quanto ao baccalauréat tiveram tal propósito: a partir desse momento, os alunos não foram mais obrigados a saber latim para ingressar no ensino superior, podendo optar por línguas modernas e ciências como suas matérias de exame. Do mesmo modo, atacou-se a cisão entre universidades e Grandes Écoles (École Normale Supérieure, École Polytechnique, École des Chartes, entre outras). Em meados da primeira década do século $X X$, os alunos dessas instituições parisienses de elite passaram a ter de assistir, ao lado dos demais estudantes, a cursos na Sorbonne. As reformas afetaram, por fim, o leque de saberes oferecidos. Alfred Espinas, Émile Durkheim, Octave Hamelin, Gustave Bloch, Albert Demangeon, Charles Seignobos, Gustave Lanson, entre outros, todos pensadores originais em suas áreas de atividade, a despeito das diferenças que os separavam, encarnaram os novos ideais da instituição. Ou seja, a Sorbonne passou também a cultivar a excelência na inovação ${ }^{9}$.

Se o CF era o único espaço do sistema de ensino no qual a heterodoxia poderia triunfar até fins da década de 1860, isso mudou com a criação da EPHE. Se até a década de 1880 ele se mantinha entre uma Sorbonne "mundana" e uma EPHE "científica", a guinada pró-ciência

\footnotetext{
${ }^{9}$ Uma análise minuciosa do contexto acima referido pode ser encontrada em RINGER, 1992: 196-237.
} 
daquela instituição alterou todo o equilíbrio do sistema. Sabe-se como os escritores da época retrataram o fenômeno ${ }^{10}$. Paul Bourget, em Le Disciple (1889), e Maurice Barrès, em Les Déracinés (1897), denunciaram a corrupção moral da juventude francesa com a deturpação dos liceus pelo regime republicano. Maurice Maindron, em L'Arbre de Science (1906), e Charles Péguy, em L'Argent Suite ${ }^{11}$, fizeram o mesmo quanto ao ensino superior. Sobretudo para estes últimos autores, o CF, emblema de uma grandeza pré-reformas e pré-Guerra de 1870, estava sendo alvo de ataques por parte de quem pretendia a "germanização" e a instrumentalização política da universidade. $O$ fato é que as reformas no sistema de ensino e o papel que nelas deveriam ter os novos e os antigos saberes mobilizaram, em uma ou outra direção, amplos setores da sociedade. O CF não escapou ao turbilhão: dentro dele enfrentaram-se várias tendências, produzindo testemunhos nada desprezíveis para o historiador. Por ocasião das candidaturas de colaboradores de L'Année Sociologique, como será visto adiante, os combates foram por vezes ferozes, mobilizando argumentos não necessariamente intelectuais.

\section{O CollÈGE DE FRANCE II: UM SISTEMA DE RECRUTAMENTO PARTICULAR}

Antes de tratar desses argumentos e das posições que eles encarnam, é preciso esclarecer certas especificidades do sistema de recrutamento do CF. Desde os primórdios da instituição, duas regras foram sempre observadas: em primeiro lugar, tão logo uma cadeira se tornasse vacante por morte, incapacidade permanente ou aposentadoria do antigo ocupante, os demais professores deveriam debater se seu título seria mantido ou alterado em função de progressos substantivos em outra área do conhecimento; em segundo lugar, para além do prestígio científico ou literário, jamais houve exigências de quaisquer títulos para viabilizar uma candidatura. $O$ derradeiro preceito era bastante compreensível no contexto de fundação do $C F$, uma vez que seus integrantes eram especialistas em saberes para os quais a universidade não fornecia treinamento. Ainda assim, tal costume resistiu ao tempo, permitindo que indivíduos operando fora do mainstream pudessem tentar aí sua sorte e, por vezes, sua consagração.

Quanto ao procedimento eleitoral, com apenas uma exceção que será tratada a seguir, toda decisão relativa aos novos integrantes do CF é atribuição exclusiva de seus professores reunidos em assembleia. Tendo chegado o dia designado, após a apresentação pública dos candidatos por um ou mais professores e as deliberações que se seguem, todos votam individual e secretamente. Ao menos a partir de fins do século XIX, o colegiado tinha a incumbência de sugerir ao estado dois nomes. Cada um deles era definido em votação própria,

\footnotetext{
${ }^{10}$ Veja-se RINGER, 1992: 237-247; e SAPIRO, 2004.

${ }^{11}$ PÉGUY, 1992: 848-996. O texto faz referências à malograda campanha de Brunetière ao CF.
} 
a qual poderia se passar, dependendo das divisões internas dos professores, em um ou mais turnos. O nome que obtivesse o maior número de votos na primeira rodada expressava o desejo da maioria simples da assembleia quanto ao candidato julgado o mais apto a integrar os quadros da instituição. No jargão do CF, este era o candidato indicado "em primeira linha" (en première ligne). Após tal escolha, tinha início uma nova votação para definir o segundo nome, o qual era indicado "em segunda linha" (en deuxième ligne).

Em geral, o estado francês, por meio do seu Ministère de I'Instruction Publique, respeitava a decisão da assembleia e atribuía a cadeira vacante ao nome que constava "em primeira linha", transformando a outra em sinal de reconhecimento e de encorajamento a futuras candidaturas. Ainda assim, ele detinha o poder de nomear o indicado "em segunda linha", invertendo a ordem sugerida. Bastava, nesse caso, alguma vontade política forte o bastante para fazer frente às reações de parte do colegiado e da opinião pública. A outra possibilidade de intervenção estatal configura a exceção antes mencionada. Durante a Terceira República, a nomeação direta do titular, sem votação, era possível. Tratava-se, entretanto, de uma alternativa pouco usual, pois restrita aos primeiros titulares de cadeiras que o próprio estado criava em acréscimo às já existentes. Mas como tal imposição também não era obrigatória, cabia aos dirigentes políticos decidir se fariam ou não uso de sua prerrogativa ${ }^{12}$. Por fim, existia uma terceira via de entrada, embora o droit de cité fosse aí parcial. Se um mecenas optasse por financiar uma cadeira específica no CF, bastava o aval dos integrantes da casa para a abertura da vaga e a continuidade dos recursos para sua manutenção. $O$ titular da nova cadeira não possuía, porém, direito de voto na assembleia. Gabriel Monod e Ernest Babelon são exemplos de professores que ingressaram na instituição por tal via ${ }^{13}$.

E quanto aos candidatos? Tendo em vista a organização do processo seletivo, resumiam-se a duas as suas alternativas: ou eles dispunham de padrinhos políticos capazes de empossá-los como titulares de uma cadeira nova, ou precisavam fazer campanha. Como entre 1897 e 1918 apenas seis cadeiras foram criadas pelo estado, a segunda alternativa foi, de longe, a mais frequente. Há toda uma série de relatos que informam detalhes do processo ${ }^{14}$. Tão logo a abertura de uma vaga era oficializada, os pretendentes encaminhavam ao administrador da instituição, um professor da casa eleito para a função, uma carta formal revelando seu interesse em participar do pleito. Tal carta era acompanhada de um currículo atualizado do candidato, o qual deveria conter detalhes de sua trajetória e uma lista de suas

\footnotetext{
${ }^{12}$ Essa situação não se aplicava, bem entendido, aos casos de mudanças de rótulos das cadeiras antigas, pois aí o primeiro titular teria de ser escolhido em consonância com os desejos do colegiado.

${ }^{13}$ Havia, por certo, a possibilidade da efetivação da cadeira por parte do estado. Foi o que aconteceu com Ernest Babelon a partir de 1908, cinco anos após sua nomeação como chargé de cours.

${ }^{14}$ Destaco aqui os casos de Alfred Loisy (1913) e de Maurice Halbwachs (1999).
} 
principais publicações. Uma vez isso feito, era preciso visitar todos os integrantes do CF, dando início à fase mais intensa da campanha, a do corpo a corpo. No intervalo entre o anúncio da candidatura e a eleição, cada um ativava seus contatos. Devido ao prestígio da instituição, era muito difícil um candidato se apresentar seriamente para a "primeira linha" sem ter algum apoio interno, seus ouvidos e olhos durante a campanha. Era também sempre possível averiguar as posições dos votantes indiretamente, por meio de investigações junto a seus círculos íntimos. Todos os interessados em uma determinada vaga, sejam eles candidatos ou professores, iam assim sentindo o terreno e fazendo seus cálculos, colecionando promessas de apoio e declarações de hostilidade. Os processos não excluíam campanhas difamatórias, das quais inúmeras correspondências e autobiografias são hoje testemunhas. Tratavam-se, em resumo, de verdadeiras batalhas, diante das quais a ingenuidade e a ambição desmedidas cobravam seu preço.

\section{O COLLÈGE DE FRANCE III: LINHAS DE FORÇA}

Ao lado da dimensão formal das votações, convém considerar as complexas relações sociais implicadas em cada caso. Quem foram, afinal, os avaliadores dos sociólogos? Quais tensões ou afinidades eletivas, de ordem institucional, econômica, política e religiosa, fizeramse sentir entre eles? Por certo, diferentes fatores, tais como o caráter secreto das votações e o número de variáveis envolvidas, impedem a formalização de um modelo capaz de tudo explicar. Ainda assim, em se tratando de uma "escola sociológica francesa" morfológica e epistemologicamente coesa, alguns padrões mais gerais podem ser reconstituídos.

Para abordar a questão, optou-se aqui por analisar junto à documentação de época as atas de assembleias, bem como cartas ou textos autobiográficos de seus professores e candidatos - as categorias com as quais os próprios contemporâneos expressaram as linhas de força atuantes no CF. Uma primeira classificação evocada de maneira sistemática é aquela que distingue "cientistas" e "literários". Tipicamente francesa, ela remete às reformas educacionais realizadas durante e após a Revolução de 1789. Até então, a universidade subsistia com a mesma estruturação herdada do século XIII, a qual supunha faculdades de direito, de medicina, de teologia e de artes. Enquanto as três primeiras atendiam aos interesses das elites burocráticas e religiosas, a faculdade de artes oferecia cursos de formação geral, servindo de antessala para os interessados em frequentar as outras instituições de ensino. A partir de 1808 , contudo, diante do progresso das ciências e do peso da literatura francesa, as faculdades de artes foram subdivididas, dando origem a instituições juridicamente equivalentes às demais. De um lado, foram criadas as faculdades de ciências, integrando a matemática, a física, a química e a biologia; de outro, dedicando-se ao estudo de línguas e de literaturas, 
nasceram as faculdades de letras. Era natural que, tendo operado às margens do sistema universitário do Antigo Regime, o CF fosse sensível a essa cisão e buscasse congregar o que havia de mais inovador e de prestigioso entre os integrantes das novas faculdades. Em fins do século XIX, tais categorias já estavam tão naturalizadas que Ernest Renan notava, não sem ironia, a tendência dos "cientistas" do CF a votar melhor quando a eleição dissesse respeito aos "literários", sendo a recíproca também verdadeira (apud CHARLE, 1997). Mas não se tratava apenas da qualidade do voto: tendo em vista as divisões internas existentes no interior de cada uma dessas comunidades, era comum que o apoio maciço de um grupo definisse a eleição de uma cadeira do outro. Observando-se a composição do CF entre 1897 e 1918, podese notar que, embora o número de cadeiras vinculadas aos cientistas fosse significativamente menor, um equilíbrio de forças se manteve entre os dois pólos.

Quadro 3.1.3 - Composição do CF (1897-1918): “cientistas" e "literários" (em números absolutos e relativos).

\begin{tabular}{|l|c|c|c|c|}
\hline & 1897 & 1904 & 1911 & 1918 \\
\hline Cadeiras de ciências/sciences & $11(26,8 \%)$ & $12(27,3 \%)$ & $14(30,4 \%)$ & $13(28,3 \%)$ \\
\hline Cadeiras de letras/lettres & $30(73,2 \%)$ & $32(72,7 \%)$ & $32(69,6 \%)$ & $33(71,7 \%)$ \\
\hline Total de cadeiras & $41(100 \%)$ & $44(100 \%)$ & $46(100 \%)$ & $46(100 \%)$ \\
\hline
\end{tabular}

Outra divisão, a qual permite complexificar a anterior, remete à organização interna do Institut de France. Criado durante a Revolução Francesa, ele serviu para reunir sob um só teto as cinco academias, quais sejam: a Académie Française, a Académie des Sciences, a Académie des Beaux-Arts, a Académie des Inscriptions et Belles-Lettres e a recém-fundada Académie des Sciences Morales et Politiques. Não é o caso de abordar aqui a história dessas instituições ${ }^{15}$. Importa sublinhar, contudo, que elas jamais mantiveram vínculos formais com o sistema de ensino, servindo apenas como instâncias visando ao mecenato e à consagração de artistas e de pesquisadores das mais váriadas áreas. Nesse sentido, era normal que um professor do CF fosse igualmente eleito ao menos para uma dessas academias, ainda que, por questões próprias a elas, isso nem sempre acontecesse.

As divisões do Institut de France interessam à presente tese porque, aos olhos dos universitários franceses da época, afirmavam e refinavam fronteiras entre saberes. A Académie des Sciences (AdS) agregava os cientistas: matemáticos, físicos, químicos e biólogos. Da Académie Française (AF) e da Académie des Beaux-Arts (ABA) participavam músicos, artistas plásticos, escritores e críticos em geral. Já a Académie des Inscriptions et Belles-Lettres

\footnotetext{
${ }^{15}$ Veja-se, para uma visão panorâmica, os livros de Antoine Marès (1995) e, sobretudo, André Damien (1999).
} 
(AIBL) reunia especialistas em línguas e literaturas, arqueólogos e epigrafistas. A Académie des Sciences Morales et Politiques (ASMP), por fim, acolhia filósofos e aqueles que, por um viés teórico, descritivo ou normativo, propunham-se a pensar questões políticas e sociais. Ora, era nesse espaço novo, potencialmente suspeito aos olhos do estado e dos demais letrados, que a sociologia teria de conquistar seu espaço. Atento a isto, Pierre Janet chegou mesmo a evocar o "equilíbrio entre as academias" para sustentar uma possível candidatura de Durkheim ao CF em 1905, tal como se verá mais adiante. Na prática, entre 1897 e 1918, constata-se que as cadeiras ligadas a Académie des Inscriptions et Belles-Lettres (AIBL) dominaram a instituição, oscilando de 18 em 1897 (43,9\% do total) a 20 em 1918 (43,5\% do total). Já a Académie des Sciences Morales (ASMP) e a Académie des Sciences (AdS), cada uma delas deteve cerca de um quarto dos postos do CF. As demais, juntas, não superaram os $5 \%$.

Quadro 3.1.4 - A composição do CF (1897-1918): o quinhão das Academias (em números absolutos e relativos).

\begin{tabular}{|l|c|c|c|c|}
\hline & 1897 & 1904 & 1911 & 1918 \\
\hline Cadeiras ligadas à AIBL & $18(43,9 \%)$ & $19(43,2 \%)$ & $20(43,5 \%)$ & $20(43,5 \%)$ \\
\hline Cadeiras ligadas à AS & $11(26,8 \%)$ & $12(27,3 \%)$ & $14(30,4 \%)$ & $13(28,3 \%)$ \\
\hline Cadeiras ligadas à ASMP & $10(24,4 \%)$ & $11(25 \%)$ & $11(23,9 \%)$ & $12(26,1 \%)$ \\
\hline Cadeiras ligadas às artes & $2(4,9 \%)$ & $2(4,5 \%)$ & $1(2,2 \%)$ & $1(2,2 \%)$ \\
\hline Total de cadeiras & $41(100 \%)$ & $44(100 \%)$ & $46(100 \%)$ & $46(100 \%)$ \\
\hline
\end{tabular}

Similar divisão do trabalho intelectual se fez sentir nas eleições para o CF. Em primeiro lugar, ela recomendava que os candidatos propusessem elos entre saberes. Afinal, a pura erudição deveria suscitar a hostilidade de cientistas, assim como, por outro lado, o cientista desconectado de um estilo autoral ou de uma formação geral poderia alimentar a antipatia dos portadores de saberes eruditos e dos artistas. É interessante observar, porém, que esses polos ideais encontravam-se dentro de cada uma das divisões institucionais dos saberes. Houve aqueles que, entre os homens de letras e eruditos, aproximaram-se dos métodos científicos, assim como existiram entre os cientistas indivíduos mais sensíveis a uma erudição de cunho literário. Já os candidatos ligados a saberes próximos a Académie des Sciences Morales et Politiques, em função da própria constituição dessa instituição, encarnavam uma posição ambígua, situada entre a ciência, a erudição e a política.

Mas as formas do entendimento professoral não se alimentam apenas de variáveis de natureza intelectual ou institucional. Maurice Halbwachs, ao comentar os resultados de sua 
campanha ao CF em 1944, descreveu da seguinte maneira as forças contrárias e favoráveis a ele (HALBWACHS, 1999: 227):

Segundo eu soube dos diversos lados (e segundo as garantias que alguns me deram), eis aqui os que devem ter votado em mim: Piéron, Tonnelat, Leriche, Gabriel, Piganiol, Grenier, Pelliot, Massignon, Maspero, Joliot, Lacassagne, Roques (todos estes, ou seja 12 com certeza), FauréFremiet, Coornaert, Robert (?), Chassigneux, Faral (?), ou seja, 17.

Votaram contra mim [estas duas palavras enquadradas], por Gouhier: Gilson, Lavelle, Baruzi, Mazon, Hazard, Siegfried, Lacau (?), Fallot, Defraisse, de Brouglie, Duclaux (?), Valéry (?), 12. Febvre deve ter sido o único a votar em Renaudet no segundo turno.

Piéron crê que Faral votou contra mim, em Gouhier, por razões administrativas, - temendo que minha eleição suscitasse dificuldades da parte do ministério. Isto me surpreenderia. Impossível desvendar esse mistério.

Em suma, eu tive contra mim os filósofos católicos, a Académie Française, os clericais, o único representante (grande burguês) da Académie des Sciences Morales et Politiques (da qual sou correspondante), os cientistas reacionários.

Eu tive a meu favor todos os linguistas, os especialistas de diversas civilizações (exceto Mazon), os historiadores, os cientistas avançados, sobretudo quatro biólogos (ou médicos). Faltaram-me dois ausentes Przyluski e Wallon (que estava ao meu lado, mas cujo curso foi suspenso), e também (segundo Piéron) Courrier: ou seja, três ausentes. (...)

Em resumo, filosofia metafísica e religiosa, literatura pura, ciência dos brucutus [brutiers], contra história sociológica, psicologia científica, linguística e biologia. Tudo isso era natural.

Poder-se-ia dizer, e com razão, que as divisões internas ao Institut ou a oposição "ciência" e "literatura" ajudam a esclarecer o resultado das eleições. Não obstante, como se percebe ao ler Halbwachs, elas são parciais e adquirem maior ou menor relevo a partir das costuras que as unem a outras variáveis. A origem social, a formação religiosa e a preferência política certamente poderiam influenciar as preferências dos eleitores. O peso de cada uma dessas variáveis é, no entanto, circunstancial. Tudo depende da composição da assembleia, de quem eram os candidatos, assim como de contextos políticos maiores (no caso, o Affaire Dreyfus, o interesse de determinado governo em se fazer representar no CF, entre outros).

Sabe-se, graças aos dados apresentados por Christophe Charle e Eve Telkès (1988), que a morfologia dos professores do CF foi, entre 1870 e 1914, bastante heterogênea. Embora os católicos prevalecessem, encontravam-se entre eles um número importante de indivíduos oriundos de minorias confessionais, com destaque para os judeus. As orientações políticas são também variadas: entre alguns monarquistas e outros tantos socialistas, a grande maioria se dividia entre os republicanos liberais e os conservadores. A mesma lógica se impõe quanto ao Affaire Dreyfus. Sobretudo entre os cientistas, o engajamento pró-Dreyfus foi considerável, assim como existiram aqueles que se colocaram do outro lado das trincheiras. Tratava-se, em suma, de um cenário bastante instável, aberto a uma série considerável de alianças e conflitos possíveis. Nesse sentido, o CF distingue-se da Nouvelle Sorbonne, onde as minorias religiosas, 
os professores de esquerda e os dreyfusards encontravam-se relativamente em maior número (CHARLE, 1985).

Por fim, antes de passar ao exame das candidaturas dos durkheimianos, cumpre destacar o peso nada desprezível de helenistas e de latinistas, estes portadores de saberes tradicionais, na composição da assembleia do CF. Entre 1897 e 1918, seu número variou de seis a oito, compreendendo as seguintes cadeiras (e seus respectivos titulares): Histoire de la Littérature Latine (Gaston Boissier e Paul Monceaux), Épigraphie et Antiquité Romaine (René Cagnat), Philologie Latine (Louis Havet), Langue et Littérature Grecques (Maurice Croiset), Épigraphie et Antiquité Grecques (Paul Foucart), Philosophie Grecque et Latine (Charles Lévêque e Henri Bergson), Histoire et Antiquités Nationales (Camille Jullian), Numismatique de I'Antiquité et du Moyen Âge (Ernest Babelon) e Histoire de l'Afrique du Nord (Stéphane Gsell) ${ }^{16}$. A única dessas cadeiras que não orbitava o universo da Académie des Inscriptions era a de Philosophie Grecque et Latine, cujos titulares, Lévêque até 1900 e Bergson entre 1900 e 1904, pertenciam à Académie des Sciences Morales et Politiques. Em 1905, porém, com transferência de Bergson para a cadeira de Philosophie Moderne, Philosophie Grecque et Latine transformou-se em Histoire et Antiquités Nationales, passando aos domínios da Académie des Inscriptions. No referido intervalo, foram instituídas apenas duas novas cadeiras ligadas ao estudo de Grécia e Roma antigas: a de Numismatique de l'Antiquité et du Moyen Âge (1908) e a de Histoire de l'Afrique du Nord (1912).

E quanto à morfologia dos antiquisants? Em termos de idade, o mais velho era Charles Lévêque (1818), seguido de Gaston Boissier (1823), Paul Foucart (1836), Maurice Croiset (1846) e Louis Havet (1849). O restante do grupo era composto de pessoas pertencentes ou próximas à geração de Durkheim (1858): René Cagnat (1852), Ernest Babelon (1854), Camille Jullian (1859), Henri Bergson (1859), Paul Monceaux (1859) e o caçula Stéphane Gsell (1866). Salvo Ernest Babelon, ex-aluno da École des Chartes, todos haviam se formado na ENS. Além disso, três haviam sido membros da École Française d'Athènes (Lévêque, Foucart e Monceaux) e outros dois, da École Française de Rome (Jullian e Gsell). Em sua grande maioria, eles provinham de famílias católicas, havendo dois protestantes (Jullian e Gsell) e um judeu (Bergson). Já quanto à atuação no Affaire Dreyfus, tomado aqui como indicador de tendências políticas, sabe-se que Havet e Gsell empenharam-se na defesa do capitão, enquanto Babelon manifestou opinião contrária. Os demais não parecem ter tomado partido publicamente.

\footnotetext{
${ }^{16}$ É preciso não se deixar aqui enganar pelo título. Gsell era um latinista de formação e participou do início das grandes explorações arqueológicas na Tunísia e na Argélia. A cadeira criada para ele no CF foi assim inteiramente dedicada ao estudo da África romana.
} 
Uma vez apresentado esse panorama geral, é o momento de observar como as variáveis evocadas atuaram nas eleições envolvendo durkheimianos.

\section{DURKHEIM: OS PRIMEIROS E PARADIGMÁTICOS FRACASSOS}

A mais antiga candidatura ao CF de alguém ligado à equipe de L'Année Sociologique foi a do próprio Émile Durkheim. Ele se apresentou oficialmente em 1897 e foi sondado extraoficialmente sete anos mais tarde. No primeiro caso, a oportunidade surgiu da decisão governamental de criar no CF uma cadeira adicional intitulada Philosophie Sociale. Pouco antes da explosão do Affaire Dreyfus, as greves nas minas de carvão de Carmaux (1892-1895) e a organização de forças políticas de esquerda trouxeram as questões ditas "sociais" ao primeiro plano. $O$ estado francês, também por intermédio de suas instituições de ensino, não quis se ausentar do debate.

Três pesquisadores dedicados às ciências sociais escreveram ao administrador do CF demonstrando interesse pela vaga. Durkheim, o mais jovem do grupo, havia acumulado até então trunfos nada desprezíveis: antigo aluno da École Normale Supérieure, de onde saiu agrégé de philosophie, ele era docteur-ès-lettres e professor efetivo da Faculdade de Letras de Bordeaux, onde ocupava as cadeiras de Science Sociale e de Pédagogie. Entre seus livros já publicados encontravam-se De la Division du Travail Social (1893), Les Règles de la Méthode Sociologique (1894) e o polêmico Le Suicide, recém-lançado. Contava ainda a seu favor o fato de estar reunindo em torno de si jovens entusiastas das ciências sociais, os quais preparavamse para lançar uma revista especializada, L'Année Sociologique, no ano seguinte.

Os outros pretendentes eram Alfred Espinas e Jean Izoulet. O primeiro, nascido em 1844, também havia frequentado a École Normale Supérieure e obtido a agrégation de philosophie. Sua trajetória profissional foi marcada por uma longa carreira docente em liceus e universidades. Na Faculdade de Letras de Bordeaux, onde esteve a partir de 1878, Espinas precedeu Durkheim como titular da cadeira de Pédagogie e assumiu uma série de encargos administrativos, entre eles o de recteur da instituição. Sua "promoção" veio dezesseis anos depois, quando designado para assumir a cadeira de Histoire de l'Économie Sociale na Sorbonne. Além de um considerável prestígio intelectual e institucional, sua tese defendida em 1877, Les Sociétés Animales, foi considerada o texto fundador da sociologia científica na França. Espinas era, entre os candidatos, o de renome mais consolidado. Jean Izoulet, por seu turno, ao menos quanto a critérios intelectuais, dava a impressão de "correr por fora". Nascido em 1854 e, tal como seus concorrentes, antigo normaliano e agrégé de philosophie, ele havia se dedicado ao estudo do pensamento social pré-revolucionário (sobretudo Rousseau) e dos primórdios da organização universitária francesa. Professor de longa data em um conceituado 
liceu parisiense, o Condorcet, sua mais conhecida obra publicada antes de 1897 era La Cité Moderne et la Métaphysique de la Sociologie.

A julgar por sua correspondência pessoal, tal como apresentada por Marcel Fournier (2007: 343-346), Durkheim manteve-se bastante cético quanto às reais chances de ser eleito. De fato, após alguns entraves orçamentários que ameaçaram barrar a criação da cadeira, ficou clara a intenção do estado de nomear o primeiro titular, evitando assim qualquer consulta junto aos professores da casa. Tendo em vista as orientações políticas conservadoras do governo Fauré, Alfred Espinas e Émile Durkheim foram descartados. A despeito das diferenças existentes entre eles, ambos representavam correntes de pensamento heterodoxas na universidade francesa, assim como eram portadores de ideias suspeitas quanto à religião e à política $^{17}$. Izoulet foi então o escolhido para ocupar a vaga. A decisão não parece ter surpreendido Durkheim, que predisse a seu sobrinho: "se não for Izoulet, será [Gabriel] Tarde" (DURKHEIM, 1998: 81). O fracasso foi tanto maior quanto mais ele fez aumentar a resistência aos durkheimianos no CF. Com efeito, na sequência, Izoulet se notabilizará por uma série de ataques às conquistas institucionais da equipe de L'Année Sociologique.

A segunda oportunidade, jamais transformada em candidatura oficial, surgiu com a morte precoce de Gabriel Tarde em 1904. Titular da cadeira de Philosophie Moderne, ao mesmo tempo interlocutor e adversário dos durkheimianos, Tarde fora na virada do século uma das maiores referências francesas quanto às principais questões sociais de seu tempo (a criminalidade, as grandes massas urbanas, entre outros $)^{18}$. Durkheim, na época, era um dos poucos pesquisadores com suficiente prestígio para substituí-lo. Com efeito, ele havia reforçado seu currículo e sua posição na universidade nos últimos anos: agora, além de colher os frutos do sucesso da revista que dirigia, ele ocupava, como suplente, a cadeira de Science de l'Éducation na Sorbonne. Some-se a isso o papel de destaque que teve como fundador da Ligue des Droits de l'Homme e como dreyfusard. Restava apenas saber o que seria feito da cadeira vacante.

Uma sequência de episódios alterou repetidas vezes o cenário. Em primeiro lugar, frustrando candidaturas já anunciadas, Henri Bergson tomou o antigo posto de Tarde, abandonando o seu, a cadeira de Philosophie Grecque et Latine. Novos candidatos apresentaram-se então para a antiga cadeira de Bergson. No entanto, a situação novamente se

\footnotetext{
${ }^{17}$ Espinas era ateu convicto, ao passo que Durkheim provinha de uma tradicional família judaica de província. Quanto à dimensão política da nomeação, Besnard (1979b), ao fazer menção aos debates do senado francês sobre a questão, mostrou como os parlamentares estavam interessados em nomear alguém abertamente contrário ao socialismo (o que certamente descredenciaria Durkheim).

${ }^{18}$ Sobre Tarde e sua relação com os durkheimianos, cf. CONSOLIM, 2008 e FOURNIER, 2007.
} 
transformou. Na assembleia do dia 28 de novembro de 1904, os professores da casa decidiram por ampla maioria, vinte e quatro contra dez, pela transformação da cadeira. De início, foram feitas cinco propostas: Histoire Générale, Philosophie Générale, Antiquités Nationales, Pédagogie e, por fim, Sociologie ${ }^{19}$.

Nesse momento, os sociólogos tiveram como "advogado" Pierre Janet, professor de Psychologie Expérimentale et Comparée e contemporâneo de Durkheim na École Normale Supérieure. Janet parece pensar em seu antigo camarada ao lançar à assembleia a seguinte proposta: "Ele [Janet] pede um ensino novo, o da sociologia, a qual tem um caráter filosófico e que lança hoje uma viva luz: há um savant que aplicou um método verdadeiramente científico e que faz escola. Seria interessante abrir a ele as portas do Collège. A cadeira de sociologia entraria no grupo das ciências morais e não modificaria o equilíbrio do Collège de France". Bergson e Le Chatelier, professor de Sociologie et Sociographie Musulmane, aderiram de imediato à proposta, embora o último tenha feito ressalvas, questionando o colega acerca de qual sociologia ele tinha em mente. Do outro lado, Histoire Générale e Antiquités Nationales foram associadas seja à tradição de ensino de Michelet e de Maury, seja à necessidade de um trabalho e erudição mais especializado. Três antiquisants (Cagnat, Boissier e Havet) e um germanista (Arthur Chuquet) sustentaram tais propostas. Não há indícios na ata sobre quem propôs a cadeira de Pédagogie e o único a sugerir a opção Philosophie Générale foi o linguísta Michel Bréal. Após dois turnos de votação, a decisão se tornou impossível: onze votos para Sociologie, onze para Histoire Générale e onze para as Antiquités Nationales.

Durkheim, sondado por Bergson e Janet, estava ciente da simpatia e do empenho de seus colegas, embora o cenário lhe parecesse pouco propício, tal como testemunham cartas que escreveu a seu sobrinho (DURKHEIM, 1998: 354-355). No dia 15 de janeiro de 1905, a assembleia voltou a se reunir para retomar o debate ${ }^{20}$. Na ocasião, a defesa da sociologia veio da parte de Bergson, o qual foi bastante explícito em relação a Durkheim: "a sociologia, como ele [Bergson] a concebe, é uma dependência das ciências históricas e das ciências positivas. Ela só pretende aplicar suas pesquisas ao passado, mas tem na realidade aplicações práticas; ela estabelece relações que não se imaginam entre fatos. Ela deu origem a uma publicação importante, L'Année Sociologique." Além disso, acrescentou ele, tal saber não encontrava acolhida na Sorbonne ${ }^{21}$. Em seguida, Grégoire Wyrouboff, professor de Histoire Générale des Sciences e um notório positivista, declarou apoio a Bergson.

\footnotetext{
${ }^{19}$ Ver nos arquivos do Collège de France, Assemblée du 29 novembre 1904, o documento G-IV-g21R.

${ }^{20}$ Arquivos do Collège de France, Assemblée du 15 janvier 1905, veja-se o documento G-IV-g22M.

${ }^{21}$ De fato, a cadeira de Durkheim só foi transformada em Science de l'Éducation et Sociologie anos mais tarde, em 1913.
} 
Mas tal discurso não demoveu os concorrentes dos sociólogos. Em verdade, tudo indica que os partidários de Histoire Générale e os de Antiquités Nationales chegaram a um entendimento antes mesmo da votação. Dois dos principais defensores dessas propostas, os antiquisants Boissier e Cagnat, reformularam suas demandas e propuseram uma nova cadeira intitulada Histoire et Antiquités Nationales. Os argumentos utilizados para sustentar tal mudança foram similares aos de Bergson: tratava-se de uma ciência nova, positiva, desprovida de espaço na Sorbonne e situada em uma encruzilhada de saberes. Essa proposta ainda recebeu o importante apoio de Albert Réville, eminente pastor protestante francês e professor de Histoire des Religions. Por fim, nadando contra a corrente, o helenista Paul Foucart requisitou que fosse mais uma vez votada a manutenção da cadeira de Philosophie Ancienne. Ao fim dos debates, o resultado da votação foi o seguinte: de trinta e três votantes, uma anulação, dezenove votos para Histoire et Antiquités Nationales, dois para Philosophie Grecque et Latine e os mesmos onze da última assembleia para Sociologie.

O que dizer desse embate? É difícil identificar com precisão quem votou com e contra a sociologia. Motivos políticos não são evocados e havia dreyfusards dos dois lados. Os membros da Académie des Sciences Morales et Politiques, embora a cadeira a ser transformada pertencesse a seus domínios, permaneceram divididos. Bergson e Janet optaram pela sociologia. Em cartas escritas a Mauss, Durkheim dá a entender que teria o apoio de Léroy-Beaulieu (Économie Politique) e Levasseur (Géographie, Histoire et Statistique Économique) $)^{22}$. Réville, ao qual certamente se somou Izoulet, permaneceram junto aos historiadores e antiquisants. Entre os especialistas em línguas e civilizações, o único apoio certo era o de Sylvain Lévi (Langue et Littérature Sanscrites). Entre os cientistas, apenas Wyrouboff se pronunciou. A proposta vencedora, por seu turno, teve ao seu lado o grosso da Académie des Inscriptions et Belles-Lettres, assim como parte da Académie des Sciences Morales et Politiques. Era já o bastante.

$\mathrm{Na}$ assembleia ocorrida em abril de 1905, dois pesquisadores se apresentaram para disputar a cadeira recém-transformada, dos quais um se dispôs a concorrer apenas para a segunda linha. Em votação tranquila, Camille Jullian, normaliano, agrégé d'histoire et de géographie, notório protestante, professor em Bordeaux e diretor de uma revista (a Révue des Études Anciennes) foi eleito contra o jovem ex-normaliano e latinista Jules Toutain ${ }^{23}$.

\footnotetext{
22 DURKHEIM, 1998: 354-355.

${ }^{23}$ Para mais detalhes sobre a eleição de Jullian, veja-se o subcapítulo 2.4 da presente tese.
} 


\section{MONSIEUR SCHMIDT: UMA REVELADORA SÁTIRA DO PATRÃO DA SOCIOLOGIA}

Quem morava na rua Saint-Jacques, lecionava na Sorbonne, era cientista social e tinha um sobrinho professor? Além de Émile Durkheim, este era também o caso de Onésime Schmidt, personagem do romance L'Arbre de Science, de Maurice Maindron.

Criado em uma família de artistas, mas naturalista de formação, Maindron converteu-se à literatura, com a qual teve um sucesso apenas relativo (DOUMIC, 1911). Em seu L'Arbre de Science, de 1906, ele denunciou a corrupção das instituições de ensino e de pesquisa francesas por forças políticas.

O enredo desse seu romance tem como pano de fundo o Muséum d'Histoire Naturelle, onde se dá o conflito entre Médéric Bonnereau, naturalista exemplar, e Mirifisc, ex-normaliano burocrata, interessado em sacrificar a ciência a seus próprios interesses. Além dos embates diretos, os dois disputam ainda o destino do jovem Chéroy, palentólogo promissor. Ao longo do romance, com a ajuda da sedutora Mme Keller, Mirifisc consegue fazer com que Chéroy trabalhe contra Bonnereau, o que leva o jovem a, na sequência, tirar a própria vida.

Schmidt, a paródia de Durkheim, é um aliado de Mirifisc. Ambos, em verdade, atendem ao mesmo patrão, Maintoulat, socialista que, vendendo-se como democrata, almeja controlar o estado nomeando seus aliados para posições- chave. Desse grupo, Schmidt é o porta-voz e o grande responsável por doutrinar os jovens. Uma de suas primeiras descrições no livro é bastante reveladora (MAINDRON, 1906: 75-6):

"Graças a Maintoulat, o Senhor Schmidt foi entronizado na Sorbonne para aí ensinar a ciência política e social. O programa essencialmente vago deste ensino que remetia a todos os temas sem se prender a nenhum permitiu ao Senhor Schmidt de falar sobre poucas coisas com uma gravidade confessional sempre prudente e velada. O governo apreciava nele este lado representativo. Sr. Schmidt foi logo alertado da estima que tinham por ele os maçons. Então, ele declarou guerra ao Deus Pai, ao Filho e ao Espírito Santo, e tentou os desautorizar com argumentos científicos ao mesmo tempo arrogantes e capciosos."

Embora o partido favorável a Durkheim no CF em 1904 tenha só enfrentado argumentos de ordem intelectual, é provável que a imagem apresentada por Maindron dois anos mais tarde já circulasse entre alguns professores da casa. 0 sucesso político de Jaurès, assim como a proximidade entre ele, Durkheim e grande parte da equipe de L'Année Sociologique não eram ignoradas. Pode-se também dizer que as teses de Durkheim sobre o fundamento social da crença, desenvolvidas sobretudo após o início da publicação de L'Année Sociologique, não o tornaram mais popular entre seus muitos colegas praticantes.

\section{MEILleT: A tRANQUILA ELEIÇÃo de UMA UNANIMIDADE}

Um ano após a segunda oportunidade perdida por Durkheim, dois pesquisadores ligados ao grupo de L'Année Sociologique obtiveram sucesso em suas candidaturas: Antoine 
Meillet e Charles Fossey foram eleitos no dia 17 de dezembro de 1905, mas em circunstâncias muito diferentes.

Meillet apresentou-se para a cadeira de Grammaire Comparée, cujo titular, Michel Bréal, de quem fora aluno, acabava de se aposentar. Com trinta e nove anos na época, ele havia feito brilhantes estudos na Sorbonne, onde se preparou para a agrégation de grammaire (1889-1 lugar). No CF, ele não era um estranho, tendo aí atuado como suplente de Bréal entre 1899 e 1900. Seus postos efetivos, porém, eram na École Pratique des Hautes Études (EPHE), onde ocupava uma cadeira homônima à do CF, a qual lhe foi atribuída em 1891, após o retorno de Ferdinand de Saussure a Suíça, e na École des Langues Orientales Vivantes. Meillet dominava como poucos as línguas eslavas, o iraniano antigo e o armeniano, aos quais se somavam o grego e o latim. Tratava-se assim de um herdeiro legítimo e bastante prestigiado entre os linguistas, dotado de um conhecimento excepcional tanto de línguas quanto dos problemas teóricos de sua disciplina.

A adesão de Meillet à empresa durkheimiana era pública e notória ${ }^{24}$. Seus primeiros contatos com os sociólogos datavam do período em que ele era professor na EPHE e devem-se certamente a Mauss e a Hubert, seus colegas na instituição. A partir de 1902, Meillet passou a colaborar regularmente com o AS, publicando resenhas em todos os números da revista e um longo artigo intitulado Comment les Mots Changent de Sens (AS, 1906: 1-37). A possibilidade de tratar a linguagem como um fato social, tal como o definia Durkheim, foi incorporada por ele como a pedra fundamental de toda pesquisa linguística moderna. Em se tratando de uma sumidade em sua área, ele trouxe prestígio e contribuições intelectuais enormes ao projeto científico encabeçado por Durkheim ${ }^{25}$.

Em sua campanha para o CF, Meillet teve de enfrentar um único candidato, Maurice Grammont, especializado na língua francesa, o qual requisitou, em sinal de respeito, que seu nome fosse apenas considerado para a votação "em segunda linha". Assim, logo no primeiro turno, ele venceu a disputa com trinta e três dos trinta e quatro votos disponíveis (houve uma anulação) $^{26}$. Mas se a eleição de Meillet se passou sob o signo da unanimidade, sua aula inaugural suscitou reações. No dia 13 de fevereiro de 1906, diante de um auditório cheio, ele teceu um elogio da sociologia em detrimento do método histórico, tal como o trecho reproduzido abaixo permite constatar (MEILLET, 1948: 18):

\footnotetext{
${ }^{24}$ Veja-se também o subcapítulo 1.2 da presente tese.

${ }^{25}$ Uma exposição concisa da trajetória de Meillet pode ser encontrada em VENDRYES, 1937. Quanto ao teor de suas teses e impacto que elas tiveram no grupo de L'Année Sociologique, remeto ao compterendu que escrevi para tratar de uma nova edição de Comment les Mots Changeant de Sens (BENTHIEN, 2011) e a um recente artigo de Pierre Swiggers (2009).

${ }^{26}$ Cf. nos Arquivos do Collège de France, a pasta Assemblée du 17 décembre 1905 (G-IV-g27).
} 
Mas é mais importante indicar os problemas novos colocados pelo progresso da ciência que de repetir as soluções, aliás necessariamente incompletas, que receberam os antigos problemas: 0 dever do professor é, sobretudo aqui, mostrar mais as pesquisas a serem feitas que os resultados dos trabalhos já feitos. O século XIX foi o século da história, e os progressos que realizou a linguística ao se colocar sob o ponto de vista histórico foram admiráveis; as ciências sociais se constituem agora e a linguística deve tomar aí o lugar que a sua natureza determina. Chegou, portanto, o momento de marcar a posição dos problemas linguísticos por um ponto de vista social. Olhar para o futuro ao invés de olhar para o passado é o meio de seguir o exemplo do mestre que me precedeu nesta cadeira [Michel Bréal] e de permanecer fiel ao espírito da nobre casa que me deu o privilégio de me acolher.

Belas e decidadas palavras, mas talvez um pouco ousadas para um público repleto de historiadores renomados e de pesquisadores não necessariamente simpáticos à sociologia. $\mathrm{A}$ resposta veio de forma rápida em uma breve nota publicada na Revue des Études Anciennes, codirigida por Camille Jullian, outro professor do CF. Nela, Meillet foi considerado ingênuo ao sustentar uma ciência nova e pouco estabelecida, a sociologia, frente a um saber preciso e erudito, a história (REA, 1906: 272-5). É bem verdade que isso não afetou seu prestígio enquanto linguista, nem impediu que ele fosse aclamado por latinistas e helenistas na sequência, graças às suas obras dedicadas à história das línguas clássicas (MEILLET, 1913 e 1928) e seu engajamento junto à Association pour l'Encouragement des Études Grecques en France. Some-se a seu favor, a despeito de seu engajamento pró-Dreyfus, a discrição no que tange às posições políticas, afastando-o da militância mantida por muitos durkheimianos. Ainda assim, sua aula inaugural certamente não serviu para acalmar os ânimos daqueles que, por vários motivos, observavam os sociólogos com desconfiança e hostilidade.

\section{FOSSEY: UM SUCESSO “ILEGÍTIMO”}

Realizada na mesma assembleia que elegeu Meillet, a eleição de Charles Fossey para a cadeira de Philologie et d'Archéologie Assyriennes, cujo titular, Jules Oppert, havia falecido, detonou uma grande controvérsia intelectual e política, a qual reverberou dentro e fora do sistema de ensino superior. Na época com 36 anos, Fossey havia obtido o que havia de mais prestigioso em termos de formação universitária. Antigo aluno da École Normale Supérieure e da EPHE (1891-1893), assim como ex-membro da École Française d'Athènes (1894-1897) e do Institut Français d'Archéologie Orientale du Caire (1897-1899), ele iniciou carreira como helenista para, em seguida, converter-se ao orientalismo. Seu primeiro posto de ensino, na EPHE, já estava ligado às antigas sociedades do Crescente Fértil, e mais especialmente às crenças mágico-religiosas desses povos, tema de sua tese (FOSSEY, 1902). Fossey notabilizou- 
se também por ter publicado o primeiro manual de assiriologia francês (1904), bem como, em conjunto com Vincent Scheil, uma gramática assíria (1901).

Data desses anos iniciais de sua atividade profissional o contato com os sociólogos, intermediado por Meillet, Mauss e Hubert, seus colegas na EPHE. Sua adesão ao grupo foi, no entanto, circunstancial, muito embora os contatos entre eles tenham se mantido. Fossey escreveu apenas duas resenhas para o sexto volume do AS e duas para o sétimo (AS, 1903: 264-266; 1904: 342-343), todas na seção de sociologia religiosa e relacionadas aos mitos e ritos babilônicos. Além disto, ele participou do projeto coletivo, coordenado por Henri Hubert e Isidore Lévy, de tradução do manual de história das religiões de Chantepie de La Saussaye (1904). A circulação de seus trabalhos entre os membros de L'Année Sociologique não foi, aliás, isenta de críticas. Na resenha que Hubert escreveu sobre sua tese, ele critica o autor por escorar-se em uma série documental bastante incompleta, composta de apenas quarenta e seis peças litúrgicas, para fundar um conceito puramente operacional da magia assíriobabilônica, além de não problematizar as traduções já publicadas do material (AS, 1904: 273275).

Concorrendo com Fossey apareceram três candidatos: Joseph Halévy, François Thureau-Dangin e Vincent Scheil. O primeiro, nascido em 1827, era um velho routier da assiriologia francesa. Ele contava com uma longa lista de publicações e uma carreira já bem estabelecida na EPHE. Mas a idade avançada, beirando aos 80 anos, não servia de grande estímulo aos professores do CF. Philippe Berger, professor de Langues et Littérature Hébraïque, Chaldaïque et Syriaque, ao apresentar a candidatura de Halévy, resume-se a sublinhar que ele permaneceu "na sombra" do antigo titular, mas que deveria ser considerado "um iniciador". Se Halévy era velho demais, Thureau-Dangin era possivelmente muito novo. Com 33 anos em 1905, ele ainda se estabelecia como assiriólogo, sendo o conservador responsável por essa área no Museu do Louvre. 0 terceiro caso era, porém, diferente ${ }^{27}$. Nascido em 1858, o padre Vincent Scheil pertencia a setores intelectualizados da Ordem Dominicana. Ele havia seguido os estudos de teologia até ingressar, em 1887, como aluno na EPHE. Uma vez na instituição, Scheil atuou em várias escavações nos atuais Irã e Iraque, inclusive fazendo parte da missão que descobriu o Código de Hamurabi, do qual foi o primeiro tradutor. Desde 1895, ele dava aulas na EPHE como maître de conférence, tendo sido promovido em 1902 a directeur d'études adjoint. Nessas circunstâncias, Fossey e Scheil despontavam como favoritos para assumir a cadeira vacante.

\footnotetext{
${ }^{27}$ Para uma apresentação mais completa da trajetória desse personagem central para a assiriologia francesa, veja-se CHARPIN, 2006. Agradeço a Marcelo Rede a indicação desse texto.
} 
Acompanhando a ata da assembleia do dia 17 de dezembro de 1905, é possível perceber uma intensa mobilização em torno de Fossey e de Scheil, tendo sido Rubens Duval, professor de Langues et Littérature Araméennes, o único a se pronunciar a favor de ThureauDangin. Entre os favoráveis a Scheil encontravam-se Adrien Barbier de Meynard (Arabe), Gaston Maspero (Philologie et Archéologie Egyptiennes) e Jacques Flach (Histoire des Légis/ations Comparées), os quais destacaram a experiência de seu candidato em missões arqueológicas no Oriente, seus vínculos institucionais e trabalhos científicos. Entrincheirados do outro lado estavam Philippe Berger (Langues et Littérature Hébraïque, Chaldaïque et Syriaque), o mesmo que apresentou Halévy, assim como Albert Réville (Histoire des Religions), Louis Havet (Philologie Latine), Edouard Chavannes (Langue et Littérature Chinoise), Arthur Chuquet (Langue et Littérature d'Origine Gérmanique) e Sylvain Lévi (Langue et Littérature Sanscrites). Esse grupo defendeu a candidatura de Fossey evocando vários argumentos. Berger, por exemplo, apresentou-o como o "aluno preferido" de Oppert; Reville, o pastor protestante, destacou em Fossey a "cultura geral" e um "grande talento de palavra"; Chavannes, por sua vez, afirmou que seu candidato era o único com o título de doutor, bem como com o treinamento de filólogo e de historiador necessários para a função; Havet, por fim, destacou a formação de classicista de Fossey. A enxurrada de argumentos pró-Fossey já denunciava as preferências pró-Scheil da maioria da Assembleia. Na primeira rodada, o padre dominicano foi eleito para ser o indicado em "primeira linha", obtendo vinte e um votos contra doze de Fossey (os outros dois candidatos somaram apenas cinco). Na rodada seguinte, Fossey obteve a maioria dos votos sem dificuldades (vinte e três votos, contra treze para ThureauDangin e duas anulações).

Mas como então Fossey logrou entrar no CF? O fato é que houve uma campanha política e midiática bem-sucedida contra a nomeação de um padre no momento em que se realizava a separação entre Igreja e Estado, sobretudo no que dizia respeito ao sistema de ensino $^{28}$. 0 então ministro da instrução pública, Jean-Baptiste Bienvenu-Martin, atendendo a pedidos de parte de sua bancada, inverteu a ordem sugerida pela assembleia dos professores, provocando reações na imprensa de direita e da parte de alguns professores. Falou-se em complô socialista e anticlerical (cf. BESNARD, 1979b). O conflito se estendeu no meio acadêmico com trocas de acusação mútuas entre Fossey e Scheil, as quais envolveram denúncias de plágio e pesadas críticas aos trabalhos alheios. A própria Académie des Inscriptions et Belles-Lettres se engajou na disputa, tomando o partido de Scheil e afastando

\footnotetext{
${ }^{28}$ Sobre o contexto de separação Igreja-Estado, cf. CHOLVY; HILLAIRE, 2000: 111-146.
} 
qualquer possibilidade de ingresso de Fossey na instituição. O evento, enfim, tornou-se conhecido como a Querelle des Orientalistes ${ }^{29}$.

O ponto a ser aqui considerado é a circunstância política peculiar que marcou a eleição. Fossey era o candidato daqueles que defendiam, por inúmeros motivos, o fim do ensino confessional católico, agora possível com a recém-instituída separação entre Igreja e Estado. Ainda que proveniente de uma família católica, ele representava a trajetória acadêmica laica por excelência, com sua cultura geral e clássica adquirida nos anos da École Normale Supérieure e a formação científica consolidada depois (na EPHE e em instituições francesas no exterior). Tal perfil deveria agradar aos intelectuais pertencentes às minorias religiosas (protestantes ou judeus), bem como aos "modernistas" no campo das reformas de ensino. Os pesquisadores próximos a Durkheim, com quem Fossey mantinha relações, certamente se enquadravam no perfil de seus apoiadores, o que pode ter favorecido a cristalização de um bloco de professores do CF arredio ao avanço de uma disciplina, a sociologia, que poderia parecer-Ihes ilegítima.

\section{MAUSS E SEU DUPLO FRACASSO}

Antes de ser eleito em 1931 para a cadeira de Sociologie, Marcel Mauss se apresentou ao CF duas vezes, uma em 1907 e outra em 1909. A morte de Albert Réville em fins de 1906, o pastor protestante titular da cadeira de Histoire de Religions, forneceu sua primeira oportunidade. Ainda jovem, com apenas trinta e cinco anos, ele já era bastante conhecido tanto por seus grandes estudos sobre o sacrifício e a magia, escritos em parceria com Henri Hubert, quanto por suas inúmeras resenhas acerca dos mais variados temas relacionados à sociologia religiosa. Embora estivesse no centro da empresa de L'Année Sociologique, Mauss destacava-se por qualidades (ou handicaps) muito particulares. No que diz respeito à sua formação acadêmica, ele havia realizado os estudos superiores como bolsista da Faculdade de Letras de Bordeaux, sob supervisão de seu tio. De lá, preparou-se para uma bem-sucedida agrégation de philosophie (1895 - terceiro lugar), à qual se seguiram dois anos de estudos na EPHE e um longo estágio no exterior (Leyde e Oxford), quando pôde entrar em contato direto com importantes personalidades das ciências sociais europeias, dentre as quais destacam-se Frazer e Tylor. Desde fins de 1901, Mauss ocupava, na condição de maître de conférence, a cadeira de Religions des Peuples Non-Civilisés na seção de ciências religiosas da EPHE. Mas além de atuar na universidade, esse antigo dreyfusard engrossava os quadros do movimento socialista francês, colaborando com seu jornal, l'Humanité, e com suas iniciativas

\footnotetext{
${ }^{29}$ Uma parte considerável das notícias de época foi preservada no dossiê de Fossey no CF. Veja-se, nos Arquivos do Collège de France, a pasta C-XIII Fossey.
} 
(cooperativas, universidades populares, entre outras). Em sinal de respeito diante de Jean Réville, seu patrão na EPHE, Mauss, por intermédio de Meillet et Sylvain Lévi, requisitou que seu nome fosse considerado apenas para a "segunda linha".

Para concorrer à cadeira vacante candidataram-se ainda Georges Foucart, Maurice Vernes e o já mencionado Jean Réville, todos para a "primeira linha"30. Arnold van Gennep completava o grupo, embora tenha se apresentado apenas para a "segunda linha". Foucart, o primeiro nome da lista, nascido em 1865, era especialista nos cultos religiosos do Antigo Egito. Sem ter passado pela École Normale Supérieure, ele havia completado seus estudos universitários no exterior (Institut Français d'Archéologie Orientale du Caire) e ocupado postos de ensino sucessivamente nas Faculdades de Letras de Bordeaux e de Aix. Seu grande apoio na assembleia e o responsável por apresentar sua candidatura era o próprio pai, o helenista Paul Foucart. $O$ temperamental Maurice Vernes, por sua vez, apresentava-se como azarão ${ }^{31}$. Então com sessenta e dois anos, este antigo discípulo de Renan era maître de conférence na EPHE (Religions des Peuples Sémites) e um dos fundadores da Revue d'Histoire des Religions. Quem defendeu a candidatura de Vernes foi o latinista Louis Havet. Ao lado destes dois nomes apresentou-se ainda ao pleito Jean Réville, nascido em 1854, filho do antigo titular, professor na EPHE (Histoire de l'Église Chrétienne) e um dos diretores da Revue d'Histoire des Réligions. Como o pai, antigo dreyfusard e pastor, ele despontava desde o início da campanha como o franco favorito à disputa. Arnold van Gennep, por fim, nascido de pais holandeses na Alemanha de 1873, havia feito seus estudos na França. Até o momento sem posto fixo, ele destacava-se pela produção científica em revistas, especializadas ou não (Mercure de France, Revue des Idées, Revue d'Histoire des Religions), e interessava-se na época pela etnologia das sociedades africanas. Como Mauss, van Gennep foi apresentado por Meillet e Lévi.

A ata da assembleia revela, porém, uma movimentação pró-Mauss encabeçada por Lévi, Meillet, Pierre Janet (Psychologie Expérimentale et Comparée) e Camille Jullian (Histoire et Antiquités Nationales)" 32 que ocorreu é que Mauss foi sim considerado para a "primeira linha", embora sem o necessário apoio para se impor. Essa rodada da votação terminou em dois turnos. No primeiro deles, Réville disparou com quatorze votos, seguido de Foucart com

\footnotetext{
${ }^{30}$ Cf., nos Arquivos do Collège de France, a pasta relativa à Assemblée du 17 février 1907, sobretudo o documento G-IV-g32M.

${ }^{31}$ A fama de difícil é explicitada nas palavras que Salomon Reinach dedica a ele em seu necrológio: "Vernes era um homem excelente, de uma honestidade intransigente, mas faltava-lhe um pouco de equilíbrio." (RA, 1923/2: 160).

${ }^{32}$ Difícil explicar por que Jullian, protestante convicto, não tenha se mantido em silêncio ou apoiado Réville. Teria alguma questão interna ao protestantismo o levado a agir assim? Ou fora o contato com Mauss já em Bordeaux, quando este era um estudante, que convenceu Jullian das qualidades do candidato?
} 
dez, Mauss com sete, e Vernes com cinco. No turno seguinte, votos de todos os candidatos migraram para Réville, fazendo com que ele obtivese vinte e quatro votos contra oito de Foucart (os demais somaram quatro votos). Quando se passou para a definição da "segunda linha", a disputa ficou entre Mauss e Foucart. Em dois turnos, contudo, o sobrinho de Durkheim obteve o apoio da maioria dos professores e conseguiu a indicação com vinte e um votos contra dez. Seria isto um sinal de reconhecimento da sociologia?

Mas eis que Jean Réville veio a falecer um ano depois. A nova eleição prevista apresentava-se como a grande chance de Mauss. Afinal, ele já havia sido indicado para a "segunda linha" no pleito anterior. Além do mais, nesses últimos dois anos ele fora nomeado directeur adjoint d'études na EPHE e publicara, em coautoria com Hubert, seu primeiro livro, Mélanges d'Histoire des Religions (1909). Mas o sociólogo não estava sozinho: além de alguns nomes já presentes na eleição passada (Georges Foucart e Maurices Vernes), cinco novos candidatos apareceram, três deles dispostos a brigar pela indicação "em primeira linha": Jules Toutain, Émile Amélineau e Alfred Loisy.

Desses candidatos, Amélineau e Toutain provinham, como Mauss, da seção de ciências religiosas da EPHE. Com cinquenta e nove anos, o primeiro era um egiptólogo de certo renome, estudioso da mitologia egípcia e responsável por importantes descobertas arqueológicas no alto Nilo (Ábidos). Jules Toutain, por seu turno, tinha uma maior inserção no meio acadêmico. Antigo aluno da École Normale Supérieure e membro da École Française de Rome, ele havia se tornado um especialista nas religiões "populares" dentro das bordas do Império Romano, tendo também uma sólida experiência com escavações no Mediterrâneo e com epigrafia latina. Reforçava ainda seu nome entre os estudiosos dos fenômenos religiosos o fato de ser o tradutor francês do célebre $O$ Ramo de Ouro, de James Frazer. Loisy, por fim, apresentava-se ao CF como uma vítima da Igreja Católica. Doutor em teologia e editor de uma importante revista especializada, a Revue d'Histoire et de Littérature Religieuses, ele provinha de grupos de letrados modernistas no seio da Igreja Católica, os quais vinham sendo perseguidos após o acirramento das tensões com o estado francês. Em 1907, por ter se recusado a reconhecer uma encíclica, ele foi sumariamente excomungado.

Diante desse quadro, Mauss estava animado e escreveu a família para deixá-los a par da evolução de sua campanha (apud FOURNIER, 1994: 328):

Eu praticamente terminei minhas visitas. Em suma, tenho 11 votos certos (...).

É um mínimo; o máximo provável é 15; talvez se possa ainda agregar os indiferentes; se eles fossem agregados poder-se-ia ter sucesso. 
Loisy, por seu turno, tem 10 votos certos, mas eu não sei se ele poderá agregar muitos prováveis (...).

Toutain e Foucart têm nove votos certos. Estes são os candidatos reacionários. Felizmente são dois. Sem isto, se Toutain estivesse só, teria chances de passar, embora se trate de um imbecil. Mas daqui até janeiro muita água passará sob a ponte (...). Em suma, a eleição será decidida por seis indiferentes, seis espertalhões quaisquer.

Com efeito, parecia-Ihe possível que, diante de uma votação polarizada entre ele e Loisy, os votos "reacionários" migrassem para o sociólogo-socialista judeu ao invés de reforçarem a candidatura do excomungado. Mas havia muito em jogo e Mauss parece ter subestimado seus handicaps. Duas cartas de seu tio endereçadas a Salomon Reinach testemunham que ele foi alvo de uma campanha difamatória. Segundo uma notícia que começou a circular entre os professores do CF, Mauss estaria ligado aos partidários de Gustave Hervé, líder de uma corrente radical e antimilitarista dentro do socialismo francês, o que o impediria de assumir um ensino delicado como o da história das religiões. Durkheim apressouse a denunciar a situação a Reinach, pedindo que ele desmentisse a calúnia junto a Joseph Bédier (Langue et Littérature Françaises du Moyen Âge) e a Gabriel Monod (professor de uma cadeira temporária intitulada Histoire Générale et Méthode Historique), prováveis origens do boato. O diretor de L'Année Sociologique ainda ironizou: "seria porém extraordinário que a qualidade de monge (Scheil) ou de pastor protestante não seja uma objeção e que, sozinha, a de socialista desqualificasse o homem" (BENTHIEN, 2010). Talvez Mauss tenha se equivocado quanto à intensidade do apoio prometido a ele, ou talvez a campanha contra sua candidatura tenha surtido efeito entre alguns de seus eleitores. O fato é que, no dia da votação, os sociólogos viram suas esperanças naufragarem rapidamente.

Uma leitura atenta da ata da assembleia do dia 9 de fevereiro de 1909 permite acompanhar quem apoiava qual candidato, bem como as alianças feitas ao longo do processo eleitoral ${ }^{33}$. Georges Foucart foi mais uma vez apresentado por seu pai, Paul Foucart, ao qual se somou Ernest Babelon, dois professores católicos e conhecidos por suas opiniões políticas conservadoras. Já a candidatura de Jules Toutain foi impulsionada pelo apadrinhado de dois outros importantes antiquisants do CF, René Cagnat e Maurice Croiset. Vernes e Aménileau foram apresentados pela mesma pessoa, Philippe Berger, o que já aponta para a fragilidade de seus apoios na assembleia. Mauss, por fim, teve mais uma vez a candidatura defendida por Antoine Meillet e Sylvain Lévi. Eis o cenário antes da votação.

O que ocorreu na sequência envolveu muita tensão e constantes interrupções. Em uma primeira contagem, de um universo de trinta e seis votantes, Foucart partiu de doze

\footnotetext{
${ }^{33}$ Veja-se, nos Arquivos do Collège de France, a pasta relativa à Assemblée du 9 février 1909 (G-IV-g45H), bem como o Dossiê administrativo de Alfred Loisy (C-XII Loisy).
} 
votos, Loisy de nove, Mauss de sete, Toutain de cinco, Vernes de dois e Aménileau de apenas um. No segundo turno, já sem os dois últimos, Foucart obteve treze votos, Loisy onze, Mauss oito e Toutain quatro. Em seguida, com Toutain descartado, Loisy passou à frente com dezessete votos, seguido por Foucart com quinze, e Mauss com apenas quatro. Alguns dos eleitores favoráveis a Mauss simplesmente não aceitaram a derrota e insistiram ainda mais uma vez em manter seu nome: em um quarto turno, Loisy obteve dezessete votos, Foucart dezesseis, Mauss dois e houve uma anulação ${ }^{34}$. Os dois últimos suportes de Mauss, provavelmente Meillet e Lévi, tiveram então de abandonar sua causa e preferiram, para utilizar a expressão de Mauss, eleger o candidato excomungado ao "reacionário". Na quinta e última rodada, Loisy obteve dezenove votos contra dezesseis de Foucart. Estava definida a indicação para a "primeira linha".

Para a votação em "segunda linha", Paul Foucart, indignado com a derrota do filho, pediu que a candidatura deste fosse retirada. A ata da assembleia registra ainda que ele abandonou o recinto acompanhado de dois professores. Restabelecida a ordem e retomada a votação, Mauss largou na frente. No primeiro turno, de trinta e três votos, ele obteve quatorze contra dez de Toutain, três de Vernes e sete votos partilhados entre os outros candidatos. No segundo turno, com o retorno daqueles que saíram antes acompanhando Paul Foucart, Mauss e Toutain empataram com dezessete votos, tendo um terceiro candidato recebido um. Novamente duas pessoas deixam a sala e a eleição termina com a vitória de Toutain, dezessete contra dezesseis votos.

Mesmo com a divisão dos eruditos "reacionários" entre Georges Foucart e Toutain, Mauss não contou com o apoio que imaginava (de onze a quinze votos, como disse na carta endereçada a sua família antes reproduzida). Ele viu, ao contrário, o excomungado ganhar terreno e firmar-se como o contraponto aos "reacionários". Foram, ao final, os seus próprios eleitores que decidiram o pleito. No segundo turno, contudo, aconteceu o que Mauss antecipara. Diande da decisão de Foucart de retirar o nome do próprio filho da votação para a "segunda linha", a candidatura de Toutain ganhou forças. Tratava-se de um candidato mais próximo à Académie des Inscriptions et Belles-Lettres, bem como politicamente conservador. Seu nome certamente suscitava menor resistência entre os "indiferentes" que o do sociólogo judeu e socialista. A eleição de François Simiand, a última de um durkheimiano antes da Guerra de 14-18, evidenciará ainda mais uma vez o papel constante e nada desprezível dessa variável política.

\footnotetext{
${ }^{34}$ Segundo as informações obtidas por Loisy após a campanha, a anulação teria vindo de Grégoire Wyrouboff (LOISY, 1913: 69)
} 


\section{O TESTEMUNHO DE VAN GENNEP (1909)}

Nos arquivos Marcel Mauss depositados no Institut Mémoires de l'Édition Contemporaine, encontra-se uma carta de Arnold van Gennep datada de 14 de fevereiro de 1909, cinco dias após a eleição de Loisy (MAS 13.20). Tratando do recente fracasso de Mauss, ela discute o cenário atual e futuro das ciências sociais francesas.

Chama atenção na avaliação de van Gennep o papel das classes de idade [Alters Klassen]. Ele via nos cientistas sociais uma vanguarda intelectual formada por indivíduos que, embora pertencessem à mesma geração, encontravam-se desunidos frente aos velhos representantes do sistema de ensino. Jovens antiquisants como Jules Toutain estariam desse modo do lado dos "velhos", dos puros eruditos ocupados com "coisas mortas". Em suas próprias palavras:

"Eu disse há alguns dias a Meillet que vocês não quiseram saber de mim agora; em 10 anos vocês virão me procurar e serei eu que colocarei minhas condições. Ele começou a rir, mas faça você mesmo a conta dos jovens de nossa geração dotados de alguma potência de trabalho e de energia prática; existem muito poucos, e mesmo se recrutarmos jovens, com uma ciência como a nossa, é preciso 10 anos de preparação ingrata, penosa e repugnante. Em 10 anos Dussaud, Alphandéry, você, Hubert, Beuchat, eu, vosso amigo Hertz, etc. seremos especialistas e, por conseguinte, mestres absolutos de nossa vida prática, cada um na sua, com esta superioridade almejada pelos Toutain $e$ Companhia que fazem do que era novo alguma coisa de admissivel, de banal. Quanto a isto, eu posso ao menos me felicitar com o que fiz no Mercure ou na Revue des Idées. Eu trabalhei por vocês todos, da minha geração; era preciso fazer frente contra os velhos. Neste sentido as candidaturas ao Collège são fruto de uma engraçada confusão e os velhos devem ter se divertido ao ver esta mistura de jovens de 35 a 40 [anos]. Bédier apresentaria meus títulos e, por combinação, eu teria 6 votos em primeira linha. E depois! Se Loisy não tivesse existido teria sido Vernes ou mesmo Amélineau que teriam passado por solidariedade de geração. Você estuda este fenômeno entre os selvagens e não vê que ele também existe entre nós. Eu poderia demonstrar a você que pessoas conhecidas, as quais pertenceriam mais à nossa geração por sua idade, instintivamente se envelhecem para se mostrar de acordo com os velhos de quem dependem as eleições, os postos, etc. Alters Klassen, meu velho, e você não fará nada sobre isso, não mais que Moret, Foucart e Toutain, que é, aliás, da classe das pessoas de cabelo grisalho, pois ele só se ocupa de coisas mortas. Ora, é isto que me irrita nele; sua voz é a do antiquíssimo ensino europeu."

Por certo, as opiniões de van Gennep se tornam mais compreensíveis à luz de sua própria posição. Então com trinta e seis anos, sem ter recebido a formação da elite letrada republicana, na qual os clássicos greco-latinos ocupavam um lugar de destaque, ou obtido os mais prestigiosos certificados, ele se via invariavelmente preso às margens do sistema de ensino. Passando de uma instituição a outra sem conseguir se firmar, ele ainda encontrou resistência da parte de quem se ocupava de temas análogos, em especial dos membros de L'Année Sociologique.

É provável que sua nova candidatura ao CF tenha sido inviabilizada pelos sociólogos e seus simpatizantes, os quais devem ter optado por concentrar suas forças na candidatura de Mauss. Isso explicaria, ao menos em parte, o tom de revolta em sua carta. 


\section{SIMIAND: NÃO À SOCIOLOGIA, NÃO AO SOCIALISMO}

Diante do recente óbito de três de seus membros, o ano de 1912 teve início no CF com intensas e longas assembleias. Alguns professores da casa foram encarregados de redigir relatórios sobre saberes específicos que até então não haviam encontrado respaldo na instituição e, ao fazê-lo, de aventar os nomes de prováveis titulares ${ }^{35}$. As sugestões foram variadas: Ethnographie (Arnold van Gennep), Faits Économiques et Sociaux (sem nomes consensuais), Géographie Humaine (Jean Bruhnes), Histoire de l'Afrique du Nord (Stephane Gsell), Histoire de la Marine et de l'Expansion Coloniale de la France (Charles de la Roncière), Statistique Économique (sem nomes consensuais), Théorie et Histoire de l'Histoire (Henri Berr), entre outras variações sobre os mesmos temas. Para decidir quais desses projetos seriam levados a cabo preparou-se no dia 21 de janeiro uma série de votações. Cada vez que uma proposta agregava a maioria simples, recomeçava-se outra votação levando em conta as opções restantes. Decretou-se então, nessa ordem, a criação das seguintes cadeiras: Études des Faits Économiques et Sociaux (uma fusão de Statistique Économique e de Faits Économiques et Sociaux), Histoire de l'Afrique du Nord e Géographie Humaine.

O debate que aqui interessa é aquele relativo às propostas Statistique e Faits Économiques et Sociaux. Nesses casos, um primeiro dado curioso é a ausência de sugestões dos pareceristas quanto aos futuros titulares, contrastando assim com a situação das demais cadeiras. Ora, o grupo responsável por elaborar o relatório que respondia à rubrica "ciências econômicas e sociais" era composto por três professores: Paul Leroy-Beaulieu, titular da cadeira de Économie Politique; Jean Izoulet, nomeado contra Durkheim em 1897; e Georges Renard, outro professor imposto pelo estado, dessa vez em 1907 e para a cadeira Histoire du Travail. O dado central neste caso são as orientações políticas dos três: enquanto LeroyBeaulieu e Izoulet eram conhecidos como pensadores liberais mais ou menos resistentes a qualquer forma de coletivismo, Renard era um militante socialista. Não parece assim fortuita a dificuldade dos três em chegar a um consenso. É também provável que a vitória da proposta Études des Faits Économiques et Sociaux ainda no primeiro turno estivesse ligada a essa indefinição. Afinal, não havendo favorito para a cadeira, todos poderiam almejar apresentar um candidato próprio.

Enquanto membro da comissão, Georges Renard fez questão de, ainda no dia 21 de janeiro, falar das qualidades do sociólogo François Simiand. Este foi apresentado como o candidato mais qualificado para ocupar a nova cadeira. Os únicos a se pronunciar na sequência

\footnotetext{
35 Essas discussões podem ser acompanhadas nas notas que compõem, nos arquivos do Collège de France, as pastas Assemblée du 14 janvier de 1912 e Assemblée du 21 janvier de 1912 (nesta última, o documento código G-IV-h 9b).
} 
foram Henri Bergson e Camille Jullian. Enquanto o primeiro declarou seu voto a Simiand, o qual foi descrito como "um dos espíritos mais vigorosos, dos mais penetrantes e dos mais filosóficos", Jullian disse apoiar a criação da nova cadeira, mas julgando ser outro candidato o mais apropriado, Marcel Marion.

Após dois meses de campanha, no dia 24 de março daquele ano, finalmente ocorreu a eleição em uma tumultuada sessão ${ }^{36}$. Diante da aparente inexistência de favoritos, nada menos que oito candidatos apresentaram-se para a "primeira linha", seguidos de outros tantos para a "segunda linha" (dentre os quais encontrava-se Henri Bourgin, colaborador de L'Année Sociologique). Ao longo das apresentações dos candidatos, as posições dos professores foram se tornando claras. Três nomes foram alvo de uma apresentação mais alentada e de expressões de simpatia, dando a entender que suas campanhas haviam sido bem-sucedidas: Marcel Marion, Louis Germain-Martin e François Simiand.

Camille Jullian voltou então a defender a candidatura de Marcel Marion, seu contemporâneo na ENS e antigo colega na Faculdade de Letras de Bordeaux, onde atuava como professor de Histoire Moderne. Católico e conservador em questões econômicas, Marion tornou-se posteriormente conhecido como um dos principais defensores do liberalismo ortodoxo na França. Paul Leroy-Beaulieu, corresponsável pelo relatório que sugeriu a criação da cadeira, embora defendesse dois candidatos, deu ênfase ao trabalho de Louis GermainMartin. Antigo aluno da École de Chartes e agrégé de droit, tratava-se de um professor provincial (universidades de Dijon e de Montpellier) dedicado ao estudo do desenvolvimento industrial regional e nacional, sobretudo no Antigo Regime. Georges Renard, por fim, apresentou uma vez mais François Simiand, este antigo normaliano, dreyfusard de primeira hora, cofundador de L'Année Socioliogique e militante socialista. Renard enfatizou o quanto os trabalhos de Simiand eram reconhecidos mundialmente e como ele era o "representante da jovem escola". O responsável pela seção "sociologia econômica" do AS ocupava então um posto na EPHE, após ter exercido durante anos atribuições junto ao Ministère du Commerce et du Travail. Dentre seus vários livros e artigos já publicados destacavam-se La Méthode Positive en Science Économique (1912) e Le Salaire des Ouvriers des Mines de Charbon en France (1907). Ainda durante a fase inicial de apresentação dos candidatos, Sylvain Lévi, embora falasse em nome de Henri Bourgin e de Paul Mantoux, declarou seu voto em "primeira linha" para Simiand.

Mas eis que um comentário de Georges Renard ao fim da longa sequência de apresentações fez explicitar a aversão aos sociólogos por parte de alguns professores. Ele, o

\footnotetext{
${ }^{36}$ Cf., nos arquivos do Collège de France, o documento G-IV-g 11 na pasta Assemblée du 24 mars 1912.
} 
mais vibrante defensor de Simiand, tomou a liberdade de questionar a qualidade dos trabalhos do candidato apresentado por Paul Leroy-Beaulieu. As respostas e contrarrespostas daí advindas ajudam a compreender quais eram os componentes não propriamente intelectuais (estilísticos e políticos) que compõem algumas das formas de classificação dos professores. É o que revela o trecho da ata reproduzido abaixo:

O Senhor Renard acrescenta que, tendo sido o relator dos títulos de muitos candidatos e, por isto, encarregado de confrontar seus méritos, ele crê ser necessário explicitar por que não poderia, mesmo em segunda linha, votar para o Senhor Germain-Martin. Ele crê que tal candidato não tem as qualidades necessárias e que the falta sobretudo originalidade; e ele ainda procura mostrar por meio de alguns exemplos que o Senhor Germain-Martin escreve de uma maneira defeituosa.

O Senhor Leroy-Beaulieu lamenta que as obras do senhor Germain-Martin sejam censuradas de um ponto de vista tão especial, sendo-lhe fácil agir da mesma maneira com o Senhor Simiand; ele gostaria que se voltasse ao antigo costume segundo o qual se deve abster o máximo possível de criticar diretamente candidatos apadrinhados por outros professores.

O Senhor Foucart reprova em Simiand o abuso das preocupações metodológicas e filosóficas. Ele diz reconhecer em seus trabalhos as manias e a fraseologia da escola dita sociológica. Ele indica ainda que o Senhor Simiand ensinou, ao menos uma vez, na Escola Socialista.

O Senhor Renard protesta contra esta última observação, a qual tenta insinuar uma questão política a uma discussão puramente científica. Ele lamenta que o Senhor Foucart critique seu candidato por ensinar na Escola Socialista e que ele o faça diante de um colega que assume abertamente sua qualidade de socialista e disto tem orgulho. Como o senhor presidente exprime o desejo de ver o debate terminado, o Senhor Renard acrescenta que, por respeito a ele e a esta assembleia, nada mais dirá sobre este ponto.

O Senhor Bergson, de quem o Senhor Simiand foi aluno por bastante tempo, insiste na qualidade filosófica de seu espírito; esta aptidão filosófica não é, como muitos o pensam, um defeito, mas sim uma qualidade, indispensável na observação e na crítica dos fatos sociais.

Tão logo iniciada a votação, Simiand enfrentou uma dupla derrota. Na definição da "primeira linha", ele foi superado em três turnos por Marcel Marion, o protegido de Jullian (vinte e três votos contra treze). Quanto à definição do segundo nome, foi Germain-Martin quem, acumulando a maior parte dos votos de Marion, faturou a indicação (dezoito votos contra dezessete do sociólogo). Em sua última chance antes da Primeira Guerra Mundial, os sociólogos conseguiram sensibilizar não muito mais que seus "fiéis" habituais: Meillet, Lévi, Fossey, Bergson, Renard, Janet e, dentre os cientistas, certamente Wyrouboff. Teria sido diferente se a quebra de decoro de Renard não tivesse ocorrido? Difícil dizer. O importante, contudo, é ver argumentos de ordem política (a filiação socialista de Simiand) convivendo no mesmo plano que críticas intelectuais. 


\section{CONSIDERAÇÕES FINAIS}

O saldo final explicita o fraco desempenho dos durkheimianos: de sete tentativas, uma vitória inconteste (Meillet) e outra bastante contestável (Fossey). Longe de ser apenas um acaso, a análise dos registros relativos às suas candidaturas indica certos padrões. Em se tratando de argumentos intelectuais, viu-se como os colaboradores de L'Année Sociologique enfrentaram obstinada resistência de certos setores do CF. Sobretudo para os portadores de saberes tradicionais e institucionalmente dominantes, a nova ciência parecia "pouco rigorosa" e afeita a "especulações filosóficas". À época, tal juízo se escorava na institucionalização precária da sociologia, assim como no caráter "essencialmente polêmico" de seus objetos. Não custa lembrar que, por ocasião da consagração de Durkheim em 1913, ano de sua nomeação como titular da cadeira de Science de l'Éducation et Sociologie na Sorbonne, todos os detentores de posições universitárias análogas eram adversários da "escola sociológica francesa". Gaston Richard, professor de Sciences Sociales em Bordeaux, havia rompido com o grupo em 1907. Quanto a Jean Izoulet e a Marcel Marion, professores de Philosophie Sociale e de Études des Faits Économiques et Sociaux no CF, eles jamais deixaram de expressar suas discordâncias frente às perspectivas defendidas pela equipe de L'Année Sociologique. E há mais: concursos específicos para regular minimamente os conteúdos disciplinares só viriam a ser criada bem após a Segunda Guerra Mundial, na segunda metade da década de 1960. Ou seja, se existia algum consenso em torno das ciências sociais, ele era ainda mais frágil que o atual. Eis aí um filão bastante explorado por todos aqueles com quem os sociólogos competiam.

Diante desse cenário adverso, restou aos partidários de Durkheim a opção de se infiltrar em especialidades mais "legítimas", tornando-as verdadeiros Cavalos de Troia. Em termos práticos, isso significa que o sucesso de um dos membros do grupo foi tanto mais fácil quanto mais claro seu compromisso com disciplinas já consagradas. Meillet e Fossey foram eleitos, a despeito de seus diferentes graus de comprometimento com a sociologia, graças ao prestígio que acumularam respectivamente como linguista e como assiriólogo. Durkheim, Mauss e Simiand, por outro lado, tiveram de seguir caminhos mais tortuosos, disputando posições que poderiam ser igualmente reclamadas por filósofos, teólogos, economistas e historiadores. Não por acaso, o impulso inicial de suas trajetórias deu-se ou graças a alguma especialização (Mauss tornando-se professor de "religiões dos povos primitivos" na EPHE), ou por meio de uma carreira em grande parte extrauniversitária (como no caso de Simiand), ou ainda pela atuação direta de forças políticas e estatais (Durkheim sendo nomeado em Bordeaux por decisão do Ministère de l'Instruction Publique). Desse modo, é possível afirmar que, paradoxalmente, a maior ou menor independência dos sociólogos diante da própria 
posição institucional da sociologia foi um elemento fundamental na definição de seus futuros profissionais.

Independente disso, pode-se acusar a existência de um núcleo de simpatizantes dos durkheimianos entre os professores do CF. Tal núcleo era formado por eruditos especialistas em várias civilizações, tais como o indologista Sylvain Lévi e o próprio Fossey, os quais encontraram na sociologia e nos sociólogos aliados no avanço de suas próprias disciplinas. Outro suporte constante veio da parte dos setores mais dinâmicos e abertos aos procedimentos científicos dentro da Académie des Sciences Morales et Politiques. É o caso particular de Bergson, que parece não ter apoiado os sociólogos apenas na ocasião da eleição de Loisy, ou então o de Pierre Janet, sucessor de Théodule Ribot na cadeira de Psychologie Expérimentale et Comparée. Com o tempo, o número desses savants parece ter aumentado: Georges Renard (Histoire du Travail) e Edouard Fuster (Prévoyance et Assistances Sociales) ingressaram na instituição em 1907 e em 1917 por nomeações de cunho político; já o geógrafo Jean Brunhes foi eleito em 1912. Por fim, entre os cientistas, os quais dificilmente se pronunciavam por ocasião das eleições de uma cadeira de "letras", o único apoio explícito foi o do positivista e historiador das ciências Grégoire Wyrouboff. Sabe-se ainda, por outras fontes, que o biólogo Emile Gley manteve relações com Durkheim e Mauss (FOURNIER, 1994: 327).

Quanto aos demais professores, a costura de alianças com os sociólogos parece ter sido mais delicada. Entre os historiadores e os especialistas em línguas e literaturas, sobretudo para os representantes das disciplinas centrais - o francês, o latim e, em menor escala, o grego -, tudo dependia do não-comprometimento de sua posição hegemônica. A quebra do monopólio da formação clássica no ensino secundário em 1902 parece ter encorajado os portadores desses saberes a adquirirem uma postura defensiva e corporativista. Entre 1897 e 1918, foram criadas três novas cadeiras no CF que, em grande medida, sobrepunham-se às já existentes: Histoire et Antiquités Nationales (1905), Numismatique de l'Antiquité et du Moyen Âge (1908) e Histoire de l'Afrique du Nord (1912). Nesse sentido, eles apenas se colocaram em conjunto contra as propostas favoráveis à sociologia quando elas ameaçaram um ou outro de seus projetos. Não por acaso, Camille Jullian aparece pedindo votos a Mauss em uma das assembleias e pode-se afirmar com relativa certeza que outros o fizeram nos bastidores. Havia, por fim, um claro núcleo de resistência dentro dos representantes da Académie des Sciences Morales et Politiques. Ele era constituído por defensores teóricos do individualismo e do liberalismo (Jean Izoulet e Gabriel Tarde) e filósofos metafísicos de formação cristã (Alfred Loisy).

Mas, para além da dimensão puramente intelectual das discussões, o interessante da documentação aqui analisada é a articulação que ela permite enxergar entre as campanhas e a 
política. Com efeito, por mais que se defenda a relativa autonomia da sociologia francesa em princípios do século $\mathrm{XX}$, esta aparece aos olhos dos contemporâneos como vinculada a um projeto político, laico para uns, socialista para outros. Esse vínculo entre projeto intelectual e projeto político comprometeu seriamente a legitimidade das pretensões institucionais dos sociólogos. A primeira tentativa de Durkheim foi paradigmática neste sentido: a nomeação política de Izoulet teve como justificativa o combate aos socialistas. O que dizer então das calúnias lançadas contra Mauss e Simiand, ou ainda das reações à nomeação de Fossey na impressa?

As campanhas ao CF de pesquisadores ligados à sociologia durkheimiana no pós-1918 parecem carregar as mesmas marcas do período anterior. É sintomático que, na década de 1920, apenas Alexandre Moret, um egiptólogo que participou da segunda série de L'Année Sociologique, tenha sido eleito. Tratava-se de mais um especialista. Mauss e Simiand tiveram de esperar a crise do pensamento liberal e a reorganização das esquerdas francesas na década de 1930 para, em eleições ainda assim disputadíssimas, obter o mesmo sucesso. Mais fácil foi a situação do orientalista Isidore Lévy, eleito em 1933 para a cadeira de Histoire Ancienne de l'Orient Sémitique. Já no dramático contexto da Segunda Guerra Mundial, André Piganiol, especialista em história romana, e Maurice Halbwachs foram os últimos durkheimianos eleitos ao CF. Depois de 1945, nem a política, nem a universidade, nem as ciências sociais seriam as mesmas. 


\subsection{OS DURKHEIMIANOS,}

\section{SALOMON REINACH E O}

\section{MUSÉE DES \\ ANTIQUITÉS}

NATIONALES

"Eu troco incidentalmente algumas palavras sobre o Année com Reinach, você quer conversar com ele sobre o tema? Eu insinuo mesmo que nós podemos enviar-lhe um exemplar sob um pretexto qualquer; explique a ele o que nós poderíamos fazer a esse respeito. Será muito divertido e muito positivo, materialmente, seduzir Reinach. Tal como os budas, façamos girar diante dele a roda da lei. Além do mais, trata-se de uma alma aberta aos diálogos."

Marcel Mauss

(Trecho de carta inédita endereçada a Henri Hubert, datada de 1897 e pertencente aos arquivos do IMEC - MAS 6.37)

\begin{abstract}
"Quero trabalhar, aproveitar este Museu. Para permanecer orientalista ocupando-me das antiguidades nacionais é necessário que eu faça antiguidades nacionais a fundo. Logo vou me ocupar da preparação do catálogo, ou seja, do primeiro estudo metódico da arqueologia merovíngia: sarcófagos, tumbas, conteúdo das tumbas. Não preciso destacar que isto me separa apenas em aparência de nossos estudos; para fazer isto de forma conveniente é preciso ter as nossas preocupações."
\end{abstract}

Henri Hubert

(Trecho de carta inédita endereçada a Marcel Mauss, não datada e pertencente aos arquivos do IMEC - MAS 6.36)

Em um texto autobiográfico produzido em 1930, por ocasião de sua derradeira campanha ao Collège de France, Marcel Mauss apresentou nos seguintes termos o projeto intelectual que o ligava a Henri Hubert (MAUSS, 1979: 215):

Nós [Hubert e eu] descobrimos juntos o mundo [da] humanidade pré-histórica, primitiva, exótica, o mundo semítico e o mundo indiano, além do mundo antigo e do mundo cristão que já conhecíamos. Quando dividimos nossos estudos e repartimos nossas competências para melhor conhecer estes mundos, fomos um pouco loucos. Ainda assim, graças ao bom senso e ao trabalho, creio eu, nós realizamos nosso projeto. Só a morte de Hubert o torna caduco. Sem ela, com a ajuda de nossos alunos, apoiados no Musée de Saint-Germain, no Institut d'Ethnologie e no Année Sociologique, confrontando os últimos resultados de nossos trabalhos com o de outros especialistas de nossas ciências tornados cada dia mais numerosos sobretudo no estrangeiro, nós recolheríamos os frutos tardios de nossos esforços.

A despeito da importância que the foi atribuída na passagem acima reproduzida, o Musée des Antiquités Nationales, situado em Saint-Germain-en-Laye, nos arredores de Paris, suscitou pouco interesse dos especialistas na história da "escola sociológica francesa". Em 
paralelo aos estudos pontuais voltados à influência da sociologia na montagem de suas salas de exposição e na análise de suas coleções arqueológicas ${ }^{1}$, a única investigação sistemática até hoje produzida sobre o tema foi o dossiê "Henri Hubert", publicado por Patrice Brun e Laurent Olivier na revista Les Nouvelles de L'Archéologie (2000). Nele, porém, tratou-se basicamente de caracterizar a formação do Hubert-arqueólogo, de mapear suas contribuições ao museu e de mensurar o impacto de sua obra no desenvolvimento da arqueologia francesa.

Ainda que se reconheça a necessidade de se reavaliar os sucessos e os fracassos da sociologia sob a perspectiva de uma disciplina particular como a arqueologia, o presente subcapítulo investe em outras direções. Com efeito, importa mais aqui compreender quais redes institucionais e intelectuais atravessaram e estruturaram o Musée des Antiquités Nationales entre fins do século XIX e inícios do XX, bem como problematizar os eventuais usos que os colaboradores de L'Année Sociologique delas fizeram. Não se pode ignorar que diretores e conservadores dessa instituição também transitaram por espaços não necessariamente ligados à arqueologia, permitindo com que mundos diferentes pudessem aí convergir. Mas quem foram essas pessoas? Quais pontes eles ajudaram a construir? E, por fim, como isso tangenciou o processo de emergência da sociologia universitária?

\section{AleXandre Bertrand e os Primórdios do Museu de Saint-Germain}

A inauguração do Musée des Antiquités Nationales, ocorrida em meio às festividades da Exposição Universal de 1867, remete às agendas políticas e científicas do Segundo Império. Alguns anos antes, interessado em alimentar o nacionalismo francês contra as ameaças advindas dos processos de unificação da Itália e da Alemanha, Napoleão III havia financiado uma série de escavações em Alice-Sainte-Reine, no departamento da Côte-d'Or, centro-leste do país. Engajado na redação de uma biografia de Júlio César, na qual a conquista da Gália ocupa um considerável espaço, o imperador almejava aí recolher vestígios da passagem do general romano. O resultado, no entanto, superou em muito as expectativas iniciais: os especialistas encarregados da exploração julgaram encontrar as ruínas da antiga cidade de Alesia, último bastião da resistência gaulesa contra a ocupação romana. O estado passou então a se preocupar com a exposição e o tratamento científico do material acumulado. Em se tratando de um dos episódios mais simbólicos para a constituição do moderno povo francês, era preciso agir rápido.

O decreto determinando a criação de um museu destinado às antiguidades célticas e galo-romanas em Saint-Germain-en-Laye foi assinado em março de 1862, em meio aos

\footnotetext{
${ }^{1}$ Cf. MOHEN, 1980-1; LORRE, 2010.
} 
entusiasmos das primeiras descobertas na Côte-d'Or. Quanto ao local designado para acolhêlo, tratava-se de uma municipalidade rica, situada cerca de vinte quilômetros a oeste da capital francesa e a ela ligada por uma linha férrea desde 1847. Mas o maior patrimônio de SaintGermain-en-Laye era mesmo outro, sua história. Entre o século XII e o término da construção de Versailles, ela dividiu com Paris a incumbência de abrigar a corte real. Pensando em vincular o novo museu a esse glorioso passado nacional, o governo francês optou por instalá-lo em um dos palácios locais, o "velho castelo", situado ao lado da estação de trens. Nomeada em abril de 1865 , uma comissão de notáveis foi incumbida das tarefas de velar pelo restauro da futura sede e de conceber seu regulamento científico. Um ano mais tarde, definiu-se a vocação da instituição nos seguintes termos: "o museu de Saint-Germain tem por finalidade centralizar todos os documentos relativos à história das raças que ocuparam o território da Gália desde os tempos mais remotos até o reino de Carlos Magno, classificar esses documentos de acordo com uma ordem metódica, tornar seu estudo fácil e disponível ao público, editá-los e difundir seu ensino". Desse modo, se o Louvre pretendia servir à França ao especializar-se cada vez mais na história dita universal, o que incluía os vestígios materiais de Civilizações Antigas e as façanhas artísticas das Modernas, Saint-Germain investiu na pré-história, na Antiguidade e no Medievo, mas privilegiando um ângulo de ataque nacional. Complementares, as duas instituições passaram a constituir o núcleo duro do que à época se considerava o melhor em termos de ensino e de pesquisa arqueológicas na França.

Dentre os vários responsáveis diretos pelo sucesso desse projeto, destaca-se o nome de Alexandre Bertrand. Ele foi o único a participar das escavações em Alice-Sainte-Reine, a integrar a comissão responsável pela criação do museu e, ainda, a ser seu primeiro diretor, posição que manteve por um período nada desprezível de trinta e cinco anos, até sua morte em 1902. Nascido na Paris de 1820, Bertrand pertenceu a uma família fortemente inclinada às atividades intelectuais: seu pai (1795-1831), de quem herdou nome e sobrenome, era um reputado médico, ao passo que seu irmão mais novo, Joseph (1822-1900), veio a se tornar professor de matemática e física no Collège de France. Sua formação escolar e profissional sofreu assim quase que naturalmente uma influência das ciências naturais. Em um primeiro momento, ele chegou mesmo a obter um bacharelado de ciências, embora tenha optado por prestar a seguir o exame de admissão na seção de letras da École Normale Supérieure, onde foi recebido em 1840. Na sequência, Bertrand atuou primeiro como professor de língua e de literatura no Collège de Pau e, mais tarde, como bolsista de agrégation em Paris.

O sucesso no exame de agrégation de lettres em 1848 lhe permitiu o primeiro contato com a arqueologia. Graças a ele, Bertrand atuou como membro da recém-fundada École Française d'Athènes. Sabe-se que as primeiras décadas dessa instituição foram marcadas por 
precariedades de toda sorte (VALENTI, 2006: 11-55). Na ausência de um projeto científico claro, ela tateava entre os exercícios literários franceses e o primeiro contato com novas disciplinas como a epigrafia e a arqueologia. Alexandre Bertrand, como bem assinala uma recente nota biográfica, encarnou perfeitamente esta ambiguidade (CHEW, 2010). Nos anos em que foi professor de retórica no liceu de Rennes (1851-1858), logo após seu retorno da Grécia, os temas de sua tese e de seus primeiros livros estiveram ligados tanto ao estudo da mitologia, quanto à arqueologia helênicas ${ }^{2}$.

A conversão definitiva de Bertrand à arqueologia deu-se ao final desse período, logo após ter assumido a direção da Revue Archéologique e, sobretudo, após ter tomado parte nas escavações iniciadas na Côte-d'Or, respectivamente em 1860 e 1861. Ao menos é o que sugere a rápida transformação de seus interesses e de suas inserções institucionais. Em meados da década de 1860, ele publicou uma edição crítica das memórias de César sobre sua campanha na Gália, a que incluía longas discussões arqueológicas ${ }^{3}$. Nas décadas de 1870 e 1880, deu ênfase à produção dos primeiros catálogos sistemáticos sobre a arqueologia céltica e gaulesa ${ }^{4}$. Por fim, em seus últimos anos de vida, explorou os vestígios dos celtas fora da Gália (no norte a Itália e ao longo do Danúbio), bem como se interessou por estudar suas crenças religiosas ${ }^{5}$. Quanto às prebendas acumuladas, além da direção do Musée des Antiquités Nationales e da Revue Archéologique, Bertrand passou a ocupar, por ocasião da fundação da École du Louvre em 1882, uma cadeira intitulada Archéologie Nationale. Ele ainda se tornou membro fundador da Association pour l'Encouragement des Études Grecques en France (1867), presidente da Société d'Anthropologie de Paris (1868) e foi eleito membro efetivo da Académie des Inscriptions et Belles-Lettres (1881).

Sem entrar aqui na questão dos méritos ou da atualidade de seus trabalhos científicos, é possível reconhecer que a trajetória de Bertrand ilumina, por si só, as circunstâncias que marcaram os primórdios do museu de Saint-Germain. Ela permite atentar, em primeiro lugar, para certas especificidades estruturais do sistema de ensino francês. Afinal, estando aí bastante implicado, Bertrand representou uma de suas possibilidades de abertura e de autosuperação. Ele permaneceu marcado por um ensino literário clássico, mas utilizou esse

\footnotetext{
${ }^{2}$ Tratam-se de Essai sur les dieux protecteurs des héros grecs et troyens dans l'lliade (BERTRAND, 1858a) e Études de Mythologie et d'Archéologie Grecques d'Athènes à Argos (BERTRAND, 1858b). É interessante comparar sua trajetória com a de outro pioneiro nos estudos científicos franceses, Michel Bréal. Também neste caso, a consagração enquanto linguista veio após os estudos sobre mitologia e semântica envolvendo basicamente a cultura greco-latina. Veja-se, por exemplo, as diferenças de conteúdo entre os artigos mais antigos e os mais recentes que compõe a coletânea Mélanges de Mythologie et de Linguistique (1877), produzidos ao longo das décadas de 1860 e 1870.

${ }^{3}$ BERTRAND; CASIMIR, 1865.

${ }^{4}$ BERTRAND, 1876 e 1884.

${ }^{5}$ BERTRAND, 1897.
} 
saber para avançar por outros caminhos. Os vínculos com a Association pour l'Encouragement des Études Grecques en France e sua eleição para o Institut mostram bem que não houve intenção de ruptura institucional de sua parte, assim como apontam para a boa acolhida que Ihe foi reservada. Já quanto à aproximação com as ciências naturais e com a antropologia nascente, tão necessária ao desenvolvimento da arqueologia moderna, ela esclarece as direções nas quais foi possível acrescentar algo ao que já se fazia no sistema francês.

O segundo ponto a ser aqui destacado é que os links institucionais e a consagração intelectual de Bertrand confundiram-se com o Musée des Antiquités Nationales, conformando seu legado à instituição. De fato, estando seu diretor em uma posição hierarquicamente dominante nos primórdios da arqueologia francesa, seus atributos passaram a ser aqueles de um patrão. Em termos práticos, isso significou que a direção da Revue Archéologique, o ensino de Archéologie Nationale na École du Louvre e o reconhecimento da Académie des Inscriptions passaram a estar necessariamente vinculados a suas atribuições junto ao referido museu ${ }^{6}$. Eis aí a rede inicial que foi herdada por seus sucessores, os quais trataram de expandi-la.

\section{SALOMON REINACH, PRODÍGIO E POLÍGRAFO}

Substituto imediato de Bertrand na direção do Musée des Antiquités Nationales, Salomon Reinach vem ganhando destaque nos estudos sobre a "escola sociológica francesa". Praticamente ignorado pela historiografia até os anos 1990, ele voltou à cena dos debates como um importante concorrente dos durkheimianos entre os "modernistas" no campo dos estudos religiosos ${ }^{7}$. Tal ajuizamento justo, centrado em uma leitura de seus escritos "antropológicos", precisa, no entanto, ser complexificado. Além de antropólogo, Reinach foi filólogo, filósofo, historiador da arte e arqueólogo, dedicando a maior parte da sua imensa produção intelectual às (pré-)histórias grega e celta. Antes mesmo de tratar de suas relações com os sociólogos, cumpre apresentar aqui, em linhas gerais, sua excepcional trajetória ${ }^{8}$.

Nascido na própria Saint-Germain-en-Laye, Salomon Reinach (1858-1932) teve por pai um banqueiro judeu de origem alemã bem integrado às elites letradas francesas de fins do Segundo Império. Foi nesse ambiente econômica e culturalmente privilegiado que ele e seus dois irmãos, Joseph (1856-1921) e Théodore (1860-1928), foram criados. Após ter realizado

\footnotetext{
6 Isto, bem entendido, no interior do próprio sistema francês. Sobre as relações que Bertrand estabelecerá com instituições de pesquisa de outros países, cf. CHEW, 2008.

${ }^{7} \mathrm{Na}$ biografia de Durkheim escrita por Lukes (1973), o nome Salomon Reinach sequer consta no índice onomástico. Quanto à tese da "concorrência", veja-se, em especial, STRENSKI, 1997: 53-81; assim como uma confirmação mais recente em FOURNIER, 2007.

${ }^{8}$ Veja-se, a esse respeito, BASCH; ESPAGNE; LECLANT, 2008. Uma recente nota biográfica bastante completa sobre Reinach de autoria de Hervé Duchêne foi também publicada no site do Dictionnaire Critique des Historiens de l'Art mantido pelo Institut National d'Histoire de l'Art (DUCHÊNE, 2009).
} 
com grande sucesso seus estudos secundários, acumulando uma série de prêmios nacionais, Salomon ingressou na École Normale Supérieure em 1876, apenas três anos antes de Durkheim. No período em que aí esteve, destacou-se pela qualidade e pela diversidade de seus interesses. Não bastasse a obtenção do primeiro lugar na agrégation de grammaire em 1879, um dos certificados nacionais almejados por quem desejasse seguir uma carreira ligada à docência e à pesquisa, Salomon ainda traduziu o Ensaio sobre o livre-arbitrio de Schopenhauer e escreveu um manual de filologia ${ }^{9}$. Tamanha desenvoltura não passou despercebida por seus mestres. Na sequência, ele obteve do governo francês uma bolsa para tornar-se membro de uma École Française d'Athènes já bem estabelecida e afinada com um programa moderno de pesquisas (VALENTI, 2006a: 59-96) ${ }^{10}$. Lá, em meio a um ambiente cosmopolita no qual conviviam e competiam pesquisadores vindos de outros países, em especial alemães e ingleses, Salomon recebeu a melhor formação disponível à época em arqueologia, epigrafia e história. Seguiu-se a Atenas um novo período de escavações, este no norte da África, até que, em 1886, ele foi nomeado attaché libre do Musée des Antiquités Nationales, tornando-se seu diretor após a morte de Bertrand, dezesseis anos mais tarde. Quanto à sua atividade docente, Reinach assumiu os cursos de Archéologie Nationale (1890-1892, 1895-1905 e 1915-1920) e de Histoire de la Peinture de la Renaissance (1906-1910) na École du Louvre. Note-se, por fim, sua inserção precoce em prestigiadas instituições como a Association pour l'Encouragement des Études Grecques en France, da qual ele se tornou sócio em 1878, e a Académie des Inscriptions et Belles-Lettres, para a qual foi eleito em 1896. Tratava-se, em suma, de um prodígio e, mais que nada, de um polígrafo.

Com efeito, a formação de helenista e os vínculos privilegiados com instituições dedicadas à arqueologia não devem obscurecer o fato de Reinach ter atuado em várias vanguardas intelectuais ao mesmo tempo. Sua imensa produção de livros inclui, sem que a lista que se segue seja exaustiva, uma história da arte ocidental, uma história das religiões, uma história da filosofia, métodos de aprendizado das línguas grega, latina e francesa, além de toda uma série de trabalhos mais específicos de história e arqueologia ${ }^{11}$. Tamanha versatilidade se verifica também em seus investimentos junto a periódicos acadêmicos. Ele se fez colaborador regular, para ficarmos com os exemplos mais significativos, da Revue des Études Grecques, da Revue des Études Juives, da Revue des Études Anciennes, da Revue Celtique, de L'Anthropologie e da Revue Archéologique, da qual se tornou codiretor em 1903.

\footnotetext{
${ }^{9}$ SCHOPENHAUER, 1877 e REINACH, S., 1880.

${ }^{10}$ Veja-se também o subcapítulo 2.1 da presente tese.

${ }^{11}$ Cf., respectivamente, REINACH, S., 1904, 1909a, 1926, 1911, 1912c, 1913a, 1888, 1889; e também POTTIER; REINACH, S., 1887.
} 
Para além do trabalho intelectual, Reinach esteve envolvido direta ou indiretamente com algumas das grandes questões da vida pública francesa na virada dos séculos XIX e XX. Joseph, seu irmão mais velho, teve uma atuação pública destacada, primeiro como secretário de Léon Gambetta e, depois, como principal defensor do capitão Dreyfus. Théodore, o caçula, embora dedicasse parte de seu tempo à docência e à pesquisa, tendo sido diretor da Revue des Études Grecques (1888-1906) e professor de numismática no Collège de France (19241928), também atuou como deputado associado à esquerda ${ }^{12}$. O próprio Salomon, por seu turno, participou ativamente do Affaire Dreyfus e posicionou-se a favor das reformas do sistema de ensino.

Importa aqui evidenciar certas semelhanças e diferenças entre a trajetória de Reinach e a de Bertrand. Por certo, ambos transitaram pelas mesmas instituições. A formação literária da École Normale Supérieure os marcou, bem como a iniciação à arqueologia na École Française d'Athènes. Ainda assim, o sistema universitário francês não era o mesmo no momento em que Bertrand iniciou sua carreira, nos anos 1850, e quando Reinach o fez, três décadas depois. Para um, a arqueologia era uma disciplina a ser construída e praticamente desprovida de qualquer enquadramento institucional. Para o outro, tratava-se de uma posição herdada e já dotada de relativa complexidade.

Reinach soube, contudo, manter as redes estabelecidas por seu antecessor. Ele foi, até o final de sua vida, diretor do Musée des Antiquités Nationales e da Revue Archéologique, atuando também como professor na École du Louvre. Sua eleição à Académie des Inscriptions e seu vínculo com a Société pour l'Encouragement des Études Grecques en France confirmam ainda o mesmo padrão. Mas não se trata apenas da manutenção de um legado. Reinach soube também ampliá-lo. Deve-se considerar, no seu caso, os vínculos com o mundo da alta política, assim como a excelência reconhecida em outras áreas. $O$ interesse pela sociologia e o contato com os portadores de tal saber, novo na universidade francesa, foi uma das facetas dessa ampliação. É ela que será discutida com mais detalhes a seguir.

\section{ENTRE TENSÕES E AFINIDADES ELETIVAS}

O primeiro contato entre os durkheimianos e Salomon Reinach ocorreu logo antes da publicação do primeiro volume de L'Année Sociologique. Hubert e Mauss manifestaram então um claro desejo de tê-lo como aliado. Em fins de 1897, este escreveu àquele: "Seria muito divertido e muito positivo, materialmente, seduzir Reinach. Tal como os budas, façamos girar

\footnotetext{
${ }^{12}$ Sobre Théodore Reinach, veja-se o subcapítulo 2.3 da presente tese.
} 
diante dele a roda da lei" ${ }^{13}$. Ao que Hubert respondeu meses depois: "é um bravo homem este Reinach (...) ; quando eu o conhecer melhor, espero que com um pouco de obstinação eu o convertirei às nossas ideias e o farei servir a nossos desejos" ${ }^{14}$. O próprio Reinach entusiasmou-se com os sociólogos, pois, após travar contato com L'Année Sociologique em março de 1898, chegou a convidar o diretor da nova revista para uma visita a Saint-Germain ${ }^{15}$. Dos quatro homens, aliás, Durkheim parece ter sido o mais reticente. Em uma carta endereçada ao seu sobrinho e datada de abril do mesmo ano, ele traça o seguinte retrato de Reinach: "trata-se certamente de um espírito ativo, [curioso?], de iniciativa. Mas, no fundo, ele continua um filólogo e está bem longe de nós"16.

Em paralelo à simpatia propriamente intelectual, outros fatores contribuíram para esse bom início da relação entre a "escola sociológica francesa" e Reinach. A militância próDreyfus foi um deles. Hubert e Durkheim mantiveram contato regular com Reinach a esse respeito, ora para sondá-lo acerca de detalhes do Affaire, ora para transmitir-Ihe informações que julgavam importantes. Com exceção de um único ponto de tensão localizado, a reprimenda que Hubert faz a Reinach por este ter preferido aderir ao Appel à l'Union ao invés do assinar o Manifeste des Intellectuels, os três manifestam a convicção de estarem a serviço da mesma causa ${ }^{17}$. Quanto ao segundo fator, este remete à presença de Hubert no Musée des Antiquités Nationales a partir de 1898. O jovem sociólogo aí obteve, com o consentimento de Reinach, sua primeira posição institucional, a qual manterá por toda a vida.

Mas o vínculo entre Reinach e os durkheimianos alternou momentos de maior e de menor proximidade. É possível caracterizar, a partir de seus artigos acadêmicos e correspondências, dois períodos distintos. No primeiro deles, situado grosso modo entre 1897 e 1906, manteve-se o ambiente de simpatia e cooperação iniciais. Em termos teóricos, Reinach acompanhou com interesse e constância a produção dos sociólogos. Em 1899, ele discutiu o trabalho de Durkheim em artigo sobre as origens do tabu do incesto ${ }^{18}$. No ano seguinte, por duas ocasiões, valeu-se do trabalho dos sociólogos para dar mais autoridade a suas teses sobre os fenômenos do tabu e do totemismo ${ }^{19}$. Em 1902, redigiu uma resenha elogiosa do ensaio de

\footnotetext{
${ }^{13}$ Carta inédita de Mauss a Hubert, datada de 1897 e pertencente ao fundo de arquivos Hubert-Mauss, do Institut Mémoire des Éditions Contemporaines (MAS 6.37).

${ }^{14}$ Carta inédita de Hubert a Mauss, não datada, pertencente ao fundo de arquivos Hubert-Mauss, do Institut Mémoire des Éditions Contemporaines (MAS 6.36).

${ }^{15}$ BENTHIEN, 2010.

${ }^{16}$ DURKHEIM, 1998: 131.

${ }^{17}$ Para as cartas de Durkheim à Reinach, cf. BENTHIEN, 2010. Já quanto à reprimenda de Hubert, veja-se, na caixa (boite) 84 das Correspondances de Salomon Reinach na Bibliothèque Méjanes, a carta datada de 25 de janeiro de 1899.

${ }^{18}$ REINACH, S., 1899.

${ }^{19}$ REINACH, S., 1900 e também um artigo publicado na Revue Celtique (RC, 1900: 267-306).
} 
Durkheim intitulado "Sur le Totemisme", publicado um ano antes ${ }^{20} . \mathrm{Em} \mathrm{1903,} \mathrm{discutiu} \mathrm{as} \mathrm{teses}$ os sociólogos sobre "as formas de classificação" ${ }^{21}$. Os durkheimianos, em contrapartida, indicaram a produção de Reinach aos seus leitores (veja-se o quadro 3.2.1). O que se depreende do conjunto desses textos, a despeito de eventuais ressalvas, é o reconhecimento da fecundidade das ideias alheias. O próprio Durkheim, em suas cartas endereçadas a Reinach, parece então relativizar suas opiniões sobre o interlocutor. Afinal, agradecendo-o sempre, não deixou de sublinhar o fato de ambos estarem geralmente de acordo "quanto ao essencial" (BENTHIEN, 2010).

Os diálogos entre Reinach e os durkheimianos foram igualmente proveitosos em outros sentidos. Quanto ao Museu de Saint-Germain, tudo indica que Reinach encontrou em Hubert um potencial sucessor. Aquele confiou a este, desde cedo, importantes coleções arqueológicas, lutou por sua promoção ao cargo de conservateur adjoint, abriu-lhe as portas de várias revistas acadêmicas (em especial, L'Anthropologie e Revue Archéologique), e, ainda, tornou-o seu suplente na École du Louvre quanto ao ensino de arqueologia nacional (LORRE, 2009). Mauss, por sua vez, soube tirar proveito da relação com Reinach em suas atividades de militante político, requisitando com sucesso junto a ele recursos financeiros para atividades socialistas $^{22}$. Já Durkheim consultou Reinach quando esteve em pauta temas relativos ao universo dos estudos greco-latinos e, em particular, à Académie des Inscriptions et Belles Lettres (BENTHIEN, 2010).

O que se observa a seguir não é exatamente uma ruptura da relação, mas a consolidação de certa distância entre as partes. Há, de início, um estranhamento grande, o qual vai progressivamente perdendo força até se estabilizar por volta de 1911-1912. Vários são os indícios nessa direção a partir de 1906: Hubert passa a publicar pouco nas revistas frequentadas por Reinach; as cartas de Durkheim e de Mauss a ele tornam-se mais esporádicas; e as alusões elogiosas aos trabalhos alheios diluem-se em meio a duras críticas. É provável que essa crise tenha sido motivada por razões puramente intelectuais e tenha partido dos sociólogos. As resenhas dos principais livros e textos de Reinach sobre religião e sobre arqueologia, todas assinadas por Hubert, passaram então a ter um tom predominantemente negativo (veja-se o quadro 3.2.2). O ponto central da crítica recaiu sobre o que os sociólogos entendiam ser o caráter por demais simplificador do raciocínio de Reinach. Quanto ao conteúdo, acusaram-no de forçar e de generalizar uma ligação entre animismo, totemismo e

\footnotetext{
${ }^{20}$ REINACH, S., 1902.

${ }^{21}$ REINACH, S., 1903.

${ }^{22}$ Cf., a este respeito, na caixa (boite) 105 dos Arquivos Reinach na Bibliothèque Méjanes, as cartas datadas de 10 de junho de 1902, de 30 de janeiro de 1904, de 9 e de 15 de maio de 1906 e de 15 de junho do mesmo ano.
} 
tabu. Quanto à forma, condenaram o fato de suas principais obras destinarem-se ao grande público, rotulando-as "de vulgarização".

Quadro 3.2.1 - Apreciações críticas dos trabalhos de Salomon Reinach em L'Année Sociologique (1898-1905).

\begin{tabular}{|c|c|c|}
\hline ANO & ARTIGO/LIVRO RESENHADO & APRECIAÇÃO CRÍTICA \\
\hline 1898 & $\begin{array}{l}\text { - La préhistoire en Egypte d'après des } \\
\text { recentes publications (L'Anthropologie, 1897) }\end{array}$ & (apenas referência) \\
\hline 1901 & $\begin{array}{l}\text { - L'Amphidromie } \\
\text { (L'Anthropologie, 1899) }\end{array}$ & “uma teoria engenhosa” (p. 228) \\
\hline 1902 & $\begin{array}{l}\text { - Le Totémisme Animal } \\
\text { (Revue Scientifique, 1900) } \\
\text { - } \quad \text { Les survivances du totémisme chez } \\
\text { les anciens celtes (Revue Celtique, 1900) } \\
\text { - } \quad \text { Quelques observations sur le Tabou } \\
\text { (L'Anthropologie, 1900) } \\
\text { - Les interdictions alimentaires et la loi } \\
\text { mosaïque (Revue des Études Juives, 1900) } \\
\text { - } \quad \text { De l'origine des prières pour les morts } \\
\text { (Revue des Études Juives, 1900) }\end{array}$ & $\begin{array}{l}\text { (apenas referência) } \\
\text { (apenas referência) } \\
\text { (apenas referência) } \\
\text { “o Sr. Reinach tenta distinguir o tabu da } \\
\text { interdição” (p. 215). } \\
\text { “[Reinach] deixa de lado a questão do sacrifício } \\
\text { aos mortos” (p. 247) }\end{array}$ \\
\hline 1903 & $\begin{array}{l}\text { - Les théoxénies et le vol des Dioscures } \\
\text { (Revue Archéologique, 1901) } \\
\text { - Une formule orphique } \\
\text { (Revue Archéologique, 1901) }\end{array}$ & $\begin{array}{l}\text { (apenas referência) } \\
\text { (apenas referência) }\end{array}$ \\
\hline 1904 & $\begin{array}{l}\text { - L'art et la magie } \\
\text { (L'Anthropologie, 1903) } \\
\text { - } \quad \text { La mort d'Orpheus } \\
\text { (Revue Archéologique, 1902) } \\
\text { - } \quad \text { Sisyphe aux enfers et quelques autres } \\
\text { damnés (Revue Archéologique, 1902) }\end{array}$ & $\begin{array}{l}\text { (apenas referência) } \\
\text { “estas hipóteses totêmicas são um terreno } \\
\text { escorregadio e o Sr. Reinach já sabe que nós } \\
\text { não ousamos segui-lo sempre” (p. 334) } \\
\text { “[Fato] interessante a ser notado” (p. 344) }\end{array}$ \\
\hline 1905 & $\begin{array}{l}\text { - } \quad \text { La flagellation rituelle } \\
\text { (L'Anthropologie, 1904) } \\
\text { - } \quad \text { Les apôtres chez les anthropophages } \\
\text { (Annales du Musée Guimet, 1904) }\end{array}$ & (apenas referência) \\
\hline
\end{tabular}


Quadro 3.2.2 - Apreciações críticas dos trabalhos de Salomon Reinach em L'Année Sociologique (1906-1913).

\begin{tabular}{|c|c|c|}
\hline ANO & ARTIGO/LIVRO RESENHADO & APRECIAÇÃO CRÍTICA \\
\hline 1906 & $\begin{array}{l}\text { - Cultes, Mythes et Religions. Tome I. } \\
\text { (Paris: Leroux, 1905) } \\
\text { - } \quad \text { Xerxès et l'Hellespont } \\
\text { (Revue Archéologique, 1905) }\end{array}$ & $\begin{array}{l}\text { "obra de apostolado"; "reserva quanto ao } \\
\text { método"; "reservas quanto à originalidade" (p. } \\
\text { 174-5) } \\
\text { (apenas referência) }\end{array}$ \\
\hline 1907 & 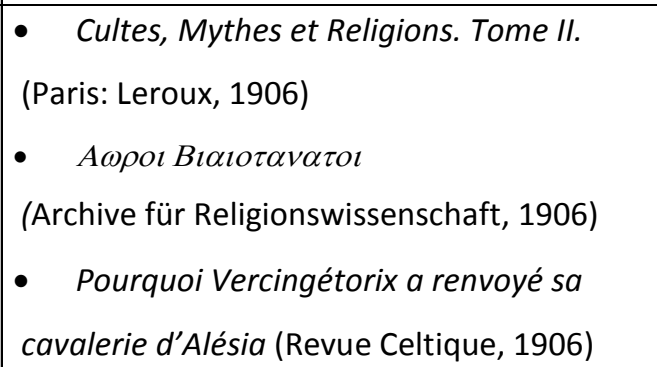 & $\begin{array}{l}\text { "pouco escrupuloso na escolha das provas"; } \\
\text { "fogos de artifício de hipóteses" (p. 218-9) } \\
\text { (apenas referência) } \\
\text { (apenas referência) }\end{array}$ \\
\hline 1910 & $\begin{array}{l}\text { - Orpheus : histoire générale de la religion. } \\
\text { (Paris: Picard, 1909) } \\
\text { - Hyppolite } \\
\text { (Archive für Religionswissenschaft, 1907) }\end{array}$ & $\begin{array}{l}\text { "manual de bolso destinado ao grande público" } \\
\text { (p. 72-73) } \\
\text { (apenas referência) }\end{array}$ \\
\hline 1913 & $\begin{array}{l}\text { - } \quad \text { Cultes, Mythes et Religions. Tome IV. } \\
\text { (Paris: Leroux, 1912) }\end{array}$ & $\begin{array}{l}\text { "[Reinach] se atém a todos os problemas que } \\
\text { não comportam soluções precisas" (p. 82) }\end{array}$ \\
\hline
\end{tabular}

A resposta de Reinach veio também na forma de textos acadêmicos. Ao resenhar os Mélanges d'Histoire des Religions, por exemplo, ele afirmou (RA, 1909/1: 192):

\begin{abstract}
A reimpressão é precedida de um prefácio destinado em parte contra minhas ideias, em parte contra as de Robertson Smith. Os Srs. H[ubert] e M[auss] bem querem convir que eu 'acrescentei muitos bons exemplos de mitos sacrificiais' e fazem alusões a minhas memórias sobre Orfeu, Hipólita, Acteon e Faeton. 'Mas, acrescentam eles, todo animal sacrificado não é um totem. Para que exista um totem é preciso que exista um clã. Mas nós esperamos ainda que o Sr. R[einach] nos demonstre a existência de clãs aos quais teriam pertencido os referidos totens'. Estes senhores esperarão por um longo tempo. Mas eu esperarei talvez ainda mais que eles deem dos mitos em questão uma explicação diferente da minha e que seja coerente.
\end{abstract}

Em geral, é sempre essa mesma linha de argumentação que se repete por parte do então diretor do Musée des Antiquités Nationales. Ele afirmava defender a teoria que, sendo a mais simples possível, resolveria o maior número de casos. Os sociólogos teriam assim, e com justiça, trabalhado para complexificar a análise dos estudos religiosos, mas não estariam em condições de propor teorias de alcance global.

Em todo caso, as críticas mútuas não impediram que, a partir de 1911, ambos trabalhassem juntos para a criação da Institut Français d'Anthropologie. Elas também não anularam, sobretudo da parte de Reinach, o reconhecimento dos méritos alheios. As hipóteses 
de Hubert sobre a divindade celta Nantosvelta foram por ele recebidas como "certezas" (RA, 1913/1: 264-5). Já quanto a Les Formes Élémentaires de La Vie Religieuse, Reinach chega a confidenciar a seu colega belga Franz Cumont que achou o livro de Durkheim um "chefd'oeuvre" ${ }^{23}$, opinião reforçada publicamente em duas resenhas publicadas ainda em $1912^{24}$. Até sua morte, em 1933, ele ainda publicou três necrológios altamente elogiosos de membros da equipe de L'Année Sociologique ${ }^{25}$, assim acolheu seus trabalhos no conturbado pós-guerra, publicando artigos seus e resenhas de seus livros ${ }^{26}$.

\section{UM MUSEU ABERTO À SOCIOLOGIA}

Se a simpatia de Reinach, por si só, permitiu com que os sociólogos se fizessem representar no leque de instituições por ele frequentadas, o próprio Museu de Saint-Germain foi transformado em uma espécie de laboratório da nova ciência. A figura central, nesse caso, foi indiscutivelmente Henri Hubert. Ainda que parte dos estudos que Ihe foram consagrados tenha destacado uma suposta incomunicabilidade entre seus trabalhos arqueológicos e sociológicos, essa opinião não se sustenta diante de uma análise mais detida da documentação hoje disponível ${ }^{27}$. No momento mesmo em que inicia suas atividades no museu, ele tem o claro intuito de promover o diálogo entre as duas ciências, tal como explicita neste trecho de uma carta sua endereçada a Mauss ${ }^{28}$ :

Quero trabalhar, aproveitar este Museu. Para permanecer orientalista ocupando-me das antiguidades nacionais é necessário que eu faça antiguidades nacionais a fundo. Logo vou me ocupar da preparação do catálogo, ou seja, do primeiro estudo metódico da arqueologia merovíngia: sarcófagos, tumbas, conteúdo das tumbas. Não preciso destacar que isto me separa apenas em aparência de nossos estudos; para fazer isto de forma conveniente é preciso ter as nossas preocupações.

Ao longo dos anos que se seguiram, Hubert manteve seu projeto original. É isso que se constata, por exemplo, em seus trabalhos de classificação das coleções arqueológicas depositadas em Saint-Germain. Os artigos que dedicou ao tema ilustram bem sua constante preocupação em encontrar, na materialidade mesma dos objetos, padrões histórica e socialmente relevantes em termos técnicos, morfológicos ou de práticas rituais (HUBERT,

\footnotetext{
${ }^{23}$ Veja-se a carta de Reinach a Cumont, datada de 01 de agosto de 1912, pertencendo aos arquivos Franz Cumont na Academia Belgica (http://www.academiabelgica.it/img_lettre/5385_page_2.jpg).

${ }^{24}$ RA, 1912/2: 182 e REINACH, S., 1912.

${ }^{25}$ Cf. RA, 1915/1: 333 (Hertz); RA, 1917/2: 458 (Durkheim); RA, 1927/2: 176-178 (Hubert).

${ }^{26}$ Quanto às resenhas, vejam-se RA, 1922/1: 204; RA, 1922/2: 363-364; RA, 1923/1: 188-189; RA, 1932/1: 325-7. Quanto aos artigos, cf. RA, 1924/1: 241-261 e RA, 1934/1: 39-47.

${ }^{27}$ Veja-se, em especial, BRUN; OLIVIER, 2000. Para uma crítica dessa leitura, bastante colada à posição aqui defendida, cf. LORRE, 2009.

${ }^{28}$ Carta inédita de Hubert a Mauss, não datada, pertencente ao fundo de arquivos Hubert-Mauss, do Institut Mémoire des Éditions Contemporaines.
} 
1902, 1906 e 1910). A Sala de Marte, cuja organização foi assumida por ele em 1910, dedicada à arqueologia comparada, é certamente a prova maior disso. Apresentada em um escrito autobiográfico como seu "trabalho principal", ela reunia coleções de todo o mundo, dispostas em função de recortes sociais (tecnológicos e rituais), cronológicos e espaciais (HUBERT, 1979). Tratava-se de um microcosmo experimental, no qual a humanidade poderia contemplar, sob certos ângulos, o conjunto de suas realizações, em sua unidade e em sua multiplicidade (vejam-se as figuras 3.2.1, 3.2.2 e 3.2.3) . $^{29}$.

Outros indícios do comprometimento de Hubert com uma arqueologia enriquecida pela sociologia, ou vice-versa, vêm de suas atividades docentes na École du Louvre e École Pratique des Hautes Études (onde ele atuou a partir de 1901). É bem verdade que não se tem hoje condições de restituir integralmente o conteúdo de suas lições, ainda mais porque se tratavam, no mais das vezes, de exercícios práticos. Ainda assim, parte de suas aulas introdutórias ou teóricas sobreviveram ao tempo, permitindo ter uma ideia mais precisa das preocupações gerais de Hubert. Chama aí atenção, em primeiro lugar, o caráter itinerante do curso. Sobretudo passado o inverno, os alunos tinham de visitar, devidamente acompanhados pelo professor, os principais museus de arqueologia (Louvre e Saint-Germain) e de etnografia (Trocadero) franceses. Estes passeios visavam ilustrar as correlações possíveis entre diferentes modalidades de objetos, do ponto de vista da arqueologia etnográfica, da linguística e da sociologia. Hubert insiste com seus alunos na necessidade de fugir a uma explicação puramente formal dos objetos e o faz assumindo uma perspectiva histórica e/ou comparatista. Referindo-se, por exemplo, ao estudo dos adornos de objetos do neolítico, ele afirma ${ }^{30}$ :

Eu sustento que estas linhas não figuram sobre os ditos objetos a título de puros ornamentos. Em outros termos, [sustento] que elas são objeto de representações e de sentimentos obscuros, não analisáveis, do tipo de nossa categoria de mana, na qual a ideia de ornamento por um lado e o prazer estético de outro se encontram incluídas, mas certamente misturadas a todo tipo de coisas [tão?] contraditórias quanto se supõe. Do caráter formal da eficácia destes instrumentos nós [passamos?] ao caráter social das representações que eles reagrupam [?] seu uso e sua invenção.

Desse modo, embora o conteúdo de seus cursos, seja na EPHE, seja na École du Louvre, estivesse centrado no conjunto dos povos europeus, Hubert não parece ter descartado nenhuma das imensas competências que possuía.

\footnotetext{
${ }^{29}$ MOHEN, 1980-1 e LORRE, 2010.

${ }^{30}$ Nos arquivos Hubert do Musée d'Archéologie Nationale, veja-se, na caixa Cours École du Louvre, o envelope contendo três subenvelopes e intitulado Conférence Complémentaire. $\mathrm{O}$ trecho citado encontra-se na página 11 do primeiro sub-envelope. Outra conferência pode ser encontrada na caixa Religions I. Agradeço a Christine Lorre por ter me comunicado esses e outros documentos previamente analisados e parcialmente transcritos por ela.
} 
Toda uma nova geração de sociólogos usufruiu das aulas de Hubert e, graças a elas, da estrutura do Museu de Saint-Germain. Entre eles estiveram, para mencionar apenas alguns nomes mais conhecidos, Stefan Czarnowski, Henri Beuchat, Raymond Lantier e Jean Marx. Sabe-se, aliás, que ao menos dois deles, Beuchat e Lantier, trabalharam com coleções inteiras do museu, uma contribuição cuja amplitude e frutos ainda precisam ser investigados.

\section{O DEUS COM O MARTELO: QUANDO A SOCIOLOGIA ENCONTROU A ARQUEOLOGIA}

Une nouvelle figure du dieu au maillet, artigo publicado na Revue Archéologique durante a Primeira Grande Guerra, ilustra perfeitamente a ambição e a substância do projeto intelectual de Henri Hubert (RA, 1915/1: 26-39). Toda a discussão parte de uma escultura em bronze encontrada em Orpierre (Hautes-Alpes), na qual aparecem sobrepostos elementos relativos a Silvanus, divindade latina, e a Sucellus, divindade celta. Do primeiro, a estatueta conservou a coroa de galhos e a vestimenta de pele de animal apoiada sobre o ombro esquerdo. Do segundo, o pote de cerveja na mão direita e o martelo seguro com a esquerda.

Hubert sustenta que tal fusão não foi nem gratuita, nem isolada. Embora a peça seja ímpar dentro do que até então se conhecia de esculturas galo-romanas, fontes epigráficas e anepigráficas sugeriam que a migração de elementos típicos do deus romano para o gaulês tenha sido comum. Mas qual a razão disso?

De início, o jovem sociólogo ataca a tese defendida por Salomon Reinach. Para o diretor do Museu de Saint-Germian, a única explicação possível era a estética, uma vez que, em termos religiosos, não haveria como fundir uma divindade agrária (Silvanus) com uma divindade infernal (Sucellus). Toda a confusão seria, portanto, fruto de um encontro de imagens, pois as divindades teriam partilhado signos (ambas seguravam algo com sua mão esquerda, assim como poderiam vir acompanhadas de um cão).

Para Hubert, tal explicação era altamente insatisfatória. Afinal, como explicar que a mesma confusão tenha ocorrido com frequência em outros suportes documentais? Para dar conta dessas regularidades, ele insistiu que, em termos de culto, o mundo celta localizou nos deuses infernais a renovação dos campos durante as colheitas, o que os tornou, por extensão, divindades agrárias em potencial. Além do mais, ele apresentou o que entende ser um dado crucial: a maior parte das representações híbridas de Silvanus e de Sucellus apareceram em regiões em que o colonato latino se estabeleceu junto a aldeamentos celtas.

Por tais motivos, o "deus com o martelo" surge a Hubert como um documento para se pensar os efeitos sociais da sobreposição, por meio de um expediente de conquista, de duas comunidades, a latina e a gaulesa. Ele permite problematizar como os "dominados" buscaram nas técnicas dos dominadores elementos para expressar e ressignificar suas próprias divindades locais, integrando-se no mesmo movimento ao mundo a que passaram a pertencer.

Ao final do artigo, devidamente munido de suas conclusões, Hubert ainda julga encontrar duas representações de peças análogas nas séries já conhecidas de esculturas antigas. 


\section{CONSIDERAÇÕES FINAIS}

Famoso por suas coleções únicas que abarcam desde a Pré-História até a Idade Média europeias, o Musée des Antiquités Nationales merece assim um espaço na história da emergência da sociologia universitária. Independente dos eventuais sucessos ou fracassos dos sociólogos em impor filiações teóricas diretas no campo da arqueologia, é preciso também levar em consideração a visibilidade e a legitimidade que tal instituição pôde conferir à própria empresa sociológica como um todo. Havia aí seu notável padrão de recrutamento: boa parte de seus conservadores e diretores provinham da École Normale Supérieure, representando assim o que havia de mais conceituado em termos de formação intelectual na França. Havia aí também as inserções sociais e honrarias acumuladas por esses mesmos homens: eles eram, em geral, membros do Institut, professores na École du Louvre e frequentadores de inúmeras sociedades científicas. Entre a invenção e a tradição, o museu de Saint-Germain foi sempre mais do que o próprio museu. Ele soube acolher os sociólogos que por ele transitaram, assim como fez ecoar seus nomes e ideias para além da disciplina específica e dos domínios que o caracterizavam. 


\subsection{AS CONTRIBUIÇÕES}

\section{DOS DURKHEIMIANOS AO}

\section{DICTIONNAIRE}

\section{DES ANTIQUITÉS}

\section{GRECQUES ET ROMAINES}

De duas instituições centrais a um empreendimento editorial único: o presente subcapítulo discute os textos publicados por sociólogos próximos a Durkheim naquela que foi a maior enciclopédia ilustrada da Antiguidade Clássica jamais concebida na França, o Dictionnaire des Antiquités Grecques et Romaines (doravante DAGR). Tal recorte se deve não apenas à importância histórica da referida publicação, a qual será discutida na sequência, mas também devido ao fato de quatro de seus cinco volumes publicados após 1898, ou seja, após o aparecimento de L'Année Sociologique, abrigarem contribuições de integrantes da "escola sociológica francesa". Daí as perguntas: como explicar a constância de sua presença e a lógica de seu recrutamento? Quais os temas abordados por eles e como a sociologia apareceu no tratamento que Ihes foi dispensado? E, por fim, além das referidas contribuições, qual o interesse despertado pelo trabalho da escola durkheimiana no conjunto da publicação? Antes mesmo de abordar essas questões, cumpre apresentar, em linhas gerais, o próprio DAGR.

\section{O Dictionnaire des ANtIQUites GRECQUES Et Romaines}

O Dictionnaire des Antiquités Grecques et Romaines, editado pela Hachette, apareceu sem interrupções, mas com frequência irregular, de 1877 à 1919. Assim, entre a publicação do primeiro volume, relativo às letras $A-B$, e o segundo, centrado exclusivamente na letra $C$, 
passaram-se dez anos, ao passo que o terceiro volume, dedicado às letras D-E, surgiu em 1892, apenas cinco anos após o anterior. $\mathrm{O}$ que se vê depois é uma tendência à estabilidade, com intervalos de três a quatro anos entre uma e outra publicação, só quebrada com a eclosão da Guerra de 14-18, tal como mostra o quadro 3.3.1. Além disso, antecipando o lançamento dos grandes tomos, a editora trazia periodicamente a público fascículos menores, o que contribuiu para dinamizar a produção e a circulação da obra.

Quadro 3.3.1 - DAGR: periodicidade e conteúdo.

\begin{tabular}{|c|c|c|c|}
\hline Tomo & Ano & Número de notícias/verbetes & Número de páginas \\
\hline A-B & 1877 & 665 & 756 \\
\hline C & 1887 & 499 & 947 \\
\hline D-E & 1892 & 402 & 946 \\
\hline F-G & 1896 & 193 & 769 \\
\hline H-K & 1900 & 269 & 880 \\
\hline L-M & 1904 & 387 & 1262 \\
\hline N-Q & 1907 & 483 & 808 \\
\hline R-S & 1911 & 403 & 792 \\
\hline T-Z & 1919 & 420 & 1077 \\
\hline
\end{tabular}

Mas se o ano em que teve início a publicação do DAGR remete à primeira década da ainda frágil Terceira República, é preciso recuar mais no tempo para que se possa abordar suas origens. O contrato no qual foram definidos o conteúdo e público-alvo da publicação, assinado entre a Hachette e Charles Daremberg, o idealizador do projeto, data de 1855 . Nele, a despeito das mudanças incorporadas mais tarde, estabeleceu-se já que os verbetes deveriam tratar de vários aspectos das civilizações grega e latina, com ênfase tanto em costumes, crenças e leis, como na vida material e nos momumentos conservados ${ }^{1}$. Já no tocante ao público-alvo, tratava-se de colocar o erudito a serviço do leigo. Daí a preocupação em dotar os verbetes de ilustrações e, se fosse o caso, de uma bibliografia geral. Os especialistas não foram, porém, esquecidos: a eles destinavam-se as copiosas notas de rodapé, nas quais se poderia, além de apresentar em detalhes o estado da arte de uma determinada questão, justificar críticas ou avançar teses.

De 1855 à 1919, ou seja, da assinatura do contrato ao término da obra, decorreram portanto 64 anos. Tamanha longevidade permite vislumbrar, sob um verniz de continuidade,

\footnotetext{
${ }^{1}$ De início, o DAGR deveria tratar também da Antiguidade Oriental e da Idade Média. Veja-se, quanto a isso, VALENTI, $2006 \mathrm{~b}$.
} 
um dos períodos mais ricos da história intelectual francesa. Eis aí, certamente, a importância do DARG para o analista interessado na história social da produção intelectual francesa: graças às transformações na direção e no recrutamento de seus colaboradores, ele sintetiza a passagem de um modus vivendi centrado nos salões eruditos e nas Academias locais ou nacionais para um registro própria e predominantemente universitário.

Veja-se, como um indício desse processo, a trajetória de seu fundador e primeiro diretor, Charles Daremberg. Nascido na Dijon de 1817, Daremberg seguiu, após ter sido aluno de um seminário provincial, a carreira de médico. Mas não se tratava de um médico qualquer: ele foi também, e sobretudo, um erudito. Sob a influência do círculo positivista reunido em torno de Émile Littré, Daremberg acabou dedicando a maior parte de seu tempo ao estudo da história da medicina. Seu primeiro grande trabalho na área foi a tese defendida em 1841 na Faculdade de Medicina de Paris, na qual ele discutiu a obra de Galenos. Em 1849, após um período como bibliotecário dessa instituição, ele se envolveu com a Académie des Inscriptions, a qual o enviou a Roma para catalogar os manuscritos sobre medicina antiga preservados na Biblioteca do Vaticano. Segundo Gourevitch (2009), sua biógrafa, tal experiência com arquivos foi determinante para fazer nascer em Daremberg a ideia de publicar um dicionário. De fato, poucos anos após ter deixado a Itália, ele iniciou as negociações com a Hachette, as quais, no entanto, só produziram resultados concretos em 1877, cinco anos após sua morte.

Quem serviu de intermediário entre esse erudito ligado aos salões científicopositivistas e os universitários da Terceira República foi o outro cofundador da obra, Edmond Saglio. Nascido na Paris de 1828, bacharel e licenciado em direito, Saglio viveu entre esses dois mundos. Com efeito, ele dividiu, por um período considerável de sua vida, o trabalho como advogado junto ao Ministério da Justiça, com os estudos sobre história da arte e arqueologia. Com o passar dos anos, contudo, sob o apadrinhamento do arqueólogo e medievalista Jules Quicherat, de quem seguira os cursos na École des Chartes, Saglio foi se desvinculando do direito. Assim, em 1879, ele passou a ocupar o cargo de conservador adjunto no Louvre, saindo de lá mais tarde, em 1893, para assumir a direção do Musée de Cluny.

Cumpre destacar aqui que a arqueologia, uma das principais áreas de interesse de Saglio, esteve na vanguarda da profissionalização dos corpos de letrados franceses (GRANAYMERICH, 1998: 141-202). Tal fato, impulsionado pelo sucesso político-científico de escavações dentro e fora da França, traduziu-se tanto pela criação de novas instituições essencialmente voltadas à pesquisa, tais como o Musée des Antiquités Nationales e certas seções da École Pratique des Hautes Études, como pela reforma das antigas. De início acanhadas, as reformulações do sistema de ensino francês foram aceleradas e aprofundadas após a derrota militar para a Prússia e a consolidação da Terceira República. Saglio, recrutado 
por Daremberg em meados da década de 1860, acompanhou de perto tais mudanças e foi, de fato, o grande responsável pela publicação do primeiro volume do DAGR. Mas como a logística dessa obra monumental era complexa demais para um só homem, um jovem helenista, formado inteiramente nos novos quadros universitários, uniu-se logo depois ao projeto. Tratava-se de Edmond Pottier.

Se a universidade moderna, instituição na qual deve predominar a educação visando à produção de conhecimento científico original, consolidou-se na França em torno de 1880, tal como sustentam os especialistas na história de seu sistema de ensino, então Edmond Pottier pertenceu à sua primeira geração ${ }^{2}$. Nascido na Särrebruck de 1855 , ele passou pelo liceu Condorcet em seu caminho à École Normale Supérieure (ENS). Membro da promoção de 1874 e primeiro colocado na agrégation de lettres de 1877, Pottier se destacou na sequência por seus anos de atividade na École Française d'Athènes, onde foi instruído sobre o que havia de mais moderno em arqueologia, epigrafia e história antiga. O retorno a França coincidiu com o início da carreira de professor universitário. Sua atividade docente teve início nas Faculdades de Letras de Rennes e de Toulouse, entre 1880 e 1883, e continuou em Paris. Lá, ele acumulou cursos de arqueologia na École des Beaux-Arts e na École du Louvre com o posto de conservador no Louvre, primeiro como attaché libre (1884) e depois como adjunto (1897). Pottier tornou-se a referência francesa em cerâmicas gregas e atuou ainda como codiretor de uma das mais antigas e prestigiadas revistas científicas francesas, a Revue Archéologique.

Ora, tem-se aí, de Daremberg à Pottier, grosso modo, três gerações reunidas em torno da direção do mesmo empreendimento editorial. Mas cada uma dessas gerações apresenta, uma em relação às outras, modalidades distintas de recursos sociais e intelectuais. Daremberg não dedicou o essencial de sua vida à pesquisa e à docência universitárias. O positivismo, sua matriz teórica, nasceu fora da Universidade e não orbitou mais que suas margens ao longo da segunda metade do século XIX (HEILBRON, 2006: 269-368). Saglio, por seu turno, embora tenha iniciado sua carreira como um erudito mundano, aderiu às primeiras vanguardas de pesquisa organizadas nos novos moldes universitários. Ele frequentou a École des Chartes e integrou as equipes dos museus nacionais. Pottier, por fim, diferenciou-se de seus antecessores graças à carreira integralmente universitária. Ele a iniciou na ENS, completou-a em estágios no exterior e a concluiu com sua atividade como professor/pesquisador.

Considerando-se os dados quantitativos apresentados por Andurand, Cazenave e Delmas quanto à morfologia do DAGR (2006), pode-se constatar que o perfil encarnado por

\footnotetext{
${ }^{2}$ Veja-se a síntese proposta em MAYEUR, 2004: 581-635. Quanto às informações sobre a trajetória de Pottier, elas foram retiradas do necrológio escrito por Raymond Lantier e Charles Picard na Revue Archéologique (RA, 1928/2: 289-307).
} 
Pottier foi, com o passar dos anos, impondo-se à maioria dos colaboradores da obra. Ao fim e ao cabo, embora não tenha se originado assim, o DAGR, incorporando as transformações do cenário intelectual francês, tornou-se uma espécie de extensão da Universidade da Terceira República. Eis um argumento-chave para que se possa compreender a presença dos sociólogos próximos a Durkheim. Afinal, ao contrário dos demais grupos que disputavam com eles o controle das ciências sociais em fins do século XIX, os membros da equipe de L'Année Sociologique possuíram também um perfil predominantemente universitário, o que supõe a obtenção de certificados de estudos análogos aos dos helenistas e dos latinistas ${ }^{3}$. Ou seja, eles foram compelidos, pela lógica do sistema ao qual pertenciam, a se encontrarem no DAGR. Resta agora explicar quem, dentre eles, aderiu a esse projeto editorial e por que o fez.

\section{HeNRI HUBERT, UMA JOVEM PROMESSA ENTRE OS ANTIQUISANTS}

Em termos cronológicos, as primeiras contribuições de um sociólogo próximo a Durkheim saíram das mãos de Henri Hubert. Ele redigiu, ao todo, duas notícias para o DAGR, uma para o quinto e outra para o sexto volume, tal como se pode constatar no quadro abaixo.

Quadro 3.3.2 - Henri Hubert e o DAGR.

\begin{tabular}{|l|c|c|c|c|}
\hline Notícias/Verbetes & Volume & $\begin{array}{c}\text { Ano de } \\
\text { publicação }\end{array}$ & $\begin{array}{c}\text { Número de } \\
\text { colunas }\end{array}$ & Paginação \\
\hline KYRÈNÉ & H-K & 1900 & 5 & $873-876$ \\
\hline MAGIA & L-M & 1904 & 51 & $1494-1521$ \\
\hline
\end{tabular}

Antes mesmo de tratar do conteúdo dessas contribuições, é importante situá-las na trajetória de Henri Hubert ${ }^{4}$. Com apenas 28 anos em 1900, ele certamente não debutou no DAGR graças ao prestígio de um pesquisador consolidado. Livros, ele não havia lançado nenhum. Artigos, possuía alguns poucos, dentre os quais se destacavam um estudo sobre a formação do estado papal e seu ensaio sobre o sacrifício escrito em parceria com Marcel Mauss, ambos de $1899^{5}$. Quanto à sua posição institucional, além do cargo não remunerado de attaché libre ocupado no Musée des Antiquités Nationales desde 1898, ele teve de esperar até 1901 para ser eleito maître de conférence na École Pratique des Hautes Études (EPHE). Em suma, o Hubert que contribuiu para o DAGR não era mais que um debutante no mundo

\footnotetext{
3 Sobre os estribos institucionais dos durkheimianos e dos demais grupos que conviviam e se enfrentavam quanto aos rumos das ciências sociais, cf. CLARK, 1973; KARADY, 1976 e 1979; MUCCHIELLI, 1998 e CONSOLIM, 2008.

${ }^{4}$ Para um apanhado recente e bastante completo da carreira e das publicações de Hubert, veja-se LORRE, 2009.

${ }^{5}$ HUBERT, 1899 e AS, 1899: 29-137 (republicado em HUBERT; MAUSS, 1909).
} 
universitário. Ainda assim, ao menos aos olhos dos diretores da publicação, ele deveria passar a impressão de um jovem responsável e, além do mais, promissor.

O contato com Salomon Reinach, seu "patrão" no Musée des Antiquités Nationales, certamente agregou valor a seu nome nos círculos dos antiquisants. Mas não se pode derivar daí a participação de Hubert no DAGR, pois ter-se-ia de esclarecer tanto como a confiança de Reinach foi conquistada quanto qual era sua real influência nas opiniões de Saglio e de Pottier. Para escapar a uma simples cadeia de causa e efeito, é preciso tratar então, para falar como Max Weber, das condições sociais de produção e de reconhecimento de uma determinada vocação. O fato é que Hubert, talvez mais do que qualquer outro fundador de L'Année Sociologique, apresentava as condições necessárias para ser visto como um jovem com potencial no campo dos estudos greco-latinos. Sua formação explica, ao menos em parte, esse fenômeno. Detentor de um prêmio de version grecque no Concours général nos tempos do liceu Louis-le-Grand, Hubert continuou estudando a fundo as línguas e os textos antigos na ENS, de onde saiu agrégé d'histoire em 1895, e na EPHE. Ainda desses mesmos anos vem o traquejo com a epigrafia, tal como testemunha seu primeiro artigo, Deux inscriptions métriques d'Asie Mineure, publicado na Revue Archéologique (RA, 1894/1: 308-314).

Ao treinamento escolar digno de um antiquisant, o jovem Hubert soube associar os contatos sociais. A análise de sua correspondência passiva, depositada no Institut Mémoires de I'Edition Contemporaine (IMEC), traz importantes revelações nessa direção. Entre seus camaradas da ENS, por exemplo, as cartas de Paul Perdrizet e Pierre Jouguet, ambos antiquisants, deixam transparecer uma grande amizade e um profundo respeito intelectual por Hubert. Em uma carta de setembro de 1894, Jouguet chegou mesmo a pedir que ele reconsiderasse sua decisão de renunciar à École Française d'Athènes, atestando ao menos que a questão um dia se colocou ${ }^{6}$. Hubert manteve também boas relações, talvez até mesmo excepcionalmente boas, com alguns dos expoentes da área. Encontram-se, entre seus correspondentes do final do século XIX, nomes como o do latinista René Cagnat, professor no Collège de France, e o do helenista Amédée Hauvette, da Sorbonne ${ }^{7}$. Deste, partem convites para soirées privadas e pedidos de ajuda quanto a pequenos trabalhos. Daquele, que o trata por "cher ami", recebe a incumbência de se ocupar das inscrições epigráficas da Síria em uma coletânea de fontes, trabalho que abdicará em prol de um de seus colegas ${ }^{8}$. E os exemplos de contatos sociais poderiam ser multiplicados ${ }^{9}$.

\footnotetext{
${ }^{6}$ Arquivos do IMEC-Caen. Fonds Mauss-Hubert, caixa MAS 49.

${ }^{7}$ Cf., nos Arquivos do IMEC-Caen, Fonds Mauss-Hubert, caixa MAS 47 (Cagnat) e MAS 49 (Hauvette).

${ }^{8}$ Hubert intercedeu junto a Cagnat para que Pierre Jouguet recebesse a tarefa, suscitando a seguinte reação de seu amigo: "o pedido que você fez junto a Cagnat me toca bastante; mas eu me sinto confuso ao te ver abandonar um título que te será útil e que você merece mais que eu" [No original: "/a
} 
A proximidade de Hubert com latinistas e helenistas transparece ainda nos vínculos que manteve com a Société pour l'Encouragement des Études Grecques en France. Ele foi o primeiro sociólogo a tornar-se, em 1898, sócio dessa instituição. Tal fato, ignorado por seus biógrafos, mostra o quão à vontade ele se sentia para investir profissional e afetivamente em um espaço no qual conhecia as pessoas e dominava os códigos. E mesmo o envolvimento cada vez maior com a publicação de L'Année Sociologique não o levou a um afastamento dos antiquisants. Afinal, Grécia e Roma Antigas, junto com os demais povos ditos "primitivos" e "arcaicos" da Europa e do Oriente Médio, constituíram o quinhão de Hubert na divisão de objetos de estudo que ele e Mauss estabeleceram desde muito cedo (MAUSS, 1979: 215). É o que atestam os verbetes de sua autoria no DAGR.

O convite para que Hubert escrevesse a primeira de suas contribuições veio da pena de Edmond Pottier. Em uma carta de 1899, ele incumbiu o jovem sociólogo, a quem chama de "cher camarade", em alusão à passagem de Hubert pela ENS, de redigir um texto pequeno sobre a deusa epônima de Cirene, a colônia grega no norte da África ${ }^{10}$. Surpreendem, nas duas páginas e meia dedicadas ao assunto, a erudição e o rigor metodológico do autor. Com efeito, Hubert não se contenta em fazer uma triagem das narrativas míticas e dos monumentos figurados relativos à Deusa. Ele lista e descreve todos os indícios à época disponíveis, a partir dos quais ele tenta depreender as linhas de força que caracterizam a "natureza" da divindade e, sobretudo, seu culto. Mantendo como pano de fundo uma perspectiva comparatista, Hubert encontra em Cirene uma divindade ligada à fecundidade vegetal e à caça, cujo mito estaria marcado por uma teomaquia (o combate com um leão) e uma hieromaquia (a união com Apolo). Autores clássicos como Usener e Roscher são citados, assim como seu ensaio sobre o sacrifício, o qual deveria esclarecer invariantes presentes nos rituais ligados à deusa. Hubert também não negligencia a história do culto de Cirene, levantando hipóteses sobre sua origem e acompanhando sua assimilação ao de Ártemis. Pode-se então considerar esse texto como absolutamente integrado às preocupações do jovem sociólogo: ele está diretamente vinculado não só às reflexões mais gerais sobre as práticas mágico-religiosas no interior do grupo de L'Année Sociologique, como antecipa as grandes análises de divindades que fará mais tarde, sobretudo quanto ao contexto celta ${ }^{11}$.

démarche que tu as faite auprès de Cagnat me touche beaucoup; mais je suis confus de te voir abandonner un titre qui te serait très utile et que tu mérites mieux que moi"]. Carta sem data (provavelmente de 1898). Arquivos do IMEC-Caen. Fonds Mauss-Hubert, caixa MAS 49.

${ }^{9}$ É o caso, para o material presente nos Arquivos do IMEC-Caen, Fonds Mauss-Hubert, de Franz Cumont (MAS 47), Albert Grenier (MAS 49) e Théodore Reinach (MAS 51).

${ }^{10}$ Arquivos do IMEC-Caen, Fonds Mauss-Hubert, caixa MAS 51.

${ }^{11}$ Faz-se aqui alusão aos ensaios reunidos em HUBERT, 1925. 
Magia, a segunda e última notícia publicada por Hubert no DAGR, difere da anterior por seu tamanho, vinte e cinco páginas e meia, e ousadia. Seu objetivo é dar conta de sistematizar as práticas mágicas existentes em toda bacia do Mediterrâneo, com destaque para o conjunto coerente formado após as expansões militares macedônica e, sobretudo, romana. Assim, muito embora a multiplicidade de contextos históricos particulares seja evocada, algo patente no tratamento das fontes literárias (Homero, Hesíodo, Heródoto, Diógenes Laércio, Apuleio, entre outras) e materiais (pinturas em cerâmica e oferendas votivas em chumbo), são os traços sistêmicos, invariantes, que mais o interessam. Tal opção, que o próprio autor reconhece como provisória e não científica, apresenta ao menos a vantagem de proteger a análise da tentação de se tornar uma paráfrase descontrolada das fontes antigas. Para tanto, o autor organiza a notícia em três grandes blocos: após uma breve introdução (pp. 1494-1497), ele discute o histórico da questão e apresenta as principais fontes antigas (pp. 1497-1506), para então problematizar os procedimentos rituais e os poderes do mágico, bem como situá-los em conjuntos cerimoniais maiores (pp. 1506-1514).

Sobre as teses aí defendidas por Hubert e seu lugar na produção de l'Esquisse d'une Théorie de la Magie, texto clássico que publicará com Mauss em 1904, não se saberia dizer aqui muito mais do que foi dito em outras ocasiões por Marcello Carastro (2006 e 2010). 0 pano de fundo da notícia remete, como bem indicou o referido helenista, a um contexto maior que o greco-latino. Hubert faz questão de citar especialistas de outros povos e civilizações, o que the permite polemizar com Frazer sobre os princípios gerais da magia. Critica-se, sobretudo, a tendência de o antropólogo britânico fazer derivar toda operação mágica de uma lógica simpática. Em oposição, ou melhor, em acréscimo à tese de Frazer, Hubert sinaliza, apoiando-se em citações de seu ensaio sobre o sacrifício, para a importância da oposição sagrado-profano como chave explicativa do conjunto do fenômeno mágico. Trata-se, enfim, de um prenúncio do que de melhor será produzido em termos de sociologia religiosa pela equipe de L'Année Sociologique. Eis aí a importância teórica da notícia publicada no DAGR.

Outro interesse da publicação remete, porém, ao prestígio que ela agrega ao nome de Hubert entre os antiquisants. As duas cartas endereçadas a ele por Saglio, ambas preservadas no IMEC, sugerem isso. Se na primeira, datada de 2 de julho de 1901, o diretor do DAGR manifesta preocupação com a amplitude que estava tomando a notícia, em 28 do mesmo mês ele felicita Hubert: "Eu admiro a coragem e a paciência com a qual você se lançou e caminhou, sabendo se reconhecer, neste [domínio?] das ciências ocultas" ${ }^{12}$. Na mesma carta, Saglio ainda

\footnotetext{
${ }^{12}$ Arquivos do IMEC-Caen, Fonds Mauss-Hubert, caixa MAS 52. No original: "J'admire le courage et la patience avec lesquelles vous vous êtes jeté et vous avez marché, en sachant vous reconnaître, dans ce [domaine?] des sciences occultes."
} 
convida o sociólogo a redigir um novo verbete, maleficium, o qual, no entanto, não figurará no dicionário. Publicada já em 1902, em um pequeno fascículo que antecipou o lançamento do sexto volume, Magia teve um certo impacto, especialmente entre os helenistas. Na Revue des Études Grecques e no Bulletin de Correspondance Hellénique foram localizadas cinco citações dessa notícia, todas entre 1903 e $1914^{13}$, ao passo que na Revue des Études Anciennes encontrou-se apenas uma menção, de 1920, o que testemunha ao menos que o texto continou circulando por um tempo considerável ${ }^{14}$.

\section{Paul Huvelin, o especialista consagrado}

Se Henri Hubert, no período em que contribui ao DAGR, não passava de um jovem promissor, Paul Huvelin ostentava a posição de especialista reconhecido e estabelecido. Nascido em 1873, um ano depois de Hubert, ele adquiriu títulos e consolidou uma obra mais cedo que o colega de L'Année Sociologique. Em 1904, quando seu primeiro texto foi publicado no DAGR, ele já era doutor em direito e professor de direito romano na Universidade de Lyon. A titulação veio em 1897 com a defesa da tese Essai Historique sur le Droit des Marchés et des Foires, cujo fôlego comparatista e histórico abarca longos períodos da história econômica dita ocidental, entre eles o da Antiguidade greco-romana. Quanto ao seu posto, Huvelin já havia passado pela Universidade de Aix em meados de 1898 como chargé de cours complémentaire d'Histoire du Droit Français, chegando a Lyon no ano seguinte. A efetivação veio na sequência, em 1901, como professor de história do direito romano, igualmente em Lyon.

A rápida ascenção de Huvelin se explica, em grande parte, pela embocadura de seus investimentos intelectuais. Como bem apontou Frédéric Audren, ele inaugurou as discussão sobre um ramo do saber até então praticamente ignorado na França, a saber, a história do direito comercial (AUDREN, 2001). Nesse caso específico, Huvelin rompeu com uma visão estritamente normativa da lei, a qual, radicalizando a autonomia do direito, ignorava a especificidade de seus vínculos com o mundo e, mais, sua capacidade de intervir no mundo. É bem verdade que sua perspectiva não implicava uma negação do estatuto próprio do direito, ou ainda, para colocar em termos mais precisos, de sua relativa independência. Mas Huvelin a complexifica de maneira considerável, como será visto na sequência. Quanto a seus estudos sobre o direito comercial e penal greco-romano, eles operaram em terrenos muito colados aos da sociologia da religião produzida em L'Année Sociologique. Interessava a ele, em linhas

\footnotetext{
${ }^{13}$ Cf. REG, 1903: 42-61; REG, 1904: 350-360; REG, 1905: 1-75; REG, 1907: 365-382; e, por fim, BCH, 1914: 250-271.

${ }^{14}$ REA, 1920: 157-171.
} 
gerais, compreender como, de uma matriz mágica ou religiosa, pode ter tido origem um direito que não é nem magia, nem religião.

O início da participação de Huvelin no DAGR praticamente coincide com sua adesão ao projeto científico encabeçado por Durkheim. Sabe-se, graças às suas cartas endereçadas a Mauss e preservadas no IMEC, que ele já orbitava o espaço da sociologia universitária desde $1899^{15}$. A recíproca também é verdadeira, haja visto que a produção de Huvelin sobre a história do antigo direito romano foi bem acolhida entre os durkheimianos ${ }^{16}$. O fato é que ele figura entre os colaboradores regulares de L'Année Sociologique a partir de 1903. No DAGR, por seu turno, ao qual esteve vinculado a partir de 1904, encontram-se ao todo dez notícias de sua autoria, as quais variam em tamanhos e temas, tal como mostra o quadro abaixo.

Quadro 3.3.3 - Paul Huvelin e o DAGR ${ }^{17}$.

\begin{tabular}{|l|c|c|c|c|}
\hline Notícias/Verbetes & Volume & $\begin{array}{c}\text { Ano de } \\
\text { publicação }\end{array}$ & $\begin{array}{c}\text { Número de } \\
\text { colunas }\end{array}$ & Paginação \\
\hline MERCATOR $\left(^{*}\right)$ & L-M & 1904 & 10 & $1731-1736$ \\
\hline MERCATURA $\left(^{*}\right)$ & L-M & 1904 & 53 & $1743-1769$ \\
\hline NAVICULARIUS & $\mathrm{N}-\mathrm{Q}$ & 1907 & 2 & $20-21$ \\
\hline NEGOTIATOR $\left(^{*}\right)$ & $\mathrm{N}-\mathrm{Q}$ & 1907 & 7 & $41-45$ \\
\hline NEGOTIUM GESTIO & $\mathrm{N}-\mathrm{Q}$ & 1907 & 6 & $47-50$ \\
\hline NEXUM & $\mathrm{N}-\mathrm{Q}$ & 1907 & 13 & $77-83$ \\
\hline NOMINA TRANSSCRIPTICIA & $\mathrm{N}-\mathrm{Q}$ & 1907 & 2 & $133-140$ \\
\hline OBLIGATIO & $\mathrm{N}-\mathrm{Q}$ & 1907 & 14 & 141 \\
\hline OBVUGULATIO & $\mathrm{N}-\mathrm{Q}$ & 1907 & 1 & $1392-1395$ \\
\hline SOLUTIO & $\mathrm{R}-\mathrm{S}$ & 1911 & 7 & 2 \\
\hline
\end{tabular}

Impossível saber como o convite para participar ao DAGR foi feito sem uma análise da correspondência passiva de Huvelin, o que ainda está para ser feito. A iniciativa pode ter partido tanto de Saglio, graças a seus contatos com o mundo do direito, como de Pottier, bem situado na universidade francesa. Em todo caso, é preciso salientar que os trabalhos de Huvelin não eram exatamente desconhecidos do meio dos antiquisants. Seus artigos e livros

\footnotetext{
${ }^{15}$ Arquivos do IMEC-Caen, Fonds Mauss-Hubert, caixa MAS 6.40. A transcrição dessas cartas está disponível também em AUDREN, 2001.

${ }^{16}$ Durkheim faz menção à sua leitura de Huvelin nas cartas endereçadas a Mauss (1998: 123). Veja-se também o compte-rendu escrito por Durkheim de um de seus livros: AS, 1903: 388-389.

${ }^{17}$ Os verbetes acompanhados de um asterisco foram divididos entre Huvelin e o latinista René Cagnat. Nesses casos, Huvelin ocupou-se apenas da antiga história grega. A paginação refere-se exclusivamente aos trechos escritos pelo sociólogo.
} 
relativos à história do direito e do comércio na Antiguidade aparecem citados com alguma frequência nas revistas especializadas ${ }^{18}$. Ele mesmo escreveu sobre um decreto comercial grego à época recém-descoberto para o Bulletin de Correspondance Hellénique (1907: 46-93).

Quanto aos verbetes publicados por Huvelin no DAGR, eles apontam justamente para os terrenos de sua especialidade, o que mostra o quão consciente foi seu recrutamento. Por um lado, encontram-se aí textos voltados para a análise da história das práticas comerciais antigas e das legislações subjacentes a elas. É o caso das notícias mercator, mercatura, navicularius, negotiator, negotium gestio e nomina transscripticia. Por outro, foram-Ihe encomendados textos sobre aspectos precisos do direito romano, não necessariamente vinculados ao comércio, como nexum, obligatio, obvugulatio e solutio. Inútil realizar aqui uma descrição pormenorizada de cada caso, tamanha a complexidade dos contextos históricos analisados. Antes, apresentar-se-á aqui o que empresta unidade ao conjunto.

Com exceção das brevíssimas notas técnicas, tais como navicularius, nomina transscripticia e obvugulatio, as colaborações de Huvelin se destacam pela combinação de uma narrativa histórica com um comparatismo sociologicamente informado. Assim, por exemplo, ele se vale de um fenômeno como o afluxo de ouro e prata decorrente da conquista da América para explicar ao leitor algo do impacto comercial da expansão macedônica (DAGR, 1904: 1754-1756), contrasta o frete praticado na Europa moderna com o do Mediterrâneo antigo (DAGR, 1907: 42-45) e evoca fatos conhecidos do direito germânico para esclarecer práticas romanas (DAGR, 1907: 79). Mas não se tratava aqui de um comparatismo chapado, simplificador. Em verdade, ele era dirigido para apreender as especificidades de planos distintos da realidade, pois, sobretudo nas notícias sobre a história do direito comercial, propõem tanto uma história "externa" do comércio, atentando para as práticas que o configuram nas sociedades antigas e para suas mudanças ao longo dos séculos, como uma história "interna", a saber, a análise das leis em suas relações tanto com as transformações sociais quanto com a própria tradição jurídica.

Outro dado importante a ser sublinhado é a sintonia de suas notícias com as grandes agendas de pesquisa dos fundadores de L'Année Sociologique. Huvelin, como eles, mas sem os citar, fala em divisão do trabalho, solidariedade, magia e religião. Tal adesão não se dá, portanto, sem ressalvas. De fato, ao observar a autonomização da legislação como um indício da complexificação das sociedades antigas, Huvelin não a associa, como teria feito Durkheim, a um grau maior de coesão social ${ }^{19}$. Ou seja, o enfraquecimento da legislação penal pautada nos

\footnotetext{
${ }^{18}$ Veja-se, excluindo as inúmeras alusões feitas aos trabalhos de Huvelin por colaboradores de L'Année Sociologique, REG, 1904: 350-360; REG, 1909: 444; REA, 1917: 188-189; REA, 1920: 291-308.

${ }^{19}$ Veja-se, em especial, DAGR, 1904: 1744-1746; 1907:79-83 e 133-135.
} 
direitos do sangue e impregnada de um fundo mágico-religioso não era necessariamente um reflexo do aumento de solidariedade, podendo indicar também uma sofisticação dos mecanismos de produção das desigualdades sociais nocivas a ela.

É muito difícil avaliar o impacto desses textos específicos de Huvelin entre latinistas, helenistas e sociólogos. Embora seus trabalhos tenham circulado bem nestes meios, apenas duas referências à sua participação no DAGR foram encontradas nos periódicos. A primeira delas, cronologicamente, foi feita por Georges Seurres. No volume do Bulletin de Correspondance Hellénique publicado em 1912, ele citou o artigo negotiator (BCH, 1912: 557 e 614). A outra referência, desta vez ao verbete obligatio, veio da pena de um jovem helenista que, à época, estava prestes à se engajar na equipe de L'Année Sociologique, Louis Gernet. Em um texto sobre o direito primitivo na Grécia publicado na Revue des Études Grecques em 1917, ele se valeu das teses de Huvelin (REG, 1917: 259-293 e 363-383). É possível, contudo, que seus contemporâneos tenham preferido referenciar os trabalhos mais alentados do autor, aos quais ele indica nas copiosas notas que acompanham os textos do DAGR. Ao menos é essa a tendência observada nas revistas especializadas (veja-se nota 18).

\section{NOTAS SOBRE O LUGAR DA SOCIOLOGIA NO DAGR E O LUGAR DO DAGR NA SOCIOLOGIA}

Se considerados os cinco volumes do DAGR publicados após o lançamento de L'Année Sociologique, constata-se que a presença da sociologia durkheimiana foi, levando em conta as dimensões da obra, pequena: das 4819 páginas publicadas entre 1900 e 1919, apenas oitenta e seis foram redigidas por sociólogos. Não havia, de fato, como ser diferente: a ênfase na vida material e no cotidiano dos antigos deixava um espaço menor para grandes ensaios de interpretação sócio-histórica, nos quais a sociologia poderia ter um importante papel. Mas pequeno não significa inexistente. Foi sobretudo nos verbetes vinculados a aspectos mais gerais das crenças e das práticas religiosas que, para além dos textos de Henri Hubert e de Paul Huvelin, a sociologia se fez presente. Jules Toutain, em sacrificium e religio, cita tanto os trabalhos coletivos de Mauss e Hubert quanto a tradução francesa do manual de Chantepie de la Saussaye, realizada sob a direção de Hubert e de Isidore Lévy ${ }^{20}$. Também Gustave Fougères, em sua notícia maimaktéria, faz alusão ao Essai sur le Sacrifice (DAGR, 1904: 1555). Isso sem listar as remissões do DAGR aos seus próprios verbetes. O fato é que, ao menos quanto às teorias sobre prática religiosa, os sociólogos durkheimianos conquistaram desde cedo um lugar de destaque. Já quanto aos outros campos da sociologia, o econômico e o jurídico, para evocar aqui as divisões próprias a L'Année Sociologique, teve-se ainda de esperar um pouco. A

\footnotetext{
${ }^{20}$ DAGR, 1911: 344 e 454.
} 
exceção, neste caso, foi o próprio Huvelin, mas sua autoridade era reconhecida apenas em domínios muito precisos: o direito comercial greco-latino e as práticas mágicas do direito "primitivo"

O outro lado da moeda é considerar o DAGR do ponto de vista da institucionalização da sociologia. Tendo em vista o espaço nada negligenciável dos estudos greco-latinos no conjunto do sistema de ensino e, em particular, no interior das Faculdades de Letras francesas, as mesmas nas quais se deu o nascimento das cadeiras de sociologia, certamente não se tratava de algo desinteressante. Com efeito, a medida que alguns pesquisadores próximos a Durkheim se fizeram representar no DAGR, seja em textos diretos, seja em citações, isso repercutia no mercado de investimentos intelectuais dos antiquisants. A sociologia, pois, passando a figurar no hall de saberes legitimamente aplicáveis ao estudo do mundo antigo, poderia também agregar valor aos investimentos intelectuais de novas gerações. Não parece fortuito o aumento do número de helenistas nas fileiras de L'Année Sociologique antes da publicação do último número de sua primeira série, em 1913. Louis Gernet, Henri Jeanmaire e Pierre Roussel, enquanto trilhavam as vias da especialização, apostaram na sociologia como algo capaz de fortalecer seus planos de carreira. Entre os latinistas, embora ele não tenha escrito para a primeira série, o mesmo raciocínio se aplica a André Piganiol. Assim, as notícias escritas por Henri Hubert e por Paul Huvelin no DAGR tiveram, mais que um impacto nas trajetórias individuais deste ou daquele indivíduo, o mérito de ampliar a visibilidade e os espaços de inserção institucional de todo um grupo.

\footnotetext{
${ }^{21} \mathrm{O}$ que reforça, aliás, aos padrões já percebidos ao longo dos subcapítulos $1.1(\mathrm{AS}), 2.1(\mathrm{BCH})$ e 2.3 (REG).
} 


\section{CONCLUSÃO}


eorges Dumézil, ao ser entrevistado por Bernard Pivot em julho de 1986 , tocou em duas questões centrais para a presente tese ${ }^{1}$. A primeira diz respeito à relação entre os clássicos greco-latinos e as ciências sociais. Com efeito, logo no início da entrevista, Dumézil afirmou ter sido estimulado ao estudo comparativo das sociedades humanas graças ao contato com as línguas clássicas. Ainda criança, fascinado com as epopeias antigas, ele quis "aprender a língua de Jasão e de Heracles"! O traquejo adquirido desde muito cedo com o grego e com o latim lhe permitiu mais tarde entrar em primeiro lugar no concurso de admissão da ENS (1916), onde ele travou contato com os trabalhos da escola sociológica francesa após a Primeira Guerra Mundial. Em sua carreira de pesquisador, na EPHE ou no Collège de France, gregos e romanos antigos jamais deixaram de estar em seu campo de estudos. Nesse sentido, Dumézil é um exemplo bastante típico dos nexos que a trajetória de um indivíduo no sistema de ensino francês permitiu estabelecer entre as diferentes disciplinas aqui abordadas (os estudos latinos, os estudos gregos e a sociologia).

A outra questão levantada por esse aluno dos primeiros durkheimianos diz respeito justamente à ideia de interdisciplinaridade. Frente ao espanto do entrevistador com a diversidade dos temas de interesse e dos procedimentos analíticos familiares à obra de Dumézil, o cientista social proferiu a seguinte sentença: "a isso se chama hoje ser interdisciplinar, mas todos foram sempre interdisciplinares".

Tal sentença explicita com simplicidade constrangedora um problema caro às ciências sociais. Como, afinal, caracterizar uma disciplina? E mais, onde estão as fronteiras que as separam umas das outras e como elas mudam com o tempo? Ao longo da presente tese se viu helenistas e latinistas franceses incorporarem constantemente outros métodos e questões em suas atividades. O mesmo pode ser dito dos sociólogos durkheimianos. Não existe, no novelo de trajetórias que compõem a história desses grupos, um só fio. Os diálogos que eles mantiveram com cada representante de outras disciplinas iluminam facetas diversas de suas carreiras e produções intelectuais. Desse modo, os estudos greco-latinos, a arqueologia, a epigrafia, a história, a geografia, a antropologia, a sociologia, entre outros, todos esses saberes

\footnotetext{
${ }^{1}$ Trata-se de uma entrevista realizada nos quadros do programa de televisão Apostrophes e difundida no dia 18 de julho de 1986. Tal documento encontra-se disponível on-line em http://www.ina.fr/art-etculture/litterature/video/CPB86009437/georges-dumezil.fr.html (última visita em 21/02/2011).
} 
se influenciaram e influenciam-se reciprocamente. O que varia são as circunstâncias e a intensidade dessa influência.

Disso não decorre, por certo, que o conceito de disciplina seja um equívoco ou uma ilusão. Dumézil, que gostava de se apresentar como "sociólogo", não o descartou em momento algum da entrevista. Como uma primeira aproximação da questão, poder-se-ia dizer, à maneira de Wittgeinstein, que uma disciplina científica é tudo aquilo que fazem dela aqueles que estão nela implicados (sejam eles críticos ou partidários do saber em questão). Ainda assim, na medida em que existem conflitos e ambiguidades nas relações entre os indivíduos concernidos, dificilmente as respostas concordam em todos os pontos. O fato é que os cientistas sociais, por mais bem argumentadas que sejam suas adesões a um único saber, raramente falam de um só lugar. Há aí, em verdade, um ponto cego no vocabulário analítico hoje à disposição dos historiadores das ciências sociais.

\section{INTERDISCIPLINARIDADES (I): OBSERVAÇÕES SOBRE A TEORIA DO CAMPO.}

O desafio todo está na articulação entre disciplina e interdisciplinaridade. Parte importante das reflexões hoje consagradas sobre o conceito de disciplina científica enfatiza, talvez demais, a existência de uma lógica interna minimamente compartilhada pelos indivíduos, de algo que se poderia chamar, remetendo a Thomas Kuhn, de "paradigma" (2003). Segundo esse autor, ao longo da história das ciências, os paradigmas que inicialmente lhes servem de base tendem a ser colocados à prova por uma série de procedimentos "normais" de pesquisa, os quais, operando ainda segundo os preceitos definidos paradigmaticamente, acumulam uma série de incongruências e paradoxos. Se o paradigma em vigor não consegue controlar ou absorver esses problemas, ele é substituído por outro, reiniciando assim o processo.

A despeito da coerência lógica do modelo kuhniano, concebido a partir da experiência concreta de seu autor como físico, vê-se aí mal como os indivíduos fazem, na prática, a ciência. Tudo se passa como se o único elemento privilegiado na análise fosse o caráter disciplinador das disciplinas, o qual demanda dos atores não só a produção de conhecimento segundo o paradigma, mas também a sua revolução mediante certas condições. Ou seja, a "tensão essencial" kuhniana entre progresso "normal" e "revolucionário" parte das ciências concretas para resolver os dilemas de suas histórias no próprio conceito de ciência. Há aí um argumento tautológico que dificulta colocar a questão sobre as relações entre os diferentes saberes.

O conceito de campo oferecido por Pierre Bourdieu é mais complexo, permitindo pensar outras articulações que certamente influenciam a história da produção do conhecimento científico. Ele também não é um algo novo na presente tese. Ao longo das 
páginas anteriores, falou-se de "campo das publicações especializadas nos estudos grecolatinos", ou mesmo em "campo disciplinar". Em todos esses casos, fez-se referência a um sistema coerente e relativamente autônomo de relações entre propriedades e indivíduos, as quais se expressam não apenas em termos de capacidades ou de capitais acumulados (saber grego e latim, por exemplo), mas também em termos de tensões ("jovens" e "velhos", simpáticos ou antipáticos à sociologia) a partir das quais um espaço se torna internamente diferenciado. Em seu último curso ministrado no Collège de France, dedicado justamente à história social das ciências, Bourdieu sintetizou o conceito de campo com as seguintes palavras (BOURDIEU, 2001: 121-122):

\begin{abstract}
O campo tem uma estrutura objetiva que é tão somente a estrutura da distribuição (no sentido ao mesmo tempo estatístico e econômico da palavra) de propriedades pertinentes, portanto eficientes, vantagens [atouts] que atuam no campo (aqui, o capital científico) e as relações de força constitutivas dessa estrutura; isto quer dizer que as propriedades, as quais podem ser tratadas como propriedades lógicas, traços distintivos que permitem dividir e classificar (...) são simultaneamente questões, enquanto objetos possíveis de apropriação, e armas, enquanto instrumentos possíveis de lutas apropriativas, para os grupos que se dividem ou se confundem em relação a eles. $O$ espaço de propriedades é também um campo de lutas pela apropriação.
\end{abstract}

Definido assim, campo representa ao menos uma clara vantagem frente ao paradigma kuhniano: ele permite a recuperação dos atores e dos diferentes capitais que eles mobilizam em função das posições que ocupam ou almejam ocupar em um plano específico de relações (uma disciplina científica, por exemplo). Mas tal modelo tem suas limitações. É difícil, em primeiro lugar, controlar as transformações de um campo. Como avaliar o efeito de uma ação específica na modificação de um equilíbrio prévio de relações? Ou ainda, por que determinados indivíduos ou grupos atuam criativamente diante de um campo e outros não? Atrelado a essa dificuldade surge outra: a mensuração do grau de autonomia de um campo. Para Bourdieu, a autonomia do campo é sempre relativa, uma vez que ele se encontra em meio a uma série de outros campos que podem afetá-lo de inúmeras maneiras. Não obstante, se o campo é minimamente autônomo, ele apresenta alguma forma de capital específico partilhada entre os indivíduos que nele se encontram. Mas se isso é verdade, como explicar que esse capital específico nem sempre seja utilizado para estabilizar ou mesmo ampliar a autonomia do campo? Por que alguns indivíduos que estão no campo se voltam contra ele, buscando associar o capital específico do campo a outros?

Bourdieu certamente não ignorava tais dificuldades. Ele procurou solucioná-las com outra noção importante em seu trabalho, a de experiência corporificada ou habitus. É, em geral, via o conceito de habitus que as transformações de um campo são discutidas. Tal noção 
permite explicar, por exemplo, a criação de novas oposições ou divergências entre indivíduos que ocupavam antes posições muito similares. Ou ainda, ela torna inteligíveis encontros e alianças entre pessoas a princípio distantes. O fato é que as experiências de vida acumuladas dotam os agentes, sem que eles tenham total consciência disso, de inúmeros recursos, muitas vezes completamente alheios à lógica de um campo no qual eles se encontram. A reboque, o habitus serve de termômetro para o problema da autonomia. Afinal, quanto mais autônomo o campo, menor a capacidade dos agentes de promover a intervenção de recursos alheios ao seu funcionamento original.

Extremamente útil em inúmeros contextos de pesquisa, essa articulação conceitual é pouco satisfatória quando se trata de pensar a questão da interdisciplinaridade. Em verdade, o próprio habitus funciona como expressão de certa interdisciplinaridade, pois se apresenta como uma porta de entrada para a importação de recursos heterônomos em um campo. Mas o problema é que, nesse caso, todas as experiências sociais de um indivíduo estão plasmadas em um mesmo espaço, o que torna o conceito uma espécie de coringa metodológico (se há algo que não se explica pela dinâmica própria do campo, ele remete ao habitus) ${ }^{2}$.

\section{INTERDISCIPLINARIDADES (II): OS CAMPOS SE SOBREPÕEM}

Ao longo da presente pesquisa, no entanto, os campos disciplinares não apareceram sobrepostos apenas nos habitus dos agentes, mas também institucional e epistemologicamente no seio de cada campo envolvido. Do mesmo modo, tal sobreposição não implicou necessariamente uma menor autonomia das disciplinas em questão. $\mathrm{O}$ diálogo entre sociólogos, latinistas e helenistas se deu de modo que uns se apropriaram dos objetos e dos trabalhos dos outros para produzirem um conhecimento que, em alguma medida, dizia respeito a ambos. Certamente se deve considerar aí, por um lado, a institucionalização precária da sociologia, a qual impelia seus membros a atuarem também como especialistas de outras áreas. Do outro lado, porém, os estudos greco-latinos estavam muito bem estabelecidos, o que não impediu o uso, mediante certas chaves de leitura, dos trabalhos sociológicos. Isso foi feito, aliás, porque a sociologia poderia fortalecer e/ou viabilizar a carreira de certos indivíduos. É preciso fazer, portanto, com que a teoria dos campos possa também considerar as confluências entre eles como algo normal e até mesmo fundamental para o funcionamento e para a transformação de ambos (o que não significa, bem entendido, que isso se dê sempre dessa forma). Em outras palavras, é preciso inserir a ideia de interdisciplinaridade no próprio cerne da noção de disciplina.

\footnotetext{
${ }^{2}$ Para uma crítica recente ao conceito de habitus, cf. BOLTANKSI, 2003.
} 
Uma imagem pode ajudar a visualizar melhor a questão. Em uma sala repleta de pessoas estão dispostos vários jogos de tabuleiros, cada um deles com regras próprias. Ocorre que os indivíduos aí presentes não restringem necessariamente suas participações a um jogo, atuando em vários deles ao mesmo tempo. Mas isso não é tudo: em função de suas regras próprias ou dos circuitos que fazem os indivíduos, os tabuleiros convergem de várias maneiras. Uma situação favorável ou desfavorável em um cenário pode se fazer sentir direta ou indiretamente em outros. Ou seja, em suma, os jogos e os jogadores supõem naturalmente algum grau de sobreposição entre eles.

A história da arte já avançou significativamente nessa direção ao relativizar e operacionalizar o conceito de "fronteira". Enrico Castelnuovo, com esse intuito, utilizou-o para mapear quais eram os centros produtores e difusores de arte na Itália renascentista a partir da própria trajetória dos artistas. Sem partir de uma definição fechada das escolas artísticas ligadas a uma ou outra cidade, ele buscou mapear quais artistas estavam então atuando, por onde eles transitaram, sob que pretexto o fizeram e como cada um transmitiu suas técnicas. Assim delimitadas, as fronteiras entre as escolas podem até parecer pouco claras, repletas de zonas de sombra por onde transitam em uma e outra direções indivíduos e técnicas. Não obstante, isso permite compreender melhor tanto a dinâmica do estabelecimento de alianças e de conflitos entre as cortes e/ou grupos financiadores de arte quanto o próprio desenvolvimento estilístico dos artistas e das escolas ${ }^{3}$.

Outro caminho possível para fazer avançar a discussão poderia vir da retomada da noção de "empréstimo" desenvolvida por Antoine Meillet ${ }^{4}$. Sua linguística histórica, hoje muito pouco revisitada, teve o mérito de explicitar o fato de que os indivíduos inserem-se em vários grupos ao mesmo tempo, que esses grupos se sobrepõem e que tal fenômeno permite a circulação de palavras. Tais circuitos (de indivíduos e, atreladas a eles, de palavras) impõem ao vocabulário e à língua dos grupos mudanças, com palavras novas e novas definições dadas às palavras antigas afetando o conjunto em questão.

Ao longo do presente trabalho, sem que se tenha tido condições de propor um modelo alternativo a partir do caso estudado, foi amplamente utilizada a noção de "afinidades eletivas". Oriunda da química, mas importada para a literatura e para a filosofia por Goethe, ela dizia respeito à força que um terceiro elemento manifesta quando ele impõe a dois outros elementos antes combinados um rearranjo (ou uma nova combinação dos três, ou a exclusão de um dos antigos). O uso que se fez aqui dessa noção é outro, ilustrando apenas a conjunção

\footnotetext{
${ }^{3}$ CASTELNUOVO, 2006. Publiquei também uma resenha sobre o livro: BENTHIEN, 2007.

${ }^{4}$ Para tanto, veja-se os subcapítulos 1.2 e 2.3 da presente tese.
} 
de certos elementos ou domínios aparentemente diferentes ${ }^{5}$. Com efeito, entre aqueles que se reclamaram da sociologia durkheimiana e os antiquisants existiram afinidades e tensões. Alguns sociólogos foram ao mesmo tempo antiquisants e a recíproca foi verdadeira. Do mesmo modo, alguns sociólogos se opuseram (a certos) antiquisants, e a recíproca também foi verdadeira. Sem que o problema da relação entre disciplina e interdisciplinaridade tenha sido resolvido, ao menos no plano teórico-conceitual, todo o esforço feito aqui foi, uma vez constatada a sobreposição das disciplinas, ver até onde ela foi, com que chaves foi vivida e, eventualmente, que heranças (institucionais e epistemológicas) legou.

\footnotetext{
${ }^{5}$ Trata-se de uma leitura bastante livre da utilização que Weber faz do conceito de Wahlverwandtschaft. Cf., para mais detalhes, LÖWY, 2004.
} 
ANEXO 
filólogo e helenista Jean Bollack, nascido na Estrasburgo de 1923, foi um informante importante para a presente pesquisa. Entre setembro de 2008 e julho de 2010, pude encontrá-lo pessoalmente em quatro ocasiões, nas quais discutimos sobre a história dos estudos greco-latinos na França. Mas não se quis então somente recolher informações sobre um cenário, o da Terceira República, que Bollack conheceu apenas indiretamente, por meio de seus professores e colegas no pós-1945. Com efeito, devido a sua proximidade com a universidade alemã (ele foi educado na Suíça alemã e deu aulas em Berlim) e com a sociologia (fortalecida e reorganizada a partir do grupo coordenado por Pierre Bourdieu) ${ }^{1}$, ele parece reeditar certas afinidades eletivas constatadas na virada dos séculos XIX e XX. Era preciso saber, portanto, se e como tais questões se colocavam para ele. Tratar-se-ia de continuidades estruturais, de novas configurações ou, ainda, de um pouco dos dois?

Nos dias 11 e 23 de fevereiro de 2010, ele aceitou registrar a entrevista que se encontra nas próximas páginas. Em um primeiro momento, tratei de formular questões que permitissem ao entrevistado se situar no sistema educacional francês, esclarecendo a história e a lógica do funcionamento da instituição. Ele pôde assim, em um intervalo de tempo relativamente curto, descrever as posições com e contra as quais se definiu, bem como os constrangimentos relativos ao funcionamento desse universo específico. A segunda parte da entrevista, por seu turno, diz respeito ao sentido de seu trabalho. Ou seja, ela trata da filologia crítica e da hermenêutica, tal como entendidas e praticadas por Bollack.

Para o público universitário brasileiro, infelizmente privado até hoje de traduções de seus livros e artigos, espero que a presente entrevista sirva não apenas como introdução a um dos intelectuais mais sofisticados e eruditos da França atual, mas também como convite a conhecê-lo melhor. Já quanto aos interesses dos especialistas familiarizados com os trabalhos de Bollack, creio poder Ihes apresentar, sobretudo na primeira parte da entrevista, informações novas, na forma e no conteúdo².

\footnotetext{
${ }^{1}$ Como será visto ao longo da entrevista, Bollack foi um amigo muito próximo de Bourdieu, colaborando com seus projetos científicos e editoriais. Ele não apenas publicou na coleção dirigida por Bourdieu na editora Minuit, como também contribuiu com três textos para os primeiros números da revista Actes de la Recherche en Sciences Sociales (1975: 9-35 e 157-161; 1976: 173-176). Um desses artigos, Ulysses chez les Philologues, encontra-se reimpresso em BOLLACK, 1998a: 29-59.

${ }^{2}$ Penso, em especial, no que foi já publicado em BOLLACK; LLORET, 2000.
} 


\section{ENTREVISTA COM JEAN}

BOLLACK $^{3}$

\section{A ENTRADA NO CAMPO DISCIPLINAR: TENSÕES E ALIANÇAS.}

RAFAEL FARACO BENTHIEN : Cher Monsieur Bollack, entre les hellénistes de votre génération, ceux qui ont commencé leur carrière juste après la guerre, nous connaissons au Brésil, à partir des traductions, l'oeuvre de Jacqueline de Romilly ${ }^{4}$, de Pierre Lévêque ${ }^{5}$ et, encore plus, celle de Jean-Pierre Vernant ${ }^{6}$. Pourtant, je me demande constamment, est-ce qu'on arrive vraiment à saisir le sens de ce qu'ils ont dit? Je m'explique. Il me semble que nous sommes à la fois mal informés sur l'histoire de l'Université française, donc sur le terrain de débat, mais aussi sur les différentes prises de positions qui ont été possibles à ce moment, y compris la vôtre. Avant même de discuter sur votre origine sociale et sur la philologie critique ou refléxive, dont vous êtes le porte-parole le plus connu, j'aimerais bien vous poser la question suivante: comment décririez-vous l'Université française, et plus spécifiquement le domaine des études grecolatines, au début de votre carrière?

\footnotetext{
${ }^{3}$ André Laks, Jean e Mayotte Bollack ajudaram-me, com uma paciência sem limites, a sanar os erros de transcrição da presente entrevista. Eu não teria como agradecê-los o suficiente por mais essa amostra de generosidade. Agradeço também a Comissão Editorial da revista PhaoS, da Unicamp, que comprou a ideia da entrevista e deve publicá-la em seu volume 9 (nesse caso, acrescida de uma introdução mais alentada).

${ }^{4}$ Chartres, 1913. Aluna do liceu Louis-le-Grand, Jaqueline de Romilly foi aceita na École Normale Supérieure de Paris em 1933. Agrégé de lettres em 1936 e doutora em 1947, ela exerceu suas atividades no ensino superior em Lille, na Sorbonne (1957-1973) e, finalmente, no Collège de France (1973-1984), onde foi eleita contra Jean-Pierre Vernant para a cadeira intitulada La Grèce et la formation de la pensée morale et politique. Ela se tornou membro efetivo da Académie des Inscriptions et Belles-Lettres dois anos depois e foi eleita em 1988 membro da Academie Française. No Brasil encontram-se traduzidos vários livros seus: DE ROMILLY, 1984, 1996, 1998 e 1999.

${ }^{5}$ Chambéry, 1921 - 2004. Aceito na École Normale Supérieure de Paris em 1940, Pierre Lévêque se tornou agrégé de lettres em 1944 e doutor onze anos mais tarde. Após um período de trabalhos na École Française d'Athènes, ele iniciou sua atividade docente na Sorbonne (como assistente), passando depois por Lille, Montpellier e, finalmente, Besançon, onde permaneceu de 1957 até sua aposentadoria. As editoras brasileiras traduziram seu A Aventura Grega (LÉVÊQUE, 1965), embora outros volumes editados em Portugal tenham circulado por aqui.

${ }^{6}$ Provins, 1914 - Sèvre, 2007. Agrégé de philosophie (1937), Jean-Pierre Vernant teve o início de sua carreira acadêmica marcada pela atuação na resistência francesa à ocupação nazista. Em 1948 ele entra no CNRS e, na sequência, na sexta seção da EPHE. Sua entrada no Collège de France se deu em 1975, quando passou a ocupar a cadeira intitulada Étude Comparée des Religions Antiques. A lista de seus trabalhos traduzidos no Brasil é enorme. Destaco aqui: VERNANT, 1996, 1999, 2002a e 2002b.
} 
JEAN BOLLACK : Je pense qu'il ne faut pas commencer avec mon arrivée à Paris après la libération. J'ai survécu en tant que juif en Suisse, mais je n'y étais pas là en tant que réfugié. II se trouvait que mon père, qui était marchand en grains - je suis né à Strasbourg dans une famille juive d'Alsace ${ }^{7}$-, a été nommé à Bâle par la maison de commerce où il travaillait. J'ai grandi dans un monde à la fois français, puisque ma maison était francophone et que mon entourage à Bâle était largement tourné vers la France, mais, par ailleurs, je vivais dans la Suisse allemande. Le lycée où je suis allé était, comme je dis souvent, helvético-prussien, c'està-dire quelque chose qui tenait à la fois du libéralisme helvétique et d'une forte tradition scolaire et académique allemande. J'ai fait des études secondaires fortes, avec beaucoup de latin et beaucoup de grec. Et donc, la question première serait de savoir pourquoi est-ce que j'ai choisi de faire du grec plus tard comme matière scolaire.

J'ai passé l'équivalent du bachot, la maturité fédérale, en Suisse, à la fin des études secondaires, dans un lycée classique. C'était un lycée classique réputé, où avaient enseigné Nietzsche et Jacob Burckhardt, et d'autres gens encore qui appartenaient à une tradition forte. Ainsi, j'avais eu pendant huit ans une heure de latin tous les jours et, à partir de la quatrième année scolaire, donc pendant cinq ans, du grec tous les jours. On apprenait à lire les textes. J'ai eu cette base, mais le système était très sélectif et élitiste, et il ne peut plus l'être. Je suis vieux, donc je suis d'un autre temps. J'ai un pied dans le XIX ${ }^{\mathrm{e}}$ siècle, et pas seulement dans le XXe , je suis né en 1923 et entré au lycée en 1934. Cela pour vous dire que j'ai ce background, qui fait toujours mieux comprendre que les choses n'étaient pas simples. Il y avait le français et l'allemand. Il y avait le fait que ma maison n'était pas seulement française, mais aussi juive. On recevait des réfugiés allemands chassés par le nazisme dès 1933 et de l'autre côté j'allais dans un lycée qui était protestant, dans une tradition chrétienne assez libérale. Cette dualité est dans mon parcours. Je l'ai vécu en tant qu'alsacien, mais elle a été accentuée par ce séjour, par le fait que j'ai grandi en Suisse allemande, dans un entourage marqué également par l'influence de réfugiés allemands.

Cela c'était un préalable qu'il faut connaître pour savoir comment je suis arrivé aux études littéraires à l'Université. J'ai toujours eu cet intérêt pour les lettres. J'ai commencé mes études supérieures à Bâle, où enseignait un professeur de grec très connu, Peter von der Mühll ${ }^{8}$; il représentait la grande tradition philologique allemande, qui était très exigeante. Mais je n'ai pas fait ce que j'aurais dû faire normalement, selon les cursus, des études de latin

\footnotetext{
${ }^{7}$ Veja-se também BOLLACK, 2008.

${ }^{8}$ Basileia, 1885 - 1970, filólogo suíço. Após ter realizado seus estudos com os grandes nomes da filologia alemã em Berlim e em Göttingen, tornou-se professor na Universidade de Basileia em 1917.
} 
et de grec dans l'enseignement supérieur. II y avait là aussi une liberté et un choix. J'ai commencé mes études en faisant du grec comme matière principale, le français et la philosophie comme matière secondaire. Je pensais qu'on pouvait tout faire, pendant longtemps, quand j'étais jeune. J'avais commencé à faire du russe, du sanscrit. J'ai passé par la période où l'on pense que tout est possible. L'enseignement de la littérature française était très important, fait par un professeur très proche de la production contemporaine. Donc, il n'y avait pas seulement les langues classiques et le grec. II y avait beaucoup d'autres ouvertures dans d'autres directions. Vous ne pouvez pas négliger ce passé si vous voulez reconstituer l'étudiant que j'étais en arrivant à Paris après la guerre.

Toujours à Bâle, le professeur de grec que j'avais avait été formé à Göttingen au début du XXe siècle, dans les années 1900 environ. Il avait été un très brillant étudiant en même temps que Pasquali ${ }^{9}$, l'italien, et d'autres, venus à Göttingen, qui était un haut lieu des études philologiques. J'ai été jeté à l'eau, c'est comme si quelqu'un jetait un enfant à l'eau pour qu'il se débrouille en apprenant à nager. Après ses cours tellement difficiles, chargés de reférences, que je suivais sur Eschyle, ou sur l'lliade, ou sur autre chose, le matin de 9 h00 à 10h00, quatre fois par semaine, je me rendais au séminaire, où il y avait une très bonne bibliothèque et regardais les livres qui avaient été cités. Si bien que j'ai grandi aussi au XIX ${ }^{\mathrm{e}}$ siècle, parce que toute cette tradition, cette grande tradition, avec des figures comme Gottfried Hermann ${ }^{10}$ ou Karl Lachmann ${ }^{11}$ et d'autres grandes figures d'histoire de la philologie, m'étaient devenues familières très tôt. Non seulement j'ai appris la philologie, la science philologique à l'allemande, mais aussi I'histoire de la discipline. Je ne pouvais pas ne pas prendre la mesure de ce qu'était I'histoire, depuis surtout le XVIII siècle, des études de l'Antiquité en Europe. Heyne $^{12}$ et les grands philologues allemands du XVIII ${ }^{e}$ siècle, tout cela m'était présenté au début de mes études, parce que quand on expliquait un texte d’Eschyle, on faisait référence aux cours professés autrefois à Leipzig ou à Berlin.

Il faut vous dire cela. Ensuite, on peut mieux voir ce que fut mon arrivée à Paris. Je ne pouvais pas commencer sans parler de ce qui a précédé.

Plus que Paris, l'Allemagne était marquée par l'Université, ce qui est en relation aussi avec la théologie protestante. J'ai étudié avant de venir dans une tradition culturelle très différente. En France, il y avait au XIX ${ }^{\mathrm{e}}$ siècle à peine une Université. Cette Université, créée

\footnotetext{
9 Roma, 1885 - Belluno, 1952. Giorgio Pasquali foi um dos mais destacados filólogos italianos da primeira metade do século XX. Tendo se formado na Alemanha, ele lecionou em diversas instituições de ensino superior na Itália, dentre as quais se destaca a École Normale Supérieure de Pisa.

${ }^{10}$ Johann Fottfried Jakob Hermann, Leipzig, 1772 - 1848, filólogo alemão.

${ }^{11}$ Karl Konrad Friedrich Wilhelm Lachmann, Brunswick, 1793 - Berlim, 1851, filólogo alemão.

${ }^{12}$ Christian Gottlob Heyne (1729 - 1812), filólogo alemão.
} 
autour de 1880, imitait et était en rivalité avec ce qui existait à l'époque en Allemagne. Avant, il n'y en avait pas vraiment. Cela ne signifie pas que Paris n'ait pas été une capitale intellectuelle, mais sans université vraiment digne de ce nom (il faut reculer jusqu'au Moyen Âge); le modèle d'Université était partiellement anglais et, surtout, allemand. C'est simplement l'histoire intellectuelle de l'Europe qui fait comprendre ces divergences. La France est un pays catholique comme l'Italie. On pense à l'Italie, mais l'Italie a été plus libre au fond de se débarrasser d'une tradition culturelle nationale. La philologie allemande a été plus facilement reçue en Italie qu'en France. Cela s'explique parce qu'il y avait en France une tradition très fortement marquée par une rhétorique, autant que par la littérature; elle était partiellement liée au catholicisme et partiellement liée à des traditions nationales, contraires aux exercices de recherche. Alors qu'en Allemagne, il y avait une prédominance du protestantisme dominant surtout en Prusse, en France, le débat n'opposait pas les religions, mais le catholicisme et son adversaire, la libre-pensée et la laïcité. C'était la religion ou pas. Le fait qu'il n'ait pas existé d'Université en France était dû à la prédominance catholique. Elle n'a pu au fond être créée que sous la Troisième République, avec une connotation anti-cléricale. C'est après la guerre de 1870 qu'on envoyait les élèves de l'École Normale Supérieure en Allemagne pour qu'ils aillent voir ce qu'était une Université. Quand on lit ces rapports qu'ils ont faits, qui ont été publiés, ce sont comme des rapports ethnologiques; ils décrivaient un pays totalement étranger et inhabituel pour eux. En France il n'y avait pas d'étudiants, donc il fallait les créer. Cela s'est accompli lentement autour de 1880. II ne faut pas diminuer l'importance de ce mouvement, mais savoir aussi qu'il a été combattu.

Dans un sens il y a toujours eu à l'Université française deux courants d'émancipation. L'Université, c'est principalement l'histoire de la discipline principale, à savoir, l'histoire. Les deux disciplines dominantes sont l'histoire et la philosophie. Les lettres classiques font partie des « lettres » et les lettres incluent d'abord le français. Il y avait pour les Français trois langues classiques, dont le français. C'est comme si le latin et le grec étaient un équivalent du français hérité du siècle de Louis XIV. C'était un peu une construction propre à la France, nationale, liée à un certain concept d'universalité. C'est comme si les langues classiques étaient réprésentées en définitive par le français et soumises à lui.

RFB : Mais à l'intérieur des langues classiques il y avait des différences très fortes aussi, non? Le latin était plus proche de l'Église, donc au coeur du système rhétorique et littéraire français. Le grec, moins central, était aussi plus libre. Ce n'est pas par hasard que les études grecques en France se sont ouvertes aux innovations universitaires allemandes beaucoup plus tôt. 
JB : Oui, vous avez raison, il y avait ces différences. Mais ce que je n'ai pas fini de dire tout à l'heure, c'est que, dans la création de l'Université, l'histoire a joué un rôle énorme. Ce qu'il y avait de plus avancé peut-être au $\mathrm{XIX}^{\mathrm{e}}$ siècle dans les domaines des sciences était lié à I'histoire. Tout cela était éloigné de la théologie. Alors qu'en Allemagne, dans les Universités, on enseignait la théologie, d'abord protestante et ensuite catholique. Le fait même de lire, d'apprendre à lire, l'herméneutique, Schleiermacher par exemple, tout cela était développé en relation avec la lecture des textes sacrés. Alors que, dans les pays catholiques, on "lisait » beaucoup moins. C'est-à-dire que la plupart des croyants catholiques lisaient au fond peu la Bible ; ils n'apprenaient pas à la lire. La philologie critique, telle que je la défends, n'était pas appliquée dans la tradition protestante allemande non plus. II faut bien mettre les points sur les « $\mathrm{i}$ ». Mais, néanmoins, mon expérience à Bâle a été centrale. C'est quand même là que j’ai appris des choses que je n'aurais pas connues ou pas cherchées en France.

Quand je suis arrivé à Paris, j'ai fait comme si Paris, c'était une Université du type allemand. C'est-à-dire que je cherchais partout où étaient les meilleurs enseignements, à I'École des Hautes Études, au Collège de France, dans tous les coins, dans toutes les disciplines. C'est-à-dire que je n'ai pas suivi un cursus, ce que les étudiants faisaient. Donc, je me distinguais déjà des étudiants par le cursus. Ils gagnaient leur vie, souvent, en étant professeurs dans les lycées et en étudiant pour réussir aux concours. C'était quand-même une organisation très scolaire ; l'enseignement que j'avais connu auparavant ne l'était pas. C'était vraiment l'enseignement "supérieur ". II faut vous dire que, dans la tradition culturelle et sociale française, le lycée était plus important que l'Université. Pour la bourgeoisie du XIX siècle, il fallait former les professeur des lycées. La recherche n'était pas centrale; elle l'était même moins que maintenant. Le plus important c'était la formation des professeurs de lycée. Le scolaire dominait aussi dans le supérieur. II est très intéressant d'étudier comment la science a pu malgré tout être introduite dans un univers comme celui-là, de façon marginale ou supplémentaire. Vous m'avez parlé des gens comme Jacqueline de Romilly...

RFB : Jacqueline de Romilly, Jean-Pierre Vernant et Pierre Lévêque. Pouvez-vous nous dresser un portrait d'eux?

JB : Pierre Lévêque était un historien, pas très éloigné du groupe de gens qui gravitait autour de Vernant. Mais Lévèque était un esprit très accueillant et ouvert. Romilly, elle était, au fond, marquée par la tradition scolaire, dans laquelle elle excellait. Et en un sens, par cette excellence, elle la dépassait. Mais elle la représentait pleinement, d'où son succès. Le système pouvait se reconnaître en elle, voire se dépasser. C'est-à-dire qu'elle était la parfaite 
représentante d'une tradition scolaire française, avec les Grandes Écoles, l'enseignement de I'hyphokhâgne et de la khâgne ${ }^{13}$, les exercices scolaires et savants. Quand on sait vraiment lire ses livres, ils restent tous marqués. Mais comme elle s'est intéressée aux idées politiques, elle représente aussi pleinement une possibilité française de réaliser, et de dépasser sa propre tradition, telle que je viens de la définir, par une ouverture qui restait tributaire de ce qui l'entravait.

Qu'est-ce que j'appelle «scolaire »? Pour revenir à mon expérience, ce que je cherchais, c'était un équivalent de l'Université allemande. Je le trouvais. Par exemple, j'ai suivi le cours de Marrou sur l'histoire de l'éducation dans l'Antiquité, qui a ensuite été publié dans un livre ${ }^{14}$. J'étais allé voir ce que l'on faisait dans le département d'histoire ancienne. Ou bien j'allais au Collège de France pour suivre le cours de philosophie du Moyen Âge d'Étienne Gilson $^{15}$. Ou de Chantraine ${ }^{16}$, ou de Benveniste ${ }^{17}$ sur la linguistique grecque à l'École des Hautes Études. Ainsi, je créais mon université au-delà des programmes scolaires. Naturellement, j'ai dû aussi passer les examens, préparer les concours. J'ai dû combiner tant bien que mal les deux choses. Je portais en moi une idée d'Université que je recréais en la repérant dans les lieux où elle se trouvait.

RFB : Vous avez cherché quels genres de diplômes dans l'Université française?

JB : J'ai passé deux licences : allemand et lettres classiques. Ensuite, j'ai préparé l'agrégation, non sans difficulté. Étant donné que je n'ai pas été élevé en France et que je n'étais pas passé par un lycée français avec ses classes préparatoires des concours, c'était plus difficile pour moi que pour un autre. Finalement j'ai réussi. Il faut dire qu'à cette époque-là, la France était un pays assez appauvri, les postes étaient peu nombreux et il y avait beaucoup de candidats. Tout était difficile. Après la guerre, après 1945, après les années 1950 et même au-delà, il y a eu une vingtaine d'année où les conditions de vie en France étaient difficiles.

RFB : Mais c'était une agrégation de grammaire, non? Et qu'est-ce que cela veut dire?

\footnotetext{
${ }^{13}$ Trata-se dos nomes dos cursos preparatórios para o concurso de entrada na École Normale Supérieure de Paris, seção de letras.

${ }^{14}$ Trata-se do historiador Henri-Irénée Marrou (Marselha, 1904 - Bourg-la-Reine, 1977). O livro em questão é MARROU, 1948.

${ }^{15}$ Paris, 1884 - Cravant, 1978. Étienne Gilson foi professor do Collège de France, cadeira intitulada Histoire de la Philosophie au Moyen Âge, entre 1932 e 1950.

${ }^{16}$ Pierre Chantraine (1899 - 1974), linguista francês.

${ }^{17}$ Émile Benveniste (Aleppo, 1902 - Paris, 1976), linguista francês.
} 
JB : Oui, de grammaire. C'était moins littéraire, moins liée à la virtuosité des exercices rhétoriques, plus axée sur la langue, à savoir les analyses linguistiques. L'agrégation de grammaire se rattachait au fond à une tradition plus scientifique. Le maître de cette "grammaire " était Chantraine. II m’a beaucoup soutenu. Je n'ai pas eu de relations personnelles, malheureusement, avec Jacqueline de Romilly, mais bien avec Jean Bayet ${ }^{18}$, le latiniste qui était un historien de la religion, et fut plus tard directeur de l'École de Rome, un peu comme avec Chantraine. J'ai trouvé des professeurs qui se sont intéressés à mes intérêts et qui ont vu ce que je pouvais faire ultérieurement. On ne peut pas dire que le système français ne m'ait pas accueilli. Mais comment? Peut-être en marge, comme quelqu'un venu de l'extérieur. Je représentais aussi une différence par mes intérêts, la qualité de mes intérêts, par ce que je me préparais à faire. Mais c'était encore une organisation assez monarchique, avec des patrons. Aujourd'hui il y a des commissions... À cette époque là, il y avait de grands savants qui étaient au centre de leurs disciplines et les dirigeaient.

\section{RFB : Avez-vous reçu l'appui de ces savants?}

JB : Ils m'ont soutenu. J'étais d'abord au CNRS et, après, dans l'enseignement supérieur, presque naturellement, comme si j'étais sorti du crû. Comme si j'avais été à l'École Normale. Et même le directeur de cette École, Chapoutier, un helléniste, qui est mort très jeune, m’a beaucoup soutenu quand j'étais son étudiant. Donc, j'étais déjà, à la fois pas comme les autres et quand même "reconnu ». Même avant que je n'eusse fait quoi que ce soit. Je n'ai pas été une victime, loin de là.

RFB : Je voudrais revenir à une des questions que je vous ai posée avant, parce qu'on n'a pas parlé de Jean-Pierre Vernant...

JB : Vernant c'est vraiment différent. Vernant et Vidal-Naquet ${ }^{19}$ ont réuni l'histoire, la psychologie sociale et I'anthropologie. Vernant venait de la philosophie et pas des lettres anciennes. Au fond, il y avait là d'un côté, en apparence, une solidarité entre nous, mais qui n'était pas très profonde. Elle existait pour deux raisons : d'abord, il était de gauche, alors que le système était plutôt conservateur. Moi, je n'ai jamais été d'un parti, mais, quand-même, j'ai des idées de gauche et lui, il était communiste. C'est un premier aspect - politique. D'autre

\footnotetext{
${ }^{18}$ Versailles, 1892 - Paris, 1969, latinista francês. Bayet, antigo membro da EFR (1917-1920), foi diretor dessa instituição entre 1952 e 1960.

${ }^{19}$ Pierre Emmanuel Vidal-Naquet (Paris, 1930 - Nice, 2006), historiador e helenista francês.
} 
part, il se distinguait dans cette tradition scolaire que nous avons évoquée, où il était quand même plus investi que moi. II a été dans des hyphokhâgnes et des khâgnes. II avait été sur les mêmes bancs que Jacqueline de Romilly. Au fond, lorsqu'ils étaient au Collège de France tous les deux, l'un a rejoint l'autre, mais dans la logique du système, à laquelle je n'appartenais pas. Mais il y avait aussi chez lui quelque chose, comment dire... d'anti-sorbonnard. II ne représentait pas la tradition, comme Mme de Romilly le faisait éminemment, étant donné qu'il introduisait une ouverture sur la société, ce que je ne faisais pas, selon lui, en tant que philologue. Il y avait bien un certain éloignement par rapport à une tradition dominante, qui nous unissait. Ce qui me sépare c'est évidemment le rôle que joue le texte, la philologie et l'importance de la compréhension de l'écrit. Vernant avait un passé politique important. C'était un tribun. II parlait très très bien. Quand il entrait ici, dans cet appartement où vous m'interrogez, il avait à peine franchi le seuil de l'entrée, qu'il s'était déjà lancé dans un discours, qu'il ne quittait plus. J'avais à peine le temps de placer un mot. C'était un tribun né. II dominait parfaitement le discours et l'argumentation. II y avait des gens qui le suivaient fidèlement, qui se réclamaient de lui. Mme de Romilly aussi parlait bien, mais elle défendait une tradition classique. Et lui, cela semblait être davantage une ouverture sur la modernité. Par rapport à cette ouverture, j'étais encore en marge.

J'ai été nommé à Lille en 1958, après une période de recherche au CNRS. Je suis resté dans l'enseignement supérieur jusqu'à la retraite, toujours à Lille. J'ai, dès la première heure de mon enseignement, essayé d'introduire dans la tradition française une enceinte scientifiquement forte, en dehors de Paris. Je me suis imposé sans être à Paris. En même temps que moi ont été nommés à Lille des gens comme Le Goff ${ }^{20}$, en histoire du Moyen Âge, ou Bourdieu ${ }^{21}$, en sociologie. Ce sont aussi de grands maîtres dans leurs disciplines, non? C'était encore un lieu très fermé, avec beaucoup moins de professeurs que maintenant. L'Université a commencé à s'ouvrir et à éclater, pas toujours dans le bon sens, dans les années soixante et, encore plus, après 1968. Auparavant les structures étaient très sélectives.

\section{RFB : Vous étiez combien?}

JB : Des professeurs titulaires et des gens d'un grade inférieur, il y en avait entre 35 et 40 . Aujourd'hui, ils sont plusieurs centaines. Par ailleurs, en 1958, il y avait seulement dix-sept universités, contre une centaine aujourd'hui. C'était donc vraiment un privilège d'avoir été choisi par un patron parisien.

\footnotetext{
20 Jacques Le Goff (Toulon, 1924), medievalista francês.

${ }^{21}$ Pierre Bourdieu (Denguin, 1930 - Paris, 2002), sociólogo francês.
} 
RFB : Puisqu'on parle de Lille, je voudrais aussi vous poser des questions autour de Pierre Bourdieu. Comment avez-vous connu l'homme et quelles étaient les relations entre vous?

JB : Nous nous sommes connus, je veux dire reconnus, dans ce milieu, après avoir été nommés au même moment, dans les mêmes conditions et, pendant une vingtaine d'années, on a fait beaucoup de choses ensemble, de toute espèce. Ensuite, il a, comme Le Goff, quitté Lille pour l'École des Hautes Études en Sciences Sociales créée par Braudel. Elle s'appelait sixième section à l'époque. C'était une autre marge de l'Université qui se créait là, et au centre, mais comparable à ce que j'avais introduit en province. Bourdieu a compris l'importance de ce que je faisais. Il connaissait le système scolaire français, il connaissait le système universitaire, il savait ce que c'était. Ce fut aussi une amitié très forte entre nous. On a beaucoup compté l'un pour l'autre. A partir, je ne sais pas, de 1959, 1960.

RFB : Et vous vous êtes connus comment?

JB : Nous avons été nommés ensemble à Lille et nous prenions le train ensemble à l'aller comme au retour. C'était comme un rendez-vous. Les trajets alors étaient plus longs. On s'est reconnu mutuellement, on s'est entendu sur beaucoup de choses, en étant quand même dans des champs opposés. J'avais été nommé à Lille par Pierre Chantraine et lui, par Raymond Aron $^{22}$. Dans une certaine mesure, nous étions comme des dauphins. C'étaient des filiations, dans un cadre, la sociologie, et dans un autre, la linguistique, si on reste dans le domaine de la philologie classique. Aujourd'hui ce n'est plus pensable. Lui, il était normalien; il avait fait du grec pour entrer à l'École Normale. II savait comment était fait le système d'enseignement français ; il comprenait ce que je voulais changer, les transformations indispensables.

RFB : Mais il a été très proche aussi de quelqu'un comme Benveniste, non?

JB : Oui, mais plus tard. Là aussi j'ai souvent joué un rôle. Il a édité Benveniste dans sa collection, "Le sens commun ", qu'il a crééé plus tard aux Éditions de Minuit. Les volumes de mon Empédocle ont paru dans cette collection, loin des Éditions Les Belles Lettres ${ }^{23}$.

RFB : Est-ce que vous avez travaillé ensemble, dans les mêmes séminaires, par exemple?

\footnotetext{
${ }^{22}$ Raymond Aron (Paris, 1905 - Paris, 1983), sociólogo francês.

${ }^{23}$ BOLLACK, 1992a, 1992b e 1992c.
} 
JB : Oui, mais bien plus souvent dans d'autres espaces. La collaboration n'était pas si directe que cela. On se téléphonait peut-être trois, quatre fois par jour. II avait son travail et moi, le mien. On se racontait nos déboires, nous parlions de nos projets. Une complicité pleine d'échanges s'est ainsi créée. Cela a beaucoup changé autour des années 1980, jusqu'à sa mort. Je vous parle des années 1960 et 1970, parce que, ensuite, il a eu une ambition politique plus forte. Il défendait une sociologie, disons, en gros, plus libératrice, autour du bien possible et impossible de l'Humanité. II ne pouvait plus se concentrer sur une discipline comme la mienne, que j'essayais de changer de l'intérieur. Cela ne signifie pas qu'il y ait eu des problèmes entre nous. Mais c'était une tranche différente de sa vie à lui et de la mienne aussi. Moi aussi, autour des années 1980, je me suis transformé en sortant des tranchées de ma discipline pour m'ouvrir à d'autres. C'est la question que vous avez posée : j'ai été toujours autre chose qu'un philologue par mes intérêts. Je m'intéressais à la littérature. Adolescent, je lisais de la littérature de plusieurs langues pour moi, en dehors de mes études. Et, inversement, je lisais Eschyle comme si c'était du Camus. C'est un peu ma force, d'avoir traité les auteurs grecs comme des contemporains, sachant qu'ils ne l'étaient pas. Je crois que c'est particulier et important, parce que j'ai transféré un intérêt de lecture très soutenu à l'intérieur de la philologie, au-delà des disciplines, même de l'histoire et de la philosophie.

RFB : Pour parler encore des années 1960 et des années 1970, vous avez publié aussi dans la collection que Pierre Bourdieu coordonnait, "Le sens commun", chez Minuit. Pouvez-vous nous parler de cela?

JB : À un certain moment, sinon dès le début, autour de 1947, à Paris, j'ai senti que je devais préparer un gros travail pour montrer ce que je cherchais et faire du nouveau. Ce sont mes travaux sur Empédocle. Ces publications ont été remarquées. Les quatre volumes se sont épuisées assez vite.

Cette publication me permet aussi de revenir à une de vos intéressantes questions. Jacqueline de Romilly représentait, malgré tout, par l'éclat dont elle jouissait, la tradition nationale. Vernant s'ouvrait à l'analyse des mentalités, au social. II faut se rappeler qu'en France, cette ouverture sur la société a toujours eu plus d'impact que ce qui était proprement lié au texte, l'herméneutique. C'est pour cela, dans ce cadre, que la linguistique française a une tradition forte. La langue, c'est du social. Le texte c'est autre chose, c'est la philologie, I'herméneutique, la théorie littéraire, etc. C'est autre chose, vraiment. On situe ainsi la différence d'une philologie que vous avez appelée, à juste titre, «critique ». Ce n'est pas le 
point de vue de Vernant. L'oeuvre de Vernant, je serais partiellement capable de l'intégrer comme un préalable à la compréhension des auteurs. Mais ensuite il y a chez ces auteurs une prise de position. C'est qu'il n'y a pas que la société, il y a deux choses. L'auteur est marqué, il représente et reflète la société où il vit et écrit, mais il y a aussi quelque chose qui le distingue dans ses créations. Ce que je mets maintenant au centre dans mes travaux, depuis 1950 ou 1960, c'est précisément la création, savoir comment la philologie peut rejoindre la création poétique elle-même, s'identifier à l'acte créateur. Comment la lecture peut conduire jusqu'à reconstituer le plus exactement possible cette prise de position. C'est central dans mon travail, évidemment: il ne faut pas éliminer pour autant l'étude des mentalités, les systèmes de représentations, qui se transmettent et qui sont héréditaires.

RFB : Donc, tout cela pour vous ne s'exclut pas.

JB : Non, cela ne s'exclut pas. Il s'agit d'un préalable qu'il faut connaître pour comprendre les transformations. On entre dans un monde et l'on en sort avec quelque chose de nouveau.

RFB : Parlons maintenant de vos rapports avec Peter Szondi ${ }^{24}$, qui a été, lui aussi, publié en France dans la collection " Le Sens Commun ».

JB : Szondi, je l'ai connu en 1959, au même moment que Bourdieu. J'ai, pendant trois ans, enseigné à l'Université de Berlin. J'ai ensuite, grâce aux relations nouées là-bas, eu la possibilité de le faire connaître. C'est un autre chapitre de ma vie. À cette époque-là, le monde était très différent. II y avait beaucoup de professeurs très importants intellectuellement, scientifiquement et socialement aussi. Mon professeur à Bâle faisait partie de ce groupe de " sommités ». Ces personnes savaient que j'existais. L'Allemagne, ce n'est pas un pays où je serais simplement revenu. C'est plutôt comme si j'y avais toujours été. Quand je suis en Allemagne, je sais parler comme un Allemand. Quand je suis en France, je sais parler comme un Français. C'est complexe. En même temps, cela m'a posé de gros problèmes. II y avait le passé nazi que l'on ignorait ; il y avait des gens, même à l'Université Libre de Berlin, dans ces années 1955-59, qui posaient des problèmes politiques en raison de leur passé. Cela se comprend. Ce n'était pas singulier. Tout un monde en recouvrait un autre et en même temps ne le recouvrait pas.

\footnotetext{
${ }^{24}$ Peter Szondi (Budapeste, 1929 - Berlim, 1971), filólogo e crítico literário. Szondi lecionou em Göttingen, Heidelberg e na Universidade Livre de Berlim.
} 
JB : Oui. J'étais juif. L'histoire du judaïsme allemand et l'importance plutôt colossale des juifs allemands depuis le XVIII ${ }^{\mathrm{e}}$ siècle, pour le monde entier dans tous les domaines, c'est encore une autre histoire, très large, qui n'a cessé de m'accompagner aussi, et qui se pose différemment en France, où le judaïsme a ses conflits propres.

RFB : En tout cas, pour revenir à Szondi, vous n'avez jamais cessé d'aller en Allemagne et d'introduire en France des auteurs allemands.

JB : Oui, cela s'est fait dans les deux sens. Szondi était un peu comme Bourdieu. J'étais plus proche peut-être de Szondi, plus semblable à lui. Ma vie a changé quand il est mort, parce que tout aurait changé s'il avait vécu. II s'est tué en 1971, ce qui a été une perte immense pour ma femme et pour $\mathrm{moi}^{25}$. On s'entendait bien, peut-être même exceptionnellement bien, à peu près sur tout. II n'avait pas fait de grec ancien. Ce qui nous unissait c'était cette grande aventure de la compréhension des textes. Il a créé, autour de 1965, comme moi à Lille, un centre de recherches, un institut où appliquer des méthodes différentes dans un esprit différent. J'ai édité son oeuvre posthume. C'est une grande partie de mon oeuvre. II y avait beaucoup de manuscrits inédits. Les parents de Szondi m'ont chargé de tout cela. Quelque chose comme sept volumes, ou plus. Cela a joué un rôle important dans ma vie, parce que, au fond, nous transcendions la France et l'Allemagne, et lui et moi. Il était venu d'un autre horizon intellectuel. II venait de Benjamin, Adorno, Lukács. Ce n'est pas exactement le marxisme, mais c'est un univers très proche de ses principes.

\section{ACERCA DA PROCURA DO SENTIDO}

RFB : Parlons maintenant de votre philologie critique. Pouvez-vous nous expliquer quels sont les rapports entre cette discipline et l'herméneutique?

JB : Je suis parti d'une pratique, où j'avais acquis une certaine liberté. La tradition allemande était au départ plus herméneutique que la française. En Allemagne, il y avait, avec Schleiermacher déjà, un programme parfaitement défini, dès le début du XIX ${ }^{\mathrm{e}}$ siècle. II se trouve que le développement du système scolaire, du positivisme, les conceptions de la science, sont entrés en contradiction avec le programme herméneutique. La chose existait,

\footnotetext{
${ }^{25}$ Sobre a relação de Jean e Mayotte Bollack com Peter Szondi, veja-se também BOLLACK, M., 2010.
} 
mais on pouvait difficilement l'appliquer. Il est intéressant de poser la question : pourquoi I'Allemagne n'a-t-elle pas pu pratiquer ce programme, qui était déjà défini depuis l'époque de Guillaume de Humbolt, le fondateur ${ }^{26}$ ? Mais il ne s'agit pas de cette histoire allemande, il s'agit de la mienne.

Dans ma pratique, il faut isoler un point. Dans ce que j'ai fait, dans mon Empédocle d'abord, c'était reconstituer une oeuvre perdue à partir des fragments qui subsistaient. J'ai passé des années à recomposer le système dans sa totalité, le reconstituer donc dans son sens. C'était déjà un dépassement. Puis, ensuite, j'ai suivi la ligne que j'ai illustrée dans mon livre sur Jacob Bernays, où j'ai également étudié comment les auteurs ont $\mathrm{lu}^{27} \cdot \mathrm{C}^{\prime}$ est-à-dire que j'ai associé à l'étude d'une œuvre des stratifications de son histoire postérieure, liée à une lecture déterminée religieusement, institutionellement, et tout ce qu'on veut.

Il faut aussi considérer, dans ce que j'entends par herméneutique, l'importance du travail collectif et les conditions dans lesquelles le sens se répète et se trouve. Autour $\mathrm{d}^{\prime}$ Héraclite, ici, dans cet appartement, je réunissais des chercheurs ${ }^{28}$. C'était là un espace où se reunissaient des étudiants qui voulaient aller plus loin. On entre dans un domaine privé. Comme s'il y avait des choses à faire qui n'étaient pas alors institutionnellement imaginables (le sont-elles maintenant?). Dans l'Université allemande cet espace de réflexion et de discussion existait. II y avait des séminaires où on pouvait, avec un professeur, rester autour d'une table et d'un problème, en étant peu nombreux, et puis réfléchir sur le sens d'un texte et en discuter. Et ainsi on est déjà dans l'herméneutique. Cela dépasse ce que j'ai appelé le système français, scolaire. Mais il ne faut pas que ce terme soit perçu comme dépréciatif. La démarche est tout simplement comparative. En Allemagne il existait des séminaires où l'on pouvait réfléchir ensemble. À Bâle, à l'Université, mon professeur de grec (von der Mühll), qui vivait dans la tradition et était lui-même très traditionaliste, nous apprenait à réfléchir. On pouvait rester autour d'une table cinq minutes sans rien dire, mais en réfléchissant à plusieurs. C'est beaucoup, c'est un des noyaux de l'herméneutique dans le sens fort. Quelqu'un a une idée, il faut la discuter. C'était, donc, réflexif. La réflexion avait sa place.

Je dis que, dans mon Empédocle, il y avait déjà deux dimensions de cette pratique. D'abord, la reconstitution d'un système, voir comment les choses, quand elles sont fragmentaires, peuvent aller ensemble. Et, d'un autre côté, considérer l'histoire de l'oeuvre, la détermination historique de sa survie, qui implique une histoire de la lecture et son apprentissage. Cet aspect essentiel de la transformation d'un sens initial a joué un très grand

\footnotetext{
${ }^{26}$ Bollack se refere aqui a Friedrich Wilhelm Christian Carl Ferdinand von Humboldt (Postdam, 1767 Tegel, 1835), filólogo alemão, um dos fundadores da nova universidade de Berlim.

${ }^{27}$ BOLLACK, 1998b.

${ }^{28}$ BOLLACK; WISMANN, 1978.
} 
rôle dans mes livres sur Oedipe Roi ${ }^{29}$. Nous sommes dans les années 1970. Dans les quatre volumes qui viennent heureusement d'être réédités, l'idée centrale est de montrer qu'il y a des interprétations différentes de chaque phrase et qu'on peut les situer, dire pourquoi on a choisi ceci ou cela. Cette question existe dès les débuts de mes travaux, et elle est devenue de plus en plus importante.

Au centre de cette interrogation sur l'herméneutique, il y a le fait de se prononcer sur la nature de ce que l'on fait. Non seulement on le fait; on se demande ce que c'est que l'on fait. Comment le légitimer, le justifier. C'est-à-dire qu'il y a une interprétation qui ne touche pas seulement les possibilités particulières de la compréhension, mais où la pratique devient elle-même l'objet de la réflexion, et l'on cherche pour savoir comment il faut faire. Là on passe à un autre niveau. L'herméneutique c'est une application, mais c'est aussi une réflexion sur la forme que prend l'opération en cours.

RFB : Mais vous n'êtes pas le seul à faire appel à l'herméneutique en France. Pourquoi et dans quelle mesure vous éloignez-vous de quelqu'un comme Paul Ricoeur ${ }^{30}$, par exemple?

JB : Ce sont plusieurs domaines. Il existe une herméneutique qui a été déterminée par Heidegger ${ }^{31}$, que les gens confondent souvent avec la mienne, pensant qu'il n'y en a qu'une seule. Je me situe par rapport à l'herméneutique qui existait auparavant, celle que Szondi décrit dans un des cours que j'ai publiés sur l'histoire de l'herméneutique et qui a abouti à Schleiermacher ${ }^{32}$. Mais je ne peux pas pour autant m'en réclamer. Je ne m'y rattache pas: simplement, il y a certaines réflexions qui ont convergé et j'irai nécessairement à leur rencontre. Une fois Ricoeur m'a écrit en disant que j'étais un pionnier. II a vu la différence grâce à sa compétence d'historien de l'herméneutique.

Vous pouvez le trouver, dans presque tous mes travaux : à un certain moment la découverte du sens implique une discussion sur la manière ou la voie qui nous a permis d'y accéder. J'ai mis cela nécessairement au centre. Mon herméneutique découle d'une réflexion qui s'est dégagée d'une pratique ; je l'ai poursuivie, améliorée et approfondie toute ma vie. Je n'ai pas fini. Je veux comprendre ce qu'on fait de juste et de faux. Comment fait-on? Pourquoi? Ces questions sont constamment présentes et sont aussi liées au fait que je me demande pourquoi telle personne ne peut pas, de son point de vue, comprendre. La question est liée,

\footnotetext{
${ }^{29}$ BOLLACK, 1991 (uma reimpressão desses volumes está sendo preparada). Veja-se também a edição reduzida lançada alguns anos depois: BOLLACK, 1995.

${ }^{30}$ Paul Ricoeur (Valence, 1913 - Châtenay-Malabry, 2005), filósofo francês.

${ }^{31}$ Martin Heidegger (Messkirch, 1889 - Freiburg, 1976), filósofo alemão.

${ }^{32}$ Cf. SZONDI, 1975: 291-315.
} 
donc, à l'étude des mécanismes de la censure. Le fait d'avoir grandi dans deux traditions culturelles m'a beaucoup servi, parce que j'étais obligé de me demander très vite pourquoi on comprend comme cela d'un côté, mais comme ceci d'un autre.

II ne faut pas perdre de vue que l'herméneutique est pour moi éminemment historique; il s'agit de comprendre l'importance d'une situation qui est particulière, se distinguant d'un point de vue général, de l'universel, de la totalité, du totalisant, d'une entité quelconque construite selon un ordre fixe, qu'il soit théologique ou autre. Ce point de vue particulier d'un auteur a, à un certain moment, transformé la situation dans laquelle il vivait. Je reviens à ce que je vous ai déjà dit. Il y a un Beckett irlandais et parisien, auteur du XX ${ }^{\mathrm{e}}$ siècle, influencé par son entourage, mais il y a aussi quelque chose qui est entièrement lié à sa personne, à l'existence d'un sujet. Et là on est, à nouveau, dans cette différence que vous me demandez de décrire par rapport à des heideggériens convaincus ou partiels comme Ricœur et à un marxiste, comme Vernant. Un auteur ne reflète pas une situation ; il écrit et réfléchit dans une situation qui demande elle-même une recherche de type herméneutique. Ce que I'historisation permet de construire, ce sont des situations herméneutiques préexistantes. Si l'on prend l'un des auteurs tragiques, on se dira qu'il est entièrement déterminé par son univers, l'Athènes qui existait; en même temps il s'est agi pour lui d'un objet de sa réflexion. II en a fait autre chose. Et cette particularité se particularise indéfiniment. Elle touche finalement la moindre phrase. En même temps, cela se fait toujours en relation avec un savoir préexistant. Pour nous, il importe de formuler des hypothèses de sens même si elles sont fausses, pour les corriger ensuite. II faut travailler avec et contre ce qu'on pense.

RFB : Et comment avez-vous pratiqué cette herméneutique dans l'univers plutôt scolaire qui caractérise la structure dominante de l'université française?

JB : Je suis plutôt vieux. J'ai vécu pendant quelque chose comme trois générations. La situation à Paris n'était pas la même en 1945, en 1965, etc. Naturellement, il faut faire de l'histoire, mon histoire et celle de mon milieu, pour comprendre comment ma pratique a pu changer, évoluer et se parfaire. Il y a des choses qui comptent beaucoup, puis beaucoup moins. Par exemple, le heideggerisme est infiniment moins présent dans les consciences qu'il y a vingt ans, et même qu'il y a quarante ans.

J'ai dû enseigner d'une part dans les cadres existants, selon les normes, pour que les étudiants réussissent et obtiennent leurs diplômes, et, d'autre part, je devais leur montrer que ce cadre ne pouvait pas les conduire à une véritable compréhension de la matière. C'était déjà herméneutique. Vous avez parmi les étudiants un public assez différencié, puis vous 
rencontrez parmi eux tel ou tel intérêt. Les études conduisent à un métier, mais aussi à des problèmes et à des auteurs. C'est la difficulté des professeurs - et de la profession. Mon enseignement a toujours été double depuis que j'ai été nommé jeune professeur. Passer un examen et lire Platon, en comprenant sa pensée, ce n'est pas la même chose. II fallait faire l'un et l'autre. La situation est propre aux sciences humaines. Ce n'est pas vrai en chimie. Mais dans les sciences humaines, on est d'emblée en désaccord avec les besoins de la société, comme vous le constatez maintenant un peu partout, non? La culture est de nouveau, et autrement, problématisée. Elle est en péril aussi. Ce à quoi on a toujours à faire, c'est à notre entourage culturel; il s'agit de voir quel rôle nous pouvons jouer dans un univers qui est culturellement et historiquement déterminé. L'enseignement des auteurs classiques pose cette question d'une façon extrême. On est avec eux à la fois dans la tradition et dans la critique de cette tradition. Elle change naturellement, de génération en génération; nous travaillons consciemment dans cette perspective, tâchant d'innover et d'étudier les possibilités d'innovation et de conservation.

RFB : On dit souvent aussi que vous avez un style particulier d'écriture. Comment l'avez-vous créé et quels sont les rapports entre votre style et votre pratique?

JB : Je suis présent dans mes phrases. On me dit souvent que cela se sent et se reconnaît. C'est intéressant de savoir quelle est la relation entre l'interprétation et cette créativité. C'est le subjectif et l'objectif qui entrent là dans le jeu. Comment puis-je être objectif en étant en même temps si fortement subjectif et engagé personnellement? Plus j'ai investi dans ma personne, plus j'ai de chance de trouver le vrai. La science en tant que telle est objective et tout le monde y est associé. J'interviens là aussi comme un auteur. Comme mes intérêts sont plutôt vastes, cela me pose des problèmes. Je m'occupe autant de la littérature moderne, en cherchant à montrer que les procédés sont les mêmes. Comment vais-je maîtriser tout cela? À la fin des années 1970, comme je vous ai déjà dit, je suis un peu sorti des limites tracées par les études classiques (je ne les ai pas quittées). Je voulais montrer l'importance que le débat prenait au théâtre, dans la psychanalyse, la littérature contemporaine. Mon cas est un peu particulier; je suis souvent mieux lu et compris par des gens qui ne sont pas des spécialistes.

RFB : C'est cela que je trouve le plus intéressant dans votre oeuvre. Vous êtes à la fois à l'intérieur et à l'extérieur de l'Université française, pour et contre cette institution. 
JB : La contradiction est inévitable. L'Université est un lieu qui empêche, mais c'est le seul lieu où la pratique peut s'exercer. Comme je vous ai dit avant, j'ai autrefois organisé des séminaires chez moi, parce que cela ne pouvait pas se faire ailleurs. Il y a aussi le problème actuel, lié à I'Université de masse, son uniformité et sa dispersion. Comment réunir un groupe de gens qui sont suffisamment liés par un intérêt commun? II y a quand même quelque chose de sectaire aussi dans une recherche véritablement scientifique, et, dans mon cas, herméneutique, dans la caractérisation d'un groupe. On reconnaît l'importance d'un intérêt commun qui lie les gens. J'ai eu la chance d'avoir toujours rencontré des gens intéressants qui ont voulu travailler avec moi. On a des élèves. Szondi aussi a connu cela. Ce n'est pas par hasard.

RFB : Je vais vous poser une dernière question, celle-là liée à votre héritage. Dans la préface de la "Grèce de personne ", un ouvrage qui, comme "Sens contre sens ", contribue beaucoup à la compréhension de l'ensemble de votre oeuvre, vous avez dit, je vous cite, "qu'il faut protéger la tradition de sa célébration ". Comment, donc, protéger votre oeuvre et la philologie critique, dans un moment où elles sont déjà très extérieures à vous et où il y a aussi des héritiers? Autrement dit, comment continuer la critique, en faisant la critique de la critique?

JB : Il faut à la fois séduire et convaincre, et on le fait par l'écriture, par une certaine présentation de l'objet. C'est l'engagement de la personne. Cela, d'un côté. On peut terminer notre entretien sur cette question parce qu'elle est cruciale. Finalement, la meilleure interprétation d'un texte rejoint l'acte de création, du côté de l'auteur dont on prend le parti. On retrouve presque la manière dont la chose a été faite. II faut savoir dans quelles conditions cela a pu se faire. Cela va dans les deux sens. On n'est pas non plus le poète, et on apprend, au fond, qu'on ne l'est pas, dans la distance.

Un débat que nous n'avons pas approché dans l'entretien, c'est le débat sur la nature du sens et le statut de la polysémie. La polysémie est de tradition religieuse, elle interprète la parole divine qui est, dans son principe, insondable. Je privilégie pour moi, au contraire, un angle d'approche qui est singulier, particulier. Les positions sont irréconciliables, extrêmes, opposées. Évidemment, elles impliquent la présence ou l'absence de ce fond divin. Le paradoxe est là. Vous l'avez bien senti, non? On s'arrête. 


\section{CADERNO}

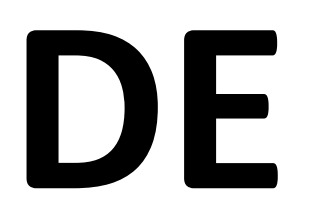

IMAGENS 


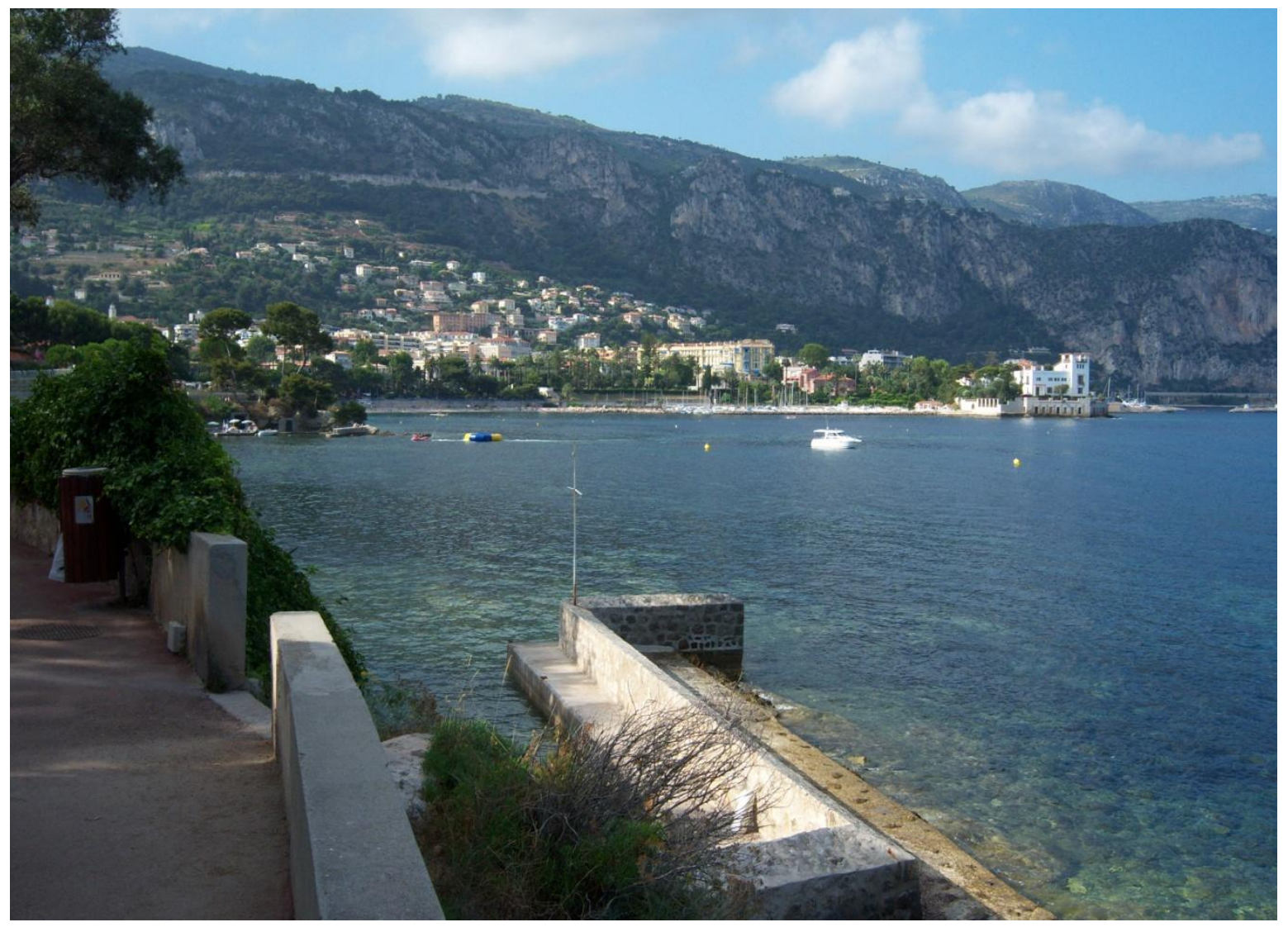

Figura 2.3.1 - A baía de Beaulieu-sur-Mer em julho de 2008. A Villa Kérylos, construída por Théodore Reinach entre 1902 e 1908, encontra-se em uma de suas extremidades (à direita na foto).

Créditos fotográficos: Rafael Faraco Benthien. 


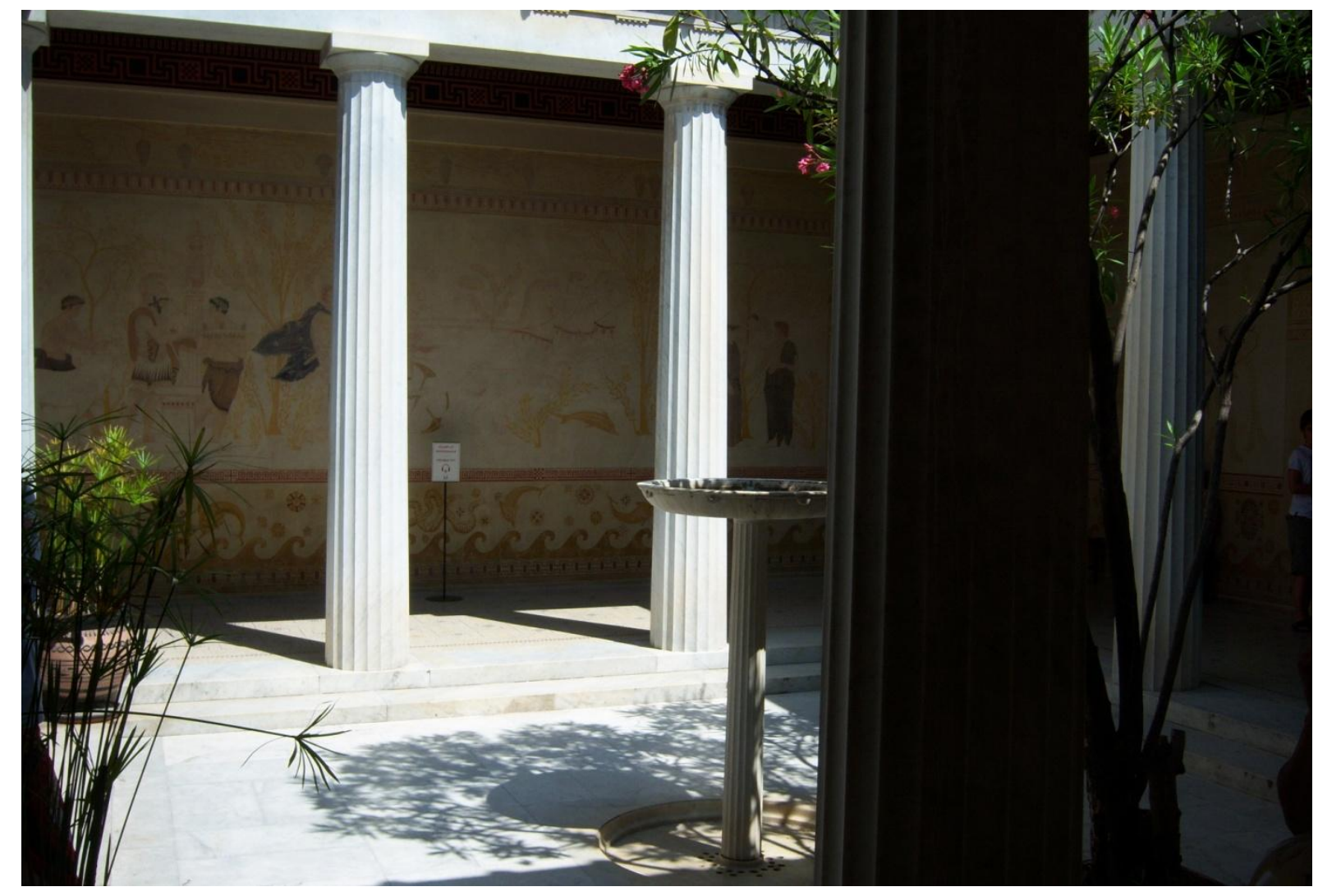

Figura 2.3.2 - 0 átrio central da Villa Kérylos. Organizado em torno de uma estrutura sustentada por doze colunas, ele ainda tinha suas paredes adornadas por pinturas murais e esculturas.

Créditos fotográficos: Rafael Faraco Benthien. 


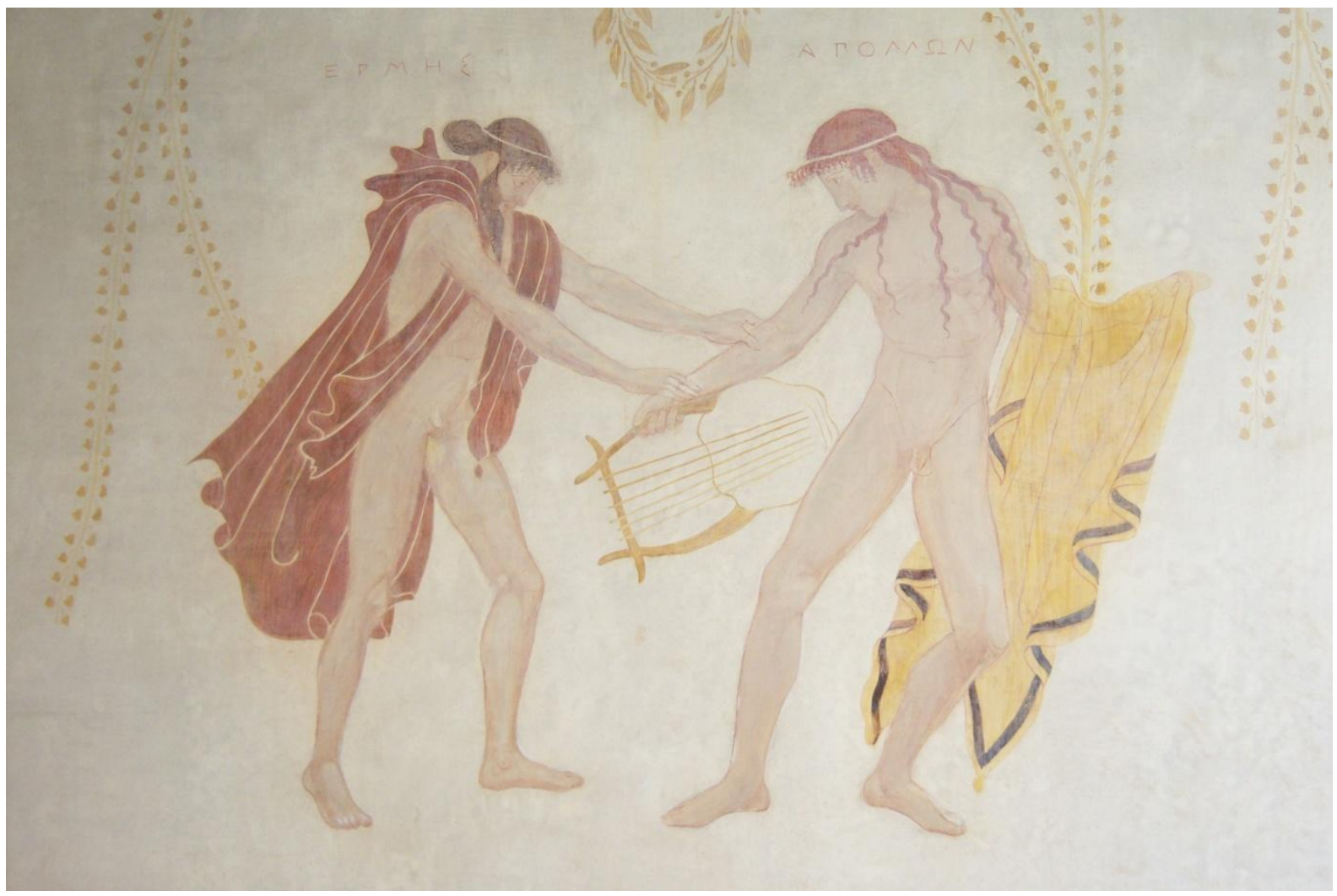

Figura 2.3.3 - A disputa da lira entre Hermes (à direita) e Apolo (à esquerda). Exemplo de pintura que adornava o átrio central da Villa Kérylos. Os motivos pictóricos vinham de cerâmicas antigas, as quais, então se imaginava, reproduziam com fidelidade a arte da pintura mural grega.

Créditos fotográficos: Rafael Faraco Benthien. 


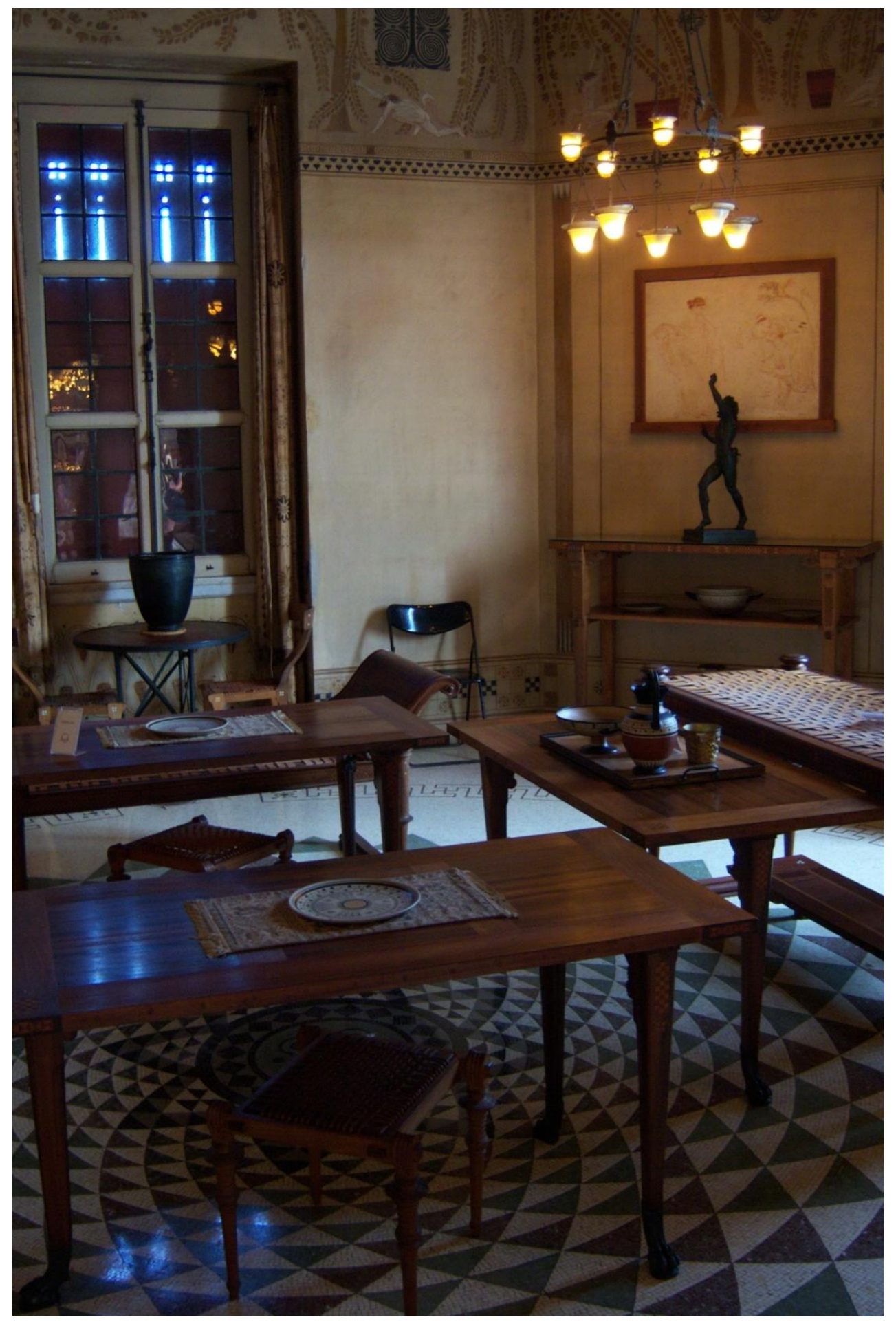

Figura 2.3.4 - A sala de refeições (triklinos) da Villa Kérylos. Também os móveis eram reproduções de objetos antigos.

Créditos fotográficos: Rafael Faraco Benthien. 


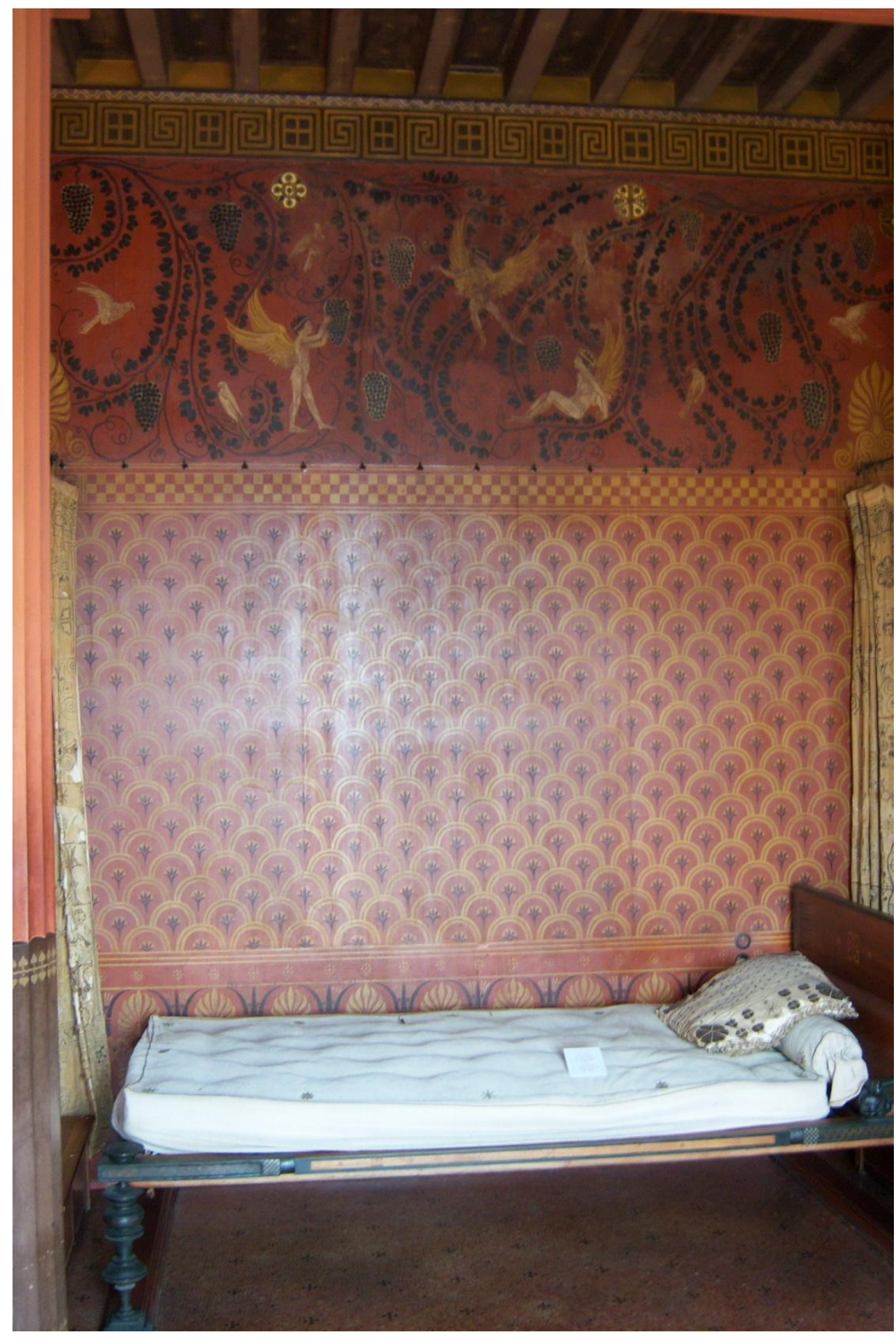

Figura 2.3.5 - Detalhe do quarto de Théodore Reinach, no segundo andar da Villa Kérylos.

Créditos fotográficos: Rafael Faraco Benthien. 


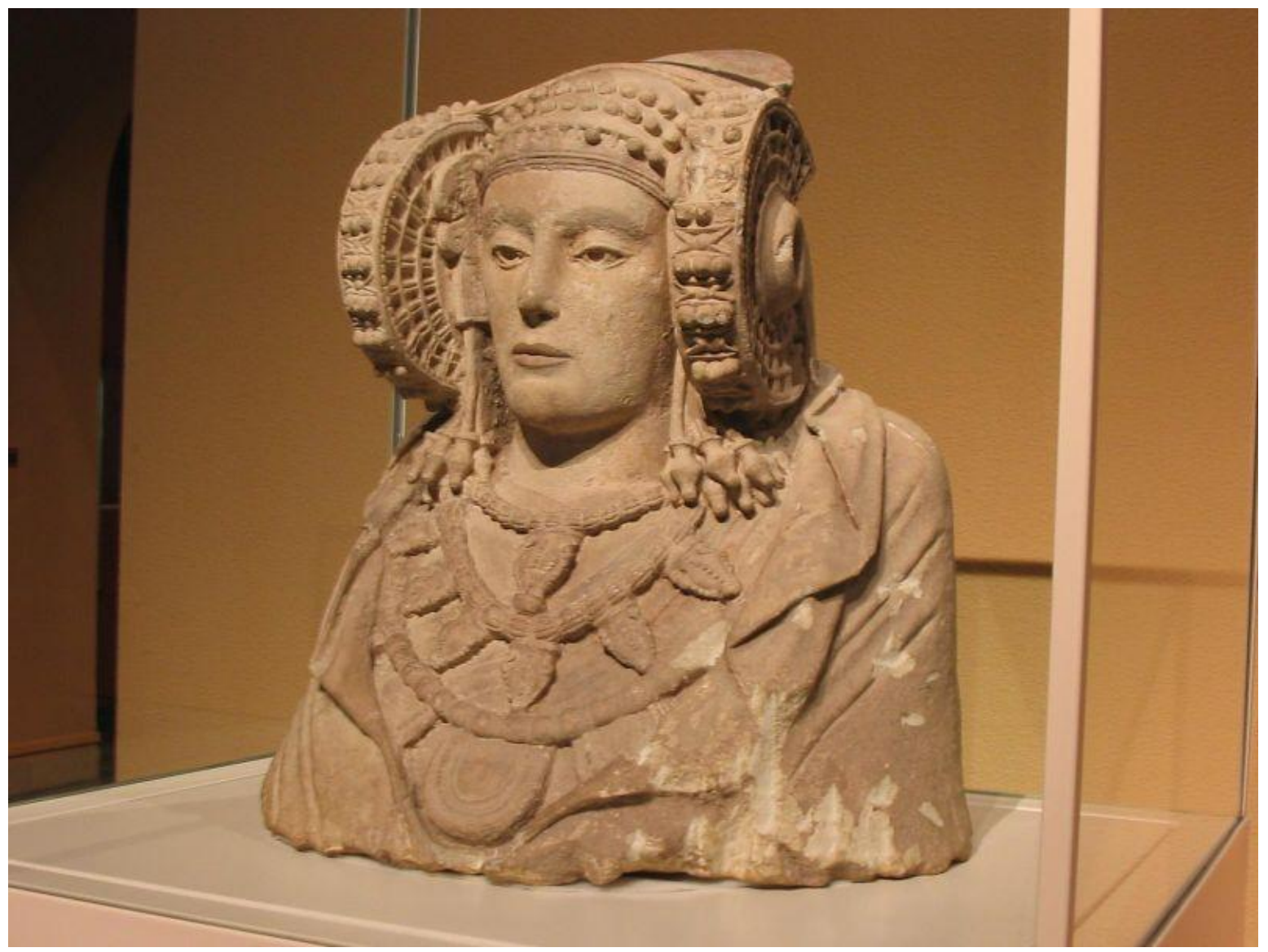

Figura 2.4.1 - O busto antigo intitulado "A Dama de Elche". Descoberta por Pierre Paris nos arredores de Elche em fins do século XIX, ela foi alvo de polêmicas na universidade francesa. Incorporada ao Louvre na sequência, ela se tornou a grande atração da sala de antiguidades hispânicas mantida pela instituição até a Segunda Guerra. Durante o conflito, seu retorno à Espanha foi negociado entre os governos do "regente do reino" Francisco Franco e de Philippe Petain, presidente da República de Vichy. Atualmente ela pertence ao acervo do Museu do Prado, em Madri.

Créditos fotográficos: Museo Nacional del Prado. 


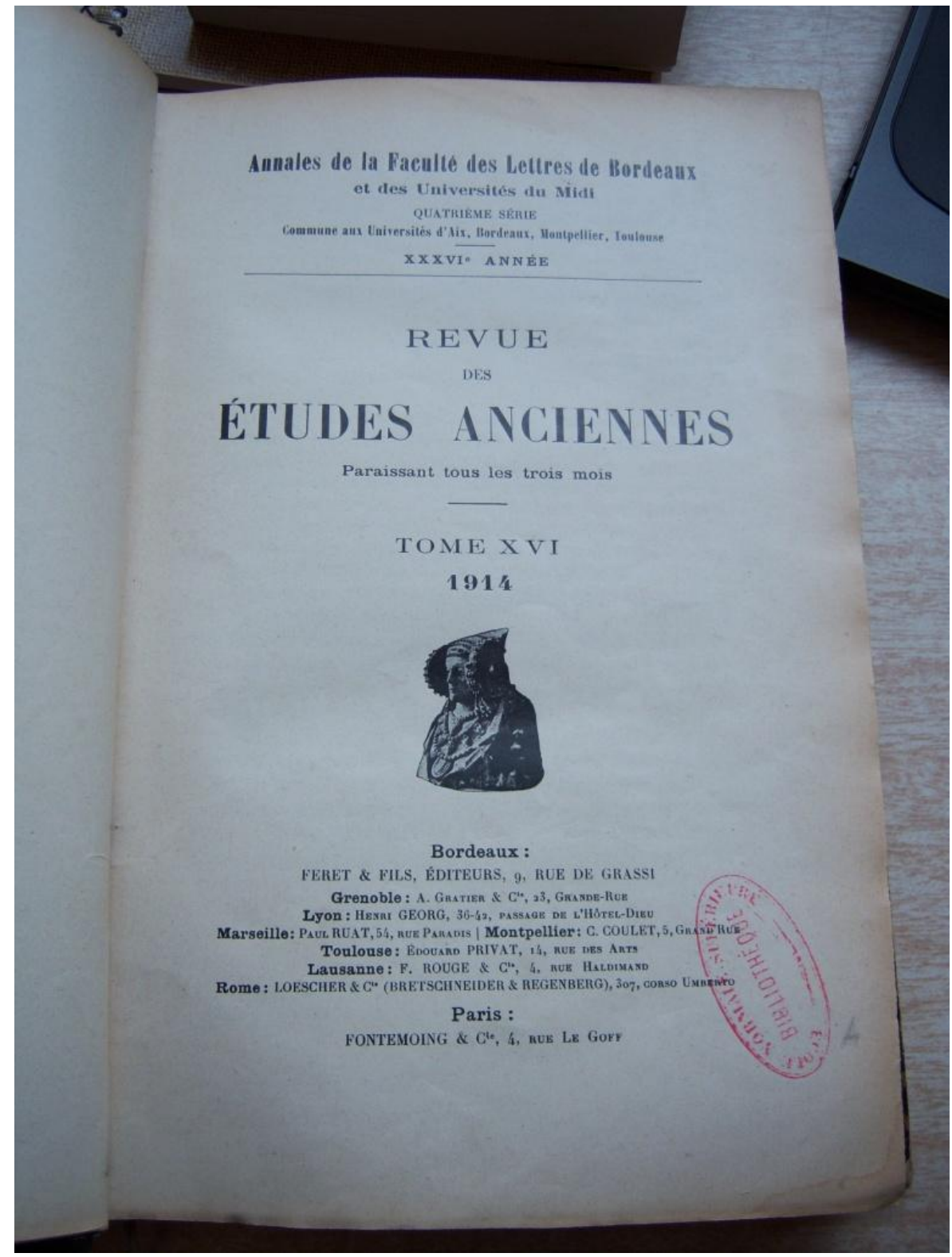

Figura 2.4.2 - A Dama de Elche na folha de rosto da REA. Entre 1899 e 1914, foi ela quem serviu de emblema para a revista dirigida por George Radet e Camille Jullian.

Créditos fotográficos: Rafael Faraco Benthien. 


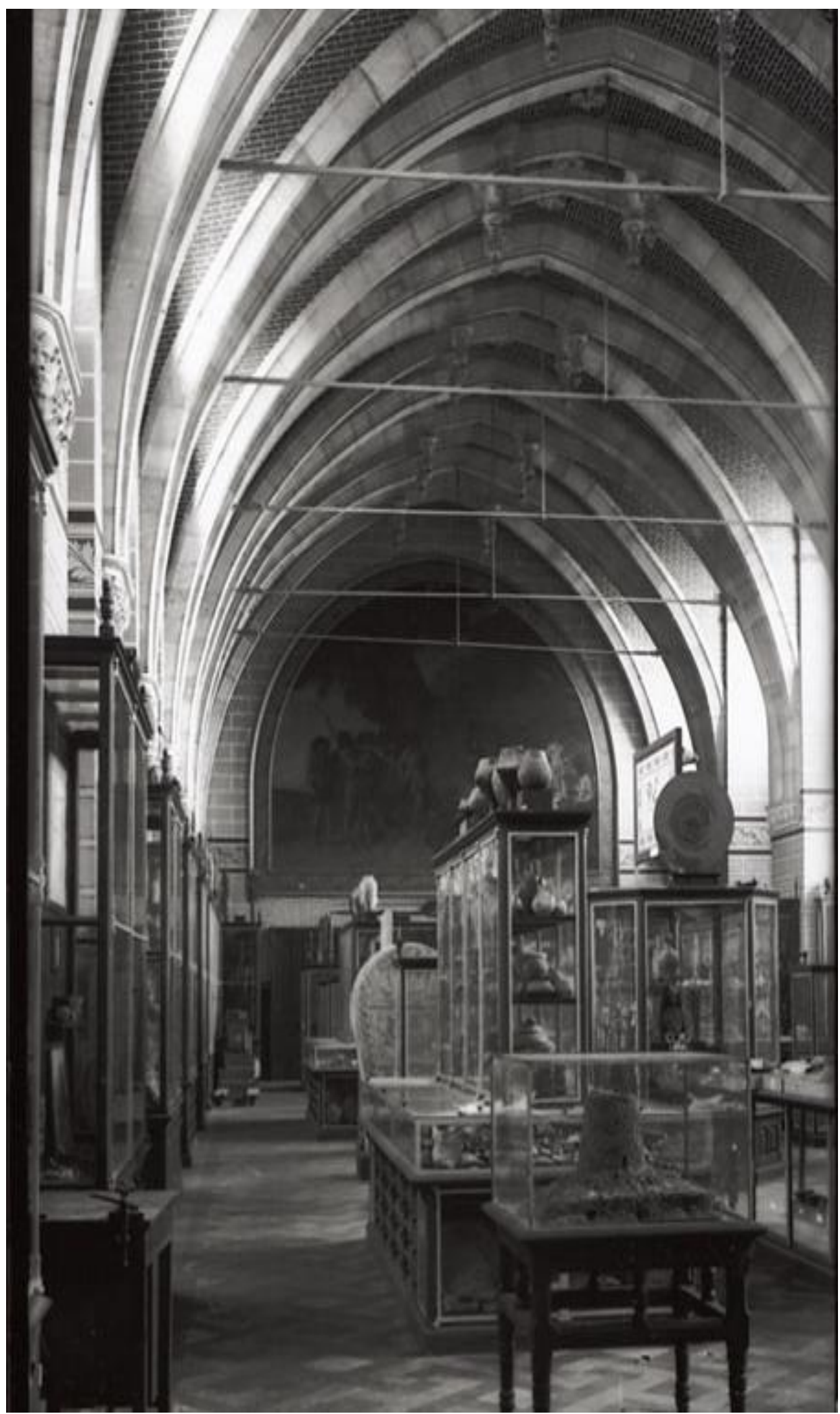

Figura 3.2.1 - A Sala de Marte ou Sala de Arqueologia Comparada no início do século XX, tal como concebida por Henri Hubert (vista para o fundo). As vitrines, reunindo peças de todos os continentes e de todas as épocas, dialogam entre si a partir de dois eixos principais, um temporal e outro geográfico. No interior de cada vitrine as peças também são apresentadas segundo contextos específicos (técnicos e/ou rituais).

Créditos fotográficos: Musée d'Archéologie Nationale. 


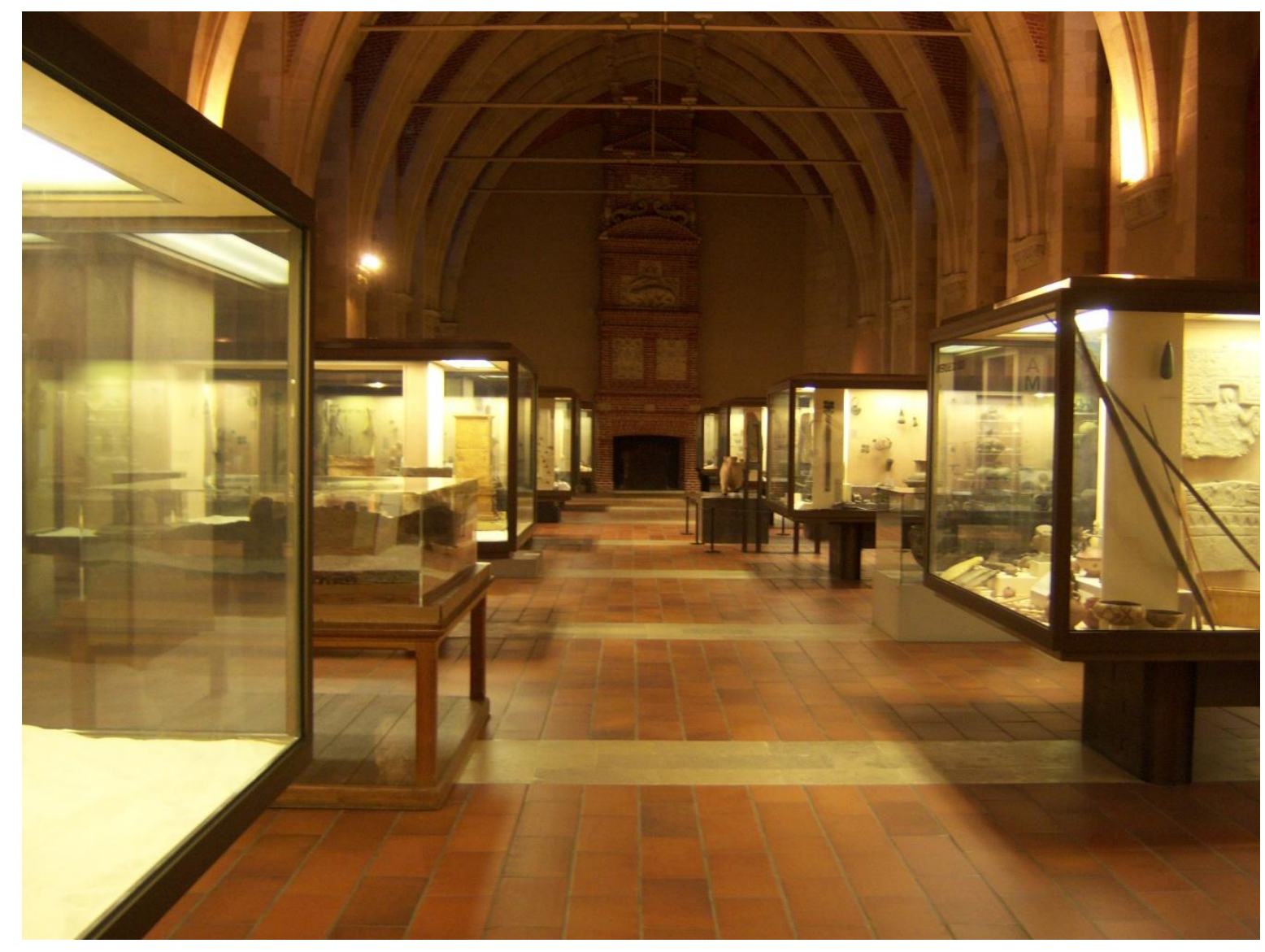

Figura 3.2.2 - A Sala de Marte ou Sala de Arqueologia Comparada no início do século XXI (vista para a entrada). 0 formato atual, concebido por Christine Lorre e Anaïs Boucher, mantém as linhas gerais do trabalho de Hubert (os dois eixos principais e as divisões internas das vitrines). Mas o material apresentado sofreu, ao longo dos anos, transformações. As antiguidades da Espanha, antes no Louvre, foram integradas na sala após a Segunda Guerra Mundial. As vitrines relativas à Oceania, contudo, foram "requisitadas" por ocasião da abertura do Musée du Quai Branly.

Créditos fotográficos: Rafael Faraco Benthien. 


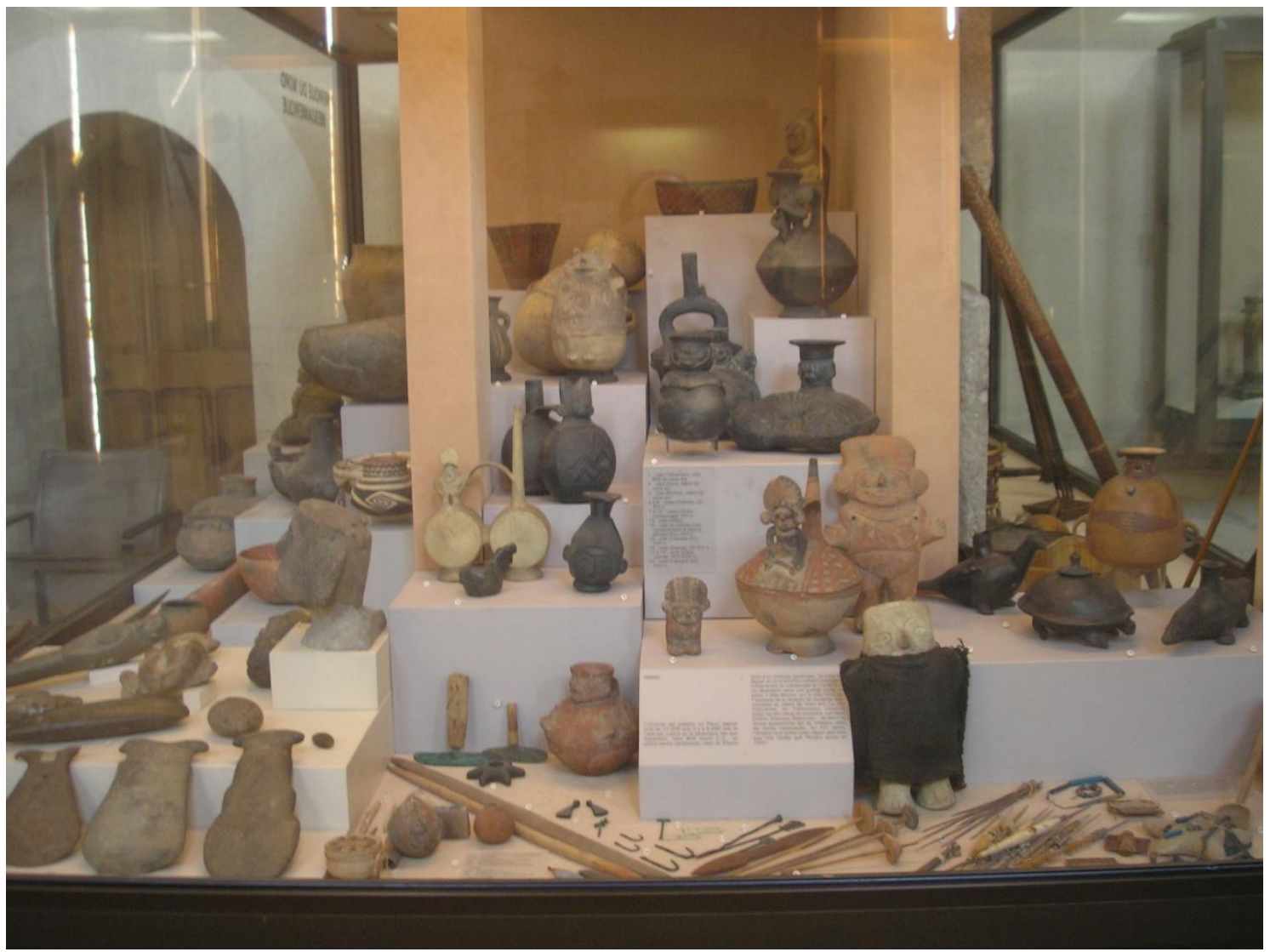

Figura 3.2.3 - Exemplo atual de vitrine da Sala de Arqueologia Comparada. Trata-se, neste caso, da vitrine relativa às Américas. As peças expostas se encontram organizadas por princípios tecnológicos e de contexto ritual.

Créditos fotográficos: Jean-Pierre Faguer. 


\section{BIBLIOGRAFIA}




\section{NOTA INTRODUTÓRIA}

A Bibliografia da presente tese foi subdividida em cinco blocos. No primeiro (a), o leitor poderá encontrar as obras de referência consultadas ao longo da pesquisa, tais como dicionários biográficos e anuários institucionais. Na sequência, o segundo bloco (b) traz listados os periódicos que constituíram os núcleos centrais e secundários da análise aqui desenvolvida. O terceiro bloco (c), por seu turno, se refere aos manuscritos não impressos encontrados em arquivos. Embaixo de cada arquivo mencionado, encontram-se discriminados seus conteúdos e a identificação numérica (cota) dos documentos consultados. Completando tais informações, o quarto bloco (d) dispõe de toda as fontes impressas. Por fim, poderá ser encontrada a bibliografia geral da tese (e), composta por trabalhos recentes acerca dos estudos greco-latinos, da sociologia e do sistema de ensino francês.

\section{a. OBRAS DE REFERÊNCIA}

CHARLE, C. 1985. Dictionnaire Biographique des Universitaires auX $\mathbf{X I X}^{\mathbf{e}}$ et $\mathbf{X X}^{\mathrm{e}}$ Siècles. Volume 1. La Faculté des Lettres de Paris (1809-1908). Paris: Editions du CNRS. . 1986. Les Professeurs de la Faculté des Lettres de Paris. Dictionnaire biographique: 1909-1939. Paris: Éditions du CNRS.

CHARLE, C.; TELKÈS, E. 1988. Les Professeurs du Collège de France. Dictionnaire biographique. 1901-1939. Paris: Éditions du CNRS/Imrp.

ÉCOLE FRANÇAISE D'ATHÈNES. 2011. École Française d'Athènes, histoire de l'École. Paris: EFA. (publicação disponível no site da instituição contendo as listas de promoções da escola desde sua fundação).

ÉCOLE FRANÇAISE DE ROME. 1987. Annuaire des Membres (1873-1986). Rome: École Française de Rome.

GRAN-AYMERICH, È. 2001. Dictionnaire Biographique d'Archéologie. 1798-1945. Paris: Éditions du CNRS.

JOLLY, J. 1960. Dictionnaire des Parlementaires Français: notices biographiques sur les ministres, sénateurs et députés français de 1889 à 1940. Paris: PUF.

JULLIARD, J.; WINOCK, M. 2009. Dictionnaire des Intellectuels Français. Paris: Seuil.

SÉNÉCHAL, C.; BABILLON, P. (sob a direção de). 2009. Dictionnaire Critique des Historiens de l'Art Actifs en France de la Révolution à la Première Guerre Mondiale (on-line: http://www.inha.fr - último acesso em 01/11/2009).

VAN HOOF, H. 1993. Dictionnaire Universel des Traducteurs. Genebra: Slatkine. 


\section{b. PERIÓdICOS}

Annuaire de l'Association pour l'Encouragement des Études Grecques en France.

Bulletin de Correspondance Hellénique ( $\mathrm{BCH}$ ).

Bulletin Administratif du Ministère de l'Instruction Publique.

Dictionnaire des Antiquités Grecques et Romaines (DAGR).

Le Nouvelliste.

Le Temps.

Mélanges d'Archéologie et Histoire (MAH).

Revue Archéologique (RA).

Revue Celtique (RC).

Revue des Études Anciennes (REA).

Revue des Études Grecques (REG).

Revue des Universités du Midi

Revue de l'Histoire des Religions (RHR).

Revue de Métaphysique et de Morale (RMM).

\section{FONTES MANUSCRITAS}

\section{c.1 Archives du Collège de France (Paris).}

c.1.1 Processos verbais de Assembleias.

Assemblée du 27 décembre 1885.

Assemblée du 16 janvier 1887.

Assemblée du 28 novembre 1904.

Assemblée du 15 janvier 1905.

Assemblée du 02 avril 1905.

Assemblée du 17 décembre 1905.

Assemblée du 17 février 1907.

Assemblée du 10 novembre 1907.

Assemblée du 5 avril 1908.

Assemblée du 17 janvier 1909.

Assemblée du 9 février 1909.

Assemblée du 14 janvier de 1912.

Assemblée du 21 janvier de 1912.

Assemblée du 24 mars 1912. 
c. 1.2 Dossiês administrativos de antigos professores.

Ernst Babelon.

Michel Bréal.

René Cagnat.

James Darmesteter.

Charles Fossey.

Paul Foucart.

Maurice Holleaux.

Jean Izoulet.

Camille Jullian.

Sylvain Lévi.

Alfred Loisy.

Marcel Marion.

Marcel Mauss.

Antoine Meillet.

Gabriel Tarde.

\section{c.2 Archives de l'Institut Mémoires de l'Édition Contemporaine (IMEC-Caen).}

c.2.1 Fonds Meillet.

c.2.1.1 Cours et Conférences.

Conférences sur les principes de la linguistique historique (MLT 11.21).

Langues et Nations Indo-Européennes (MLT 9.9).

Les Causes Sociales des Faits Linguistiques (MLT 7.2).

c. 2.1.2 Carnet des Notes.

1904-1909 (MLT 22.2).

1910-1914 (MLT 22.3).

1915-1918 (MLT 22.4).

1919-1922 (MLT 22.5).

c.2.1.3 Correspondance.

Arbois de Jubainville (MLT 12.7).

Babelon (MLT 12.8).

Boisacq (MLT 12.26).

Bréal (MLT 12.32).

Casanova (MLT. 12.45).

Chavannes (MLT 12.48). 
Cuny (MLT 12.59).

Dottin (MLT 12.68).

Durkheim (MLT 12.70).

Fournier (MLT 12.84).

Gaidoz (MLT 12.87).

Granet (MLT 12.99).

Havet (MLT 12.108).

Hertz (MLT 12.111).

Jullian (MLT 13.5).

Lévy-Bruhl (MLT 13.30).

Marx (MLT 13.45).

Monod (MLT 13.60).

Piganiol (MLT 13.79).

Vendryes (MLT 14.17).

\subsection{Fonds Mauss-Hubert.}

2.2.1 Correspondance (todas as cartas são destinadas a Marcel Mauss, salvo indicação contrária).

Bergson (MAS 1.56).

Beuchat (MAS 1.67).

Bianconi (MAS 1.68).

Bouglé (MAS, 1.95).

Bourgin, H. (MAS 1.97).

Bréal para Durkheim (MAS 1.105).

Bréhier (MAS 1.106).

Davy (MAS 3.6).

Espinas (MAS 3.74).

De Félice (MAS 4.19).

Frazer (MAS 4.46).

Gernet (MAS 5.12).

Halbwachs (MAS 5.70).

Hamelin (MAS 5.74).

Hertz e família (MAS 6.12 e 6.13).

Hubert (MAS 6.36 e 6.37).

Huvelin (MAS 6.40).

Jeanmaire (MAS 6.64). 
Marillier (MAS 8.60).

Marx (MAS 8.71).

Maspero (MAS 8.72)

Meillet (MAS 9.2 e 9.3).

Reinach, S. (MAS 10.104).

Reinach, Th. (MAS 10.105).

Rodier (MAS 11.30).

Van Gennep (MAS 13.20).

Wyrouboff (MAS 13.82).

Diversos remetentes a Henri Hubert (MAS 46, 47, 48, 50, 51 e 52).

c.3 Archives du Musée d'Archéologie Nationale (Saint-Germain-en-Laye).

c.3.1 Dossiers de Correspondance (indentificação por sobrenome do remetente).

Audollent.

Beuchat.

Chaillan.

Cumont.

Czarnowski.

Dangibeaud.

Déchelette.

Deonna.

Durkheim.

Frazer.

Génin-Ricard.

Glotz.

Jeanmaire.

Jullian.

Lizop

Perdrizet.

Paris.

Toutain.

Vendryes.

Verneau.

c.3.2 Fonds Henri Hubert.

Cours École du Louvre.

Religions I. 
Salle de Mars.

Correspondances (vários remetentes não classificados).

c.4 Archives de la Bibliothèque Méjanes-Fonds Salomon Reinach (Aix-en-Provence).

Boîte ${ }^{\circ} 16$ (Cartas de BIANCONI, A.)

Boîte $n^{\circ} 54$ (Cartas de DURKHEIM, Émile e de DURKHEIM, André)

Boîte $n^{\circ} 72$ (Cartas de GERNET, Louis e de GLOTZ, Gustave)

Boîte $n^{\circ} 81$ (Cartas de HERTZ, Robert)

Boîte $n^{\circ} 84$ (Cartas de HUBERT, Henri)

Boîte $\mathrm{n}^{\circ} 105$ (Cartas de MAUSS, Marcel)

Boîte $n^{\circ} 145$ (Cartas de ROUSSEL, Pierre - também erroneamente grafado ROUSSEL, T.)

Boîte $n^{\circ} 175$ (Cartas de RADET, Georges)

\section{d. FONTES IMPRESSAS}

ANDLER, C.; HERR, L. Correspondance entre Charles Andler et Lucien Herr. 1891-1926. (Établie, présentée et annotée par Antoinette BLUM). Paris: Presses de L'ENS.

ARISTOTE. 1891. La République athénienne. Paris: Hachette. (traduite en français pour la première fois par Théodore Reinach).

BALZAC, H. De 2006. O Lírio do Vale. Porto Alegre: L\&PM.

BARRÈS, M. 1897. Les Déracinés. Paris: E. Fasquelle.

BENDA, J. 1936. La Jeunesse d'un clerc. Paris: Gallimard.

BERTRAND, A. 1897. La Religion des Gaulois, les druides et le druidisme. Paris: s.e. 1884. La Gaule avant les Gaulois: d'après les monuments et les textes. Paris: Leroux. 1876. Archéologie celtique et gauloise: mémoires et documents relatifs aux premiers temps de notre histoire nationale. Paris: Didier.

. 1958a. Essai sur les dieux protecteurs des héros grecs et troyens dans l'lliade. Paris: C. Catel.

1958b. Études de Mythologie et d'Archéologie Grecques d'Athènes à Argos. Paris: C. Catel.

BERTRAND, A. ; CASIMIR, C. 1865. Commentaires de Jules César. Guerre des Gaules. Paris: Didier.

BERGSON, H. 2005. Cursos sobre a Filosofia Grega. São Paulo: Martins Fontes.

BLOCH, G. 1901. Histoire de la France. Tome Premier, vol. II (Les origines. La Gaule Indépendante et la Gaule Romaine). Paris: Hachette. 
BLOCH, M., FEBVRE, L. 1994. Correspondance I. La naissance des Annales (1928-1933). Paris: Fayard.

BOUGLÉ, C. 1935. Bilan de la Sociologie Française Contemporaine. Paris: Alcan.

BOURGET, P. 1889. Le Disciple. Paris: Lemerre.

BROCHARD, V. 1903. La Morale de Platon. In: Année Philosophique, 27, p. 170-83.

BRÉAL, M. 1877. Mélanges de Mythologie et de Linguistique. Paris: Hachette.

CAGNAT, R. 1886. Cours Élémentaire d’Epigraphie Latine. Paris: Thorin.

CHANTEPIE DE LA SAUSSAYE, P. -D. 1904. Manuel d'Histoire de Religions. Paris: Colin (Tradução sob a direção de Henri Hubert e Isidore Lévy).

CLERC, M. 1973. Aquae Sextae . Aix-en-Provence: Dragon.

. 1895. Leçon d'ouverture. Chaire départamentale d'histoire de Provence. Facultés des lettres d'Aix et des sciences de Marseille. Marselha: Barthelet. . 1893a. Les Métèques Athéniens. Paris: Thorin \& Fils.

. 1893b. Leçon d'Ouverture: histoire de la provence dans l'antiquité, jusqu'à la création de la province romaine. Aix \& Marseille, Samedi 9 et Lundi 11 Décembre 1893. Marseille: Typographie et Lithographie Barlatier et Barthelet.

DE LA VILLE DE MIRMONT, H. 1894. Apollonios de Rhodes et Virgile: la mythologie et les dieux dans les "Argonautiques" et dans I'"Énéide". Paris: Hachette.

DE LA VILLE DE MIRMONT, J. 1917. Lettres de Guerre. Bordeaux: Gounouilhou.

DE LA VILLE DE MIRMONT, Mme. de. 1935. Vie de Jean de la Ville de Mirmont. Ses vers inédits, ses lettres à ses parents, à ses amis, ses lettres de guerre. Cahors: I'Imp. A. Coueslant.

DÉCHELETTE, J., 1908. Manuel d'archéologie préhistorique, celtique et gallo-romaine. Vol. I. Paris: Picard.

DE MARIEN. 1934. Nécrologie Camille Jullien. Bayonne: s.e.

DOUMIC, R. Maurice Maindron. Discours prononcé au cimetière de Montparnasse, le 21 juillet 1911. Paris: s.e.

DUHEM, P. 1905. Paul Tannery (Extrait de la Revue Philosophique). Montligeon: Montligeon.

DUMONT, A. 1870. Essai sur la chronologie des archontes athéniens postérieurs à la CXXII olympiade et sur la succession des magistrats éphébiques. Paris: Firmin-Didot.

DURKHEIM, E. 2010. Lettres à Salomon Reinach. (Veja-se BENTHIEN, 2010). 2007. Prefácio à Primeira Edição do Année Sociologique. In: Teoria \& Pesquisa, vol. XVI, no. 1, jan./jun. 2007, p. 7-12 (Tradução de Rafael Faraco Benthien). 2000 [1912]. As Formas Elementares da Vida Religiosa. São Paulo: Martins Fontes. 1999 [1938]. L’Évolution Pédagogique en France. Paris: Puf. 
1998. Lettres à Marcel Mauss. Paris: Puf.

1982. Documents inédits: lettres de Durkheim. In: Études durkheimiennes. Bulletin d'information préparé par Le groupe d'études durkheimiennes. Juin 1982, n. 7, p. 2-3.

.1975a . Oeuvre. T. I. Paris: Minuit.

. 1975b . Oeuvre. T. II. Paris: Minuit.

.1975c . Oeuvre. T. III. Paris: Minuit.

ESPINAS, A. 1878. Les Sociétés Animales. Paris: Germer Baillière.

FAVARO, A. 1905. Paolo Tannery: nota commemorativa letta alla R. Accademia di scienze lettere et art in Padova nell'adunanza del 15 Gennaio de 1905. Padova: s.e.

FINLEY, M. 2002 [1954]. The World of Odysseus. Nova York: Nyrb.

FOSSEY, C. 1904. Manuel d'assyriologie: fouilles, écriture, langue, littérature, géographie, histoire, religion, institutions. Paris: Leroux.

. 1902. La Magie Assyrienne, étude suivie de textes magiques traduits, transcrits et commentés. Paris: Leroux.

FOSSEY, C. ; SCHEIL, V. 1901. Grammaire Assyrienne. Paris: Welter.

FRANÇOIS, M. 1959. Georges Bourgin. In: Bibliothèque de l'école des chartes, tome 117. p. 368-374.

FUSTEL DE COULANGES, N. D. 1893. Questions Historiques. Paris: Hachette.

. 1891a. La Gaule Romaine. Paris: Hachette.

. 1891b. L'Invasion Germanique et la Fin de l'Empire. Paris: Hachette.

. 1885. Recherches sur Quelques Problèmes d'Histoire. Paris: Hachette.

. 1874. Histoire des Institutions Politiques de l'Ancienne France. Paris: Hachette.

GERNET, L. 2001 [1917]. Recherches sur le développement de la pensée juridique et morale en Grèce: étude sémantique. Paris: Albin Michel.

. 1983. Les Grecs sans Miracle. Paris: La Découverte/Maspero. (Organização de Riccardo di Donato).

1982. Anthropologie de la Grèce Antique. Paris: Flammarion.

GLOTZ, G. 1928. Éloge Funèbre de M. Théodore Reinach. In: Comptes-rendus des séances de I année - Académie des inscriptions et belles-lettres, $72^{\mathrm{e}}$ année, N. 4, p. 321-326.

1928. La Cité Grecque. Paris: La Renaissance du Livre.

1923. La Civilisation Égéenne. Paris: La Renaissance du Livre.

1920. Le Travail dans la Grèce Ancienne: histoire économique de la Grèce depuis la période homérique jusqu'à la conquête romaine. Paris: Alcan.

. 1906. Études Sociales et Juridiques sur I'Antiquité Grecque. Paris: Hachette. . 1904a. La Solidarité de la Famille dans le Droit Criminel en Grèce. Paris: Fontemoing. 
1904b. L'Ordalie dans la Grèce primitive, étude de droit et de mythologie. Paris: Fontemoing.

GUIRAUD, P. 1893. La Propriété Foncière en Grèce jusqu'à la Conquête Romaine. Paris: Alcan. HALBWACHS, M. 1999. Ma campagne au Collège de France. In: Revue d'Histoire des Sciences Humaines, t. 1, vol. 1, p. 189-229.

HAMELIN, O. 1931. Le Système d’Aristote. Paris: Alcan.

HERTZ, R. 1999. Lettres à Pierre Roussel. In: Durkheimian Studies/Études Durkheimiennes, vol. 5, n.s., p. 39-59.

HUBERT,. H. 2001. Les Celtes. Paris: Albin Michel.

. 1925. Divinités gauloises: Sucellus et Nantosuelta, Epona, dieux de l'autre monde. Mâcon: Protat frères.

. 1899. Étude sur la formation des états de l'Église: les papes Grégoire II, Grégoire III, Zacharie e Étienne II et leurs rélations avec les empereurs iconoclastes (726-757). In: Revue Historique, t. LXIV, p. 1-40 e 241-272.

HUBERT, H.; MAUSS, M. 1909. Mélanges d'Histoire des Religons. Paris: Alcan.

HUVELIN, P. 1917. Une Guerre d'Usure: la deuxième guerre punique. Paris: Perrin. . 1907. La Solidarité de la famille en Grèce et la méthode du droit comparé, d'après un livre récent. Paris: L. Larouse et L. Tenin.

. 1903. La Notion de I'"injuria" dans le très ancien droit romain. Paris: A. Rey. . 1897. Essai historique sur le droit des marchés et des foires. Paris: Rousseau.

JAMOT, P. 1928. Théodore Reinach. Paris: s.e. . 1926. Henri Lechat. In: Gazette des Beaux-Arts, p. 17.

JULLIAN, C. 1936. Lettres des Jeunesse. Bordeaux: Delmas.

. 1905. La Vie et l'Étude des Monuments Français. Leçon d'inauguration de la Chaire d'Histoire et d'Antiquités Nationales au Collège de France le 7 décembre 1905. Paris: Éditions de la Revue Politique et Littéraire (Revue Bleue) et de la Revue Scientifique. . 1903a. Recherches sur la Religion Gauloise. Bordeaux: Féret et Fils.

. 1903b. Discours prononcé à la séance générale du Congrès. Le Samedi 18 avril 1903. Congrès des Sociétés Savantes à Bordeaux. Paris: Imprimerie Nationale. 1901. Vercingétorix. Paris: Hachette. . 1897a. L’Orientalisme à Bordeaux. Bordeaux: Féret et Fils. 1897b. Commentaire. In: MONTESQUIEU. Livre premier de I'Esprit des Lois. Paris: Hachette.

1897c. Extraits des Historiens du XIX $\mathbf{X}^{\mathbf{e}}$ siècles. Publiés, annotés et précédés d'une introduction sur l'histoire de France. Paris: Hachette. 
1895. Histoire des Bordeaux depuis les Origines jusqu'à 1895. Bordeaux: Féret et Fils.

1893. Ausone et Bordeaux. Étude sur les derniers temps de la Gaule romaine. Bordeaux: Gounouilhou.

1892. Gallia: tableau sommaire de la Gaule sous la domination romaine. Paris: Hachette.

. 1890. Inscriptions Romaines de Bordeaux. T. II. Bordeaux: Gounouilhou.

1888. Discours prononcé par M. Camille Jullian, le 23 février 1888, lors de sa réception

à l'Académie de Bordeaux. Bordeaux: Gounouilhou.

. 1887. Inscriptions Romaines de Bordeaux. T. I. Bordeaux: Gounouilhou.

1886. Notes d’Épigraphie. Viena: Savigné.

. 1884a. Les Transformations Politiques de I'Italie sous les Empereurs Romains, 43 av. J.

C. -330 ap. J. C. Paris: Thorin.

. 1884b. Études d'Épigraphie Bordelaise. Les Bordelais dans I'Armée Romaine. Bordeaux: Féret et fils.

1883. De protectoribus et domesticis Augustorum. Paris: Thorin.

LANTIER, R. 1949. Notice sur la vie et les travaux de M. Pierre Roussel, membre de l'Académie.

In: Compte-rendus des séances de l'année - Académie des inscriptions et belleslettres, n.1, p. 26-38.

LOISY, A. 1913. Choses Passées. Paris: E. Nourry.

LYZOP, R. 1934. Un Grand Savant de Chez Nous. Camille Jullian de l'Académie Française. Toulouse: Editions de l'Archer.

MAINDRON, M. 1906. L'Arbre de Science. Paris: Alphonse Lemerre.

MAUSS, M. 1983a. Oeuvre T. I. Paris: Minuit.

1983b. Oeuvre T. II. Paris: Minuit.

.1983c. Oeuvre T. III. Paris: Minuit.

. 1979. L'oeuvre de Marcel Mauss par lui-même. In: Revue Française de Sociologie, vol.

20-1, p. 209-220.

MEILLET, A. 1948 [1921]. Linguistique Historique et Linguistique Générale. Paris: Champion. . 1928. Esquisse d'une Histoire de la Langue Latine. Paris: Hachette. . 1913. Aperçu d'une Histoire de la Langue Grecque. Paris: Hachette. . 1908. Les Dialectes Indo-Européens. Paris: Champion.

1903. Introduction à l'Étude Comparative des Langues Indo-Européennes. Paris: Hachette.

MILHAUD, G. Paul Tannery. In: La Revue des Idées. Tiré à part du no. 25 (15 janvier 1906).

PARIS, P. 1928a. Goya. Paris: Plon. 
1928b. La Peinture Espagnole depuis les Origines Jusqu'au Début du XIX ${ }^{\mathrm{e}}$ Siècle. Paris/Bruxelas: G. Van Oest.

. 1903-4. Essaie sur l'Art et l'Industrie de l'Espagne Primitive. Paris: Leroux.

. 1892. Elatée, la ville, le temple d'Athéna Cranaia. Paris: E. Thorin.

PARIS, P.; ROQUES, G. 1909. Lexique des Antiquités Grecques. Paris: Fontemoing.

PÉGUY, C. 1992. Oeuvre. T. III. Paris: Gallimard.

PLUTARQUE. 1900. De la Musique. Paris: Leroux. (édition critique et explicative, par Henri Weil et Th. Reinach).

POTTIER, E.; REINACH, S. 1887. La Nécropole de Myrina: recherches archéologiques exécutées au nom et aux frais de l'École française d'Athènes. Paris: Thorin.

PUECH, A. 1935. Jullian In: Association Amicale de Secours des Anciens Élèves de l'École Normale Supérieure. Paris: Soc. Gén. D'Imp. et d'Édit., p. 37-42.

RADET, G. 1901. L'Histoire et l'Oeuvre de l'École Française d'Athènes. Paris: Fontemoing. . 1893. La Lydie et le Monde Grec au Temps des Mermnades. Paris: Thorin \& Fils.

REINACH, S. 1994. Types de Normaliens. In: BERSONT, E.; REINACH, S.; ZOLA, É. Notre École Normale. Textes réunis et présentés par Hervé Duchêne. Paris: Les Belles Lettres. 1926. Lettres à Zoé sur I'histoire des philosophes. Paris: Hachette. 1913. Sidonie, ou Le français sans peine. Paris: Hachette. 1912b. Une étude sur les réligions primitives. In: Revue Critique des Livres Nouveaux, 15 Octobre, p. 153-154. . 1912c. Cornélie, ou Le latin sans pleurs. Paris: Hachette. . 1911. Eulalie, ou Le grec sans larmes. Paris: Hachette. . 1909a. Orpheus, histoire générale des religions. Paris: Picard. . 1904. Apollo: histoire générale des arts plastiques professée en 1902-1903 à l'École du Louvre. Paris: Hachette.

1903. É. Durkheim et M. Mauss. De quelques formes primitives de la classification. In: L'Anthropologie, vol. 14, p. 601-603.

. 1902. É. Durkheim. Sur le totemisme. In: L'Anthropologie, vol. 13, p. 664-669.

1900. Quelques observations sur le tabou. In: L'Anthropologie, vol. 11, p. 401-407. 1899. La prohibition de l'inceste et ses origines. In: L'Anthropologie, vol. 10, p. 59-70. 1895. Épona, la déesse gauloise des chevaux. Paris: Leroux. 1890. L'Histoire du Travail en Gaule. Paris: Leroux. 1889. Les Gaulois dans L'Art Antique. Paris: Leroux. 1888. Esquisses archéologiques. Paris: Leroux. 1880. Manuel de Philologie Classique. T. I. Paris: Hachette. 
REINACH, Th. 1888. Numismatique ancienne. Trois royaumes de I'Asie Mineure: Cappadoce, Bithynie, Pont. Paris: C. Rollin et Feuardent. . 1887. Les Monnaies Juives. Paris: Leroux. . 1885. De l'État de siège, étude historique et juridique. Paris: Pichon. . 1884. Histoire des Israëlites, depuis l'époque de leur dispersion jusqu'à nos jours. Paris: Hachette. . 1880. De l'Extinction des privilèges et hypothèques. Paris: Pichon.

ROBIN, L. 1913. Platon et la Science Sociale. In: Revue de Métaphysique et de Morale, 29, p. 211-55.

ROUSSEL, P. 1922. Le thème du sacrifice volontaire dans la tragédie d'Euripide. In: Revue Belge de Philologie et d'Histoire. T. I, fasc. 2, p. 225-240. . 1916a. Délos, colonie athénienne. Paris: E. Boccard. . 1916b. Les Cultes égyptiens à Délos du Ille au 1er siècle av. J.-C., thèse complémentaire. Nancy: Berger-Levrault.

SAMARAN, C. 1979. Enfance et Jeunesse d'un Centenaire. Paris: Rotonde de la Villette.

SAINT-ROCH, P. 1995. (org). Correspondance de Giovanni Battista De Rossi et de Louis Duchesne (1873-1894). Paris: De Boccard.

SHAKESPEARE, W. Hamlet, prince de Danemark, tragédie en 5 actes. Paris: Hachette. (traduite en prose et en vers, avec une préface et un commentaire critique et explicatif par Théodore Reinach).

SCHOPENHAUER, A. 1877. Essai sur le libre arbitre. Paris: Germer Baillière. (Tradução de Salomon Reinach).

SIMIAND, F. 1912. La Méthode Positive en Science Économique. Paris: Alcan. . 1904. Le Salaire des Ouvriers des Mines de Charbon en France. Paris: Cornély.

VENDRYES, J. 1968 [1913]. Le Langage, introduction linguistique à I'histoire. Paris: Albin Michel.

. A. Meillet. 1937. Extrait du Bulletin de la Société de Linguistique. T. XXXVI, número 112.

\section{e. BIBLIOGRAFIA GERAL}

ACKERMAN, R. 2002. The Myth and Ritual School. Londres: Routledge.

ACKERMAN, W.; LE ROUX, B.; ROUANET, H. 2005. A análise geométrica de questionários. In: Sociologia (Universidade do Porto), vol. 15, p. 43-52. 
ANDURAND, A.; CAZENAVE, J.; DELMAS, S. 2006. Appréhender le Dictionnaire des Antiquités Grecques et Romaines par sa table d'auteurs. Les données statistiques comme outil d'analyse. In: Anabases, vol. 4, p. 219-223.

AUDREN, F. 2001. Paul Huvelin (1873-1924): juriste et durkheimien. In: Revue d'Histoire des Sciences Humaines, 4, p. 117-130.

AVLAMI, C. 2000. L'Antiquité grecque à la française. Modes d'appropriation de la Grèce au $\mathbf{X I X}^{\mathbf{e}}$ siècle. Lille : Presses universitaires du Septentrion.

BASCH, S.; ESPAGNE, M; LECHANT, J. (orgs). 2008 Les Frères Reinach: colloque réuni les 22 et 23 juin 2007 à l'Académie des inscriptions et belles-lettres, palais de I'Institut de France. Paris: AIBL.

BENJAMIN, W. 1994. Magia e Técnica, Arte e Política. São Paulo: Brasiliense.

BENTHIEN, R. F. 2011. Comment les mots changent de sens (compte-rendu/resenha do livro de Antoine Meillet) In: Atelier du Centre de Recherches Historiques, $n^{0} 7$, Paris: Ehess (disponível em português e em francês no site http://acrh.revues.org/). 2010. Lettres d'Émile Durkheim à Salomon Reinach. In: Durkheimian Studies/Études Durkheimiennes, volume 16, p. 19-35.

2007. Retrato e Socieade na Arte Italiana (resenha do livro de Enrico Castelnuovo). In: Revista de História, 156, p. 311-316.

2004. O Triunfo da Vontade: Ésquilo nos limites da imaginação acadêmica. In: Revista de História, 151, p. 73-111.

BENTHIEN, R. F.; DIMITROV, E. 2008. Monadologia e Sociologia (resenha). In: Mana, vol. 14, $\mathrm{n}^{\circ}$ 1, p. 259-261.

BERGOUNIOUX, G. 2006. Entre épistémologie de la grammaire comparée et figure de I'intelectuel: a situation d'Antoine Meillet. In: BERGONIOUX, G.; LAMBERTERIE, C. Meillet Aujourd'hui. Leuven/Paris: Peeters, p. 109-135.

BESNARD, P. 1979a. La formation de l'équipe de l'Année Sociologique. In: Revue Française de Sociologie, 20, p. 7-31.

. 1979b. Durkheim, les durkheimiens et le Collège de France. In: Etudes Durkheimiennes. Bulletin d'information préparé par le Groupe d'études durkheimiennes. Avril 1979, número 3, p. 4-7.

BINÉTRUY, M.-S. 1994. De l'Art Roman à la Préhistoire, des Sociétés Locales à I'Institut. Itinéraires de Joseph Déchelette. Lyon: Lugd.

BLANCHET, B. 2004. La Toge et la Tribune: Engagements publics des classicistes français et britanniques au XXe siècle. Paris: L'Harmattan. 
BOLLACK, J. 2008. Dans une famille juive en Alsace. In: Revue des Sciences Sociales, $n^{\circ} 40, p$. 212-215. . 1998a. La Grèce de Personne. Paris: Seuil. . 1998b. Jacob Bernays, un homme entre deux mondes. Villeneuve d'Ascq: Presses Universitaires du Septentrion. . 1995. La Naissance d'Oedipe. Paris: Gallimard. . 1992a. Empédocle. T. I. Paris: Gallimard. . 1992b. Empédocle. T. II. Paris: Gallimard. . 1992c. Empédocle. T. III. Paris: Gallimard. . 1991. L'Oedipe Roi de Sophocle : le texte et ses interprétations (em quatro volumes). Lille: Presses Universitaires de Lille. . 1972 Lettre à un Président, sur le découragement des études grecques en France. Paris: Minuit.

BOLLACK, J.; LLORET, P. 2000. Sens Contre Sens, comment lit-on? Paris: La Passe du Vent. BOLLACK, J.; WISMANN, H. 1978. Héraclite ou la séparation. Paris: Minuit. BOLLACK, J.; BOLLACK, M.; WISMANN, H. 1971. La Lettre d'Épicure. Paris: Minuit. BOLLACK, M. 2010. Fragments de Vies. In: KÖNIG, C.; THOUARD, D. (orgs). La Philologie au Présent. Villeneuve d'Ascq: Presses Universitaires du Septentrion, p. 359-362 BOLTANSKI, L. 2003. Usages Faibles, Usages Forts de I'Habitus. In: ENCREVÉ, P.; LAGRAVE, R.M. Travailler avec Bourdieu. Paris: Flammarion, p. 153-161.

BOSCHETTI, A. 1985. Sartre et "Les Temps Modernes". Paris: Minuit. BOURDIEU, P. 2004. Os Usos Sociais da Ciência. São Paulo: Editora Unesp. . 2001. Science de la Science et Réflexivité. Paris: Raison d'Agir. . 1998. O Poder Simbólico. Rio de Janeiro: Bertrand Brasil, $2^{a}$. edição. 1997. Razões Práticas. Campinas: Papirus. . 1996. As Regras da Arte. São Paulo: Cia das Letras. 1984. Homo Academicus. Paris: Minuit. 1977. Postface. In: PANOFSKY, E.

BOYANCÉ, P. 1972. Une édition dans le vent. In: Revue de Philologie, 46, p. 66-91.

BROOKS, J. 2002. Institutionalizing Durkheimian Sociology of Religion: the case of the $V$ section. In: Thinking about religion, volume 2 (artigo disponível on-line em http://organizations.uncfsu.edu/ncrsa/journal/v02/johnbrooks.htm)

BRUN, P.; OLIVIER, R. 2000. Henri Hubert. In: Les Nouvelles de l'Archéologie, n 79, p. 5-32. 
CARASTRO, M. 2010. La fabrique de la notion moderne de magie: pratiques du comparatisme chez Frazer, Hubert et Mauss. In: Revista de História (USP), edição especial, p. 231248.

2006. La magie entre histoire et anthropologie. Relire la contribution d'Henri Hubert au DAGR. In: Anabases, vol. 4, p. 251-255.

CASTELNUOVO, E. 2006. Retrato e Sociedade na Arte Italiana. São Paulo: Cia das Letras.

CHAMBOREDON, J.-C. 1975. Sociologie de la sociologie et intérêts sociaux des sociologues. In: Actes de la Recherche en Sciences Sociales, 2, p. 2-20.

CHARLE, Ch. 2008. Théâtres en capitales: naissance de la société du spectacle à Paris, Berlin, Londres et Vienne, 1860-1914. Paris: Albin Michel. . 2004. Enseignement supérieur et expansion internationale. In: HEILBRON, J.; et alii. Pour une Histoire des Sciences Sociales. Paris: Fayard, p.323-347. . 1997. Le Collège de France. In: AGERON, C.-R.; NORA, P. Lieux de Mémoire. T. 3. Paris: Gallimard, p. 1983-2008. . 1994. La République des Universitaires, 1870-1940. Paris: Seuil. . 1990. Naissance des “Intellectuels" 1880-1900. Paris: Minuit.

CHARPIN, D. 2006. Une Figure de la Section: le P. Vincent Scheil. Conferência disponível em http://www.digitorient.com/wp/wp-content/uploads/2006/09/p-027.pdf (último acesso em 10/10/2009).

CHEW, H. 2010. Alexandre Bertrand. In: SÉNÉCHAL, C.; BABILLON, P. (org.). Dictionnaire Critique des Historiens de l'Art (cf. http://www.inha.fr/spip.php?article2197)

- 2008. Les échanges archéologiques internationaux au XIXe siècle. L'éxemple d'Aléxandre Bertrand et du Musée des Antiquités Nationales. In: Ministère de la Culture et de la Communication. Les Dépots de l'État au $\mathbf{X I X}^{\mathbf{e}}$ siècle. Politiques patrimoniales et destin d'oeuvres. Paris: Louvre, 2008.

CHOLVY, G.; HILAIRE, Y.-M. 2000. Histoire Religieuse de la France. 1880-1914. Toulouse: Privat.

CLARK, T. N. 1973. Prophets and Patrons. Cambridge: Harvard University Press.

COMPAGNON, A. 1989. La Troisième République des Lettres. Paris: Seuil.

CONSOLIM, M. C. 2008. Gabriel Tarde e as ciências sociais francesas: afinidades eletivas. In: Mana. Rio de Janeiro, v. 14, n. 2.

DAMIEN, A. 1999. L'Institut de France. Paris: Puf.

DARNTON, R. 1989. Boemia Literária e Revolução. São Paulo: Cia das Letras.

DE ROMILLY, J. 1999. A Tragédia Grega. Brasília: Unb. . 1998. História e Razão em Tucídides. Brasília: Unb. 
. 1996. Alcibíades. Rio de Janeiro: Ediouro.

1984. Fundamentos da Literatura Grega. Rio: Zahar.

DETIENNE, M. 2000. Comparer l'incomparable. Paris: Seuil.

DUCHÊNE, H. Salomon Reinach. In: SÉNÉCHAL, C.; BABILLON, P. (org.). Dictionnaire Critique des Historiens de l'Art (http://www.inha.fr/spip.php?article2511)

DUMONT, L. 1997. Homo Hierarchicus. São Paulo: Edusp.

FABIANI, J-L. 1993. Métaphysique, morale, sociologie. Durkheim et le retour à la philosophie. In: Revue de Métaphysique et Morale, 1, p. 175-191. . 1988. Les Philosophes de la Republique. Paris: Minuit.

FAGUER, J.-P. 1995. Kâgneux pour la Vie. Noisy-le-Grand: CET.

FOURNIER, M. 2007. Émile Durkheim. Paris: Fayard. . 1994. Marcel Mauss. Paris: Fayard.

GADAMER, H. G. 2006. Interroger les Grecs. Paris: Fides.

GOBLOT, E. 1989 [1925]. A Barreira e o Nível. Rio de Janeiro: Papirus.

GOUREVITCH, D. 2009. Charles Daremberg. In: SÉNÉCHAL, C.; BABILLON, P. (org.). Dictionnaire Critique des Historiens de l'Art (http://www.inha.fr/spip.php?article2265).

GRAN-AYMERICH, É. 1998. La Naissance de l’Archéologie Moderne. Paris: CNRS.

GREEL, C. 1995. Le Dix-huitième Siècle et l'Antiquité en France. Oxford: Voltaire Fondation.

HEILBRON, J. 2006. La Naissance de la sociologie. Marseille: Agone.

1985. Les métamorphoses du durkheimisme, 1920-1940. In: Revue Française de Sociologie, 26, p. 203-237.

HÜLTENSCHMIDT, E. 1990. L'École Normale de l'An III: une utopie encyclopédiste. In: ESPAGNE, M; WERneR, M. (orgs.). Philologiques I. Paris: Éditions de la Maison des Sciences de l'Homme, p. 105-133.

KARADY, V. 1988. Durkheim et les Débuts de l'Éthnologie Universitaire. In: Actes de la Recherche en Sciences Sociales, $n^{\circ} 74$, p. 23-32.

. 1979. Stratégies de réussite et modes de faire-valoir de la sociologie chez les durkheimiens. In: Revue Française de Sociologie, 20, p. 49-82.

1976. Durkheim, les sciences sociales et l'Université: bilan d'un semi-échec. In: Revue Française de Sociologie, 17, p. 267-311.

1973. L'expansion universitaire et l'évolution des inégalités devant la carrière d'enseignant au début de la Ille République. In: Revue Française de Sociologie, 13, 443-470.

KUHN, T. 2003. A Estrutura das Revoluções Científicas. São Paulo: Perspectiva.

LE ROUX, B.; ROUANET, H. 2010. Multiple Correspondence Analysis. Los Angeles: Sage. 
LÉON, A.; ROCHE, P. 2008. Histoire de l'Enseignement en France. Paris: Puf.

LEPENIES, W. 1985. As Três Culturas. São Paulo: Edusp.

LÉVÊQUE, P. A Aventura Grega. Rio de Janeiro: Cosmos, 1965.

LÉVI-STRAUSS, C. 2001. Introduction à l'oeuvre de Marcel Mauss. In: MAUSS, Marcel. Sociologie et Anthropologie. Paris: Puf, pp. IX-LII.

LORRE, C. 2010. Henri Hubert et l'aménagement de la salle de comparaison du musée des Antiquités nationales: un atelier de sociologie durkheimienne. In: Antiquités Nationales, $n^{\circ} 41$ (no prelo).

. 2009. Henri Hubert. In: SÉNÉCHAL, C.; BABILLON, P. (org.). Dictionnaire Critique des Historiens de l'Art (http://www.inha.fr/spip.php?article2370).

LÖWY, M. 2004. Le Concept d’Affinité Élective chez Max Weber. In: Archives de Sciences Sociales des Religions. $N^{\circ} 127$, p. 93-103.

LUKES, S. 1973. Emile Durkheim. Londres : A. Lane.

MARÈS, A. 1995. L'Institut de France, le parlement des savants. Paris: Gallimard.

MARROU, H.-I. 1948. Histoire de l'éducation dans l'Antiquité (em dois volumes). Paris: Seuil. MARTIN-FUGIER, A. 2003. Les Salons de la Ille République. Paris: Perrin.

MAYEUR, F. 2004. Histoire de l'Enseignement et de l'Éducation. T. III. 1789-1930. Paris: Perrin.

MOHEN, J.-P. 1980-1981. Henri Hubert et la Salle de Mars. In: Antiquités Nationales, nº 12-13, p. $85-89$.

MOTTE. O. 1990. Camille Jullian: les années de formation. Paris: Boccard.

MUCCHIELLI, L. 2001. O nascimento da sociologia na universidade francesa (1880-1914). In: Revista Brasileira de História, 21/41, p. 35-54.

. 1998a. La découverte du social. Naissance de la sociologie en France, Paris: Editions La découverte.

. 1998b. Les Durkheimiens et la Revue de l'Histoire des Religions: (1896-1916) une zone d'influence méconnue. In: Durkheimian Studies/Études Durkheimiennes, volume 4, p. 51-72.

MÜLLER, D.; RINGER, F.; SIMON, B. (orgs.). 1898 The Rise of Modern Educational System. Cambridge/Paris: Cambridge University Press/Maison de Sciences de l'Homme.

MURRAY, S. 1989. A 1934 Interview with Marcel Mauss. In: American Ethnologist, 16/1, p. 163-8.

PAOLETTI, G. 1998. L'Année Sociologique et les philosophes: histoire d'un débat (1898-1913). In: L’Année Sociologique, 48(1), p. 77-114. 
PICKERING, W. S. F. 1979. Gaston Richard: collaborateur et adversaire. In: Revue Française de Sociologie, 20-1, p. 163-182.

PROCHASSON, C. 1997. Histoire e sociologie. In: BIARD, A.; BOUREL, D.; BRIAN, E. (orgs). Henri Berr et la Culture du XX $X^{\mathrm{e}}$ Siècle. Paris: Albin Michel.

PROST, A. 2007. Régards Historiques sur l'Éducation en France. Paris: Belin.

QUÉNIART, J.; LÉBRUN, F.; VÉNARD, M. 1981. Histoire Générale de I'Enseignement et de l'Éducation en France. Paris: Labat.

RÉBÉRIOUX, M. 1983. Le débat de 1903: historiens et sociologues. In: LIVET, G.; et alii. (éds). Au Berceau des Annales. Toulouse: I'IEP, p. 219- 30.

REVEL, J. 1989. Do Antigo Regime ao Império: a identidade regional, inevitável e impensável. In: REVEL, J. A Invenção da Sociedade. Rio de Janeiro: Bertrand Brasil, p. 159-180

REY, S. 2009. Comment on a Écrit l'Histoire Ancienne à l'École Française de Rome. Thèse soutenue à l'Université de Toulouse.

RINGER, F. 2000. O Declínio dos Mandarins Alemães. São Paulo: Edusp. 1992. Fields of Knowledge. Cambridge: Cambridge University Press.

ROQUEFEUIL, P. 2001. L'oeuvre de Charles Dangibeaud. Historien, archéologue et artiste saintongeais (1851-1935). Saintes: Société des Archives Historiques de la Saintonge et de l'Aunis.

ROUILLARD, P. 2009. Pierre Paris. In: SÉNÉCHAL, C.; BABILLON, P. (org.). Dictionnaire Critique des Historiens de l'Art Actifs en France de la Révolution à la Première Guerre Mondiale. (http://www.inha.fr/spip.php?article2480). . 1997. Antiquités de l’Espagne. Paris: RMN.

. 1996. Dis-moi qui tu es: Espagnole, Salammbô ou Carmen. In: ROUILLARD, P ; OLMOS, R. ; Formes Archaïques et Arts Ibériques. Madri: Casa de Vélazquez, p. 33-42.

SAPIRO, G. 2004. Le savant et le littéraire. Les hommes de lettres contre la sociologie durkheimienne. In: HEILBRON, J.; LENOR, R.; SAPIRO, G. Pour une Histoire des Sciences Sociales. Paris: Fayard, p. 83-106.

SIGAUD, L. 1999. As vicissitudes do "ensaio sobre o dom". In: Mana, Rio de Janeiro, vol. 5, número 2, p. 89-124.

SMITH, R. 1982. The Ecole Normale Supérieure and the Third Republic. Albany: State University of Chicago Press.

STRENSKI, I. 2000. Durkheimians and Protestans in the École Pratique, Fifth Section: the dark side. In: Durkheimian Studies/Études Durkheimiennes, volume 6, p. 105-114. 1997. Durkheim and the Jews of France. Chicago: University of Chicago Press. 
SWIGGERS, P. 2009. Antoine Meillet et sa visée de la Linguistique (Générale). In: Anamnese, $\mathrm{n}^{\circ}$ 5. Paris: L'Harmattan, p. 21-50.

SZONDI, P. 1975. L'herméneutique de Schleiermacher. In: Ibid. Poésie et Poétique de I'Idéalisme Allemand. Paris: Minuit/Gallimard, p. 291-315.

TRABULSI, J. A. D. 2008. Tradição clássica, ensino e política na França da Terceira República. In: CHEVITARESE, A. L.; CORNELLI, G. SILVA, M. A. de O. A Tradição Clássica e o Brasil. São Paulo: Fortium.

. 1998. Religion Grecque et Politique Française au XIXe. siècle. Dionysos et Marianne. Paris: L'Harmattan.

THIESSE, A.-M. Écrire la France. Le mouvement littéraire régionalista de langue française entre la Belle Époque et la Libération. Paris: Puf.

VALENTI, C. 2006a. L’École Française d'Athènes. Paris: Belin. . 2006b. Daremberg et Saglio " ou "Saglio et Pottier "? La difficile gestation d'un dictionnaire savant. In: Anabases, vol. 4, p. 159-167.

2002. Le voyage en Grèces des Membres de l'École Française d'Athènes. In: Balkanologie (VI), 1-2, p. 155-166.

1996. Les membres de l'École française d'Athènes: étude d'une élite universitaire (1846-1992). In: Bulletin de Correspondance Hellénique. Vol. 120, pp. 157-172.

VERNANT, J.-P. 2002a. Entre Mito e Política. São Paulo: Edusp. . 2002b. Mito e Pensamento. Rio de Janeiro: Paz e Terra. . 1996. As Origens do Pensamento Grego. Rio de Janeiro: Bertrand.

VERNANT, J.-P. e VIDAL-NAQUET, P. 1999. Mito e Tragédia na Grécia Antiga I e II. São Paulo: Perspectiva.

VIAN DE RIVES, R. (org.). 2002. La Villa Kérylos. Paris: Éd. de l'Amateur.

VOUGT, W. P. 1982. Identifying Scholarly and Intellectual Communities: a note on french philosophy. In: Theory and History, 21/2, p. 267-278.

WACHÉ, B. 1992. Monseigneur Louis Duchesne (1843-1922): historien de l'Église, directeur de l'École française de Rome. Paris-Roma: De Boccard.

WACQUANT, L. 1995. Durkheim e Bourdieu: le socle commun et ses fissures. In: Critique, 579580 , p. 646-60.

WAQUET, F. 1998. Le Latin ou l'Empire d'un Signe. Paris: Albin Michel.

WERNER, M. 1990. A propos de la notion de philologie moderne: problèmes de définition dans I'espace franco-allemand. In: ESPAGNE, M; WERNER, M. (orgs.). Philologiques I. Paris: Éditions de la Maison des Sciences de l'Homme, p. 11-21. 